DANIEL FELIPE SEMPÉRTEGUI TAPIA

\title{
ANÁLISE EXPERIMENTAL DO EFEITO DA GEOMETRIA \\ DA SEÇÃO TRANSVERSAL E DO DESEMPENHO DE FLUIDOS DE REDUZIDO GWP NA EBULIÇÃO CONVECTIVA EM CANAIS DE DIMENSÕES REDUZIDAS.
}

Tese apresentada à Escola de Engenharia de São Carlos da Universidade de São Paulo para a obtenção do título de Doutor em Engenharia Mecânica.

Área de Concentração: Térmica e Fluidos

ORIENTADOR: Professor Gherhardt Ribatski

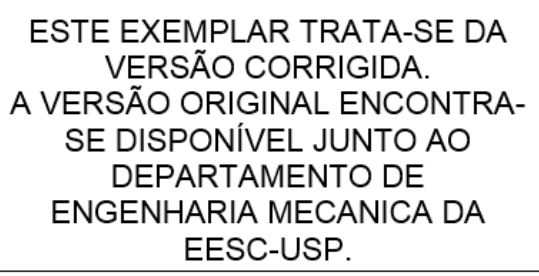

São Carlos, SP 
AUTORIZO A REPRODUÇÃO TOTAL OU PARCIAL DESTE TRABALHO, POR QUALQUER MEIO CONVENCIONAL OU ELETRONNICO, PARA FINS DE ESTUDO E PESQUISA, DESDE QUE CITADA A FONTE.

S473a Sempértegui-Tapia, Daniel Felipe

Análise experimental do efeito da geometria da seção transversal e do desempenho de fluidos de reduzido GWP na ebulição convectiva em canais de dimensões reduzidas / Daniel Felipe sempértegui-Tapia; orientador Gherhardt Ribatski. São Carlos, 2016.

Tese (Doutorado) - Programa de Pós-Graduação em Engenharia Mecânica e Área de Concentração em Térmica e Fluídos -- Escola de Engenharia de São Carlos da Universidade de São Paulo, 2016.

1. Microcanais. 2. Ebulição convectiva. 3. Efeito da geometria. 4. Fluidos de reduzido GWP. 5. Coeficiente de transferência de calor. 6. Perda da pressão. 7. Fluidos naturais. I. Título. 


\section{FOLHA DE JULGAMENTO}

Candidato: Licenciado DANIEL FELIPE SEMPERTEGUI TAPIA.

Tífulo da tese: "Análise experimental do efeito geometria da seção transversal e do desempenho de fluidos de reduzido GWP na ebulição convectiva em canais de dimensões reduzidas".

Data da defesa: $23 / 03 / 2016$.

Comissão Julgadora:

Prof. Associado Gherhardi Ribatski

(Orientador)

(Escola de Engenharia de São Carlos/EESC)

Prof. Dr. José Maria Saiz Jabardo

(Escola de Engenharia de Săo Carlos/EESC)

Prof. Titular Jurandir Itizo Yanagihara

(Escola Politécnica/EP-USP)

Prof. Dr. Alexandre Kupka da Silva

(Universidade Federal de Santa Catarina/UFSC)

Prof. Dr. Jader Riso Barbosa Junior

(Universidade Federal de Santa Catarina/UFSC)
Resultado:

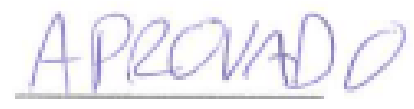

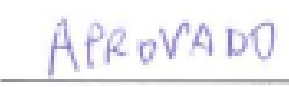
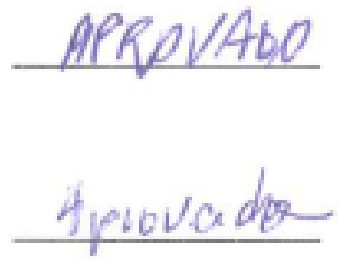

Coordenador do Programa de Pós-Graduação em Engenheira Mecânica: Prof. Associado Gherhardt Ribatski

Presidente da Comissão de Pós-Graduação:

Prof. Associado Paulo César Lima Segantine 

A mis padres Eloina Tapia y Jaime Sempertegui y a mis hermanos, Gabriela, Aldo, Diego y Yerko. 



\section{AGRADECIMENTOS}

Agradeço inicialmente ao Prof. Gherhardt, pela oportunidade concedida para realizar o doutorado, pela excelente orientação, formação acadêmica e amizade brindada no decorrer do doutorado.

À Fundação de Apoio à Pesquisa do Estado de São Paulo, FAPESP, pela bolsa de estudos concedida para a realização deste doutorado ( ${ }^{\circ}$ Processo 2010/17605-4).

A Jose Roberto Bogni, pela amizade e ajuda na montagem da bancada experimental.

Um agradecimento especial ao professor William Gonzáles Mamani pela formação acadêmica durante a graduação e o apoio e amizade brindados até agora.

Ao pessoal do laboratório de refrigeração: Chicão, Cristian, Erivelto, Gustavo, Jaqueline, Livia, Karime, Fabio, Tiago, Hugo, Francisco pela ajuda e companheirismo.

Aos professores Oscar M. Hernandez Rodriguez, Antonio Moreira dos Santos, Timothy Shedd, Jose Maria Jabardo, Daniel Varela Magalhães e Harry Schulz pela formação acadêmica. Aos técnicos Jorge Nicolau dos Santos, Helio Trebi e Roberto Prataviera pela colaboração técnica durante o doutorado.

À Universidade de São Paulo, USP, e a Escola de Engenharia de São Carlos, EESC, pela oportunidade de realização do doutorado. 



\section{RESUMO}

SEMPÉRTEGUI-TAPIA, D. F. Análise experimental do efeito da geometria da seção transversal e do desempenho de fluidos de reduzido GWP na ebulição convectiva em canais de dimensões reduzidas. 288p. Tese (Doutorado) - Escola de Engenharia de São Carlos, Universidade de São Paulo, São Carlos, 2016.

A presente tese trata da análise experimental do efeito da geometria da seção transversal do canal e do desempenho de refrigerantes de reduzido GWP (Global Warming Potential) durante a ebulição convectiva em canais de reduzidas dimensões. A tese inclui ainda um estudo extenso e crítico da literatura sobre métodos de previsão da perda de pressão e do coeficiente de transferência de calor, e sobre estudos experimentais em canais nãocirculares e de refrigerantes com reduzido GWP na ebulição convectiva em canais de dimensões reduzidas. Resultados para o coeficiente de transferência de calor e perda de pressão durante a ebulição convectiva foram obtidos para canais com geometrias de seção circular, quadrada e triangular para o refrigerante R134a. Nos testes utilizou-se canais com perímetros internos similares obtidos a partir da conformação de um tubo com diâmetro interno igual a $1,1 \mathrm{~mm}$. No caso do canal circular, dados foram também levantados para os HFOs R1234ze(E) e R1234yf e o hidrocarboneto R600a, fluidos com reduzido GWP. Ensaios foram executados para amplas faixas de fluxos de calor e velocidades mássicas, temperaturas de saturação de 31 e $41^{\circ} \mathrm{C}$ e títulos de vapor entre 0 e 0,95. Aspectos relacionados aos efeitos da geometria e do fluido refrigerante foram minuciosamente investigados através da análise paramétrica dos resultados. Com base na comparação do banco de dados coletado com os métodos de previsão disponíveis na literatura, constatou-se que estes proporcionam previsões satisfatórias apenas para condições experimentais especificas. Portanto, novos métodos de previsão da perda de pressão e do coeficiente de transferência de calor foram desenvolvidos com base nos dados levantados no presente estudo. Os métodos propostos preveem satisfatoriamente o banco de dados do presente estudo e resultados independentes disponíveis na literatura. Adicionalmente, com base nos resultados levantados, verificou-se que dissipadores de calor baseados em multi-microcanais com canais de seção triangular apresentam desempenho superior comparados a dissipadores com canais quadrados e circulares.

Palavras chave: microcanais, ebulição convectiva, efeito da geometria, fluidos de reduzido GWP, fluidos naturais, coeficiente de transferência de calor, perda de pressão. 



\begin{abstract}
SEMPÉRTEGUI-TAPIA, D. F. Experimental analysis of the cross-sectional geometry effect and low GWP refrigerants performance during convective boiling inside micro-scale channels. 288p. Tese (Doutorado) - Escola de Engenharia de São Carlos, Universidade de São Paulo, São Carlos, 2016.
\end{abstract}

The present thesis concerns an experimental study on the effects of cross-sectional geometry and low GWP refrigerants on the thermal-hydraulic performance for convective boiling inside micro-scale channels. Experimental results for heat transfer coefficient and pressure drop gradient during convective boiling were obtained for circular, square and triangular channels for the fluid R134a. The evaluated channels present the same external perimeter and equivalent diameters of $1.1,0.977$ and $0.835 \mathrm{~mm}$, respectively. In the case of the circular geometry, experimental results were also acquired for the HFO's R1234ze(E) and R1234yf and the hydrocarbon R600a (isobutane), which are fluids with low GWP and null ODP. Experiments were performed for a wide range of heat fluxes and mass velocities, saturation temperatures of 31 and $41^{\circ} \mathrm{C}$ and vapor qualities up to 0.95. The experimental data were carefully analyzed and discussed based on a parametrical analysis focusing on the effect of the cross-sectional geometry and the working fluid. Subsequently, the experimental data were compared against the most quoted predictive methods from literature. In general, it was verified that none of the predictive methods were able to accurately capture the experimental trends of the overall database. So, new predictive methods for the pressure drop and heat transfer coefficient were developed based on the broad database obtained in the present study. The proposed methods provided satisfactory results not only for the experimental database used for its development, but also for independent databases collected in the literature. Additionally, based on the data obtained in the present study and a performance analysis taken into account pressure drop, heat transfer coefficient and the channel packing factor, triangular cross sectional geometry is recommended for heat sinks.

Palavras chave: convective boiling, micro-channels, geoemtry effect, low GWP fluids, heat transfer coeffcient,pressure drop, isobutane. 



\section{LISTA DE FIGURAS}

Figura 1.1. Evolução de fluxo de calor dissipado pelos microprocessadores produzidos pela Intel.

31

Figura 1.2. a) Ilustração do efeito da perda de pressão no evaporador num ciclo de de refrigeração, para condiçoes de $T_{\text {evap }}=-15^{\circ} \mathrm{C}, T_{\text {cond }}=50^{\circ} \mathrm{C}, \Delta P=100 \mathrm{kPa}$, b) Variação do coeficiente de desempenho com o incremento da perda de pressão no evaporador. 33

Figura 2.1. Ilustração esquematica das formas de caracterização da fraçao de vazio: a) local, b) linear, c) superficial, d) volumétrica.

Figura 2.2. Comparação da fração de vazio superficial experimental com métodos de previsão da literatura, Sempértegui-Tapia et al. (2013)........................ 44

Figura 2.3. Padrões de escoamento em tubos verticais, Collier e Thome (1996) .......... 49

Figura 2.4. Padrões de escoamento em dutos horizontais, Barbieri (2005). .................. 50

Figura 2.5. Padrões de escoamento em canais de diâmetro reduzido, R245fa, $D=1,1 \mathrm{~mm}$, Sempértegui-Tapia et al. (2013).... 50

Figura 2.6. Evolução dos padrões de escoamento durante a ebulição convectiva em canais convencionais, adaptado de Collier e Thome (1996). 51

Figura 2.7. Evolução dos padrões de escoamento durante a ebulição convectiva em canais de reduzido diâmetro e ilustrações esquemáticas dos perfis de temperaturas de parede e fluido, CTC e gradiende da perda de pressao ao longo do canal.

Figura 2.8. Núcleos ativos observados no filme líquido nos padroes anular e bolhas alongadas, Tibiriça e Ribatski (2014).

Figura 3.1. Comparação dos modelos de viscosidade da mistura homogênea em funçao do título de vapor e a fração de vazio homogênea, R134a, $T_{\text {sat }}=20^{\circ} \mathrm{C} .58$

Figura 3.2. Efeito do diâmetro e da temperatura de saturação no gradiente de perda de pressão segundo Lockhart e Martinelli (1949), R134a, G = 100 [kg/m²s].

Figura 3.3. Efeito do fator de forma na relação entre o parâmetro de Lockhart-Martinelli e o multiplicador bífasico segundo Chen et al. (2007), R134a, $\mathrm{T}_{\mathrm{sat}}=31^{\circ} \mathrm{C}$, $\mathrm{G}=500 \mathrm{~kg} / \mathrm{m}^{2} \mathrm{~s}$.

Figura 3.4.- Efeito do diametro, temperatura de saturaçao e velocidade massica nos metodos, a) Kim e Mudawar (2012), b) Del Col et al. (2103).

Figura 3.5. Comparação entre os dados experimentais de Da Silva e Ribatski (2013), e métodos de previsao da literatura, R245fa, $T_{\text {sat }}=41^{\circ} \mathrm{C}, \mathrm{G}=500 \mathrm{~kg} / \mathrm{m}^{2} \mathrm{~s}$.

Figura 3.6.- Configuração do escoamento estratificado, Moreno-Quibén e Thome (2007).

Figura 3.7. Efeito do diâmetro e da temperatura de saturação no gradiente de perda de pressão segundo Moreno-Quibén e Thome (2007), R22, G= 300 [kg/m²s]. 
Figura 3.8. Efeito da velocidade mássica, temperatura de saturação e do diâmetro no gradiente da perda de pressao por atrito segundo o método de Cioncolini et al. (2009), R134a.

Figura 3.9. Gradientes de pressão estimados pelos distintos métodos de previsão, $G=200$ $\mathrm{kg} / \mathrm{m}^{2} \mathrm{~s}, \mathrm{~T}_{\text {sat }}=22^{\circ} \mathrm{C}$ e D $=3 \mathrm{~mm}$, para a) R134a, b) R600a.

Figura 3.10. Gradientes de pressão estimados pelos distintos métodos de previsão de microcanais para $G=200\left[\mathrm{~kg} / \mathrm{m}^{2} \mathrm{~s}\right], T_{\text {sat }}=40^{\circ} \mathrm{C}$ e $D=1,1 \mathrm{~mm}$ para a) R1234ze(E) e b) R1234yf. 81

Figura 3.11. Perda de pressão vs. fator de forma, Singh et al. (2008). 85

Figura 3.12. Efeito da geometria do canal na perda de pressão, Harirchian e Garimella (2012). 86

Figura 4.1. Efeito da temperatura de saturação, diâmetro, velocidade massica e fluxo de calor no CTC segundo método de previsão de Kandlikar e Balasubramanian (2004), R134a. 95

Figura 4.2. Efeito da temperatura de saturação e diâmetro no CTC segundo método de previsão de Liu e Winterton (1991), R290a, $G=400 \mathrm{~kg} / \mathrm{m}^{2} \mathrm{~s}$. 99

Figura 4.3. Comparação do fator de intensificação, $\mathrm{F}$, entre os métodos de previsao na literatura, $\mathrm{D}=1 \mathrm{~mm}, \mathrm{G}=300 \mathrm{~kg} / \mathrm{m}^{2} \mathrm{~s}, \mathrm{~T}_{\text {sat }}=31^{\circ} \mathrm{C}$ e $\phi=15 \mathrm{~kW} / \mathrm{m}^{2} \ldots 103$

Figura 4.4. Comparação do fator de supressão, $\mathrm{S}$, entre os métodos de previsão na literatura, R134a, $D=1 \mathrm{~mm}, \mathrm{G}=300 \mathrm{~kg} / \mathrm{m}^{2} \mathrm{~s}, \mathrm{~T}_{\mathrm{sat}}=31^{\circ} \mathrm{C}$ e $\phi=15 \mathrm{~kW} / \mathrm{m}^{2}$.

104

Figura 4.5. Contribuções ao CTC das parcelas convectiva e de ebulição nucleada segundo o método proposto por Bertsch et al. (2009). 106

Figura 4.6. Contribuções ao CTC das parcelas convectiva e de ebulição nucleada segundo o método proposto por Kanizawa et al. (2016). 106

Figura 4.7. Diagrama ilustrativo do modelo de 3 zonas proposto por Thome et al. (2004). 110

Figura 4.8. Efeito do diâmetro e da temperatura de saturação no método de previsão de Thome et al. (2004), R134a, G = 500 kg/m² s, $\phi=20 \mathrm{~kW} / \mathrm{m}^{2}$. 112

Figura 4.9. Representação esquemática de escoamento anular, Cioncolini e Thome (2011). 113

Figura 4.10. Comparação dos métodos empiricos de coeficiente de transferência de calor para microcanais, $\mathrm{G}=500 \mathrm{~kg} / \mathrm{m}^{2} \mathrm{~s}, \mathrm{D}=1,0 \mathrm{~mm}, \mathrm{~T}_{\mathrm{sat}}=31{ }^{\circ} \mathrm{C}, \phi=15$ $\mathrm{kW} / \mathrm{m}^{2}, \mathrm{R} 134 \mathrm{a}$ 117

Figura 4.11. Comparação dos métodos de coeficiente de transferência de calor para microcanais, $\mathrm{G}=200 \mathrm{~kg} / \mathrm{m}^{2} \mathrm{~s}, \mathrm{D}=1,0 \mathrm{~mm}, \mathrm{~T}_{\mathrm{sat}}=22{ }^{\circ} \mathrm{C}, \phi=15 \mathrm{~kW} / \mathrm{m}^{2}$, a) $\mathrm{R} 134 \mathrm{a}, \mathrm{b})$ Isobutano. 118

Figura 4.12. Efeito da geometria do canal no coeficiente de transferencia de calor, R134a, $\mathrm{G}=100 \mathrm{~kg} / \mathrm{m}^{2} \mathrm{~s}, \mathrm{D}_{\mathrm{eq}}=2,2 \mathrm{~mm}, \phi=10 \mathrm{~kW} / \mathrm{m}^{2} \mathrm{e} \mathrm{T}_{\mathrm{sat}}=31^{\circ} \mathrm{C}$, Tibiriçá et al, (2013). 123

Figura 4.13. Efeito do fator de forma nos tubos achatados, Tibiriçá et al. (2013): a) $\mathrm{G}=$ $100 \mathrm{hg} / \mathrm{m}^{2} \mathrm{~s}$ e $\left.\phi=10 \mathrm{~kW} / \mathrm{m}^{2}, \mathrm{~b}\right) \mathrm{G}=400 \mathrm{hg} / \mathrm{m}^{2} \mathrm{~s}$ e $\phi=15 \mathrm{~kW} / \mathrm{m}^{2}$ 124 
Figura 4.14. Comparação dos dados experimentais de Agostini et al. (2008b) e CostaPatry et al. (2012) para condições experimentais proximas e fatores de forma distintos. 125

Figura 4.15. Comparação do banco de dados experimentais levantado na literatura com os métodos de previsao de: a) Bertsch (2009) e b) Liu e Winterton (1991).

Figura 5.1. Registro fotográfico da bancada experimental (Nov-2014) ....................... 131

Figura 5.2. Diagrama esquemático do circuito auxiliar............................................... 132

Figura 5.3. Diagrama esquemático do circuito do refrigerante. .................................. 133

Figura 5.4. Diagrama pressão vs. entalpia do refrigerante ao longo do circuito de testes

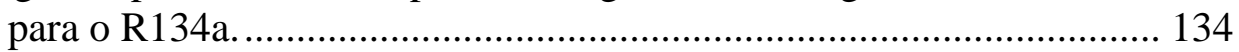

Figura 5.5. a) Imagem da superficie interna do tubo, b) Relevo em 3D da superficie

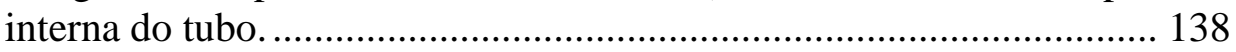

Figura 5.6. a) Matriz composta de duas peças de aço inoxidável utilizadas na conformação do tubo circular, b) Vista de um corte da seção transversal quadrada obtida a partir do processo de conformação. 140

Figura 5.7. Seção transversal dos tubos, a) quadrado, b) triangular............................. 140

Figura 5.8. Diagrama esquemático da seção de pré-aquecimento e testes. 141

Figura 5.9. Variação do comprimento onde $T_{p}$ torna-se igual à temperatura do fluido. 143

Figura 5.10. Diagrama esquemático indicando os componetnes do sistema de aquisição e

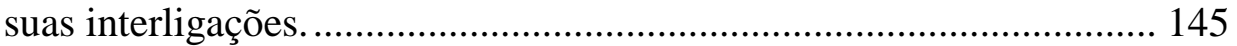

Figura 5.11. Registro fotográfico do detector de gases inflamáveis fixo, marca RIKEN, serie SD-705, modelo GP........................................................... 147

Figura 5.12. Registro fotográfico do sensor de gases inflamáveis.

Figura 5.13. Estimativa da perda de calor na seçao de pré-aquecimento ou de testes para o ambiente em função da temperatura de ambiente.

Figura 5.14. Comparação entre diversos métodos para a estimativa da temperatura local do fluido.

Figura 5.15. Gradiente da perda de pressão monofasica para os testes em canal circular. 165

Figura 5.16. Dimensão caracteristica para poligonos regulares segundo Ahmed e Brundrett (1971) ......................................................................... 166

Figura 5.17. Gradiente da perda de pressão monofásica para os testes em canal quadrado. 168

Figura 5.18. Gradiente da perda de pressão monofásica para os testes em canal triangular. 169

Figura 5.19. Coeficiente de transferência de calor monofásico para os fluidos testados. 170

Figura 5.20. Coeficiente de transferência de calor monofásico para as diversas geometrias testadas. 
Figura 5.21. Comparação dos resultados para CTC durante a ebuliçao convectiva levantados em diferentes datas para o canal triangular, $\mathrm{G}=500 \mathrm{~kg} / \mathrm{m}^{2} \mathrm{~s}$ e $\phi=55 \mathrm{~kW} / \mathrm{m}^{2}$. 172

Figura 6.1. Distribuição do banco de dados experimental correspondente a: a) geometria da seção transversal, b) fluido de trabalho e c) temperatura de saturação.

Figura 6.2. Distribuição do banco de dados experimental segundo as faixas de: a) velocidades mássicas e b) títulos de vapor. 177

Figura 6.3. Distribuição do banco de dados experimental segundo os resultados de gradiente de pressão. 177

Figura 6.4. Distribuição dos regimes de escoamento do banco de dados experimental baseado no número de Reynolds das fases separadas. 178

Figura 6.5. Ilustração do efeito da velocidade mássica no gradiente da perda de pressao. 179

Figura 6.6. Ilustrações do efeito da temperatura de saturação no gradiente da perda de pressão. 180

Figura 6.7. Ilustraçoes do efeito do fluido no gradiente da perda de pressao bifasica num tubo circular, $D=1,1 \mathrm{~mm}$.

Figura 6.8. Ilustração do efeito da geometria da seção transversal no gradiente da perda de pressao bifasica.

Figura 6.9. Efeito da geometria da seção transversal no gradiente da perda de pressao bifasica.

Figura 6.10. Comparação dos dados experimentais do gradiente da perda de pressao com o modelo homogenêo com a viscosidade da mistura dada por Cicchitti et al. (1960). 188

Figura 6.11. Comparação dos dados experimentais do gradiente da perda de pressão com os métodos de a) Sun e Mishima (2009b) e b) Kim e Mudawar (2012).

Figura 6.12. Comparação dos dados experimentais do gradiente da perda de pressão com o método de Del Col et al. (2013). 190

Figura 6.13. Comparação dos dados experimentais do gradiente da perda de pressão com o método de Müller-Steinhagen e Heck (1986). 191

Figura 6.14. Comparação das tendências da perda de pressão de acordo aos métodos de previsão da literatura e dados experimentais para o fluido R134a, a) canal quadrado e b) canal triangular. 193

Figura 6.15. Comparação das tendências da perda de pressão de acordo aos métodos de previsão da literatura e dados experimentais para o fluido a) R1234ze(E) e b) R600a. 194

Figura 6.16. Comparação das tendências da perda de pressão de acordo aos métodos de previsão da literatura e dados experimentais para o fluido R1234yf., . 195

Figura 6.17. Coeficiente $\omega$ ideal em funçao do número de Reynolds da mistura escoando como a fase gasosa. 
Figura 6.18. Fluxograma para a implementação do método proposto para perda de pressão.

Figura 6.19. Comparação do banco de dados experimental com o método de previsão proposto no presente estudo. 201

Figura 6.20. Parcela dos dados experimentais previstos segundo métodos da literatura com erro inferior a $20 \%$ de acordo com o fluido de trabalho. 202

Figura 6.21. Parcela dos dados experimentais previstos segundo métodos da literatura com erro inferior a $20 \%$ de acordo com a geometria da seção transversal da tubulação. 202

Figura 6.22. Parcela dos dados experimentais previstos segundo métodos da literatura com erro inferior a $20 \%$ de acordo com a) a faixa de título de vapor, b) faixa de velocidade mássica.

Figura 6.23. Parcela dos dados experimentais previstos segundo métodos da literatura com erro inferior a $20 \%$ de acordo à faixa do gradiente da perda de pressão. 204

Figura 6.24. Efeito da velocidade mássica no gradiente da perda de pressão previsto pelo método proposto no presente estudo. 205

Figura 6.25. Efeito da temperatura de saturação no gradiente da perda de pressão previsto pelo método proposto no presente estudo 205

Figura 6.26. Efeito do fluido de trabalho e do diametro no gradiente da perda de pressão previsto pelo método proposto no presente estudo. 206

Figura 7.1. Distribuição do banco de dados experimental correspondente a: a) geometria da seção transversal, b) fluido de trabalho. 210

Figura 7.2. Distribuição do banco de dados experimental segundo as faixas de: a) velocidades mássicas, b) fluxos de calor, c) títulos de vapor. 211

Figura 7.3. Distribuição do banco de dados segundo as faixas de coeficientes de transferência de calor.

Figura 7.4. Distribuição do banco de dados experimental segundo regimes de escoamento baseado no número de Reynolds das fases separadas.

Figura 7.5. Ilustrações do efeito do fluxo de calor no CTC para ebulição convectiva dos fluidos: a) R1234ze(E) e b) R600a.

Figura 7.6. Ilustrações do efeito da velocidade massica no CTC durante a ebulição convectiva do R600a. 215

Figura 7.7. Ilustração do efeito da temperatura de saturação no CTC para a ebulição convectiva do R134a. 216

Figura 7.8. Ilustração do efeito da temperatura de saturação no CTC durante a ebulição convectiva do R600a. 217

Figura 7.9. Ilustração do efeito do fluido no CTC durante a ebulição convectiva para $T_{\text {sat }}$ $=31^{\circ} \mathrm{C}$. 218

Figura 7.10. Ilustração do efeito do fluido no CTC durante a ebulição convectiva para $T_{\text {sat }}$ $=41^{\circ} \mathrm{C}$. 
Figura 7.11. Ilustração do efeito da geometria da seção transversal do canal no CTC durante a ebulição convectiva em condiçoes de fluxos de calor reduzidos.

220

Figura 7.12. Ilustração do efeito da geometria da seção transversal do canal no CTC durante a ebulição convectiva para o R134a, $\mathrm{G}=500 \mathrm{~kg} / \mathrm{m}^{2} \mathrm{~s}, \mathrm{~T}_{\mathrm{sat}}=31^{\circ} \mathrm{C}$ e $\phi=55 \mathrm{~kW} / \mathrm{m}^{2}$. 221

Figura 7.13. Ilustração do efeito da geometria da seção transversal do canal no CTC durante a ebulição convectiva do R134a, $\mathrm{T}_{\text {sat }}=41^{\circ} \mathrm{C}, \mathrm{G}=400 \mathrm{~kg} / \mathrm{m}^{2} \mathrm{~s}$ e $\phi$ $=45 \mathrm{~kW} / \mathrm{m}^{2}$.

Figura 7.14. Comparação dos dados experimentais de CTC com o método de previsão de Kew e Cornwell (1997). 226

Figura 7.15. Comparação dos dados experimentais de CTC com o método de previsão de: a) Sun e Mishima (2009b), b) Kim e Mudawar (2013a). 228

Figura 7.16. Comparação dos dados experimentais de CTC com o método de previsão de Kanizawa et al. (2016) segregados por a) geometria da seçao transversal, b) fluido de trabalho. 229

Figura 7.17. Comparação das tendencias do CTC de acordo com os métodos de previsão da literatura e dados experimentais para o fluido R134a na geometria quadrada. 230

Figura 7.18. Comparação das tendencias do CTC de acordo aos métodos de previsão da literatura e dados experimentais para o fluido R134a. 231

Figura 7.19. Comparação das tendencias do CTC de acordo aos métodos de previsão da literatura e dados experimentais para o fluido R1234ze(E). 232

Figura 7.20. Comparação das tendencias do CTC de acordo aos métodos de previsão da literatura e dados experimentais para o fluido R1234yf. 233

Figura 7.21. Comparação das tendencias do CTC de acordo aos métodos de previsão da literatura e dados experimentais para o fluido isobutano..................... 234

Figura 7.22. Fluxograma para a implementação do método proposto para coeficiente de transferencia de calor pré-secagem de parede. 238

Figura 7.23. Comparação dos dados experimentais de CTC com o método de previsão proposto segregados por fluido para um canal circular. 240

Figura 7.24. Parcela dos dados experimentais previstos com erro inferior a $\pm 20 \%$ segundo métodos da literatura e o proposto neste estudo de acordo ao fluido de trabalho. 241

Figura 7.25. Parcela dos dados experimentais previstos com erro inferior a $\pm 30 \%$ segundo métodos da literatura e o proposto neste estudo de acordo à faixa de fluxo de calor $\left(\mathrm{kW} / \mathrm{m}^{2}\right)$. 241

Figura 7.26. Parcela dos dados experimentais previstos com erro menor a $\pm 30 \%$ segundo métodos da literatura e o proposto neste estudo de acordo à faixa: a) título de vapor, b) velocidade mássica $\left(\mathrm{kg} / \mathrm{m}^{2} \mathrm{~s}\right)$.

Figura 7.27. Parcela dos dados experimentais previstos com erro inferior a $\pm 20 \%$ segundo métodos da literatura e o proposto de acordo à faixa de coeficiente de transferência de calor $\left(\mathrm{kW} / \mathrm{m}^{2} \mathrm{~K}\right)$. 
Figura 7.28. Comparação do efeito do fluxo de calor no comportamento do CTC com o acréscimo de $\mathrm{x}$ segundo o método proposto e os dados experimentais, $\mathrm{R} 1234 \mathrm{ze}(\mathrm{E})$. 244

Figura 7.29. Comparação do efeito do fluxo de calor no comportamento do CTC com o acréscimo de $\mathrm{x}$ segundo o método proposto e os dados experimentais, R600a. 245

Figura 7.30. Comparação do efeito da velocidade mássica no comportamento do CTC com o acréscimo de $\mathrm{x}$ segundo o método proposto e os dados experimentais, R134a. 245

Figura 7.31. Comparação do efeito da velocidade mássica no comportamento do CTC com o acréscimo de $\mathrm{x}$ segundo o método proposto $\mathrm{e}$ os dados experimentais, R1234yf. 246

Figura 7.32. Comparação do efeito da temperatura de saturação no comportamento do CTC com o acréscimo de x segundo o método proposto e os dados experimentais, $\mathrm{R} 1234 \mathrm{ze}(\mathrm{E})$. 247

Figura 7.33. Comparação do efeito da temperatura de saturação no comportamento do CTC com o acréscimo de $\mathrm{x}$ segundo o método proposto e os dados experimentais, R600a.

Figura 7.34. Comparação do efeito do fluido no comportamento do CTC com o acréscimo de $\mathrm{x}$ segundo o método proposto e os dados experimentais, $\mathrm{T}_{\mathrm{sat}}=31^{\circ} \mathrm{C}$. 248

Figura 7.35. Comparação do efeito do fluido no comportamento do CTC com o acréscimo de $\mathrm{x}$ segundo o método proposto e os dados experimentais, $\mathrm{T}_{\mathrm{sat}}=41^{\circ} \mathrm{C}$.

Figura 7.36. Comparação do efeito do diametro no comportamento do CTC com o acréscimo de $x$ segundo o método proposto e dados experimentais do presente estudo, de Tibiriçá e Ribatski (2010) e Kanizawa et al. (2016). 251

Figura 7.37. Configuração geometrica dos microtrocadores para seçoes circular, quadrada e triangular. 252

Figura 7.38. Fator de desempenho para as geometria de seção transversal avaliadas neste estudo, considerando as configuraçoes ilustradas na Figura 7.37....... 254

Figura A.1.- Desenvolvimento da camada limite laminar num tubo circular, Incropera et al. (1990). 


\section{LISTA DE TABELAS}

Tabela 3.1. Correlações da literatura para a viscosidade da mistura homogênea. 57

Tabela 3.2. Métodos de previsão da perda de pressão baseados em multiplicadores bífasicos desenvolvidos para canais convencionais.

Tabela 3.3. Métodos de previsao da perda de pressão baseados em multiplicadores bifasicos desenvolvidos para canais de reduzido diâmetro. ................... 64

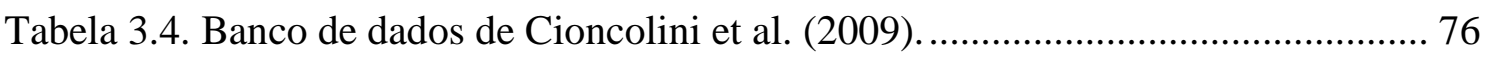

Tabela 3.5. Parâmetros para a equação de Olimeans et al. (1986)................................ 77

Tabela 3.6. Estudos de perda de pressão em dutos não circulares. ............................... 83

Tabela 3.7. Dimensões dos microcanais retangulares avaliados por Harirchian e Garimella (2012)................................................................................ 85

Tabela 3.8. Estudos sobre preda de pressão para fluidos de reduzido GWP e naturais. 87

Tabela 4.1. Cálculo do CTC referente a ebuliçao nucleada segundo o método de Shah (1982). 91

Tabela 4.2. Constante do par fluido/superficie propostas por Kandlikar (1990). .......... 92

Tabela 4.3. Métodos de previsão do CTC estritamente empíricos para microcanais..... 93

Tabela 4.4. Análise dos comportamentos dos métodos estrictamente empiricos. *........ 96

Tabela 4.5. Métodos de previsão do CTC baseados na superposição de efeitos para

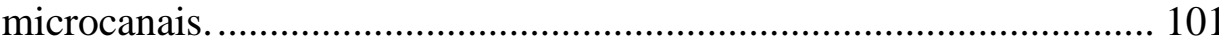

Tabela 4.6. Comparação entre os comportamentos do CTC segundo os métodos baseados na superposição de efeitos.

Tabela 4.7. Análise dos comportamentos dos métodos baseados em aspectos fenomenológicos. 116

Tabela 4.8. Estudos sobre o coeficiente de transferência de calor em canais retangulares.

Tabela 4.9. Erro médio absoluto (EMA) e a porcentagem de prediçoes dentro do $\pm 30 \%$ para diferentes faixas de fatores de forma........................................ 127

Tabela 4.10. Estudos sobre o CTC para fluidos de reduzido GWP e naturais ............. 128

Tabela 5.1. Características operacionais da microbomba........................................... 136

Tabela 5.2. Dimensões dos canais nas matrizes utilizadas no processo de conformação.

Tabela 5.3. Características geométricas dos canais avaliados no presente estudo....... 141

Tabela 5.4. Especificações da câmera de alta velocidade. .......................................... 144

Tabela 5.5. Relação entre a resolução da câmera e a frequência de aquisição de imagens. 144

Tabela 5.6.- Sensores e atuadores utilizados na bancada experimental. ...................... 146

Tabela 5.7. Características do detector de gases inflamáveis.................................... 148 
Tabela 5.8. Propriedades físicas, químicas e termodinâmicas dos fluidos avaliados no

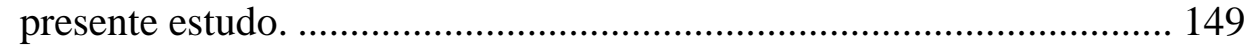

Tabela 5.9. Condições experimentais avaliadas para escoamento monofásico............. 150

Tabela 5.10. Condições experimentais avaliadas para escoamento bifásico................ 150

Tabela 5.11. Incertezas dos parâmetros medidos e estimados. .................................... 173

Tabela 6.1. Condições experimentais do banco de dados levantado no presente estudo. 175

Tabela 6.2. Velocidade in situ da fase gás para as condiçoes experimentais ilustradas na

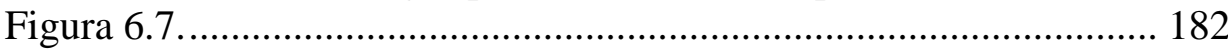

Tabela 6.3. Erro médio absoluto e parcela dos dados com previsões com erro entre $\pm 20 \%$

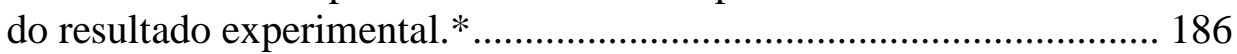

Tabela 6.4. Parámetros estatísticos da comparação entre o método proposto e dados

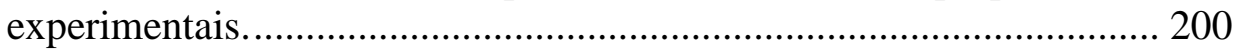

Tabela 6.5. Erro médio absoluto e porcentagem de previsões dentro do $\pm 30 \%$ resultante da comparação entre o método proposto e o banco de dados da literatura.

Tabela 7.1. Condições experimentais do banco de dados para o CTC levantados neste estudo. 210

Tabela 7.2. Erro médio absoluto e parcela das previsões com erro entre $\pm 30 \%$ do resultado experimental.* 224

Tabela 7.3. Parâmetros estatísticos resultantes da comparação do método desenvolvido e o banco de dados experimental levantado no presente estudo. 239

Tabela 7.4. Parâmetros estatísticos resultantes da comparação do método desenvolvido e dados independentes levantados na literatura. 250

Tabela 7.5. Valores do calor dissipado e da potência de bombeamento para os disspadores de calor não-circulares comparados ao circular, $x_{i n}=0,20, \Delta T=4^{\circ} \mathrm{C}, m_{\text {total }}$ $=0,00655 \mathrm{~kg} / \mathrm{s}$ 



\section{LISTA DE SÍMBOLOS}

\section{Letras latinas}

\begin{tabular}{|c|c|c|c|}
\hline$A$ & Area, $\mathrm{m}^{2}$ & $X$ & Parametro de Martinelli. \\
\hline$B d$ & Número de Bond & $z$ & Posicao ao longo do tubo, m. \\
\hline Bo & Número de ebulição & & \\
\hline$C_{C}$ & $\begin{array}{l}\text { Razao da áreas da vena contracta, } \\
\text { adimensional. }\end{array}$ & \multicolumn{2}{|c|}{ Letras griegas } \\
\hline Co & Número de confinamento & $\alpha$ & Fração de vazio, adimensional. \\
\hline$d p / d z$ & Gradiente da perda de pressão, $\mathrm{kPa} / \mathrm{m}$ & $\beta$ & $\begin{array}{l}\text { Coeficiente da energia de movimento, } \\
\text { adimensional }\end{array}$ \\
\hline$D$ & Diametro, m. & $\eta$ & $\begin{array}{l}\text { Parcela de dados prevista dentro de } \\
\text { uma determinada faixa de erro, } \% \text {. }\end{array}$ \\
\hline$F$ & Fator de intensificaçao & $\phi$ & Fluxo de calor, kW/m². \\
\hline$f$ & Fator de atrito, adimensional. & $\lambda$ & Coeficiente empirico, dimensionless. \\
\hline$G$ & Velocidade massica, $\mathrm{kg} / \mathrm{m}^{2} \mathrm{~s}$. & $\mu$ & Viscosidade dinamica, Pa.s. \\
\hline$J$ & Velocidade superficial, $\mathrm{m} / \mathrm{s}$ & $\rho$ & Densidade, $\mathrm{kg} / \mathrm{m}^{3}$. \\
\hline$h$ & $\begin{array}{l}\text { Coeficiente de transferência de calor, } \\
\mathrm{kW} / \mathrm{m} 2 \mathrm{~K}\end{array}$ & $\varsigma$ & Fator de forma, adimensional. \\
\hline$i$ & Entalpia, J/kg. & $\sigma_{A}$ & $\begin{array}{l}\text { Razao da area de } \\
\text { expansao/contracçao, adimensional. }\end{array}$ \\
\hline$I$ & Electrical current, A. & $\omega$ & Coeficiente empirico, adimensional. \\
\hline$K$ & $\begin{array}{l}\text { Coeficiente de irreversibilidade, } \\
\text { adimensional }\end{array}$ & \multicolumn{2}{|l|}{ Subscripts } \\
\hline$k$ & $\begin{array}{l}\text { Fator de correção devido à quantidade } \\
\text { de movimento, adimensional. }\end{array}$ & $1 \phi$ & Monofásico \\
\hline$L$ & Comprimento, m. & $2 \phi$ & Bifasico \\
\hline$\dot{m}$ & Vazão mássica, kg/s. & $A c$ & Aceleracional. \\
\hline$p$ & Pressão, kPa. & con & Contracçao \\
\hline$P$ & Potência elétrica, W. & $\exp$ & Expansão \\
\hline$P e$ & Perimetro, m. & $e q$ & Equivalente \\
\hline$Q$ & Calor, W. & $f$ & Friccional \\
\hline$R a$ & Rugosidade media aritmetica, $\mu \mathrm{m}$. & eff & Efetivo \\
\hline$R e$ & Número de Reynolds, adimensional. & ent & Entrada \\
\hline$R t$ & Maximum roughness height, $\mu \mathrm{m}$. & int & Interno \\
\hline$S$ & Fator de supressão de bolhas & $I$ & Irreversivel \\
\hline$T$ & Temperatura, ${ }^{\circ} \mathrm{C}$. & $H$ & Hidraulico \\
\hline$V$ & Voltagem, V. & $L$ & Líquido saturado \\
\hline$W e$ & Número de Weber & $L 0$ & Mistura bifasica como líquido \\
\hline$x$ & Título de vapor, adiomensional. & $G$ & Gás saturado \\
\hline
\end{tabular}




$\begin{array}{llll}L G & \begin{array}{l}\text { Diferença entre propriedades do } \\ \text { líquido e gás }\end{array} & R & \text { Reversivel } \\ G 0 & \text { Mistura bifasica como gas } & s a t & \text { Saturaçao } \\ \text { Sai } & \text { Saída } & s t & \text { Seção de testes } \\ p a & \text { Pre-aquecimento } & s v & \text { Seção de visualização } \\ \text { Siglas } & & & \\ \text { CTC } & \text { Coeficiente de transferência de calor } & \text { ODP } & \text { Ozone Depletion Potential } \\ \text { EMA } & \text { Erro Médio Absoluto } & G W P & \text { Global Warming Potential }\end{array}$




\section{SUMÁRIO}

CAPÍTULO 1 - Introdução............................................................................................ 31

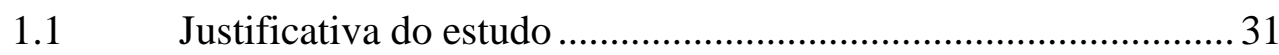

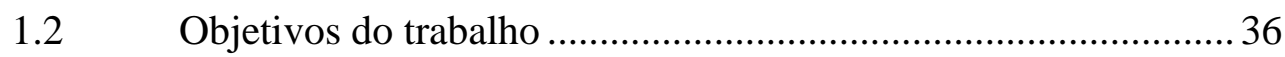

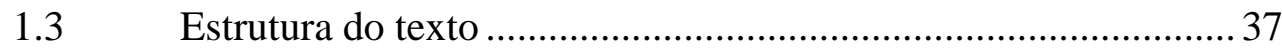

CAPÍTULO 2 - Fundamentos de ebulição convectiva .......................................... 39

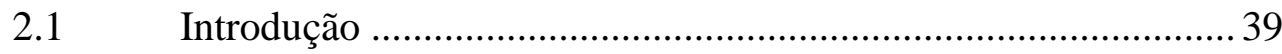

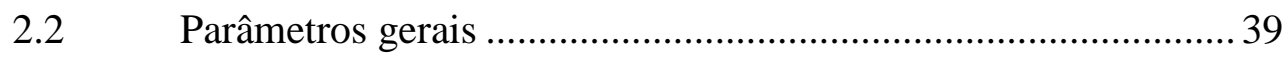

2.3 Números Adimensionais ...................................................... 45

2.4 Padrões de escoamento ..................................................... 48

2.4.1 Padrões de escoamento em canais convencionais ...................... 48

2.4.2 Padrões de escoamento em canais de reduzido diâmetro............. 50

2.5 Ebulição convectiva no interior de tubos ................................ 51

CAPÍTULO 3 - Revisão bibliográfica sobre Perda de pressão .......................... 54

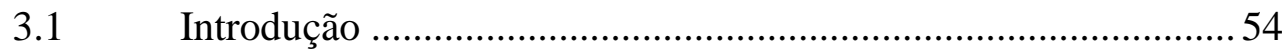

3.2 Componentes da perda de pressão ….........................................54

3.3 Métodos de previsão da perda de pressão por atrito em escoamento

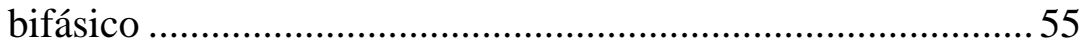

3.3.1 Modelo homogêneo............................................................ 56

3.3.2 Métodos baseados em multiplicadores bifásicos ........................ 58

3.3.3 Métodos estritamente empíricos ................................................ 68

3.3.4 Métodos baseados em análises fenomenológicas ..................... 71

3.3.5 Análise e comparação entre métodos de previsão de perda de

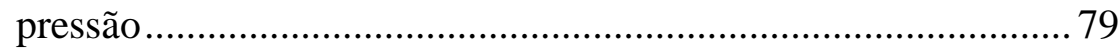

3.4 Descrição dos estudos experimentais da literatura..................... 82

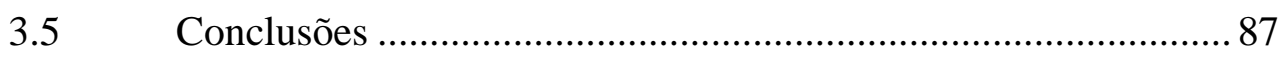


CAPÍTULO 4 - Revisão bibliográfica sobre o Coeficiente de Transferência de calor ....................................................................................................... 89

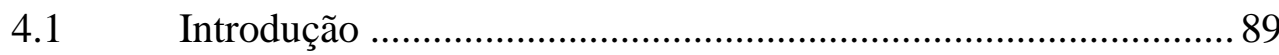

4.2 Métodos de previsão do CTC em escoamento bifásico .............. 89

4.2.1 Métodos de previsão do CTC estritamente empíricos ................ 90

4.2.2 Métodos de previsão do CTC baseados na superposição de

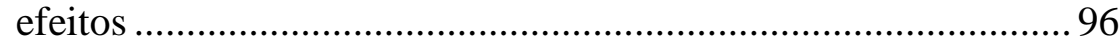

4.2.3 Métodos fenomenológicos para previsão do CTC ..................... 108

4.2.4 Comparação das tendências fornecidas pelos métodos de previsão do CTC

4.3 Descrição dos estudos experimentais da literatura sobre o

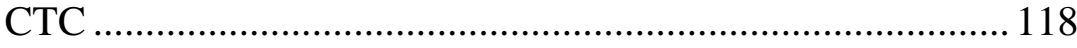

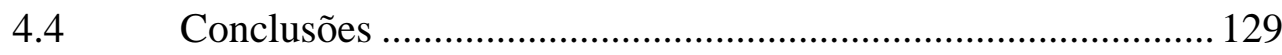

CAPÍTULO 5 - Bancada e Metodologia Experimental ................................. 131

Introdução .................................................................. 131

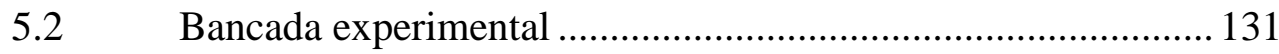

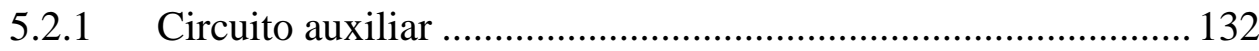

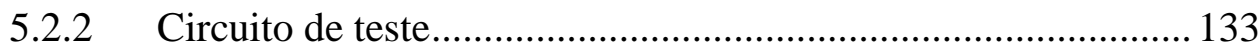

5.2.3 Principais componentes do circuito de testes .......................... 135

5.3 Procedimento experimental.............................................. 148

5.3.1 Condições experimentais da banco de dados levantado............ 148

5.3.2 Procedimento de carga e descarga do fluido refrigerante ......... 151

5.3.3 Procedimento experimental para escoamento monofásico ....... 152

5.3.4 Procedimento experimental para escoamento bifásico ............. 153

5.4 Tratamento de dados ...................................................... 154

5.4.1 Velocidade mássica............................................................. 154

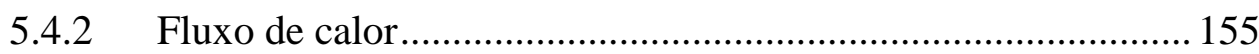

5.4.3 Comprimento de escoamento monofásico na seção de préaquecimento 157 
5.4.4 Temperatura de saturação local do fluido ................................ 157

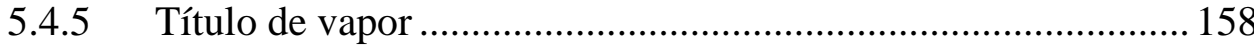

5.4.6 Perda de pressão em escoamento monofásico ........................... 159

5.4.7 Gradiente da perda de pressão por atrito em escoamento bifásico

5.4.8 Coeficiente de transferência de calor ..................................... 162

5.5 Validação do aparato experimental .......................................... 164

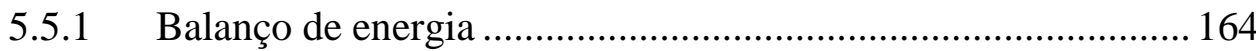

5.5.2 Resultados para perda de pressão monofásica .......................... 164

5.5.3 Resultados para coeficiente de transferência de calor monofásico ............................................................................... 169

5.5.4 Repetitividade dos experimentos ......................................... 171

5.6 Incertezas de parâmetros medidos e estimados......................... 172

CAPÍTULO 6 - Resultados para Perda de pressão e desenvolvimento de um método de previsão......................................................................... 175

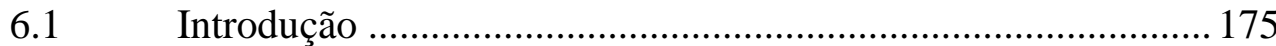

6.2 Descrição e caracterização do banco de dados experimental.... 175

6.3 Análise paramétrica dos resultados experimentais................... 178

6.3.1 Efeitos da velocidade mássica e título de vapor....................... 178

6.3.2 Efeito da temperatura de saturação ........................................... 180

6.3.3 Efeito do fluido de trabalho................................................. 181

6.3.4 Efeito da geometria da seção transversal ................................. 182

6.4 Comparação com métodos de previsão da literatura.................. 184

6.4.1 Avaliação estatística dos métodos de previsão .......................... 185

6.4.2 Avaliação de tendências dos métodos de previsão ................... 192

6.5 Proposição de um método para a previsão da perda de pressão 196

6.5.1 Descrição do método proposto................................................. 196

6.5.2 Comparação com o banco de dados utilizado em seu desenvolvimento ..................................................................... 200 
6.5.3 Análise paramétrica das tendências fornecidas pelo novo

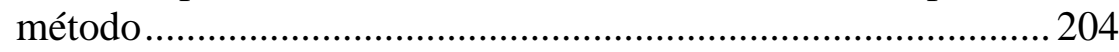

6.5.4 Comparação do novo método com dados da literatura ............. 207

CAPÍTULO 7 - Resultados para coeficiente de transferÊncia de calor e desenvolvimento de um método de previsão............................ 209

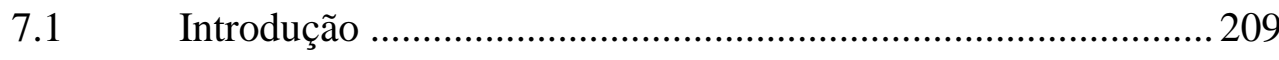

7.2 Descrição e caracterização do presente banco de dados

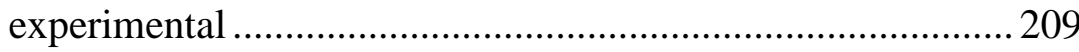

7.3 Análise paramétrica dos resultados experimentais................... 213

7.3.1 Efeito do fluxo de calor e título de vapor.............................. 213

7.3.2 Efeito da velocidade mássica .................................................. 215

7.3.3 Efeito da temperatura de saturação ........................................ 216

7.3.4 Efeito do fluido de trabalho................................................. 217

7.3.5 Efeito da geometria da seção transversal ................................ 220

7.4 Comparação com métodos de previsão da literatura................. 223

7.4.1 Avaliação estatística dos métodos de previsão .......................... 223

7.4.2 Avaliação de tendências dos métodos de previsão .................... 230

7.5 Desenvolvimento de um método de previsão do CTC.............. 235

7.5.1 Descrição do método proposto ................................................. 236

7.5.2 Comparação do novo método com o banco de dados

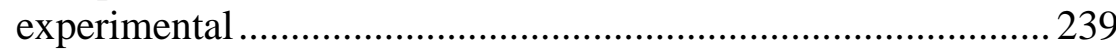

7.5.3 Análise paramétrica das tendências fornecidas pelo método.... 244

7.5.4 Comparação do método proposto com dados independentes da

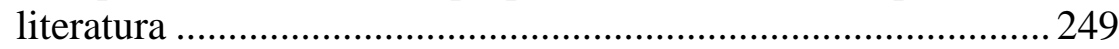

7.6 Análise global do efeito da geometria................................... 251

CAPÍTULO 8 - Conclusões e Recomendações............................................... 257

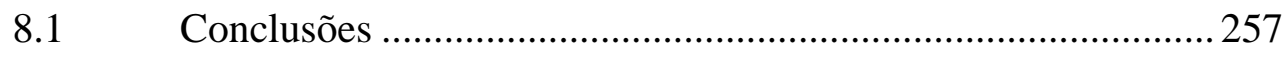

8.2 Recomendações para trabalhos futuros ................................. 261 
REFERENCIAS.

APÊNDICE A - Escoamento monofásico

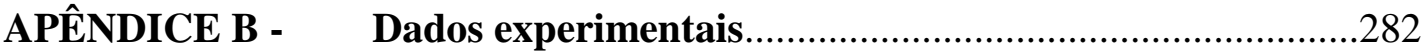





\section{CAPÍTULO 1 - INTRODUÇÃO}

\subsection{Justificativa do estudo}

A partir do início da década de 1990, o número de estudos sobre a ebulição convectiva em canais de diâmetro reduzido se elevou drasticamente devido a diversos motivos, entre os quais se destacam: $i$ ) dissipadores de calor baseados em microcanais possuem claras vantagens, destacando-se superior área de contato com o fluido por unidade de volume, tolerância a operação em pressões elevadas, redução do material usado na fabricação do trocador de calor, decréscimo da carga de refrigerante, e consequentemente, redução de custos e de impactos ambientais; ii) o fluxo de calor a ser dissipado em microprocessadores se elevou exponencialmente nas últimas duas décadas, conforme ilustrado na Figura 1.1; iii) os Protocolos de Montreal e Kyoto trouxeram a necessidade de fluidos refrigerantes com potencial de destruição da camada de ozônio $(O D P$, Ozone depletion potential) nulo e com fator de aquecimento global (GWP, Global warming potential) inferior a 150, este último responsável pela expectativa de redução progressiva do uso dos fluidos refrigerantes HFCs.

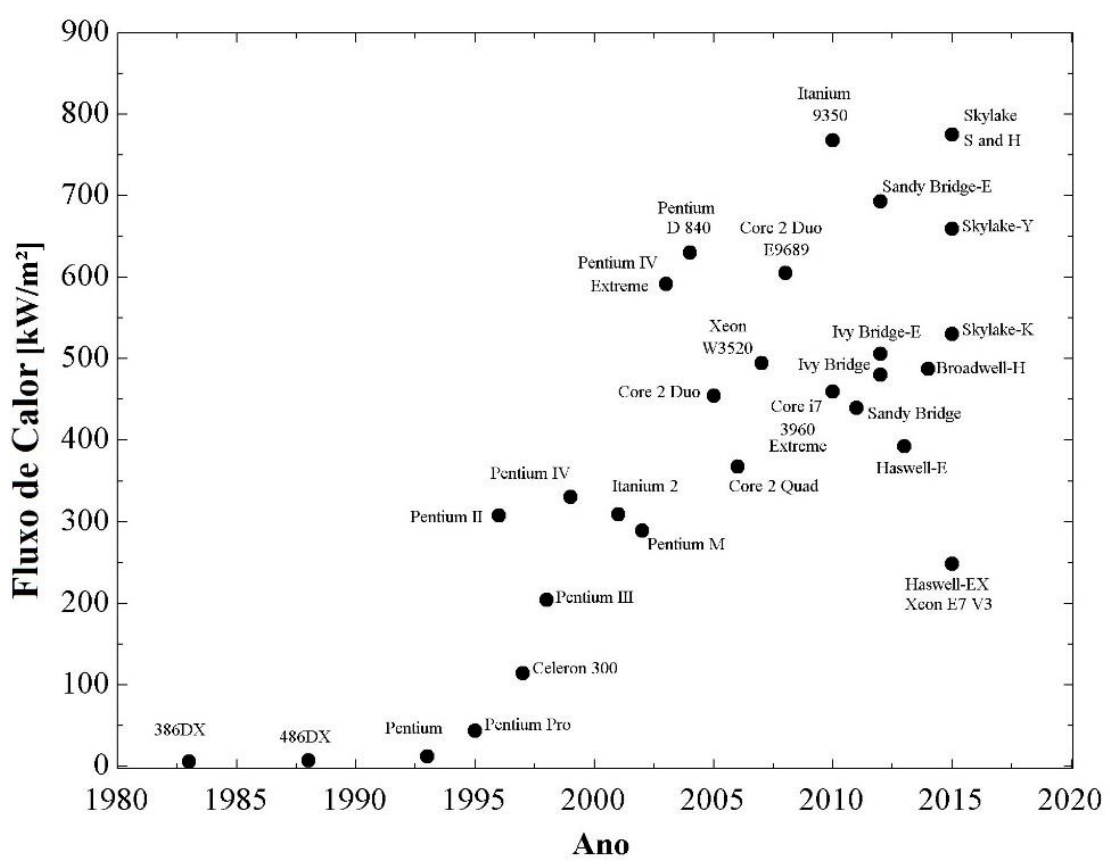

Figura 1.1. Evolução de fluxo de calor dissipado pelos microprocessadores produzidos pela Intel. 
Parcela significativa dos estudos disponíveis na literatura sobre a ebulição convectiva em canais de reduzido diâmetro se dedicaram ao levantamento experimental de resultados para o coeficiente de transferência de calor (CTC), de forma que possam ser utilizados no desenvolvimento de métodos de previsão confiáveis para o projeto de trocadores e dissipadores de calor. Entretanto, vale destacar a importância da correta avaliação da perda de pressão durante o processo de evaporação, pois ela está relacionada à potência de bombeamento, e consequentemente, ao desempenho global do sistema. Além disso, em processos com mudança de fase, variações na pressão estão relacionadas a alterações na temperatura de saturação e, consequentemente, nas diferenças de temperatura entre o refrigerante e o ambiente refrigerado, alterando também, o desempenho do sistema. Este comportamento se acentua em canais de dimensões reduzidas para os quais o gradiente de pressão ao longo dos canais se eleva drasticamente. Soma-se ainda o fato de elevadas perdas de pressão no evaporador implicarem temperaturas de descarga do compressor superiores podendo danificar ou reduzir a vida útil deste equipamento. Tal problema se intensifica para refrigerantes de mais elevada pressão como o R410A, R22 e a amônia.

A Figura 1.2 ilustra o efeito da perda de pressão no evaporador no desempenho de um ciclo de refrigeração de compressão de vapor. O ciclo ilustrado considera um processo de compressão isoentrópico com um título de vapor na aspiração do compressor unitário, um processo de condensação isobárico ocorrendo a temperatura de $50{ }^{\circ} \mathrm{C}$ e expansão isoentálpica.

A partir dos estados termodinâmicos ilustrados na Figura 1.2a e considerando uma mesma vazão mássica, é possível estimar que a perda de pressão no evaporador acarreta um incremento da potência de compressão de $50 \%$ e uma redução da capacidade de refrigeração de aproximadamente $10 \%$. Tal efeito acarreta a redução substancial do coeficiente de desempenho (COP) do ciclo de refrigeração. A Figura 1.2b ilustra a variação do coeficiente de desempenho do ciclo de refrigeração indicado na Figura 1.2a, com a variação da perda de pressão no evaporador. Segundo esta figura, o COP apresenta uma redução de $40 \%$ para uma perda de pressão de $100 \mathrm{kPa}$ em relação a condições com gradientes de pressão desprezíveis. 


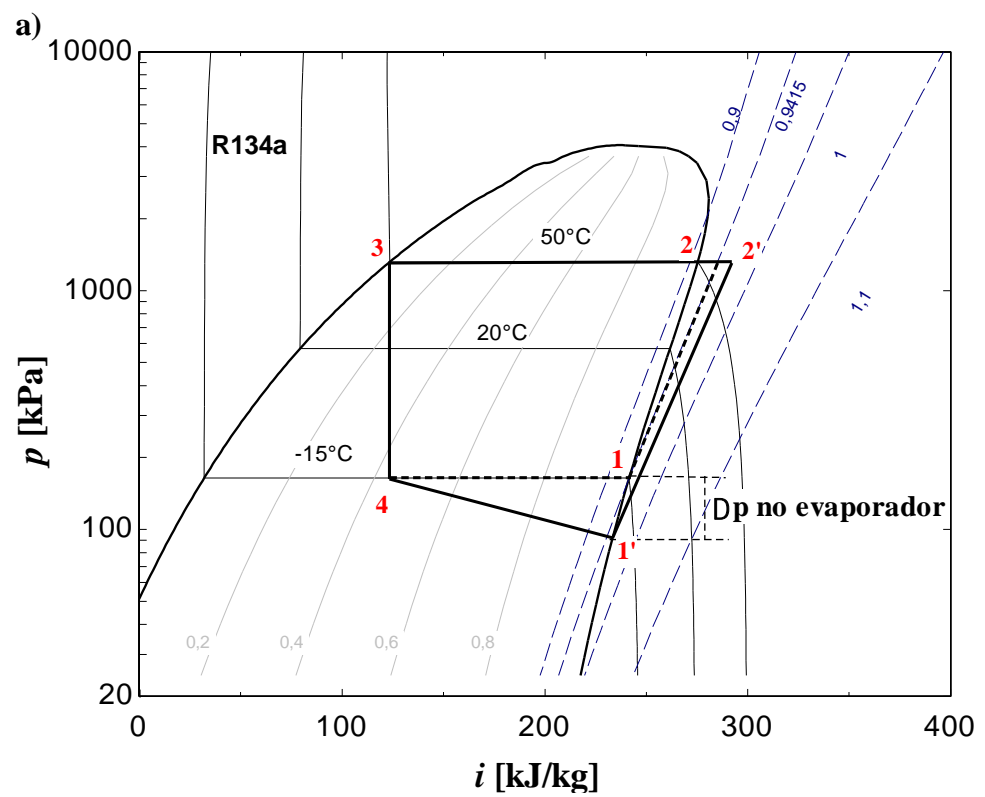

b)

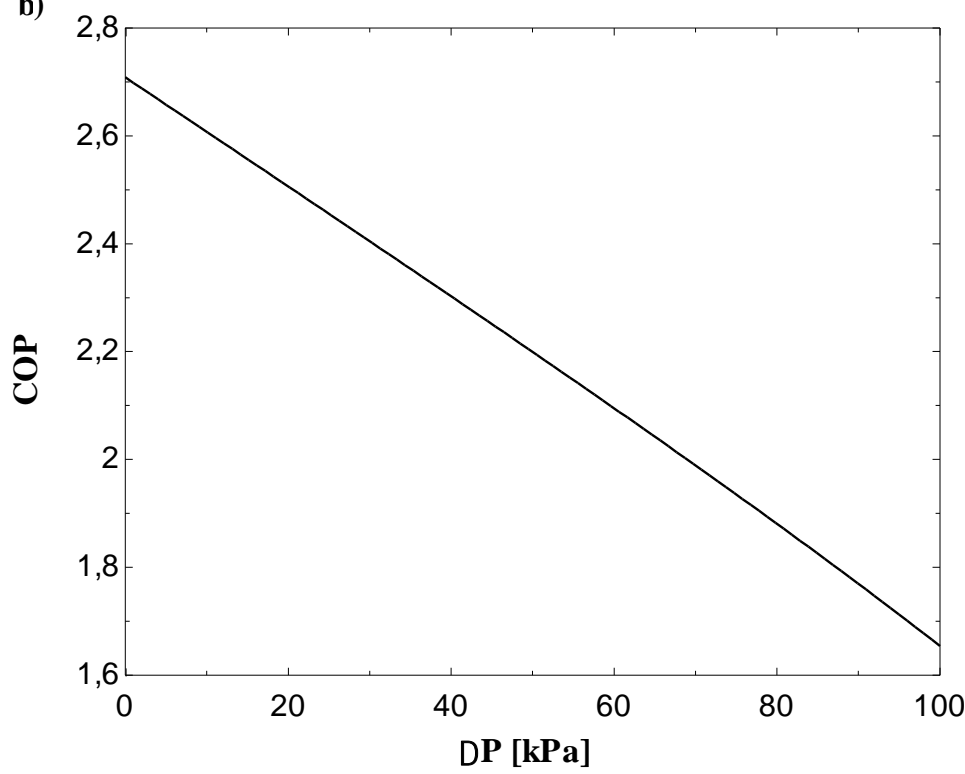

Figura 1.2. a) Ilustração do efeito da perda de pressão no evaporador num ciclo de de refrigeração, para condiçoes de $\left.T_{\text {evap }}=-15^{\circ} \mathrm{C}, T_{\text {cond }}=50^{\circ} \mathrm{C}, \Delta P=100 \mathrm{kPa}, \mathrm{b}\right)$ Variação do coeficiente de desempenho com o incremento da perda de pressão no evaporador.

De uma forma geral, os estudos da literatura sobre ebulição convectiva em canais de reduzido diâmetro cobrem uma ampla faixa de condições experimentais, diferentes fluidos de trabalho e configurações envolvendo canais únicos e multicanais. No entanto, apesar do elevado número de resultados disponíveis, segundo Tibiriçá e Ribatski (2013), cerca de $97 \%$ dos estudos experimentais para canais únicos foram efetuados para geometrias circulares devido, principalmente, a facilidade de adquirir tal configuração no mercado. No entanto, o comportamento da ebulição convectiva em um canal circular pode diferir significativamente do observado para outras geometrias (retangular, quadrado ou 
triangular), devido a parâmetros como: o fator de forma (no caso de um canal retangular), os ângulos dos cantos e orientação das faces (no caso de um canal triangular), o número de faces aquecidas, a possível acumulação de líquido nos cantos com a consequente redução da espessura do filme líquido nas regiões intermediárias das faces, devido a efeitos de tensão superficial.

Mini-trocadores e dissipadores de calor avaliados na literatura e na indústria (trocadores de calor de ar-condicionado) são geralmente constituídos de canais retangulares, principalmente, devido às facilidades no seu processo de fabricação como verificado no setor de condicionamento de ar automotivo. Este fato se evidencia através de uma análise das publicações levantadas no estudo de Tibiriçá e Ribatski (2013), segundo o qual $87 \%$ dos trabalhos relativos a configurações de dissipadores baseados em multicanais envolveram canais retangulares e 9\% canais triangulares. Neste contexto é importante evidenciar a inexistência na literatura de estudos sistemáticos relacionados ao levantamento de comportamentos do coeficiente de transferência de calor característicos da geometria. Comparações envolvendo resultados de laboratórios independentes visando caracterizar tais comportamentos são raramente possíveis devido a discrepâncias entre as condições experimentais avaliadas pelos autores dedicados ao estudo de configurações constituídas de multi-microcanais.

É importante também mencionar, as discrepâncias elevadas de resultados para o coeficiente de transferência de calor para canais únicos encontradas na literatura, as quais podem decorrer de procedimentos experimentais inadequados e da presença de instabilidades. Neste contexto, Ribatski (2013) destaca o relato frequente em publicações da presença de oscilações de pressão e temperatura para os padrões agitante, anular e secagem de parede em estudos de vários autores. Tibiriçá e Ribatski (2010) verificaram a presença de frentes de ondas intermitentes contendo gotículas movendo-se a velocidades aparentemente superiores ao núcleo de vapor ocorrendo concomitantemente a picos na pressão e temperatura locais. Estes autores especulam que essas frentes de ondas de líquidos se encontram num estado metaestável a uma temperatura superior à temperatura de saturação avaliada a partir da pressão local média. Consolini et al. (2007) identificaram oscilações do escoamento devido a instabilidades relacionadas a volumes compressíveis. 
Considerando as dispersões verificadas na literatura entre resultados do coeficiente de transferência de calor e perda de pressão durante a ebulição convectiva em canais de dimensões reduzidas, não é surpresa que os métodos de previsão destes parâmetros não forneçam resultados satisfatórios de bancos de dados para refrigerantes naturais e halogenados. Tal cenário se acentua quando tais métodos são comparados com bancos de dados incluindo resultados para multi-microcanais, distintas geometrias e amplas faixas de diâmetros, velocidades mássicas e fluxos de calor. Ressalta-se, deste modo, a importância de resultados em canais únicos para amplas faixas de condições experimentais para o desenvolvimento de métodos de previsão, pois resultados para multi-microcanais são típicos da configuração avaliada e no caso de canais únicos aspectos como instabilidades podem ser isolados, tornando o resultado adquirido geral.

Por outro lado, é importante mencionar que a maioria dos estudos experimentais envolvendo ebulição convectiva para refrigerantes foram realizados para fluidos tipo HFCs (hidrofluorocarbonetos), que embora apresentem um potencial nulo de destruição da camada de ozônio $(O D P)$ apresentam, geralmente, fatores de aquecimento global $(G W P)$ superiores a 150. Segundo Calm (2008) e Mota-Babiloni et al. (2014), os potenciais substitutos dos HFCs são os hidrocarbonetos, fluidos naturais $\left(\mathrm{CO}_{2}\right.$ e amônia), hidrofluorolefinas (HFOs), refrigerantes HFCs de reduzido GWP e misturas de HFCs e HFOs.

Segundo Thome et al. (2008), os hidrocarbonetos (isobutano, propano, propileno, entre outros) com $O D P$ nulos e GWP desprezíveis se apresentam como soluções interessantes para sistemas de refrigeração devido as propriedades termodinâmicas e de transporte como o volume especifico do vapor saturado cerca de quatro 4 vezes superior aos HFCs. No entanto, apresentam o inconveniente de possuírem elevada flamabilidade, fato que para aplicações com inventário reduzido pode ter sua relevância amortizada. Por outro lado, resultados experimentais com hidrocarbonetos para o CTC e para a perda de pressão por atrito em canais únicos de reduzido diâmetro não são frequentes na literatura.

Os HFOs (R1234ze(E), R1234yf, R1234ze(Z) e R1234zd) também apresentam características positivas em termos ambientais com GWPs inferiores a 10 e ODP nulo. Estes refrigerantes foram desenvolvidos com o objetivo de substituírem o R134a, desta forma, durante seu desenvolvimento buscou-se propriedades termo-físicas próximas às deste fluido. Na literatura, verifica-se um número superior de estudos experimentais para 
estes fluidos em relação aos hidrocarbonetos, considerando investigações sobre ebulição convectiva em canais de reduzidas dimensões, este número se eleva particularmente para o R1234yf, no entanto, para condições experimentais restritas.

Dentro deste contexto, uma vez caracterizadas as lacunas na literatura, o presente estudo trata da análise experimental do efeito da geometria da seção transversal para canais únicos na perda de pressão por atrito e no coeficiente de transferência de calor durante a ebulição convectiva do R134a. São levantados resultados para canais de seção circular, retangular e triangular. Além disso, o estudo também trata da avaliação do desempenho termo-hidráulico de fluidos refrigerantes com GWP desprezíveis em relação ao R134a. Para esta análise resultados foram levantados para um canal com geometria de seção circular para os refrigerantes R1234ze(E), R1234yf e R600a (isobutano). Com base nestes dados, métodos de previsão foram desenvolvidos para o coeficiente de transferência de calor e perda de pressão por atrito. Os métodos propostos preveem satisfatoriamente o banco de dados utilizado em sua elaboração e resultados independentes da literatura. Realizou-se também a análise comparativa do desempenho global para dissipadores de calor das geometrias circular, quadrada e triangular, concluindo ser esta última a melhor opção.

\subsection{Objetivos do trabalho}

A presente tese de doutoramento tem como objetivo geral a caracterização dos efeitos da geometria do fluido refrigerante na perda de pressão e no coeficiente de transferência de calor para canais de dimensões reduzidas durante a ebulição convectiva. Também consta como objetivo a avaliação do desempenho termo-hidráulico de fluidos refrigerantes. Como objetivos específicos se apresentam os seguintes:

Desenvolver um estudo amplo e crítico da literatura envolvendo trabalhos experimentais sobre a perda de pressão e transferência de calor durante o escoamento bifásico em canais não circulares e métodos para previsão deste parâmetro;

> Levantamento e análise de resultados experimentais para a perda de pressão e coeficiente de transferência de calor para diferentes geometrias (circular, retangular e triangular), velocidades mássicas, temperaturas de saturação e fluidos refrigerantes; 
Avaliar comparativamente o desempenho durante a ebulição convectiva em canais de dimensões reduzidas dos refrigerantes HFOs (R1234ze(E) e R1234yf) e isobutano, de reduzido GWP em relação ao R134a com GWP de aproximadamente $1430^{1}$;

- Comparar o banco de dados levantado para gradiente de pressão e coeficiente de transferência de calor com os modelos existentes na literatura;

Desenvolvimento de métodos de previsão para perda de pressão e coeficiente de transferência de calor que incorporem aspectos relacionados ao efeito da geometria dos canais;

\subsection{Estrutura do texto}

A tese encontra-se dividida em 8 capítulos e 1 apêndice. Os capítulos iniciais descrevem aspectos fundamentais do escoamento bifásico e a literatura recente sobre a ebulição convectiva em canais de reduzida dimensão. Seguem descrições do aparato e procedimentos experimentais utilizados neste estudo e a apresentação dos resultados para perda de pressão e coeficiente de transferência de calor. Ao final são apresentados as conclusões deste estudo e recomendações para trabalhos futuros. $\mathrm{O}$ apêndice descreve os métodos da literatura para previsão do fator de atrito e do coeficiente de transferência de calor em escoamentos monofásicos. O texto encontra-se distribuído da seguinte forma:

Capítulo 2: descreve os aspectos fundamentais e as definições dos termos utilizados na descrição de escoamentos bifásicos e da ebulição convectiva no interior de dutos;

Capítulo 3: apresenta estudo crítico da literatura sobre perda de pressão. Nele são descritos os métodos de previsão do gradiente de perda de pressão por atrito. Estudos disponíveis para perda de pressão para escoamento em geometrias não-circulares e para fluidos de reduzido GWP também são detalhados;

Capítulo 4: descreve e analisa criticamente a literatura sobre coeficiente de transferência de calor durante a ebulição convectiva no interior de dutos. Nele são discutidos os métodos para previsão de transferência de calor para macro- e micro escala. Uma análise dos estudos encontrados na literatura para canais não-circulares e fluidos de

\footnotetext{
${ }^{1}$ Valor fornecido pelo fabricante Dupont, para 100 anos.
} 
GWP reduzido também é realizada. Este capítulo inclui ainda uma comparação entre um banco de dados experimentais coletado a partir da literatura e os métodos de previsão do coeficiente de transferência de calor;

Capítulo 5: descreve a bancada e os procedimentos experimentais empregados no presente estudo. Também apresenta as hipóteses adotadas e as metodologias utilizadas no tratamento de dados, validação experimental e propagação de incertezas das medidas calculadas;

Capítulo 6: descreve os resultados levantados no presente estudo para a perda de pressão por atrito com base em uma análise paramétrica do efeito dos parâmetros experimentais. Neste capítulo, os métodos de previsão disponíveis na literatura são comparados aos resultados experimentais. Além disso, o capítulo descreve o desenvolvimento de um novo método para a previsão da perda de pressão por atrito;

Capítulo 7: descreve os resultados obtidos para a coeficiente de transferência de calor. Nele também é apresentada uma análise paramétrica do banco de dados experimental e comparações destes com métodos de previsão disponíveis na literatura. $\mathrm{O}$ capítulo também apresenta um novo método para previsão do coeficiente de transferência de calor durante a ebulição convectiva em canais de reduzido diâmetro.

Capítulo 8: apresenta as principais conclusões baseadas na análise da literatura e nos resultados experimentais. O capítulo também apresenta recomendações para trabalhos futuros;

Apêndice A: neste apêndice são descritas as correlações da literatura para perda de pressão por atrito e coeficiente de transferência de calor durante escoamento monofásico.

Apêndice B: neste apêndice sao mostrados os dados experimentais adquiridos neste estudo. 


\section{CAPÍTULO 2 - FUNDAMENTOS DE EBULIÇÃO CONVECTIVA}

\subsection{Introdução}

Este capítulo descreve os termos e parâmetros quantitativos utilizados na caracterização do escoamento bifásico e da ebulição convectiva no interior de dutos. Conceitos fundamentais necessários para a compreensão do tema são também detalhados.

\subsection{Parâmetros gerais}

Os parâmetros gerais que caracterizam o escoamento bifásico gás-líquido são descritos a seguir:

\section{Velocidade mássica}

A velocidade mássica também denominada de fluxo mássico é dada pela razão entre a vazão mássica e a área transversal do duto, podendo ser definida para as fases gás, líquida e para a mistura bifásica, sendo dada respectivamente pelas seguintes equações:

$$
\begin{aligned}
& G_{G}=\frac{\dot{m}_{G}}{A} \\
& G_{L}=\frac{\dot{m}_{L}}{A} \\
& G=G_{L}+G_{G}
\end{aligned}
$$

\section{Velocidade superficial}

A velocidade superficial de uma fase é a velocidade da parcela da mistura escoando em um canal de dimensões similares. Desta forma, a velocidade superficial de cada fase é definida como a razão entre a vazão volumétrica da fase e a seção transversal do canal, conforme indicado abaixo:

$$
J_{G}=\frac{Q_{G}}{A}=\frac{\dot{m}_{G}}{\rho_{G} A}=\frac{G_{G}}{\rho_{G}}=\frac{x \cdot G}{\rho_{G}}=u_{G} \alpha
$$




$$
J_{L}=\frac{Q_{G}}{A}=\frac{\dot{m}_{L}}{\rho_{L} A}=\frac{G_{L}}{\rho_{L}}=\frac{(1-x) \cdot G}{\rho_{L}}=u_{L}(1-\alpha)
$$

As velocidades superficiais das fases são parâmetros importantes na caracterização de escoamentos bifásicos, e desta forma são encontrados como parâmetros nos eixos coordenados de mapas de padrões de escoamentos isotérmicos. A velocidade superficial da mistura que representa a velocidade do centro de volume da mistura bifásica pode ser calculada segundo a seguinte equação:

$$
J=J_{G}+J_{L}
$$

\section{Razão e velocidade de deslizamento}

A razão de deslizamento entre as fases (slip ratio) é definida como a razão entre as velocidades das fases gasosa, $u_{G}$, e líquida, $u_{L}$ :

$$
S=\frac{u_{G}}{u_{L}}
$$

A velocidade de deslizamento representa a velocidade de deslocamento de cada fase em relação à velocidade do centro de volume da mistura sendo dada para fases gás e líquida respectivamente por:

$$
\begin{aligned}
& u_{G J}=u_{G}-J \\
& u_{L J}=u_{L}-J
\end{aligned}
$$

\section{Título de vapor}

O título de vapor, também denominado de fração de gás do escoamento, é definido como a relação entre as vazões mássicas da fase vapor e a total, conforme a seguinte equação:

$$
x=\frac{\dot{m}_{G}}{\dot{m}}
$$

No caso de processos envolvendo mudança de fase, define-se também o título de vapor de equilíbrio termodinâmico dado por: 


$$
x=\frac{i_{l o c a l}-i_{L, s a t}}{i_{L G}}
$$

onde $i_{\text {local }}$ é a entalpia média local do fluido em uma determinada seção transversal, $i_{L, s a t}$ é a entalpia do líquido saturado e $i_{L G}$ o calor latente de vaporização na temperatura de saturação, com ambos determinado à pressão local.

\section{Fração de vazio}

A fração de vazio está relacionada à parcela de um escoamento bifásico ocupada pela fase gasosa. A fração de vazio pode ser definida de forma local, linear, superficial e volumétrica, conforme ilustrados na Figura 2.1.

a) Local

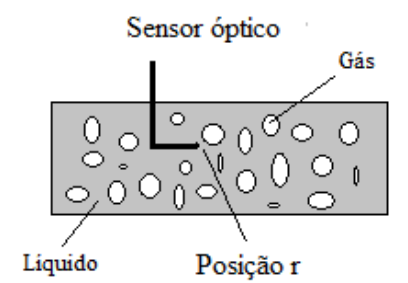

c) Superficial

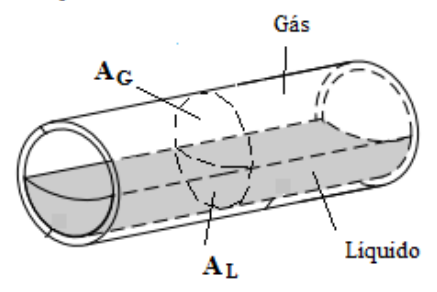

b) Linear

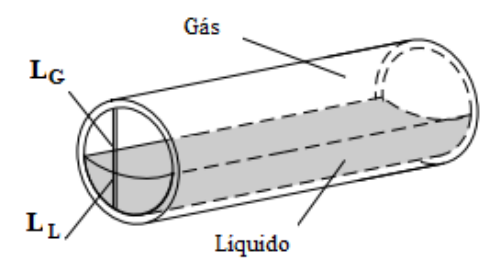

d) Volumétrica

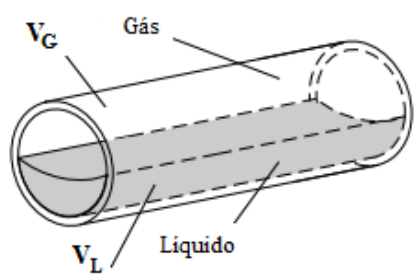

Figura 2.1. Ilustração esquematica das formas de caracterização da fraçao de vazio: a) local, b) linear, c) superficial, d) volumétrica.

A fração de vazio local é definida como a fração de tempo na qual a fase gasosa se apresenta para uma determinada posição do escoamento bifásico. A ausência ou presença da fase $\mathrm{k}$ instantânea numa dada posição, $r$, pode ser caracterizada através da seguinte função binária:

$P_{k}(r, t)=\left\{\begin{array}{l}1 \rightarrow r=G \\ 0 \rightarrow r=L\end{array}\right.$

Assim a fração local é dada por: 


$$
\alpha_{\text {local }}=\frac{1}{t} \int_{t} P_{G}(r, t) \cdot d t
$$

A fração de vazio linear é dada pela média temporal da fração espacial linear instantânea da fase gás, definida como a razão entre os segmentos de reta correspondentes à fase gás, $L_{G}$, e o comprimento total, segundo a seguinte equação:

$$
\alpha_{1 D}=\frac{1}{\Delta t} \int_{\Delta t} \frac{L_{G}}{L_{L}+L_{G}} \cdot d t
$$

A fração de vazio superficial é a média temporal da razão entre a área transversal do escoamento correspondente à fase gás e a área total conforme à seguinte equação:

$$
\alpha_{2 D}=\frac{1}{\Delta t} \int_{\Delta t} \frac{A_{G}}{A_{L}+A_{G}} \cdot d t
$$

A fração de vazio volumétrica para um determinado trecho da tubulação é definida como a média temporal da fração espacial volumétrica instantânea da fase gasosa dada pela razão entre o volume ocupado pela fase gás e o volume total de um segmento de duto, conforme indicado na seguinte equação:

$$
\alpha_{3 D}=\frac{1}{\Delta t} \int_{\Delta t} \frac{\forall_{G}}{\forall_{L}+\forall_{G}} \cdot d t
$$

Neste texto, a partir desta seção, será utilizado o símbolo $\alpha$ para referir-se à fração de vazio superficial. A fracão de vazio superficial pode ser estimada atraves de diversos métodos. A continuacão são descritos os mais importantes:

\section{Modelo homogêneo}

Baseia-se na hipótese que as duas fases do fluido escoam segundo velocidade similar $\left(u_{G}=u_{L}\right)$ e que ambas as fases estão distribuídas uniformemente ao longo da seção transversal. A fração de vazio segundo este modelo pode ser deduzida a partir de relação entre as velocidades superficiais das fases, sendo dada pela seguinte equação:

$$
\alpha=\frac{1}{1+\left(\frac{1-x}{x}\right) \cdot \frac{\rho_{G}}{\rho_{L}}}
$$


O modelo homogêneo pode ser considerado uma aproximação razoável para padrões de escoamento dispersos como bolhas e névoa em que uma fase encontra-se dispersa na outra apresentando velocidades próximas.

\section{Método de Rouhani e Axelsson (1970)}

Rouhani e Axelsson (1970) baseados no modelo cinemático “drift-flux”, proposto por Zuber e Findlay (1965), obtiveram:

$$
\alpha=\frac{x}{\rho_{G}}\left[C_{o}\left(\frac{x}{\rho_{G}}+\frac{1-x}{\rho_{L}}\right)+\frac{u_{G J}}{G}\right]^{-1}
$$

A partir daí, considerando dados experimentais para escoamento vertical ajustaram correlações para o parâmetro de distribuição das fases e a velocidade de deslizamento. Posteriormente, Steiner (1993) com base em dados experimentais próprios para escoamento horizontal ajustou novas correlações para os parâmetros empíricos do modelo drift flux obtendo:

$C_{o}=1+0,12(1-x)$

$u_{G J}=1,18(1-x)\left[\frac{g \sigma\left(\rho_{L}-\rho_{G}\right)}{\rho_{L}^{2}}\right]^{1 / 4}$

Esta correlação foi indicada por Ursenbacher et al. (2004) como a mais precisa para escoamentos horizontais em canais com diâmetros convencionais (>3 mm).

\section{Método de Zivi}

Zivi (1964) desenvolveu um modelo para a fração de vazio com base no princípio de geração mínima de entropia, assumindo escoamento em regime permanente, padrão anular sem líquido disperso e negligenciando a dissipação de energia devido ao atrito com a parede.

O cálculo da fração de vazio segundo este modelo é dado por:

$$
\alpha=\frac{1}{1+\left(\frac{1-x}{x}\right) \cdot\left(\frac{\rho_{G}}{\rho_{L}}\right)^{0,67}}
$$


A Figura 2.2 ilustra uma comparação dos resultados experimentais para fração de vazio de Sempértegui-Tapia et al. (2013) com os valores previstos pelos modelos previamente descritos. Sempértegui-Tapia et al. (2013) realizaram testes para canais de diâmetro reduzido e avaliaram a velocidade da fase gasosa mediante a correlação cruzada dos sinais de dois lasers através de uma seção transparente atenuados pelo escoamento. Como observado na figura, o modelo de Zivi (1964) proporcionou os melhores resultados, prevendo $75 \%$ dos dados experimentais dentro de uma faixa de erro de $\pm 20 \%$.

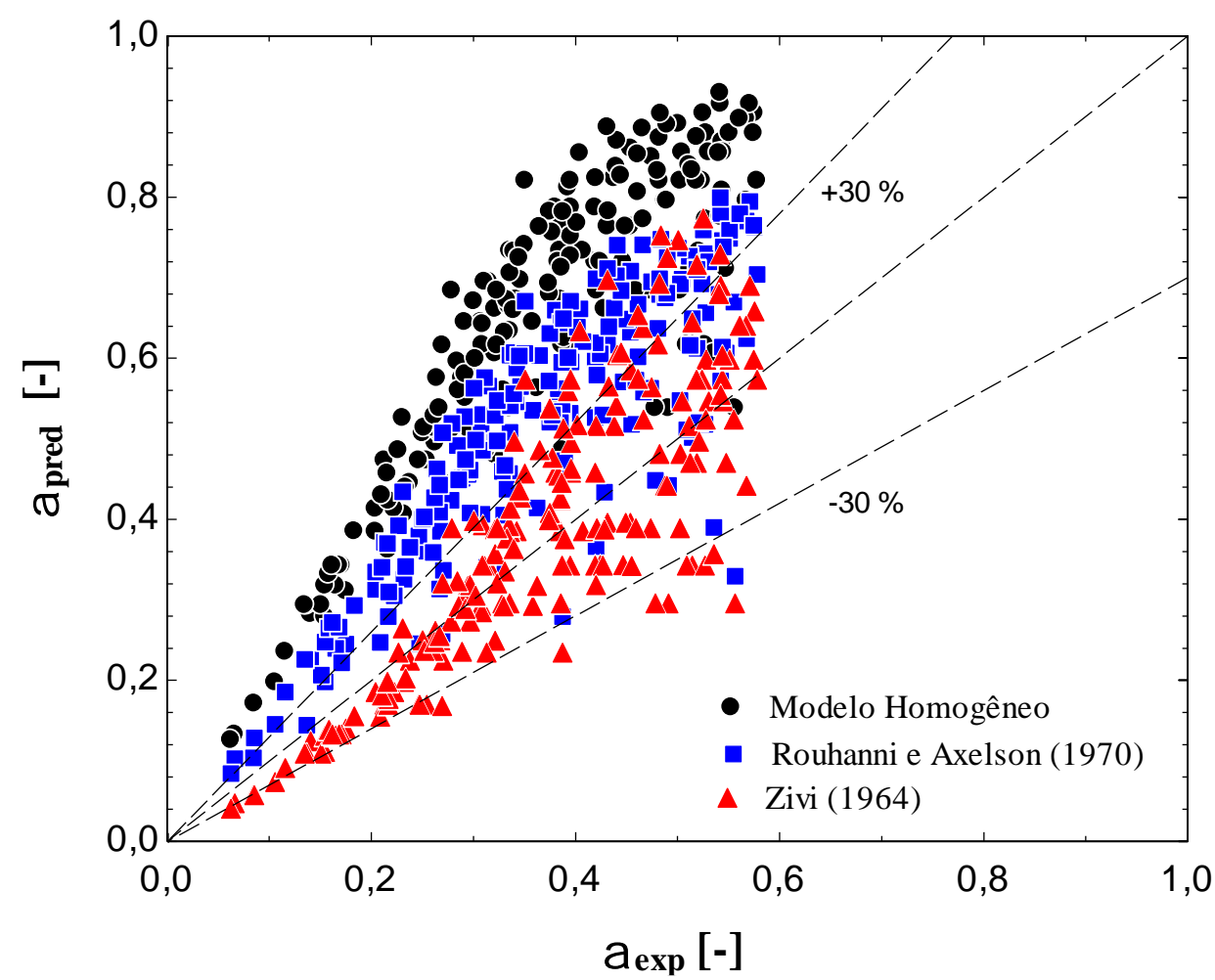

Figura 2.2. Comparação da fração de vazio superficial experimental com métodos de previsão da literatura, Sempértegui-Tapia et al. (2013).

Recentemente, Kanizawa e Ribatski (2015) propuseram um novo método para a estimativa da fração de vazio baseados no modelo de Zivi (1964). Os autores consideram efeitos de não uniformidade da velocidade e da distribuição das fases ao longo da seção transversal na determinação de uma correlação para a fração de vazio. A fração de vazio para escoamentos horizontais segundo este método é dada por:

$\alpha=\left[1+1,021 F r_{m}^{-0,092}\left(\frac{\mu_{L}}{\mu_{G}}\right)^{-0,368}\left(\frac{\rho_{G}}{\rho_{L}}\right)^{1 / 3}\left(\frac{1-x}{x}\right)^{2 / 3}\right]^{-1}$ 
O ajuste dos coeficientes empíricos da correlação foi realizado baseado num banco de dados compreendendo 1877 dados experimentais. O banco de dados inclui estudos para misturas de fluidos de gases não-condensáveis e líquido (ar/água e ar/querosene) e escoamentos saturados (R12, R22, R410A e R134a). O banco de dados abrange uma faixa de diâmetros de 0,508 a 13,84 mm, velocidades mássicas de 70 a 800 $\mathrm{kg} / \mathrm{m}^{2} \mathrm{~s}$ e temperaturas de saturação de 5 a $50^{\circ} \mathrm{C}$.

\subsection{Números Adimensionais}

Devido a complexidade do escoamento bifásico, geralmente seu estudo baseia-se em resultados empíricos apresentados em função de números adimensionais. Entre estes números adimensionais destacam-se os seguintes:

\section{Número de Reynolds}

Define-se o número de Reynolds de forma a caracterizar em escoamentos a relação entre efeitos inerciais e viscosos. Este adimensional é dado por:

$$
\operatorname{Re}=\frac{\rho u D}{\mu}=\frac{G D}{\mu}
$$

No caso de escoamentos bifásicos, comumentemente, define-se o número de Reynolds relacionados às parcelas da mistura bifásica correspondentes as fases gás e líquido dados respectivamente por:

$$
\begin{aligned}
& \operatorname{Re}_{L}=\frac{G(1-x) D}{\mu_{L}} ; \\
& \operatorname{Re}_{G}=\frac{G x D}{\mu_{G}}
\end{aligned}
$$

Também define-se os números de Reynolds da mistura escoando como uma das fases da seguinte forma:

$$
\operatorname{Re}_{L 0}=\frac{G D}{\mu_{L}}
$$


$\operatorname{Re}_{G 0}=\frac{G D}{\mu_{G}}$

\section{Número de Weber}

O numero de Weber é definido como a razão entre as forças de inércia e de tensão superficial e é dado por:

$W e=\frac{\rho u^{2} D}{\sigma}$

Em escoamentos bifásicos, de forma análoga ao número de Reynolds, este adimensional pode ser definido em termos da velocidade mássica de cada fase:

$$
\begin{aligned}
& W e_{L}=\frac{G^{2} D(1-x)}{\rho_{L} \sigma} \\
& W e_{G}=\frac{G^{2} D x}{\rho_{G} \sigma}
\end{aligned}
$$

ou da mistura bifásica escoando como uma das fases, neste caso dado por:

$$
\begin{aligned}
& W e_{L 0}=\frac{G^{2} D}{\rho_{L} \sigma} \\
& W e_{G 0}=\frac{G^{2} D}{\rho_{G} \sigma}
\end{aligned}
$$

O número de Weber é frequentemente encontrado em modelos e correlações para previsão de parâmetros que caracterizem o escoamento bifásico, relacionando a formação de ondas na interface gás-líquido.

\section{Número de confinamento}

Este adimensional avalia o grau de confinamento das bolhas em relação as dimensões de um canal. O numero de confinamento é definido pela seguinte equação:

$$
C o=\frac{\left[\sigma /\left(\left(\rho_{L}-\rho_{G}\right) g\right)\right]^{1 / 2}}{L}
$$


onde L é o comprimento do espaço confinador, que no caso de canais com seção transversal circular ou um polígono regular, é dado pelo diâmetro hidráulico. Já, para canais retangulares, o confinamento está delimitado pela menor dimensão entre a altura e largura do canal, neste caso, o comprimento do espaço confinador estaria definido como:

$L=\operatorname{Min}(l, w)$

onde $l$ e $w$ são a altura e a largura da seção transversal de um canal retangular.

O número de confinamento e o número de Bond, $B d$, diferenciam-se através de um expoente da seguinte forma:

$$
B d=\frac{1}{C o^{2}}
$$

\section{Número de ebulição}

Define-se o número de ebulição $(B o)$ como a razão entro o fluxo de calor fornecido e aquele relacionado a evaporação de um determinado fluxo mássico, sendo dado por:

$$
B o=\frac{\phi}{i_{L G} G}
$$

\section{Número de Suratman}

É definido como uma função dos números de Reynolds e de Weber:

$$
S u=\frac{\operatorname{Re}^{2}}{W e}=\frac{\rho \sigma D}{\mu^{2}}
$$

O número de Suratman pode ser definido para as duas fases e relaciona efeitos de tensão superficial e viscosos. Números de Suratman do líquido reduzidos para a fase liquida implicam em filmes líquidos espessos favorecendo a formação de ondas interfaciais.

\section{Número de Froude}

Este adimensional representa a relação entre forças de inércia e gravitacionais e é definido pela seguinte equação: 


$$
F r=\frac{G^{2}}{g D \rho^{2}}
$$

Em escoamentos liquido - gás horizontais o número de Froude relaciona-se a efeitos de estratificação, os quais podem ser relevantes inclusive para canais de diâmetro reduzido

\subsection{Padrões de escoamento}

As fases gás e líquido escoam simultaneamente dentro da tubulação segundo diferentes topologias. Esta distribuição de fases é denominada de "padrão de escoamento". O estabelecimento de diferentes padrões de escoamento está relacionado às características do sistema de transporte, das variáveis operacionais do sistema e das propriedades físicas dos fluidos que compõem a mistura bifásica. Parâmetros como a aceleração gravitacional, geometria da seção transversal do canal, suas dimensões e o grau de inclinação do canal em relação ao plano horizontal podem determinar a presença de um determinado padrão. As densidades e as viscosidades das fases e a tensão superficial são propriedades de transporte e termodinâmicas que também estão relacionadas ao estabelecimento dos padrões de escoamento.

Os mecanismos de transporte predominantes durante o escoamento bifásico relacionados à transferência de massa, quantidade de movimento e calor são influenciados pelos padrões de escoamento. Autores indicam ser necessário características dos padrões para que modelos precisos para perda de pressão e coeficiente de transferência de calor e massa sejam desenvolvidos.

\subsubsection{Padrões de escoamento em canais convencionais}

A Figura 2.3 ilustra os padrões para escoamento vertical definidos por Collier e Thome (1996). Para escoamento vertical, conforme ilustrado na figura, estes autores definem os seguintes padrões:

Bolhas: A fase gás distribui-se segundo bolhas não necessariamente esféricas e com diâmetros equivalentes inferiores ao do tubo. A fase gás encontra-se envolta pelo líquido; 
> Pistonado: Neste padrão estão presentes bolhas de dimensões próximas ao diâmetro do duto que escoam de modo intermitente e com frequência regular. Entre duas bolhas consecutivas escoa um pistão de líquido em cujo interior se verificam bolhas de tamanho reduzido;

Agitante: Neste padrão de escoamento a ponte de líquido entre os pistões é rompida por ação hidrodinâmica formando um escoamento com interface irregular;

$>$ Anular: É quando o filme de líquido escoa junto a toda a periferia do duto com a fase gasosa escoando na região central,

> Anular + Névoa: Devido à elevada velocidade do gás durante o padrão anular ocorre o desprendimento de gotículas do filme líquido, as quais passam a escoar dispersas no núcleo de gás na forma de gotículas de reduzidas dimensões, as quais se depositam intermitentemente na superfície do canal.

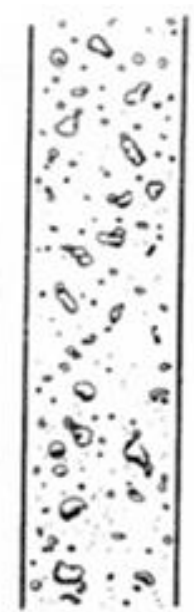

Bolhas

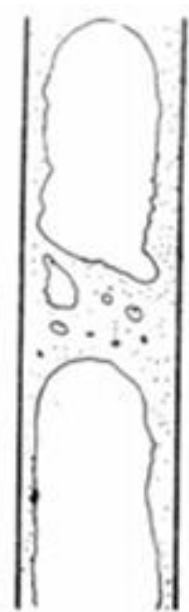

Pistonade

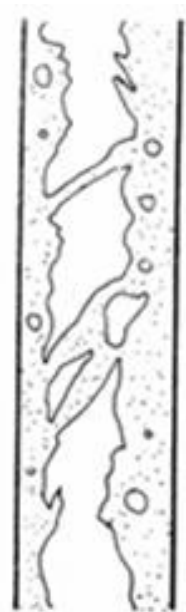

Agitante

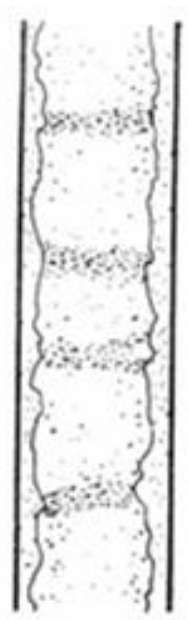

Anular

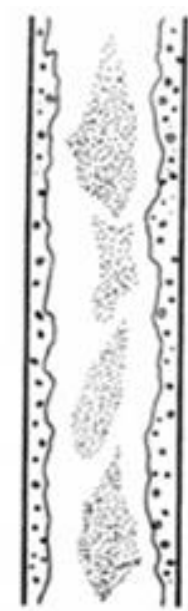

Anular + Névoa

Figura 2.3. Padrões de escoamento em tubos verticais, Collier e Thome (1996)

Na Figura 2.4 observam-se os padrões de escoamento em dutos horizontais observados por Barbieri (2005). Conforme a figura, devido a efeitos gravitacionais, além das topologias de distribuição de fases indicadas para escoamento vertical, são observados os seguintes padrões:

> Estratificado Liso: O líquido se concentra na região inferior do duto e o gás na região superior com a interfase de separação das fases relativamente lisa;

> Estratificado Ondulado: Devido à ação do arraste do gás, a interface para o padrão estratificado apresenta ondulações; 


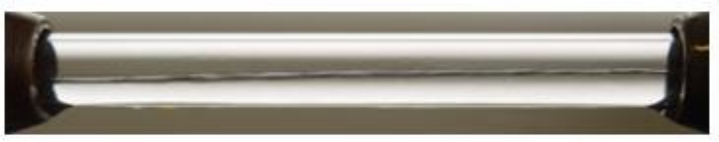

Estratificado Liso. $T_{x a t}={ }^{\circ} 5 \mathrm{C}, G=50 \mathrm{~kg} / \mathrm{m}^{2} \mathrm{~s}, x=0,28$ e $D=12,6 \mathrm{~mm}$

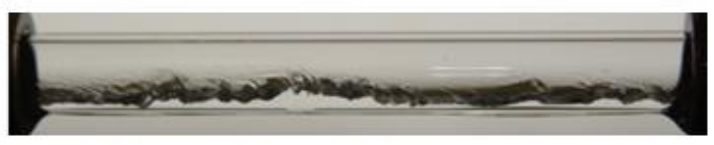

Estratificado Ondulado. $T_{x s i}={ }^{\circ} 5 \mathrm{C}, G=100 \mathrm{~kg}^{2} \mathrm{~s}, x=0,40$ e $D=9,5 \mathrm{~mm}$

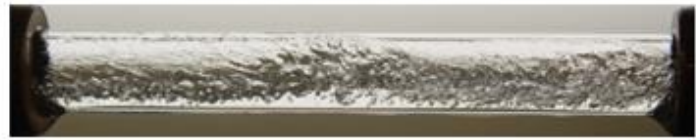

Intermitente. $T_{s e:}={ }^{\circ 5} \mathrm{C}, \mathrm{G}=300 \mathrm{~kg} \mathrm{~m}^{2} \mathrm{~s}, x=0,17$ eD=7,8 mm

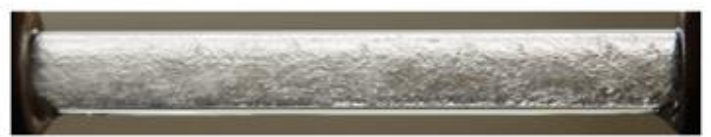

Anular. $T_{x a t}={ }^{\circ} 5 \mathrm{C}, G=300 \mathrm{~kg}^{2} \mathrm{~s}, x=0,26$ e $D=9,5 \mathrm{~mm}$

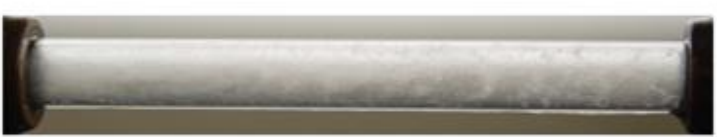

Névoa. $T_{s a t}={ }^{5} 5 \mathrm{C}, G=500 \mathrm{~kg} / \mathrm{m}^{2} \mathrm{~s}, x=0,95$ e $D=7,8 \mathrm{~mm}$

Figura 2.4. Padrões de escoamento em dutos horizontais, Barbieri (2005).

\subsubsection{Padrões de escoamento em canais de reduzido diâmetro}

A Figura 2.5 ilustra os padrões de escoamento identificados por SempérteguiTapia et al. (2013) para um canal de diâmetro igual a 1,1 mm. Como pode ser observado na figura, os autores não verificaram a presença do padrão estratificado, fato utilizado por Tibiriçá (2011) para caracterizar a transição entre micro e macro-escala.

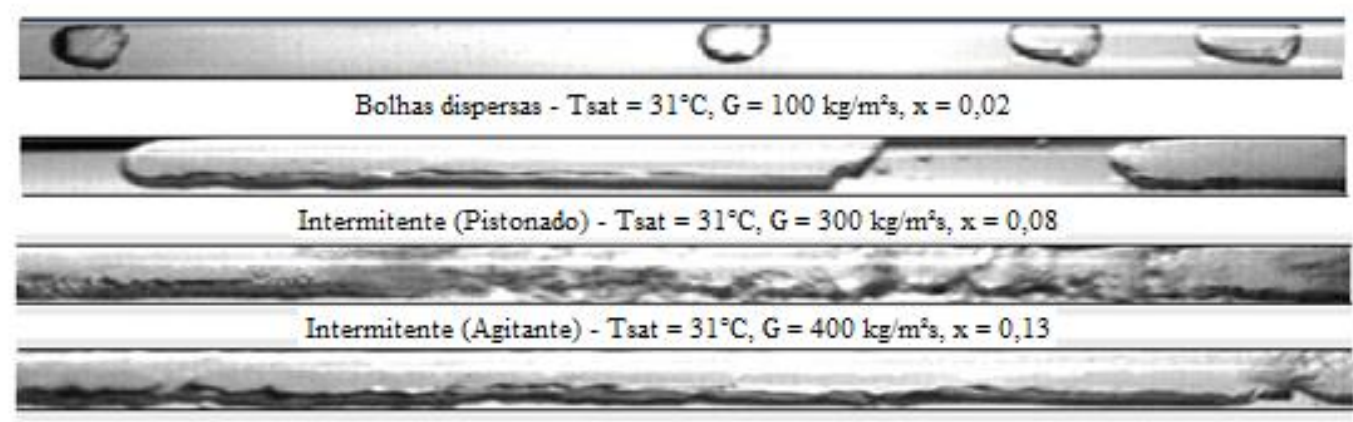

Anvlar $-T_{s a t}=31^{\circ} \mathrm{C}, \mathrm{G}=600 \mathrm{~kg} / \mathrm{m}^{2} \mathrm{~s}, \mathrm{x}=0,34$

Figura 2.5. Padrões de escoamento em canais de diâmetro reduzido, R245fa, D = 1,1 mm, SempérteguiTapia et al. (2013). 
Pode-se observar também na Figura 2.6, que a região frontal das bolhas alongadas apresentam a tendência de escoar na parte superior do tubo. É importante mencionar que para padrões anulares e segundo bolhas alongadas, a espessura do filme líquido ao longo do perímetro do tubo se torna progressivamente uniforme com a redução do diâmetro.

\subsection{Ebulição convectiva no interior de tubos}

A ebulição convectiva envolve diferentes mecanismos de transferência de calor cuja predominância encontra-se relacionado ao padrão de escoamento. A Figura 2.6 ilustra a sequência de padrões de escoamento durante o processo de evaporação no interior de tubos convencionais.

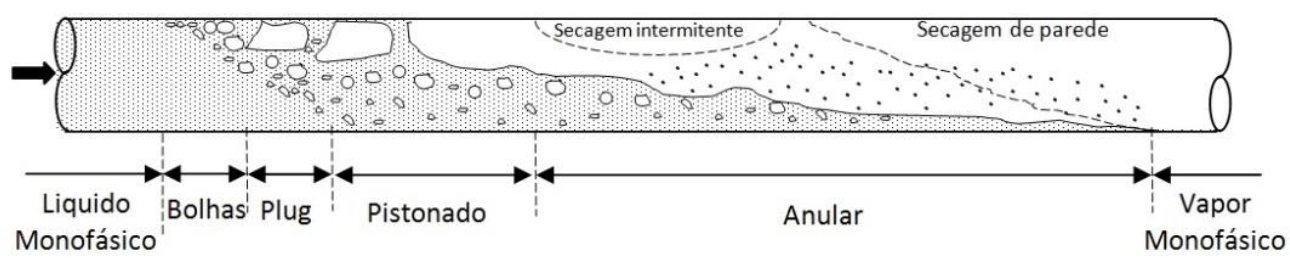

Figura 2.6. Evolução dos padrões de escoamento durante a ebulição convectiva em canais convencionais, adaptado de Collier e Thome (1996).

Como ilustrado na Figura 2.6, no início do processo de ebulição, o escoamento se dá segundo o padrão de bolhas com o mecanismo de transferência de calor predominante sendo a ebulição nucleada. Com a elevação do título de vapor ocorre o padrão pistonado, para o qual efeitos de condução através do filme líquido (que se encontra aprisionado entre a bolha alongada e a tubulação) e convecção forçada devido ao pistão de líquido prevalecem e efeitos de nucleação de bolhas são progressivamente suprimidos. Aumentos adicionais do título de vapor resultam na transição para o padrão anular. Neste padrão a condução através do filme líquido com a evaporação na interfase líquido - vapor torna-se o mecanismo dominante. O movimento relativo das fases no escoamento anular, somado a ondulações interfaciais, provocam o arrasto de gotículas de líquido para a região central do escoamento, efeito que reduz a espessura do filme líquido intensificando a transferência de calor. Entretanto, para títulos de vapor elevados tal mecanismo pode provocar a secagem de parede, reduzindo drasticamente o coeficiente de transferência de calor. 
A Figura 2.9 ilustra a sequência de padrões de escoamento durante o processo de ebulição convectiva no interior de canais de reduzido diâmetro para um fluxo calor uniforme. Esta figura também ilustra esquematicamente os perfis da temperatura do fluido e da parede, do coeficiente de transferência de calor e o gradiente de pressão ao longo do canal.

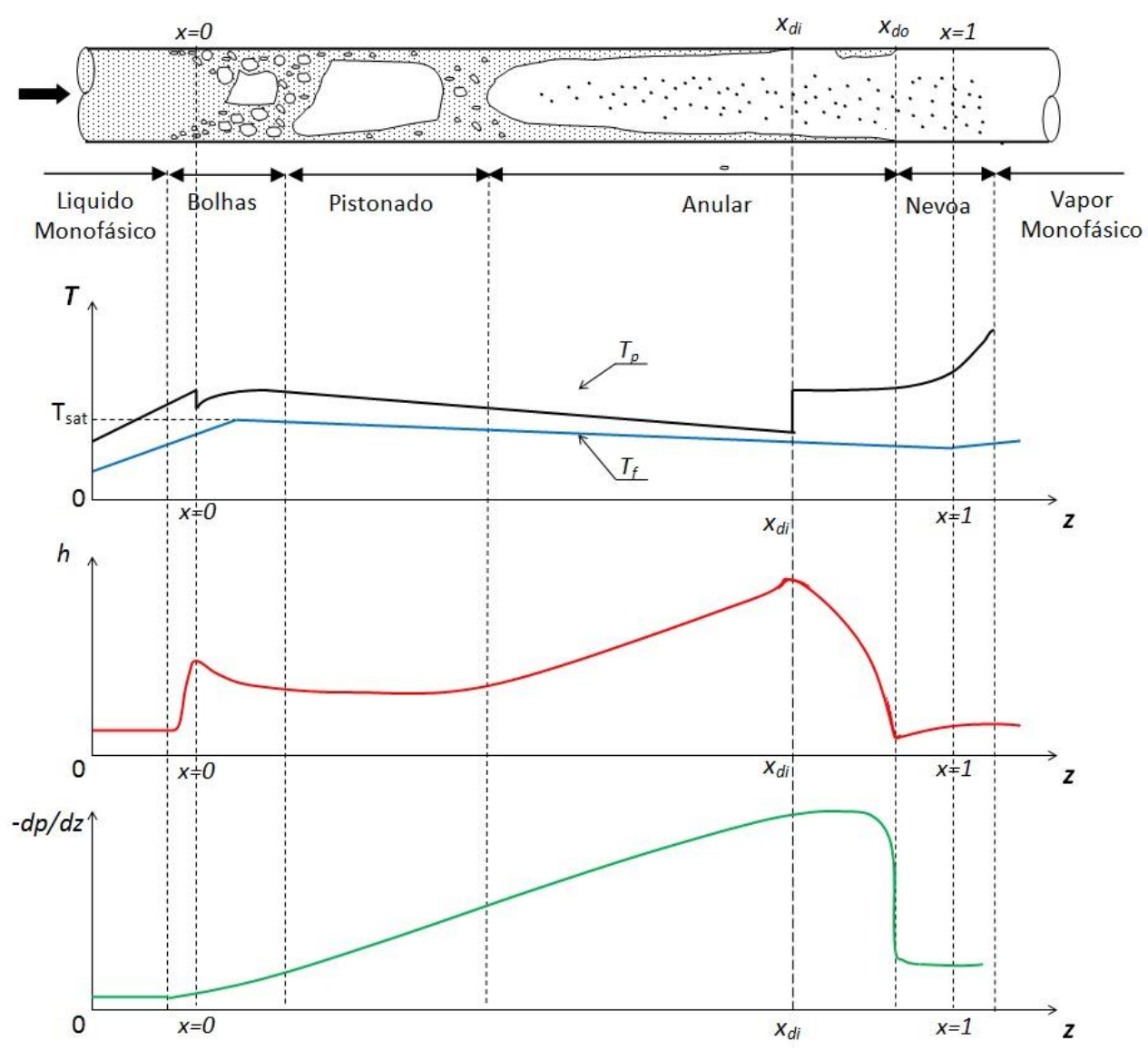

Figura 2.7. Evolução dos padrões de escoamento durante a ebulição convectiva em canais de reduzido diâmetro e ilustrações esquemáticas dos perfis de temperaturas de parede e fluido, CTC e gradiende da perda de pressao ao longo do canal.

A sequência de padrões de escoamento para canais de diâmetro reduzido, conforme ilustrado na Figura 2.9, é similar à observada em canais convencionais (ver Fig. 2.8), exceto pela ausência da estratificação do escoamento. Segundo a Figura 2.9 uma vez iniciado o processo de ebulição, o padrão observado é bolhas, com a elevação do título de vapor ocorre o padrão segundo bolhas alongadas e elevações adicionais de $x$ resultam no padrão anular. Nestes padrões, além da contribuição dos efeitos convectivos preponderantes, foram reportados na literatura contribuições significativas da ebulição nucleada no filme líquido (ver KASZA; DIDASCALOU; WAMBSGANSS, 1997, 
KANDLIKAR; STUMM, 1995 e TIBIRIÇÁ; RIBATSKI, 2014). Tibiriçá e Ribatski (2014), por exemplo, reportaram núcleos ativos no filme líquido durante a ebulição de R134a num tubo de 0,4 mm de diâmetro, conforme ilustrado na Figura 2.10.

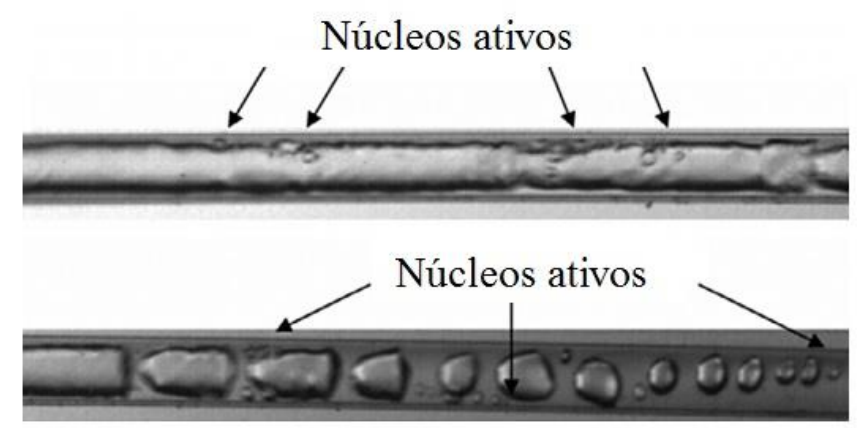

Figura 2.8. Núcleos ativos observados no filme líquido nos padroes anular e bolhas alongadas, Tibiriça e Ribatski (2014).

A partir de um título de vapor de equilíbrio termodinâmico, observa-se na Figura 2.9 o decréscimo moderado da temperatura do fluido devido à perda de pressão ao longo do duto. Por outro lado, o coeficiente de transferência de calor se eleva refletindo no decréscimo da diferença de temperatura entre a parede e o fluido $\left(T_{p}-T_{f}\right)$. Observa-se também, que a jusante do início da ebulição (Onset Nucleate Boiling, ONB), o gradiente da perda de pressão se eleva com o acréscimo do título de vapor. Com o estabelecimento de efeitos de secagem de parede, ocorre um aumento abrupto na temperatura da parede, implicando em uma redução drástica do coeficiente de transferência de calor. Embora, ainda tema controverso na literatura, segundo alguns autores o início do processo de secagem da parede coincide com o estabelecimento do decréscimo do gradiente de pressão a partir de um valor máximo com o aumento do título de vapor. 


\section{CAPÍTULO 3 - REVISÃo BIBLIOGRÁFICA SOBRE PERDA DE PRESSÃO}

\subsection{Introdução}

Este capítulo inicialmente descreve os componentes da perda de pressão para escoamentos no interior de dutos. Segue, uma apresentação crítica dos métodos de previsão disponíveis na literatura e dos estudos experimentais sobre perda de pressão em escoamentos bifásicos. Esta análise foca em investigações envolvendo geometrias nãocirculares e fluidos com reduzido GWP e "naturais". Finalmente, o capítulo apresenta conclusões, ressaltando aspectos relevantes da revisão bibliográfica sobre perda de pressão em escoamentos bifásicos.

\subsection{Componentes da perda de pressão}

A perda de pressão total num escoamento é dada pela soma das parcelas gravitacional, aceleracional e friccional, conforme a seguinte equação:

$$
\Delta p_{\text {total }}=\Delta p_{\text {gravitacional }}+\Delta p_{\text {aceleracional }}+\Delta p_{\text {friccional }}
$$

A queda de pressão gravitacional, $\Delta p_{\text {gravitacional }}$, se deve à diferença de cotas no escoamento, sendo determinada por:

$$
\Delta p_{\text {gravitacional }}=\int_{0}^{L}\left[\rho_{G} \alpha+(1-\alpha) \rho_{L}\right] g \sin (\theta) d z
$$

A queda de pressão aceleracional, $\Delta p_{\text {aceleracional }}$, deve-se à variação da energia cinética do escoamento, sendo desprezível para escoamentos adiabáticos e tubulações de seção transversal constante e com dimensões convencionais. Não obstante, com a redução do diâmetro do canal, ela pode se tornar relevante, devido à redução da pressão do escoamento implicar em variações significativas do título de vapor e da fração de vazio, causando a aceleração do escoamento, fenômeno denominado na literatura por efeito flash. 
A relação para avalição do gradiente de pressão aceleracional pode ser derivada analiticamente a partir das equações da continuidade e conservação da quantidade de movimento na direção do escoamento, $z$, resultando na seguinte equação:

$$
\left(\frac{d p}{d z}\right)_{\text {aceleracional }}=\frac{d}{d z}\left[G^{2}\left(\frac{x^{2}}{\rho_{G} \alpha}+\frac{(1-x)^{2}}{\rho_{L}(1-\alpha)}\right)\right]-\frac{1}{2}\left(\frac{x^{2}}{\rho_{G} \alpha}+\frac{(1-x)^{2}}{\rho_{L}(1-\alpha)}\right) \frac{d G^{2}}{d z}
$$

No caso de escoamentos através de dutos com área de seção transversal fixa, a velocidade mássica se mantém constante, portanto, o segundo termo da equação anterior se anula. Deste modo, o cálculo de pressão aceleracional para processos adiabáticos e seção constante é dado pela seguinte equação:

$$
\Delta p_{\text {Aceleracional }}=G^{2}\left\{\left[\frac{x^{2}}{\rho_{G} \alpha}+\frac{(1-x)^{2}}{\rho_{L}(1-\alpha)}\right]_{\text {Saida }}-\left[\frac{x^{2}}{\rho_{G} \alpha}+\frac{(1-x)^{2}}{\rho_{L}(1-\alpha)}\right]_{\text {Entrada }}\right\}
$$

No caso da parcela devido ao atrito, relações derivadas de forma analítica a partir das equações de conservação não são frequentes. Neste caso utiliza-se, geralmente, métodos empíricos segundo os quais a perda de pressão do escoamento bifásico é determinada a partir de um valor correspondente avaliado para o escoamento monofásico. A perda de pressão friccional, $\Delta p_{\text {friccional }}$, em escoamento monofásico é dada por:

$$
\Delta p_{\text {Atrito }}=2 f \frac{G^{2} L}{\rho D}
$$

onde o fator de atrito tipo Fanning, $f$, é função do regime do escoamento e da geometria da seção transversal do canal.

Equações e procedimentos para o cálculo do fator de atrito em escoamento monofásico são detalhados no Apêndice A.

\subsection{Métodos de previsão da perda de pressão por atrito em escoamento bifásico}

Para a previsão da perda de pressão por atrito em escoamentos bifásicos os métodos disponíveis podem ser classificados como: derivados do modelo homogêneo, métodos baseados em multiplicadores bifásicos, correlações estritamente empíricas e 
modelos baseados em análises fenomenológicas. Neste item são descritos os métodos mais representativos de cada tipo.

\subsubsection{Modelo homogêneo}

Conforme já indicado no Item 2.4.1, este modelo trata a mistura bifásica como um pseudofluido com suas propriedades de transporte ponderadas entre aquelas do gás e do líquido. Desta forma, a perda de pressão por atrito é dada pela Eq. 3.5, utilizando as propriedades da mistura e o fator de atrito estimado de maneira análoga ao escoamento monofásico.

Neste modelo, a densidade da mistura homogênea, $\rho_{H}$, é dada pela seguinte equação:

$$
\rho_{\text {Hom }}=\left(\frac{x}{\rho_{G}}+\frac{1-x}{\rho_{L}}\right)^{-1}
$$

A Tabela 3.1 indica as correlações frequentemente citadas na literatura para determinação da viscosidade dinâmica da mistura bifásica.

A Figura 3.1 ilustra uma comparação entre os métodos para a determinação da viscosidade da mistura bifásica homogênea. Estes métodos proporcionam $\mu_{2 \phi}=\mu_{L}$ e $\mu_{2 \phi}=$ $\mu_{G}$ para $x=0$ e $x=1$, respectivamente, exceto por Owens (1961) e García et al. (2003). Entre as correlações, Cicchitti et al. (1960) apresenta uma variação linear da viscosidade com o título de vapor. As correlações de McAdams (1942), Dukler et al. (1964), Beattie e Whalley (1982), Lin et al. (1991) e Awad Muzychka (2010) proporcionam tendências próximas. Constata-se também na figura, que o modelo de Beattie e Whalley (1982) fornece viscosidades da mistura bifásica superiores à viscosidade do líquido saturado para uma faixa determinada de título de vapor, comportamento inconsistente com os resultados apresentados pelos demais métodos. É importante ressaltar também que o modelo homogêneo despreza efeitos de velocidade mássica na estimativa da fração de vazio, os quais para determinados padrões de escoamento são relevantes. 
Tabela 3.1. Correlações da literatura para a viscosidade da mistura homogênea.

\begin{tabular}{|c|c|}
\hline Autor & Correlação \\
\hline McAdams (1942) & $\frac{1}{\mu_{2 \phi}}=\frac{x}{\mu_{G}}+\frac{(1-x)}{\mu_{L}}$ \\
\hline Owens (1961) & $\mu_{2 \phi}=\mu_{L}$ \\
\hline Cicchitti et al. (1960) & $\mu_{2 \phi}=x \mu_{G}+(1-x) \mu_{L}$ \\
\hline Dukler et al. (1964) & $\mu_{2 \phi}=\rho_{H}\left(x \frac{\mu_{G}}{\rho_{G}}+(1-x) \frac{\mu_{L}}{\rho_{L}}\right)$ \\
\hline Beattie e Whalley (1982) & $\mu_{2 \phi}=\alpha_{\text {Hom }} \mu_{G}+\left(1-\alpha_{\text {Hom }}\right)\left(1+2,5 \alpha_{\text {Hom }}\right) \mu_{L}$ \\
\hline Lin et al. (1991) & $\mu_{2 \phi}=\frac{\mu_{L} \mu_{G}}{\mu_{G}+x^{1,4}\left(\mu_{L}-\mu_{G}\right)}$ \\
\hline García et al. (2003) & $\mu_{2 \phi}=\mu_{L} \frac{\rho_{H o m}}{\rho_{L}}$ \\
\hline Awad e Muzychka (2010)* & $\mu_{2 \phi}=\mu_{G} \frac{2 \mu_{G}+\mu_{L}-2\left(\mu_{G}-\mu_{L}\right)(1-x)}{2 \mu_{G}+\mu_{L}+\left(\mu_{G}-\mu_{L}\right)(1-x)}$ \\
\hline
\end{tabular}

Wong e Ooi (1995) compararam um banco de dados de perda de pressão para tubos com dimensões capilares com previsões obtidas através do modelo homogêneo empregando diferentes correlações para o cálculo da viscosidade da mistura. Estes autores obtiveram um erro absoluto médio de 5\% para o método de Dukler et al. (1964). Analogamente, Kawahara et al. (2002), para um canal circular com diâmetro de $100 \mu \mathrm{m}$, verificaram que o modelo homogêneo com a viscosidade da mistura bifásica dada por Dukler et al. (1964) fornece erros inferiores aos demais. Mais recentemente, Ribatski et al. (2006) compararam um extenso banco de dados de gradientes de pressão com 12 diferentes métodos de previsão. O banco de dados dos autores engloba dados experimentais de perda de pressão para diâmetros hidráulicos entre 0,1 e 3,25 mm e velocidades mássicas de 10 a $5090 \mathrm{~kg} / \mathrm{m}^{2} \mathrm{~s}$. Eles obtiveram erros inferiores para o método de previsão proposto por Müller-Steinhagen e Heck (1986) e com o modelo homogêneo com a viscosidade da mistura bifásica dada por Cicchitti et al. (1960). Vale mencionar 
que apesar destes métodos fornecerem as melhores previsões, seus resultados foram ainda insatisfatórios.
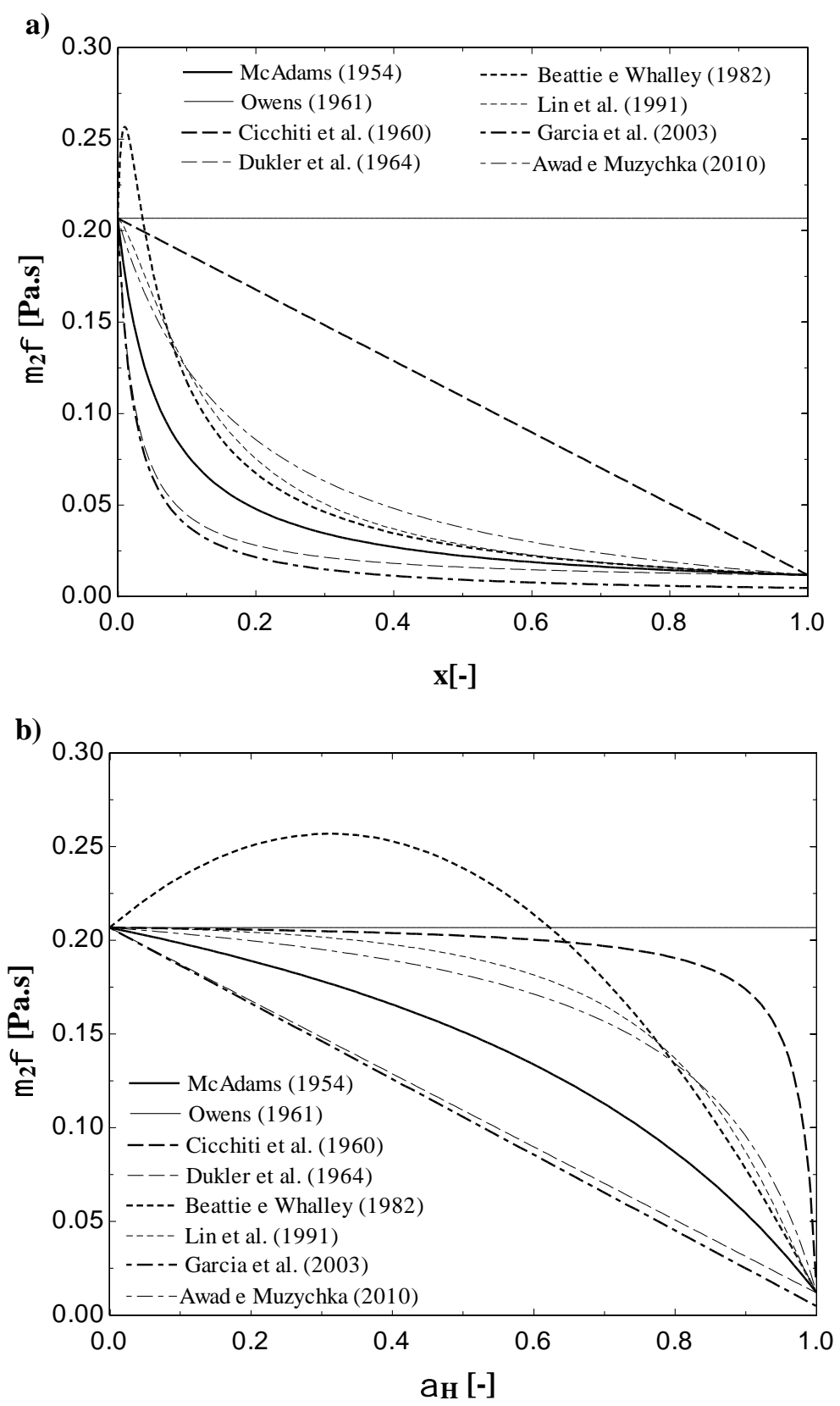

Figura 3.1. Comparação dos modelos de viscosidade da mistura homogênea em funçao do título de vapor e a fração de vazio homogênea, R134a, $T_{\text {sat }}=20^{\circ} \mathrm{C}$.

\subsubsection{Métodos baseados em multiplicadores bifásicos}

O método de previsão de perda de pressão baseado em multiplicadores bifásicos foi inicialmente proposto por Lockhart e Martinelli (1949). Os multiplicadores bifásicos consistem em correlações que determinam a perda de pressão por atrito do escoamento 
bifásico a partir do valor correspondente para o escoamento monofásico. No método de Lockhart e Martinelli (1949) os seguintes multiplicadores bifásicos são definidos:

$\phi_{G}^{2}=\frac{\Delta p_{2 \phi}}{\Delta p_{G}}$

$\phi_{L}^{2}=\frac{\Delta p_{2 \phi}}{\Delta p_{L}}$

onde $\Delta p_{2 \phi}$ é a perda de pressão do escoamento bifásico e $\Delta p_{G}$ e $\Delta p_{L}$ são as perdas de pressão considerando apenas as parcelas gás ou líquido, respectivamente, escoando em um duto de características similares. Também são definidos na literatura os seguintes multiplicadores bifásicos:

$\phi_{G O}^{2}=\frac{\Delta p_{2 \phi}}{\Delta p_{G O}}$

$\phi_{L O}^{2}=\frac{\Delta p_{2 \phi}}{\Delta p_{L O}}$

onde, as parcelas $\Delta p_{G O}$ e $\Delta p_{L o}$ são as perdas de pressão considerando a mistura bifásica escoando apenas como gás ou líquido, respectivamente, em um mesmo duto.

Abordagens baseadas em multiplicadores bifásicos são frequentes na literatura sendo extensamente aplicada a canais convencionais, e recentemente são utilizadas no desenvolvimento de métodos para previsão da perda de pressão em microcanais. A seguir são descritos os métodos baseados em multiplicadores bifásicos relevantes disponíveis na literatura.

\section{Métodos para canais convencionais:}

A Tabela 3.2 apresenta os diferentes métodos de previsão da perda de pressão por atrito para canais convencionais. Nela são apresentados as correlações e o banco de dados utilizado em seus desenvolvimentos. 
Tabela 3.2. Métodos de previsão da perda de pressão baseados em multiplicadores bífasicos desenvolvidos para canais convencionais.

\begin{tabular}{|c|c|c|}
\hline Autor & Correlações & Observações \\
\hline $\begin{array}{l}\text { Lockhart e Martinelli } \\
\qquad(1949)\end{array}$ & $\begin{array}{c}\phi_{L}^{2}=1+\frac{C}{X}+\frac{1}{X^{2}} ; \phi_{G}^{2}=1+C X+X^{2} \\
X^{2}=\frac{\phi_{G}^{2}}{\phi_{L}^{2}}=\frac{\Delta p_{L}}{\Delta p_{G}} \\
C_{t t}=20, C_{l t}=12, C_{t l}=10, C_{l l}=5\end{array}$ & $\begin{array}{c}\text { Água, SAE } 40 \text { óleo, } \\
\text { benzeno, querosene, } \\
\text { diesel. } \\
\begin{array}{c}\mathrm{D}_{\mathrm{H}}=1,49-25,83 \\
\text { mm } \\
\text { Valores do } \\
\text { coeficiente C } \\
\text { determinados por } \\
\text { Chisholm (1967) }\end{array}\end{array}$ \\
\hline Chisholm (1973) & $\begin{array}{ccc}\phi_{L O}^{2}=1+\left(\Upsilon^{2}-1\right)\left[B x^{(2-n) / 2}(1-x)^{(2-n) / 2}+x^{2-n}\right] \\
& \Upsilon^{2}=\frac{\Delta p_{G O}}{\Delta p_{L O}} \\
& \leq 500 & \mathrm{~B}=4,8 \\
\Upsilon \leq 9,5 & 500<\mathrm{G}<1900 & \mathrm{~B}=2400 / \mathrm{G} \\
& \geq 1900 & \mathrm{~B}=55 / \mathrm{G}^{0,5} \\
9,5<\Upsilon & \leq 600 & \mathrm{~B}=520 /\left(\Upsilon \mathrm{G}^{0,5}\right) \\
<28 & >600 & \mathrm{~B}=21 / \Upsilon \\
\geq 28 & & \mathrm{~B}=15000 /\left(\Upsilon^{2} \mathrm{G}^{0,5}\right)\end{array}$ & $\begin{array}{l}\text { Água/vapor, água/ar } \\
\text { Transformação do } \\
\text { método gráfico de } \\
\text { Baroczy (1966) em } \\
\text { correlações. }\end{array}$ \\
\hline Friedel (1979) & $\begin{array}{c}\phi_{L O}^{2}=E+\frac{3,24 F H_{F r}}{F r_{H}^{0,045} W e_{L}^{0,035}} ; E=(1-x)^{2}+x^{2}\left(\frac{\Delta p_{G O}}{\Delta p_{L O}}\right) \\
H=\left(\frac{\rho_{L}}{\rho_{G}}\right)^{0,91}\left(\frac{\mu_{G}}{\mu_{L}}\right)^{0,19}\left(1-\frac{\mu_{G}}{\mu_{L}}\right)^{0,7} \\
F=x^{0,78}(1-x)^{0,224}\end{array}$ & $\begin{array}{c}\text { Água/ar, R12 } \\
\mathrm{D}_{\mathrm{H}}>4 \mathrm{~mm} \\
25000 \text { dados } \\
\text { Geometrias circular e } \\
\text { retangulares }\end{array}$ \\
\hline Grönnerud (1979) & $\begin{array}{l}\quad \phi_{L O}^{2}=1+\left(\frac{d p}{d z}\right)_{F r}\left[\left(\rho_{L} / \rho_{G}\right)\left(\mu_{L} / \mu_{G}\right)^{-0,25}-1\right] \\
\quad\left(\frac{d p}{d z}\right)_{F r}=f_{F r}\left[x+4\left(x^{1,8}-x^{10} f_{F r}^{0,5}\right)\right] \\
\text { Para } \quad F r_{L 0}<1 \quad f_{F r}=1 \\
\text { Para } \quad \operatorname{Fr}_{L 0}<1 \quad f_{F r}=F r_{L O}^{0,3}+0,0055\left(\ln \frac{1}{F r_{L O}}\right)^{2}\end{array}$ & $\begin{array}{c}\mathrm{R} 12, \text { Amônia } \\
\mathrm{D}_{\mathrm{H}}=26,2 \mathrm{~mm} \\
\mathrm{G}=50-1600 \\
1000 \text { dados }\end{array}$ \\
\hline $\begin{array}{l}\text { Jung e Radermacher } \\
\text { (1989) }\end{array}$ & $\begin{aligned} \phi_{L O}^{2} & =12,87 X_{t t}^{-1,47}(1-x)^{1,8} \\
X_{t t} & =0,551\left(\frac{1-x}{x}\right)^{0,9} p_{r e d}^{0,492}\end{aligned}$ & $\begin{array}{c}\text { R22, R114, R12, } \\
\text { R152a e misturas } \\
\mathrm{D}=9,1 \mathrm{~mm} \\
\mathrm{G}=230-720 \mathrm{~kg} / \mathrm{m}^{2} \mathrm{~s} \\
600 \text { dados } \\
\text { Diabático }\end{array}$ \\
\hline Chen et al. (2007) & $\begin{array}{c}\phi_{L}^{2}=1+\frac{C}{X}+\frac{1}{X^{2}} ; C=a X^{b} \\
a=5,55-0,7555 \cdot \zeta^{-0,805}+0,00439 \cdot \mathrm{Re}_{L 0} \\
b=0,1001-0,0005 \cdot \zeta^{0,895}\end{array}$ & $\begin{array}{c}\text { Água/ar } \\
\mathrm{D}_{\mathrm{H}}=3 ; 4 \text { e } 4,5 \mathrm{~mm} \\
\mathrm{G}=100-700 \\
\mathrm{x}=0,001 \text { e } 0,95 \\
\mathrm{AR}=0,1-1 \\
337 \text { dados }\end{array}$ \\
\hline
\end{tabular}


Lockhart e Martinelli (1949) foram pioneiros ao desenvolver um método para a previsão da perda de pressão bifásica. Estes autores propuseram as correlações clássicas dos multiplicadores bifásicos da fase líquida e gasosa em função do parâmetro de Martinelli e do coeficiente C, estimado a partir de curvas em figuras elaboradas baseadas num extenso banco de dados. Posteriormente, Chisholm (1967) ajustou valores do coeficiente $\mathrm{C}$ em função do regime de escoamento das fases. A Figura 3.2 ilustra o efeito da temperatura de saturação e do diâmetro no gradiente de pressão bifásico segundo o método de Lockhart e Martinelli (1949). Como observado na figura, o método apresenta descontinuidades no gradiente de pressão com o incremento do título de vapor, decorrentes das transições entre os regimes laminar e turbulento para as duas fases. Com o incremento do diâmetro pode-se observar um acentuado decréscimo do gradiente de pressão.

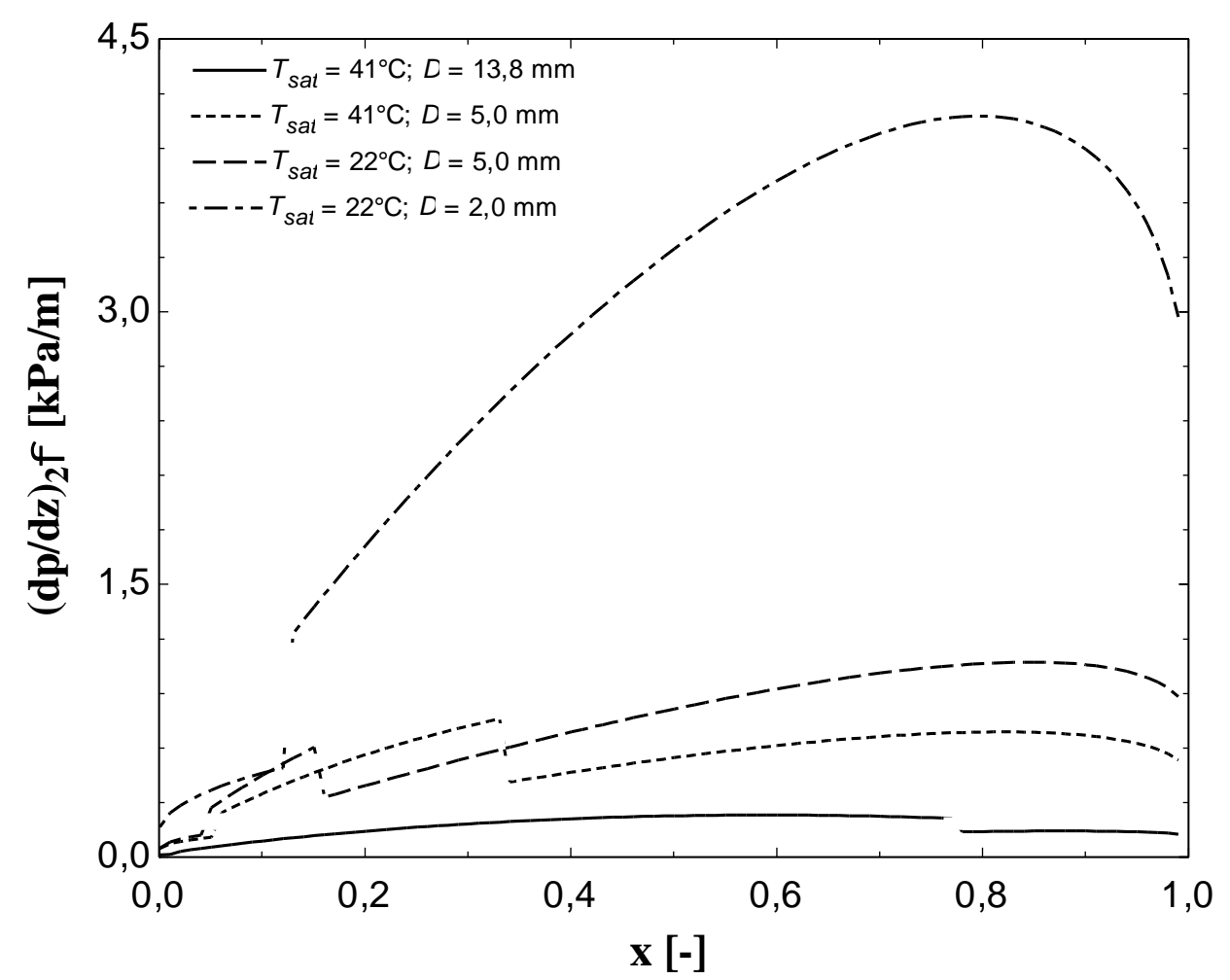

Figura 3.2. Efeito do diâmetro e da temperatura de saturação no gradiente de perda de pressão segundo Lockhart e Martinelli (1949), R134a, G = 100 [kg/m²s].

Grönnerud (1979) incluiu o número de Froude no cálculo da perda de pressão na tentativa de capturar efeitos de padrões de escoamento, já que elevados valores do número de Froude implicam no predomínio das forças de inércia sobre os gravitacionais favorecendo o padrão anular (área de contato líquido/parede superior). Já para números de Froude reduzidos, efeitos gravitacionais predominam o que resulta no padrão 
estratificado e uma área de contato líquido/parede inferior, incorrendo em menor dissipação viscosa. Kanizawa e Ribastki (2012) indicaram o método de Grönnerud (1979) como aquele que proporcionou as melhores previsões de seus resultados experimentais para tubos lisos sem fitas retorcidas. Entretanto, vale destacar que tal conclusão não pode ser estendida a tubos de reduzido diâmetro, pois estes autores realizaram seus experimentos para canais com $\mathrm{D}=15,9 \mathrm{~mm}$. Mauro et al. (2007) reportaram o método de Grönnerud como o método que obteve melhores previsões dos seus dados experimentais abrangendo 7 fluidos refrigerantes, velocidades mássicas entre 190 e $1100 \mathrm{~kg} / \mathrm{m}^{2} \mathrm{~s}$ e diâmetros de 6 e 13,8 mm. Revellin e Haverschill (2009) também compararam dados de perda de pressão com os métodos de previsão da literatura. $\mathrm{O}$ banco de dados dos autores abrange 4 fluidos refrigerantes, velocidades mássicas entre 70 e $800 \mathrm{~kg} / \mathrm{m}^{2} \mathrm{~s}$. Segundo estes autores o método de Gronnerud (1979) proporcionou as melhores previsões, prevendo $71 \%$ dos dados dentro da faixa de erro de $\pm 30 \%$.

Chen et al. (2007) propuseram alterações do parâmetro C, conforme proposto por Wambsganss et al. (1992), com a incorporação de efeitos do fator de forma para canais retangulares através dos parâmetros $a$ e $b$ (ver Tabela 3.2). A Figura 3.3 ilustra o efeito do fator de forma na relação entre o multiplicador bifásico e a perda de pressão bifásica com o parâmetro de Martinelli. Esta comparação foi realizada mantendo um perímetro interno equivalente ao de um tubo circular com diâmetro interno igual a 1,1 mm.

Como observado na figura, o multiplicador bifásico referente à fase líquida decresce com a redução do fator de forma, implicando numa perda de pressão superior para o canal com o fator de forma de 1/8 e inferior para fator de forma unitário. Vale também mencionar que os autores recomendam o cálculo do número de Reynolds utilizando o diâmetro hidráulico como dimensão característica. O método proposto por Chen et al. (2007) forneceu previsões satisfatórias para o banco de dados experimental utilizado em sua elaboração e também para resultados independentes obtidos por Wambsganss et al. (1992) e Ide e Fukano (2005) 


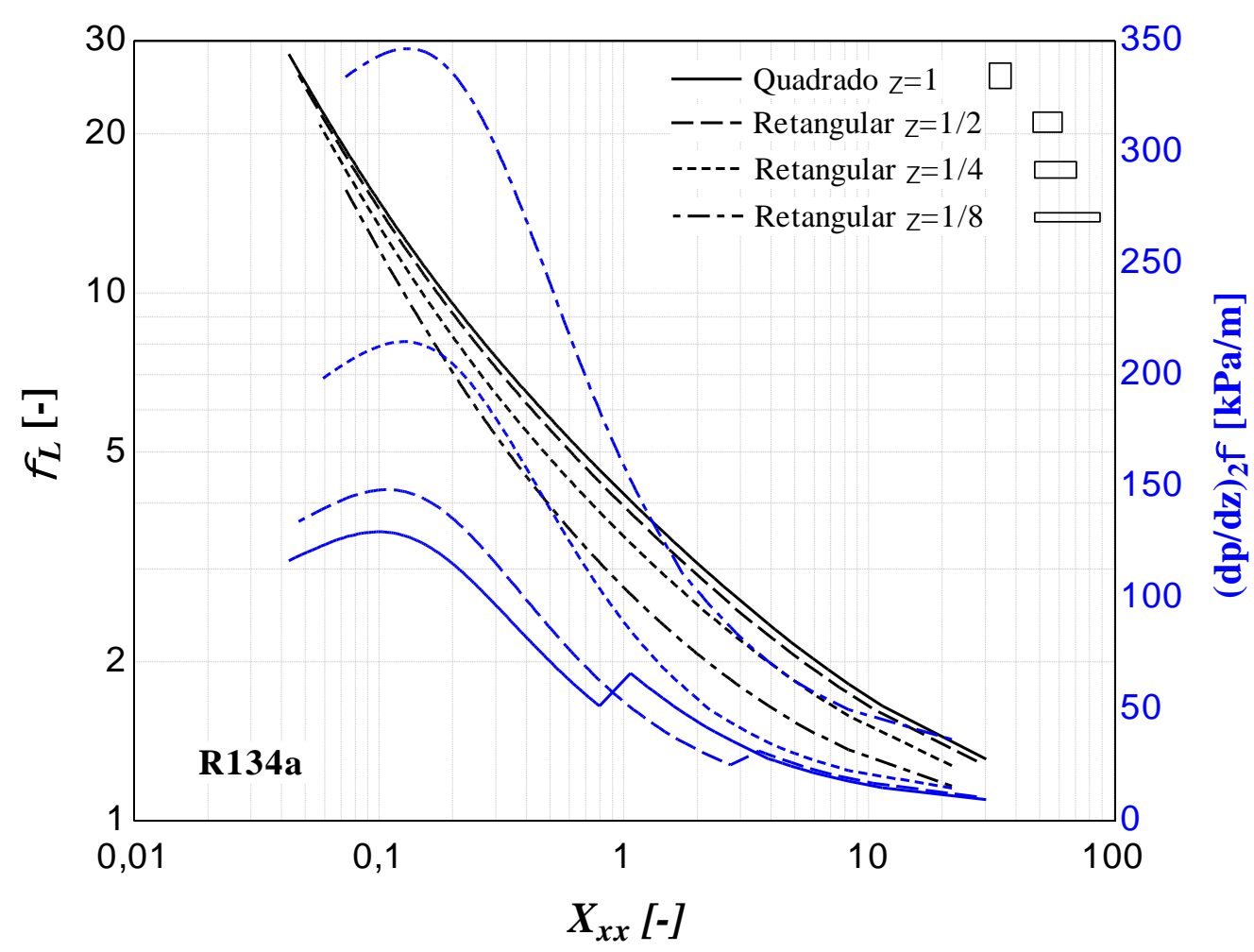

Figura 3.3. Efeito do fator de forma na relação entre o parâmetro de Lockhart-Martinelli e o multiplicador bífasico segundo Chen et al. (2007), R134a, $\mathrm{T}_{\text {sat }}=31^{\circ} \mathrm{C}, \mathrm{G}=500 \mathrm{~kg} / \mathrm{m}^{2} \mathrm{~s}$.

\section{Canais de reduzido diâmetro}

A Tabela 3.3 apresenta os métodos de previsão da perda de pressão baseados em multiplicadores bifásicos desenvolvidos para canais de dimensões reduzidas e descreve os bancos de dados utilizados no seu desenvolvimento.

Conforme ilustrado na Tabela 3.3, os métodos de previsão da perda de pressão baseados em multiplicadores bifásicos em sua maioria consideram em bancos de dados experimentais amplos, a partir dos quais os autores obtém novas correlações para o parâmetro C, inicialmente proposto por Chisholm (1967), ou para os multiplicadores bifásicos.

Entre os fluidos de trabalho incluídos no desenvolvimento das correlações de previsão da perda de pressão podem ser mencionado água, HFCs (R134a, R245fa), $\mathrm{CO}_{2}$, misturas de refrigerantes (R410A, R404A, entre outros), amônia, hidrocarbonetos (PAMITRAN et al., 2010 e LI; WU, 2011) e HFOs (R1234yf por DEL COL et al., 2013). 
Tabela 3.3. Métodos de previsao da perda de pressão baseados em multiplicadores bifasicos desenvolvidos para canais de reduzido diâmetro.

\begin{tabular}{|c|c|c|}
\hline Autor & Correlações & Banco de dados/Observações \\
\hline $\begin{array}{l}\text { Mishima e Hibiki } \\
\text { (1996) }\end{array}$ & $\begin{array}{l}\left(\frac{d p}{d z}\right)_{2 \phi}=\left(\frac{d p}{d z}\right)_{L} \phi_{L}^{2} ; \phi_{L}^{2}=1+C / X+1 / X^{2} \\
\text { Para canais retangulares: } C=21\left(1-\mathrm{e}^{-0,319 \times 10^{3} D_{n}}\right) ; \text { Para canais circulares: } C=21\left(1-\mathrm{e}^{-0,333 \times 10^{3} D}\right)\end{array}$ & $\begin{array}{c}\text { Ar/Água } \\
\text { Escoamento vertical } \\
\mathrm{D}_{\mathrm{H}}=1,05 ; 2,05 ; 3,12 \text { e } 4,08 \mathrm{~mm}\end{array}$ \\
\hline Tran et al. (2000) & $\left(\frac{d p}{d z}\right)_{2 \phi}=\left(\frac{d p}{d z}\right)_{L 0} \phi_{L 0}^{2}, \phi_{L O}^{2}=1+\left(4,3 \Upsilon^{2}-1\right)\left[C o \cdot x^{0,875}(1-x)^{0,875}+x^{1,75}\right]$ & $\begin{array}{l}\mathrm{R} 134 \mathrm{a}, \mathrm{R} 12 \text { e R113 } \\
\text { Circular e retangular } \\
\mathrm{D}=2,46 \text { e } 2,96 \mathrm{~mm} ; 4,06 \times 1,07 \mathrm{~mm}\end{array}$ \\
\hline Zhang e Webb (2001) & $\left(\frac{d p}{d z}\right)_{2 \phi}=\left(\frac{d p}{d z}\right)_{L 0} \phi_{L 0}^{2}, \phi_{L O}^{2}=(1-x)^{2}+2,87 x^{2}\left(p_{r}\right)^{-1}+1,68 x^{0,8}(1-x)^{0,25}\left(p_{r}\right)^{-1,64}$ & $\begin{array}{c}\mathrm{R} 134 \mathrm{a}, \mathrm{R} 22, \mathrm{R} 404 \mathrm{a} \\
\mathrm{D}_{\mathrm{H}}=2,13 \mathrm{~mm}\end{array}$ \\
\hline Lee e Lee (2001a) & $\begin{array}{l}\left(\frac{d p}{d z}\right)_{2 \phi}=\left(\frac{d p}{d z}\right)_{L} \phi_{L}^{2}, \phi_{L}^{2}=1+C / X+1 / X^{2}, \lambda=\frac{\mu_{L}^{2}}{\rho_{L} \sigma D} \psi=\frac{\mu_{L} J_{L}}{\sigma} \\
C_{l l}=6,833 \times 10^{-8} \lambda^{-1,317} \psi^{0,719} \operatorname{Re}_{L 0}^{0,557} ; C_{l t}=6,185 \times 10^{-2} \operatorname{Re}_{L 0}^{0,726} ; C_{t l}=3,627 \operatorname{Re}_{L 0}^{0,174} ; C_{t t}=0,408 \operatorname{Re}_{L 0}^{0,451}\end{array}$ & $\begin{array}{l}\text { Ar/Água, canais retangulares } \\
\quad \mathrm{D}_{\mathrm{H}}=0,78 ; 6,67 \mathrm{~mm} \\
\text { Para fatores de forma inferiores a } 0,2 . \\
\quad 305 \text { dados. }\end{array}$ \\
\hline Yu et al. (2002) & $\left(\frac{d p}{d z}\right)_{2 \phi}=\left(\frac{d p}{d z}\right)_{L} \phi_{L}^{2} ; \phi_{L}^{2}=1+C / X+1 / X^{2} ; C=X_{l t}^{-1,9}$ & 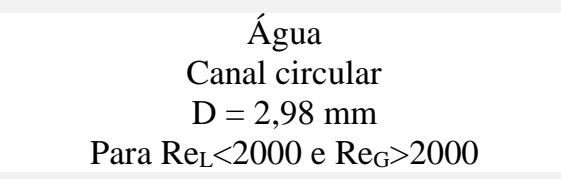 \\
\hline Qu e Mudawar (2003) & $\left(\frac{d p}{d z}\right)_{2 \phi}=\left(\frac{d p}{d z}\right)_{L} \phi_{L}^{2} ; \phi_{L}^{2}=1+C / X+1 / X^{2} ; C=X_{u}^{-1,9} ; C=21\left(1-\mathrm{e}^{-0,319 \times 10^{3} D_{u}}\right)(0,00418 G+0,0613)$ & $\begin{array}{c}\mathrm{R} 134 \mathrm{a} \\
231 \times 713 \mu \mathrm{m}\end{array}$ \\
\hline Lee e Mudawar (2005a) & $\left(\frac{d p}{d z}\right)_{2 \phi}=\left(\frac{d p}{d z}\right)_{L} \phi_{L}^{2}, \phi_{L}^{2}=1+C / X+1 / X^{2}, C_{l l}=2,16 \operatorname{Re}_{L 0}^{0,047} W e_{L 0}^{0,6} ; C_{l t}=1,45 \operatorname{Re}_{L 0}^{0,25} W e_{L 0}^{0,23}$ & $\begin{array}{c}\text { R134a } \\
231 \times 713 \mu \mathrm{m} \\
\text { Dados experimentais para multicanais }\end{array}$ \\
\hline Hwang e Kim (2006) & $\left(\frac{d p}{d z}\right)_{2 \phi}=\left(\frac{d p}{d z}\right)_{L} \phi_{L}^{2}, \phi_{L}^{2}=1+C / X+1 / X^{2}, C=0,227 \operatorname{Re}_{L 0}^{0,452} X^{-0,32} C o^{-0,82}$ & $\begin{array}{c}\text { Circular, R134a } \\
\mathrm{D}=0,244 ; 0,43 ; 0,792 \mathrm{~mm}\end{array}$ \\
\hline Sun e Mishima (2009b) & $\begin{array}{l}\left(\frac{d p}{d z}\right)_{2 \phi}=\left(\frac{d p}{d z}\right)_{L} \phi_{L}^{2}, \phi_{L}^{2}=1+C / X^{n}+1 / X^{2}, C_{v v}=26\left(1+\frac{\operatorname{Re}_{L}}{1000}\right)\left[1-\exp \left(\frac{-0.153}{0.27 C o+0.8}\right)\right], n_{v v}=1 \\
C_{v t}=C_{t v}=C_{t}=1.79\left(\frac{\operatorname{Re}_{G}}{\operatorname{Re}_{L}}\right)^{0.4}\left(\frac{1-x}{x}\right)^{0.5}, n_{v t}=n_{t v}=n_{t t}=1.19\end{array}$ & $\begin{array}{l}\text { Canais circular, retangular e triangular. } \\
\text { Ar/Água, } \mathrm{CO}_{2}, \mathrm{R} 22 ; \mathrm{R} 134 \mathrm{a} ; \mathrm{R} 236 \mathrm{ea} ; \\
\text { R245fa; R404A, R410A; R407C. } \\
\mathrm{D}_{\mathrm{H}}=0,506-12 \mathrm{~mm} \\
2092 \text { dados de } 19 \text { trabalhos } \\
\text { independentes.. }\end{array}$ \\
\hline
\end{tabular}


Tabela 3.3 (Continuação).- Estudos sobre o coeficiente de transferencia de calor em canais retangulares

\begin{tabular}{|c|c|c|}
\hline Autor & Correlações & Banco de dados/Observações \\
\hline Zhang et al. (2010)* & $\begin{array}{l}\left(\frac{d p}{d z}\right)_{2 \phi}=\left(\frac{d p}{d z}\right)_{L} \phi_{L}^{2} ; \phi_{L}^{2}=1+C / X+1 / X^{2} \\
\text { líquido-gas : } C=21[1-\exp (-0.142 / C o)] ; \text { líquido - vapor : } C=21[1-\exp (-0.674 / C o)]\end{array}$ & $\begin{array}{l}\text { Canais circular, retangular } \\
\text { Água, Etanol, R113, R22, R134a, } \\
\text { R236ea, R410A, R404a Amônia- } \\
\text { Ar, } \mathrm{N}_{2} \text {, vapor. } \\
\mathrm{D}_{\mathrm{H}}=0,07-6,25 \mathrm{~mm} ; 2201 \text { dados. }\end{array}$ \\
\hline Pamitran et al. (2010) & $\begin{array}{l}\left(\frac{d p}{d z}\right)_{2 \phi}=\left(\frac{d p}{d z}\right)_{L} \phi_{L}^{2} ; \phi_{L}^{2}=1+C / X+1 / X^{2} ; C=0,003 \operatorname{Re}_{2 \phi}^{1,23} W e_{2 \phi}^{-0,433} ; \operatorname{Re}_{2 \phi}=\frac{G D}{\mu_{2 \phi}} ; W e_{2 \phi}=\frac{G^{2} D}{\rho_{2 \phi} \sigma} \\
\rho_{2 \phi}=\alpha \rho_{G}+(1-\alpha) \rho_{L} \text { com } \alpha \text { dado por Steiner (1993); } \mu_{2 \phi} \text { dado por Beattie e Whalley (1982) }\end{array}$ & $\begin{array}{c}\text { Canal circular } \\
\text { R22; R134a; R410A; Propano; } \mathrm{CO}_{2} \\
\text { D = 0,5; } 1,5 ; 3 \mathrm{~mm} ; 812 \text { pontos }\end{array}$ \\
\hline Li e Wu (2011) & $\begin{array}{l}\text { Para.Bd }<0.1:\left(\frac{d p}{d z}\right)_{2 \phi}=\left(\frac{d p}{d z}\right)_{L} \phi_{L}^{2} ; \phi_{L}^{2}=1+C / X+1 / X^{2}, C=0.56 B d^{0.28} . \\
\text { Para.Bd } \geq 0.1 \text { e } B d \operatorname{Re}_{L}^{0.5} \leq 200:\left(\frac{d p}{d z}\right)_{2 \phi}=\left(\frac{d p}{d z}\right)_{L 0} \phi_{L 0}^{2}, \phi_{L 0}^{2}=(1-x)^{2}+2.87 x^{2} p_{r e d}^{-1}+1,54 B d^{0.19}\left(\frac{\rho_{L}-\rho_{G}}{\rho_{H}}\right)^{0.81} . \\
\text { Para.Bd } \operatorname{Re}_{L}^{0.5} \leq 200: \text { Modelo homogêneo com a viscosidade dada por Beattie e Whalley (1982) }\end{array}$ & $\begin{array}{l}\text { Canais circular, retangular } \\
\text { R22, R134a, R245fa, R236ea, R410A, } \\
\text { R404A, R422D, R32, R290, amônia e } \\
\mathrm{N}_{2} . \\
\mathrm{D}_{\mathrm{H}}=0,148-3,25 \mathrm{~mm} \\
762 \text { dados de } 9 \text { trabalhos } \\
\text { independentes }\end{array}$ \\
\hline Kim e Mudawar (2012) & $\begin{array}{l}\left(\frac{d p}{d z}\right)_{2 \phi}=\left(\frac{d p}{d z}\right)_{L} \phi_{L}^{2} ; \phi_{L}^{2}=1+C / X+1 / X^{2} ; \operatorname{Re}_{L 0}=\frac{G D_{H}}{\mu_{L}} \\
C_{t t}=0,39 \operatorname{Re}_{L 0}^{0,03} S u_{G 0}^{0,1}\left(\rho_{L} / \rho_{G}\right)^{0,35} ; C_{t v}=0,00087 \operatorname{Re}_{L 0}^{0,17} S u_{G 0}^{0,5}\left(\rho_{L} / \rho_{G}\right)^{0,14} \\
C_{v t}=0,0015 \operatorname{Re}_{L 0}^{0,59} S u_{G 0}^{0,19}\left(\rho_{L} / \rho_{G}\right)^{0,36} ; C_{v v}=0,000035 \operatorname{Re}_{L 0}^{0,44} S u_{G 0}^{0,5}\left(\rho_{L} / \rho_{G}\right)^{0,48}\end{array}$ & $\begin{array}{l}\text { Canais circular, retangular } \\
\text { R12; R22; R134a; R236ea; R245fa; } \\
\text { R404A; R410A; R407C; propano; } \\
\text { metano; amônia; } \mathrm{CO}_{2} ; \text { agua; } \\
\text { Ar/ } \mathrm{CO}_{2} / \mathrm{N}_{2} \text {-água } \\
\mathrm{D}_{\mathrm{H}}=0,0695-6,22 \mathrm{~mm} \\
7115 \text { pontos de } 36 \text { trabalhos distintos. }\end{array}$ \\
\hline Del Col et al. (2013) & $\begin{array}{l}\left(\frac{d p}{d z}\right)_{2 \phi}=\left(\frac{d p}{d z}\right)_{L 0} \phi_{L 0}^{2} ; \phi_{L 0}^{2}=Z+3.595 F H(1-E)^{W} ; F=x^{0.9525}(1-x)^{0.414}, Z=(1-x)^{2}+x^{2} \frac{\rho_{L}}{\rho_{G}}\left(\frac{\mu_{G}}{\mu_{L}}\right)^{0.2}, W=1,398 p_{\text {red }} \\
H=\left(\frac{\rho_{L}}{\rho_{G}}\right)^{1.132}\left(\frac{\mu_{G}}{\mu_{L}}\right)^{0.44}\left(1-\frac{\mu_{G}}{\mu_{L}}\right)^{3.542} ; \rho_{G C}=\frac{x+(1-x) E}{x / \rho_{L}+(1-x) E / \rho_{G}} ;\left(\frac{d p}{d z}\right)_{L 0}=2 f_{L 0} \frac{G^{2}}{D_{H} \rho_{L}} ; \operatorname{Re}_{L 0}=\frac{G D_{H}}{\mu_{L}} \\
f_{L 0}=0,046 \operatorname{Re}_{L 0}^{-0.2}+0,7 R R \cdot X ; E=0,015+0,44 \log \left[\frac{\rho_{G C}}{\rho_{L}}\left(\frac{\mu_{L} j_{G}}{\sigma}\right)^{2} 10^{4}\right] ; \text { Para.E} \leq 0: E=0, \text { Para.E } \geq 0,95: E=0,95 \\
\text { Para } \operatorname{Re}_{L 0} \leq \operatorname{Re}_{L 0}^{+}: X=0 ; \text { Para } \operatorname{Re}_{L 0} \geq 3500: X=1 ; \text { Para } \operatorname{Re}_{L 0}^{+}<\operatorname{Re}_{L 0}<3500: X=1+\frac{8,99 \times 10^{-3}-0,046 \mathrm{Re}_{L 0}^{-0.2}}{0,7 R R}\end{array}$ & $\begin{array}{l}\text { Canais circular, quadrado e forma } \\
\text { irregular. } \\
\text { Atualização do método de Cavallini et } \\
\text { al. (2009) } \\
\text { R134a, R1234yf, R32, R245fa, } \\
\text { R236ea, R410A. } \\
\text { DH }=0,51-3,25 \text { mm; } 347 \text { pontos } \\
\text { Correlações empíricas para a } \\
\text { densidade do núcleo gasoso e o } \\
\text { entranhamento de gotas de líquido. }\end{array}$ \\
\hline
\end{tabular}


A Figura 3.4 ilustra os efeitos do diâmetro, velocidade mássica e temperatura de saturação na perda de pressão previstos segundo Kim e Mudawar (2012) e Del Col et al. (2013). Como observado na figura, para os dois métodos o gradiente da perda de pressão se eleva com o decréscimo da temperatura de saturação e do diâmetro. Também se observa o incremento da perda de pressão com o acréscimo da velocidade mássica. Ambos comportamentos são indicados por resultados experimentais encontrados na literatura e proporcionados pelos demais métodos apresentados na Tabela 3.5.

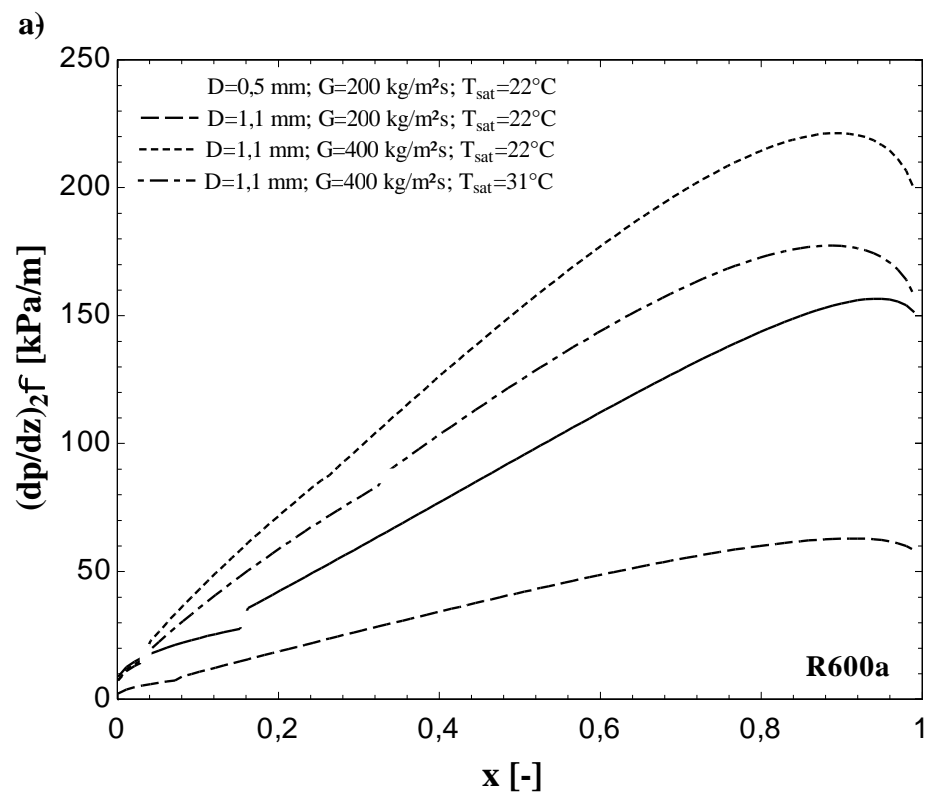

b)

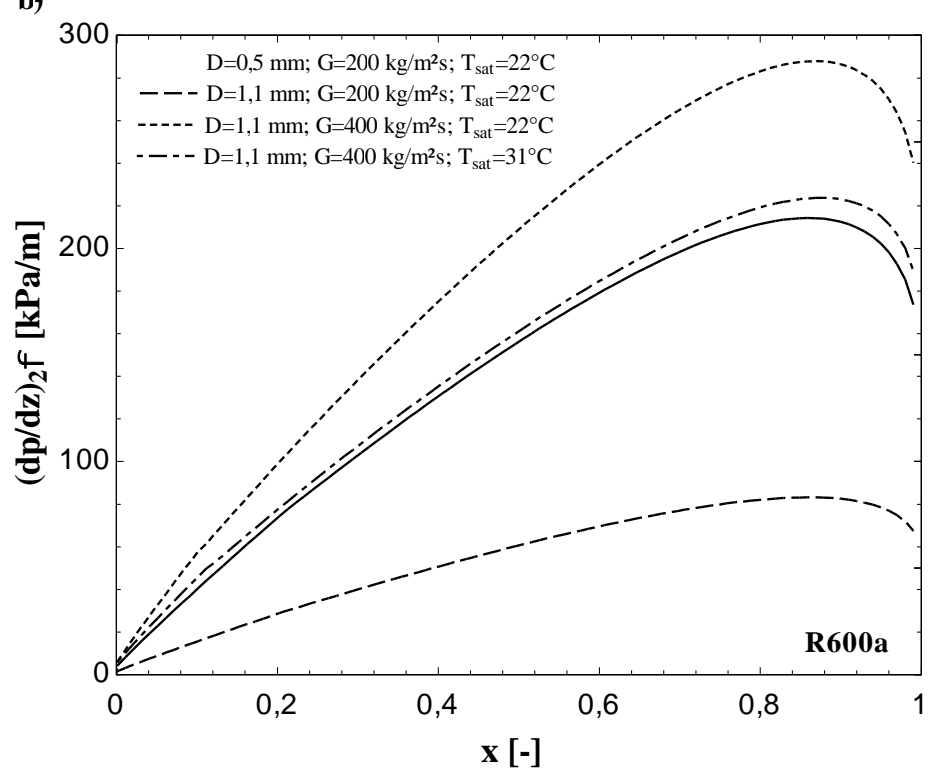

Figura 3.4.- Efeito do diametro, temperatura de saturaçao e velocidade massica nos metodos, a) Kim e Mudawar (2012), b) Del Col et al. (2103). 
Pode-se observar também na Figura 3.4a, que o método de Kim e Mudawar (2012) apresenta descontinuidades, as quais estão relacionadas à existência de diferentes correlações para o parâmetro C. Como Lockart-Martinelli, os autores relacionam o parâmetro C diretamente com o regime de escoamento das fases. Lee e Lee (2001b), Lee e Mudawar (2005a) e Sun e Mishima (2009b) são autores que também propuseram correlações baseadas no regime de escoamento das fases. Vale mencionar que as descontinuidades que estes métodos preveem não são observadas experimentalmente segundo a literatura. Por outro lado, também se observa que os métodos de Kim e Mudawar (2012) e Del Col et al. (2013) preveem o pico do gradiente da perda de pressão, comportamento amplamente reportado na literatura e já mencionado no Item 2.6. Segundo Thome (2007), este comportamento está relacionado ao início da secagem de parede. No entanto, Shedd (2010) sugere que o pico da perda de pressão é anterior ao início de secagem de parede e ocorre devido ao desaparecimento da perturbação interfacial de ondas e a subsequente formação de anéis de líquido que incrementariam efeitos de dissipação viscosa. Da Silva (2012), mediante o análise de imagens obtidas com uma câmera de alta velocidade, constatou a redução de ondulações interfaciais para títulos de vapor superiores ao correspondente ao pico da perda de pressão.

Lee e Mudawar (2005a), Sun e Mishima (2009b), Zhang et al. (2010), Li e Wu (2011) e Kim e Mudawar (2012) utilizaram um banco de dados que inclui dados experimentais da perda de pressão para multicanais, os quais conforme indicado por Tibiriçá e Ribatski (2013), podem diferenciar-se substancialmente de dados experimentais para canais únicos devido a vários aspectos adicionais a considerar, como:

$>$ Interação entre canais vizinhos;

$>$ Efeito dos plenums;

> Ausência de restrições a montante dos canais (as quais são facilmente implementadas para testes em canais únicos);

$>$ Possibilidade de escoamento reverso;

$>$ Instabilidades térmicas;

Por último, é importante ressaltar que os métodos de previsão que incluem dados para canais retangulares e circulares usam o diâmetro hidráulico como dimensão característica para o cálculo do número de Reynolds. No entanto, nenhum dos autores listado efetuou análise detalhada sobre a razão do emprego desta dimensão característica. 


\subsubsection{Métodos estritamente empíricos}

Os métodos classificados neste estudo como estritamente empíricos são baseados no ajuste de dados experimentais a uma série matemática de forma que para título de vapor igual a zero $(x=0)$ o resultado seja a perda de pressão monofásica do líquido $\Delta p_{2 \phi}$ $=\Delta p_{L}$ e para título de vapor igual a um $(x=1)$ o resultado seja a perda de pressão monofásica do gás $\Delta p_{2 \phi}=\Delta p_{G}$.

\section{Canais convencionais}

\section{Müller-Steinhagen e Heck (1986)}

Estes autores desenvolveram um método empírico que consiste na interpolação dos gradientes de pressão para o escoamento, assumindo a mistura bifásica apenas como líquido ou vapor, em função do título de vapor. Os autores utilizaram um extenso banco de dados contendo 9313 resultados experimentais de perda de pressão em canais circulares, tendo como fluidos ar - água, vapor - água, água - óleo, R11, R12, R22, Argônio, $\mathrm{N}_{2}$ e Neônio, e cobrindo uma faixa de diâmetros de 4 a 203 mm. Este método é dado pela seguinte equação:

$$
\Delta p_{2 \phi}=\left(\Delta p_{L O}+\omega \cdot\left(\Delta p_{G O}-\Delta p_{L O}\right) \cdot x\right) \cdot(1-x)^{1 / \lambda}+\Delta p_{G O} \cdot x^{\lambda}
$$

Através do análise de regressão do banco de dados, os autores obtiveram valores de $\omega$ e $\lambda$ iguais a 2 e 3 , respectivamente.

Ribastki et al. (2006) e Felcar e Ribatski (2008) avaliaram respectivamente 12 e 18 métodos de previsão através de comparações com um banco de dados abrangente levantado na literatura. Para a avaliação dos métodos de previsão que não especificam uma dimensão característica, os autores utilizaram o diâmetro hidráulico. As correlações que proporcionaram os melhores resultados foram os métodos de Müller-Steinhagen e Heck (1986) e o modelo homogêneo com a viscosidade bifásica dada por Cicchitti et al. (1960).

Revellin e Thome (2007) indicaram que os métodos desenvolvidos para canais de dimensão reduzida não proporcionam previsões satisfatórias da perda de pressão do 
banco de dados levantados por eles na literatura para microcanais circulares. Entretanto, os autores reportaram o método de Muller-Steinhagen e Heck (1986) como aquele que proporciona os melhores resultados, prevendo $62,5 \%$ dos dados com erro inferior a \pm 20 $\%$, para resultados com números de Reynolds bifásicos superiores a 8000. Eles definiram o número de Reynolds bifásico baseados no modelo homogêneo com a viscosidade bifásica dada por McAdams et al. (1942).

Segundo Thome et al. (2008), o método proposto por Müller-Steinhagen e Heck (1986) apresenta resultados satisfatórios para a estimativa da perda de pressão bifásica para a amônia em tubulação com diâmetro de 10 mm. Cioncolini et al. (2009) e Da Silva e Ribatski (2013) também indicaram que este método fornece as melhores previsões de seus resultados experimentais para canais circulares. Entretanto, tais previsões são insatisfatórias, motivo pelo qual estes autores propuseram seus próprios métodos de previsão da perda de pressão que serão descritos mais adiante.

Na literatura emprega-se o método de Müller-Steinhagen e Heck (1986) para canais não-circulares usando o diâmetro hidráulico como dimensão característica sem justificativas para esta escolha. Neste contexto vale destacar o fato dos autores não terem utilizado dados para canais não-circulares no desenvolvimento deste método, não capturando assim, possíveis efeitos da geometria.

\section{Canais de diâmetro reduzido}

\section{Xu e Fang (2012)}

Os autores compararam um banco de dados composto por 2622 resultados experimentais (90\% dos dados para canais circulares, 15 fluidos distintos, diâmetros hidráulicos entre 0,81 e 19,1 mm) com 29 métodos de previsão da perda de pressão existentes na literatura. Os métodos que resultaram em melhores previsões foram MüllerSteinhagen e Heck (1986), Friedel (1979) e o modelo homogêneo com a viscosidade dada por Cicchitti et al. (1960). O método de Muller-Steinhagen e Heck (1986) proporcionou previsões satisfatórias dos dados para canais com dimensões convencionais, no entanto, subestimou resultados para microcanais. Considerando tal fato, os autores modificaram o método inicialmente proposto Müller-Steinhagen e Heck mediante a adição de um fator 
dado como função do número de confinamento. A correlação proposta por estes autores é a seguinte:

$$
\Delta p_{2 \phi}=\left[F \cdot(1-x)^{1 / \lambda}+\Delta p_{G O} \cdot x^{\lambda}\right] \cdot\left[1+1,54 \cdot(1-x)^{0,5} \cdot C O^{1,47}\right]
$$

\section{Da Silva e Ribatski (2013)}

A partir de um banco de dados composto por 487 resultados experimentais para os refrigerantes R245fa e R134a, canais circulares com diâmetros de 1,1 e 2,32 mm, velocidades mássicas entre 200 e 1400 kg/m²s. Da Silva e Ribatski (2013) ajustaram o coeficiente e expoente do correlação de Müller-Steinhagen e Heck (1986). Eles obtiveram valores para $\omega$ e $\lambda$ iguais a 1,037 e 1,026 , respectivamente.

A Figura 3.5 ilustra uma comparação entre as correlações propostas por Xu e Fang (2012), Da Silva (2012), Muller-Steinhagen e Heck (1986) e dados experimentais obtidos por Da Silva (2012).

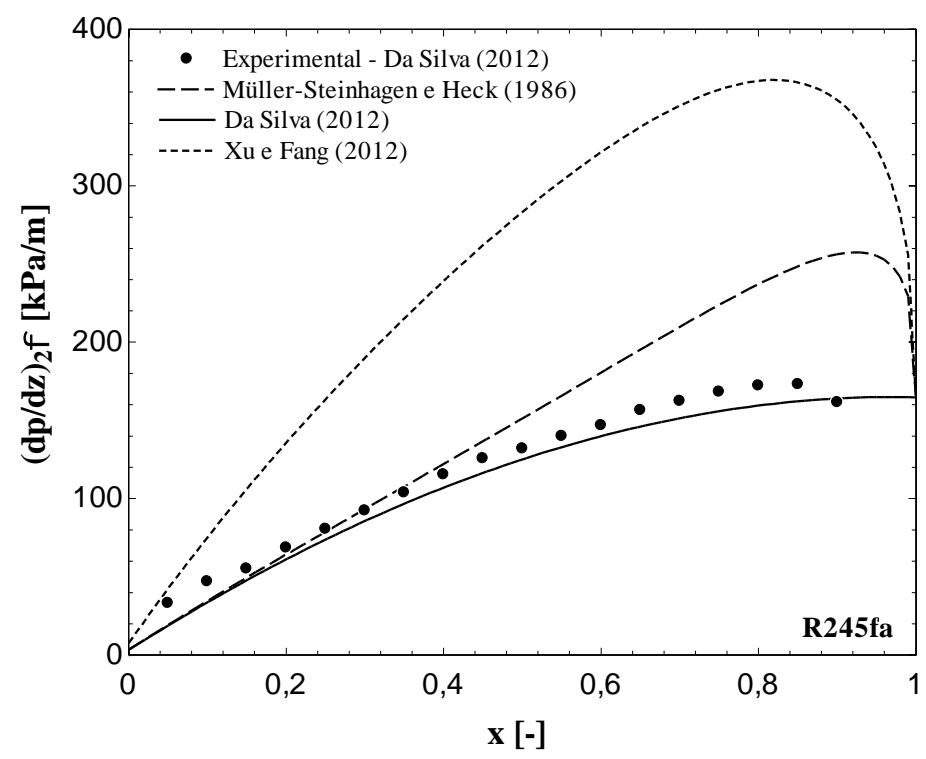

Figura 3.5. Comparação entre os dados experimentais de Da Silva e Ribatski (2013), e métodos de previsao da literatura, $\mathrm{R} 245 \mathrm{fa}, \mathrm{T}_{\mathrm{sat}}=41^{\circ} \mathrm{C}, \mathrm{G}=500 \mathrm{~kg} / \mathrm{m}^{2} \mathrm{~s}$.

Através da figura, conclui-se que a correlação de Da Silva (2012) captura parcelas das tendências dos resultados experimentais e que a discrepância com o método original se acentua com o incremento do título de vapor. A correlação proposta por Xu e Fang (2012) prevê valores superiores aos obtidos pela correlação original e superestima os valores experimentais. Na figura também se observa que os métodos desenvolvidos por 
Muller-Steinhagen e Heck (1986) e Xu e Fang (2012) não preveem adequadamente o pico do gradiente da perda de pressão, apresentando para esta condição erros superiores a $40 \%$ e $100 \%$, respectivamente. Por outro lado, Da Silva (2012) não prevê o pico, mas prevê satisfatoriamente os valores da perda de pressão para títulos de vapor elevados.

\subsubsection{Métodos baseados em análises fenomenológicas}

Recentemente métodos de previsão da perda de pressão baseados em padrões de escoamento foram propostos. Estes métodos, descritos neste item, consideram na sua modelagem características geométricas e fenomenológicas próprias de cada padrão do escoamento.

\section{Canais convencionais}

\section{Moreno-Quiben e Thome (2007)}

O método proposto por estes autores incorpora efeitos de padrões de escoamento na perda de pressão por atrito. Na sua elaboração foi utilizado um banco de dados que inclui refrigerantes R134a, R22 e R410A, velocidades mássicas entre 70 e 700 kg/m²s e diâmetros entre 8 e 13,8 mm. No método, a perda de pressão é estimada considerando as características da distribuição das fases na tubulação, as quais são identificadas a partir do mapa de padrões de escoamento desenvolvido por Wojtan et. (2005).

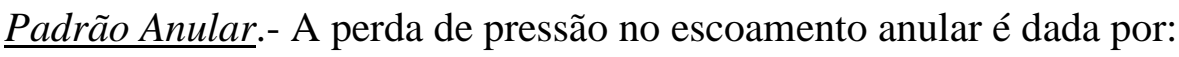

$$
\Delta p_{\text {Anular }}=2 f_{i, \text { Anular }}\left(\frac{L}{D}\right) \rho_{G} u_{G}^{2}
$$

onde $f_{i, \text { Anular }}$ é o fator de atrito interfacial estimado segundo a seguinte equação:

$$
f_{i, \text { Anular }}=0,67\left(\frac{\delta}{D}\right)^{2}\left(\frac{\left(\rho_{L}-\rho_{G}\right) g \delta^{2}}{\sigma}\right)^{-0,4}\left(\frac{\mu_{G}}{\mu_{L}}\right)^{2} W e_{L}^{-0,034}
$$


Vale mencionar que o coeficiente e os expoentes desta equação foram ajustados através de um banco de dados experimental. A espessura do filme líquido é dada pela seguinte equação:

$$
\delta=\frac{D}{2}-\left[\left(\frac{D}{2}\right)^{2}-\frac{(1-\alpha) \pi D^{2}}{2\left(2 \pi-\theta_{\sec o}\right)}\right]^{1 / 2}
$$

Na equação acima a fração de vazio $(\alpha)$ é calculada mediante o método de Rouhani e Axelson (1970) e $\theta_{\text {seco }}$ é o ângulo da parte da superfície do tubo em contato com a fase gasosa, como ilustrado na Figura 3.6. No caso do padrão anular e pistonado este ângulo é nulo.

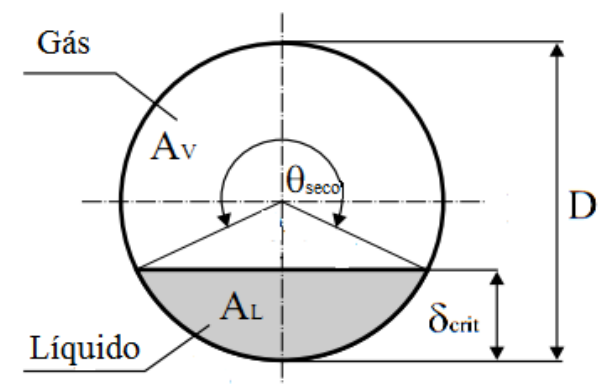

Figura 3.6.- Configuração do escoamento estratificado, Moreno-Quibén e Thome (2007).

Padrão Pistonado e Intermitente.- Moreno-Quibén e Thome (2007) assumem que as tendências do fator de atrito com a variação da fração de vazio se mantem para os padrões pistonado e intermitente. Assim, eles propuseram procedimento único para o cálculo da perda de pressão para estes padrões dado pela seguinte equação:

$$
\Delta p_{\text {Pistonado+Intermitente }}=\Delta p_{L O}\left(1-\frac{\alpha}{\alpha_{I A}}\right)^{0,25}+\Delta p_{\text {Anular }}\left(\frac{\alpha}{\alpha_{I A}}\right)^{0,25}
$$

Vale observar que para uma fração de vazio nula a solução da equação anterior resulta na perda de pressão para o escoamento líquido, $\Delta p_{L O}$, e para uma fração de vazio igual a $\alpha_{I A}$, correspondendo a transição intermitente -anular, resulta na perda de pressão para escoamento anular, $\Delta p_{\text {anular }}$. $\mathrm{O}$ expoente 0,25 foi encontrado com base em um ajuste de regressão segundo os dados experimentais levantados por estes autores. 
Estratificado-ondulado.- No padrão estratificado-ondulado o cálculo da perda de pressão é dado pelas seguintes equações:

$$
\begin{aligned}
& \Delta p_{\text {Estratificado_ondulado }}=2 f_{\text {Estratificado_ondulado }}\left(\frac{L}{D}\right) \rho_{G} u_{G}^{2} \\
& f_{\text {Estratificado_ondulado }}=\theta_{\mathrm{sec} o}^{*} f_{G}-\left(1-\theta_{\mathrm{sec} o}^{*}\right) f_{i, \text { Anular }}
\end{aligned}
$$

onde $\theta_{\operatorname{seco}}^{*}=\theta_{\text {sexo }} / 2 \pi$ e o ângulo $\theta_{\sec o}$ são calculados a partir das seguintes equações:

$$
\begin{aligned}
& \theta_{\text {seco }}=\left[\frac{G_{\text {Ondulado }}-G}{G_{\text {Ondulado }}-G_{\text {Estratificado }}}\right]^{0,61} \theta_{\text {Estratificado }} \\
& \theta_{\text {Estratificado }}=2 \pi-2\left\{\begin{array}{l}
\pi(1-\alpha)+\left(\frac{3 \pi}{2}\right)^{1 / 3}\left[1-2(1-\alpha)+(1-\alpha)^{1 / 3}-\alpha^{1 / 3}\right] \\
-\frac{1}{200}(1-\alpha) \alpha[1-2(1-\alpha)]\left[1+4(1-\alpha)^{2}+\alpha^{2}\right]
\end{array}\right\}
\end{aligned}
$$

Pistonado + Estratificado-ondulado.- A perda de pressão para este padrão de escoamento é calculada a partir da seguinte equação:

$$
\Delta p_{\text {Pistonado+Estr.Ond. }}=\Delta p_{L O}\left(1-\frac{\alpha}{\alpha_{I A}}\right)^{0,25}+\Delta p_{\text {Estratificado_ondulado }}\left(\frac{\alpha}{\alpha_{\text {IA }}}\right)^{0,25}
$$

De forma análoga ao padrão pistonado e intermitente a Eq. 3.21 também se adequa aos valores limites. Para uma fração de vazio nula, ela fornece a perda de pressão para o escoamento apenas da fase líquida, $\Delta p_{L O}$, e para uma fração de vazio correspondendo à transição intermitente-anular fornece a perda de pressão para o padrão estratificado ondulado, $\Delta p_{\text {Estratificado_ondulado }}$.

Névoa.- O padrão de escoamento nevoa é considerado por eles um escoamento homogêneo, portanto, a perda de pressão é calculada a partir da Eq. 3.5, utilizando a densidade homogênea $\rho_{H}$. Para a viscosidade da mistura estes autores indicam a correlação de Cicchitti et al. (1960). 
Secagem de parede.- $\mathrm{O}$ valor da perda de pressão na região de secagem de parede é uma ponderação baseada no título de vapor entre a perda de pressão no início e final da região de secagem de parede, conforme a seguinte equação:

$$
\Delta p_{\text {Secagem }}=\Delta p_{2 \phi} x_{s p, o}-\frac{\left(x-x_{s p, o}\right)}{\left(x_{s p, f}-x_{s p, o}\right)}\left[\Delta p_{2 \phi} x_{s p, o}-\Delta p_{\text {Nevoa }} x_{s p, f}\right]
$$

onde $x_{s p, o}$ e $x_{s p, f}$ são o título de vapor de início e finalização da região de secagem de parede, respectivamente.

A Figura 3.7 ilustra o efeito do diâmetro e da temperatura de saturação no gradiente de pressão segundo o método de Moreno-Quibén e Thome (2007). Como observado na figura, o gradiente da perda de pressão apresenta um pico o qual corresponde ao início da secagem de parede para título de vapor igual a $x_{s p, o}$, este pico se desloca para títulos de vapor superiores com o acréscimo da temperatura de saturação. Tal comportamento é distinto do levantado por Tibiriçá e Ribatski (2013) como o mais frequente na literatura. $\mathrm{O}$ decréscimo do gradiente da perda de pressão com o incremento do título de vapor é abrupto após o pico.

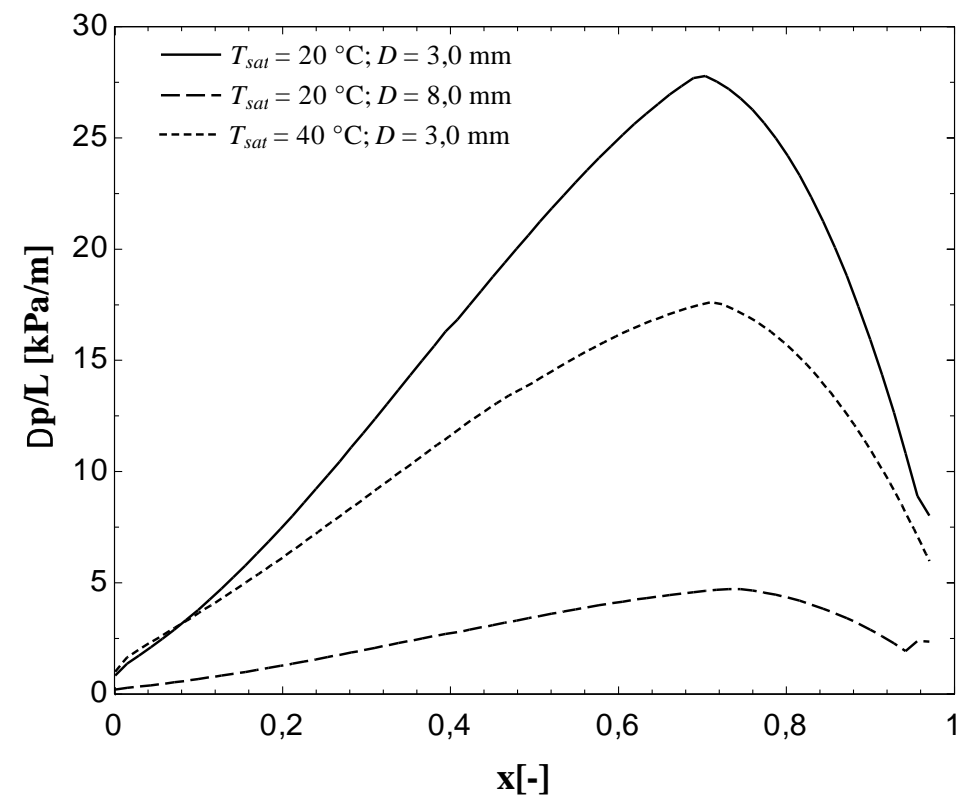

Figura 3.7. Efeito do diâmetro e da temperatura de saturação no gradiente de perda de pressão segundo Moreno-Quibén e Thome (2007), R22, G = 300 [kg/m²s]. 
Segundo a Figura 3.7, com o acréscimo do diâmetro de 3 para $8 \mathrm{~mm}$, o gradiente da perda de pressão decresce cerca de $500 \%$ considerando o pico máximo do gradiente da perda de pressão para cada diâmetro.

\section{Cioncolini et al. (2009)}

Cioncolini et al. (2009) propuseram um método para previsão da perda de pressão por atrito para escoamento anular baseados em 3908 dados experimentais levantados na literatura. Inicialmente, estes autores compararam este banco de dados a métodos de previsão disponíveis, concluindo que os métodos de Lombardi e Carsana (1992), MullerSteinhagen e Heck (1986) e o modelo homogêneo, implementado com a correlação de Cicchitti et al. (1960) para viscosidade da mistura, proporcionam as melhores previsões. Este resultado é similar ao obtido por Ribastki et al. (2006), Felcar e Ribatski (2008) e Da Silva e Ribatski (2013) ao compararem métodos de previsão da literatura com seus banco de dados.

A Tabela 3.4 descreve o banco de dados utilizado por Cioncolini et al. (2009). A análise deste permite concluir que aproximadamente $85 \%$ do banco de dados corresponde a resultados para escoamento vertical em canais convencionais também denominados de macrocanais (adotando como critério para transição microcanais de diâmetros inferiores a $3 \mathrm{~mm}$ ) e $15 \%$ para escoamento horizontal em microcanais. Os dados para macrocanais, que envolvem líquidos não-condensáveis (água - argônio, água - $\mathrm{N}_{2}$, álcool - árgônio), foram segregados segundo padrão anular com a visualização através de uma seção de testes transparente. Já os dados experimentais para ebulição convectiva foram segregados como padrão anular com base no mapa de padrões proposto por Hewitt e Robertson (1969), devido à ausência de uma seção transparente durante seus ensaios.

Baseado neste banco de dados, os autores desenvolveram um novo método válido para macrocanais e microcanais, baseado no número de Weber da fase gasosa. Este método proporcionou previsões satisfatórias do banco de dados utilizado no seu desenvolvimento. 
Tabela 3.4. Banco de dados de Cioncolini et al. (2009).

\begin{tabular}{|c|c|c|c|c|}
\hline Referencia & Fluidos & Diâmetro & $\begin{array}{c}\Delta P[\mathrm{MPa}] \\
G\left[\mathrm{~kg} / \mathrm{m}^{2} \mathrm{~s}\right] \\
x[-]\end{array}$ & $\begin{array}{l}\text { Número de } \\
\text { dados }\end{array}$ \\
\hline $\begin{array}{l}\text { Silvestri et al. (1963) } \\
\text { Gaspari et al. (1964) }\end{array}$ & Água - Vapor & $\begin{array}{c}4,9 ; 4,99 ; 5 ; \\
5,04 ; 5,08 ; \\
5,2 ; 6,3 ; 8,078,2 ; 9,1 \\
8 ; 1015,2 ; 24,9\end{array}$ & $\begin{array}{c}2-9,4 \\
497-4398 \\
0,02-0,87\end{array}$ & 1501 \\
\hline $\begin{array}{l}\text { Silvestri et al. (1963) } \\
\text { Adorni et al. (1963) } \\
\text { Casagrande et al. (1963) } \\
\text { Cravarolo et al. (1964) }\end{array}$ & $\begin{array}{c}\text { Água - Argônio } \\
\text { Água - } \mathrm{N}_{2} \\
\text { Álcool - Argônio } \\
\text { Água/Álcool - } \\
\text { Argônio }\end{array}$ & $\begin{array}{l}15,1 \\
25,0\end{array}$ & $\begin{array}{c}0,3-2,4 \\
255-3420 \\
0,04-0,84\end{array}$ & 1529 \\
\hline $\begin{array}{l}\text { Anderson e Mantzouranis (1960) } \\
\text { Gill et al. (1964) } \\
\text { Shearer e Nedderman (1965) } \\
\text { Willis (1965) }\end{array}$ & Água - Argônio & $\begin{array}{l}10,8 \\
12,7 \\
15,9 \\
31,7\end{array}$ & $\begin{array}{c}0,1-0,2 \\
39,4-1391 \\
0,01-0,97\end{array}$ & 296 \\
\hline $\begin{array}{c}\text { Revellin (2005) } \\
\text { Revellin e Thome (2007b) } \\
\text { Consolini (2008) }\end{array}$ & $\begin{array}{l}\text { R134a } \\
\text { R245fa }\end{array}$ & $\begin{array}{c}0,517 \\
0,803 \\
1,03\end{array}$ & $\begin{array}{c}0,2-0,9 \\
184-1694 \\
0,09-0,95\end{array}$ & 582 \\
\hline
\end{tabular}

O modelo proposto por Cioncolini et al. (2009) assume perdas de pressão na região central de gás (core) e no filme líquido similares. Desta forma, o gradiente de pressão por atrito pode ser escrito como:

$\frac{\Delta p_{2 \phi}}{L}=2 f_{2 \phi} \frac{G_{\text {core }}^{2}}{\rho_{\text {core }} D}$

com a velocidade mássica do núcleo, que inclui o escoamento de gotículas dispersas envoltas em vapor, dada por:

$G_{\text {core }}=\frac{4}{\pi} \cdot \frac{[x+e \cdot(1+x)] \cdot \dot{m}}{D_{\text {core }}^{2}}$

e o diâmetro do núcleo de gás, $D_{\text {core }}$, igual a:

$D_{\text {core }}=D-2 \delta$

A espessura do filme líquido na equação acima é dada pela seguinte equação: 
$\delta=\frac{D}{2} \cdot[1-\sqrt{(\alpha+\gamma-\alpha \cdot \gamma)}]$

A fração de líquido arrastado segundo gotículas dispersa na fase gasosa, $e$, durante o escoamento anular é estimado a partir da equação de Oliemans et al. (1986), dada por:

$\frac{e}{1-e}=10^{b_{o}} \rho_{L}^{b_{1}} \rho_{G}^{b_{2}} \mu_{L}^{b_{3}} \mu_{G}^{b_{4}} \sigma^{b_{5}} D^{b_{6}} J_{L}^{b_{7}} J_{G}^{b_{8}} g^{b_{9}}$

Os coeficientes empíricos de $b_{0}$ a $b_{9}$ assumem os valores apresentados na Tabela 3.5 e são função de $\operatorname{Re}_{\text {filme }}$, dado por:

$\operatorname{Re}_{\text {filme }}=(1-e)(1-x) \frac{G D}{\mu_{L}}$

A Tabela 3.5 apresenta também valores gerais para estas constantes independentes da faixa de número de Reynolds.

Tabela 3.5. Parâmetros para a equação de Olimeans et al. (1986).

\begin{tabular}{|c|c|c|c|c|c|c|c|c|c|c|}
\hline $\operatorname{Re}_{\text {filme }}$ & $b_{0}$ & $b_{1}$ & $b_{2}$ & $b_{3}$ & $b_{4}$ & $b_{5}$ & $b_{6}$ & $b_{7}$ & $b_{8}$ & $b_{9}$ \\
\hline Todos os valores & $-2,52$ & 1,08 & 0,18 & 0,27 & 0,28 & $-1,8$ & 1,72 & 0,7 & 1,44 & 0,46 \\
\hline $10^{2}-3 \times 10^{2}$ & $-0,69$ & 0,63 & 0,96 & $-0,8$ & 0,09 & $-0,88$ & 2,45 & 0,91 & $-0,16$ & 0,86 \\
\hline $3 \times 10^{2}-10^{3}$ & $-1,73$ & 0,94 & 0,62 & $-0,63$ & 0,5 & $-1,42$ & 2,04 & 1,05 & 0,96 & 0,48 \\
\hline $10^{3}-3 \times 10^{3}$ & $-3,31$ & 1,15 & 0,4 & $-1,02$ & 0,46 & -1 & 1,97 & 0,95 & 0,78 & 0,41 \\
\hline $3 \times 10^{3}-10^{4}$ & $-8,27$ & 0,77 & 0,71 & $-0,13$ & $-1,18$ & $-0,17$ & 1,16 & 0,83 & 1,45 & $-0,32$ \\
\hline $10^{4}-3 \times 10^{4}$ & $-6,38$ & 0,89 & 0,7 & $-0,17$ & $-0,55$ & $-0,87$ & 1,67 & 1,04 & 1,27 & 0,07 \\
\hline $3 \times 10^{4}-10^{5}$ & $-0,12$ & 0,45 & 0,25 & 0,86 & $-0,05$ & $-1,51$ & 0,91 & 1,08 & 0,71 & 0,21 \\
\hline
\end{tabular}

A fração superficial de gotículas escoando no núcleo de gás, $\gamma$, igual a:

$$
\gamma=e \cdot\left(\frac{\alpha}{1-\alpha}\right) \cdot\left(\frac{1-x}{x}\right) \cdot\left(\frac{\rho_{G}}{\rho_{L}}\right)
$$

A fração de vazio superficial é estimada a partir da correlação Woldesemayat e Ghajar (2007): 


$$
\alpha=\frac{J_{G}}{J_{G}\left[1+\left(\frac{J_{L}}{J_{G}}\right)^{\left(\rho_{G} / \rho_{L}\right)^{0.1}}\right]+2,9\left[\frac{g D \sigma(1+\cos \theta)\left(\rho_{L}-\rho_{G}\right)}{\rho_{L}^{2}}\right] \cdot[1,22+1,22 \cdot \sin \theta]^{p_{\text {amm }}} / p_{\text {sat }}}
$$

A densidade do núcleo gasoso é dada por:

$$
\rho_{\text {core }}=\left(1-\alpha_{\text {core }}\right) \cdot \rho_{L}+\alpha_{\text {core }} \cdot \rho_{G}
$$

onde a fração de vazio na região central do escoamento da fase gás é dado por:

$$
\alpha_{\text {core }}=\frac{\alpha}{\alpha+\gamma \cdot(1-\alpha)}
$$

Com base no banco de dados, os autores ajustaram a seguinte correlação para o fator de atrito bifásico:

$$
f_{2 \phi}=0,0196 W e_{\text {core }}^{-0,372} \operatorname{Re}_{\text {filme }}^{0,318}
$$

onde número de Weber do núcleo de gás é dado por:

$$
W e_{\text {core }}=\frac{G_{\text {core }}^{2} D_{\text {core }}}{\rho_{\text {core }} \sigma}
$$

A Figura 3.8 ilustra o efeito da velocidade mássica, temperatura de saturação e diâmetro no gradiente da perda de pressão segundo o método de Cioncolini et al. (2009). Considerando o fato do método ser proposto para escoamento anular, as curvas ilustradas na figura se restringem a região de títulos de vapor correspondente a este padrão adotando como critério de transição o método de Felcar et al. (2007). Na figura constata-se que com o incremento da velocidade mássica de 300 para $600 \mathrm{~kg} / \mathrm{m}^{2} \mathrm{~s}$, o gradiente da perda de pressão se eleva em cerca de $300 \%$. Também nota-se o decréscimo do gradiente de perda de pressão com o incremento da temperatura de saturação. Já com o decréscimo do diâmetro de $1 \mathrm{~mm}$ para $400 \mu \mathrm{m}$, o gradiente de pressão se eleva em cerca de $250 \%$. 


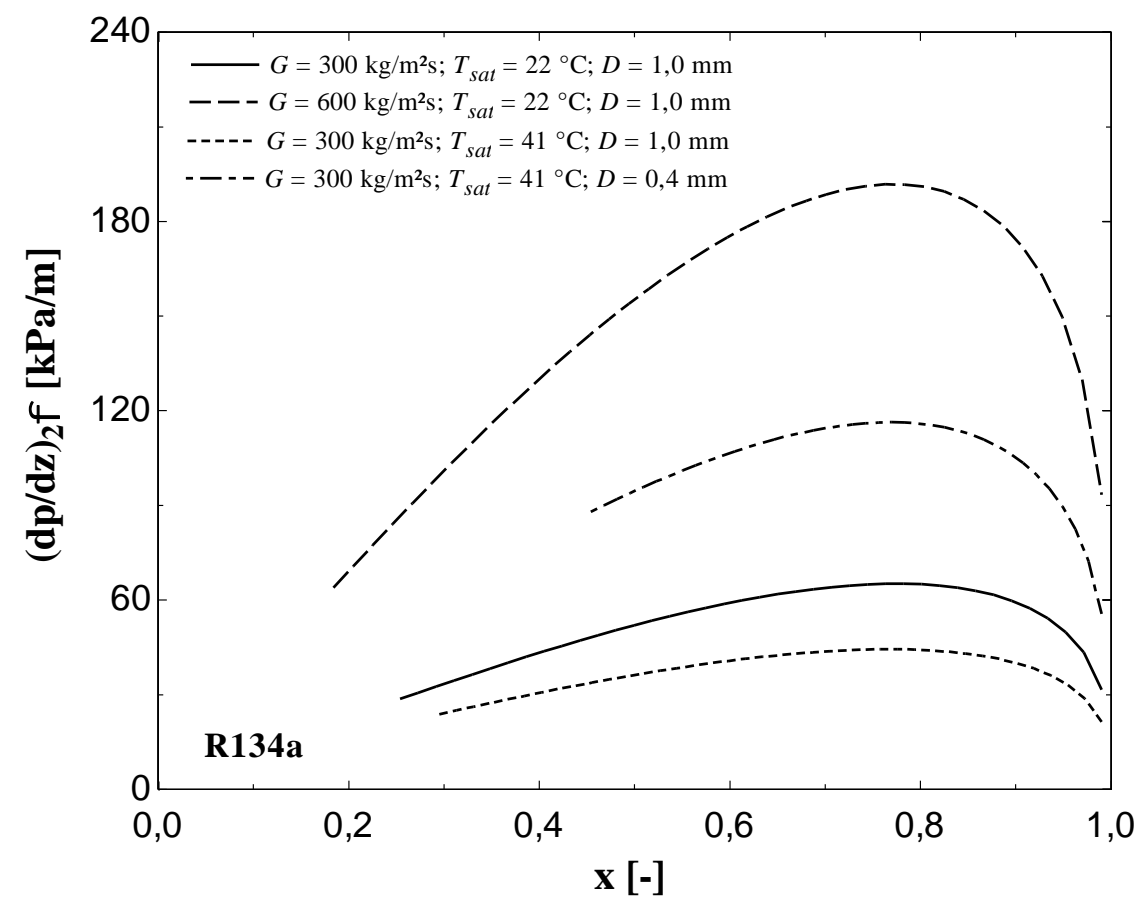

Figura 3.8. Efeito da velocidade mássica, temperatura de saturação e do diâmetro no gradiente da perda de pressao por atrito segundo o método de Cioncolini et al. (2009), R134a.

\subsubsection{Análise e comparação entre métodos de previsão de perda de pressão}

A Figura 3.9 ilustra para os refrigerantes R134a e R600a, a variação com o título de vapor do gradiente de pressão estimado segundo os métodos de previsão para canais convencionais descritos neste capítulo. Como pode ser observado nesta figura, os métodos contemplam corretamente os extremos correspondendo a títulos de vapor iguais a 0 e 1 , relacionado às perdas de pressão para escoamento monofásico de líquido e vapor, respectivamente.

De uma forma geral, constata-se que os métodos disponíveis fornecem previsões distintas. Grönnerud (1979) e Moreno-Quiben e Thome (2007) apresentam valores superiores quando comparados aos demais métodos de previsão, independentemente do fluido. O método de Lockart e Martinelli (1949), com o parâmetro C dado por Chisholm (1967), apresenta duas descontinuidades na previsão do gradiente da perda de pressão para o R134a e o isobutano, resultantes da mudança de regimes de escoamento para as fases. A Figura 3.9 também ilustra que os métodos de Müller-Steinhagen e Heck (1986) e Friedel (1979) apresentam tendências similares e previsões próximas. O método de Moreno-Quiben e Thome (2007) prevê um título de vapor correspondente ao pico do 
gradiente da perda de pressão inferior para o isobutano quando comparado ao R134a sob as mesmas condições experimentais.
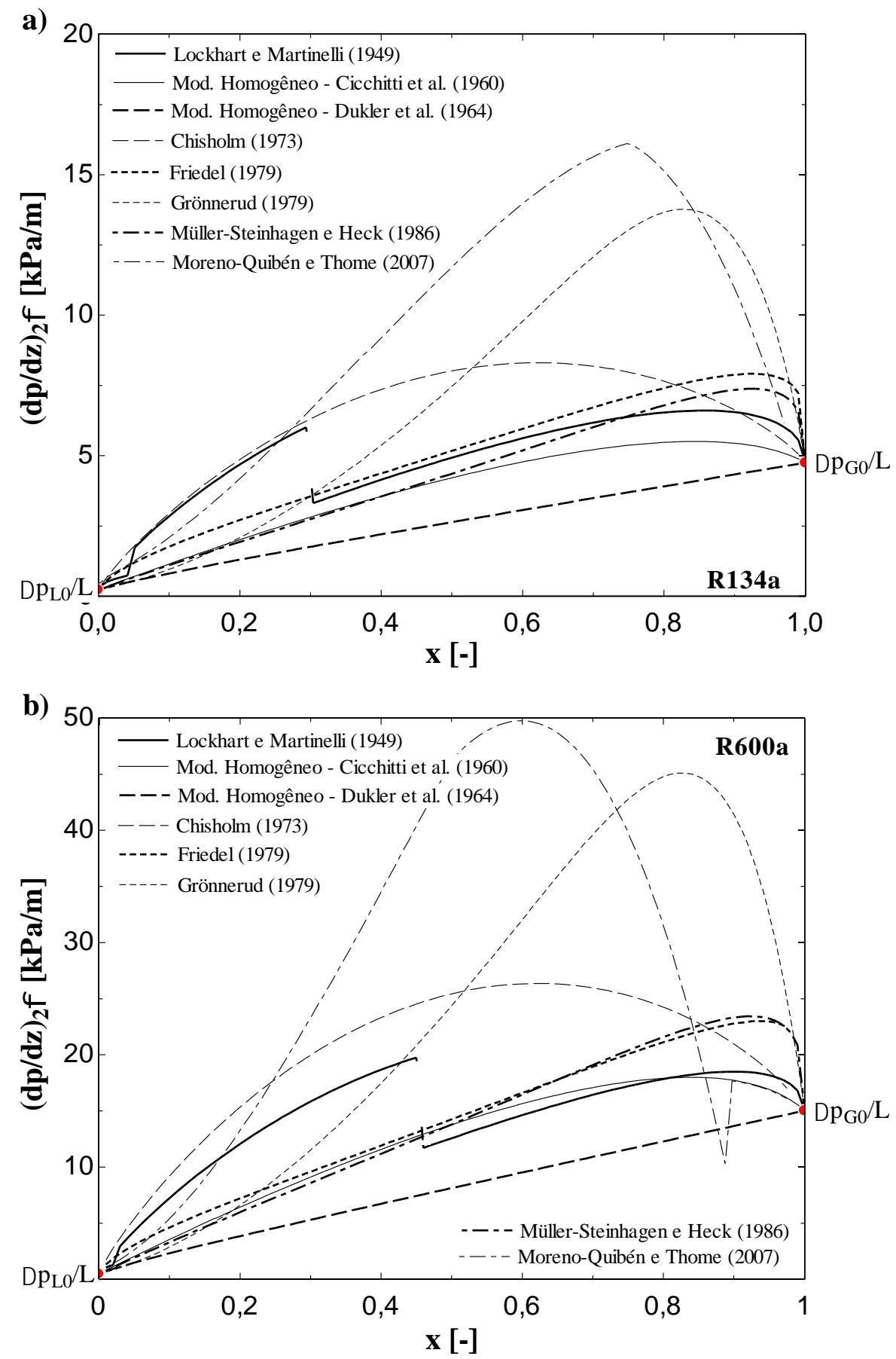

Figura 3.9. Gradientes de pressão estimados pelos distintos métodos de previsão, $\mathrm{G}=200 \mathrm{~kg} / \mathrm{m}^{2} \mathrm{~s}, \mathrm{~T}_{\mathrm{sat}}=22^{\circ} \mathrm{C}$ e D $=3 \mathrm{~mm}$, para a) R134a, b) R600a.

A Figura 3.10 ilustra comparações dos gradientes de perda de pressão para os refrigerantes R1234ze(E) e R1234yf segundo os métodos de previsão de perda de pressão para microcanais apresentados neste capítulo. 
a)

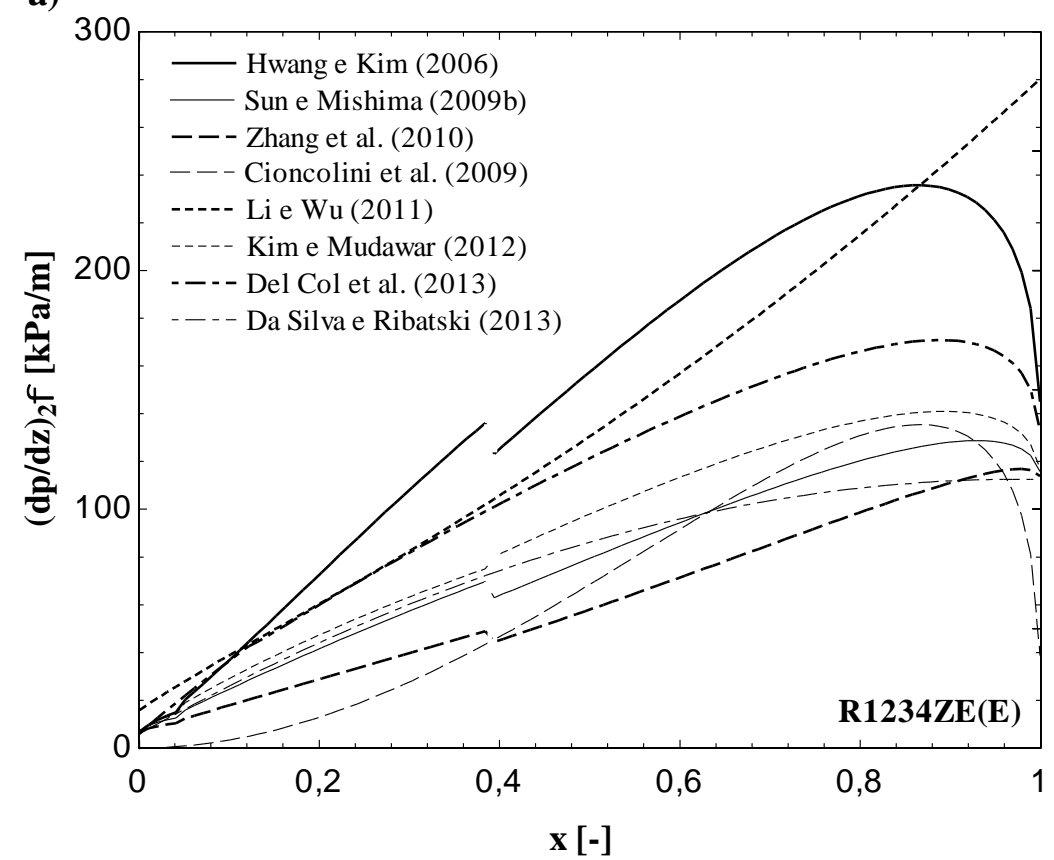

b)

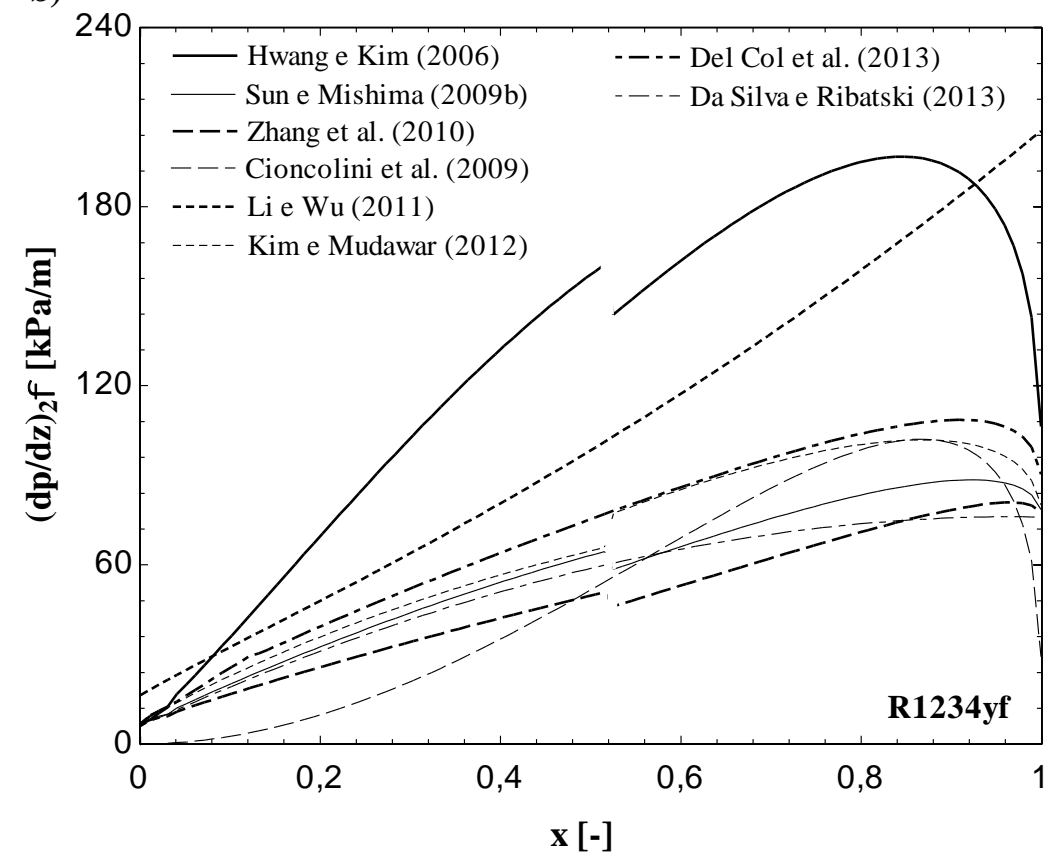

Figura 3.10. Gradientes de pressão estimados pelos distintos métodos de previsão de microcanais para $G=200\left[\mathrm{~kg} / \mathrm{m}^{2} \mathrm{~s}\right], T_{\text {sat }}=40^{\circ} \mathrm{C}$ e $D=1,1 \mathrm{~mm}$ para a) $\mathrm{R} 1234 \mathrm{ze}(\mathrm{E})$ e b) $\mathrm{R} 1234 \mathrm{yf}$.

Como observado na figura, em geral existem diferenças significativas entre valores e tendências proporcionadas pelos métodos. No entanto, Sun e Mishima (2009a), Kim e Mudawar (2012), Del Col et al. (2013) e Da Silva e Ribatski (2013) apresentam tendências próximas. Os picos dos métodos de Hwang e Kim (2006) e Cioncolini et al. (2009) ocorrem para títulos de valor próximos. Os métodos de Da Silva e Ribatski (2013) 
e Cioncolini et al. (2009) apresentam previsões inferiores para títulos de vapor reduzidos quando comparados aos demais. Li e Wu (2011) é o único método que não proporciona o pico do gradiente de pressão. Pico que foi extensamente observado na literatura, e cuja justificativa ainda é controversa. Vale mencionar que os métodos de Hwang e Kim (2006), Sun e Mishima (2009b) e Kim e Mudawar (2012) apresentam descontinuidades devido à mudança de regime das fases, comportamento não observado para os resultados experimentais disponíveis na literatura.

Cavallini et al (2005) comparou seu banco de dados com métodos de previsão da literatura. Eles encontraram que as correlações de Friedel (1979), Zhang e Webb (2001), Mishima e Hibiki (1996b) e Muller-Steinhagen e Heck (1986) proporcionam previsões satisfatórias para resultados o R134a. Já, para o R236ea, o método de Muller-Steinhagen e Heck (1986) é o que apresenta melhores resultados apesar de ter sido desenvolvido para macrocanais. Para o fluido R410A, o modelo de Zhang e Webb (2001) apresentou as melhores previsões.

\subsection{Descrição dos estudos experimentais da literatura}

Este item apresenta uma descrição dos estudos experimentais sobre perda de pressão por atrito em canais de reduzido diâmetro. Atenção especial é dada aos estudos envolvendo canais não circulares e estudos para fluidos de GWP reduzido e naturais.

A Tabela 3.6 descreve esquematicamente estudos disponíveis na literatura sobre perda de pressão em microcanais de geometria não circular. Nela são apresentadas as dimensões dos canais, geometria, número de canais, condições experimentais avaliadas e

fluidos utilizados. É importante ressaltar que a maioria dos trabalhos envolvem dissipadores de calor com multicanais.

Os estudos listados na Tabela 3.1 envolvem fluidos saturados e misturas de gases não-condensáveis com líquidos (ar/água, ar/n-propanol, ar/etanol). Resultados foram levantados para diâmetros equivalentes de até $2,97 \mathrm{~mm}$, velocidades mássicas entre $50 \mathrm{e}$ $2370 \mathrm{~kg} / \mathrm{m}^{2} \mathrm{~s}$, títulos de vapor entre 0 e 1 e faixas amplas de temperatura de saturação. 
Tabela 3.6. Estudos de perda de pressão em dutos não circulares.

\begin{tabular}{|c|c|c|c|c|c|}
\hline Autores & Fluido & $\begin{array}{l}\mathbf{N}^{\circ} \text { canais/ } \\
\text { Orientação }\end{array}$ & Geometria & $\begin{array}{l}\text { Seção transversal } \\
\text { h [mm] x w [mm] }\end{array}$ & $\begin{array}{c}\mathrm{G}\left[\mathrm{kg} / \mathrm{m}^{2} \mathrm{~s}\right] \\
\phi\left[\mathrm{kW} / \mathrm{m}^{2}\right] \\
x[-]\end{array}$ \\
\hline Yang e Webb (1996) & $\mathrm{R} 12$ & $4 / \mathrm{H}$ & Retangular & $2,64 \times 2,64$ & $\mathrm{G}=400-1400$ \\
\hline Coleman (2000) & $\mathrm{R} 134 \mathrm{a}$ & $20 / \mathrm{H}$ & Quadrada & $1,52 \times 1,52$ & $G=150-750$ \\
\hline Lee e Lee (2001a) & R113 & $1 / \mathrm{H}$ & Retangular & $\begin{array}{c}20 \times 0.4 \\
20 \times 2\end{array}$ & $\begin{array}{c}G=50-200 \\
x=0.15-0.75\end{array}$ \\
\hline Lee e Lee (2001b) & Ar/Água & $1 / \mathrm{H}$ & Retangular & $\begin{array}{c}20 \times 0.4 \\
20 \times 2\end{array}$ & $G=72-2050$ \\
\hline Qu e Mudawar (2003a) & Água & $21 / \mathrm{H}$ & Retangular & $0,231 \times 0,713$ & $\mathrm{G}=135-400$ \\
\hline Wen e Kenning (2004) & Água & $1 / \mathrm{V}$ & Retangular & $2 \times 1$ & $\begin{array}{l}G=57-211 \\
\phi=25-105\end{array}$ \\
\hline Cavallini et al. (2005) & $\begin{array}{c}\text { R134a, R236ea } \\
\text { R410A }\end{array}$ & $11 / \mathrm{H}$ & Quadrada & $1.4 \times 1,4$ & $\begin{array}{c}G=200-1400 \\
x=0-1.0\end{array}$ \\
\hline Lee e Mudawar (2005a) & $\mathrm{R} 134 \mathrm{a}$ & $-/ \mathrm{H}$ & Retangular & $0,231 \times 0,713$ & $\begin{array}{c}G=127-654 \\
x=0-0.90\end{array}$ \\
\hline Jassim e Newell (2006) & $\begin{array}{c}\text { R134a, R410A } \\
\text { Ar/Água }\end{array}$ & $6 / \mathrm{H}$ & Retangular & $1,54 \times 1,54$ & $\mathrm{G}=50-300$ \\
\hline Sobierska et al. (2006) & Água & $1 / \mathrm{V}$ & Retangular & $0,86 \times 2,0$ & $\begin{array}{c}G=81-700 \\
x=0-0.5\end{array}$ \\
\hline Field e Hrnjak (2007) & $\begin{array}{l}\mathrm{R} 134 \mathrm{a}, \mathrm{R} 410 \mathrm{~A} \\
\text { Propano, R717 }\end{array}$ & $1 / \mathrm{H}$ & Retangular & $0,1 \times 0,185$ & $\begin{array}{c}G=290-1200 \\
\quad x=0-1\end{array}$ \\
\hline Singh et al. (2008) & Água & $1 / \mathrm{H}$ & Retangular & $\begin{array}{l}0,127 \times 0,156 \\
0,122 \times 0,175 \\
0,115 \times 0,180\end{array}$ & $\begin{aligned} G & =80-170 \\
x & =0-0,29\end{aligned}$ \\
\hline Megahed e Hassan (2009) & FC-72 & $45 / \mathrm{H}$ & Retangular & $0,276 \times 0,225$ & $\mathrm{G}=341-531$ \\
\hline Ma et al. (2010) & $\begin{array}{c}\text { Ar/Água } \\
\text { Ar/Etanol } \\
\text { Ar/n-Propanol }\end{array}$ & $1 / \mathrm{H}$ & Retangular & $\begin{array}{l}0,1 \times 0,4 \\
0,1 \times 0,2 \\
0,1 \times 0,8\end{array}$ & $\begin{aligned} G & =20-300 \\
x & =0-0,3-\end{aligned}$ \\
\hline $\begin{array}{l}\text { Choi et al. (2010) } \\
\text { Choi et al. (2011) }\end{array}$ & Agua/ $\mathrm{N}_{2}$ & $1 / \mathrm{H}$ & Retangular & $\begin{array}{c}0,51 \times 0,47 \\
0,68 \times 0,41 \\
0,51 \times 0,237 \\
0,503 \times 0,085\end{array}$ & $\begin{array}{c}G=66-1080 \\
x=0-1\end{array}$ \\
\hline Costa-Patry et al. (2011b) & $\begin{array}{l}\text { R236fa } \\
\text { R245fa }\end{array}$ & $135 / \mathrm{H}$ & Retangular & $0,085 \times 0,56$ & $\begin{array}{l}\mathrm{G}=499-1100 \\
\phi=130-1400-\end{array}$ \\
\hline Kaew-On et al. (2011) & $\mathrm{R} 134 \mathrm{a}$ & $8-14 / \mathrm{H}$ & Retangular & $1,25 \times 1$ & $\begin{array}{c}\mathrm{G}=300-800 \\
\phi=15-65 \\
-\end{array}$ \\
\hline $\begin{array}{l}\text { Harirchian e Garimella } \\
\qquad(2012)\end{array}$ & FC-77 & $2-61 / \mathrm{H}$ & Retangular & $0,1-5,85 \times 0,4$ & $\begin{array}{c}\mathrm{G}=630 \\
\phi=0-250\end{array}$ \\
\hline Costa-Patry et al. (2012) & $\begin{array}{l}\text { R134a, R245fa } \\
\text { R1234ze(E) }\end{array}$ & $52 / \mathrm{H}$ & Retangular & $0,63 \times 1,56$ & $\begin{array}{c}G=291-568 \\
x=0-0,7\end{array}$ \\
\hline
\end{tabular}

H $\rightarrow$ Horizontal; V $\rightarrow$ Vertical; I $\rightarrow$ Inclinado; VA $\rightarrow$ Vertical ascendente; VI $\rightarrow$ Vertical descendente 
Tabela 3.6 (continuação). Estudos de perda pressão em dutos não circulares.

\begin{tabular}{|c|c|c|c|c|c|}
\hline Autores & Fluido & $\begin{array}{l}\mathbf{N}^{\circ} \text { canais/ } \\
\text { Orientação }\end{array}$ & Geometria & $\begin{array}{l}\text { Seção transversal } \\
\text { h }[\mathrm{mm}] \times \mathbf{w}[\mathrm{mm}]\end{array}$ & $\begin{array}{c}\mathrm{G}\left[\mathrm{kg} / \mathrm{m}^{2} \mathrm{~s}\right] \\
\phi\left[\mathrm{kW} / \mathrm{m}^{2}\right] \\
x[-]\end{array}$ \\
\hline Szczukiewiez (2013) & $\begin{array}{c}\text { R245fa } \\
\text { R236fa } \\
\text { R1234ze(E) }\end{array}$ & $67 / \mathrm{H}$ & Retangular & $0,100 \times 0,100$ & $\begin{array}{c}G=283-2370 \\
\phi=0-486\end{array}$ \\
\hline Lee et al. (2014) & FC72 & $20 / \mathrm{H}$ & Retangular & $0,231 \times 1$ & $\begin{array}{c}G=151-834 \\
\phi=21-98\end{array}$ \\
\hline Leão et al. (2015) & R245fa & 50/H, I, VA & Retangular & $0,123 \times 0,494$ & $\begin{array}{c}\mathrm{G}=300-1000 \\
\phi=0-300\end{array}$ \\
\hline Gan et al. (2015) & Acetona & $10 / H$ & Triangular & $\begin{array}{c}0,212 \text { (altura) x } 0,3 \\
\text { (base) }\end{array}$ & $\begin{array}{c}G=66-289,6 \\
\phi=141-481\end{array}$ \\
\hline Markal et al. (2016a) & Água deionizada & $29 / \mathrm{H}$ & Retangular & $\begin{array}{c}0,070 \times 0,190 \\
0,090 \times 0,110 \\
0,110 \times 0,090 \\
0,190 \times 0,070 \\
0,230 \times 0,065 \\
0,300 \times 0,060\end{array}$ & $\begin{array}{c}G=151-324 \\
\phi=71-131\end{array}$ \\
\hline Markal et al. (2016b) & Água deionizada & $29 / \mathrm{H}$ & Quadrada & $0,150 \times 0,150$ & $\begin{array}{c}\mathrm{G}=51 ; 64,5 \\
\quad 78 ; 92,6 \\
\phi=59,3-84,1\end{array}$ \\
\hline
\end{tabular}

H $\rightarrow$ Horizontal; V $\rightarrow$ Vertical; I $\rightarrow$ Inclinado; VA $\rightarrow$ Vertical ascendente; VI $\rightarrow$ Vertical descendente

Singh et al. (2008) investigou o efeito do fator de forma na perda de pressão durante o escoamento bifásico de água, mantendo o diâmetro hidráulico constante. Os autores fabricaram microcanais retangulares com diâmetro hidráulico de $142 \pm 2 \mu$ m e 20 mm de comprimento, para uma faixa de diâmetros hidráulicos desde 1,25 ate 3,75. Os autores reportaram um valor mínimo da perda de pressão para um fator de forma igual a 1,6 para certas condições experimentais.

A Figura 3.11 ilustra o efeito do fator de forma na perda de pressão nos resultados experimentais de Singh et al. (2008). As linhas tracejadas representam a perda de pressão monofásica para a vazão mássica indicada. Segundo a figura, observa-se que a perda de pressão bifásica é inferior à perda de pressão monofásica para fatores de forma superiores a 2,5. Pode-se observar também a existência de diferenças significativas dos valores da perda de pressão bifásica para fatores de forma inferiores a 1,75. 


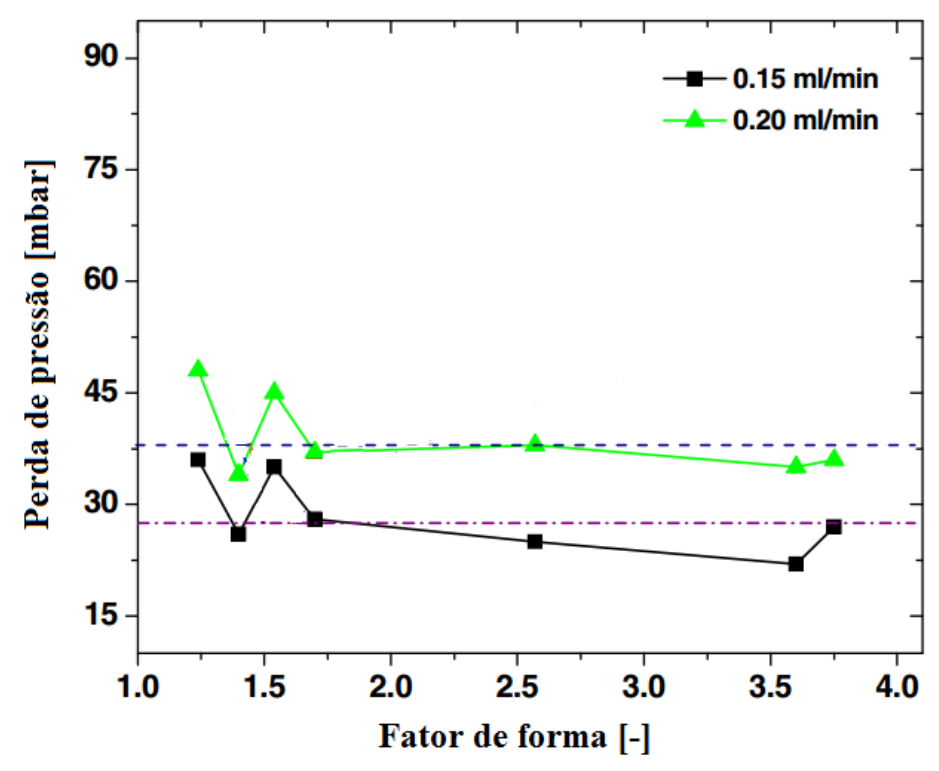

Figura 3.11. Perda de pressão vs. fator de forma, Singh et al. (2008).

Entre os estudos realizados para canais não circulares, destaca-se o trabalho de Harirchian e Garimella (2012) que investigaram o efeito da geometria do canal na perda de pressão diabática para seções de teste de comprimento similar. Eles realizaram experimentos para o fluido FC-77 e 12 diferentes seções transversais retangulares cujas características encontram-se detalhadas na Tabela 3.7.

Tabela 3.7. Dimensões dos microcanais retangulares avaliados por Harirchian e Garimella (2012)

\begin{tabular}{ccccc}
\hline $\begin{array}{c}\text { Dimensão largura } \\
\text { Nominal/Real } \\
{[\boldsymbol{\mu \mathrm { m } ]}}\end{array}$ & $\begin{array}{c}\text { Dimensão altura } \\
\text { Nominal/Real } \\
{[\boldsymbol{\mu \mathrm { m } ]}}\end{array}$ & $\begin{array}{c}\text { Numero de } \\
\text { canais }\end{array}$ & $\mathbf{D}_{\text {eq }}[\boldsymbol{\mu m}]$ & $\begin{array}{c}\text { Fator de } \\
\text { forma }\end{array}$ \\
\hline $100(99)$ & $100(94)$ & 61 & 108 & 1,05 \\
$100(97)$ & $220(217)$ & 63 & 163 & 0,45 \\
$100(102)$ & $400(369)$ & 60 & 219 & 0,27 \\
$250(240)$ & $400(371)$ & 35 & 336 & 0,64 \\
$400(398)$ & $100(65)$ & 25 & 181 & 6,12 \\
$400(400)$ & $220(197)$ & 25 & 318 & 2,03 \\
$400(395)$ & $400(365)$ & 24 & 428 & 1,08 \\
$700(686)$ & $400(376)$ & 14 & 573 & 1,83 \\
$1000(1024)$ & $220(226)$ & 10 & 542 & 4,53 \\
$1000(978)$ & $400(374)$ & 10 & 682 & 2,62 \\
$2200(2203)$ & $400(370)$ & 5 & 1018 & 5,95 \\
$5850(5851)$ & $400(376)$ & 2 & 1673 & 15,55 \\
\hline
\end{tabular}


A Figura 3.12 ilustra o efeito da geometria do microcanal na perda de pressão segundo os resultados de Harirchian e Garimella (2012). Como observado na figura, a perda de pressão se eleva com a redução do diâmetro equivalente da seção. Para seções de diâmetro equivalente próximos, mas com fator de forma distintos, observa-se também perdas de pressão distintas. Para canal com seção transversal de 102 x $369 \mu \mathrm{m}\left(\mathrm{D}_{\mathrm{eq}}=218\right.$ $\mu \mathrm{m})$ e um fluxo de calor $\phi=150 \mathrm{~kW} / \mathrm{m}^{2}$, a perda de pressão foi de $20 \mathrm{kPa}$, mas para a seção de 398 x $65\left(D_{\text {eq }}=181 \mu \mathrm{m}\right)$ e as mesmas condições se tem uma perda de pressão de $28 \mathrm{kPa}$.

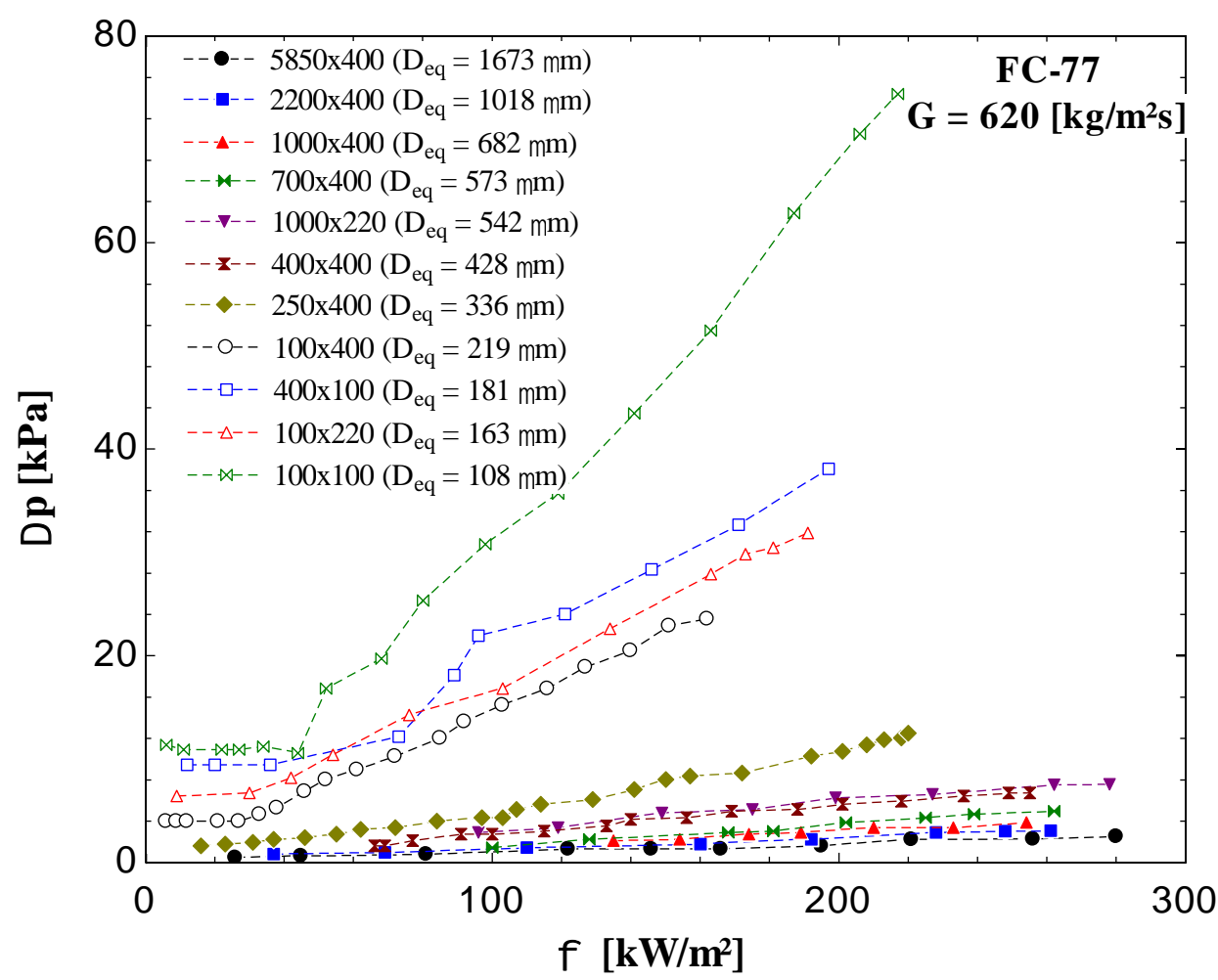

Figura 3.12. Efeito da geometria do canal na perda de pressão, Harirchian e Garimella (2012).

Markal et al. (2016a) também investigaram o efeito do fator de forma do canal na perda de pressão diabática durante a ebulição convectiva de água deionizada em um dissipador de calor baseado em multi-microcanais. Da mesma forma que Singh et al. (2008), os autores mantiveram o diâmetro hidráulico constante em cerca de $100 \mu \mathrm{m}$. Os fatores de forma por eles testados variam de 0,37 a 5 . Os autores não reportaram nenhum efeito característico do fator de forma sobre a perda de pressão bifásica.

A Tabela 3.8 lista os trabalhos experimentais sobre perda de pressão para fluidos de reduzido GWP, canais únicos, seção circular e retangulares e os fluidos R1234ze(E), 
R1234yf, $\mathrm{CO}_{2}$, propano e $\mathrm{NH}_{3}$ obtido através de uma ampla revisão da literatura. Vale ressaltar a ausência de estudos sobre perda de pressão para isobutano e propileno.

Tabela 3.8. Estudos sobre preda de pressão para fluidos de reduzido GWP e naturais.

\begin{tabular}{|c|c|c|c|c|c|}
\hline Autor (es) & Fluido & $\begin{array}{l}\text { Geometria/ } \\
\text { Condições }\end{array}$ & $\begin{array}{c}\text { Seção } \\
\text { transversal }\end{array}$ & $\begin{array}{c}\text { Numero de } \\
\text { canais/ } \\
\text { Orientação }\end{array}$ & $\begin{array}{c}\mathrm{G}\left[\mathrm{kg} / \mathrm{m}^{2} \mathrm{~s}\right] \\
\phi\left[\mathrm{kW} / \mathrm{m}^{2} \mathrm{~s}\right] \\
\mathrm{x}[-]\end{array}$ \\
\hline Pamitran et al. (2010) & $\begin{array}{c}\text { Propano } \\
\mathrm{CO}_{2} \\
\mathrm{NH}_{3}\end{array}$ & $\begin{array}{l}\text { Circular } \\
\text { Diabático }\end{array}$ & $\begin{array}{c}\mathrm{D}=0,5 ; 1,5 ; 3 \\
\mathrm{~mm}\end{array}$ & $1 / \mathrm{H}$ & $\begin{array}{c}50-60 \\
0-40 \\
0-1\end{array}$ \\
\hline $\begin{array}{l}\text { Ducoulombier et al. } \\
\qquad(2011)\end{array}$ & $\mathrm{CO}_{2}$ & $\begin{array}{c}\text { Circular } \\
\text { Adiabático }\end{array}$ & $\mathrm{D}=0,529 \mathrm{~mm}$ & $1 / \mathrm{H}$ & $\begin{array}{c}200-1400 \\
- \\
0-1\end{array}$ \\
\hline Del Col et al. (2013) & R1234yf & $\begin{array}{l}\text { Quadrada } \\
\text { Adiabático }\end{array}$ & $\mathrm{D}_{\mathrm{H}}=1,23 \mathrm{~mm}$ & $1 / \mathrm{H}$ & $\begin{array}{c}200-800 \\
- \\
0-1\end{array}$ \\
\hline Del Col et al. (2014) & Propano & $\begin{array}{c}\text { Circular } \\
\text { Adiabático }\end{array}$ & $\mathrm{D}=0,96 \mathrm{~mm}$ & $1 / \mathrm{H}$ & $\begin{array}{c}200-800 \\
- \\
0-1\end{array}$ \\
\hline $\begin{array}{l}\text { López-Belchí et al. } \\
\text { (2014) }\end{array}$ & R1234yf & $\begin{array}{c}\text { Retangular } \\
\text { Condensação }\end{array}$ & $\mathrm{D}_{\mathrm{H}}=1,16 \mathrm{~mm}$ & $10 / \mathrm{H}$ & $350-940$ \\
\hline Del Col et al. (2015) & R1234ze(E) & $\begin{array}{c}\text { Circular } \\
\text { Adiabático }\end{array}$ & $\mathrm{D}=0,96 \mathrm{~mm}$ & $1 / \mathrm{H}$ & $\begin{array}{c}200-800 \\
- \\
0-1\end{array}$ \\
\hline
\end{tabular}

\subsection{Conclusões}

As conclusões que podem ser extraídas da análise da literatura apresentada neste capítulo são:

Os métodos de previsão desenvolvidos baseados em dados experimentais para canais convencionais e de diâmetro reduzido proporciona resultados com divergências significativas entre eles;

Os métodos de previsão que incluíram dados para canais não-circulares no seu desenvolvimento utilizam o diâmetro hidráulico como dimensão característica, entretanto, não justificam tal opção;

Trabalhos experimentais sobre perda de pressão para canais únicos de diâmetro reduzido com seção transversal triangular em condições adiabáticas não foram verificadas na literatura apesar da ampla pesquisa realizada. Verificou-se apenas um estudo experimental sobre perda de pressão bifásica em condições diabáticas em um dissipador de calor baseado em multi-microcanais com seção transversal triangular; 
Os trabalhos sobre perda de pressão bifásica em canais não-circulares para microcanais não buscaram caracterizar a definição da dimensão característica;

O número de estudos disponíveis na literatura aberta sobre perda de pressão para os fluidos HFO's (R1234ze(E) e R1234yf) e propano em microcanais é reduzido. Já para o isobutano e o propileno tais dados são inexistentes. 


\section{CAPÍTULO 4 - REVISÃo BIBLIOGRÁFICA SOBRE O COEFICIENTE DE TRANSFERÊNCIA DE CALOR}

\subsection{Introdução}

Este capítulo se inicia com a apresentação dos métodos de previsão para o CTC durante a ebulição convectiva no interior de dutos disponíveis na literatura. Posteriormente, descreve trabalhos experimentais cujos resultados encontram-se disponíveis na literatura envolvendo o coeficiente de transferência de calor durante a ebulição convectiva. Tal descrição, foca em estudos realizados para canais não-circulares e para fluidos de baixo GWP e "naturais". Finalmente, o capítulo apresenta conclusões, ressaltando aspectos relevantes da revisão bibliográfica realizada.

\subsection{Métodos de previsão do CTC em escoamento bifásico}

A previsão do coeficiente de transferência de calor durante a ebulição convectiva trata-se de um desafio para pesquisadores e engenheiros, devido aos inúmeros fatores que o afetam. Entre eles destacam-se: o fluido, direção de escoamento, fluxo de calor, velocidade mássica, título de vapor, temperatura de saturação, diâmetro, geometria do canal, aceleração gravitacional, material e rugosidade do canal e instabilidade de escoamento.

Diversas correlações foram propostas na literatura visando prever o coeficiente de transferência de calor durante a ebulição convectiva. No presente trabalho os métodos de previsão do CTC durante a ebulição convectiva foram classificados da seguinte forma: $i$ ) estritamente empíricos; ii) baseados na superposição de efeitos de ebulição nucleada e convectivos; e iii) baseados em aspectos fenomenológicos. Este item trata da descrição destes métodos dando atenção especial para aqueles desenvolvidos para microcanais. Métodos para canais convencionais também são descritos, devido aos seguintes aspectos:

Métodos para microcanais foram desenvolvidos a partir de métodos anteriormente propostos para canais convencionais; 
Geralmente na literatura, métodos para canais convencionais são comparados com resultados obtidos em dutos de dimensões reduzidas, obtendo-se em alguns casos previsões satisfatórias.

\subsubsection{Métodos de previsão do CTC estritamente empíricos}

Os métodos estritamente empíricos envolvem o ajuste de uma correlação para o cálculo do coeficiente de transferência de calor baseada em números adimensionais e em bancos de dados extensos.

\section{Canais convencionais}

\section{Shah (1982)}

Shah (1982) propôs um método de previsão do CTC estritamente empírico, neste método adota-se o maior valor entre o coeficiente de transferência de calor devido a efeitos estritamente de ebulição nucleada e a de efeitos convectivos:

$h_{2 \phi}=\operatorname{Max}\left(h_{c o n v}, h_{e b}\right)$

O coeficiente de transferência de calor para o qual predominam efeitos de convecção é calculado a partir da seguinte equação:

$$
h_{c o n v}=\frac{1,8}{N^{0,8}} \cdot h_{1 \phi}
$$

onde $h_{1 \phi}$ é o CTC monofásico calculado mediante a correlação de Dittus-Boelter e N é função da relação das densidades das fases, do número de Froude da mistura bifásica escoando como líquido e do título de vapor. Este adimensional é estimado a partir das seguintes equações:

$$
\begin{aligned}
& N=\left(\frac{1-x}{x}\right)^{0,8}\left(\frac{\rho_{G}}{\rho_{L}}\right)^{0,5} \quad \text { Para: } \quad F r_{L 0} \geq 0,04 \\
& N=0,38 \cdot F r_{L 0}^{-0,3}\left(\frac{1-x}{x}\right)^{0,8}\left(\frac{\rho_{G}}{\rho_{L}}\right)^{0,5} \quad \quad \text { Para: } \quad F r_{L 0}<0,04
\end{aligned}
$$


O coeficiente de transferência de calor referente a ebulição nucleada é calculado segundo a Tabela 4.1 .

Tabela 4.1. Cálculo do CTC referente a ebuliçao nucleada segundo o método de Shah (1982).

\begin{tabular}{c|c|c}
\hline Faixa de N & Faixa de Bo & $h_{e b}$ \\
\hline$N>0,1$ & $B o>3 \times 10^{-5}$ & $h_{e b}=230 B o^{0,5} h_{1 \phi}$ \\
& $B o \leq 3 \times 10^{-5}$ & $h_{e b}=\left(1+46 B o^{0,5}\right) \cdot h_{1 \phi}$ \\
$0,1<N \leq 1,0$ & $B o \geq 11 \times 10^{-4}$ & $h_{e b}=\left(14,7 B o^{0,5} e^{(2,74 N-0,1)}\right) \cdot h_{1 \phi}$ \\
& $B o<3 \times 10^{-5}$ & $h_{e b}=\left(15,43 B o^{0,5} e^{(2,74 N-0,1)}\right) \cdot h_{1 \phi}$ \\
$N \leq 0,1$ & $B o>3 \times 10^{-5}$ & $h_{e b}=\left(14,7 B o^{0,5} e^{(2,47 N-0,1)}\right) \cdot h_{1 \phi}$ \\
& $B o \leq 3 \times 10^{-5}$ & $h_{e b}=\left(15,43 B o^{0,5} e^{(2,47 N-0,1)}\right) \cdot h_{1 \phi}$ \\
\hline
\end{tabular}

\section{Kandlikar (1990)}

Este autor desenvolveu uma correlação para o cálculo do coeficiente de transferência de calor bifásico considerando um banco de dados incluindo 5246 pontos experimentais, envolvendo diâmetros de tubo entre 4,6 e $32 \mathrm{~mm}$ e 10 fluidos refrigerantes. Analogamente a Shah (1982), Kandlikar (1990) define o coeficiente de transferência de calor bifásico como o maior valor entre o coeficiente de transferência de calor devido a efeitos estritamente de ebulição nucleada e efeitos convectivos (ver Eq. 4.1), com estes sendo estimados, respectivamente, através das seguintes relações:

$$
\begin{aligned}
& h_{e b}=\left[0,6683\left[\left(\frac{1-x}{x}\right)^{0,8}\left(\frac{\rho_{G}}{\rho_{L}}\right)^{0,5}\right]^{-0,2}\left(25 F r_{L 0}\right)^{0,3}+1058 B o^{0,7} F_{f l}\right] \cdot h_{L} \\
& h_{\text {conv }}=\left[1,136\left[\left(\frac{1-x}{x}\right)^{0,8}\left(\frac{\rho_{G}}{\rho_{L}}\right)^{0,5}\right]^{-0,9}\left(25 F r_{L 0}\right)^{0,3}+667,2 B o^{0,7} F_{f l}\right] \cdot h_{L}
\end{aligned}
$$

onde $F_{f l}$ é um parâmetro cujo valor depende do par fluido - superfície de forma análoga ao modelo de ebulição nucleada em piscina proposto por Rohsenow (1952). Com base no seu banco de dados, Kandlikar (1990) ajustou valores para o parâmetro característico para 13 refrigerantes para superfície de cobre ou latão, cujos valores encontram-se na Tabela 4.2 . 
Tabela 4.2. Constante do par fluido/superficie propostas por Kandlikar (1990).

\begin{tabular}{c|ccccccccccccc}
\hline Fluido & Água & $\mathrm{R} 11$ & $\mathrm{R} 12$ & $\mathrm{R} 13 \mathrm{~B} 1$ & $\mathrm{R} 22$ & $\mathrm{R} 113$ & $\mathrm{R} 114$ & $\mathrm{~N}_{2}$ & Neônio R134a & R404A R407C R152a \\
\hline$F_{f l}$ & 1,00 & 1,30 & 1,50 & 1,31 & 2,20 & 1,30 & 1,24 & 4,70 & 3,50 & 1,63 & 1,55 & 1,50 & 1,10 \\
\hline
\end{tabular}

Na estimativa do parâmetro $F_{f l}$ para fluidos distintos dos listados na Tabela 4.2, os autores indicam que este o parâmetro deve ser igual ao fator necessário na equação de Foster e Zuber (1955) para correlacionar adequadamente dados experimentais para ebulição nucleada em piscina para esse fluido. Portanto, o método requer dados precisos para o coeficiente de transferência de calor para a ebulição nucleada em piscina, tais dados nem sempre encontram-se disponíveis na literatura, especialmente para os fluidos novos (R1234ze(E), R1234yf, R1234zd) ou hidrocarbonetos (R290, R600a, R1270). O coeficiente de transferência de calor monofásico, $h_{L}$, é dado pela correlação de DittusBoelter independentemente da faixa de números de Reynolds. Posteriormente, Kandlikar (1991) propôs as correlações de Petukhov e Popov (1963) e Gnielinski (1976) para a estimativa do $h_{L}$ (ver Apêndice A para detalhes das correlações do CTC monofásico).

\section{$\underline{\text { Microcanais }}$}

A Tabela 4.3 apresenta métodos estritamente empíricos propostos para canais de reduzidas dimensões. Ela inclui também a descrição do banco de dados usado pelos autores para o ajuste das constantes empíricas. Nota-se na Tabela 4.3, que a maioria dos métodos estritamente empíricos são baseados em bancos de dados limitados restritos a um único fluido. Entretanto, vale destacar que os métodos propostos por Sun e Mishima (2009a) e Liu e Wu (2010) foram desenvolvidos com base em dados coletados na literatura incluindo 2505 e 3744 resultados experimentais, respectivamente.

A análise da Tabela 4.3 indica que a maioria dos autores correlaciona o coeficiente de transferência de calor bifásico como função dos números de ebulição, Weber, Reynolds da fase líquida, parâmetro de Martinelli e da razão das densidades das fases líquido e gás. Apenas Li e Wu (2010) introduziram o número de Bond visando capturar efeitos de confinamento com a redução do diâmetro do canal. 
Tabela 4.3. Métodos de previsão do CTC estritamente empíricos para microcanais.

\begin{tabular}{|c|c|c|c|}
\hline Autor & Correlações & Banco de dados & $\begin{array}{c}\mathrm{G}\left[\mathrm{kg} / \mathrm{m}^{2} \mathrm{~s}\right] \\
\mathbf{x}[-] \\
\phi\left[\mathrm{kW} / \mathrm{m}^{2}\right] \\
\end{array}$ \\
\hline Lazarek e Black (1982) & $h_{2 \phi}=30 \operatorname{Re}_{L 0}^{0,857} B o^{0,714} \frac{k_{L}}{D}$ & $\begin{array}{c}\mathrm{R} 113 \\
\text { Circular } \\
\mathrm{D}=3,1 \mathrm{~mm}\end{array}$ & $\begin{array}{l}\mathrm{G}=125-750 \\
\mathrm{x}=0-1 \\
\phi=14-380\end{array}$ \\
\hline Tran et al. (1996) & $h_{2 \phi}=8,4 \times 10^{5}\left(B o^{2} W e_{L 0}\right)^{0,3}\left(\frac{\rho_{L}}{\rho_{G}}\right)^{-0,4}$ & $\begin{array}{c}\mathrm{R} 12 \\
\text { Retangular/circular } \\
\mathrm{D}=2,4 \text { e } 2,46 \mathrm{~mm} \\
296 \text { dados }\end{array}$ & $\begin{array}{c}G=44-832 \\
x=0-0,94 \\
\phi=3,6-129\end{array}$ \\
\hline Kew e Cornwell (1997) & $h_{2 \phi}=30 \operatorname{Re}_{L 0}^{0,857} B o^{0,714}(1-x)^{-0,143} \frac{k_{L}}{D}$ & $\begin{array}{c}\mathrm{R} 141 \mathrm{~b} \\
\text { Retangular/circular } \\
\mathrm{D}=1,39 \text { a } 3,69 \mathrm{~mm} \\
697 \text { dados }\end{array}$ & $\begin{array}{l}\mathrm{G}=188-1480 \\
\mathrm{x}=0-0,95 \\
\phi=9,7-90\end{array}$ \\
\hline Lee e Lee (2001b) & $\begin{array}{c}h_{2 \phi}=E \cdot h_{1 \phi} \\
E=10,3 \cdot A R^{0.393} \phi_{L}^{0,598} \\
\phi_{L}^{2}=1+C / X+1 / X^{2} \\
C=6,185 \times 10^{-2} \operatorname{Re}_{L 0}^{0,726}\end{array}$ & $\begin{array}{c}\mathrm{R} 113 \\
\text { Retangular } \\
0,4-2 \times 20 \mathrm{~mm}\end{array}$ & $\begin{array}{c}\mathrm{G}=50-200 \\
\mathrm{x}=0,15-0,75 \\
\phi=0-15 \\
\mathrm{AR}<0,1\end{array}$ \\
\hline Yu et al. (2002) & $h_{2 \phi}=6,4 \times 10^{6}\left(B o^{2} W e_{L 0}\right)^{0,27}\left(\frac{\rho_{L}}{\rho_{G}}\right)^{-0,2}$ & $\begin{array}{c}\text { Água } \\
\text { Circular } \\
\mathrm{D}=2,98 \mathrm{~mm}\end{array}$ & $\begin{aligned} \mathrm{G} & =50-200 \\
\mathrm{x} & =0,15-1 \\
\phi & =20-300\end{aligned}$ \\
\hline Warrier et al. (2002) & $\begin{array}{c}h_{2 \phi}=E \cdot h_{1 \phi} \\
E=1+6 B o^{1 / 16}-5,3(1-855 B o) x^{0,65}\end{array}$ & $\begin{array}{c}\text { FC-84 } \\
\text { Retangular } \\
\mathrm{D}_{\mathrm{H}}=0,75 \mathrm{~mm}\end{array}$ & $\begin{array}{c}\mathrm{G}=557-1600 \\
\mathrm{x}=0,03-0,55 \\
\phi=0-45\end{array}$ \\
\hline $\begin{array}{c}\text { Kandlikar e } \\
\text { Balasubramanian (2004) }\end{array}$ & $\begin{array}{c}h_{2 \phi}=\operatorname{Max}\left(h_{c o n v}, h_{e b}\right) \\
h_{e b}=\left[\begin{array}{c}0,6683 \mathrm{Cn}^{-0,2}(1-x)^{0,8} \\
+1058 B o^{0,7}(1-x)^{0,8} F_{f l}\end{array}\right] \cdot h_{L 0} \\
h_{c o n v}=\left[\begin{array}{l}1,136 \mathrm{Cn}^{-0,9}(1-x)^{0,8}+ \\
667,2 B o^{0,7}(1-x)^{0,8} F_{f l}\end{array}\right] \cdot h_{L 0} \\
\text { Para, } \operatorname{Re}_{L 0}<1600: h_{L 0}=4,36 \mathrm{k} / \mathrm{D} \\
\text { Para, } 1600<\operatorname{Re}_{L 0}<3000: \text { Pond. linear } \\
\text { Para, } R e_{L 0} \geq 3000: \text { Gnielinski }(1976) \\
\text { Cobre/latão } \rightarrow F_{f l} \text { da Tabela } 4.2 \\
\text { Aço } \rightarrow F_{f l .}=1 . \text { Se } R e_{L 0}<100: \\
h_{2 \phi}=h_{e b}\end{array}$ & $\begin{array}{c}\text { Água, R113, R134a, } \\
\text { R404A, R407C, R152a } \\
\text { D = 0,19 a 2,92 mm }\end{array}$ & $\begin{array}{c}G=50-570 \\
x=0-0,98 \\
\phi=5,46-90,75\end{array}$ \\
\hline Lee e Mudawar (2005b) & $\begin{array}{l}\text { Para } \mathrm{x}<0,05: \\
\qquad h_{2 \phi}=3,856 \cdot X^{0,267} h_{1 \phi, L} \\
\text { Para } 0,05<\mathrm{x}<0,55: \\
\quad h_{2 \phi}=436,48 B o^{0,522} W e_{L 0}^{0,351} X^{0,665} h_{1 \phi, L} \\
\text { Para } \mathrm{x}>0,55: \\
\quad h_{2 \phi}=\max \left\{\left(108,6 \cdot X^{1,665} h_{1 \phi, G}\right), h_{1 \phi, G}\right\}\end{array}$ & $\begin{array}{c}\text { R134a, Agua } \\
\text { Retangular } \\
\mathrm{D}_{\mathrm{H}}=0,348 \mathrm{~mm} \\
318 \text { dados }\end{array}$ & $\begin{array}{l}x=0,23-0,87 \\
\phi=15,9-93,8\end{array}$ \\
\hline
\end{tabular}


Tabela 4.3 (continuação). Métodos de previsão do CTC estritamente empíricos para microcanais.

\begin{tabular}{|c|c|c|c|}
\hline Autor & Correlações & Banco de dados & $\begin{array}{c}\mathrm{G}\left[\mathrm{kg} / \mathrm{m}^{2} \mathrm{~s}\right] \\
\mathbf{x}[-] \\
\phi\left[\mathrm{kW} / \mathrm{m}^{2}\right]\end{array}$ \\
\hline Sun e Mishima (2009a) & $h_{2 \phi}=\frac{6 \operatorname{Re}_{L 0}^{1,05} B o^{0,54}}{W e_{L 0}^{0,191}\left(\rho_{L} / \rho_{G}\right)^{0,142}} \frac{k_{L}}{D}$ & $\begin{array}{c}\text { R11, R12, R123, } \\
\text { R134a, R141b, R22, } \\
\text { R404a, R407c, R410a, } \\
\mathrm{CO}_{2} \text {, agua } \\
\text { Retangular/circular } \\
\mathrm{D}_{\mathrm{H}}=0,21-6,5 \mathrm{~mm} \\
2505 \text { dados }\end{array}$ & $\begin{array}{c}\mathrm{G}=44-1500 \\
\mathrm{x}=0-1,0 \\
\phi=5-109\end{array}$ \\
\hline Li e Wu (2010) & $h_{2 \phi}=334 B o^{0,3}\left(B d \operatorname{Re}_{L}^{0,36}\right)^{0,4} \frac{k_{L}}{D}$ & $\begin{array}{l}\text { Refrigerantes, agua, } \\
\text { etanol, } \mathrm{FC}-77, \mathrm{CO}_{2}, \\
\text { propano. } \\
\begin{array}{c}\mathrm{D}=0,16-3,1 \mathrm{~mm} \\
3744 \text { dados }\end{array}\end{array}$ & $\begin{aligned} \mathrm{G}= & 23,4- \\
& 3570 \\
\mathrm{x}= & 0,1-1,0\end{aligned}$ \\
\hline Basu et al. (2011) & $h_{2 \phi}=1,44 \times 10^{5}\left(B o^{2} W e_{L 0}\right)^{0,32}\left(\frac{\rho_{L}}{\rho_{G}}\right)^{0,31}$ & $\begin{array}{c}\mathrm{R} 134 \mathrm{a} \\
\text { Circular } \\
\mathrm{D}=0,5 ; 0,96 ; 1,6 \mathrm{~mm} \\
3459 \text { dados }\end{array}$ & $\begin{array}{l}\mathrm{G}=300- \\
1500 \\
\mathrm{x}=0-1,0 \\
\phi=0-350\end{array}$ \\
\hline Oh e Son (2011) & $h_{2 \phi}=0,05372 \operatorname{Re}_{L}^{0,8} \operatorname{Pr}_{L}^{0,3}\left(\frac{1}{X_{t t}}\right)^{0,87} \frac{k_{L}}{D}$ & $\begin{array}{c}\mathrm{R} 22 ; \mathrm{R} 134 \mathrm{a} \\
\text { Circular } \\
\mathrm{D}=1,77 ; 3,36 ; 5,35 \\
\mathrm{~mm}\end{array}$ & $\begin{array}{c}\mathrm{G}=200-600 \\
\mathrm{x}=0-1,0 \\
\phi=5-30\end{array}$ \\
\hline
\end{tabular}

Tran et al. (1996) verificaram efeitos marginais da geometria ao comparar o CTC para canais circulares e retangulares. Os resultados destes autores também indicaram efeitos de ebulição nucleada dominantes para títulos de vapor entre 0,2 e 0,8. O método proposto por Tran et al. (1996) prevê um CTC independente do título de vapor de forma análoga aos métodos de Yu et al. (2002), Lazareck e Black (1982), Sun e Mishima (2009a) e Basu et al. (2011).

A análise da Tabela 4.4 também permite constatar que os métodos propostos por Yu et al. (2002) e Basu et al. (2011) consistem em ajustes do método de Tran et al. (1996) segundo dados experimentais próprios. Por outro lado, Kew e Cornwell (1997) modificaram a correlação de Lazareck e Black (1982) introduzindo um termo relativo aos efeito do título de vapor, já que seus dados experimentais indicaram o incremento do CTC com a elevação do título de vapor. Lee e Lee (2001) desenvolveram um método de previsão para canais retangulares com fator de forma inferiores a 0,1 . Eles propuseram um método estritamente convectivo em que o CTC é dado como função do fator de forma, número de Reynolds, parâmetro de Martinelli e do título de vapor.

Kandlikar e Balasubramanian (2004) propuseram um método de previsão baseado no método para canais convencionais proposto por Kandlikar $(1990,1991)$. Os autores 
verificaram que para microcanais números de Reynolds reduzidos eram reportados, portanto, modificaram o procedimento de cálculo do CTC monofásico proposto por Kandlikar (1991). Como indicado na Tabela 4.3, os autores propuseram o método de Gnielinski (1976) para números de Reynolds superiores a 3000, uma ponderação linear entre laminar e turbulento para números de Reynolds entre 1600 e 3000 e um número de Nusselt constante para regime laminar correspondendo a Reynolds inferiores a 1600. Adicionalmente, Kandlikar e Balasubramanian (2004) verificaram através de resultados experimentais a predominância dos efeitos de ebulição nucleada para números de Reynolds monofásicos inferiores a 100.

A Figura 4.1 ilustra o efeito da variação das condições experimentais $\left(G, \phi, T_{s a t} \mathrm{e}\right.$ D) no CTC segundo o método de Kandlikar e Balasubramanian (2004). De acordo com a figura, o coeficiente de transferência de calor se eleva com o acréscimo do fluxo de calor. O método prevê também o aumento do coeficiente de transferência de calor com o acréscimo do diâmetro, comportamento contrário ao apontado frequentemente na literatura. O método também não captura os comportamentos frequentemente apontados na literatura com o acréscimo da velocidade mássica e a temperatura de saturação.

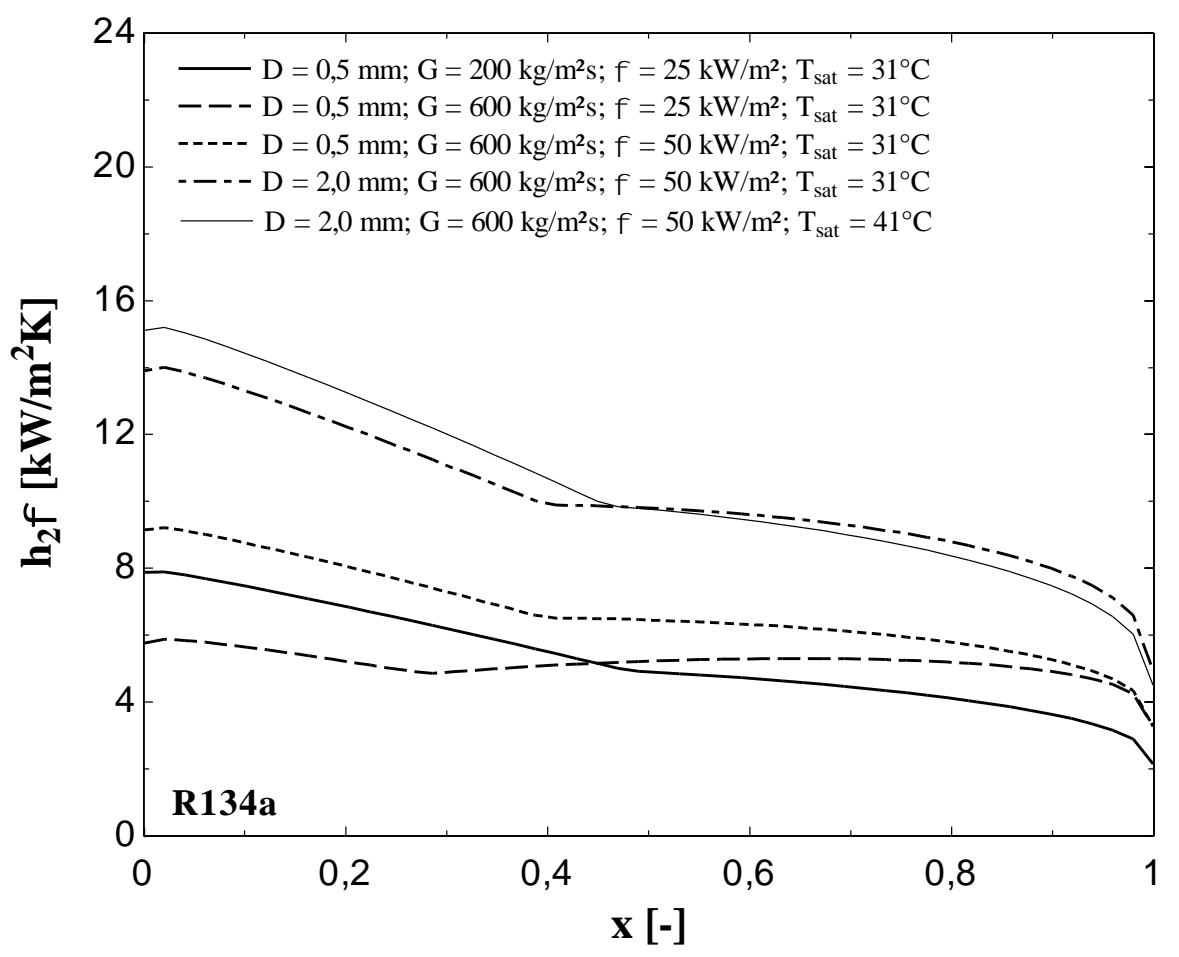

Figura 4.1. Efeito da temperatura de saturação, diâmetro, velocidade massica e fluxo de calor no CTC segundo método de previsão de Kandlikar e Balasubramanian (2004), R134a. 
A Tabela 4.4 compara os comportamentos do coeficiente de transferência de calor com a variação dos parâmetros experimentais indicados com maior frequência na literatura segundo Ribatski (2013), com aqueles fornecidos pelos métodos de previsão listados na tabela anterior. Segundo a Tabela 4.4, Lazareck e Black (1982), Kew e Cornwell (1997) e Sun e Mishima (2009a) previram comportamentos similares aos indicados por Ribatski (2013) como típicos na literatura. Basu et al (2011) e Warrier et al. (2002) capturam apenas o comportamento indicado por Ribatski para o acréscimo do fluxo de calor. Já, Tran et al. (1996) indica comportamentos distintos da maioria dos estudos da literatura para a velocidade mássica e o diâmetro da seção. Yu et al. (2002) proporciona valores de CTC irreais para refrigerantes halogenados $\left(\mathrm{h}>100 \mathrm{~kW} / \mathrm{m}^{2} \mathrm{~K}\right)$, por este motivo não foi incluído na Tabela 4.4.

Tabela 4.4. Análise dos comportamentos dos métodos estrictamente empiricos.*

\begin{tabular}{|c|c|c|c|c|}
\hline Autor (es) & $\mathbf{G} \uparrow \rightarrow \mathbf{h} \uparrow$ & $\phi \uparrow \rightarrow \mathbf{h} \uparrow$ & $\mathbf{T}_{\text {sat }} \uparrow \rightarrow \mathbf{h} \uparrow$ & $\mathbf{D} \downarrow \rightarrow \mathbf{h} \uparrow$ \\
\hline Lazarek e Black (1982) & $\checkmark$ & $\checkmark$ & $\checkmark$ & $\checkmark$ \\
\hline Tran et al. (1996) & $x$ & $\checkmark$ & $\checkmark$ & $x$ \\
\hline Kew e Cornwell (1997) & $\checkmark$ & $\checkmark$ & $\checkmark$ & $\checkmark$ \\
\hline Lee e Lee (2001b) & $\checkmark$ & $\checkmark$ & $x$ & $x$ \\
\hline Warrier et al. (2002) & $x$ & $\checkmark$ & $x$ & $x$ \\
\hline $\begin{array}{c}\text { Kandlikar e } \\
\text { Balasubramanian (2004) }\end{array}$ & $\checkmark / x$ & $\checkmark$ & $\checkmark / x$ & $x$ \\
\hline Lee e Mudawar (2005b) & $\checkmark$ & $\checkmark$ & $x$ & $x$ \\
\hline Sun e Mishima (2009a) & $\checkmark$ & $\checkmark$ & $\checkmark$ & $\checkmark$ \\
\hline Li e Wu (2010) & $x$ & $\checkmark$ & $\checkmark$ & $\checkmark$ \\
\hline Basu et al. (2011) & $x$ & $\checkmark$ & $x$ & $x$ \\
\hline Oh e Son (2011) & $\checkmark$ & $x$ & $x$ & $\checkmark$ \\
\hline
\end{tabular}

\subsubsection{Métodos de previsão do CTC baseados na superposição de efeitos}

Os métodos de previsão do coeficiente de transferência de calor baseados na superposição de efeitos consideram que o CTC é dado pela adição das parcelas devido a 
efeitos convectivos e de ebulição nucleada. Esta abordagem foi primeiramente proposta por Chen (1966).

\section{Canais convencionais}

\section{Chen (1966)}

Chen (1966) foi pioneiro ao propor um método de previsão do coeficiente de transferência de calor em ebulição convectiva que combina efeitos de ebulição nucleada e convectiva. O método está baseado em um banco de dados experimental envolvendo 600 dados, 6 fluidos de trabalho (água, benzeno, pentano, heptano, ciclohexano e metanol), escoamento vertical descendente e ascendente e é dado através da seguinte relação:

$$
h_{2 \phi}=F \cdot h_{L}+S \cdot h_{e n}
$$

Para a estimativa do coeficiente de transferência de calor monofásico, $h_{L}$, os autores recomendam a correlação de Dittus-Boelter. Chen (1966) introduziu o conceito do fator de intensificação, $F$, que está relacionado ao incremento dos efeitos convectivos devido à aceleração do escoamento inerente ao processo de evaporação. Com base no banco de dados experimental, Chen (1966) relacionou este fator como uma função do parâmetro de Lockhart-Martinelli através de curvas fornecidas em um diagrama. Posteriormente, Collier (1981) ajustou correlações com base nas curvas fornecidas por Chen (1966), dadas por:

$$
\begin{array}{ll}
F=2,35 \cdot\left(\frac{1}{X_{t t}}+0,213\right)^{0,736} & \text { Para: } \frac{1}{X_{t t}} \geq 0,1 \\
F=1 & \text { Para: } \frac{1}{X_{t t}} \leq 0,1
\end{array}
$$

Chen (1966) recomenda o uso da equação de Foster e Zuber (1955) para a estimativa do coeficiente de transferência de calor por ebulição nucleada.

O fator $S$ está diretamente relacionado à velocidade do escoamento bifásico e de seu efeito na espessura da subcamada limite laminar, cuja redução implica a inibição/supressão de núcleos ativos. Vale mencionar que para uma velocidade igual a 0 , 
o valor de $S$ seria igual a 1, fornecendo como resultado o coeficiente de transferência de calor da ebulição em piscina. Chen (1966) apresentou um diagrama para a determinação de $S$ em função do número de Reynolds da mistura bifásica. Da mesma maneira que para o fator $F$, Collier (1981) ajustou uma relação matemática à curva do Chen, dada pela seguinte equação:

$$
S=\frac{1}{\left(1+2,53 \times 10^{-6} \mathrm{Re}_{2 \phi}^{1,17}\right)}
$$

\section{Lie e Winterton (1991)}

Liu e Winterton (1991) desenvolveram um novo método assintótico, também baseado na superposição de efeitos, ao verificarem que o método de Chen (1963) superestima o coeficiente de transferência de calor para títulos elevados e subestima para títulos de vapor reduzidos. Eles adotaram um expoente assintótico igual a 2 conforme sugerido por Kutateladze (1961). Este método é dado por:

$$
h_{2 \phi}^{2}=\left(F \cdot h_{L} \cdot e_{F}\right)^{2}+\left(S \cdot h_{e n} \cdot e_{S}\right)^{2}
$$

Neste método, os coeficientes de transferência de calor por convecção forçada e ebulição nucleada são calculados a partir da equação de Dittus e Boelter (1930) e Cooper (1955), respectivamente.

Os fatores de intensificação dos efeitos convectivos e de supressão da ebulição nucleada foram ajustados com base em um banco de dados contendo 5193 dados experimentais que inclui 9 fluidos de trabalho (água, R12, R22, R11, R113, R114, etilenoglicol, n-butanol, etanol), diâmetros de 2,95 a $32 \mathrm{~mm}$, velocidades mássicas de 12,4 a 8157 e títulos de vapor de 0 a 0,948 . Neste método, o fator de intensificação, $F$, e de supressão, $S$, são dados respectivamente por:

$$
\begin{aligned}
& F=\left[1+x \operatorname{Pr}_{L}\left(\frac{\rho_{L}}{\rho_{G}}-1\right)\right]^{0,35} \\
& S=\frac{1}{\left(1+0,055 F^{0,1} \operatorname{Re}_{L}^{0,16}\right)}
\end{aligned}
$$


No caso das forças gravitacionais predominarem sobre as de inercia, correspondendo segundo os autores, a um número de Froude inferior a 0,05 , os fatores $F$ e $S$ são corrigidos através dos seguintes parâmetros:

$$
e_{F}=F r_{L 0}^{\left(0,1-2 F r_{L 0}\right)}, \quad e_{S}=F r_{L 0}^{1 / 2}
$$

caso contrário, $e_{F}$ e $e_{S}$ são iguais a 1 .

A Figura 4.2 ilustra o efeito da temperatura de saturação, diâmetro e velocidade mássica no CTC segundo o método de Liu e Winterton (1991). De acordo com a figura, o coeficiente de transferência de calor se eleva com o acréscimo do título de vapor e do fluxo de calor. No entanto, o método prevê o decréscimo do coeficiente de transferência de calor com o incremento da temperatura de saturação, comportamento contrário ao frequentemente apontado na literatura. Com o decréscimo do diâmetro de 3 para $1 \mathrm{~mm}$ o coeficiente de transferência de calor apresenta um aumento aproximado de $20 \%$.

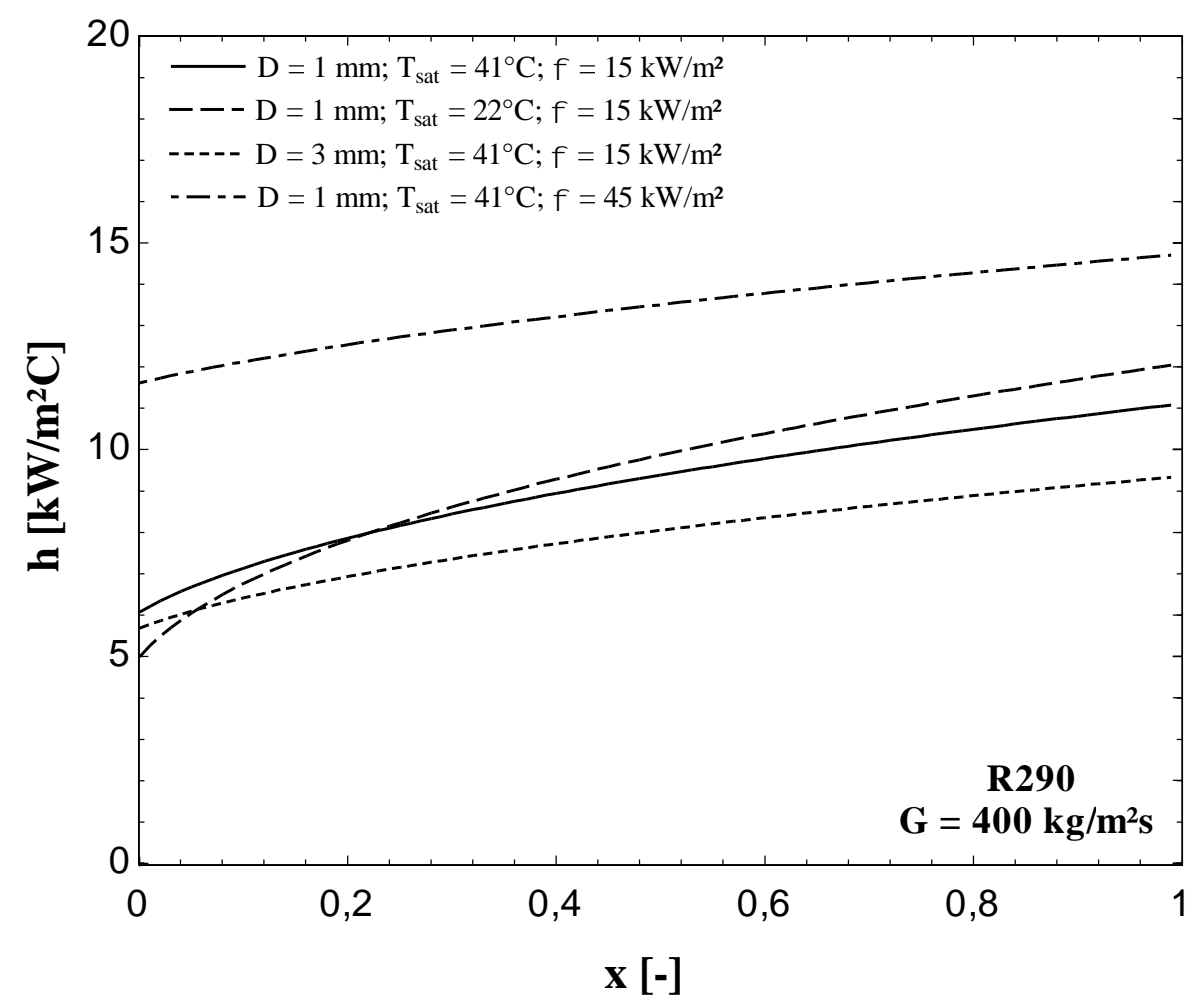

Figura 4.2. Efeito da temperatura de saturação e diâmetro no CTC segundo método de previsão de Liu e Winterton (1991), R290a, $G=400 \mathrm{~kg} / \mathrm{m}^{2} \mathrm{~s}$. 


\section{Microcanais}

A Tabela 4.5 apresenta métodos baseados na superposição de efeitos propostos para a previsão do coeficiente de transferência de calor em canais de diâmetros reduzidos. Nela são apresentados as correlações sugeridas pelos autores para a estimativa do fator de intensificação, fator de supressão, CTC devido a ebulição nucleada, CTC devido à convecção forçada. A tabela descreve ainda o banco de dados utilizados pelos autores para o ajuste das constantes e expoentes empíricos.

Através da análise da Tabela 4.5, nota-se que a maioria dos métodos de previsão para microcanais se baseia em bancos de dados extensos, ainda que com restrições em relação a alguns fluidos refrigerantes e geometrias da seção de transversal. Neste contexto, destaca-se o fato de apenas Kanizawa et al. (2016) e Oh et al. (2015) considerarem respectivamente em seu bancos de dados resultados para isobutano e propano. No caso dos HFOs (R1234ze(E)/R1234yf) resultados para estes refrigerantes foram considerados no ajuste de coeficientes empíricos apenas por Kim e Mudawar (2013a).

Parcela significativa dos autores se baseia na correlação de Dittus-Boelter para estimar o coeficiente de transferência de calor devido a efeitos convectivos, apesar deste método ser indicado na literatura para números de Reynolds superiores a $10^{4}$. Tal fato se dá pela simplicidade desta correlação e ao fato de, combinada ao fator de intensificação de efeitos convectivos, proporcionar previsões satisfatórias, ainda que para números de Reynolds inferiores. Bertsch et al (2009) considera um coeficiente de transferência de calor de ebulição convectiva, dado através de uma interpolação linear, adotando o título de vapor como parâmetro de ponderação entre os CTCs para convecção forçada das fases líquida e gasosa. Os coeficientes de transferência de calor monofásicos são encontrados através da correlação de Hausen (1943).

Segundo a Tabela 4.5 para a estimativa do coeficiente de transferência de calor devido a efeitos de ebulição nucleada, os autores se baseiam nas correlações para a ebulição nucleada em condições de convecção natural propostas por Foster e Zuber (1955), Cooper (1984) e Stephan e Abdelsalam (1980). 
Tabela 4.5. Métodos de previsão do CTC baseados na superposição de efeitos para microcanais.

\begin{tabular}{|c|c|c|c|}
\hline Autor (es) & $\mathbf{F}, \mathbf{h}_{\text {conv }}$ & $\mathbf{S}, \mathbf{h}_{\mathbf{e b}}$ & Banco de dados \\
\hline \multirow{2}{*}{$\begin{array}{l}\text { Zhang et al. } \\
\text { (2004) }\end{array}$} & $h_{\text {conv }}=\max \left(4,36 \frac{k_{L}}{D} ;\right.$ Dittus - Boelter $)$ & $h_{e b}:$ Foster e Zuber (1955) & \multirow{2}{*}{$\begin{array}{c}\text { Agua, R11, R12 e R113. } \\
\mathrm{D}_{\mathrm{H}}=0,78-6 \mathrm{~mm} \\
1203 \text { dados }\end{array}$} \\
\hline & $F=\operatorname{Max}\left(0,64 \phi_{L}, 1\right)$ & $S=\frac{1}{\left(1+2,53 \times 10^{-6} \operatorname{Re}_{2 \phi}^{1,17}\right)}$ & \\
\hline \multirow{2}{*}{$\begin{array}{l}\text { Saitoh et al. } \\
\qquad(2007)\end{array}$} & $\begin{array}{l}\operatorname{Re}_{L}<1000: \text { Teoria laminar } \\
\operatorname{Re}_{L} \geq 1000 \text { : Dittus-Boelter }\end{array}$ & $\begin{array}{c}h_{e b}: \text { Stephan e Abdelsalam } \\
\text { (1980) }\end{array}$ & \multirow{2}{*}{$\begin{array}{c}\mathrm{R} 134 \mathrm{a} \\
\mathrm{D}_{\mathrm{H}}=0,5-10,92 \mathrm{~mm} \\
2224 \text { dados }\end{array}$} \\
\hline & $F=1+\left(\frac{1}{X_{t t}}\right)^{1,05} \frac{1}{1+W e_{G}^{-0,4}}$ & $S=\frac{1}{1+0,4\left(10^{-4} \operatorname{Re}_{L} \cdot F^{1,25}\right)^{1,4}}$ & \\
\hline \multirow{2}{*}{$\begin{array}{l}\text { Bertsch et } \\
\text { al. }(2009)\end{array}$} & $\begin{array}{c}h_{c o n v, 2 \phi}=h_{c o n v, L} \cdot(1-x)+h_{c o n v, G} \cdot x \\
h_{c o n v, L}, h_{c o n v, G} \rightarrow \text { Hausen }(1943)\end{array}$ & $h_{e b}:$ Cooper (1984) & \multirow{2}{*}{$\begin{array}{l}\text { R134a, R236fa, R245fa, } \\
\text { R11, R123, R113, } \\
\text { R141b, R12, R410A, } \\
\text { agua , FC-77 e } \mathrm{N}_{2} \\
\mathrm{D}_{\mathrm{H}}=0,16-2,92 \mathrm{~mm} \\
\text { 3988 dados }\end{array}$} \\
\hline & $F=1+80 e^{-0,6 C o} \cdot\left(x^{2}-x^{6}\right)$ & $S=1-x$ & \\
\hline \multirow[b]{2}{*}{$\begin{array}{l}\text { Pamitran et } \\
\text { al. (2011) }\end{array}$} & $\forall \operatorname{Re}_{L}:$ Dittus-Boelter & $h_{e b}:$ Cooper (1984) & \multirow[b]{2}{*}{$\begin{array}{c}\text { Propano, } \mathrm{NH}_{3} \text { e } \mathrm{CO}_{2} \\
\mathrm{D}_{\mathrm{H}}=1,5 ; 3 \mathrm{~mm}\end{array}$} \\
\hline & $F=\operatorname{Max}\left[0,009 \phi_{L}^{2,2}+0,76 ; 1\right]$ & $\begin{array}{c}S=C_{r e f}\left(\phi_{L}^{2}\right)^{-0,2093} B o^{0,7402} \\
\mathrm{C}_{\mathrm{NH}_{3}}=0,45 ; \mathrm{C}_{\mathrm{C}_{3} \mathrm{H}_{8}}=0,4 ; \mathrm{C}_{\mathrm{CO}_{2}}=0,25\end{array}$ & \\
\hline \multirow[t]{2}{*}{$\begin{array}{l}\text { Oh et al. } \\
(2011)\end{array}$} & $\begin{array}{c}\operatorname{Re}_{L} \leq 3000: \text { Teoria laminar } \\
3000 \leq \operatorname{Re}_{L}<10^{4}: \text { Gnielinski }(1976) \\
10^{4} \leq \operatorname{Re}_{L}<10^{6}: \text { Petukov e Popov (1963) } \\
\operatorname{Re}_{L} \geq 10^{6}: \text { Dittus- Boelter }\end{array}$ & $h_{e b}:$ Cooper $(1984)$ & \multirow[t]{2}{*}{$\begin{array}{l}\mathrm{R} 22, \mathrm{R} 134 \mathrm{a}, \mathrm{R} 410 \mathrm{~A} \\
\text { propano e } \mathrm{CO}_{2} \\
\mathrm{D}_{\mathrm{H}}=0,5 ; 1,5 ; 3 \mathrm{~mm}\end{array}$} \\
\hline & $F=\operatorname{Max}\left[0,023 \phi_{L}^{2,2}+0,76 ; 1\right]$ & $S=0,279\left(\phi_{L}^{2}\right)^{-0,029} B o^{-0,098}$ & \\
\hline $\begin{array}{l}\text { Kim e } \\
\text { Mudawar } \\
(2013 a)\end{array}$ & \multicolumn{2}{|c|}{$\begin{array}{c}F h_{\text {conv }}=\left[5,2\left(B o \frac{P e_{a q}}{P e_{m}}\right)^{0,08} W e_{L 0}^{-0,54}+3,5\left(\frac{1}{X_{t t}}\right)^{0,94}\left(\frac{\rho_{G}}{\rho_{L}}\right.\right. \\
S h_{e b}=\left[2345\left(B o \frac{P e_{a q}}{P e}\right)^{0,7} p_{\text {red }}^{0,38}(1-x)^{-0,51}\right] h_{L}\end{array}$} & $\begin{array}{c}\text { FC72, R11, R113, } \\
\text { R123, R1234yf, } \\
\text { R1234ze(E), } \\
\text { R134a,R152a, R22, } \\
\text { R236fa, R245fa, R32, } \\
\text { R404A, R407C, R410A, } \\
\text { R417A, água e CO2 } \\
\text { DH= 0,19-6,5 mm } \\
\text { 10805 dados }\end{array}$ \\
\hline \multirow{2}{*}{$\begin{array}{l}\text { Mahmoud e } \\
\text { Karayiannis } \\
\quad(2013)\end{array}$} & $\begin{array}{l}\operatorname{Re}_{L} \leq 2000: \text { Teoria laminar } \\
\operatorname{Re}_{L}>3000 \text { : Dittus- Boelter }\end{array}$ & $h_{e b}:$ Cooper $(1984)$ & \multirow{2}{*}{$\begin{array}{c}\mathrm{R} 134 \mathrm{a} \\
\mathrm{D}=0,52-4,26 \mathrm{~mm} \\
5152 \text { dados }\end{array}$} \\
\hline & $F=\left(1+\frac{2,812 C o^{-0,408}}{X}\right)^{0,64}$ & $S=\frac{1}{\left(1+2,53 \times 10^{-6} \operatorname{Re}_{2 \phi}^{1,17}\right)}$ & \\
\hline \multirow[b]{2}{*}{$\begin{array}{l}\text { Kanizawa et } \\
\text { al. (2016) }\end{array}$} & $\forall \operatorname{Re}_{L}:$ Dittus-Boelter & $\begin{array}{c}h_{e b}: \text { Stephan e Abdelsalam } \\
\quad(1980) \text { com } d_{b}=D_{e q}\end{array}$ & \multirow[b]{2}{*}{$\begin{array}{c}\text { R134a; R245fa; R600a } \\
\text { D = 0,38-2,6 mm } \\
2050 \text { dados }\end{array}$} \\
\hline & $\begin{array}{c}F=1+\frac{2,5 X_{t x}^{-1,32}}{1+W e_{u G}^{0,24}} \\
\alpha \rightarrow \text { Kanizawa e Ribatski (2015) } \\
X_{t x} \rightarrow \text { Da Riva et al. (2012) }\end{array}$ & $S=\frac{1,06 B d^{-0,008}}{1+0,12\left(10^{-4} \operatorname{Re}_{L} \cdot F^{1,25}\right)^{0,86}}$ & \\
\hline
\end{tabular}


$\mathrm{Na}$ Tabela 4.5, constata-se também diferentes abordagens para a estimativa do fator de intensificação. Zhang et al. (2004), Pamitran et al. (2011) e Oh et al. (2011) relacionam o fator de intensificação, basicamente, como função do parâmetro de Martinelli e dos regimes de escoamento. Bertsch et al. (2009) se baseia em um polinômio que inclui o número de confinamento e o título de vapor com $F$ apresentando o valor igual a 1 para títulos de vapor iguais a 0 e 1 . Mahmoud e Karayiannis (2015) verificaram, com base em um banco de dados envolvendo 5152 dados experimentais, que o fator de intensificação está relacionado ao parâmetro de Lockhart-Martinelli e ao número de confinamento. Já Saitoh et al. (2007) e Kanizawa et al. (2016) incluíram além do parâmetro de Martinelli, visando capturar efeitos da aceleração do escoamento, o número de Weber, buscando incluir efeitos da geração de ondulações na interface com o conseguinte desprendimento de gotículas que são arrastradas pelo vapor (entrainment).

A Figura 4.3 ilustra o comportamento do fator de intensificação $F$ segundo os métodos de Chen (1963), Liu e Winterton (1991) e os demais listados na Tabela 4.6. Segundo esta figura, o fator de intensificação fornecido pelos métodos apresenta um valor igual a unidade para título de vapor nulo e, exceto por Liu e Winterton (1991) e Bertsch et al. (2009), tende assintotaticamente a um valor infinito conforme o título de vapor se aproxima da unidade. O método de Liu e Winterton (1991) prevê o crescimento continuo do fator de intensificação com o aumento do título de vapor, apresentando gradientes superiores para títulos de vapor reduzidos e tendendo a um valor finito para um título de vapor igual à unidade. Já o fator de intensificação previsto por Bertsch et al. (2009) apresenta uma redução a partir de títulos de vapor elevados. O fato do fator de intensificação de efeitos convectivos tenderem a um valor infinito conforme o título de vapor aproxima-se da unidade segundo os métodos de Kanizawa et al. (2016) e Saitoh et al. (2007), não prejudicam as previsões fornecidas por eles, já que estes métodos incluem procedimentos distintos para o cálculo do coeficiente de transferência de calor nas regiões pré e pôs-secagem de parede, sendo esta última correspondente a títulos de vapor elevados independentemente do fator de intensificação de efeitos convectivos.

Observa-se também na Tabela 4.5 diferentes abordagens para a estimativa do fator de supressão. Bertsch et al. (2009) indicaram, de forma análoga a Tran et al. (2000) e Steinke e Kandlikar (2004), um fator de supressão independente do diâmetro do canal, e segundo eles, decresce linearmente com o incremento do título de vapor. Vale destacar 
que a previsão do fator de supressão como proposta por estes autores despreza a dependência do fator de supressão da velocidade mássica. Tal influência consta no estudo pioneiro de Chen (1966) e foi corroborada por diversos autores. Os fatores de supressão propostos por Zhang et al. (2004), Saitoh et al. (2007) e Kanizawa et al. (2016) se baseiam na correlação de Chen (1966), no entanto, vale mencionar que Kanizawa et al. (2016) adicionaram a esta equação o número de Bond com o intuito de capturar efeitos do crescimento da bolha em condições confinadas. Mahmoud e Kariayannis (2013) recomendam a utilização do fator de supressão conforme proposto por Zhang et al. (2004). Pamitran et al. (2011) e Oh et al. (2011) propuseram um fator de supressão dado como função do número de Boiling e do multiplicador bifásico líquido.

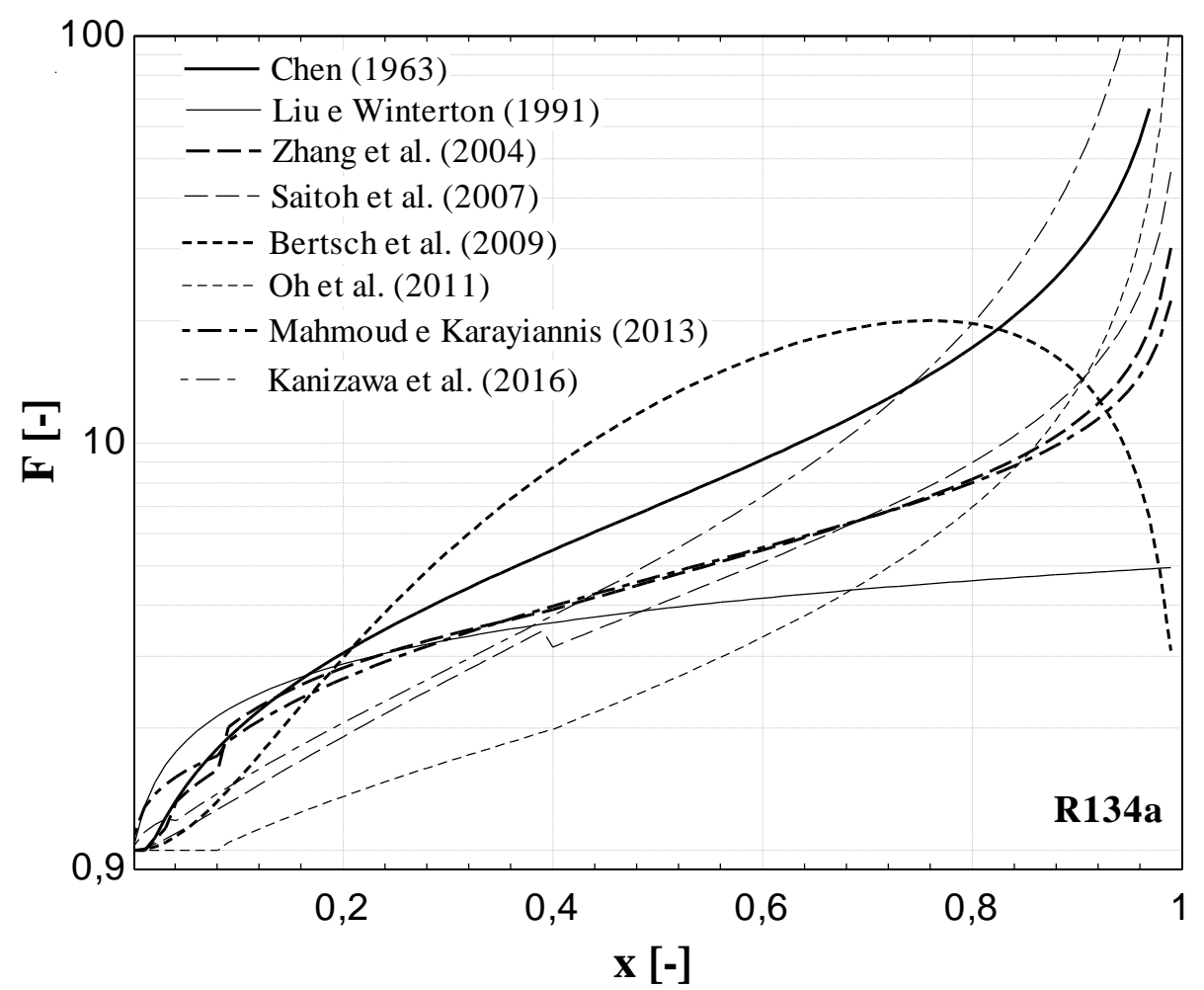

Figura 4.3. Comparação do fator de intensificação, $\mathrm{F}$, entre os métodos de previsao na literatura, $\mathrm{D}=1$ $\mathrm{mm}, \mathrm{G}=300 \mathrm{~kg} / \mathrm{m}^{2} \mathrm{~s}, \mathrm{~T}_{\text {sat }}=31^{\circ} \mathrm{C}$ e $\phi=15 \mathrm{~kW} / \mathrm{m}^{2}$.

A Figura 4.4 ilustra o comportamento do fator de supressão com a variação do título de vapor segundo os métodos de Chen (1966), Liu Winterton (1991) para canais convencionais e os métodos listados na Tabela 4.5 para canais de dimensões reduzidas. Segundo esta figura, os procedimentos para o cálculo do fator de supressão proposto por Chen (1963), Zhang et al. (2004) e Saitoh et al. (2007) proporcionam resultados próximos. Observa-se também que de acordo ao método de Liu e Winterton (1991) e Oh et al. 
(2011), o fator de supressão varia apenas marginalmente com o incremento do título de vapor. Como mencionado anteriormente, Bertsch et al. (2009) prevê uma diminuição linear do fator de supressão com o incremento do título de vapor. Kanizawa et al. (2016) prevê um fator de supressão ligeiramente superior a 1 para título de vapor nulo, comportamento dado devido a que os autores consideram o grau de confinamento da bolha, o qual justifica a intensificação do coeficiente de transferência de calor por efeitos de ebulição nucleada. Kanizawa et al. (2016) conforme esperado prevê o decréscimo do fator de supressão com o incremento do título de vapor.

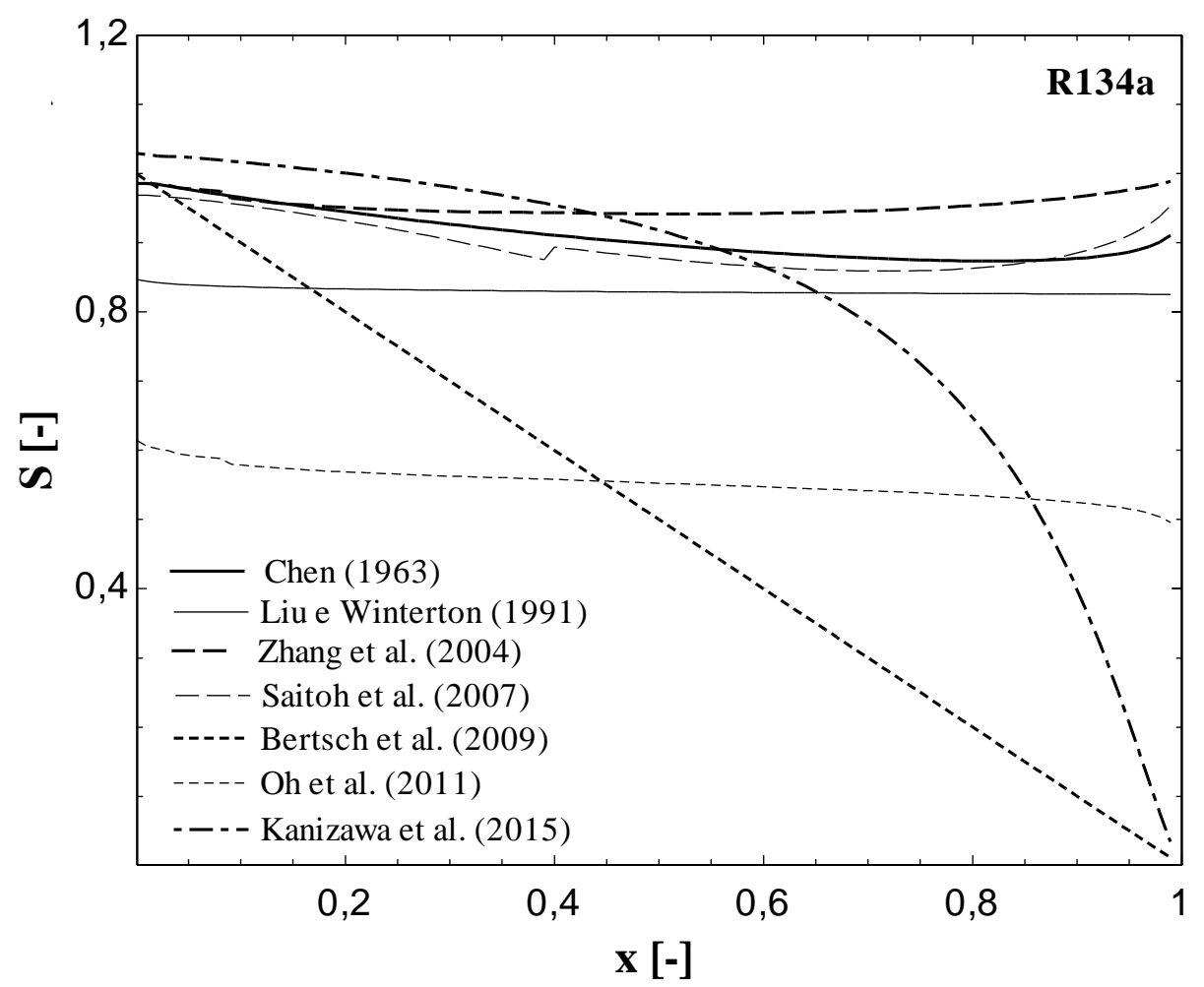

Figura 4.4. Comparação do fator de supressão, S, entre os métodos de previsão na literatura, R134a, D = 1 $\mathrm{mm}, \mathrm{G}=300 \mathrm{~kg} / \mathrm{m}^{2} \mathrm{~s}, \mathrm{~T}_{\mathrm{sat}}=31^{\circ} \mathrm{C}$ e $\phi=15 \mathrm{~kW} / \mathrm{m}^{2}$.

Conforme já mencionado, os métodos propostos por Saitoh et al. (2007) e Kanizawa et al. (2015) se destacam por incluírem um procedimento distinto para o cálculo do coeficiente de transferência de calor em condições após a secagem de parede. Kim e Mudawar (2013a) embora tenham proposto um método para a estimativa de título de vapor para o início da secagem de parede (ver KIM; MUDAWAR, 2013b), não especificam nenhum procedimento para a previsão do CTC após o título de vapor do início de secagem de parede. O método proposto por Kim e Mudawar (2013b) se baseia 
em um banco de dados contendo aproximadamente 1000 resultados experimentais envolvendo 13 fluidos refrigerantes. A correlação proposta pelos autores é dada por:

$$
x_{d i}=1,4 W e_{L 0}^{0,03} p_{r e d}^{0,08}-15\left(B o \frac{P e_{a q}}{P e_{m}}\right)^{0,15} C a^{0,35}\left(\frac{\rho_{G}}{\rho_{L}}\right)^{0,06}
$$

Kanizawa et al. (2016) adotaram o método de Zhang et al. (2006), desenvolvido para a estimativa do fluxo crítico de calor para o cálculo do título de secagem de parede. O procedimento proposto por eles, calcula-se o título de vapor de secagem de parede (ou crítico) a partir do fluxo de calor imposto correspondente ao FCC. Este procedimento proporcionou previsões satisfatórias dos resultados experimentais de secagem de parede obtidos por Saitoh et al. (2005), Tibiriçá e Ribatski (2010) e Ali e Palm (2011). No método de Kanizawa et al. (2016), o coeficiente de transferência de calor para títulos de vapor superiores ao de secagem de parede é estimado através da interpolação linear entre o CTC correspondente ao título de início de secagem, calculado segundo a Tabela 4.5, e o CTC monofásico da fase gás tendo o título de vapor como parâmetro de ponderação.

As Figuras 4.5 e 4.6 ilustram a contribuição dos efeitos de ebulição convectiva e nucleada no coeficiente de transferência de calor bifásico segundo os métodos de Bertsch et al. (2009) e Kanizawa et al. (2016), respectivamente.

Segundo a Figura 4.6, o método de Bertsch et al. (2009) prevê a parcela de coeficiente de transferência de calor relacionada à ebulição nucleada significativamente superior à parcela devido a efeitos convectivos. Nota-se também que o coeficiente de transferência de calor por ebulição em piscina, $h_{e b}$, em geral apresenta valores superiores ao coeficiente de transferência devido a ebulição convectiva, $h_{2 \phi}$. A Figura 4.4 ilustra também que o método de Bertsch et al. (2009) indica o aumento do CTC com o acréscimo da temperatura de saturação. Já, para o decréscimo do diâmetro de 2 para 0,5 mm, o coeficiente de transferência de calor varia apenas marginalmente, elevando-se para títulos de vapor reduzidos e um decréscimo para títulos superiores a 0,4. 


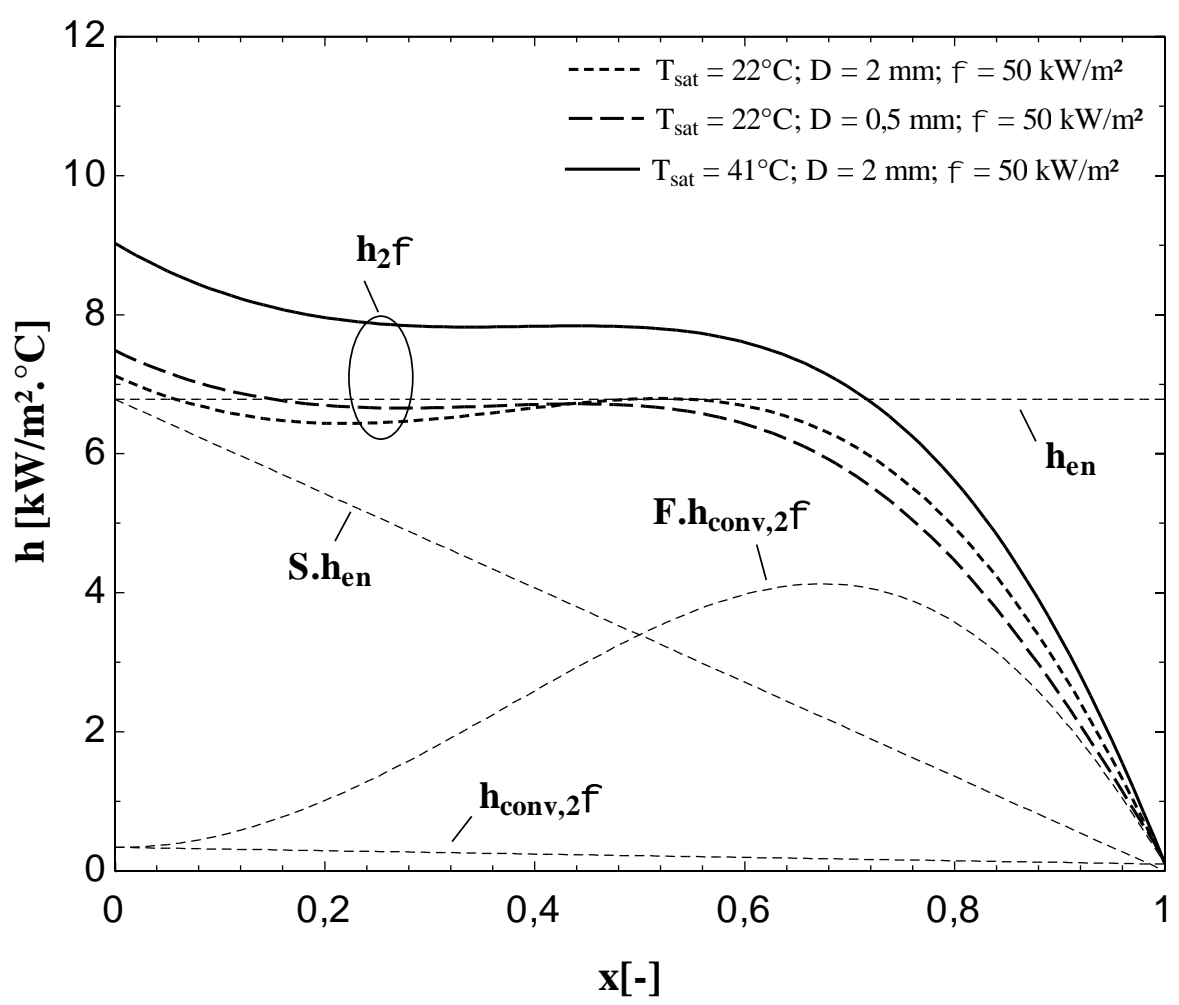

Figura 4.5. Contribuções ao CTC das parcelas convectiva e de ebulição nucleada segundo o método proposto por Bertsch et al. (2009).

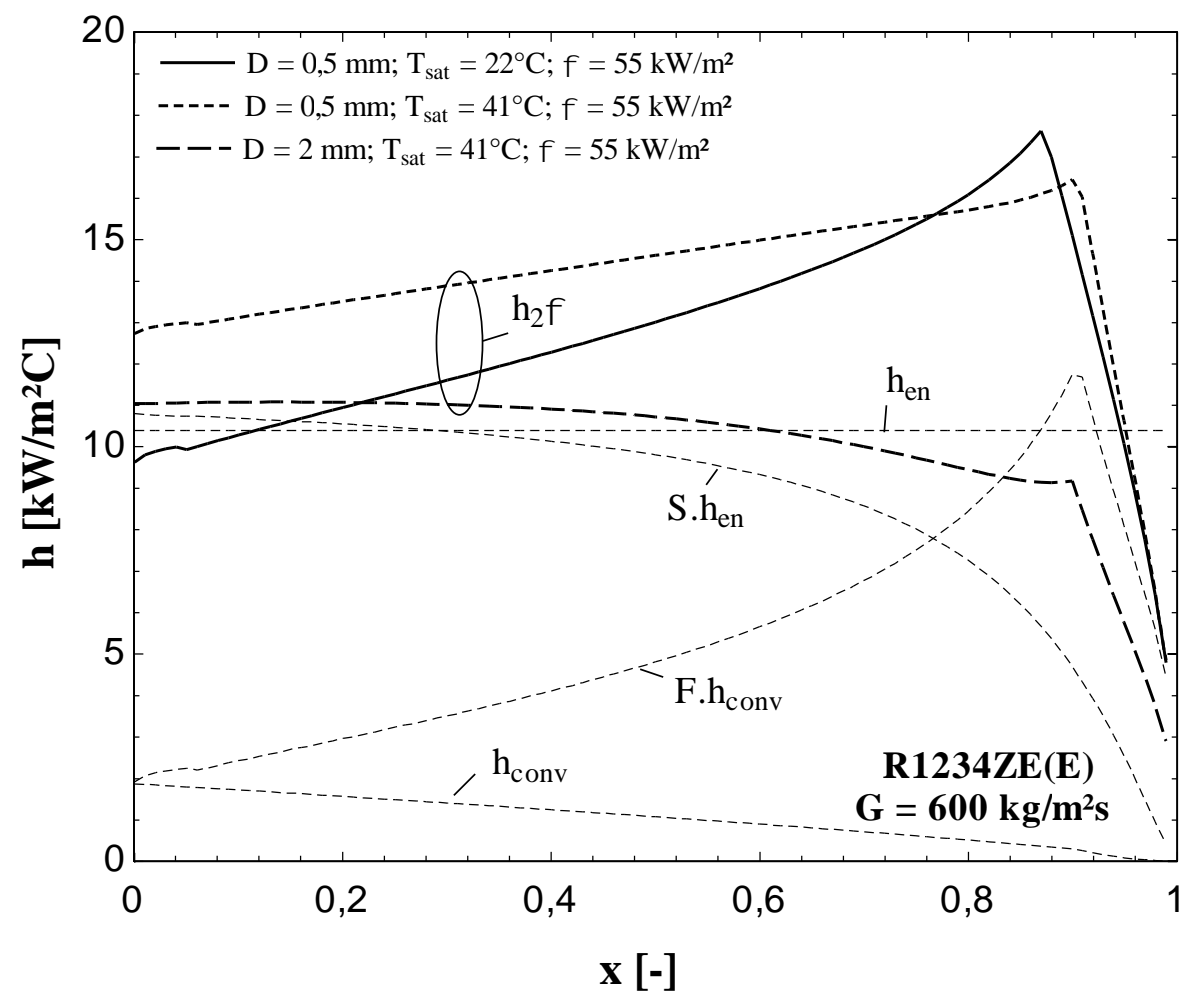

Figura 4.6. Contribuções ao CTC das parcelas convectiva e de ebulição nucleada segundo o método proposto por Kanizawa et al. (2016). 
Conforme ilustrado na Figura 4.6, o CTC segundo o método de Kanizawa et al. (2016) compõe-se predominante da contribuição dos efeitos de ebulição nucleada para títulos de vapor inferiores a 0,7 , a partir do qual efeitos convectivos passam a ser predominantes. Esta figura ilustra também o incremento do CTC com o acréscimo da temperatura de saturação para uma ampla faixa de títulos de vapor. Este comportamento se inverte para condições de títulos de vapor próximos à secagem de parede. Já, com o decréscimo do diâmetro de 2 para $0,5 \mathrm{~mm}$, o coeficiente de transferência de calor se eleva conforme indicado pela maioria dos estudos experimentais da literatura, segundo Ribatski (2013).

A Tabela 4.6 compara os comportamentos para o coeficiente de transferência de calor com a variação dos parâmetros experimentais indicados com maior frequência na literatura segundo Ribatski (2013) com aqueles fornecidos pelos métodos de previsão listados na tabela anterior e os métodos para canais convencionais de Chen (1963) e Liu e Winterton (1991).

Tabela 4.6. Comparação entre os comportamentos do CTC segundo os métodos baseados na superposição de efeitos.

\begin{tabular}{c|c|c|c|c}
\hline Autor (es) & $\mathbf{G} \uparrow \rightarrow \mathbf{h} \uparrow$ & $\phi \uparrow \rightarrow \mathbf{h} \uparrow$ & $\mathbf{T}_{\text {sat }} \uparrow \rightarrow \mathbf{h} \uparrow$ & $\mathbf{D} \downarrow \rightarrow \mathbf{h} \uparrow$ \\
\hline Chen (1966) & $\checkmark$ & $\checkmark$ & $\checkmark$ & $\checkmark$ \\
Liu e Winterton (1991) & $\checkmark$ & $\checkmark$ & $\mathbf{X}$ & $\checkmark$ \\
Zhang et al. (2004) & $\checkmark$ & $\checkmark$ & $\checkmark$ & $\mathbf{X}$ \\
Saitoh et al. (2007) & $\checkmark$ & $\checkmark$ & $\checkmark$ & $\mathbf{X}$ \\
Bertsch et al. (2009) & $\checkmark$ & $\checkmark$ & $\checkmark$ & $\mathbf{X}$ \\
$\begin{array}{l}\text { Oh et al. (2011) } \\
\text { Kim e Mudawar (2013a) }\end{array}$ & $\checkmark$ & $\checkmark$ & $\mathbf{X}$ & $\mathbf{X}$ \\
$\begin{array}{l}\text { Mahmoud e Karayiannis } \\
\text { (2013) }\end{array}$ & $\checkmark$ & $\checkmark$ & $\checkmark$ & $\checkmark / \mathbf{X}$ \\
Kanizawa et al. (2015) & $\checkmark$ & $\checkmark$ & $\checkmark$ & $\checkmark$ \\
\hline $\begin{array}{l}\text { * } \checkmark \rightarrow \text { Prevê o comportamento indicado como mais frequente na literatura por Ribatski (2013) } \\
\mathbf{X} \rightarrow \text { Não prevê o comportamento indicado como mais frequente na literatura por Ribatski (2013). }\end{array}$
\end{tabular}

Conforme indicado na Tabela 4.6, todos os métodos preveem o incremento do CTC com o acréscimo do fluxo de calor. Os métodos de Oh et al. (2011), Liu e Winterton (1991) não capturam o comportamento típico na literatura segundo o qual o CTC se eleva 
com o acréscimo da temperatura de saturação. Os métodos de Chen (1966), Liu e Winterton (1991), Kim e Mudawar (2013a) e Kanizawa et al. (2015) preveem satisfatoriamente o incremento do CTC com a redução do diâmetro do canal.

\subsubsection{Métodos fenomenológicos para previsão do CTC}

Com o intuito de capturar aspectos fenomenológicos relacionados à distribuição das fases, foram propostos na literatura métodos de previsão baseados em padrões de escoamento. Estes métodos incorporam características especificas dos padrões na modelagem do coeficiente de transferência de calor.

\section{Canais convencionais}

Kattan et al (1998) modificado por Wojtan et al. (2005)

Wojtan et al. (2005) modificaram o método de previsão do CTC proposto inicialmente por Kattan et al. (1998). Ambos os métodos elaborados pelo grupo do Professor John R. Thome foram desenvolvidos para canais convencionais e buscam descrever o processo de transferência de calor segundo os mecanismos predominantes em cada padrão. Neste método o CTC local médio ao longo do perímetro do duto é dado por:

$$
h_{2 \phi}=\frac{\theta_{\sec o} h_{G}+\left(2 \pi-\theta_{\text {seco }}\right) \cdot h_{\text {molhado }}}{2 \pi}
$$

onde $\theta_{\text {seco }}$ é o ângulo correspondente ao perímetro do tubo em contato com a fase vapor, conforme ilustrado na Figura 3.6, $h_{G}$ é o coeficiente de transferência de calor assumindo apenas a parcela de vapor no duto calculado segundo Dittus-Boelter e $h_{\text {molhado }}$ é dado do modelo assintótico com o expoente $\mathrm{n}$ igual a 3 , referido ao filme líquido, conforme a seguinte equação:

$$
h_{\text {molhado }}=\left(h_{\text {conv }}^{3}+h_{e b}^{3}\right)^{1 / 3}
$$

onde o CTC devido a efeitos de ebulição nucleada é dado por Cooper (1984) e o convectivo é calculado para o filme líquido, através das seguintes correlações:

$$
h_{\text {conv }}=0,0133 \operatorname{Re}_{\delta}^{0,69} \operatorname{Pr}_{L}^{0,4} \frac{k_{L}}{\delta}
$$




$$
\delta=\frac{\pi D(1-\alpha)}{2\left(2 \pi-\theta_{\operatorname{seco} o}\right)}
$$

onde a fração de vazio é estimada através da correlação de Steiner (1993), dada pelas Eqs. 2.37 e 2.38 .

No caso do padrão nevoa, o coeficiente de transferência de calor para o padrão nevoa é calculado a partir da seguinte relação:

$$
h_{\text {nevoa }}=0,0117 \operatorname{Re}_{H}^{0,79} \operatorname{Pr}_{G}^{1,06}\left[1-0,1 \cdot\left[\left(\frac{\rho_{L}}{\rho_{G}}-1\right)(1-x)\right]^{0,4}\right]^{-1,83} \frac{k_{G}}{D}
$$

Considerando que a secagem de parede ocorre progressivamente, o coeficiente de transferência de calor para esta faixa é calculado mediante a interpolação linear entre o CTC dado pela Eq. 4.16 e o CTC para o padrão nevoa.

\section{Microcanais}

\section{Thome et al. (2004)}

Thome et al. (2004) propuseram um modelo mecanicista para a previsão do coeficiente de transferência de calor segundo o padrão bolhas alongadas. No seu modelo, os autores descrevem o processo de transferência de calor local transiente durante a passagem de uma bolha em um duto de dimensões reduzidas. Eles identificam 3 zonas de transferência de calor caracterizados por uma região seca (ou pistão de gás), região da bolha alongada contendo um filme líquido aprisionado entre o pistão de vapor e a superfície do canal e o pistão de líquido, como ilustrado na Figura 4.7.

O modelo envolve basicamente os seguintes mecanismos de transferência de calor: $i$ ) condução transiente através do filme líquido e evaporação na interface durante a passagem da bolha alongada; ii) convecção forçada para o vapor com a secagem de parede do filme líquido; iii) convecção forçada para a fase líquida durante a passagem do pistão de líquido. A partir daí, o coeficiente de transferência local é dado pela soma dos coeficientes de calor proporcionados por estes mecanismos, ponderados pela parcela de tempo durante o ciclo de passagem de uma bolha (tempo de passagem de uma bolha 
alongada + pistão de líquido) em que cada mecanismo se apresentam, conforme a seguinte equação:

$$
h_{2 \phi}=\frac{t_{L}}{\tau} \cdot h_{L}+\frac{t_{\text {filme }}}{\tau} \cdot h_{\text {filme }}+\frac{t_{G}}{\tau} \cdot h_{G}
$$

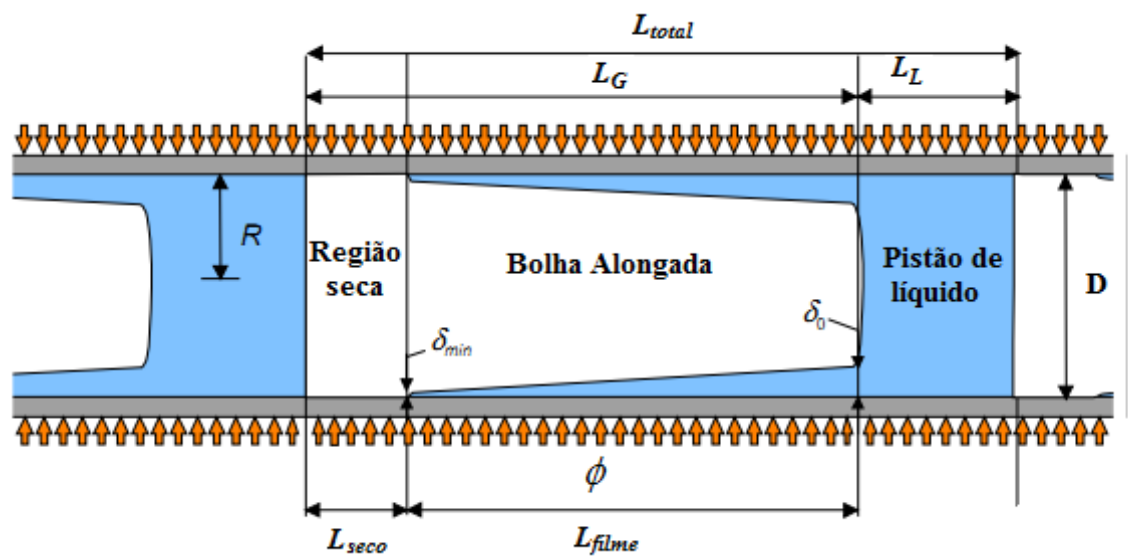

Figura 4.7. Diagrama ilustrativo do modelo de 3 zonas proposto por Thome et al. (2004).

Neste método, o cálculo do coeficiente de transferência de calor monofásico para o regime turbulento é realizado mediante a correlação de Gnielinski (1976) e para o regime laminar através da correlação de Shah e London (1978) para escoamento em desenvolvimento.

O coeficiente de transferência de calor no filme líquido é dado por:

$$
h_{\text {filme }}=\frac{k_{L}}{\delta_{o}-\delta_{\text {final }}} \ln \left(\frac{\delta_{o}}{\delta_{\text {final }}}\right) \text {, }
$$

onde a espessura do filme líquido é estimada através da equação:

$$
\frac{\delta_{o}}{D}=C_{\delta_{o}}\left[3 \sqrt{\frac{v_{L}}{u_{p} D}}\right]^{0,84} \cdot\left[\left(0,07 \cdot B d^{0,41}\right)^{-8}+0,1^{-8}\right]^{-1 / 8},
$$

A velocidade da bolha, $u_{p}$, é calculada assumindo o modelo homogêneo com os tempos referentes a cada mecanismo de transferência de calor dados por: 


$$
\begin{aligned}
& t_{L}=\frac{\tau}{1+\frac{\rho_{L}}{\rho_{G}} \cdot \frac{x}{1-x}} \\
& t_{G}=\frac{\tau}{1+\frac{\rho_{G}}{\rho_{L}} \cdot \frac{1-x}{x}} \\
& t_{\text {seco }}=t_{G}-t_{\text {filme }}
\end{aligned}
$$

A partir da equação de conservação da energia aplicada ao filme líquido tem-se o tempo máximo de passagem da bolha alongada para que ocorra sua secagem:

$$
t_{\text {max }, \text { filme }}=\frac{\rho_{L} i_{L G}}{\phi} \cdot\left(\delta_{o}-\delta_{\min }\right),
$$

Caso $t_{\text {max } \text { filme }}$ seja superior ao tempo de passagem da bolha, $t_{G}$, a secagem do filme líquido não se verifica, resultando em:

$$
\delta_{\text {final }}=\delta_{o}-\frac{\phi \cdot t_{\text {filme }}}{\rho_{L} h_{L G}} \quad \text { e } \quad t_{\text {filme }}=t_{G}
$$

Caso $t_{\max , \text { filme }}$ seja inferior ao tempo de passagem de bolha, verifica-se:

$$
\delta_{\text {final }}=\delta_{\text {min }} \quad \text { e } \quad t_{\text {filme }}=t_{\text {max }, \text { filme }}
$$

Sendo $\tau$, o período necessário ao ciclo de uma bolha dado pela seguinte equação:

$$
\tau=\left(\frac{C_{q} \operatorname{Pr}^{n_{q}}}{\phi}\right)^{-n_{f}}
$$

Onde $C_{q}, n_{q}, n_{f}, \delta_{\text {min }}$, e $C_{\delta o}$ são constantes ajustadas com base em banco de dados experimentais levantados na literatura. A partir de 5 laboratórios independentes incluindo resultados para canais únicos e multicanais, 6 fluidos refrigerantes $(\mathrm{R} 11, \mathrm{R} 12, \mathrm{R} 113$, R123, R134a, R141b e $\mathrm{CO}_{2}$ ), diâmetros hidráulicos entre 0,77 e 3,1 mm, velocidades mássicas entre 50 e $574 \mathrm{~kg} / \mathrm{m}^{2} \mathrm{~s}$, pressões de saturação entre 1,24 e 57,66 bar, fluxos de calor de 5 a $178 \mathrm{~kW} / \mathrm{m}^{2}$ e títulos de vapor entre 0,01 e 0,99 . Vale mencionar que para títulos de vapor intermediários e elevados em canais de diâmetro reduzido verifica-se o 
padrao anular e não bolhas alongadas. Logo resultados para tais condições não deveriam constar no banco de dados utilizado pelos autores para o ajuste dos seus coeficientes.

A Figura 4.8 ilustra o efeito do diâmetro e da temperatura de saturação no coeficiente de transferência de calor segundo o método de previsão de Thome et al. (2004). As curvas do CTC com a variação do título de vapor apresentam um pico para títulos de vapor reduzidos $(\mathrm{x}<0,04)$, posteriormente, o coeficiente de transferência de calor decresce com o acréscimo do título de vapor. Como observado na figura, o coeficiente de transferência de calor se eleva em aproximadamente $20 \%$ com o incremento da temperatura de saturação de 22 a $41{ }^{\circ} \mathrm{C}$, mantendo-se as demais condições experimentais. Segundo este modelo, com a redução do diâmetro de 3 para $0,5 \mathrm{~mm}$ o CTC decresce significativamente, efeito contrário ao reportado por resultados experimentais da literatura.

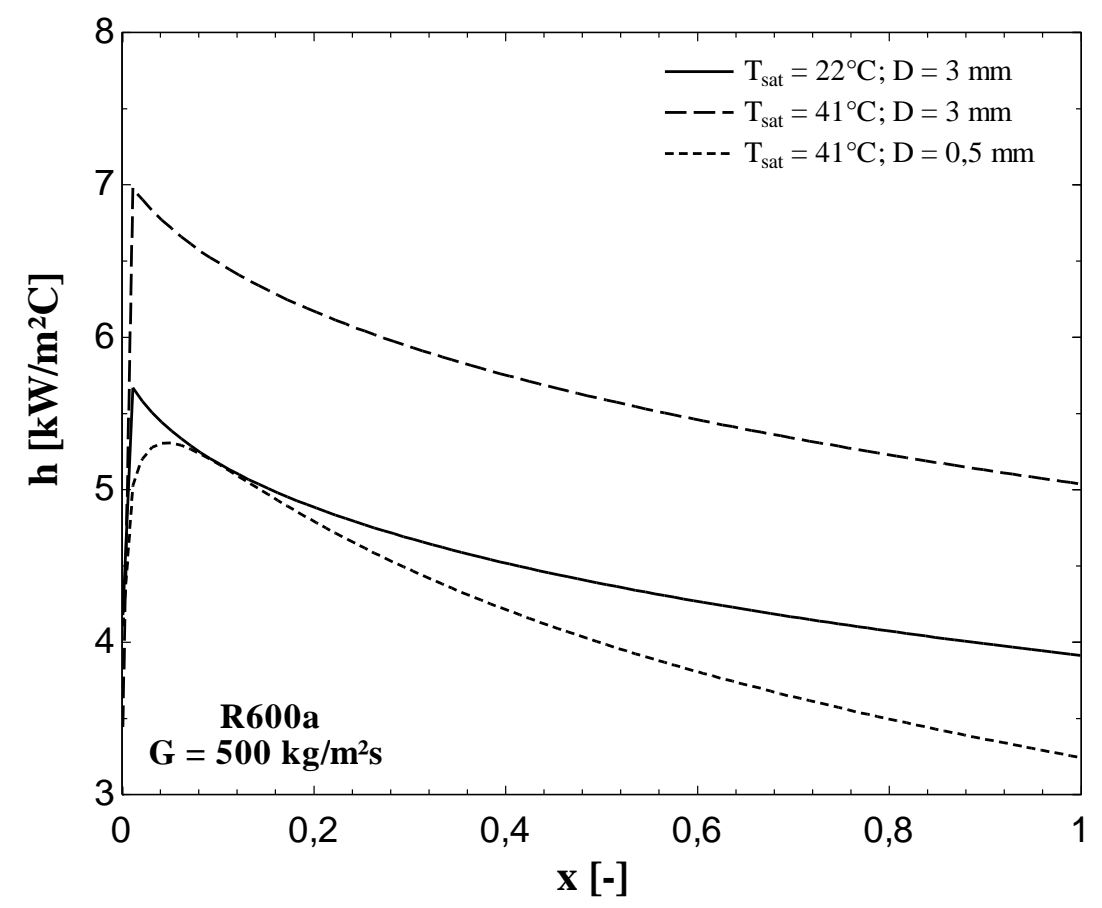

Figura 4.8. Efeito do diâmetro e da temperatura de saturação no método de previsão de Thome et al. (2004), R134a, G $=500 \mathrm{~kg} / \mathrm{m}^{2} \mathrm{~s}, \phi=20 \mathrm{~kW} / \mathrm{m}^{2}$.

\section{Cioncolini e Thome (2011)}

Cioncolini e Thome (2011) desenvolveram um modelo algébrico de turbulência durante a ebulição convectiva para o padrão de escoamento anular. A Figura 4.9 ilustra esquematicamente um escoamento anular típico, com a presença de filme líquido junto a parede e na região central o escoamento da fase gasosa. Os autores consideram que devido 
ao fato da velocidade do núcleo gasoso ser superior a do líquido, ondulações se formam no filme a partir das quais gotículas se desprendem.

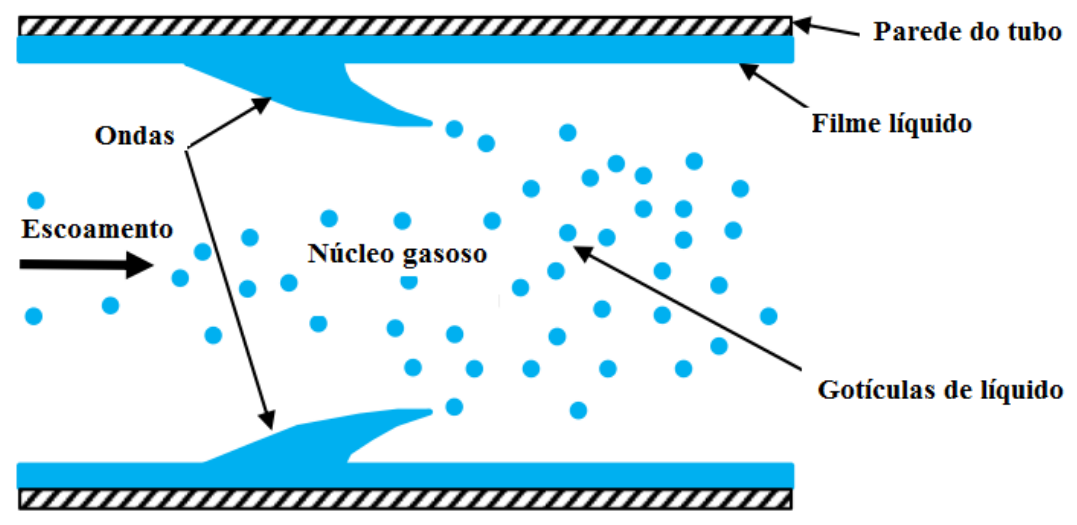

Figura 4.9. Representação esquemática de escoamento anular, Cioncolini e Thome (2011).

O método é baseado na estimativa da espessura do filme, que para canais circulares e de reduzido diâmetro os autores consideram uniforme. O coeficiente de transferência de calor segundo este método é dado por:

$h_{2 \phi}=0,076 \cdot \frac{k_{L}}{\delta} \cdot\left(\delta^{+}\right)^{0,9} \cdot \operatorname{Pr}_{L}^{0,52}$

onde $\delta$ é a espessura do filme líquido, $\delta^{+}$é a espessura do líquido adimensional e ambas se relacionam de acordo com a seguinte equação:

$\delta=\frac{\mu_{L}}{\rho_{L} \sqrt{\tau_{p} / \rho_{L}}} \delta^{+}$

onde a espessura adimensional do filme líquido é dada por:

$\delta^{+}=\operatorname{Max}\left[\sqrt{\frac{2(1-e)(1-x) G D}{4 \mu_{L}}} ; 0,066 \frac{(1-e)(1-x) G D}{4 \mu_{L}}\right]$

com o fator de entranhamento, $e$, calculada em função do número de Weber do núcleo gasoso como indicado por Cioncolini e Thome (2010): 
$e=\left(1+279,6 \cdot W e_{\text {nucleo }}^{-0,8395}\right)^{-2,209}$

A tensão de cisalhamento na parede, $\tau_{w}$, é encontrada de acordo a seguinte relação:

$\tau_{p}=\frac{1}{2} f_{2 \phi} \rho_{\text {nucleo }} u_{\text {nucleo }}^{2}$

onde a fator de atrito é estimado através de:

$f_{2 \phi}=0,0172 \cdot W e_{\text {nucleo }}^{-0,372}$

A densidade do núcleo gasoso e o número de Weber do núcleo gasoso são respectivamente calculados através das relações:

$$
\begin{gathered}
\rho_{\text {nисleo }}=\frac{x+e(1-x)}{\frac{x}{\rho_{G}}+e\left(\frac{1-x}{\rho_{L}}\right)} \\
W e_{\text {nucleo }}=\frac{\rho_{\text {nucleo }} J_{G}^{2} D}{\sigma}
\end{gathered}
$$

\section{Costa-Patry e Thome (2012)}

Costa-Patry e Thome (2012) combinaram o método de previsão do coeficiente de transferência de calor das três zonas de Thome et al. (2004), para o padrão bolhas alongadas, e o modelo de Cioncoloni e Thome (2011) para a previsão do CTC para escoamento anular. A transição entre os padrões pistonado e anular é dada pela seguinte relação:

$$
x_{I A}=425 \cdot\left(\frac{\rho_{G}}{\rho_{L}}\right)^{0,1} \cdot \frac{B o^{1,1}}{C o^{0,5}}
$$

cujo ajuste envolveu dados próprios e resultados experimentais de Ong e Thome (2011) e Costa-Patry et al. (2011a), incluindo 4 fluidos refrigerantes (R134a, R245fa, R236fa e R1234ze(E)), diâmetros entre 0,146 e 3,04 mm e velocidades mássicas entre 100 e 1100 $\mathrm{kg} / \mathrm{m}^{2} \mathrm{~s}$. 
Vale mencionar que além de combinar os métodos de Thome et al. (2004) e Cioncolini e Thome (2011), Costa-Patry et al. (2012) sugeriram modificações para estes métodos. Para o modelo de 3 zonas, os autores propuseram o uso da rugosidade média do canal como espessura mínima do filme, $\delta_{\min }$, e modificaram a correlação para o coeficiente de transferência de calor do filme líquido (Eq. 4.22) com o intuito de evitar erros nos cálculos computacionais quando $\delta_{o} \simeq \delta_{\text {final }}$. A nova equação para o CTC do filme líquido é dada por:

$$
h_{\text {fime }}=\frac{k_{L}}{\delta_{o}-\delta_{\text {final }}+1 \times 10^{-9}} \cdot \ln \left(\frac{\delta_{o}}{\delta_{\text {final }}}\right)
$$

Costa-Patry et al. (2012) apresentam também uma modificação do método de Cioncolini e Thome (2011) para adaptá-lo a canais retangulares. Os autores sugerem estimar a área do filme líquido num canal retangular a partir da equação:

$$
A=\left(\frac{\pi}{4}\right) \cdot\left[D_{e q}^{2}-\left(D_{e q}-2 \cdot \delta\right)^{2}\right]
$$

onde a espessura do filme líquido é estimado através da equação:

$$
\delta=\frac{A}{2 \cdot(l+w)}
$$

onde $l$ e $w$, são os lados do canal retangular.

A Tabela 4.7 ilustra a análise dos comportamentos dos métodos baseados em aspectos fenomenológicos para canais convencionais e de dimensões reduzidas. Como observado na figura, todos os métodos capturam o incremento típico do coeficiente de transferência de calor com os aumentos da velocidade mássica e do fluxo de calor. $\mathrm{O}$ efeito do acréscimo do coeficiente de transferência de calor com o incremento da temperatura de saturação foi capturada adequadamente somente pelo método de Thome et al. (2004), enquanto que o efeito do acréscimo do coeficiente de transferência de calor com o decréscimo do diâmetro é capturado pelos métodos de Wojtan et al. (2005) e Cioncolini e Thome (2011). 
Tabela 4.7. Análise dos comportamentos dos métodos baseados em aspectos fenomenológicos.

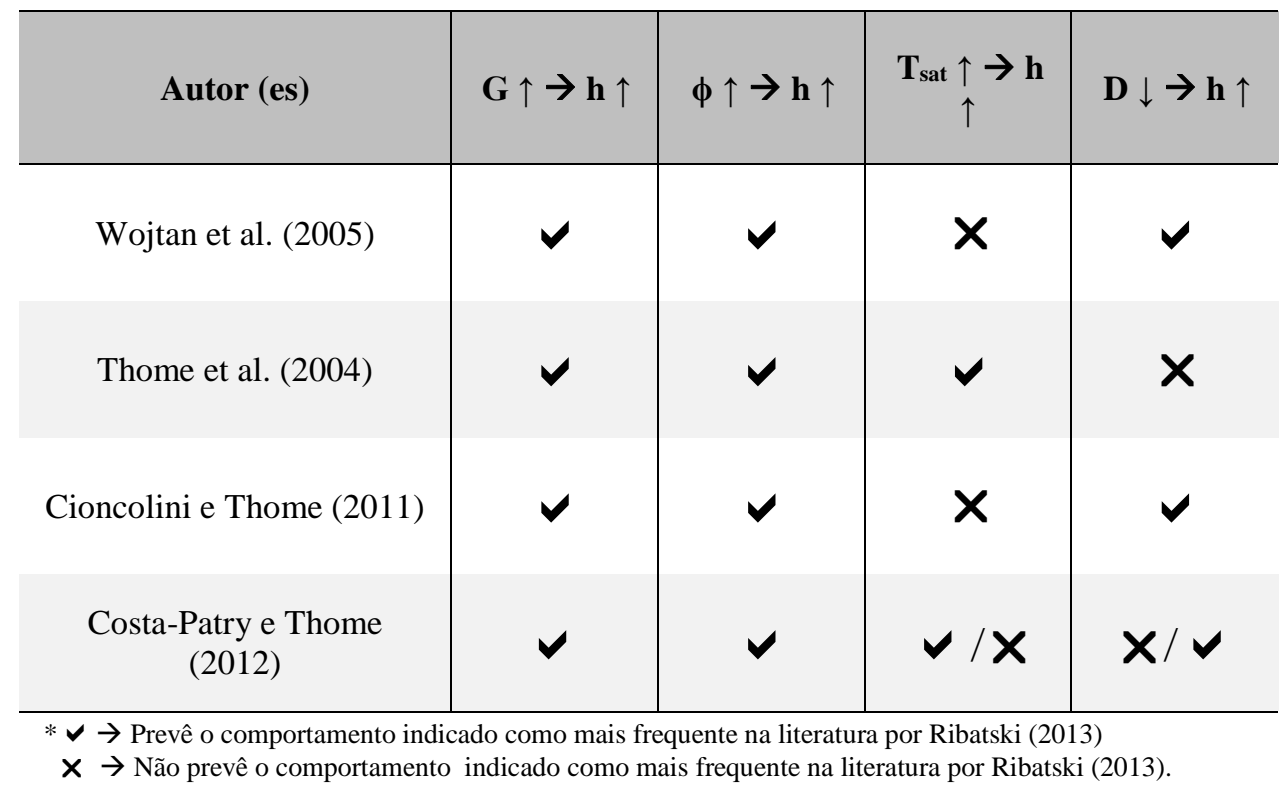

\subsubsection{Comparação das tendências fornecidas pelos métodos de previsão do CTC}

A Figura 4.10 ilustra a variação do coeficiente de transferência de calor com o título de vapor para o fluido R134a segundo os métodos de previsão estritamente empíricos. De uma forma geral constata-se que os métodos fornecem previsões significativamente distintas. Lazareck e Black (1982), Tran et al. (2006), Sun e Mishima (2009a) e Basu et al. (2011) proporcionam coeficiente de transferência de calor constante independentes do título de vapor. Já, o método de Warrier et al. (2002) e Li e Wu (2010) preveem o decréscimo do CTC com o aumento do título de vapor, enquanto que o método de Kew e Cornwell (1997) prevê o incremento do coeficiente de transferência de calor.

A Figura 4.11 ilustra uma comparação dos métodos de previsão baseados na superposição de efeitos, para os fluidos R134a e isobutano em condições experimentais similares. De maneira geral, constata-se que os métodos proporcionam tendências próximas para ambos os fluidos. 


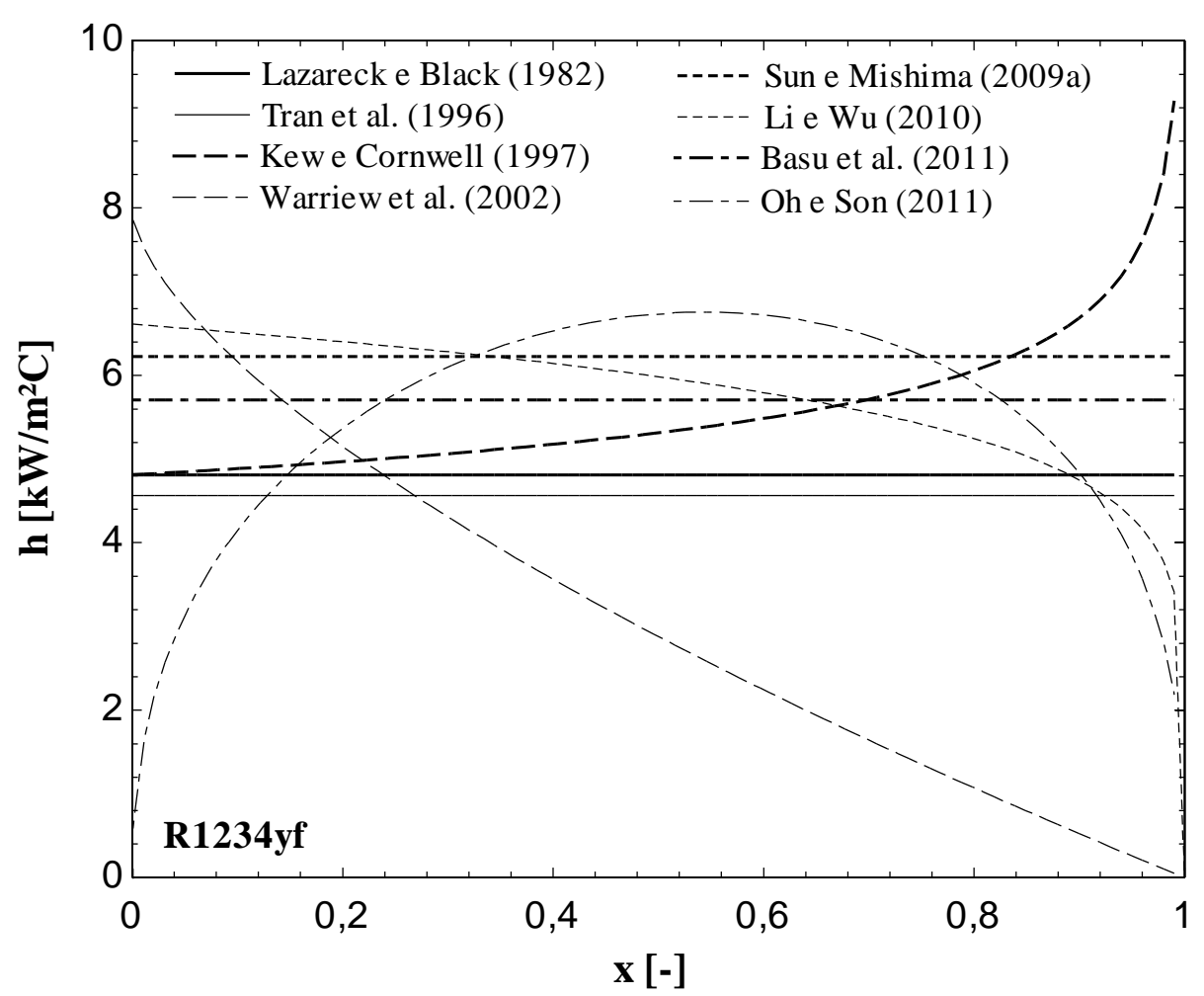

Figura 4.10. Comparação dos métodos empiricos de coeficiente de transferência de calor para microcanais, $\mathrm{G}=500 \mathrm{~kg} / \mathrm{m}^{2} \mathrm{~s}, \mathrm{D}=1,0 \mathrm{~mm}, \mathrm{~T}_{\mathrm{sat}}=31^{\circ} \mathrm{C}, \phi=15 \mathrm{~kW} / \mathrm{m}^{2}, \mathrm{R} 134 \mathrm{a}$.

De acordo com a Figura 4.11, o coeficiente de transferência de calor fornecido pelo método de Saitoh et al. (2007) apresenta descontinuidade para título de vapor de aproximadamente 0,4 , a partir dessa descontinuidade o coeficiente de transferência de calor se eleva continuamente com o incremento do título de vapor até atingir condições de secagem de parede. Os métodos de Zhang et al. (2004), Liu e Winterton (1991), Kim e Mudawar e Oh et al. (2011) preveem o acréscimo do coeficiente de transferência de calor com o incremento do título de vapor, enquanto que os métodos de Bertsch et al. (2009a) e Chen (1966) preveem o decréscimo do CTC para determinadas faixas do título de vapor.

Como ilustrado na Figura 4.11, é importante ressaltar que Kanizawa et al. (2016) e Saitoh et al. (2007) são os únicos métodos que consideram a estimativa do coeficiente de transferência de calor para condições posteriores à secagem de parede. Saitoh et al. (2007) proporciona um título de vapor de secagem de parede de aproximadamente 0,75 e 0,7 para o R134a e o R600a, respectivamente. Já Kanizawa et al. (2016) prevê títulos de secagem de parede de aproximadamente 0,9 para ambos os fluidos. 

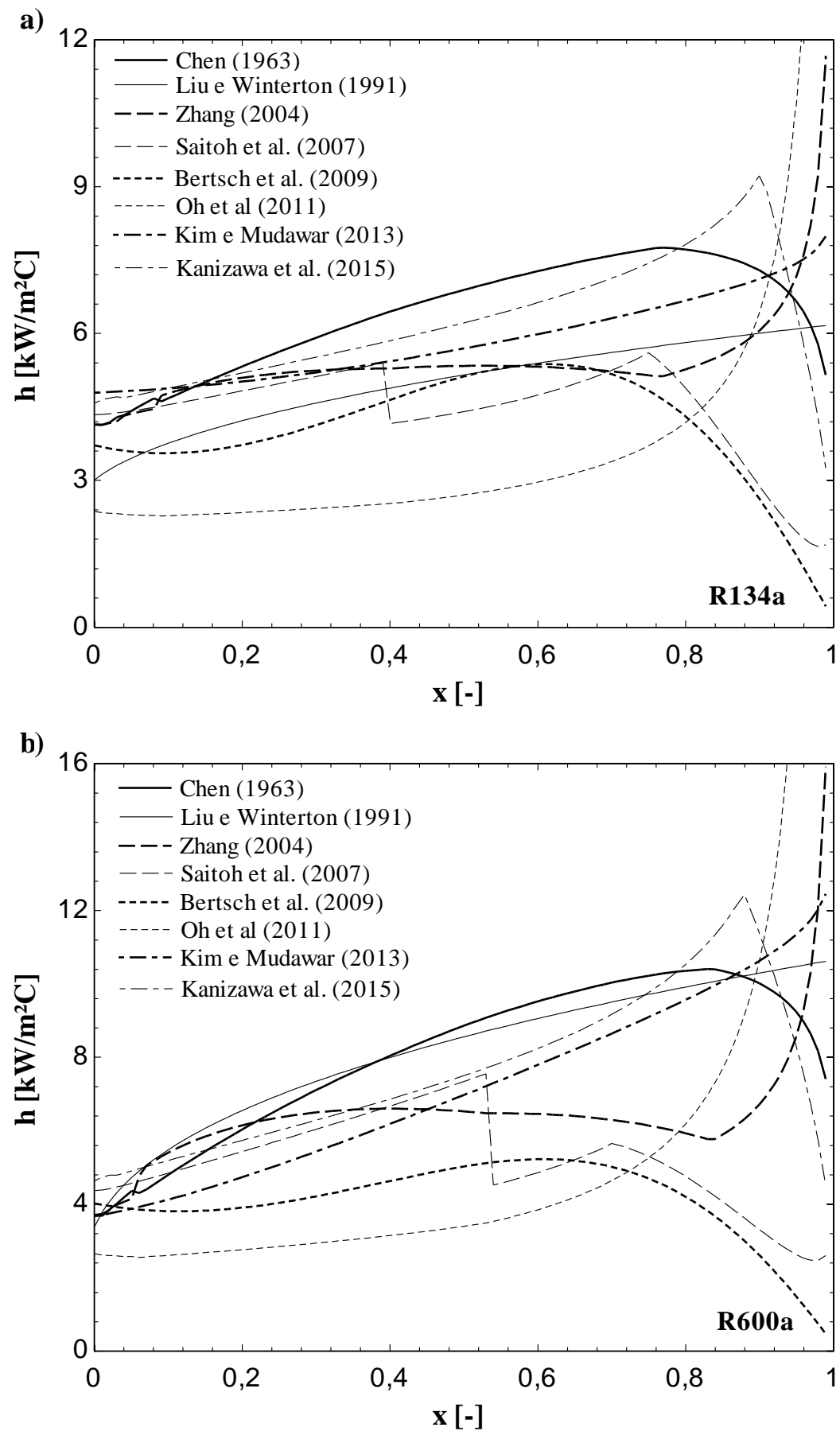

Figura 4.11. Comparação dos métodos de coeficiente de transferência de calor para microcanais, $\mathrm{G}=200$ $\mathrm{kg} / \mathrm{m}^{2} \mathrm{~s}, \mathrm{D}=1,0 \mathrm{~mm}, \mathrm{~T}_{\text {sat }}=22^{\circ} \mathrm{C}, \phi=15 \mathrm{~kW} / \mathrm{m}^{2}$, a) $\left.\mathrm{R} 134 \mathrm{a}, \mathrm{b}\right)$ Isobutano.

\subsection{Descrição dos estudos experimentais da literatura sobre o CTC}

A Tabela 4.8 descreve esquematicamente estudos sobre o coeficiente de transferência de calor em microcanais de geometria não-circular. Nesta tabela são apresentadas as seguintes informações referentes a cada estudo: dimensões dos canais, geometria, fator de forma (no caso de canais retangulares), número de canais, velocidades 
mássicas, títulos de vapor, temperatura de saturação, fluxo de calor e os fluidos de teste. É importante ressaltar que devido a razões já explicitadas em itens anteriores, parcela significativa destes estudos envolvem dissipadores de calor baseados em multimicrocanais.

Segundo a Tabela 4.8, a maioria dos estudos envolve refrigerantes halogenados como fluido de trabalho. Entretanto, investigações em número inferior se verificam para água, etanol, FC84, FC72, FC77, acetona e HTE7000 também ocorrem. Os estudos de Cortina-Diaz e Schmidt (2007), Costa-Patry et al. (2011a) e Costa-Patry et al. (2012) obtiveram resultados para canais retangulares com $\zeta<0,2$. Já, Do Nascimento et al. (2013b), Bertsch et al. (2009b), Agostini et al. (2008b), Leão et al. (2013), Kutnetsov et al. (2013), Leão et al. (2014), Lee et al. (2014), Leão et al. (2015) e Law e Lee (2015) investigaram canais retangulares $\operatorname{com} \zeta>2,5$.

Soupremanien et al. (2011) investigou o efeito do fator de forma na ebulição convectiva em canais retangulares para um diâmetro hidráulico fixo. Eles verificaram que com o incremento do fluxo de calor, canais com um mesmo diâmetro hidráulico mas apresentando maior fator de forma apresentam desempenho superior. Isto é, o canal com $\zeta=0,143$ apresentou coeficientes de transferência de calor superiores em condições de fluxo de calor reduzido, já o canal com $\zeta=0,43$ apresentou CTC superiores para condições de elevado fluxo de calor.

Hetsroni et al. (2005) estudaram os padrões de escoamento e o coeficiente de transferência de calor durante a ebulição convectiva de água num dissipador de calor baseado em multi-microcanais paralelos de seção triangular. Vale destacar que este estudo foi o único verificado na literatura envolvendo seções transversais triangulares. Hetsroni et al. (2005) observaram o decréscimo do coeficiente de transferência de calor com o incremento do título de vapor e condições de secagem de parede após a passagem da bolha alongada. Vale mencionar também que estes autores relataram o crescimento abrupto das bolhas alongadas para determinadas condições experimentais de fluxo de calor e velocidades mássicas. 
Tabela 4.8. Estudos sobre o coeficiente de transferência de calor em canais retangulares.

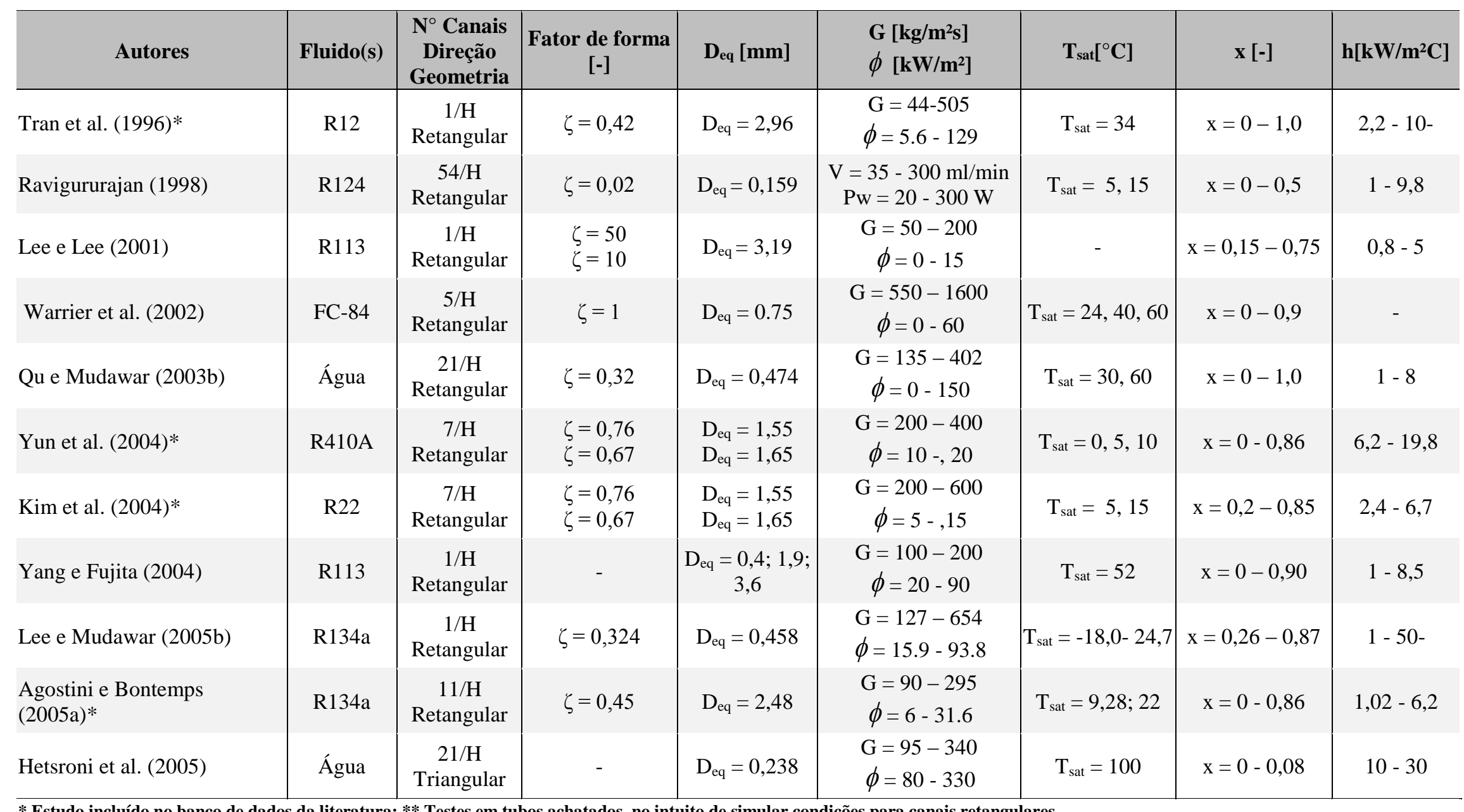

* Estudo incluído no banco de dados da literatura; ** Testes em tubos achatados, no intuito de simular condições para canais retangulares.

$\mathrm{H} \rightarrow$ Horizontal; VA $\rightarrow$ Vertical ascendente; VD $\rightarrow$ Vertical descendente; I $\rightarrow$ Inclinado 
Tabela 4.9 (Continuação). Estudos sobre o coeficiente de transferencia de calor em canais retangulares

\begin{tabular}{|c|c|c|c|c|c|c|c|c|}
\hline Autores & Fluido(s) & $\begin{array}{c}\mathbf{N}^{\circ} \text { Canais/ } \\
\text { Direção } \\
\text { Geometria }\end{array}$ & $\begin{array}{c}\text { Fator de forma } \\
{[-]}\end{array}$ & $\mathbf{D}_{\text {eq }}[\mathbf{m m}]$ & $\begin{array}{l}\mathbf{G}\left[\mathrm{kg} / \mathrm{m}^{2} \mathbf{s}\right] \\
\phi\left[\mathrm{kW} / \mathrm{m}^{2}\right]\end{array}$ & $\mathbf{T}_{\text {sat }}\left[{ }^{\circ} \mathbf{C}\right]$ & $\mathbf{x}[-]$ & $\mathrm{h}\left[\mathrm{kW} / \mathrm{m}^{2} \mathbf{C}\right]$ \\
\hline Sobierka et al. (2006)* & Água & $\begin{array}{c}1 / \mathrm{V} \\
\text { Retangular }\end{array}$ & $\zeta=0,43$ & $\mathrm{D}_{\mathrm{eq}}=1,48$ & $\begin{aligned} \mathrm{G} & =81-700 \\
\phi & =22-101\end{aligned}$ & $\mathrm{~T}_{\text {sat }}=91$ & $x=0-0,43$ & $6,09-16,8$ \\
\hline $\begin{array}{l}\text { Cortina-Diaz e Schmidt } \\
(2007)^{*}\end{array}$ & $\begin{array}{l}\text { Água/ } \\
\text { Etanol }\end{array}$ & $\begin{array}{c}1 / \mathrm{V} \\
\text { Retangular }\end{array}$ & $\zeta=0,024$ & $\mathrm{D}_{\mathrm{eq}}=2,2$ & $\begin{array}{l}G=50-500 \\
\phi=66,8-138\end{array}$ & $\mathrm{~T}_{\mathrm{sat}}=76$ & $x=0-0,64$ & $4,98-20,8$ \\
\hline Schneider et al. (2007) & $\mathrm{R} 123$ & $\begin{array}{c}5 / \mathrm{H} \\
\text { Retangular }\end{array}$ & $\zeta=0,79$ & $\mathrm{D}_{\mathrm{eq}}=0,259$ & $\begin{array}{c}\mathrm{G}=622-1368 \\
\phi=0-2130\end{array}$ & $\mathrm{~T}_{\mathrm{sat}}=38-79$ & $x=0-0,9$ & $1-13,8$ \\
\hline Kuo e Peles (2007) & Água & $\begin{array}{c}5 / \mathrm{H} \\
\text { Retangular }\end{array}$ & $\zeta=0,79$ & $\mathrm{D}_{\mathrm{eq}}=0,253$ & $\begin{aligned} G & =83-303 \\
\phi & =0-6430\end{aligned}$ & $\mathrm{~T}_{\mathrm{sat}}=100$ & $x=0-1$ & $3-14$ \\
\hline Agostoni et al. (2008b) & R245fa & $\begin{array}{c}\text { 67/H } \\
\text { Retangular }\end{array}$ & $\zeta=3,05$ & $\mathrm{D}_{\mathrm{eq}}=0,44$ & $\begin{array}{c}\mathrm{G}=280-1370 \\
\phi=34-1490\end{array}$ & $\mathrm{~T}_{\mathrm{sat}}=25$ & $x=0-0,92$ & $2,3-28,6$ \\
\hline Bertsch et al $(2009 b)^{*}$ & $\begin{array}{l}\mathrm{R} 134 \mathrm{a} \\
\mathrm{R} 245 \mathrm{fa}\end{array}$ & $\begin{array}{c}\text { 33/H } \\
\text { Retangular }\end{array}$ & $\zeta=2,5$ & $\mathrm{D}_{\mathrm{eq}}=0,674$ & $\begin{array}{c}\mathrm{G}=20-350 \\
\phi=0-220\end{array}$ & $\mathrm{~T}_{\mathrm{sat}}=8-30$ & $x=0-0,9$ & $1,4-14$ \\
\hline Kaew-On et al. (2011) & $\mathrm{R} 134 \mathrm{a}$ & $\begin{array}{c}\text { 8-14/H } \\
\text { Retangular }\end{array}$ & $\zeta=1,25$ & $\begin{array}{c}\mathrm{D}_{\mathrm{eq}}=1,18 \mathrm{e} \\
1,26\end{array}$ & $\begin{array}{c}\mathrm{G}=300-800 \\
\phi=15-65\end{array}$ & $\mathrm{~T}_{\mathrm{sat}}=8,9 ; 21,55$ & $x=0-0,55$ & $4-19$ \\
\hline Soupremanian et al. (2011) & $\begin{array}{l}\text { Forane } \\
365 \mathrm{HX}\end{array}$ & $\begin{array}{c}1 / \mathrm{H} \\
\text { Retangular }\end{array}$ & $\begin{array}{l}\zeta=0,143 \\
\zeta=0,43\end{array}$ & $\begin{array}{c}\mathrm{D}_{\mathrm{eq}}=1,72 \mathrm{e} \\
2,38\end{array}$ & $\begin{array}{c}\mathrm{G}=200-400 \\
\phi=2,3-160\end{array}$ & $\mathrm{~T}_{\mathrm{sat}}=39,56$ & $x=0-1$ & $0-10$ \\
\hline Harirchian e Garimella (2012) & FC-77 & $\begin{array}{c}\text { 2-61/H } \\
\text { Retangular }\end{array}$ & $0,1-5,85 \times 0,4$ & $\begin{array}{c}\mathrm{D}_{\mathrm{eq}}=0,22 \mathrm{a} \\
1,73\end{array}$ & $\begin{array}{c}\mathrm{G}=630 \\
\phi=0-250\end{array}$ & - & $x=0-0,9$ & $1-9$ \\
\hline Costa-Patry et al. (2011a)* & $\begin{array}{l}\text { R245fa } \\
\text { R236fa }\end{array}$ & $\begin{array}{c}\text { 135/H } \\
\text { Retangular }\end{array}$ & $\zeta=0,15$ & $D_{\text {eq }}=0,246$ & $\begin{array}{c}G=500-1051 \\
\phi=18,4-190\end{array}$ & $\mathrm{~T}_{\mathrm{sat}}=30,05$ & $x=0,03-0,53$ & $5,7-18$ \\
\hline Costa-Patry et al. (2012)* & $\begin{array}{c}\text { R134a } \\
\text { R245fa } \\
\text { R1234ze }\end{array}$ & $\begin{array}{c}\text { 52/H } \\
\text { Retangular }\end{array}$ & $\zeta=0,42$ & $\mathrm{D}_{\mathrm{eq}}=0,563$ & $\begin{array}{l}G=291-568 \\
\phi=130-1400\end{array}$ & $\mathrm{~T}_{\mathrm{sat}}=30,05 ; 50,7$ & $x=0-0,55$ & $5,69-27,2$ \\
\hline Fu etl al. (2013) & HFE-7100 & $\begin{array}{c}\text { 6/H } \\
\text { Retangular }\end{array}$ & $\begin{array}{c}\zeta=0,83 ; 0,99 \\
1,65 ; 2,47 \\
4,23 ; 6,06\end{array}$ & $\mathrm{D}_{\mathrm{eq}}=1,61$ & $\begin{array}{l}\mathrm{G}=39-180 \\
\phi=0-1140\end{array}$ & - & $x=0,1-0,97$ & $4-42$ \\
\hline
\end{tabular}

* Fstudo inclú́do no banco de dados da literatura; ** Testes em tubos achatados, no intuito de simular condições para canais retangulares.

$\mathrm{H} \rightarrow$ Horizontal; VA $\rightarrow$ Vertical ascendente; VD $\rightarrow$ Vertical descendente; I $\rightarrow$ Inclinado 
Tabela 4.9 (Continuação). Estudos sobre o coeficiente de transferencia de calor em canais retangulares

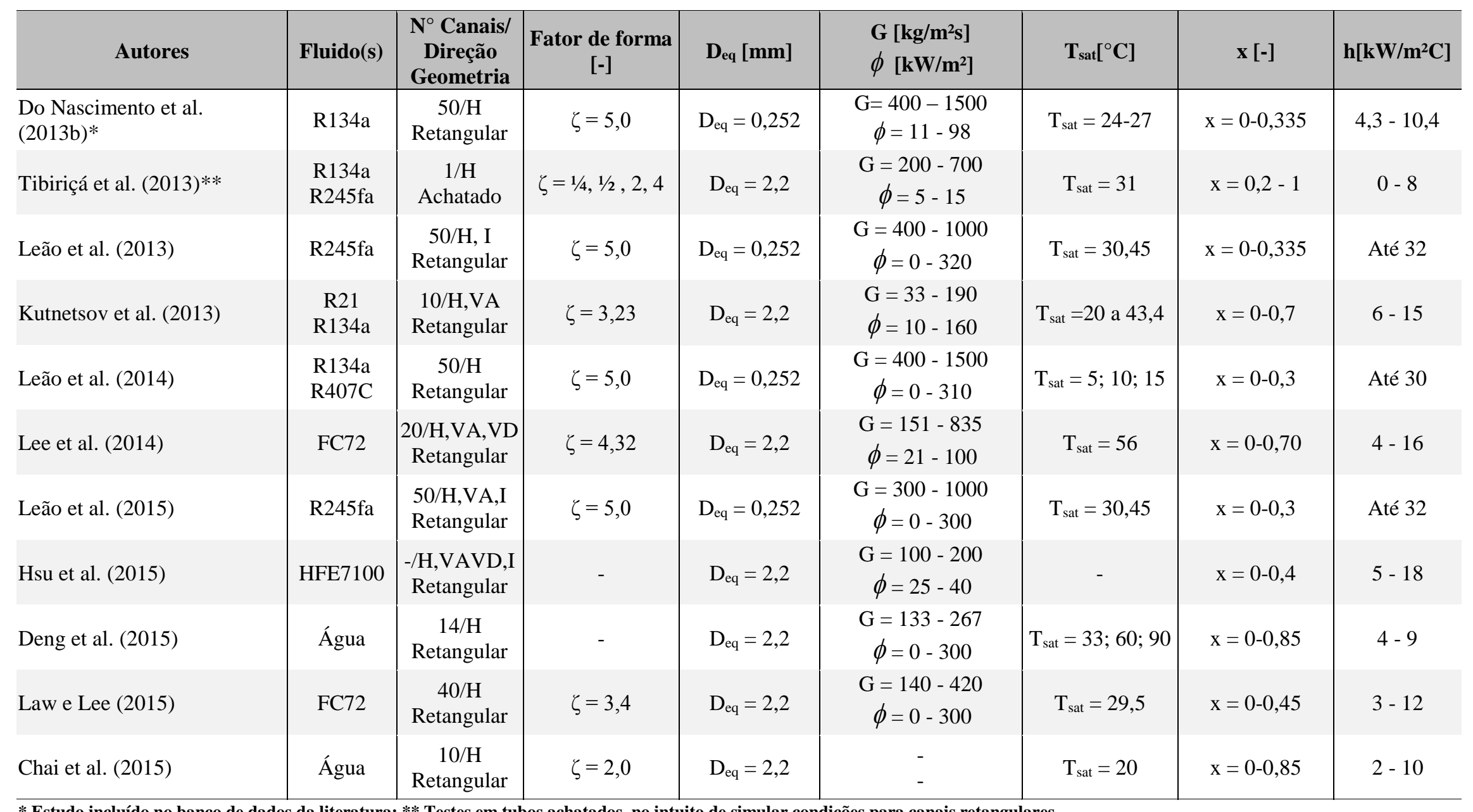

* Estudo inclú́do no banco de dados da literatura; ** Testes em tubos achatados, no intuito de simular condições para canais retangulares.

$\mathrm{H} \rightarrow$ Horizontal; VA $\rightarrow$ Vertical ascendente; VD $\rightarrow$ Vertical descendente; I $\rightarrow$ Inclinado 
Tibiriçá et al. (2013) investigaram o efeito da geometria do tubo no CTC mantendo o diâmetro equivalente do canal. A Figura 4.12 ilustra seus resultados para as geometrias nela indicadas, Constata-se comportamentos do coeficiente de transferência de calor com a variação do título de vapor similares para as três geometrias. Observa-se também que o coeficiente de transferência de calor para o canal achatado com fator de forma igual a $1 / 2$ apresenta valores de coeficiente de transferência de calor superiores aos CTCs do canal circular e do canal achatado com fator de forma $1 / 4$.

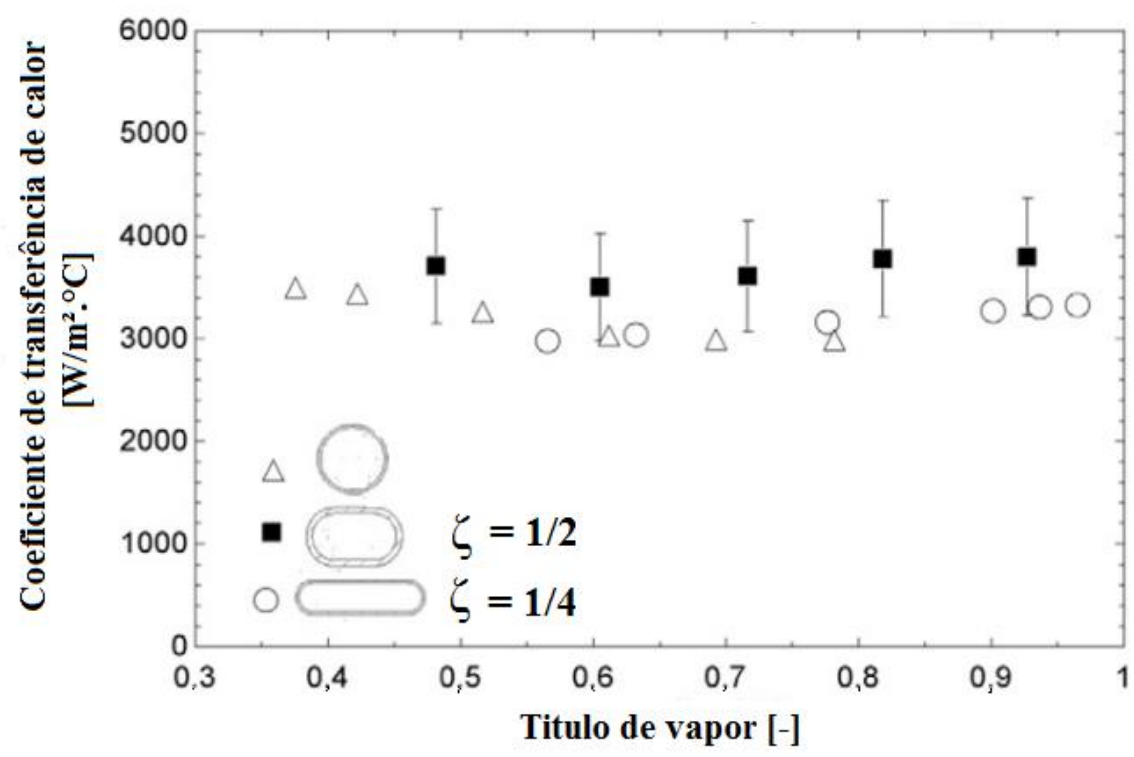

Figura 4.12. Efeito da geometria do canal no coeficiente de transferencia de calor, $\mathrm{R} 134 \mathrm{a}, \mathrm{G}=100$ $\mathrm{kg} / \mathrm{m}^{2} \mathrm{~s}, \mathrm{D}_{\mathrm{eq}}=2,2 \mathrm{~mm}, \phi=10 \mathrm{~kW} / \mathrm{m}^{2} \mathrm{e} \mathrm{T}_{\mathrm{sat}}=31^{\circ} \mathrm{C}$, Tibiriçá et al, (2013).

A Figura 4.13, também elaborada por Tibiriçá et al. (2013), ilustra o efeito da orientação do canal no coeficiente de transferência de calor. Segundo a Figura 4.13a, para velocidades mássicas reduzidas o tubo achatado com $\zeta=4$ apresenta condições de secagem de parede para um título de vapor aproximado de 0,6 , enquanto que para o tubo achatado $\operatorname{com} \zeta=1 / 4$, o coeficiente de transferência de calor mantém o comportamento de se elevar com o incremento do título de vapor. Para velocidades mássicas superiores, o efeito da orientação torna-se marginal conforme ilustrado na Figura 4.13b. A estratificação do filme líquido na parte inferior do tubo achatado vertical $(\zeta=4)$ é superior à estratificação do tubo achatado horizontal $(\zeta=1 / 4)$, o que ocasiona a secagem de parede antecipada na parte superior do tubo. Este fato provoca o decréscimo do coeficiente de transferência de calor para o tubo achatado com sua face orientada verticalmente $(\zeta=4)$, conforme ilustrado na Figura 4.13a. 

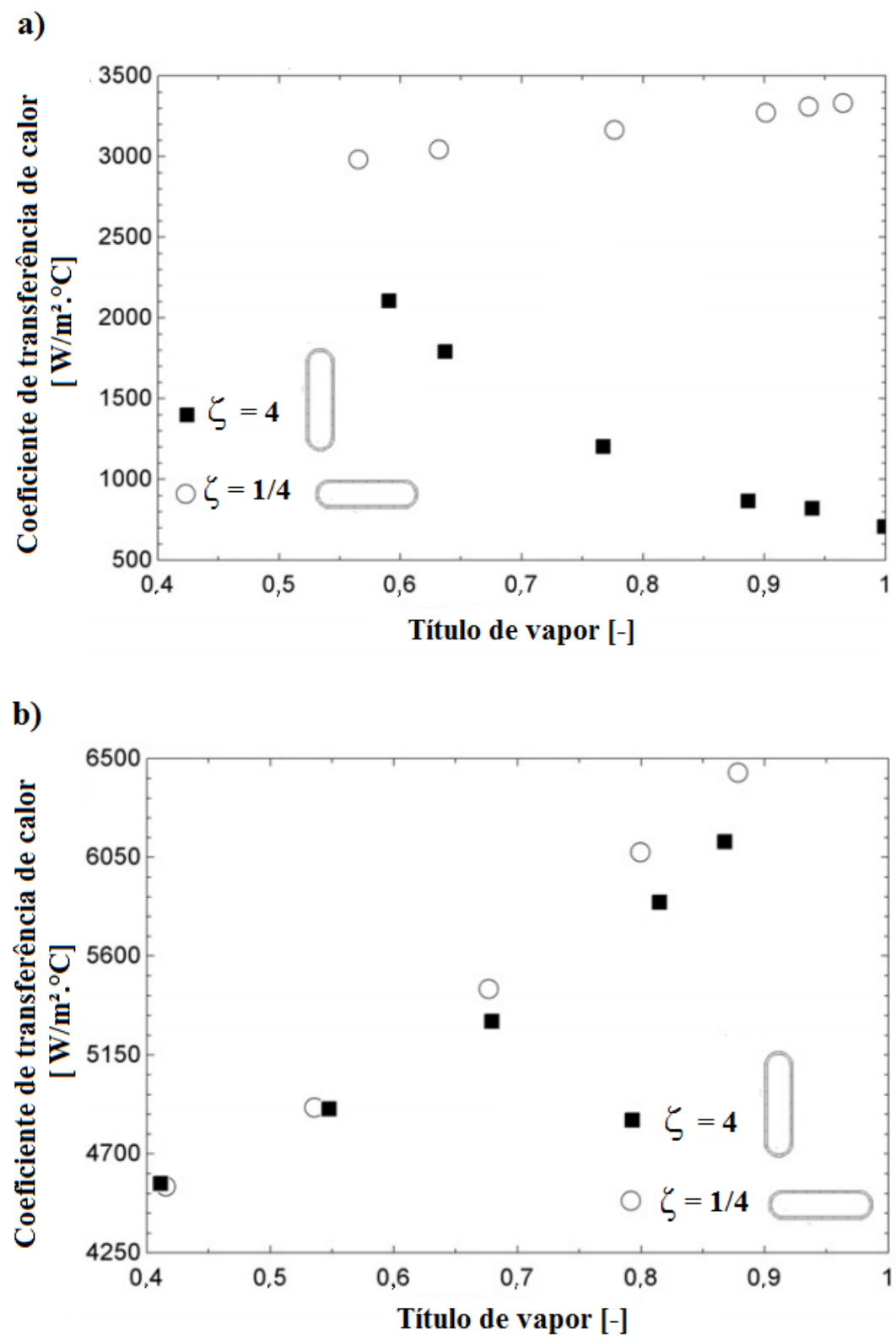

Figura 4.13. Efeito do fator de forma nos tubos achatados, Tibiriçá et al. (2013): a) $\mathrm{G}=100 \mathrm{hg} / \mathrm{m}^{2} \mathrm{~s}$ e $\phi=$ $\left.10 \mathrm{~kW} / \mathrm{m}^{2}, \mathrm{~b}\right) \mathrm{G}=400 \mathrm{hg} / \mathrm{m}^{2} \mathrm{~s}$ e $\phi=15 \mathrm{~kW} / \mathrm{m}^{2}$

A Figura 4.14 compara os resultados experimentais de Agostini et al. (2008b) e Costa-Patry et al. (2012), ambos levantados no laboratório da EPFL coordenado pelo Prof. Thome, para condições experimentais próximas, incluindo o diâmetro equivalente, no entanto com fatores de forma distintos. Nela constatam-se discrepâncias elevadas entre os resultados. Tal comportamento pode estar relacionada às diferenças entre os fatores de forma conforme indicado nos estudos de Choi et al. (2010), Choi et al. (2011), Soupremanien et al. (2011) e Tibiriçá et al. (2013). No entanto, vale destacar que os resultados indicados nesta figura foram obtidos para multicanais e assim tal hipótese tratase de especulação, pois em multi-microcanais, conforme mencionado por Tibiriçá e 
Ribatski (2013), vários outros aspectos podem conduzir a essa discrepância, destacam-se os seguintes: instabilidades térmicas, rugosidade do material a qual pode variar significativamente dado que a seção de teste de Costa-Patry et al. (2012) é de cobre e a de Agostini et al. (2008b) de silício, efeitos de entrada e saída na seção de teste e procedimentos experimentais e de tratamento de dados distinto.

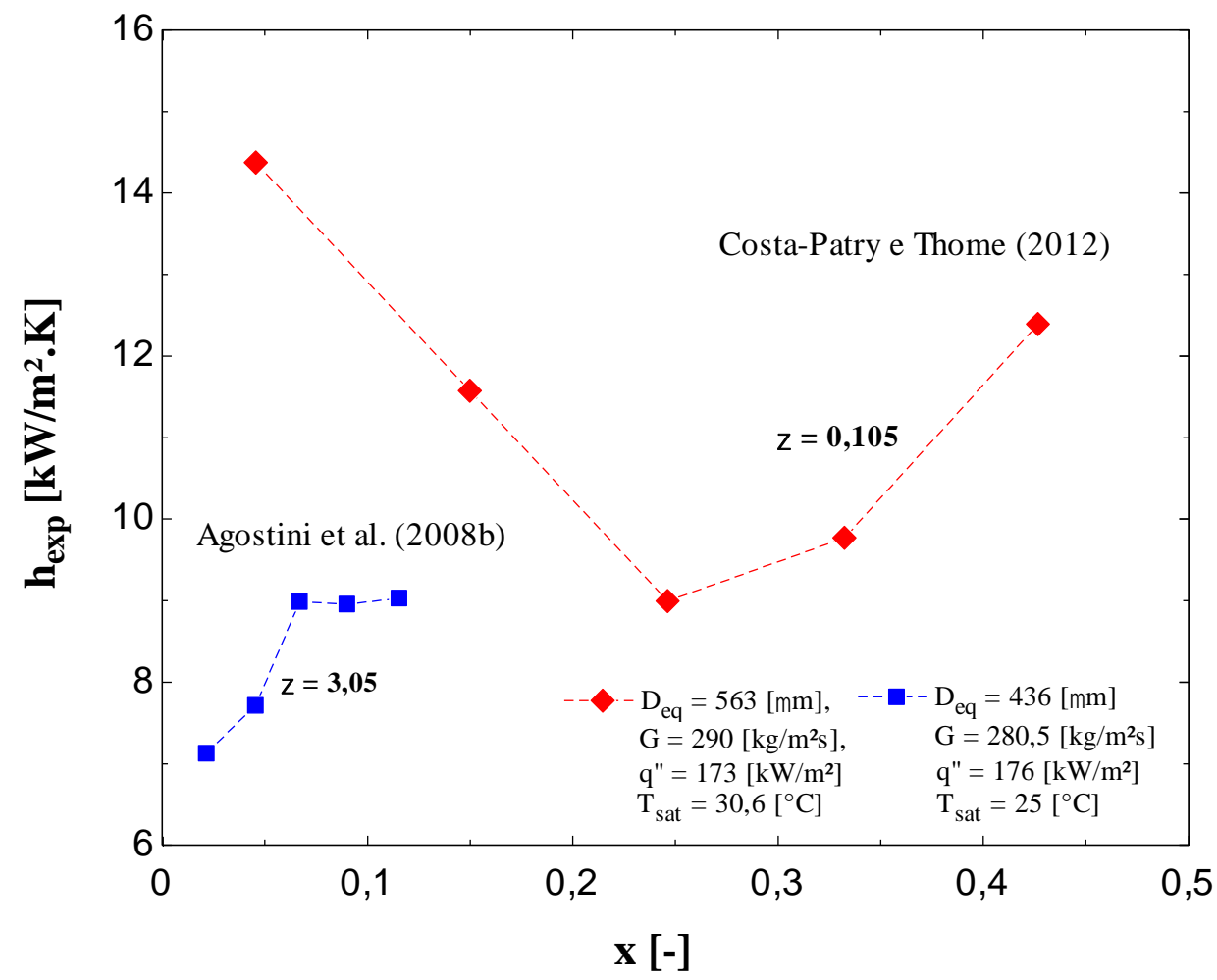

Figura 4.14. Comparação dos dados experimentais de Agostini et al. (2008b) e Costa-Patry et al. (2012) para condições experimentais proximas e fatores de forma distintos.

Comparações adicionais entre bancos de dados independentes, para condições experimentais próximas, visando a identificação de comportamentos coincidentes, não foram possíveis devido às diferenças entre condições experimentais de estudos distintos impossibilitando análises paramétricas.

Um banco de dados experimental foi levantado da literatura incluindo os estudos cujos autores estão indicados com * na Tabela 4.9, vale mencionar que este banco de dados so inclui dados para canais retangulares. Este banco de dados foi comparado com resultados fornecidos pelos métodos de previsão mais citados na literatura. De acordo com esta comparação, os métodos de Bertsch et al. (2009) e Liu e Winterton (1991) proporcionaram as melhores previsões com parcela de 45 e 46,5\% dos dados com desvios na faixa $\pm 30 \%$, respectivamente. Vale mencionar que embora apresentando os menores 
desvios as previsões proporcionadas por estes métodos ainda são insatisfatórias. A Figura 4.14 ilustra a comparação destes dois métodos com o banco de dados segregados segundo padrões de escoamento de acordo com o método de previsão de padrões proposto por Felcar et al. (2007). Como observado na figura, os métodos de previsão não capturam efeitos do padrão de escoamento.
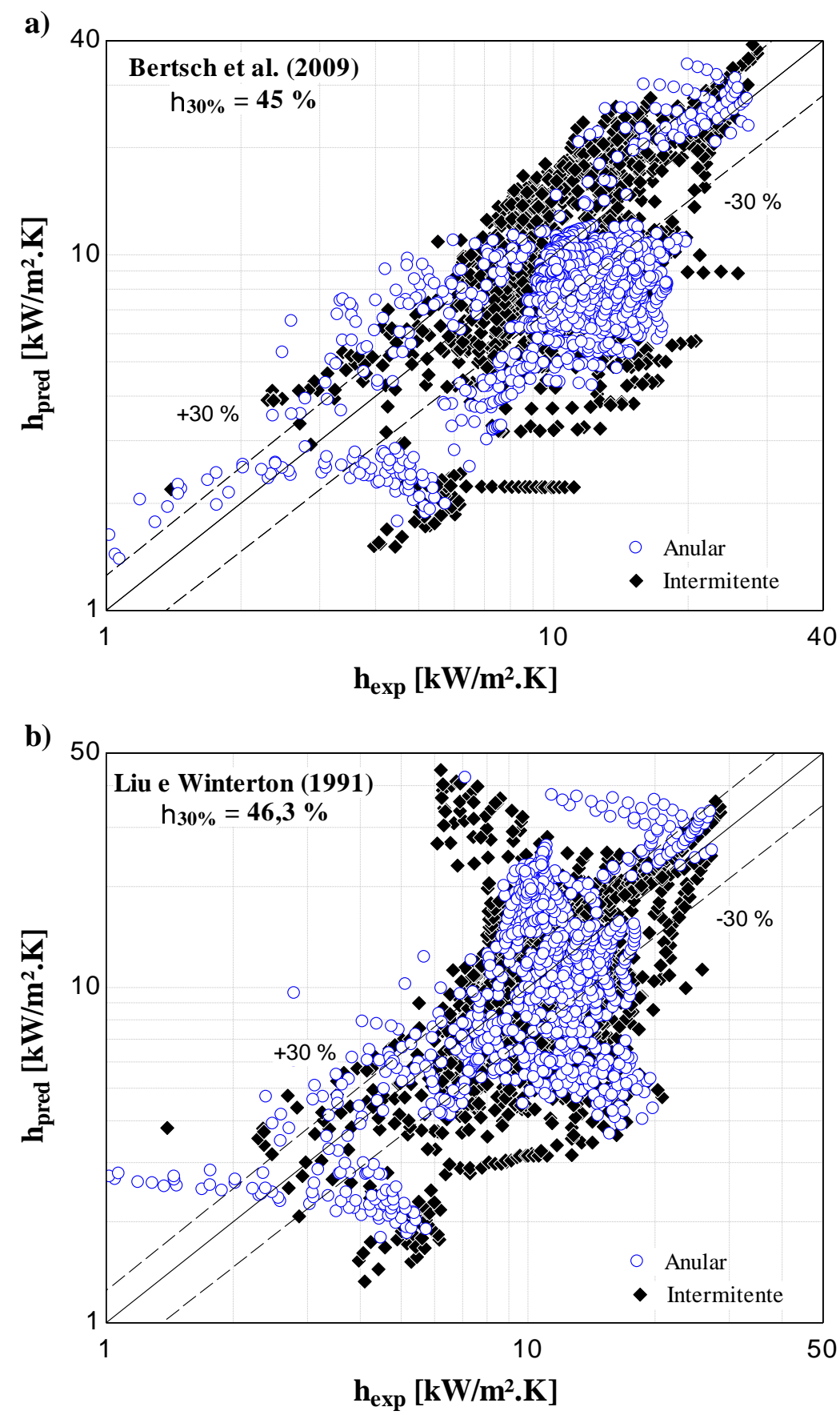

Figura 4.15. Comparação do banco de dados experimentais levantado na literatura com os métodos de previsao de: a) Bertsch (2009) e b) Liu e Winterton (1991). 
A comparação para canais retangulares com os dados segregados segundo faixas de fatores de forma revela que os métodos de previsão proporcionam resultados distintos de acordo com a faixa de fatores de forma. Segundo a Tabela 4.9, os métodos de Zhang et al. (2004), Liu e Winterton (1991) e Bertsch et al. (2009) proporcionam previsões satisfatórias para fatores de forma superiores a 2,5, prevendo entre 78 e $87 \%$ dos dados com desvios dentro da margem $\pm 30 \%$ e EMAs inferiores a $21 \%$. Resultados experimentais para fatores de forma entre 0,4 e 2,5 apresentam desvios superiores em relação aos métodos de previsão. A partir desta análise, especula-se que o fator de forma (ou características geométricas da seção transversal) é um aspecto a ser considerado para a previsão adequada do coeficiente de transferência de calor em canais retangulares (ou de outra geometria não-circular). Porém, como mencionado anteriormente, vários outros aspectos podem acarretar na discrepância entre resultados experimentais de distintos laboratórios e métodos de previsão.

Tabela 4.9. Erro médio absoluto (EMA) e a porcentagem de prediçoes dentro do $\pm 30 \%$ para diferentes faixas de fatores de forma.

\begin{tabular}{|c|c|c|c|c|c|c|c|}
\hline \multirow{2}{*}{$\begin{array}{c}\text { Faixa fatores } \\
\text { de forma }\end{array}$} & \multirow[t]{2}{*}{ \#Dados } & \multicolumn{2}{|c|}{$\begin{array}{c}\text { Liu e Winterton } \\
\text { (1991) }\end{array}$} & \multicolumn{2}{|c|}{$\begin{array}{c}\text { Zhang et al. } \\
\text { (2004) }\end{array}$} & \multicolumn{2}{|c|}{$\begin{array}{l}\text { Bertsch et al } \\
(2009 a)\end{array}$} \\
\hline & & $\eta$ & EMA & $\eta$ & EMA & $\eta$ & EMA \\
\hline$\zeta<0,1$ & 380 & 28 & 56 & 50 & 31 & 47 & 31 \\
\hline $0,1 \leq \zeta<0,4$ & 1141 & 54 & 31 & 44 & 30 & 40 & 36 \\
\hline $0,4 \leq \zeta<1,0$ & 361 & 20 & 88 & 27 & 58 & 35 & 36 \\
\hline $1,0 \leq \zeta<2,5$ & 100 & 12 & 57 & 14 & 56 & 20 & 48 \\
\hline$\zeta \geq 2,5$ & 335 & 78 & 20 & 82 & 21 & 87 & 16 \\
\hline Total & 2317 & 46 & 43 & 45 & 35 & 45 & 32 \\
\hline
\end{tabular}

A Tabela 4.10 lista os trabalhos experimentais disponíveis na literatura envolvendo o levantamento de resultados experimentais do coeficiente de transferência de calor para fluidos de reduzido GWP ou "naturais" em canais únicos de diâmetro reduzido. Ressalta-se o fato destes estudos envolverem apenas canais com seção transversal circular. Estudos para fluidos de reduzido GWP para microcanais únicos nãocirculares não foram verificados na literatura. 
Tabela 4.10. Estudos sobre o CTC para fluidos de reduzido GWP e naturais

\begin{tabular}{|c|c|c|c|}
\hline Autor(es) & Fluido & $\mathbf{D}[\mathbf{m m}]$ & $\begin{array}{c}\mathbf{G}\left[\mathrm{kg} / \mathrm{m}^{2} \mathrm{~s}\right] \\
\Phi\left[\mathrm{kW} / \mathrm{m}^{2} \mathrm{~s}\right] \\
\mathbf{x}[-]\end{array}$ \\
\hline Saitoh et al. (2011) & R1234yf & 2 & $\begin{array}{c}100-400 \\
6-24 \\
0-0,5\end{array}$ \\
\hline Li et al. (2012) & R1234yf & 2 & $\begin{array}{c}100-400 \\
6-24 \\
0,2-1\end{array}$ \\
\hline Mortada et al. (2012) & R1234yf & 1,1 & $\begin{array}{c}20-100 \\
2-15 \\
0-1\end{array}$ \\
\hline Del Col et al. (2013) & R1234yf & 0,96 & $\begin{array}{c}200-600 \\
15-65 \\
0-0.68\end{array}$ \\
\hline Copetti et al. (2013) & R600a & 2,6 & $\begin{array}{c}240-440 \\
44-95 \\
0-0,7\end{array}$ \\
\hline Choi et al. (2014) & $\begin{array}{c}\text { R290 } \\
\text { R1234yf }\end{array}$ & $\begin{array}{l}1,5 ; 3 \\
1,5 ; 3\end{array}$ & $\begin{array}{c}200-500 \\
5-25 \\
0-0,97\end{array}$ \\
\hline Anwar et al. (2015) & R1234yf & 1,6 & $\begin{array}{c}100-500 \\
5-130 \\
0-0,95\end{array}$ \\
\hline
\end{tabular}

Choi et al. (2014) e Copetti et al. (2013) levantaram resultados do coeficiente de transferência de calor para propano e isobutano, respectivamente. Ambos os estudos reportaram o decréscimo do coeficiente de transferência de calor a partir de títulos de vapor entre 0,3 e 0,4 , comportamento distinto do observado na literatura para outros fluidos para os quais decréscimos significativos no CTC ocorrem geralmente para títulos de vapor superiores a 0,8. Copetti et al. (2013) reportaram que o método para microcanais de Kandlikar e Balasubramanian (2004), versão modificada do método de Kandlikar (1990), proporcionou as melhores previsões de seus resultados para o isobutano, embora ainda insatisfatórias. Por outro lado, Choi et al. (2014) indicaram que o método para canais convencionais desenvolvido por Gungor e Winterton (1987), versão anterior do método de Liu e Winterton (1991), fornece as melhores do seu banco de dados para o propano, também um hidrocarboneto.

Saitoh et al. (2011), Li et al. (2012), Mortada et al. (2012), Del Col et al. (2013), Choi et al. (2014) e Anwar et al. (2015) levantaram resultados para o coeficiente de transferência de calor com o fluido R1234yf. Mortada et al. (2012) indicaram coeficientes de transferência de calor para o R1234yf cerca de $40 \%$ superiores aos valores observados 
para o R134a. Já Del Col et al. (2013) e Anwar et al. (2015) constataram valores similares para o coeficiente de transferência de calor destes fluidos. Mortada et al. (2012) verificou a predominância dos efeitos convectivos para o R1234yf, enquanto que Saitoh et al. (2011), Li et al. (2012) e Choi et al. (2014) indicaram a predominância dos efeitos de ebulição nucleada para os testes com o R1234yf.

É importante ressaltar a ausência de estudos na literatura sobre coeficiente de transferência de calor para o fluido R1234ze(E) em canais únicos de dimensões reduzidas. Já, para canais convencionais únicos, verificam-se os estudos de Grauso et al. (2013) e Diani et al. (2014).

\subsection{Conclusões}

As seguintes conclusões são formuladas a partir da análise da literatura apresentada neste capítulo:

> Entre os métodos de previsão estritamente empíricos, Lazareck e Black (1982), Kew e Cornwell (1997) e Sun e Mishima (2009a) são os que capturam os comportamentos do CTC com a variação dos parâmetros experimentais $\left(G, \phi, T_{s a t}, D\right)$ indicados como típicos por Ribatski (2013);

$>$ Entre os métodos de previsão baseados na superposição de efeitos, Chen (1966), Kim e Mudawar (2013a) e Kanizawa et al. (2016) são os que proporcionam os comportamentos adequados do CTC com a variação dos parâmetros experimentais $\left(G, \phi, T_{s a t}, D\right)$ indicados com maior frequência na literatura por Ribatski (2013);

$>$ Os métodos de previsão desenvolvidos baseados em dados experimentais para canais convencionais e de diâmetro reduzido apresentam divergências significativas quando comparados entre eles;

Apenas um trabalho experimental sobre o coeficiente de transferência de calor para canal triangular de dimensões reduzidas com refrigerantes foi verificadona literatura, apesar da ampla pesquisa realizada. Este estudo refere-se ainda a uma configuração de multi-microcanais;

Comparações entre bancos de dados independentes, para condições experimentais próximas, não são possíveis devido às diferenças entre 
condições experimentais de estudos distintos impossibilitando análises paramétricas;

No geral, nenhum dos métodos de previsão comparados com o banco de dados levantado na literatura forneceu previsões satisfatórias;

Resultados experimentais para multi-microcanais podem se diferenciar substancialmente de dados experimentais para canais únicos por vários aspectos como a interação entre canais vizinhos, efeito de mal-distribuição entre os canais relacionadas a configuração geométrica do plenum, efeito de restrições de dimensões distintas nas entradas dos canais a montante dos canais, possibilidade de escoamento reverso, instabilidades térmicas; O número de estudos disponíveis na literatura sobre coeficiente de transferência de calor em canais únicos de dimensões reduzidas para hidrocarbonetos é reduzido. Verificam-se para o R1234yf estudos em maior número, entretanto constatam-se divergências significativas entre resultados de laboratórios independentes. Já, para o R1234ze(E), resultados em canais únicos de dimensão reduzida para o CTC são inexistentes. 


\section{CAPÍTULO 5 - BANCADA E METODOLOGIA EXPERIMENTAL}

\subsection{Introdução}

Neste capítulo descreve-se o aparato experimental, seus componentes e a instrumentação utilizada. Também apresenta os procedimentos experimentais e de redução de dados, validação dos resultados experimentais e as incertezas experimentais.

\subsection{Bancada experimental}

A bancada experimental utilizada neste estudo encontra-se localizada no Laboratório de Engenharia Térmica e Fluidos no Departamento de Engenharia Mecânica da Escola de Engenharia de São Carlos (EESC - USP) e foi construída durante o doutoramento de Tibiriçá (2011), visando o estudo da ebulição convectiva de refrigerantes halogenados no interior de canais de diâmetro reduzido. Um registro fotográfico da bancada encontra-se ilustrado na Figura 5.1.

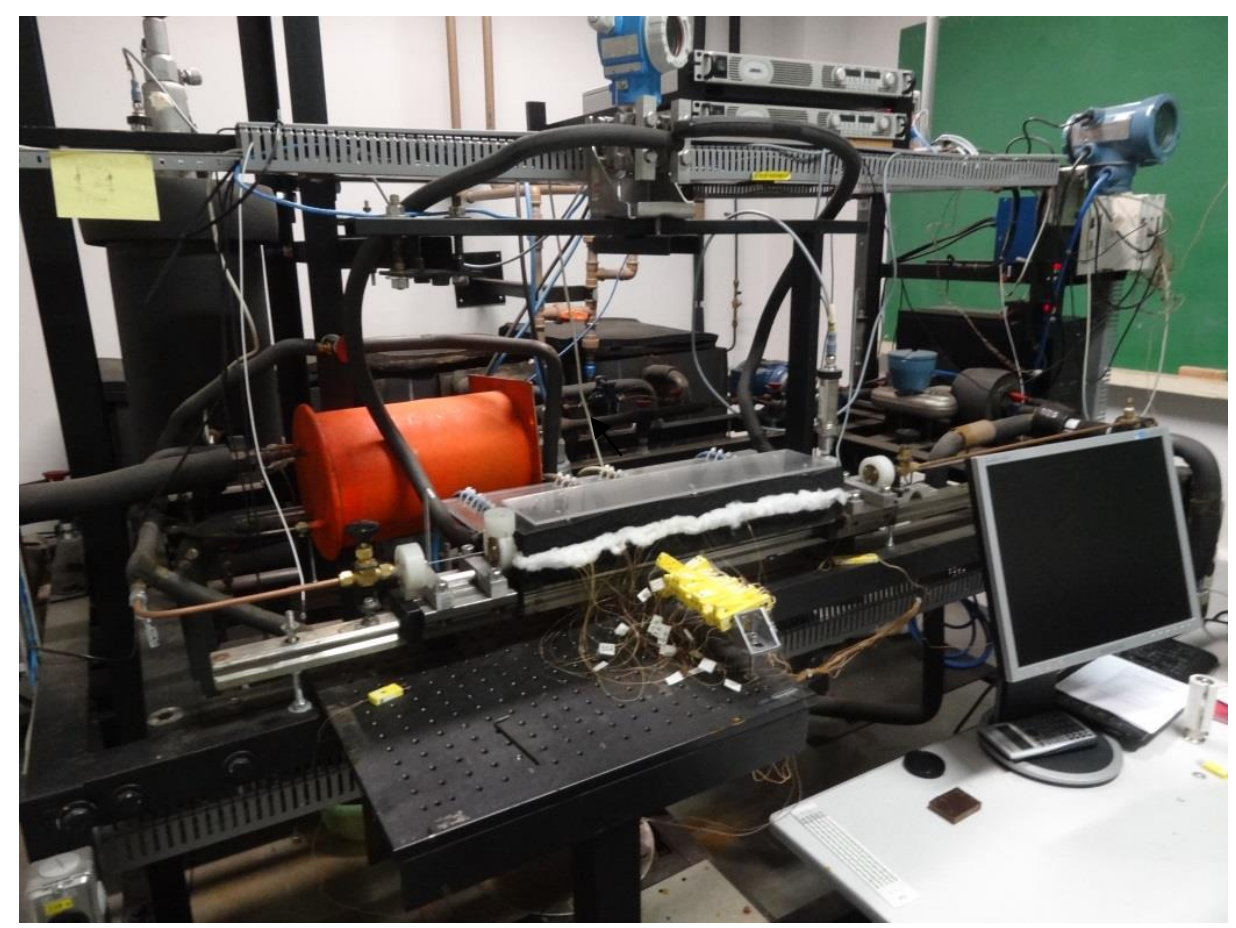

Figura 5.1. Registro fotográfico da bancada experimental (Nov-2014) 
A bancada experimental compõe-se basicamente do circuito do refrigerante (ou de testes) e do circuito auxiliar descritos a seguir.

\subsubsection{Circuito auxiliar}

O circuito auxiliar tem como função condensar e subresfriar o fluido de testes. Nele circula água, que opera como fluido intermediário num sistema composto por aquecedores elétricos atuados por controladores PID, reservatórios de água, trocadores de calor e um sistema de refrigeração por compressão de vapor. O diagrama esquemático deste circuito encontra-se ilustrado na Figura 5.2.

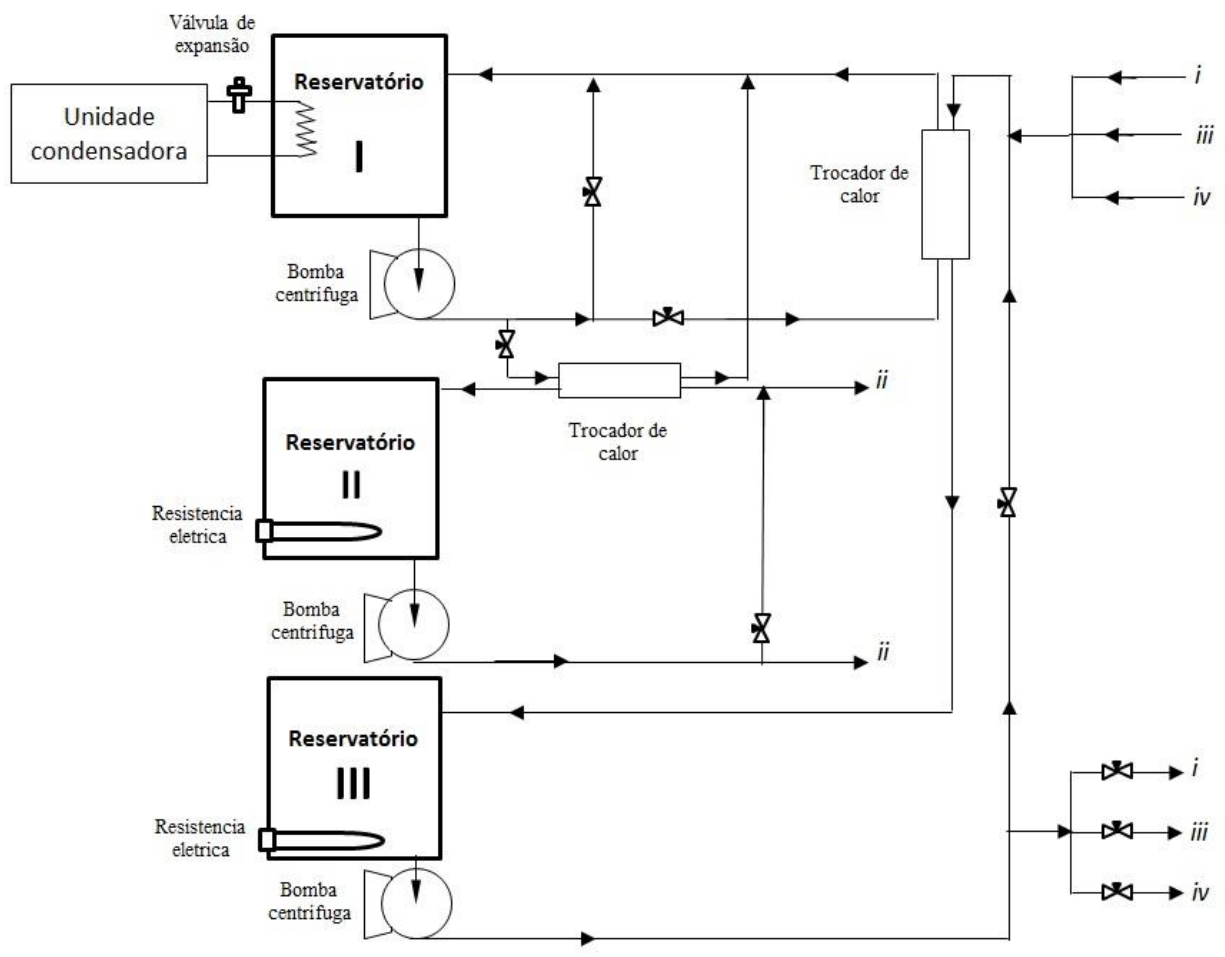

Figura 5.2. Diagrama esquemático do circuito auxiliar.

O Reservatório I é resfriado a partir de um sistema de refrigeração por compressão de vapor. Os Reservatórios II e III contem resistências elétricas atuadas por controladores PID, as quais, em conjunto com os trocadores de calor no interior dos quais circula fluido bombeado a partir do Reservatório I, estabelecem a temperatura da água contida nestes reservatórios. A atuação em válvulas de agulha nas linhas do circuito auxiliar permitem também o ajuste das temperaturas no interior dos Reservatórios II e III. A água armazenada no reservatório II é utilizado no controle da temperatura de saturação no 
reservatório do refrigerante. Já a água contida no Reservatório III circula nos trocadores de calor do circuito principal sendo utilizada na condensação e resfriamento do refrigerante de testes. Bombas centrífugas promovem o deslocamento da água a partir dos Reservatórios.

\subsubsection{Circuito de teste}

O circuito do refrigerante, também denominado de circuito de testes, encontra-se esquematicamente ilustrado na Figura 5.3. Nele, o fluido de testes escoa em circuito fechado. De maneira geral, este circuito compõe-se de microbomba, medidor de vazão, seções de pré-aquecimento, de testes (circular, quadrado, retangular ou triangular), de visualização, um trocador de calor do tipo tubo-em-tubo, responsável por condensar e resfriar o vapor gerado nas seções aquecidas, e o reservatório de refrigerante.

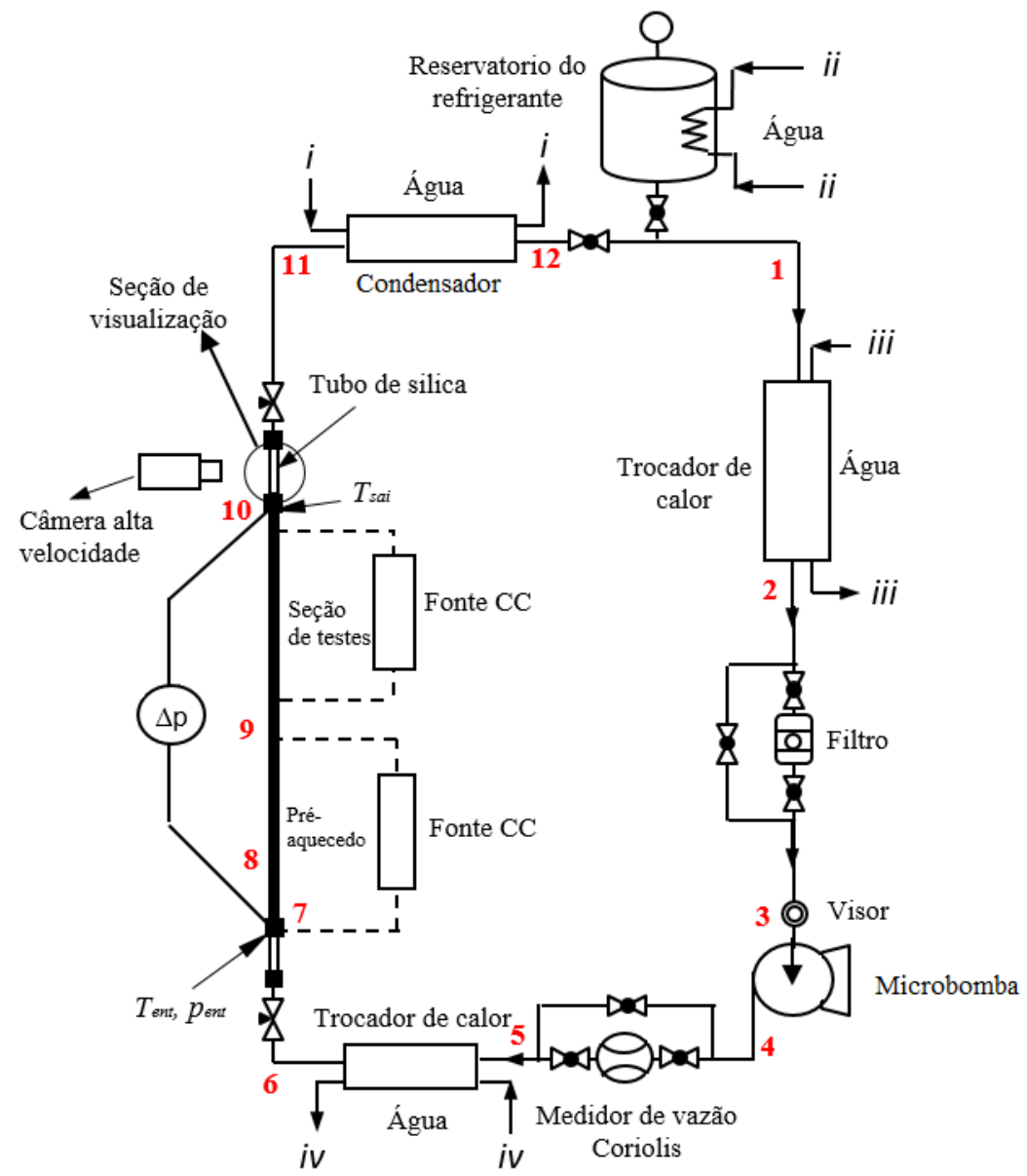

Figura 5.3. Diagrama esquemático do circuito do refrigerante. 
A vazão de refrigerante na seção de testes é controlada através do variador de frequência que atua na rotação da microbomba, responsável pelo deslocamento do fluido no circuito. A Figura 5.4 ilustra os estados termodinâmicos do fluido refrigerante ao longo do circuito de teste num diagrama pressão vs. entalpia. Nela, os números indo-arábicos correspondem as localizações no circuito de testes indicadas na Figura 5.3.

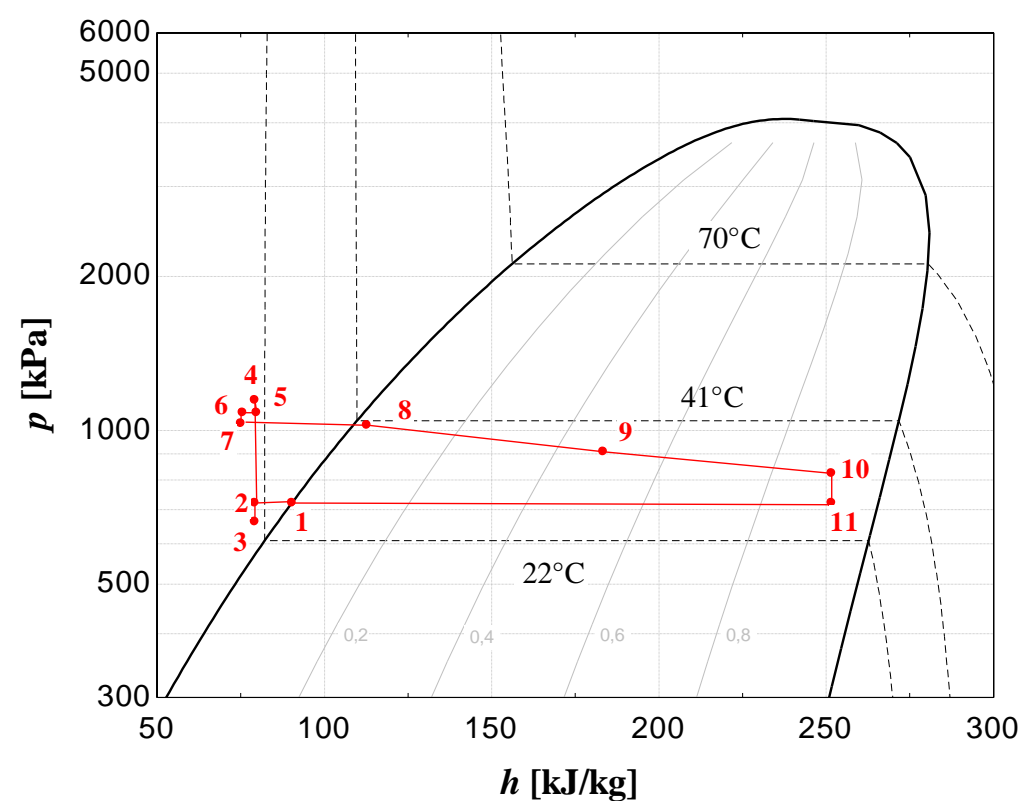

Figura 5.4. Diagrama pressão vs. entalpia do refrigerante ao longo do circuito de testes para o R134a.

A pressão de operação no circuito de teste é determinada e controlada com o auxílio do reservatório através da retirada ou adição de fluido refrigerante ao circuito. A partir da linha conectada a este reservatório, o fluido escoa por um trocador de calor, que tem como objetivo subresfriar o fluido de teste $(1 \rightarrow 2)$, e pelo filtro/secador $(2 \rightarrow 3)$. Após o filtro encontra-se um visor de líquido, cuja função é permitir verificar a presença de bolhas a montante da microbomba $(3 \rightarrow 4)$, as quais poderiam implicar em danos prematuros a este componente. Devido a efeitos de cavitação, a jusante da microbomba encontra-se o medidor de vazão tipo Coriolis $(4 \rightarrow 5)$, o qual determina a vazão mássica do fluido. Após este componente, encontra-se um segundo trocador de calor $(5 \rightarrow 6)$ com a função de subresfriar o fluido de trabalho e assegurar a ausência de vapor na entrada do pré-aquecedor. Logo após este trocador e a montante do pré-aquecedor, encontra-se uma válvula do tipo agulha $(6 \rightarrow 7)$ com a função de impor uma restrição ao escoamento através de uma perda de pressão local, reduzindo assim, a propagação de instabilidades a partir das seções aquecidas. A jusante desta válvula encontra-se um visor, para através de inspeção visual ser possível, assegurar a ausência de bolhas no escoamento. A montante 
do pré-aquecedor e em uma região com diâmetro similar ao da superfície aquecida são determinadas a temperatura, $T_{e n t}$, e a pressão do fluido de trabalho, $p_{e n t}$, permitindo através de seus valores estimar a entalpia do fluido na entrada da seção aquecida. A temperatura $T_{\text {ent }}$ e a pressão $p_{\text {ent }}$ são respectivamente fornecidas por um termopar tipo $\mathrm{K}$ com diâmetro de junção quente igual a $0,125 \mathrm{~mm}$ e um transdutor de pressão absoluta tipo piezoresistivo. Na seção de pré-aquecimento, $(7 \rightarrow 9)$ o fluido é aquecido por efeito Joule com a aplicação direta de corrente contínua à parede do tubo. Nesta seção o refrigerante é aquecido até desejado na entrada da seção de testes (8). A partir daí, o fluido escoa através da seção de teste, também aquecida por efeito Joule. A Figura 5.4 ilustra a perda de pressão bifásica entre o estado de entrada (8) e o fim da seção de testes (10), após a qual se encontra a seção de visualização. A jusante desta seção, o refrigerante escoa através de uma segunda válvula do tipo agulha com funções similares à anterior. A jusante desta válvula, ocorre a condensação e o resfriamento do fluido de trabalho em um trocados de calor do tipo tubo-em-tubo $(11 \rightarrow 1)$.

Ao final da seção de testes, o fluido tem sua temperatura, $T_{s a i}$, determinada através de um termopar com diâmetro de junção quente igual a $0,125 \mathrm{~mm}$. A pressão absoluta nesta região é estimada a partir da pressão absoluta na entrada da seção de testes e da perda de pressão entre a entrada da seção de pré-aquecimento e a entrada da seção de visualização, $\Delta p$, fornecida por um transdutor de pressão diferencial. $\mathrm{Na}$ seção de visualização são capturadas imagens do escoamento através de uma câmera de alta velocidade.

\subsubsection{Principais componentes do circuito de testes}

Este item apresenta uma descrição detalhada dos componentes do circuito do refrigerante da bancada experimental.

\section{Reservatório do fluido de teste}

O reservatório do fluido de teste possui volume aproximado de $0,01 \mathrm{~m}^{3}$ e tem a função de adição e retirada de refrigerante do circuito, procedimento adotado para o estabelecimento da pressão de saturação na seção de testes. Este componente encontra-se suspenso através de um dinamômetro, permitindo avaliar a quantidade do refrigerante no reservatório e no circuito, através do registro apropriado dos processos de carga e 
descarga de refrigerante. Este dinamômetro apresenta escala de 0 a 20 kgf com divisões de escala de 100 gf.

\section{Microbomba}

Uma microbomba produzida pela Micropump, modelo GA-V21J8KS4 é utilizada para deslocar o fluido refrigerante através do circuito de testes. A bomba possui um par de engrenagens não metálicas conectada a um motor elétrico através de um acoplamento magnético. A vazão imposta pela bomba é controlada a partir de um variador de frequência modelo ABB-ACS150 de 0,5 CV/220V, atuando na rotação do motor, através de um sinal de 0 a $10 \mathrm{~V}$ fornecido pelo sistema de aquisição. A Tabela 5.1 apresenta as principais características da microbomba utilizada.

Tabela 5.1. Características operacionais da microbomba.

\begin{tabular}{cc}
\hline Característica & Valor \\
\hline Pressão diferencial máxima & $880 \mathrm{kPa}$ \\
Rotação máxima & $6000 \mathrm{rpm}$ \\
Vazão máxima & $0,0007 \mathrm{~m}^{3} / \mathrm{s}$ \\
Temperatura máxima & $260^{\circ} \mathrm{C}$ \\
Rendimento & $61,90 \%$ \\
Viscosidade máxima & $2,5 \mathrm{~kg} / \mathrm{m} . \mathrm{s}$ \\
\hline
\end{tabular}

\section{Fontes de corrente contínua}

Duas fontes de corrente fabricadas pelo Lambda/Genesys, modelo GEN 20-38 com potência máxima de $750 \mathrm{~W} / 220 \mathrm{~V}$, encontram-se instaladas na bancada experimental, alimentando com corrente elétrica as seções de testes e de pré-aquecimento. As duas fontes fornecem tensões de 0 a $20 \mathrm{~V}$ e corrente de 0 a 38 A. Estas fontes possuem um dispositivo que permite corrigir a queda de tensão ao longo da fiação, conectores e alimentação mediante a regulação da tensão e corrente na saída. A fonte inclui uma interface digital (16 bit) R232. A tensão imposta na seção de testes é controlada a partir do sistema de aquisição. 


\section{Transdutores de pressão}

Dois transdutores de pressão absoluta tipo piezoresistivos da marca Endress Hauser PMP 131, com erro máximo de 0,5\% em relação ao fundo de escala são utilizados na bancada experimental. Um deles encontra-se na entrada da seção de pré-aquecimento e o outro no reservatório do refrigerante. Os transdutores utilizados apresentam fundo de escala igual a $1 \mathrm{Mpa}$.

A diferença de pressão entre a entrada do pré-aquecedor e a saída da seção de testes foi avaliado através de um transdutor de pressão diferencial da marca Endress Hauser, modelo Deltabar S tipo piezoresistivo. Este transdutor apresenta sensor cerâmico e abrange uma faixa de 0 a $300 \mathrm{kPa}$, com erro máximo de $0,075 \%$ do fundo de escala. $\mathrm{O}$ sinal de saída dos transdutores de pressão absoluta e diferencial é a corrente elétrica com valores entre 4 a $20 \mathrm{~mA}$.

\section{Termopares}

Para a avaliação de temperaturas superficiais e do fluido de testes, utilizou-se termopares tipo K produzidos pela Omega Inc. Os termopares são constituídos de fios de alumel e cromel com sensibilidade de $41 \mu \mathrm{V} /{ }^{\circ} \mathrm{C}$, com diâmetro de fio de $0,125 \mathrm{~mm}$.

Os termopares tipo $\mathrm{K}$ instalados externamente na superfície de teste e no préaquecedor são isolados eletricamente através de uma reduzida camada de esmalte de forma a evitar interferências da fonte de corrente em suas medidas reduzindo resistências térmicas de contato. Eles são pressionados contra as superfícies aquecidas através de fitas de kapton tensionadas. O diâmetro aproximado da junta quente do termopar utilizado é de $0,25 \mathrm{~mm}$. Vale mencionar também que conectores e extensores, com diâmetros de fio igual a $0,125 \mathrm{~mm}$, ambos do tipo $\mathrm{K}$ fabricados pela Omega Inc., foram utilizados para acoplar o termopares instalados na seção de testes ao sistema de aquisição.

Termopares tipo K também foram instalados na entrada e saída da seção de testes, em contato com o fluido refrigerante no interior dos canais.

Termopares tipo T, de cobre e constantan, foram instalados nos reservatórios I, II e III com o objetivo de monitorar a temperatura nestes tanques. Estes termopares possuem diâmetro de fio de aproximadamente $1 \mathrm{~mm}$ e são fabricados pela Omega Inc. 


\section{Seção de pré-aquecimento e de testes}

Os testes para canal circular foram realizados com tubo de aço inoxidável AISI304 fabricado pela "Goodfellow Cambridge Limited". O tubo tem $490 \mathrm{~mm}$ de comprimento, diâmetro externo de $1,47 \mathrm{~mm}$, espessura da parede de $0,185 \mathrm{~mm}$, diâmetro interno de 1,1 mm. A rugosidade aritmética média do tubo foi avaliada com o equipamento Wiko® NT1100. Um valor de $\mathrm{Ra}=0,289 \mu \mathrm{m}$ foi encontrado baseado no valor médio de 3 medidas na superfície interna do tubo. A Figura 5.5 ilustra uma imagem da superfície interna do tubo e o seu relevo tridimensional.
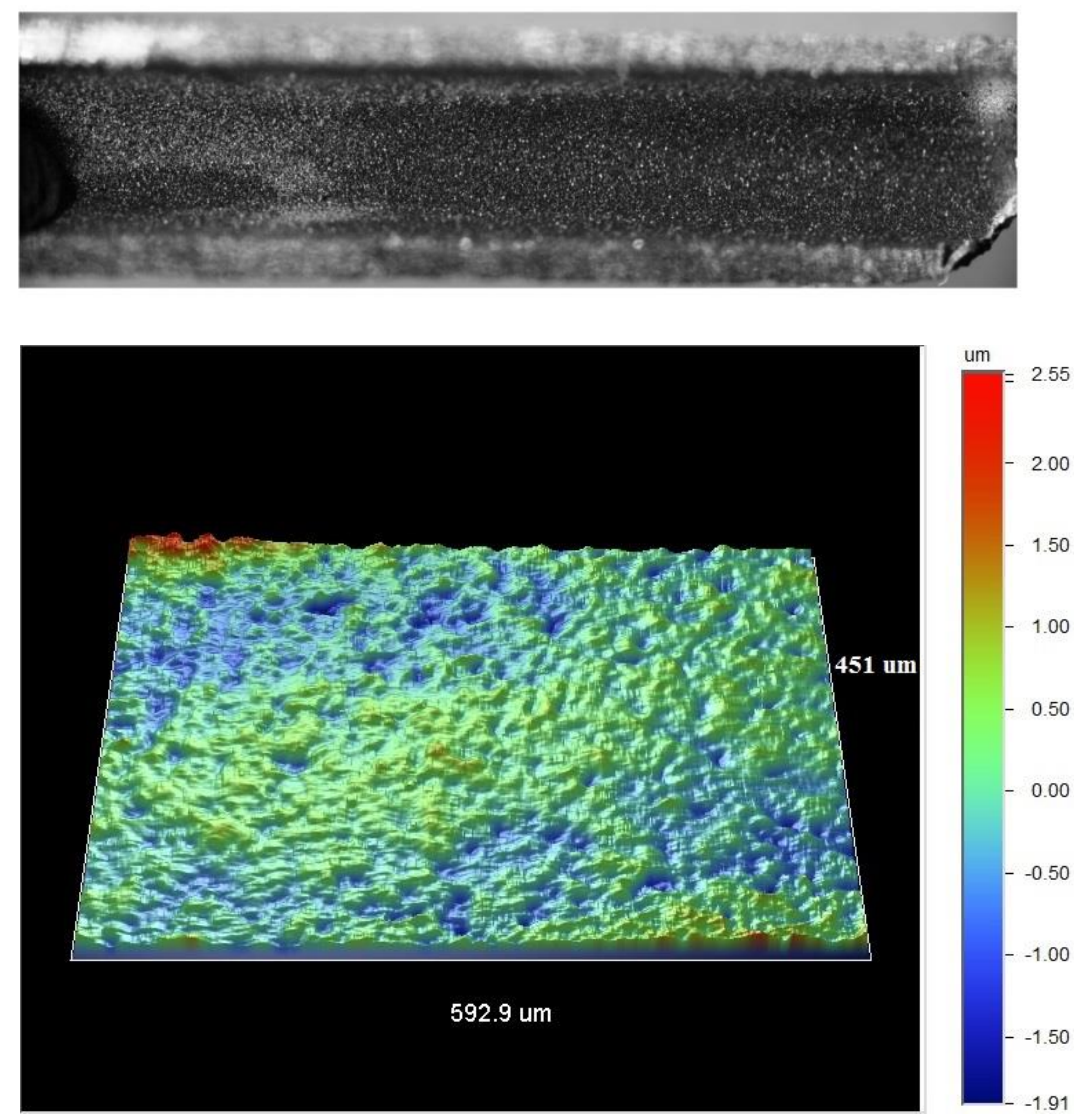

Figura 5.5. a) Imagem da superficie interna do tubo, b) Relevo em 3D da superficie interna do tubo.

Os canais não circulares foram obtidos a partir de um processo de conformação numa matriz especialmente fabricada para cada seção transversal. Neste processo foram utilizados dois blocos de aço, contendo fendas com dimensões previamente determinadas (dependendo da geometria da seção transversal a ser formada). Para a conformação, o tubo de seção transversal circular é colocado na fenda da matriz e conformado com pressão elevada de forma a se obter a geometria da seção transversal especificada. Através 
deste procedimento, fixa-se o perímetro externo do tubo. A opção por se manter tal dimensão fixa deu-se pelos seguinte aspectos:

Fixando o perímetro exterior, o comprimento do canal e a área de transferência de calor se mantêm para as 3 geometrias avaliadas;

Manter a área de troca torna-se relevante ao efetuar-se uma avaliação que busca identificar o grau de empacotamento de canais em uma estrutura 3D, composta de multicanais;

A Tabela 5.2 ilustra as dimensões dos canais das matrizes utilizadas na conformação do tubo de seção circular. Conforme ilustrado nesta tabela, todas as seções apresentam perímetro externo aproximadamente similar ao do tubo original $\left(\pi \mathrm{D}_{\text {ext }}\right)$, portanto, suas definições se deram a partir do perímetro do tubo.

Tabela 5.2. Dimensões dos canais nas matrizes utilizadas no processo de conformação.

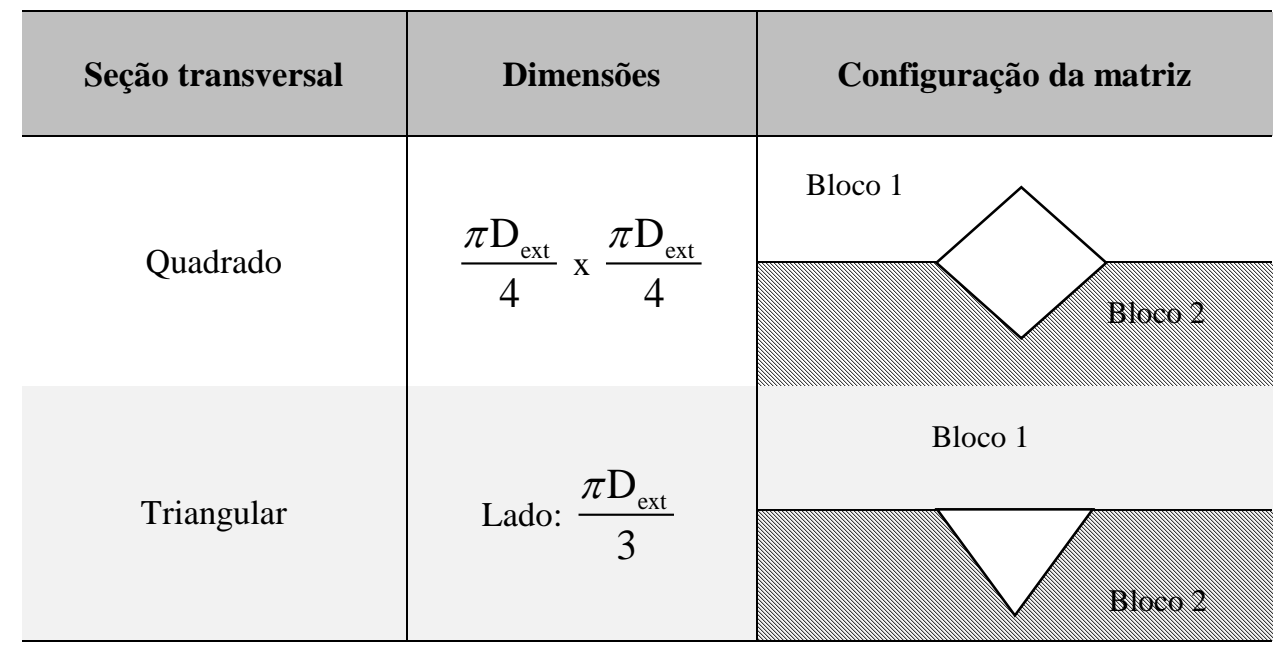

$* D_{\text {ext }} \rightarrow$ Diâmetro externo da seção circular

A Figura 5.6a ilustra uma das matrizes de aço utilizada para a obtenção de um canal de seção transversal quadrada a partir da conformação de um tubo de seção circular. As medidas das fendas nesta matriz são $\pi D_{\text {ext }} / 4$ x $\pi D_{\text {ext }} / 4$ como indicado na Tabela 5.2. A Figura 5.6b ilustra um corte da seção transversal do tubo quadrado formado com a matriz anteriormente descrita. 

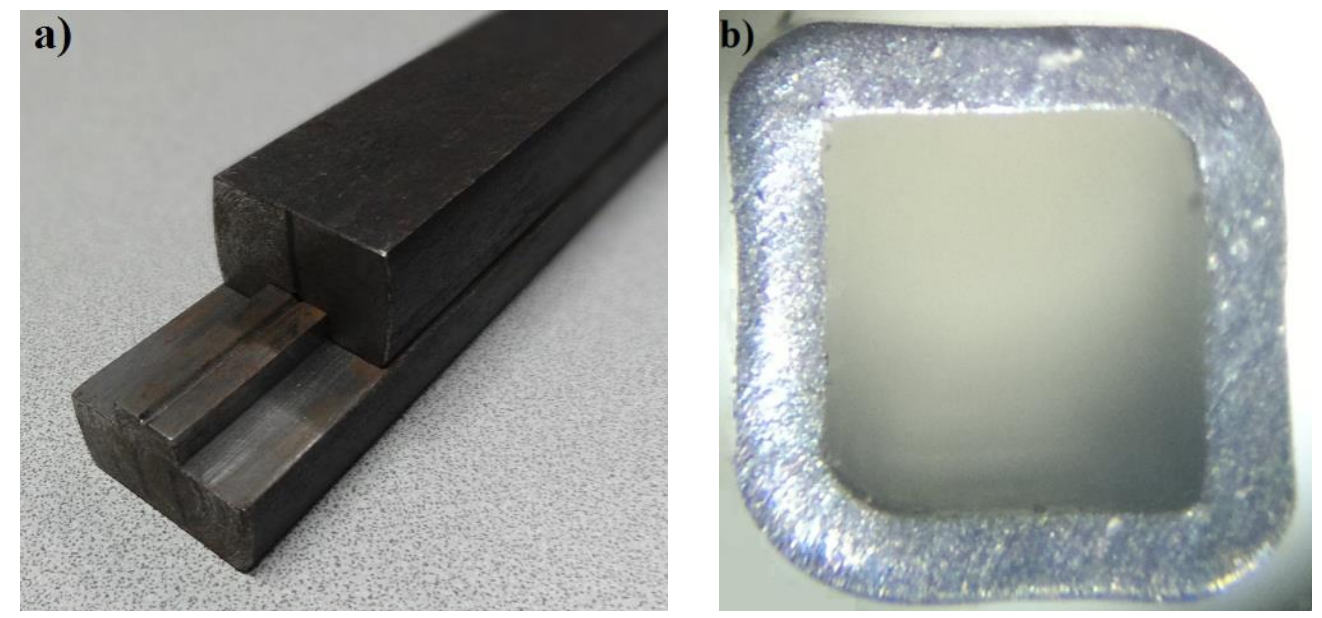

Figura 5.6. a) Matriz composta de duas peças de aço inoxidável utilizadas na conformação do tubo circular, b) Vista de um corte da seção transversal quadrada obtida a partir do processo de conformação.

A Figura 5.7 ilustra os perfis da seção transversal dos canais quadrado e triangular determinados através do sistema ótico de perfis Wiko® NT1100. A partir destes perfis foram estimados o diâmetro equivalente e hidráulico dos canais quadrado e triangular, mediante processamento destas imagens no programa MATLAB R2010a.
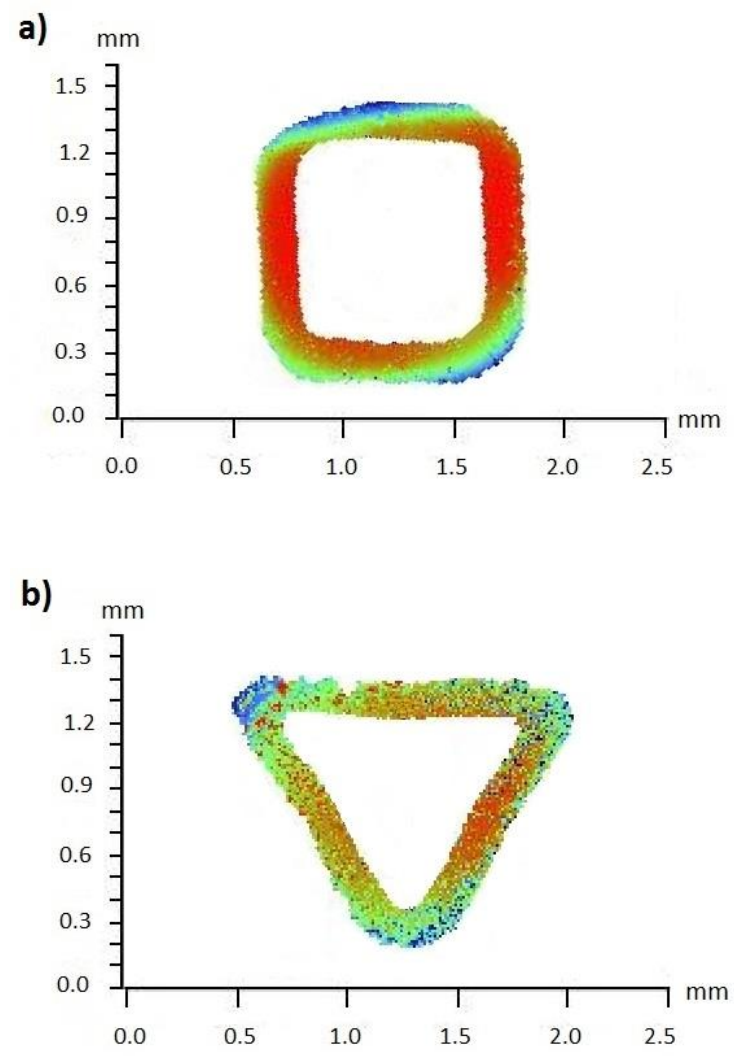

Figura 5.7. Seção transversal dos tubos, a) quadrado, b) triangular. 
A Tabela 5.3 lista as características geométricas das seções de teste avaliadas neste estudo. Esta tabela revela significativas diferenças da rugosidade aritmética média para as diferentes seções de testes, fato decorrente do processo de conformação.

Tabela 5.3. Características geométricas dos canais avaliados no presente estudo.

\begin{tabular}{cccccc}
\hline $\begin{array}{c}\text { Geometria } \\
\text { da seção } \\
\text { transversal }\end{array}$ & $\begin{array}{c}\boldsymbol{D}_{\boldsymbol{H}} \\
{[\mathrm{mm}]}\end{array}$ & $\begin{array}{c}\boldsymbol{D}_{\boldsymbol{e q}} \\
{[\mathrm{mm}]}\end{array}$ & $\varsigma[-]$ & $\boldsymbol{R} \boldsymbol{a}[\boldsymbol{\mu m}]$ & $\boldsymbol{R} \boldsymbol{t}[\boldsymbol{\mu m}]$ \\
\hline Circular & 1,1 & 1,1 & - & 0,289 & 4,45 \\
Quadrado & 0,868 & 0,977 & 1.06 & 0,840 & 6,81 \\
Triangular & 0,634 & 0,835 & - & 1,780 & 8,31 \\
\hline
\end{tabular}

As seções de pré-aquecimento e de testes são constituídas de um canal único com comprimento total de $490 \mathrm{~mm}$. A Figura 5.8 ilustra um diagrama esquemático das seções de pré-aquecimento e de testes. Nela pode-se observar entre os termopares C e D e os termopares E e F, as transições entre o tubo circular e o canal de seção transversal nãocircular. A seção de testes circular não apresenta estas transições. Vale mencionar que a montante e jusante destas transições foram instalados termopares, com o intuito de avaliar as perdas de pressão locais, no entanto, considerando sua elevada incerteza experimental esses dados so foram utilizados como referencia.

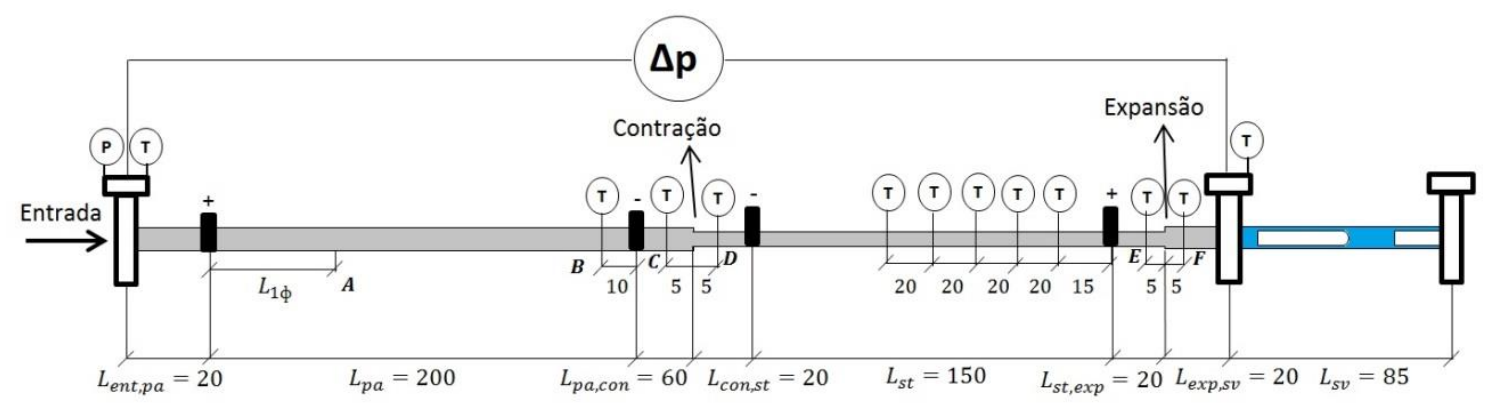

Figura 5.8. Diagrama esquemático da seção de pré-aquecimento e testes.

A seção de pré-aquecimento apresenta comprimento total de $280 \mathrm{~mm}$, dos quais, $200 \mathrm{~mm}$ correspondem à região aquecida. Nela, encontra-se instalado um termopar próximo ao eletrodo de saída (termopar B na Figura 5.9) com o objetivo de detectar condições próximas ao fluxo crítico. Tal condição é caracterizada por um aumento 
drástico na temperatura indicada por este termopar, implicando no corte imediato a partir do sinal proveniente do sistema de aquisição da alimentação da corrente elétrica à superfície aquecida. A seção de teste possui um comprimento total de $190 \mathrm{~mm}$, dos quais $150 \mathrm{~mm}$ correspondem à região aquecida. Os termopares $\mathrm{D}$ e $\mathrm{E}$, instalados a $5 \mathrm{~mm}$ da entrada e saída da seção de teste, respectivamente, são utilizados para a determinação da perda de pressão a partir da temperatura de saturação por eles indicadas (detalhes adicionais consultar Item 5.4.7). Portanto, o comprimento para a determinação do gradiente da perda de pressão corresponde a $180 \mathrm{~mm}$.

Adotou-se um comprimento para desenvolvimento do escoamento a jusante do pré-aquecedor de cerca de $60 \mathrm{~mm}$, correspondendo a aproximadamente 60 diâmetros. Vale destacar que a teoria para avaliação de distâncias necessárias para o desenvolvimento de escoamentos bifásicos ainda não se encontra estabelecida.

Para avaliação do coeficiente de transferência de calor, 10 termopares tipo K foram instalados na região compreendida pelos eletrodos da seção de teste. Os termopares foram posicionados em 5 diferentes seções do canal conforme ilustrado na Figura 5.9. O primeiro par de termopares encontra-se posicionado a $75 \mathrm{~mm}$ do eletrodo com o intuito de evitar efeitos de alteração da geometria da seção transversal. Para a seção circular, os termopares encontram-se em posições opostas correspondendo as regiões inferior e superior do canal. Para a seção quadrada, os termopares foram posicionados nas faces superior e inferior. Na seção triangular, um termopar foi fixado na base e outro na região intermediária de uma das faces laterais. O comprimento aquecido na seção de testes é de $150 \mathrm{~mm}$, como anteriormente mencionado.

Termopares foram fixados conforme ilustrado na Figura 5.9 nas posições indicadas por D e E que correspondem a uma distância de $15 \mathrm{~mm}$ dos eletrodos, estes termopares encontram-se localizados em regiões não aquecidas. As temperaturas avaliadas a partir destes termopares foram utilizadas para estimar a temperatura do fluido escoando internamente ao duto. Para tal distância, tornam-se desprezíveis efeitos de condução longitudinal através da parede do tubo na temperatura medida pelos termopares. Este procedimento foi avaliado considerando o duto a partir do eletrodo como uma aleta infinita, rejeitando calor apenas através de sua superfície interna. O resultado desta análise encontra-se ilustrado na Figura 5.10, a qual ilustra o efeito do coeficiente de transferência de calor interno na distância, a partir do eletrodo, necessária para que a superfície do tubo 
alcance uma temperatura dentro da faixa de incerteza da temperatura de saturação do fluido escoando internamente ao duto. Na Figura 5.10 constata-se que a temperatura da parede do tubo fornecida pelo termopar torna-se "similar" à temperatura do fluido para comprimentos superiores a $11 \mathrm{~mm}$, para um CTC interno de aproximadamente 1 $\mathrm{kW} / \mathrm{m}^{2} \mathrm{~K}$. É possível concluir, desta forma, que a distância de $15 \mathrm{~mm}$ adotada no presente estudo é satisfatória inpendentemente da temperatura de saturação.

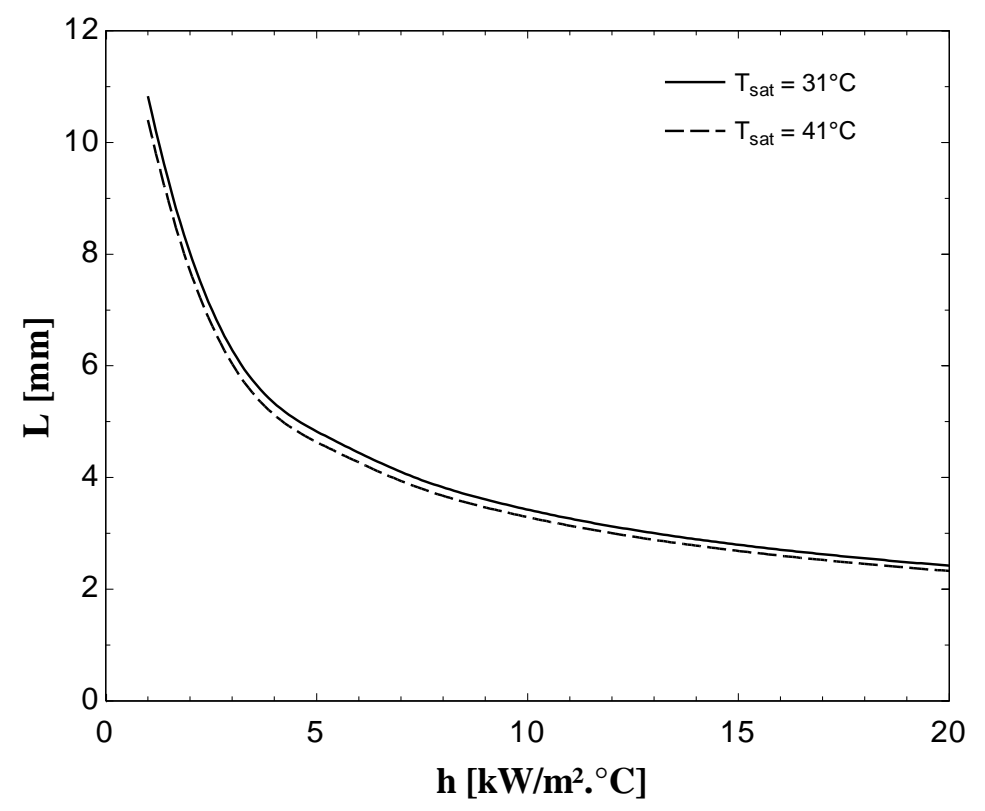

Figura 5.9. Variação do comprimento onde $T_{p}$ torna-se igual à temperatura do fluido.

Visando reduzir perdas de calor para o ambiente as seções de pré-aquecimento e testes foram isoladas primeiro com uma camada de lã de pedra, recoberta com espuma elastomérica isolante térmica fabricada pela Armaflex.

\section{Seção de visualização e câmera de alta velocidade}

A seção de visualização ilustrada na Figura 5.9 consiste em um tubo transparente de sílica fundida com diâmetro interno de 1,0 mm, espessura de parede de $0,1 \mathrm{~mm}$ e comprimento de $85 \mathrm{~mm}$. Para os ensaios com canais de seção transversal não circular devido as distinções de geometrias, considera-se o padrão visualizado apenas como um parâmetro indicativo do escoamento. Conforme mencionado a seção de visualização encontra-se localizada a jusante da seção de testes e tem por finalidade proporcionar a visualização do escoamento bifásico. Ela encontra-se conectada à seção de testes e ao circuito através de flanges de PVDF, cuja vedação se dá através de anéis de vedação pressionados contra a parede dos tubos. 
A câmera empregada na visualização do escoamento é fabricada pela Optronics, modelo Cam Record 600. Ela é utilizada em conjunto com um lente AF Micro-NIKKOR $60 \mathrm{~mm}$ f/2,8D. A Tabela 5.4 lista as principais características da câmera de alta velocidade utilizada neste estudo.

Tabela 5.4. Especificações da câmera de alta velocidade.

\begin{tabular}{l|l}
\hline Imagem: & Monocromática \\
Resolução máxima: & 1280 x 1024 pixels \\
Área Ativa/Pixels: & $15,36 \mathrm{~mm}$ x $12,29 \mathrm{~mm} / 12 \mu \mathrm{m} \times 12 \mu \mathrm{m}$ \\
Sincronização: & Interna e externa \\
Peso: & $1,7 \mathrm{~kg}$ \\
Condições de ambiente: & Temperatura: $0 \mathrm{a} 40^{\circ} \mathrm{C} ;$ umidade relativa $<80 \%$ \\
Dimensões: & $250 \mathrm{~mm}$ x $100 \mathrm{~mm} \times 131,5 \mathrm{~mm}$ \\
\hline
\end{tabular}

A resolução da câmera decresce com o incremento da velocidade de aquisição de imagens. Para a obtenção de imagens nítidas do padrão de escoamento foi necessária uma resolução mínima de 1280 pixels na horizontal e 128 na vertical. Para esta resolução pode ser utilizada uma velocidade de captura entre 50 e 4000 imagens/s, conforme indica a Tabela 5.5. Tal especificação permite identificar os padrões e observar os fenômenos do escoamento bifásico como ondulações da interface e a coalescência de bolhas para a faixa de velocidades mássicas avaliadas no presente estudo.

Tabela 5.5. Relação entre a resolução da câmera e a frequência de aquisição de imagens.

\begin{tabular}{c|c}
\hline Velocidade [imagens/s] & Resolução, $\mathbf{H}$ x V [pixels] \\
\hline $50-500$ & $1280 \times 1024$ \\
$50-850$ & $800 \times 600$ \\
$50-875$ & $720 \times 576$ \\
$50-1000$ & $1280 \times 512 ; 640 \times 480$ \\
$50-2000$ & $1280 \times 256 ; 320 \times 256$ \\
$50-4000$ & $1280 \times 128 ; 160 \times 128$ \\
$50-10000$ & $1280 \times 50 ; 80 \times 50$ \\
$50-25000$ & $1280 \times 20$ \\
$50-50000$ & $1280 \times 8$ \\
\hline
\end{tabular}


O sistema de iluminação utilizado consta de 100 LEDs distribuídos uniformemente em duas placas de 60 × $50 \mathrm{~mm}$ cada. Tal dispositivo permite uma iluminação adequada com geração de calor mínima, isto evita que o calor gerado por métodos de iluminação convencionais induzam a evaporação do fluido de testes.

\section{Sistema de aquisição de dados e controle da bancada}

A aquisição de dados e controle do sistema foi realizada através de um sistema de aquisição de dados e controle da National Instruments.

O sistema é composto da placa multifunção NI PCI-6221 acoplada ao chassis NI SCXI-1100. A este chassis encontra-se acoplado o modulo condicionador de sinal NI SCXI-1102 de 32 entradas e aquisição multiplexada no tempo. A este modulo encontrase acoplado o bloco terminal isotérmico SCXI-1303, no qual são conectados as extensões dos termopares, os cabos conectados aos dispositivos de medida de pressão absoluta, diferencial de pressão e vazão.

No chassi encontra-se instalado também o painel de passagem direta NI SCXI1180, que estabelece a conexão com os terminais da placa multifunção NI PCI-6221. O bloco terminal SCXI-1302 encontra-se acoplado ao painel NI SCXI-1180. No bloco terminal SCXI 1302 conecta-se o variador de frequência responsável por estabelecer a vazão no circuito de testes através de sua atuação na velocidade da microbomba. A Figura 5.10 apresenta um diagrama esquemático ilustrando os componentes do sistema de aquisição de dados e como estes se encontram interligados.

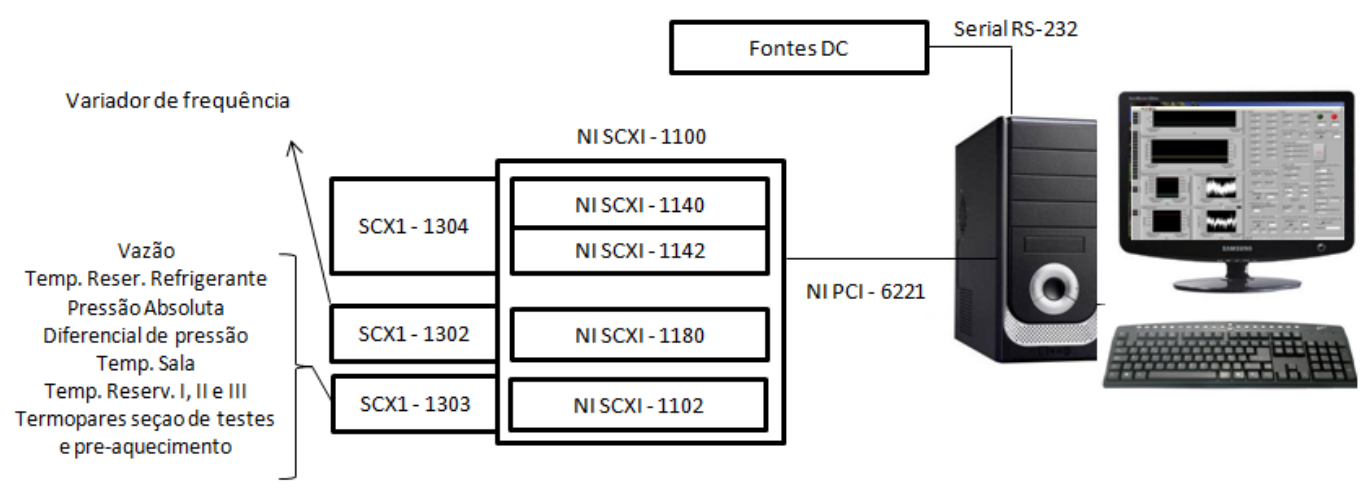

Figura 5.10. Diagrama esquemático indicando os componetnes do sistema de aquisição e suas interligações. 
No caso de sinais de transdutores que fornecem saída em corrente, resistores de precisão térmica de $249 \Omega \pm 0,1 \% /{ }^{\circ} \mathrm{C}$ encontram-se ligados em série com a saída dos transdutores com o objetivo de converter a corrente em tensão. A Tabela 5.6 apresenta os sensores e atuadores utilizados na bancada experimental e descreve os sinais a eles relacionados.

Tabela 5.6.- Sensores e atuadores utilizados na bancada experimental.

\begin{tabular}{|c|c|c|c|}
\hline Sensores e Atuadores & Modelo & Quantidade & Tipo de Sinal \\
\hline Termopares (Sensor) & Tipo K-Omega & 16 & $\sim 40 \mu \mathrm{V} /{ }^{\circ} \mathrm{C}$ \\
\hline Pressão Absoluta (Sensor) & $\begin{array}{c}\text { Endress+Hauser } \\
\text { PMP } 131\end{array}$ & 2 & 4-20 mA \\
\hline Pressão Diferencial (Sensor) & $\begin{array}{c}\text { Endress+Hauser } \\
\text { Deltabar S }\end{array}$ & 1 & 4-20 mA \\
\hline Vazão Coriolis (Sensor) & $\begin{array}{l}\text { Micromotion } \\
\text { Modelo } 2700\end{array}$ & 1 & 4-20 mA \\
\hline $\begin{array}{l}\text { Fonte Elétrica DC } \\
\text { (Atuador/Sensor) }\end{array}$ & $\begin{array}{c}\text { Lambda Genesys } \\
\text { 750W DC }\end{array}$ & 2 & Digital/RS-232 \\
\hline Inversor/Microbomba (Atuador) & $\begin{array}{c}\text { ABB-ACS } \\
\text { 150/Micropump }\end{array}$ & 1 & $0-5 \mathrm{~V}$ \\
\hline
\end{tabular}

Um programa em Labview foi desenvolvido para atuar como interface entre o sistema de aquisição e o operador da bancada. Através desta interface as condições de ensaio são impostas e controladas e os dados adquiridos.

\section{Detector de gases inflamáveis}

Foi implementado um sistema de segurança para a sala contendo a bancada experimental baseado na norma EN 378:2008 ${ }^{1}$, considerando a realização no presente estudo de ensaios para isobutano, o qual trata-se de um refrigerante inflamável. Esta norma estabelece uma taxa de reposição mínima do volume de ar na sala de 4 vezes/hora, ou o equivalente de $0,0352 \mathrm{~m}^{3} / \mathrm{s}$, valor atendido pelo sistema de exaustão de ar existente no laboratório, composto de um ventilador centrífugo e dutos retangulares contendo janelas próximas ao piso, comunicando o ambiente interno do laboratório com o externo. Este sistema é acionado por um detector de gases inflamáveis, da marca RIKEN (indústria japonesa), tipo difusor, série SD-705, modelo GP. A Figura 5.12 apresenta um registro fotográfico do detector de gases.

1 European Standard Norm EN-378: "Refrigerating systems and heat pumps - Safety and environmental requirements" 


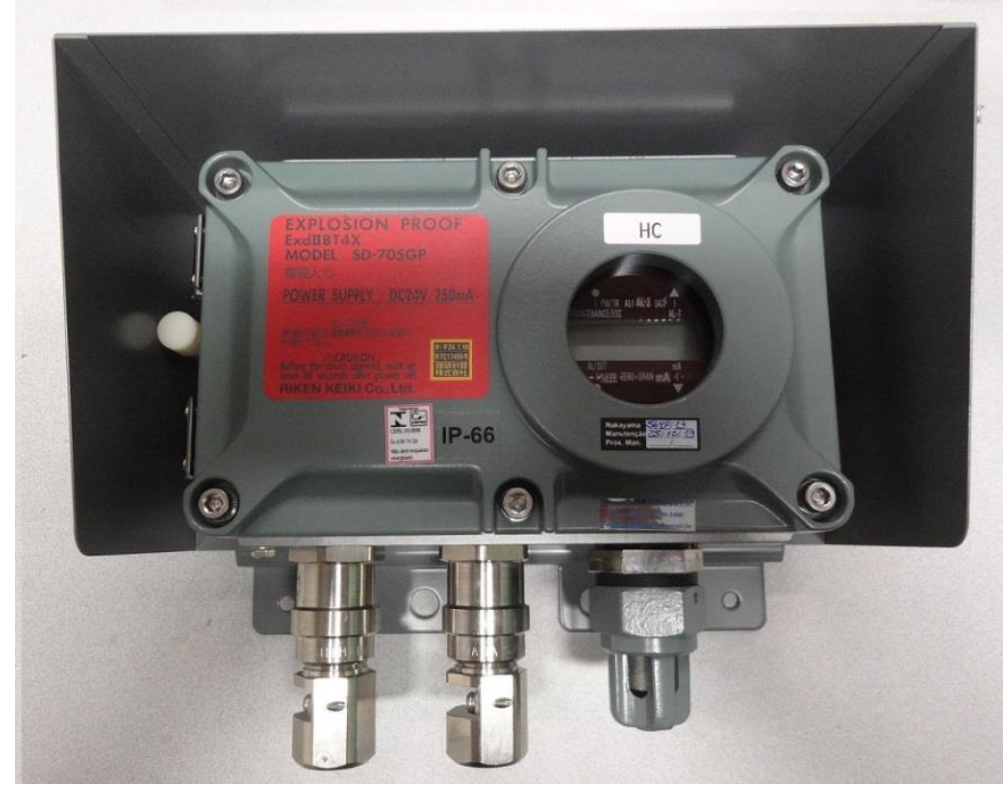

Figura 5.11. Registro fotográfico do detector de gases inflamáveis fixo, marca RIKEN, serie SD-705, modelo GP.

A Figura 5.13 apresenta um registro fotográfico do sensor de gases inflamáveis, o qual foi instalado cerca de $40 \mathrm{~cm}$ abaixo do circuito do refrigerante.

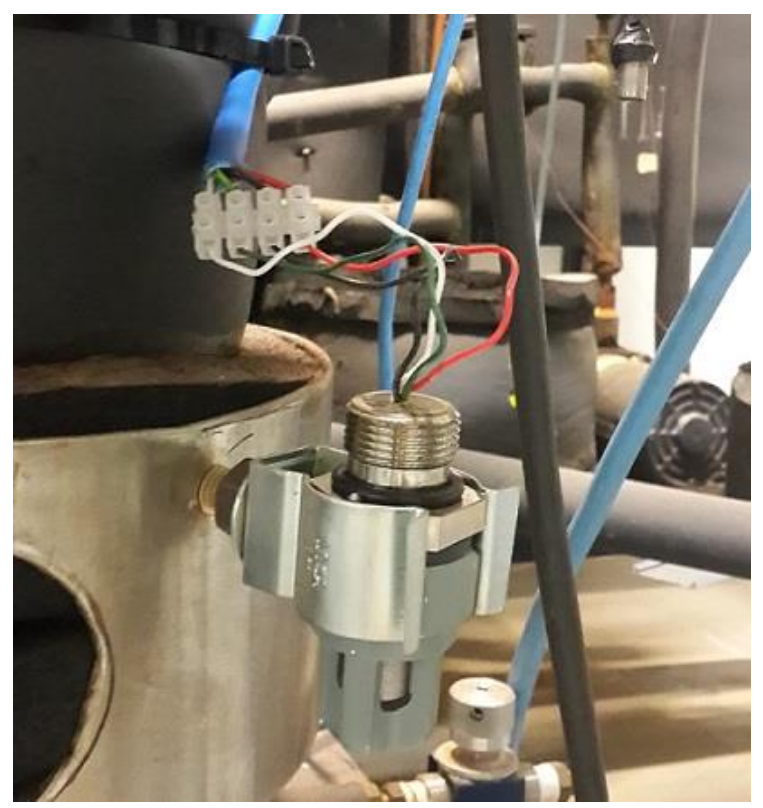

Figura 5.12. Registro fotográfico do sensor de gases inflamáveis.

A Tabela 5.7 lista as principais características do detector de gases inflamáveis instalado no laboratório. 
Tabela 5.7. Características do detector de gases inflamáveis.

\begin{tabular}{|c|c|c|}
\hline \multicolumn{2}{|c|}{ Detecção de gás } & Gases combustíveis \\
\hline \multicolumn{2}{|c|}{ Principio de detecção } & Combustão catalítica \\
\hline \multicolumn{2}{|c|}{ Faixa de detecção } & $0 \sim 100 \% \mathrm{LEL}^{1}$ \\
\hline \multicolumn{2}{|c|}{ Condições operacionais } & $-10^{\circ} \mathrm{C} \sim+40^{\circ} \mathrm{C}$ \\
\hline Saída externa & $\begin{array}{l}\text { Contato do alarme } \\
\text { Sinal de transmissão }\end{array}$ & $\begin{array}{l}\text { Alarme de gás: Normalmente aberto } \\
4-20 \mathrm{~mA}\end{array}$ \\
\hline \multicolumn{2}{|l|}{ Potência } & $24 \mathrm{VDC} \pm 10 \%(\operatorname{Max} 6.0 \mathrm{~W})$ \\
\hline \multicolumn{2}{|l|}{ Estrutura } & A prova de fogo Exd II BT4X \\
\hline \multicolumn{2}{|c|}{ Distância do sinal de transmissão } & $\begin{array}{l}\text { Max } 1,25 \mathrm{~km} \text { com CVVS cabo de } 1.25 \\
\mathrm{~mm}^{2}\end{array}$ \\
\hline \multicolumn{2}{|l|}{ Dimensões } & $205(\mathrm{H}) \times 134(\mathrm{H}) \times 92(\mathrm{D}) \mathrm{mm}$ \\
\hline \multicolumn{2}{|l|}{ Peso } & $4,3 \mathrm{~kg}$ \\
\hline
\end{tabular}

\subsection{Procedimento experimental}

Neste item são descritos as condições e procedimentos experimentais adotados no presente estudo.

\subsubsection{Condições experimentais da banco de dados levantado}

Ensaios visando a determinação de perda de pressão e do coeficiente de transferência de calor foram realizadas para um HFC (R134a), dois HFOS (R1234ze(E) e R1234yf) e um alcano (R600a).

O R134a (1,1,1,2-tetrafluoroetano) é um hidrofluorcarboneto (HFC) frequente em aplicações de refrigeração como substituto dos clorofluorocarbonetos (CFCs), os quais apresentam fabricação restrita, devido ao elevado potencial de destruição da camada de ozônio. O R134a é um fluido de pressão intermediária. O R1234ze(E) (trans 1,3,3,3tetrafluoropropene) e o R1234yf (2,3,3,3-tetrafluoropropene) são hidrofluorolefinas (HFOs) criados recentemente visando substituir o R134a. OS HFOs apresentam potencial

\footnotetext{
${ }^{1}$ LEL é a sigla para "Lower Explosive Limit"
} 
de aquecimento global próximo a zero, ao contrário do R134a com potencial relativamente elevado. O isobutano (R600a) é um hidrocarboneto alifático saturado de formula $\mathrm{C}_{4} \mathrm{H}_{10}$, sendo utilizado em alguns países como fluido refrigerante em sistemas de refrigeração domestico e na indústria petroquímica.

A Tabela 5.8 ilustra uma comparação das propriedades físicas, químicas e termodinâmicas dos fluidos avaliados no presente estudo. A partir da análise desta tabela, conclui-se que os refrigerantes halogenados apresentam propriedades próximas, as quais diferem significativamente das propriedades do isobutano. Neste contexto, vale destacar que a entalpia de vaporização do isobutano a uma temperatura de saturação de $25^{\circ} \mathrm{C}$ é cerca de $85 \%$ superior aos demais fluidos.

Tabela 5.8. Propriedades físicas, químicas e termodinâmicas dos fluidos avaliados no presente estudo. ${ }^{1}$

\begin{tabular}{|c|c|c|c|c|}
\hline Propriedades & R134a & R1234ze(E) & R1234yf & R600a \\
\hline Peso molecular $[\mathrm{g} / \mathrm{mol}]$ & 102 & 114 & 114 & 58,12 \\
\hline Ponto de ebulição a pressão atmosférica $\left[{ }^{\circ} \mathrm{C}\right]$ & $-26,09$ & $-19,58$ & $-29,78$ & $-12,01$ \\
\hline Pressão critica $[\mathrm{kPa}]$ & 4059 & 3632 & 3382 & 3640 \\
\hline Temperatura critica $\left[{ }^{\circ} \mathrm{C}\right]$ & 101 & 109,4 & 94,7 & 134,7 \\
\hline Pressão de saturação a $25^{\circ} \mathrm{C}[\mathrm{kPa}]$ & 665,8 & 500.1 & 682.5 & 350,4 \\
\hline Densidade do líquido saturado a $25^{\circ} \mathrm{C}\left[\mathrm{kg} / \mathrm{m}^{3}\right]$ & 1207 & 1162 & 1092 & 549,9 \\
\hline Densidade do gás saturado a $25^{\circ} \mathrm{C}\left[\mathrm{kg} / \mathrm{m}^{3}\right]$ & 32,37 & 26,76 & 37,94 & 9,123 \\
\hline Relação de densidades a $25^{\circ} \mathrm{C}[-]$ & 37,27 & 43,44 & 28,79 & 60,27 \\
\hline $\begin{array}{l}\text { Condutividade térmica do líquido saturado a } \\
25^{\circ} \mathrm{C}[\mathrm{W} / \mathrm{m}-\mathrm{K}]\end{array}$ & 0,08323 & 0,07435 & 0,06525 & 0,08894 \\
\hline $\begin{array}{l}\text { Condutividade térmica do vapor saturado a } 25 \\
{ }^{\circ} \mathrm{C}[\mathrm{W} / \mathrm{m}-\mathrm{K}]\end{array}$ & 0,01456 & 0,009184 & 0,01096 & 0,01694 \\
\hline Viscosidade do líquido saturado a $25^{\circ} \mathrm{C}$ [Pa.s] & 0,0001944 & 0,0002034 & 0,0001611 & 0,00015 \\
\hline Viscosidade do gás saturado a $25^{\circ} \mathrm{C}$ [Pa.s $]$ & 0,00001197 & 0,00001497 & 0,00001222 & 0,000007739 \\
\hline Entalpia de vaporização a $25^{\circ} \mathrm{C}[\mathrm{KJ} / \mathrm{Kg}]$ & 177,8 & 166,5 & 146,4 & 329,1 \\
\hline Tensão superficial a $25^{\circ} \mathrm{C}[\mathrm{N} / \mathrm{m}]$ & 0,008028 & 0,008881 & 0,006173 & 0,009857 \\
\hline Fator de aquecimento global $(G W P)$ & 1430 & 7 & 4 & 3 \\
\hline $\begin{array}{l}\text { Potencial de destruição da camada de ozônio } \\
(O D P)\end{array}$ & 0 & 0 & 0 & 0 \\
\hline
\end{tabular}

\footnotetext{
${ }^{1}$ Informações adquiridas no programa Engineering Equation Solver, EES.
} 
A Tabela 5.9 apresenta a faixa de números de Reynolds coberta neste estudo para ensaios com escoamento monofásico. Valores superiores de número de Reynolds para os fluidos R1234ze(E) e R1234yf não foram possíveis devido a limitações impostas ao aparato pela reduzida quantidade de fluido disponível.

Tabela 5.9. Condições experimentais avaliadas para escoamento monofásico.

\begin{tabular}{cccc}
\hline Fluido & $\begin{array}{c}\text { Seção } \\
\text { transversal }\end{array}$ & $\boldsymbol{T}_{\text {ent }}\left[{ }^{\circ} \mathbf{C}\right]$ & $\boldsymbol{R} \boldsymbol{~ [ - ]}$ \\
\hline R134a & Circular & 20 & $200-10000$ \\
R134a & Quadrado & 20 & $300-9000$ \\
R134a & Triangular & 20 & $500-9000$ \\
R1234ze(E) & Circular & 20 & $500-6000$ \\
R1234yf & Circular & 20 & $300-7000$ \\
R600a & Circular & 20 & $300-7000$ \\
\hline
\end{tabular}

A Tabela 5.10 apresenta as condições experimentais avaliadas neste estudo para escoamentos bifásicos. As faixas de velocidade mássica para os testes em escoamentos bifásico com os fluidos R1234ze(E) e R1234yf foram também limitadas pela reduzida quantidade de fluido refrigerante disponível. Para o isobutano, a faixa de velocidades foi limitada pela ocorrência de efeitos severos de instabilidade no escoamento em vazões superiores.

Tabela 5.10. Condições experimentais avaliadas para escoamento bifásico.

\begin{tabular}{|c|c|c|c|c|c|c|c|c|}
\hline Fluido & $\begin{array}{c}\text { Seção } \\
\text { transversal }\end{array}$ & $\begin{array}{c}D_{H} \\
{[\mathrm{~mm}]}\end{array}$ & $\begin{array}{c}D_{e q} \\
{[\mathrm{~mm}]}\end{array}$ & $\begin{array}{c}\text { Parâmetro } \\
\text { estudado }\end{array}$ & $\boldsymbol{T}_{\text {sat }}\left[{ }^{\circ} \mathbf{C}\right]$ & $G\left[\mathrm{~kg} / \mathrm{m}^{2} \mathrm{~s}\right]$ & $x[-]$ & $\begin{array}{c}\phi \\
{\left[k W / m^{2}\right]}\end{array}$ \\
\hline $\mathrm{R} 134 \mathrm{a}$ & Circular & 1,1 & 1,1 & $\begin{array}{c}d p / d z \\
h\end{array}$ & $31 ; 41$ & $\begin{array}{c}400-1600 \\
100-700\end{array}$ & $0,05-0,95$ & $\begin{array}{l}\text { Adiab. } \\
15-85\end{array}$ \\
\hline R134a & Quadrado & 0,868 & 0,977 & $\begin{array}{c}d p / d z \\
h\end{array}$ & $31 ; 41$ & $\begin{array}{c}400-1600 \\
100-700\end{array}$ & $0,1-0,95$ & $\begin{array}{l}\text { Adiab. } \\
15-85\end{array}$ \\
\hline $\mathrm{R} 134 \mathrm{a}$ & Triangular & 0,634 & 0,835 & $\begin{array}{c}d p / d z \\
h\end{array}$ & $31 ; 41$ & $\begin{array}{c}400-1400 \\
100-700\end{array}$ & $0,1-0,95$ & $\begin{array}{l}\text { Adiab. } \\
15-85\end{array}$ \\
\hline R1234ze(E) & Circular & 1,1 & 1,1 & $\begin{array}{c}d p / d z \\
h\end{array}$ & $31 ; 41$ & $\begin{array}{l}100-600 \\
100-600\end{array}$ & $0,05-0,95$ & $\begin{array}{l}\text { Adiab. } \\
15-85\end{array}$ \\
\hline R1234yf & Circular & 1,1 & 1,1 & $\begin{array}{c}d p / d z \\
h\end{array}$ & $31 ; 41$ & $\begin{array}{l}100-400 \\
100-400\end{array}$ & $0,05-0,95$ & $\begin{array}{l}\text { Adiab. } \\
15-85\end{array}$ \\
\hline R600a & Circular & 1,1 & 1,1 & $\begin{array}{c}d p / d z \\
h\end{array}$ & $31 ; 41$ & $\begin{array}{l}100-500 \\
100-500\end{array}$ & $0,05-0,95$ & $\begin{array}{l}\text { Adiab. } \\
15-125\end{array}$ \\
\hline
\end{tabular}




\subsubsection{Procedimento de carga e descarga do fluido refrigerante}

Considerando que neste estudo foram avaliados 4 fluidos refrigerantes, fez-se frequente a necessidade de carga e descarga dos refrigerantes. O procedimento geral de carga e descarga do fluido inclui os seguintes passos:

A descarga do fluido se inicia com o resfriamento do reservatório de refrigerante com o intuito de drenar do circuito de testes para o reservatório a maior parcela possível do fluido. O reservatório do refrigerante é resfriado até temperaturas inferiores a $5^{\circ} \mathrm{C}$, através de uma serpentina em cujo interior circula água provinda do Reservatório II. Este tem a solução contida no interior resfriada através do fluido no Reservatório I, o qual contem uma serpentina na qual evapora fluido refrigerante proveniente do sistema de compressão de vapor;

Uma vez assegurado que a uma parcela significativa do fluido se encontra no reservatório do refrigerante, fecha-se as válvulas que conectam este reservatório ao circuito do refrigerante;

$>$ Conecta-se então o reservatório do refrigerante a um cilindro de armazenamento mediante um conjunto analisador manifold. Manipula-se as válvulas do manifold de forma a permitir o escoamento do fluido de testes do reservatório de refrigerante para o cilindro por diferença de pressões absolutas e de saturação. Vale destacar que o cilindro foi previamente evacuado e durante o processo de transferência mantem-se resfriado através de sua inserção em uma solução de agua e gelo;

Uma vez recuperado o fluido do reservatório do refrigerante, desconectase o cilindro do manifold, o qual é então estocado em local adequado;

Então realiza-se vácuo no circuito e reservatório do refrigerante ate uma pressão inferior a $1 \mathrm{kPa}$, com o intuito de eliminar vestígios do fluido anterior. Este vácuo é mantido durante período de 4 horas após o qual nitrogênio é inserido no circuito até alcançar uma pressão em torno a 12 bares. Mantem-se o circuito com nitrogênio durante 12 horas, após este período realiza-se um novo vácuo no circuito até uma pressão inferior a 1 $\mathrm{kPa}$, estando este então adequado para uma nova recarga de fluido de 
testes. Vazamentos através da constatação de variações significativas de pressão no circuito são verificados durante todo este processo;

$>$ Durante o processo de carga do fluido testes, inicialmente, resfria-se o reservatório do refrigerante através da circulação na serpentina em seu interior de água do Reservatório II;

O cilindro contendo o fluido a ser carregado é posicionado em uma altura superior a do reservatório do refrigerante do circuito de testes. Então, este é conectado ao reservatório do refrigerante mediante o manifold;

$>$ Uma vez o cilindro e reservatório conectados, manipula-se as válvulas do manifold de forma a proporcionar o escoamento do fluido para o reservatório do refrigerante. $\mathrm{O}$ procedimento é cessado e o manifold desconectado assim que alcançado a quantidade de refrigerante desejado no circuito de testes a qual é avaliada através de um dinamômetro.

\subsubsection{Procedimento experimental para escoamento monofásico}

O procedimento de ensaios para escoamento monofásico se inicia com o acionamento das bombas dos reservatórios I, II e III (ver Figura 5.2). Uma vez estabelecida a pressão no circuito do refrigerante, impõe-se a circulação do fluido de teste segundo uma determinada velocidade mássica estabelecida através do variador de frequência que atua na microbomba.

Para ensaios de perda de pressão monofásico, dados são adquiridos para determinada condição experimental após atingir condições de regime permanente.

Para ensaios visando o levantamento de resultados para o coeficiente de transferência de calor monofásico, fluxos de calor são impostos à seção de préaquecimento e de testes, de forma que o comprimento de desenvolvimento térmico ocorra na seção de pré-aquecimento e condições de mudança de fase não sejam alcançadas. Para isto, além da inspeção visual do escoamento, assegurasse um subresfriamento elevado do fluido refrigerante. Dados são adquiridos após atingir condições de regime permanente.

O regime permanente se caracteriza quando as oscilações dos parâmetros medidos (pressão de entrada, medidas dos termopares e diferencial de pressão) apresentam variações inferiores à incerteza de suas medidas. 


\subsubsection{Procedimento experimental para escoamento bifásico}

O procedimento experimental para a obtenção de dados de perda de pressão e coeficiente de transferência de calor em escoamento bifásico é descrito a seguir:

$>$ Os testes se iniciam com o acionamento das bombas dos Reservatórios I, II e III e da unidade condensadora (ver Fig. 5.1);

Então aciona-se a resistência elétrica do Reservatório II é impõe-se uma temperatura para este tanque através de um controlador PID atuando em um relé de estado solido responsável pela alimentação da resistência elétrica;

Após estabelecida a temperatura no reservatório II, progressivamente é estabelecida a temperatura do fluido no reservatório do refrigerante através da solução anti-congelante provinda do Reservatório II em uma serpentina localizada em seu interior;

> Uma vez estabelecida a temperatura e consequentemente a pressão de saturação no circuito, uma vazão mássica é especificada através do sistema de aquisição de dados e estabelecida através um controle PI com base no sinal do medidor de vazão. Este controlador PI atua no inversor de frequência que alimenta a microbomba;

$>$ Em seguida, aplica-se uma determinada pôtencia elétrica na seção de préaquecimento de forma a obter o título de vapor desejado na entrada da seção de testes (ponto D na Figura 5.8);

$>$ Dados para o perda de pressão são adquiridos para a condição desejada após a constatação do regime permanente;

> Uma vez adquiridos os resultados experimentais para uma condição experimental, a pôtencia fornecida na seção de pré-aquecimento é alterada de forma a ter-se um novo título de vapor na entrada da seção de testes;

> Uma vez adquirido resultados experimentais para uma condição de velocidade mássica, esta é alterada através do controlador PI na microbomba;

Para o levantamento de resultados para o coeficiente de transferência de calor, uma condição de fluxo de calor é aplicada também na seção de testes; 
Mudanças no título de vapor local, na posição desejada, são realizadas através do acréscimo da potência fornecida na fonte do pré-aquecedor;

Dados para o coeficiente de transferência de calor são adquiridos para a condição desejada após a constatação do regime permanente, o qual se caracteriza quando as oscilações dos parâmetros medidos (pressão de entrada, medidas dos termopares e diferencial de pressão) apresentam variações inferiores à incerteza de suas medidas;

Uma vez adquiridos os resultados experimentais para uma condição de velocidade mássica e diversos fluxos de calor, a velocidade mássica é alterada mediante o controlador PI na microbomba.

\subsection{Tratamento de dados}

Nesta seção são descritos os procedimentos e as hipóteses adotadas para a determinação dos parâmetros experimentais do escoamento bifásico, a perda de pressão na seção de testes e o coeficiente de transferência de calor local.

\subsubsection{Velocidade mássica}

A velocidade mássica é dada pela razão entre a vazão mássica fornecida pelo medidor tipo Coriolis e a área interna da seção transversal do canal, conforme a seguinte equação:

$G=\frac{\dot{m}}{A_{\text {in }}}$

A área interna da seção circular é calculada através da seguinte relação:

$$
A_{\text {in, }, \text { iirc }}=\frac{\pi D^{2}}{4}
$$

A área transversal do canal quadrado e triangular foram estimadas através do processamento de imagens similares as ilustradas na Figura 5.7, usando o programa MATLAB R2010a. Vale mencionar que foram utilizados 3 perfis de cada seção transversal para a estimativa de uma área média, a qual posteriormente foi empregada para o cálculo dos diâmetros hidráulico e equivalente. 


\subsubsection{Fluxo de calor}

Os fluxos de calor na seção de pré-aquecimento, $\phi_{p a}$, e de seção de teste, $\phi_{s t}$, são avaliados através da razão entre a potência elétrica efetiva e a área superficial interna do canal $\left(A_{S}\right)$. Nestes cálculos são considerados apenas os comprimentos aquecidos, isto é, as regiões compreendidas pelos terminais de alimentação de corrente contínua que são 200 e 150 mm para a seção de pré-aquecimento e de testes, respectivamente (ver Figura 5.8). Os fluxos de calor no pré-aquecedor e na seção de teste são dados respectivamente pelas seguintes equações:

$$
\begin{gathered}
\phi_{p a}=\frac{P_{p a, \text { efetivo }}}{A_{s, p a}}, \\
\phi_{s t}=\frac{P_{s t, e f e t i v o}}{A_{s, s t}}
\end{gathered}
$$

A potência elétrica efetiva é dada pela diferença entre a potência elétrica aplicada (produto entre a tensão e a corrente fornecidas pela fonte de corrente contínua) e a perda de calor para o ambiente:

$$
\begin{aligned}
& P_{p a, \text { efetivo }}=V_{p a} I_{p a}-Q_{p a, \text { perdido }} \\
& P_{\text {st,efetivo }}=V_{s t} I_{s t}-Q_{s t, \text { perdido }}
\end{aligned}
$$

O calor cedido para o ambiente é estimado experimentalmente com base em ensaio caracterizado pela imposição de uma pôtencia de aquecimento e a temperatura média da superfície aquecida e do ambiente verificadas após seus valores atingirem regime permanente. Uma vez alcançada tal condição, e tendo apenas vapor no interior do canal assume-se que para esta diferença de temperaturas entre a superfície e o ambiente toda a potência aplicada dissipa-se para o ambiente. Assim, variando-se a potência de aquecimento levantou-se os dados ilustrados na Figura 5.14 que inclui também uma curva ajustada a partir desses resultados, dada por: 
$Q_{\text {perdido }}=0,0112 \cdot\left(\bar{T}_{p}-T_{\text {amb }}\right)-0,0625$

onde $\bar{T}_{p}$ é a temperatura média da superfície estimada com base nos valores indicados pelos termopares posicionados na região aquecida.

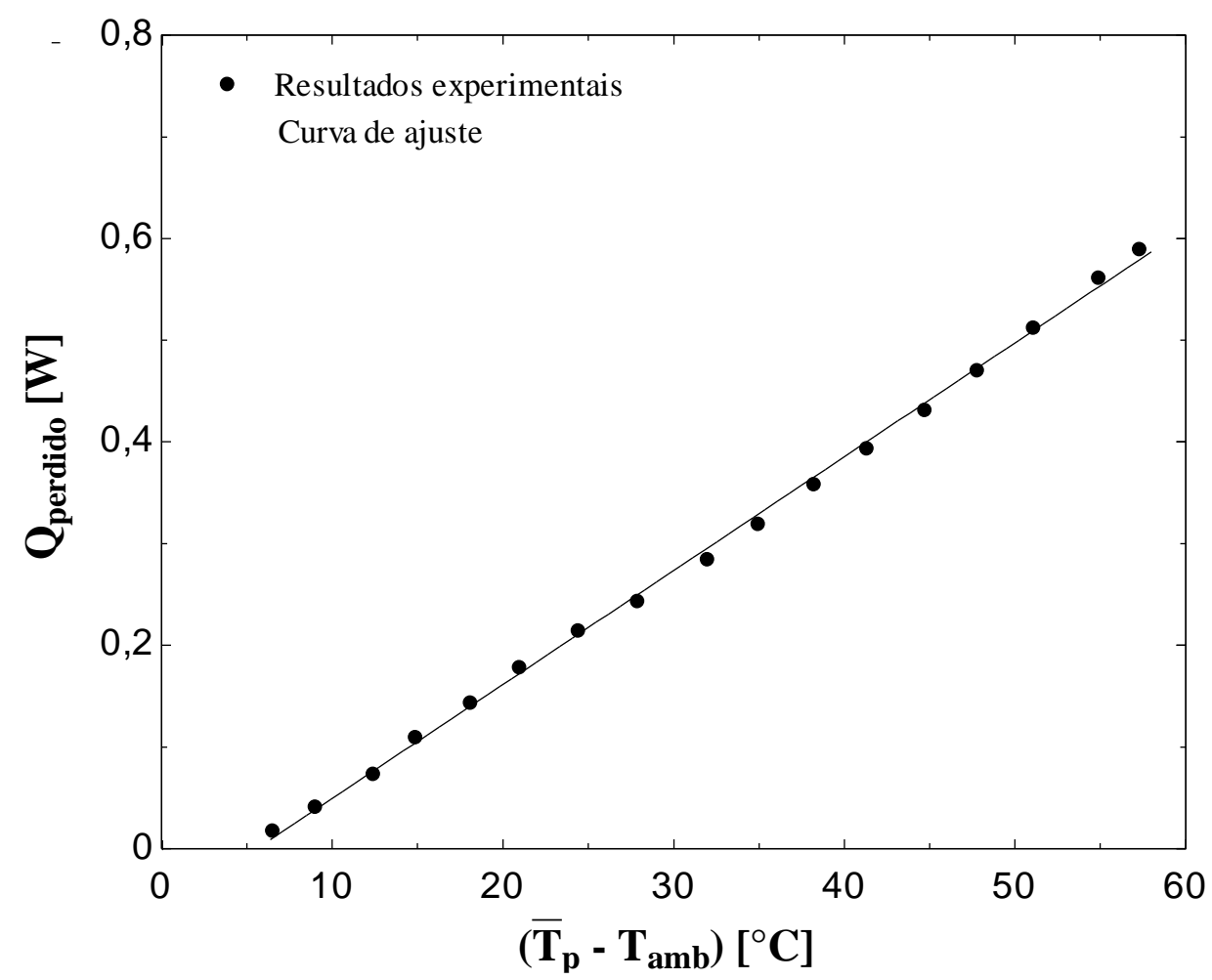

Figura 5.13. Estimativa da perda de calor na seçao de pré-aquecimento ou de testes para o ambiente em função da temperatura de ambiente.

As áreas superficiais internas são estimadas a partir de:

$A_{s, p a}=\pi D_{\text {int }} L_{p a}$

$$
A_{s, s t}=\pi D_{\text {int }} L_{s t}
$$

Nestes cálculos, assume-se a superfície do canal com espessura uniforme ao longo do seu perímetro e comprimento e composição homogênea. Desta forma, tem-se a hipótese de geração uniforme de fluxo de calor. 


\subsubsection{Comprimento de escoamento monofásico na seção de pré-aquecimento}

No presente estudo, a região a partir da qual o escoamento se torna bifásico corresponde àquela em que o título de vapor de equilíbrio termodinâmico apresenta valor nulo. Assim, o comprimento para o início do escoamento bifásico, $\mathrm{L}_{1 \phi}$ (ver Figura 5.8), é calculado a partir da solução simultânea de três equações. A primeira considera um balanço de energia ao longo do comprimento do pré-aquecedor, igualando-se a potência fornecida pela fonte de corrente contínua à variação de calor sensível do fluido refrigerante. A segunda equação está relacionada à variação de pressão devido à perda de pressão entre a entrada do pré-aquecedor e a região onde o fluido atinge a pressão de saturação e o escoamento se torna bifásico. A última relação trata-se de uma equação de estado relacionado a pressão e a temperatura de saturação, dada pela função " $T$ sat" do programa Equation Engineering Solver, EES (2009). As equações mencionadas são as seguintes:

$$
\begin{aligned}
& \phi_{p a} \cdot \pi \cdot D_{\text {int }} \cdot L_{1 \phi}=G \cdot A_{\text {int }} \cdot\left[i_{L}\left(T=T_{\text {sat }}\right)-i_{L, e n t}\right] \\
& p_{\text {sat }}=p_{\text {ent }}-\frac{f \cdot\left(L_{1 \phi}+L_{e n t, p a}\right) \cdot G^{2}}{2 \cdot D \cdot \rho_{L, e n t}} \\
& T_{\text {sat }}=T_{\text {sat }}\left(p=p_{\text {sat }}\right)
\end{aligned}
$$

\subsubsection{Temperatura de saturação local do fluido}

De acordo com Ribastki (2013), sob certas condições experimentais, é razoável assumir um perfil linear da pressão de saturação na seção de testes para a estimativa da temperatura de saturação local do fluido, sem implicar em erros significativos no calculo do CTC experimental. No entanto, neste estudo a temperatura de saturação local será estimada através do método de previsão da perda de pressão proposto neste estudo e apresentado no Capítulo 6.

A Figura 5.14 ilustra o perfil de temperaturas de saturação ao longo da seção de testes com base nos valores fornecidos pelos termopares assumindo a temperatura indicada por eles similar a temperatura de saturação no interior do canal, perfil linear, perfil baseado na perda de pressão estimada segundo o método de Müller-Steinhagen e 
Heck (1986) e segundo o método proposto no presente estudo. Conforme ilustrado, a adoção do perfil linear e os valores de temperatura de saturação fornecidos utilizando o método proposto neste estudo fornecem resultados dentro da faixa da incerteza da medida da temperatura. Tal resultado implica em erros no coeficiente de transferência de calor devido a adoção do método proposto de perda de pressão inferiores a 5\%. Já para o método de Müller-Steinhagen e Heck (1986) observa-se uma maior discrepância entre os valores previstos da temperatura de saturação local e a experimental.

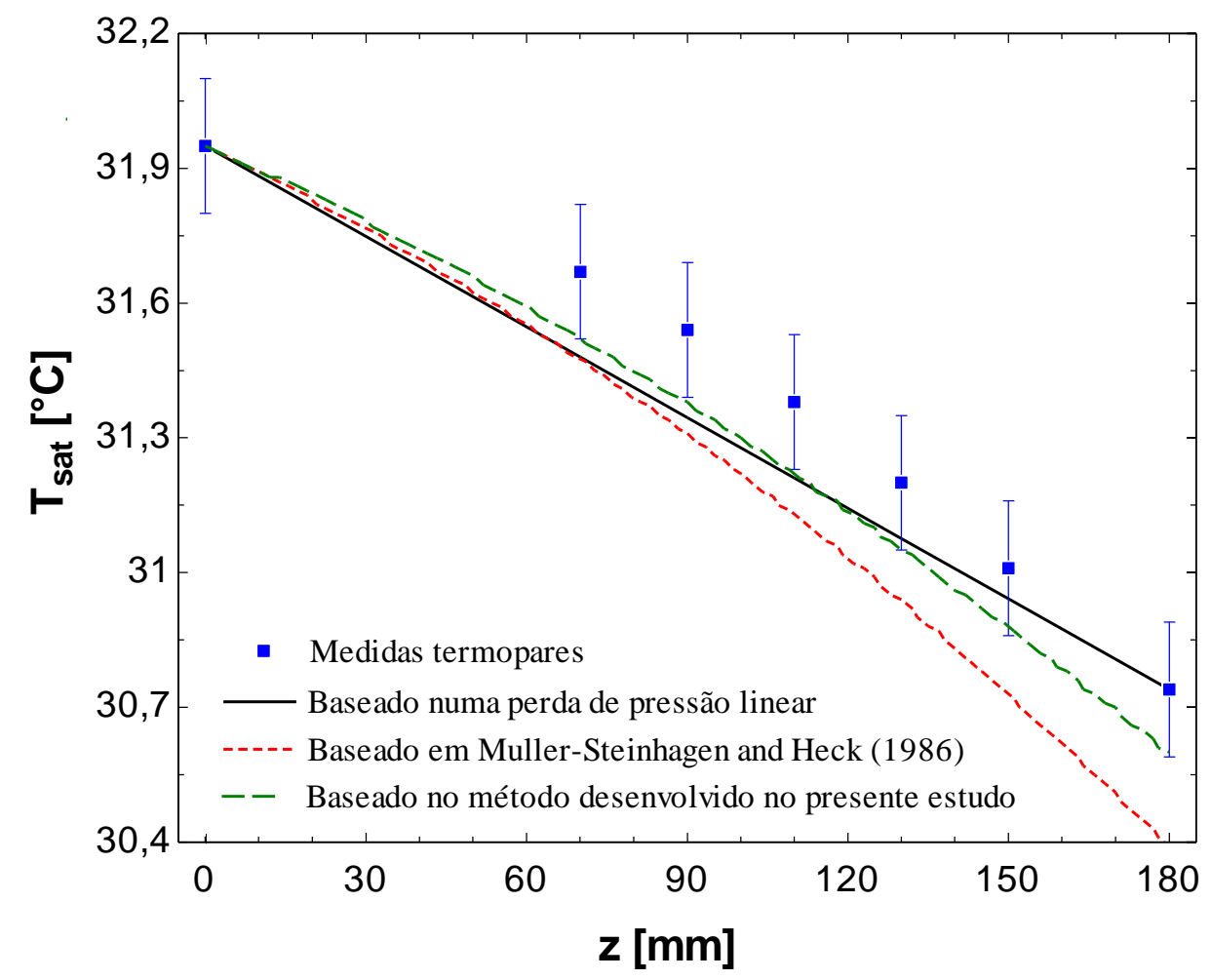

Figura 5.14. Comparação entre diversos métodos para a estimativa da temperatura local do fluido.

\subsubsection{Título de vapor}

O título de vapor local é estimado através de um balanço de energia entre a entrada do pré-aquecedor e a posição z ao longo da seção de testes, segundo a seguinte equação:

$$
\begin{aligned}
& x(z)=\frac{1}{i_{L G}(z)}\left[\frac{P_{s t, e f e t i v o}(z)+P_{p a, \text { efetivo }}}{\dot{m}}+\left(i_{L, \text { ent }}-i_{L}(z)\right)\right] \\
& P_{s t, \text { efetivo }}(z)=\phi_{s t} \cdot \pi \cdot D_{\mathrm{int}} \cdot z
\end{aligned}
$$


onde $i_{L, e n t}$ é a entalpia do líquido sub-resfriado na entrada do pré-aquecedor, $i_{L}(z)$ é a entalpia do líquido saturado na temperatura na posição $\mathrm{z}$, e $i_{L G}(z) e ́$ o calor latente de vaporização à temperatura na posição $\mathrm{z}$.

O título médio da seção de testes, necessário para a caracterização das condições experimentais do gradiente da perda de pressão na seção de testes, é dado por:

$$
\bar{x}_{s t}=\frac{x\left(L_{s t}\right)+x(0)}{2}=\frac{x_{s a i}+x_{D}}{2}
$$

\subsubsection{Perda de pressão em escoamento monofásico}

Dados experimentais para escoamento monofásico foram utilizados na validação do aparato experimental e do procedimento de regressão de dados. A correta estimativa da perda de pressão monofásica também é necessária para assegurar a precisão dos resultados para escoamento bifásico pois este são estimados subtraindo a parcela monofásica da perda de pressão total.

Para os testes com canal circular, a perda de pressão monofásica é dada pelo transdutor diferencial de pressão. Já, para os testes no canal com seção transversal quadrada e triangular, a perda de pressão medida pelo transdutor de pressão diferencial é a soma das seguintes parcelas: perda de pressão ao longo da parcela da seção transversal circular, perda de pressão ao longo da parcela da seção não-circular, e as perdas de pressão locais devido a contração e expansão do canal, conforme ilustrado na Figura 5.9. Portanto, para este caso a perda de pressão experimental na secão de testes é dada por:

$$
\Delta p_{f, s t}=\Delta p_{\text {medido }}-\left(\Delta p_{f, \text { circ }}+\Delta p_{\text {con }}+\Delta p_{\text {exp }}\right)
$$

onde a perda de pressão devido à expansão abrupta é estimada a partir da seguinte equação:

$$
\Delta p_{\exp }=\Delta p_{\exp , R}+\Delta p_{\exp , I}=\left(\sigma_{A}^{2}-1+K_{\exp }\right) \cdot \frac{G^{2}}{2 \rho_{L}}
$$


onde $K_{\text {exp }}$ é o coeficiente de perda local irreversível dado como função da relação das áreas das seções, do fator de correção da variação da quantidade de movimento do canal do inicio da expansão, $k_{\text {nao-circ, }}$ e do canal de saída, $k_{\text {circ }}$ :

$$
K_{\exp }=1-2 k_{\text {nao-circ }} \sigma_{A}+\sigma_{A}^{2}\left(2 k_{\text {circ }}-1\right)
$$

O fator de correção da variação da quantidade de movimento para escoamento laminar é 1,33, 1,377 e 1,41 para canal circular, triangular e quadrado, respectivamente. Estes valores foram estimados utilizando a correlação de Rehbock apud Chow (1959), dado por:

$$
k=\frac{\int_{0}^{A} v^{2} d A}{\bar{v}^{2} A} \approx 1+\frac{\left(v_{\max } / \bar{v}-1\right)^{2}}{3}
$$

onde $v_{\max } / \bar{v}$ são valores obtidos mediante Hagen-Pouseuille, Shah e London (1978) e Shah (1975) para canal circular, quadrado e triangular, respectivamente. Para regime turbulento, este fator de correção do momentum pode ser aproximado como a unidade $\left(k_{\text {nao-circ }} \approx k_{\text {circ }} \approx 1\right)$ e a Eq. 5.19 reduz-se à equação de Borda-Carnot.

De acordo com Kays (1950), a perda de pressão devido a uma contração abrupta pode ser estimada a partir da seguinte equação:

$$
\Delta p_{c o n}=\left[\frac{1-\beta_{c} \sigma_{A}^{2} C_{c}^{2}-2 C_{c}+2 C_{c}^{2} k_{\text {nao-circ }}}{C_{c}^{2}}\right] \cdot \frac{G^{2}}{2 \rho_{L}}
$$

onde $C_{c}$ é a relação de áreas da vena-contracta e da seção menor e $\beta_{c}$ e $k_{n a-c i r c}$ são os fatores de correção da energia cinética e da quantidade de movimento, respectivamente. O fator de correção da energia é igual a 2 para regime laminar e 1 para regime turbulento. A relação de áreas da vena-contracta e a seção do canal menor pode ser estimada através da correlação dada por Geiger (1964):

$$
C_{c}=1-\frac{1-\sigma_{A}}{2.08\left(1-\sigma_{A}\right)+0.5371}
$$




\subsubsection{Gradiente da perda de pressão por atrito em escoamento bifásico}

Para o canal circular estimou-se, a perda de pressão por atrito através da seguinte equação:

$\Delta p_{s t, f}=\Delta p_{\text {medido }}-\Delta p_{1 \phi}-\Delta p_{2 \phi, p a}-\Delta p_{a c c}$

onde $\Delta p_{\text {medido }}$ é a perda de pressão fornecida pelo transdutor diferencial de pressão, $\Delta p_{1 \phi}$ é a perda de pressão monofásica, $\Delta p_{2 \phi, p a}$ é a perda de pressão bifásica ao longo da seção de pré-aquecimento e $\Delta p_{a c c}$ é a perda de pressão aceleracional referente à parcela bifásica ao longo do pré-aquecedor e da seção de teste.

Estima-se a perda de pressão monofásica, $\Delta p_{1 \phi}$, conforme procedimento descrito na Seção 5.4.6 e no comprimento monofásico correspondente determinado conforme a Seção 5.4.3.

A perda de pressão bifásica ao longo da seção de pré-aquecimento, $\Delta p_{2 \phi, p a}$, é estimada através de um processo iterativo considerando a soma da perda de pressão em 100 elementos discretos compreendendo o inicio da região saturada no pré-aquecedor, correspondendo ao término da região monofásica $(x=0)$, e o final da seção de preaquecimento. Neste procedimento, as propriedades termodinâmicas e de transporte são calculadas localmente baseadas na temperatura de saturação média de cada elemento. A parcela de perda de pressão por atrito correspondente a cada elemento foi calculada segundo o método de previsão desenvolvido no presente estudo, cuja descrição encontrase no Capítulo 6. No entanto, na primeira iteração, o método de Müller-Steinhagen e Heck (1986) foi adotado para a previsão da perda de pressão por atrito bifásica ao longo do préaquecedor. Posteriormente, novos dados de $\Delta p_{s t}$ foram obtidos resultando em um novo método de previsão para perda de pressão, e consequentemente novos valores para $\Delta p_{2 \phi, p a}$ eram estimados. Tal procedimento foi repetido até a convergência da solução, caracterizada por uma diferença entre valores sucessivos da perda de pressão bifásica ao longo da seção de teste inferiores a $10^{-3} \mathrm{kPa} / \mathrm{m}$.

A perda de pressão medida pelo transdutor de pressão diferencial não foi considerada adequada para a estimativa da perda de pressão para canais não-circulares devido a presença de singularidades (contração e expansão) ao longo do tubo. Na 
literatura, encontram-se reportados número razoável de métodos de previsão da perda de pressao bifásica através de contrações e expansões abruptas para canais convencionais. No entanto, como mencionado por Abdelall et al. (2005), Chalfi e Ghiaasiaan (2008) e Chen et al. (2010), estes métodos não são recomendados para escoamentos bifásicos em canais de dimensões reduzidas. Por este motivo, Abdelall et al. (2005), Chen et al. (2010) e mais recentemente Kawahara et al. (2015) desenvolveram novos métodos para a previsão da perda de pressão em singularidades em microcanais. No entanto, estes métodos estão baseado em resultados experimentais para misturas de dois fluidos (água/ar, água/ $\mathrm{N}_{2}, \mathrm{HF} 7200 / \mathrm{N}_{2}$ e etanol/ $\mathrm{N}_{2}$ ), os quais diferenciam-se dos resultados para refrigerantes devido à tensão superficial e a relação de densidades líquido/gás para líquidos não-condensáveis apresentarem valores entre 8 e 15 vezes superiores aos da maioria dos refrigerantes.

Desta forma, estimou-se o gradiente de perda de pressão por atrito para os canais quadrado e triangular com base nas pressões de saturação locais, calculadas a partir das temperaturas fornecidas pelos termopares, conforme a seguinte equação:

$$
\left(\frac{d p}{d z}\right)_{s t}=\frac{\left(p_{D}-p_{E}\right)-\Delta p_{a c, D-E}}{L_{s t}+2 \cdot L_{2}}
$$

onde $p_{E}$ e $p_{D}$ são estimados mediante as temperaturas fornecidas pelos termopares localizados nos pontos $\mathrm{D}$ e $\mathrm{E}$ e a perda de pressão aceleracional estimada segundo a seguinte equação:

$$
\Delta p_{a c, e n t-s a i}=G^{2}\left\{\left[\frac{x_{s a i}^{2}}{\rho_{G, s a i} \alpha_{s a i}}+\frac{\left(1-x_{s a i}\right)^{2}}{\rho_{L, s a i}\left(1-\alpha_{s a i}\right)}\right]_{s a i}-\left[\frac{x_{e n t}^{2}}{\rho_{G, e n t} \alpha_{e n t}}+\frac{\left(1-x_{e n t}\right)^{2}}{\rho_{L, e n t}\left(1-\alpha_{e n t}\right)}\right]_{D}\right\}
$$

onde $x_{s a i}$ e $x_{D}$ são calculados através da Eq. 5.12. As frações de vazio $\alpha_{s a i}$ e $\alpha_{D}$ são estimadas utilizando o método recentemente proposto por Kanizawa e Ribatski (2015).

\subsubsection{Coeficiente de transferência de calor}

Calcula-se o coeficiente de transferência de calor local através da Lei de resfriamento de Newton, conforme a seguinte equação: 
$h(z)=\frac{\phi_{s t}}{T_{p}(z)-T_{s a t}(z)}$

onde a temperatura local interna de parede, $T_{p}(z)$, é estimada através da lei de Fourier, assumindo condução unidimensional e superfície externa adiabática.

Para a seção circular é dada por:

$$
T_{p}(z)=T_{i}(z)+\frac{\dot{q}}{16 k} \cdot\left(D_{e x t}^{2}-D_{i n t}^{2}\right)-\frac{\dot{q}}{8 k} \cdot D_{e x t}^{2} \cdot \ln \left(\frac{D_{e x t}}{D_{\text {int }}}\right)
$$

já, para as seções com paredes planas é dada por:

$$
T_{p}(z)=T_{i}(z)+\frac{\dot{q}}{2 k} \cdot x^{2}
$$

onde independentemente da geometria $\dot{q}$ é estimado como:

$$
\dot{q}=\frac{P_{s t, e f e t i v o}}{\frac{\pi}{4} \cdot\left(D_{\text {ext }}^{2}-D_{\text {int }}^{2}\right) \cdot L_{s t}}
$$

Para estes cálculos adota-se a condutividade térmica do aço inoxidável AISI 304 como $16,3 \mathrm{~W} / \mathrm{m} . \mathrm{K}^{1}$. O coeficiente de transferência de calor médio ao longo do perímetro das seções de teste circular e quadrada é dado por:

$$
\bar{h}=\frac{h_{\text {topo }, z}+h_{\text {base }, z}}{2}
$$

Já, para o canal de seção transversal triangular o coeficiente de transferência de calor médio ao longo do perímetro é dado por:

$$
\bar{h}=\frac{h_{\text {base }, z}+2 \cdot h_{\text {lateral }, z}}{3}
$$

\footnotetext{
${ }^{1}$ Valor fornecido pelo programa Engineering Equation Solver, EES.
} 


\subsection{Validação do aparato experimental}

Esta seção trata da validação do aparato experimental e dos procedimentos de redução de dados a partir dos parâmetros medidos.

\subsubsection{Balanço de energia}

Balanços de energia ao longo da seção de teste em escoamento monofásico foram realizados com o objetivo de avaliar a taxa efetiva de calor transferida das fontes de corrente contínua para o fluido de trabalho e, desta forma, assegurar a estimativa adequada do título de vapor e da temperatura local do fluido. Para tal avaliação foi calculada a taxa de calor transferida para o ambiente em relação à potência fornecida às superfícies aquecida, dada pela seguinte equação:

$$
\frac{\Delta E}{E}=\frac{\left[\dot{m}\left(i_{\text {sai }}-i_{\text {ent }}\right)-\left(P_{p a, \text { efetivo }}+P_{\text {st, efetivo }}\right)\right]}{P_{p a, \text { efetivo }}+P_{\text {st,efetivo }}} \times 100
$$

Através desta análise verificou-se perdas inferiores a 10\%, independentemente da geometria da seção de testes, é fato que os erros relativos decrescem com o acréscimo da velocidade mássica e da potência fornecida. Além disso, vale destacar que em condições de ebulição convectiva o coeficiente de transferência de calor apresenta um valor 5 vezes superior ao de convecção forçada monofásica, o que implica em uma redução significativa das perda de calor para o ambiente.

\subsubsection{Resultados para perda de pressão monofásica}

Nesta análise adotou-se a hipótese do escoamento monofásico estar hidrodinamicamente desenvolvido na entrada da seção de pré-aquecimento devido a existência de uma seção de visualização de $100 \mathrm{~mm}$ de comprimento a montante dela.

A Figura 5.15 ilustra a comparação entre resultados teóricos e experimentais para a perda de pressão em escoamento monofásico para tubulação circular. Nesta comparação, para o levantamento das curvas correspondentes as previsões da perda de pressão monofásica adotou-se o fator de atrito segundo a teoria laminar (HagenPousiuille) e conforme Blasius (1913) para escoamento turbulento. Na figura constata-se 
que os dados experimentais para escoamento laminar e turbulento coincidem satisfatoriamente com as previsões. Em particular, no caso de regime turbulento a perda de pressão segundo Blasius (1913) prevê os resultados com um EMA de apenas 8,1\%.

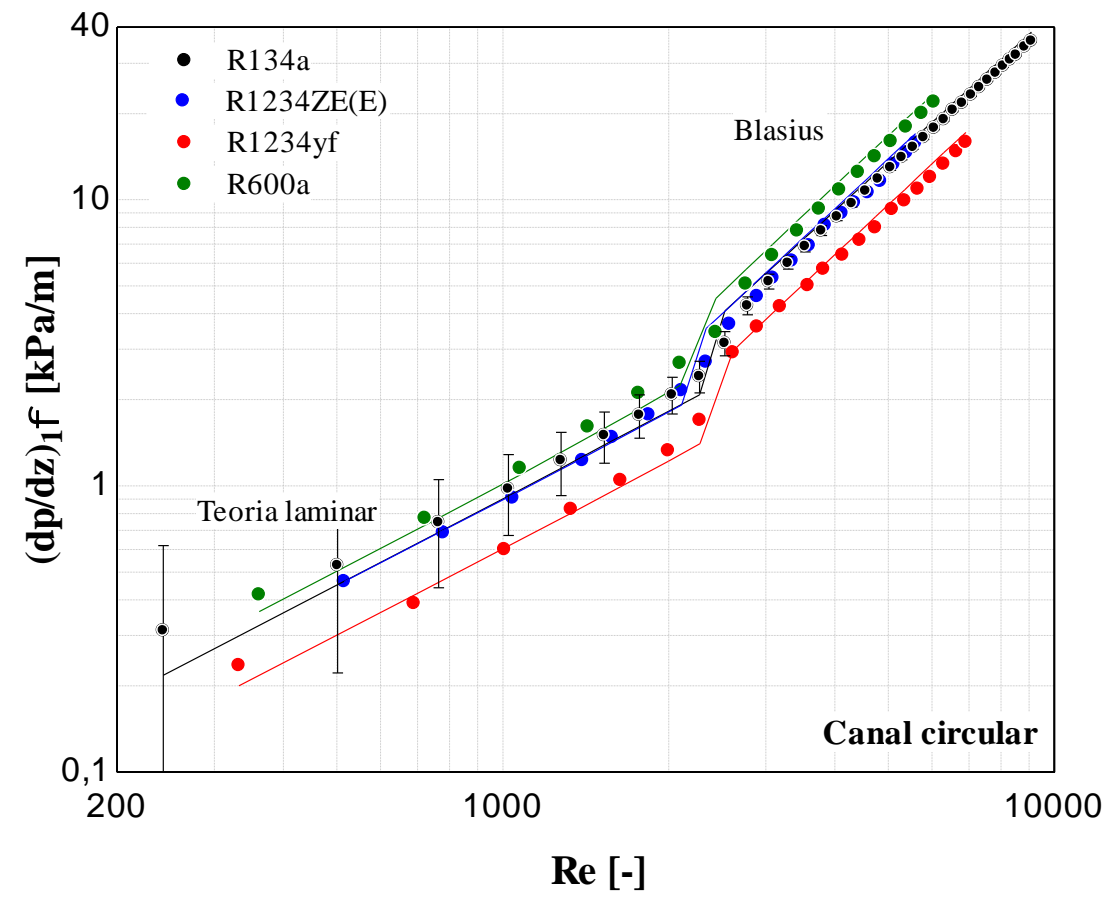

Figura 5.15. Gradiente da perda de pressão monofasica para os testes em canal circular.

Para canais de seção transversal não-circular, a dimensão característica adequada é ainda um tema controverso na literatura. A maioria dos estudos da literatura indica o uso do diâmetro hidráulico como dimensão característica. Entretanto a literatura reporta que este procedimento superestima os resultados experimentais para perda de pressão para canais não-circulares em regime turbulento (ver CLAIBORNE, 1952 e ALTEMANI; SPARROW, 1980).

Jones Jr (1976) propôs uma modificação do diâmetro hidráulico incluindo nele uma função do fator de forma (ver Apêndice A). Mediante esta modificação, Jones Jr. (1976) indica que correlações desenvolvidas para a previsão do fator de atrito em canais circulares tornam-se adequadas para a comparação com resultados experimentais em canais retangulares. Ahmed e Brundrett (1971) recomendaram uma nova dimensão característica para canais com seções transversais segundo polígonos regulares dada pela soma da maior e menor distâncias do centro à parede (isovels), conforme ilustrado na Figura 5.17. 


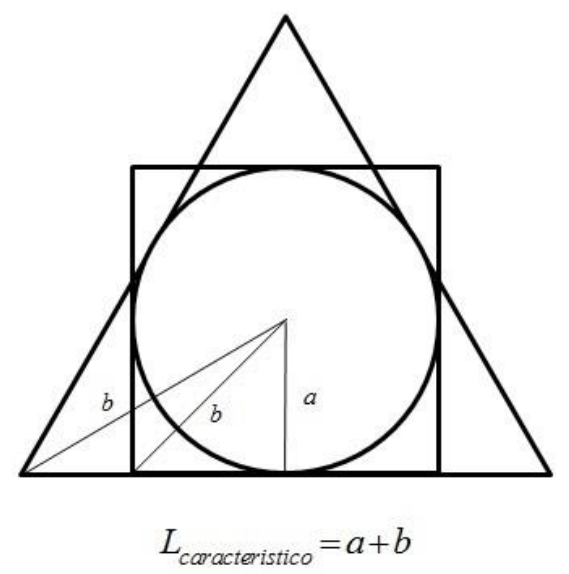

Figura 5.16. Dimensão caracteristica para poligonos regulares segundo Ahmed e Brundrett (1971).

Bandopadhayay e Ambrose (1980) também propuseram uma dimensão característica para canais não-circulares, definida como a média da distância da parede ao ponto de máxima velocidade. Para canais retangulares os autores obtiveram a seguinte correlação para a distância característica:

$L_{\text {caracteristico }}=\min (l, w) \cdot[2(1-\varsigma)+1,1226 \varsigma]$

onde $l$ e $w$ são os lados do canal retangular e $\varsigma$ o fator de forma.

Bahrami et al. (2006) recomendou em substituição do diâmetro hidráulico a raiz quadrada da área da seção transversal, $\sqrt{A}$, como dimensão característica para canais não circulares. Os autores propuseram novas correlações baseadas nas soluções analíticas para regime laminar considerando um número de Reynolds baseado na raiz quadrada da área como dimensão característica. Duan et al. (2012) indicaram que a raiz quadrada da área da seção transversal como dimensão característica proporciona concordância satisfatória entre resultados experimentais para canais não-circulares e as correlações propostas para canais circulares. No entanto, estes autores implementaram uma alteração no método de Blasius variando a constante multiplicativa de 0,0791 para o caso de dutos circulares, para 0,0767 para o Reynolds baseado em $\sqrt{A}$ aplicado a seções nãocirculares.

Neste contexto, no presente estudo adotou-se o diâmetro equivalente como a dimensão característica para canais de seção transversal não-circular, parâmetro relacionado à raiz quadrada da área $\left(D_{e q}=\sqrt{4 A / \pi}\right)$. Desta forma, a adaptação das 
correlações desenvolvidas para canais circulares em escoamentos turbulentos, como realizada por Duan et al. (2012), torna-se desnecessária.

Para escoamento laminar plenamente desenvolvido, Shah e London (1978) propuseram uma solução analítica para o fator de atrito num canal retangular, o qual adaptado para o número de Reynolds baseado no diâmetro equivalente é dado por:

$$
f=\frac{24\left(1-1.3553 \zeta+1.9467 \zeta^{2}-1.7012 \zeta^{3}+0.9564 \zeta^{4}-0.2537 \zeta^{5}\right)}{\operatorname{Re}_{D e q}} \cdot \frac{D_{e q}}{D_{H}}
$$

onde $\zeta$ é o fator de forma do canal retangular e $\operatorname{Re}_{D e q}$ é o número de Reynolds baseado no diâmetro equivalente.

Para canais triangulares em regime laminar plenamente desenvolvido, Shah (1975) propuseram uma solução analítica para o fator de atrito, a qual adaptads para o número de Reynolds baseado no diâmetro equivalente é dada por:

$$
f=\frac{15.993}{\operatorname{Re}_{D e q}} \cdot \frac{D_{e q}}{D_{H}}
$$

Vale mencionar que o escoamento em canais não-circulares está considerado plenamente desenvolvido, devido a que o comprimento entre a entrada da seção de préaquecimento e o começo da seção não-circular corresponde a mais de 250 vezes o diâmetro, $250 D$.

A Figura 5.17 ilustra resultados do gradiente da perda de pressão para o canal quadrado em escoamento monofásico. Como observado na figura, a teoria laminar de Shah e London (1978) proporciona estimativas satisfatórias dos dados experimentais, resultando um erro absoluto médio de 3\%. Para regime turbulento, as correlações de Blasius (1913) e Petukhov (1970) utilizando o diâmetro equivalente como dimensão característica proporcionam resultados razoáveis, obtendo EMAs de 13,1 e 15,4\% respectivamente. 


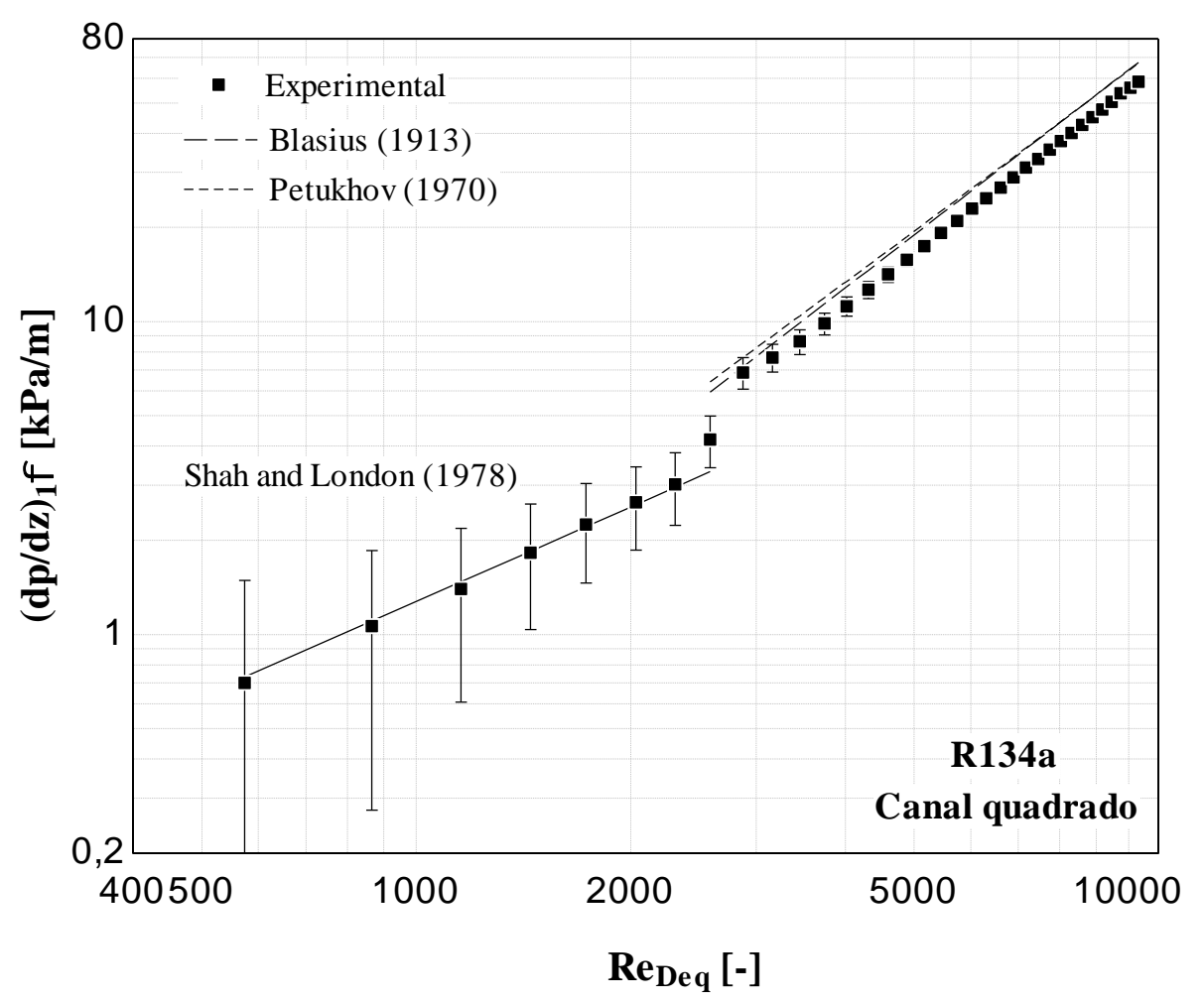

Figura 5.17. Gradiente da perda de pressão monofásica para os testes em canal quadrado.

A Figura 5.18 ilustra resultados do gradiente da perda de pressão monofásico para o canal triangular. Para escoamento laminar, pode-se observar que correlação de Shah (1975) proporciona previsões satisfatórias dos resultados experimentais, fornecendo um erro absoluto médio de 7\%. Para escoamento turbulento, os métodos de Blasius (1913) e Petukhov (1970) proporcionam previsões satisfatórias dos dados experimentais, fornecendo EMAs inferiores a $8 \%$. Por outro lado, é importante mencionar que a soma das perdas de pressão por contração e expansão varia entre 0,04 a 3,4\% da perda de pressão total para canais não-circulares. Portanto, esta estimativa das perdas de pressão locais é próxima a incerteza das medições e desta forma poderia ter sido desprezada.

Como observado, para escoamento turbulento, as correlações para perda de pressão monofásica proporcionam resultados satisfatórios para os dados experimentais dos 4 fluidos (R1234a, R1234ze(E), R1234yf e R600a) e também para canais nãocirculares (quadrado e triangular) utilizando o diâmetro equivalente como dimensão característica. Para escoamento laminar em canais não-circulares, os métodos analíticos de Shah e London (1975) e Shah (1975), também proporcionam previsões satisfatórias. 


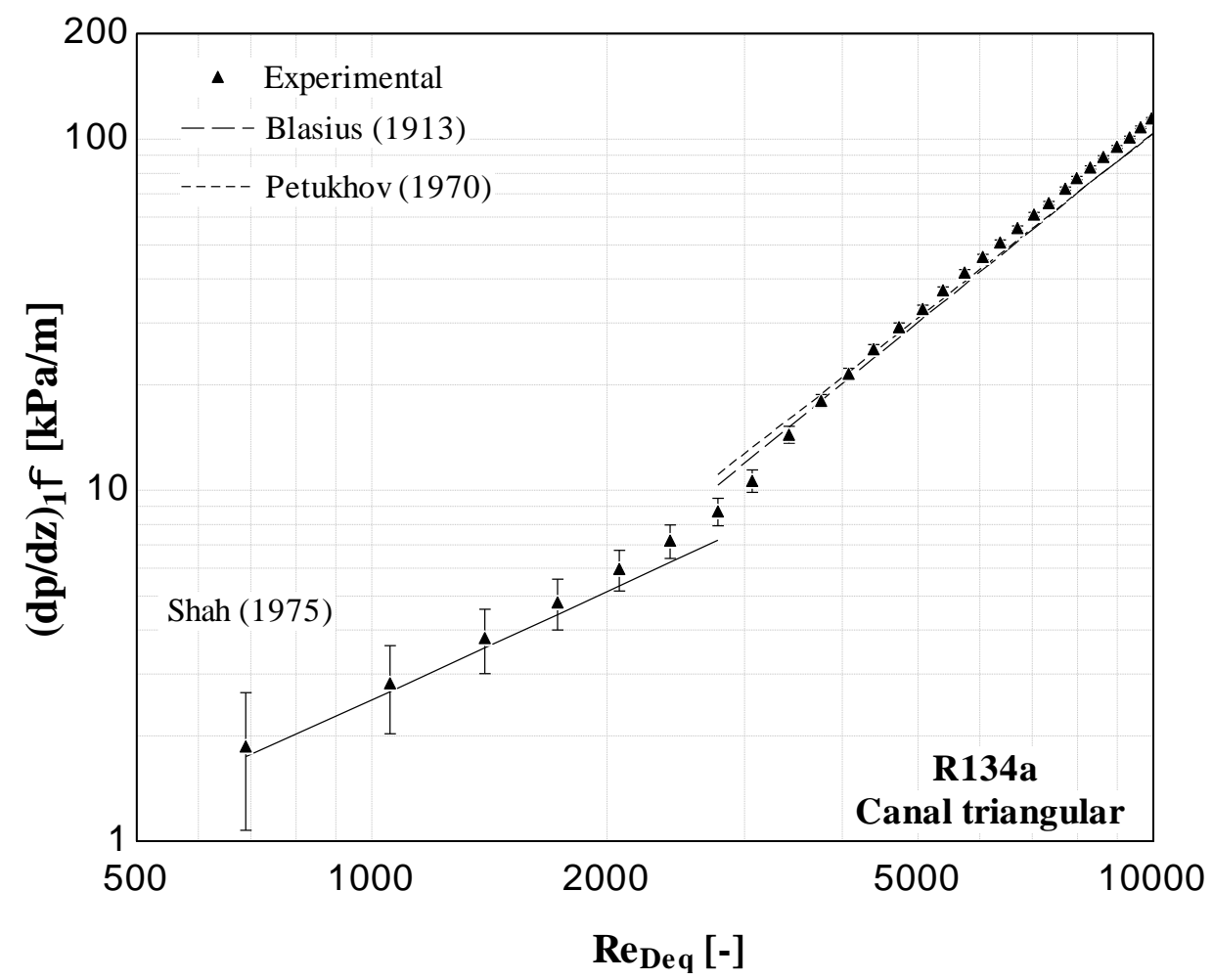

Figura 5.18. Gradiente da perda de pressão monofásica para os testes em canal triangular.

\subsubsection{Resultados para coeficiente de transferência de calor monofásico}

Experimentos para o coeficiente de transferência de calor monofásico são importantes devido a permitirem validar o balanço de energia, e consequentemente, a temperatura local do fluido e o título de vapor para ensaios em ebulição convectiva.

O comprimento necessário para atingir uma condição de escoamento termicamente desenvolvido segundo Kays e Crawford (1993) no regime turbulento é 60D. Portanto, o coeficiente de transferência de calor monofásico foi estimado considerando o último termopar da seção de testes, com o intuito de garantir um escoamento termicamente desenvolvido para regime turbulento. Já, para regime laminar, o comprimento da seção de testes aquecida não é suficiente para alcançar a condição de termicamente desenvolvido e assim os resultados experimentais foram comparados com a correlação de Siegel et al. (1958), que é indicada para canais circulares com escoamento termicamente em desenvolvimento.

A Figura 5.19 ilustra comparações entre valores estimados segundo métodos de previsão da literatura e os resultados experimentais levantados no presente estudo para o 
coeficiente de transferência de calor monofásico em tubo circular. De uma maneira geral, conforme indicado nesta figura, a correlação de Siegel et al. (1958) para escoamento laminar em desenvolvimento captura adequadamente as tendências dos resultados experimentais, entretanto, subestima os valores em cerca de $20 \%$. Já para regime turbulento, a correlação de Gnielinski (1976) fornece estimativas satisfatórias dos dados experimentais independentemente do fluido avaliado. No entanto, as diferenças entre resultados estimados e experimentais tende a se elevar com o incremento do número de Reynolds.

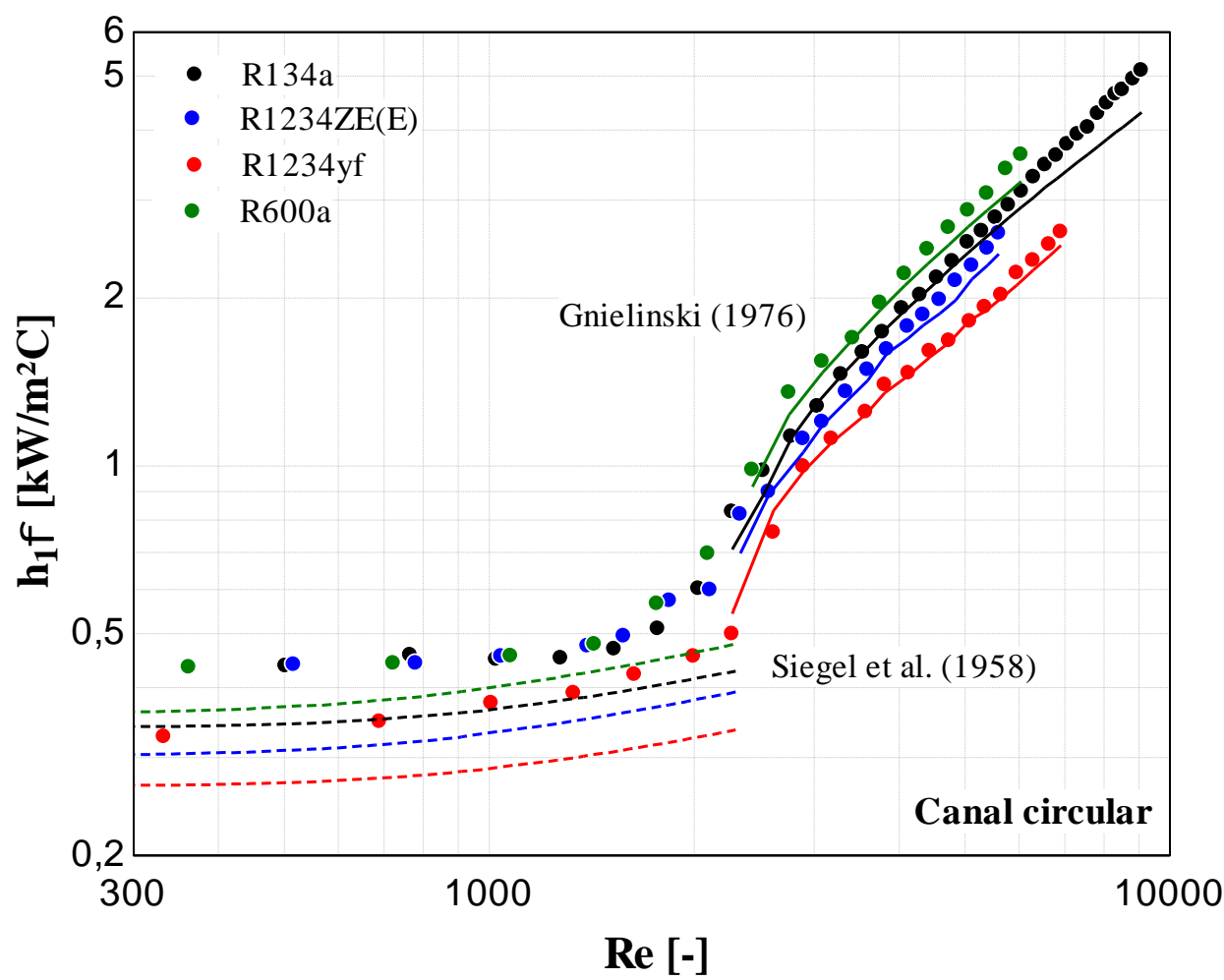

Figura 5.19. Coeficiente de transferência de calor monofásico para os fluidos testados.

A Figura 5.20 ilustra o coeficiente de transferência de calor monofásico experimental para o fluido R134a e as diferentes geometrias avaliadas neste estudo. Os métodos para escoamento laminar termicamente em desenvolvimento de Siegel et al. (1958), Chandrupatla e Sastri (1977) e Wibulswas (1960) foram utilizados para canais circulares, quadrados e triangulares, respectivamente.

De forma análoga ao observado na Figura 5.20, a Figura 5.21 ilustra que os métodos para escoamento termicamente em desenvolvimento proporcionam estimativas inferiores aos dados experimentais das geometrias quadrada e triangular, no entanto, vale 
mencionar que estes métodos capturam adequadamente a tendência do acréscimo do CTC monofásico com o número de Reynolds. Para regime turbulento termicamente desenvolvido, o método de Gnielinski (1976) estimou resultados próximos aos experimentais para as geometrias quadrada e circular. No entanto, para a geometria triangular os valores estimados são até $15 \%$ inferiores para números de Reynolds elevados.

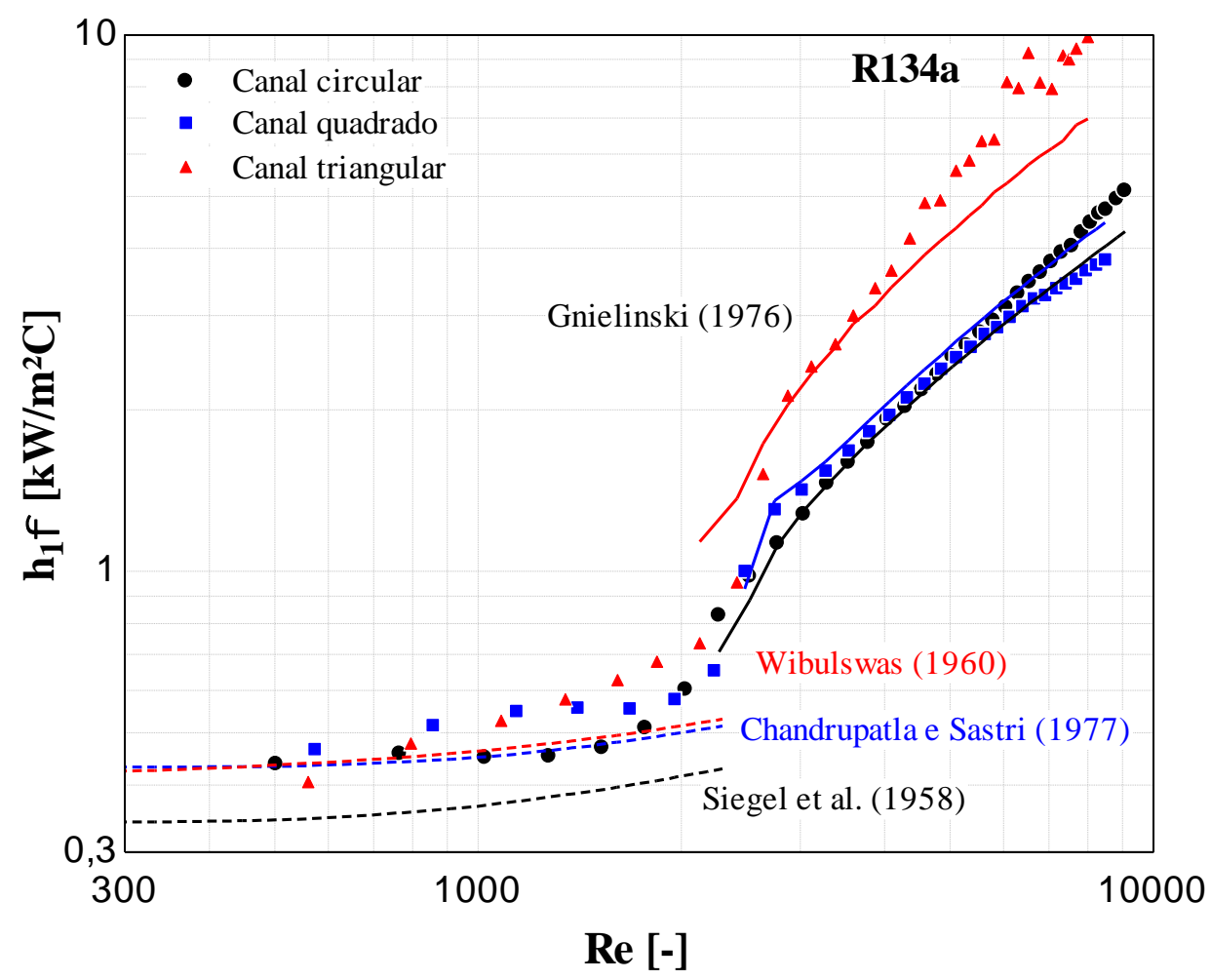

Figura 5.20. Coeficiente de transferência de calor monofásico para as diversas geometrias testadas.

\subsubsection{Repetitividade dos experimentos}

Com o objetivo de avaliar a repetitividade dos experimentos, resultados para ebulição convectiva para as mesmas condições experimentais foram obtidos com intervalos aproximados de 3 semanas. Este período envolveu o início e o final dos testes para uma determinada condição experimental caracterizada pelo par geometria da seção transversal e fluido refrigerante. Estes resultados encontram-se ilustrados na Figura 5.22. Nesta figura constata-se que as diferenças entre os resultados são inferiores às incertezas em suas medições. Tal fato indica a manutenção e repetitividade dos dados ao longo do tempo. 


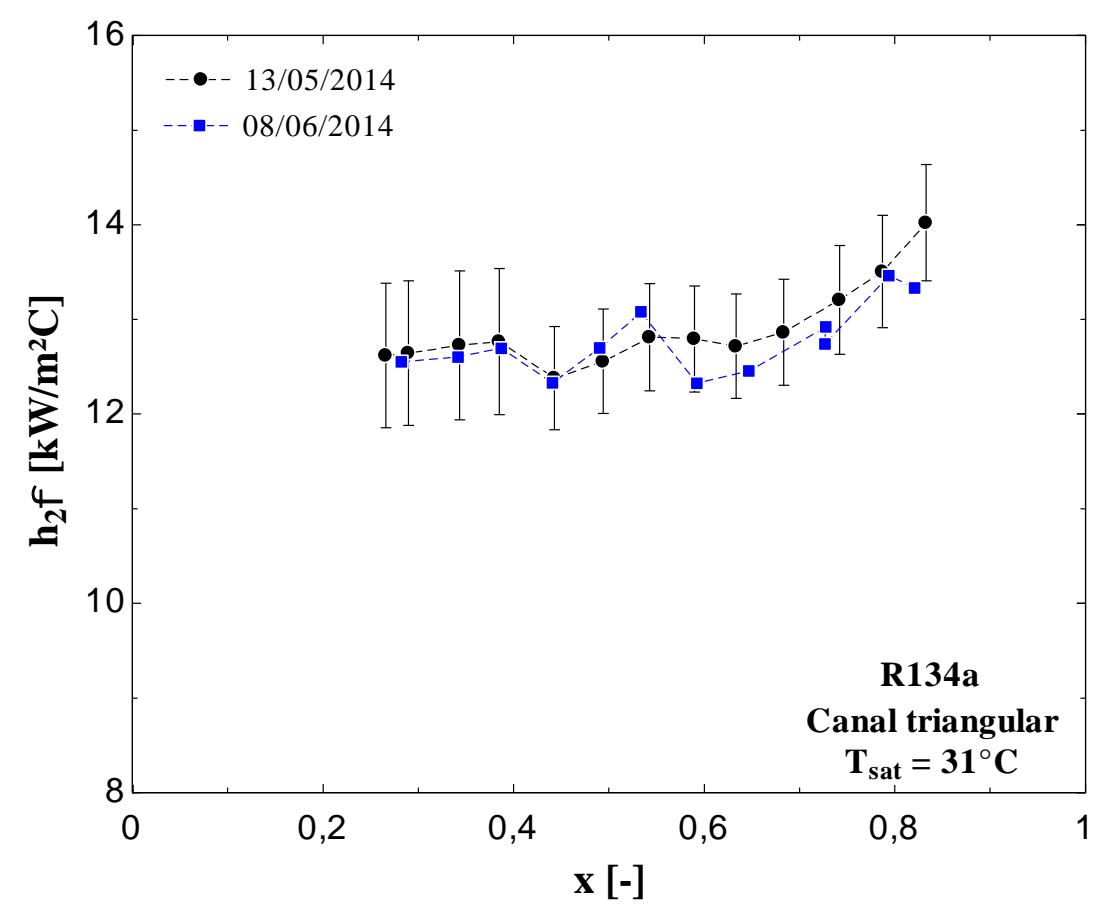

Figura 5.21. Comparação dos resultados para CTC durante a ebuliçao convectiva levantados em diferentes datas para o canal triangular, $\mathrm{G}=500 \mathrm{~kg} / \mathrm{m}^{2} \mathrm{~s}$ e $\phi=55 \mathrm{~kW} / \mathrm{m}^{2}$.

\subsection{Incertezas de parâmetros medidos e estimados}

A incerteza dos termopares foi estimada segundo o procedimento proposto por Abernethy e Thompson (1973). Para determinar os erros experimentais dos parâmetros medidos foram utilizados os erros dos instrumentos de medição segundo especificações técnicas e manuais fornecidos pelo fabricante. O cálculo de incertezas dos parâmetros estimados for realizado através do método de perturbação sequencial apresentado por Taylor e Kuyatt (1994) e dado pela seguinte equacão:

$U_{Y}=\sqrt{\sum_{i=1}^{n}\left(\frac{\partial Y}{\partial X_{i}}\right)^{2} U_{X_{i}}}$

onde $U_{Y}$ é a incerteza estimada da variável $Y$ e $U_{X}$ a incerteza da variável medida $\mathrm{X}_{\mathrm{i}}$. $\mathrm{O}$ calculo de incertezas foi realizado no programa EES.

Todas as incertezas associadas aos parâmetros medidos e estimados encontram-se listados na Tabela 5.11. 
Tabela 5.11. Incertezas dos parâmetros medidos e estimados.

\begin{tabular}{cc|cc}
\hline $\begin{array}{c}\text { Parâmetro } \\
\text { medido }\end{array}$ & Incerteza & $\begin{array}{c}\text { Parâmetro } \\
\text { estimado }\end{array}$ & Incerteza \\
\hline$D$ & $20 \mu \mathrm{m}$ & $D_{e q}$ & $\square, \Delta:<20 \mu \mathrm{m}$ \\
$L_{p a}, L_{s t}$ & $1 \mathrm{~mm}$ & $x$ & $<5 \%$ \\
$p$ & $4,5 \mathrm{kPa}$ & $G$ & $<2 \%$ \\
$\Delta p$ & $150 \mathrm{~Pa}$ & $(d p / d z)_{2 \phi}$ & $\bigcirc:<10 \%$ \\
$P_{p a}, P_{s t}$ & $0,8 \%$ & $(d p / d z)_{2 \phi}$ & $\square, \Delta:<20 \%$ \\
$T$ & $0,15{ }^{\circ} \mathrm{C}$ & $h_{2 \phi^{*}}$ & $\phi$ reduzido: $7-18 \%$ \\
$\dot{m}$ & $0,1 \%$ & $h_{2 \phi^{* *}}$ & $\phi$ elevado: $4-6 \%$ \\
\hline
\end{tabular}

** Fluxos de valor elevados correspondem a valores superiores a $45 \mathrm{~kW} / \mathrm{m}^{2}$. 



\section{CAPÍtulo 6 - RESUltados PARA PERdA DE PRESSÃo E DESENVOLVIMENTO DE UM MÉTODO DE PREVISÃO}

\subsection{Introdução}

Este capítulo apresenta inicialmente a descrição e caracterização do banco de dados levantado para a perda de pressão durante escoamento bifásico em condições adiabáticas. Segue, uma análise detalhada do comportamento do gradiente de pressão com a variação da velocidade mássica, título de vapor, temperatura de saturação, geometria da seção transversal e fluido de trabalho. Posteriormente, os métodos de previsão da literatura são comparados ao banco de dados experimental. Finalmente, o capítulo apresenta o desenvolvimento de um novo método de previsão, o qual é comparado com o banco de dados experimental levantado neste estudo e resultados independentes levantados na literatura.

\subsection{Descrição e caracterização do banco de dados experimental}

A Tabela 6.1 apresenta uma descrição detalhada do banco de dados de perda de pressão para escoamento bifásico em condições adiabáticas levantado no presente estudo. Este banco de dados compreende 1468 resultados experimentais, envolvendo 4 fluidos, 3 geometrias de seção de testes e uma ampla faixa de velocidades mássicas.

Tabela 6.1. Condições experimentais do banco de dados levantado no presente estudo.

\begin{tabular}{|c|c|c|c|c|c|c|}
\hline Fluido & & R134a & & R1234ze(E) & R1234yf & R600a \\
\hline Geometria & Circular & Quadrada & Triangular & Circular & Circular & Circular \\
\hline $\mathrm{D}_{\mathrm{H}}[\mathrm{mm}]$ & 1,1 & 0,868 & 0,634 & 1,1 & 1,1 & 1,1 \\
\hline $\mathrm{G}\left[\mathrm{kg} / \mathrm{m}^{2} \mathrm{~s}\right]$ & $400-1600$ & $400-1600$ & $400-1500$ & $100-600$ & $100-400$ & $100-500$ \\
\hline $\mathrm{T}_{\text {sat }}\left[{ }^{\circ} \mathrm{C}\right]$ & $31-41$ & $31-41$ & $31-41$ & $31-41$ & $31-41$ & $31-41$ \\
\hline$x[-]$ & $0,08-0,96$ & $0,05-0,97$ & $0,048-0,97$ & $0,05-0,98$ & $0,092-0,98$ & $0,055-0,98$ \\
\hline $\begin{array}{c}d p / d z \\
{[\mathrm{kPa} / \mathrm{m}]}\end{array}$ & $8,7-411,4$ & $13,7-610,3$ & $12,3-920,5$ & $1,75-186,1$ & $1,75-62,2$ & $3,55-293,8$ \\
\hline $\mathrm{N}^{\circ}$ de dados & 253 & 295 & 365 & 229 & 140 & 186 \\
\hline
\end{tabular}


A Figura 6.1 ilustra a distribuição do banco de dados segundo as condições experimentais. De acordo com a Figura 6.1a, parcela aproximada de 55\% dos dados corresponde a seção transversal circular, com as geometrias quadrada e triangular correspondendo respectivamente a 20 e $25 \%$ dos resultados. Devido a limitações operacionais do aparato experimental e reduzida disponibilidade dos fluidos de trabalho, apenas parcelas entre 10 e 15\% do banco de dados compreendem os fluidos R1234ze(E), R1234yf e R600a, resultando em mais de 60\% dos dados correspondentes ao fluido R134a. De acordo com a Figura 6.1c, cerca de 60\% dos dados foram levantados para temperatura de saturação aproximada de $31^{\circ} \mathrm{C}$ e ,consequentemente, $40 \%$ para temperatura de saturação de $41^{\circ} \mathrm{C}$.
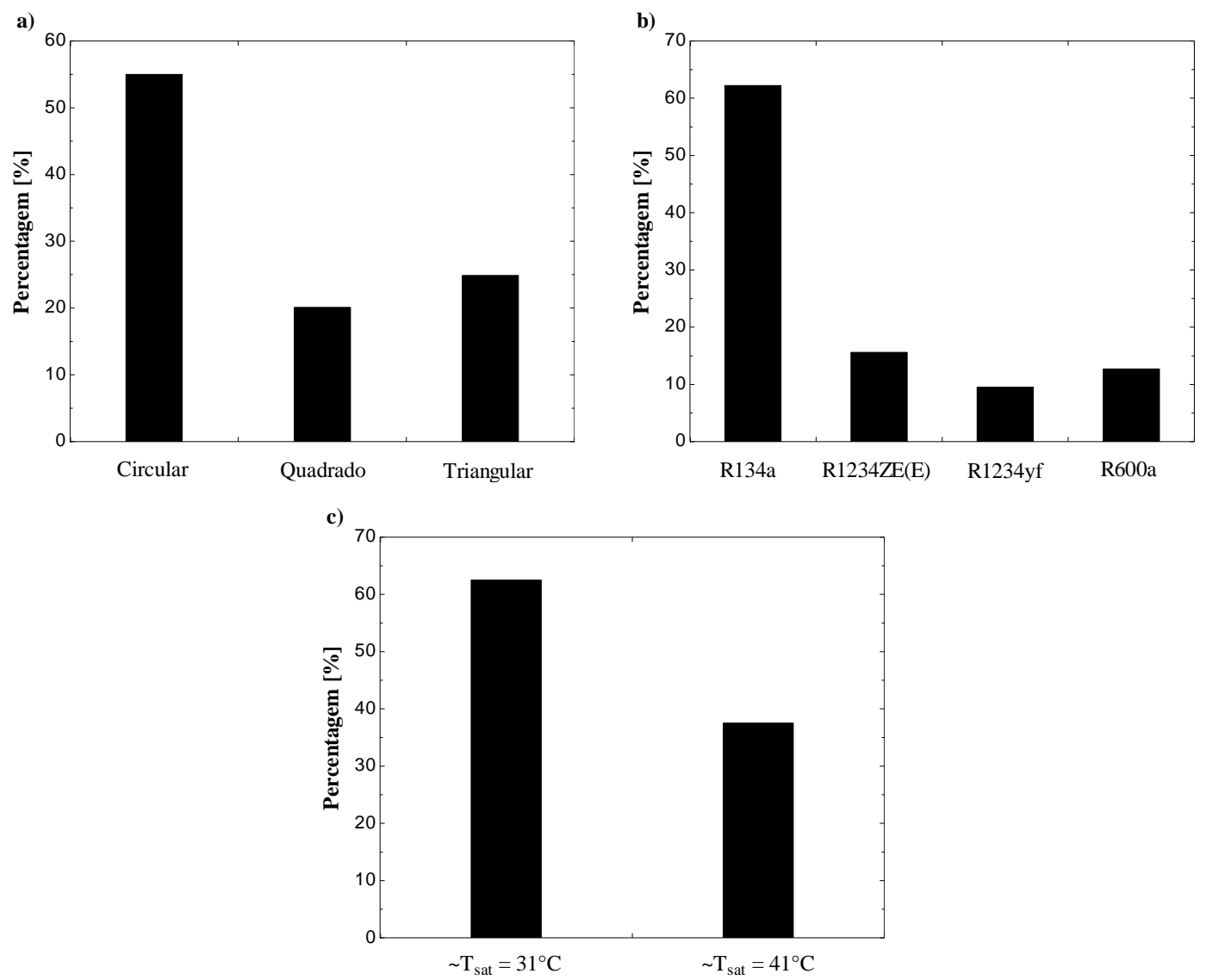

Figura 6.1. Distribuição do banco de dados experimental correspondente a: a) geometria da seção transversal, b) fluido de trabalho e c) temperatura de saturação.

A Figura 6.2 ilustra a distribuição dos dados experimentais segundo as faixas de velocidades mássicas e títulos de vapor. Pode-se observar que aproximadamente $70 \%$ dos dados experimentais correspondem a velocidades mássicas inferiores a $800 \mathrm{~kg} / \mathrm{m}^{2}$. Segundo a Figura 6.2b, a maior parcela dos dados (superior a 90\%) corresponde a títulos 
de vapor entre 0,1 e 0,9. Entretanto, verifica-se também um número razoável de resultados experimentais para títulos de vapor superiores a 0.9 .
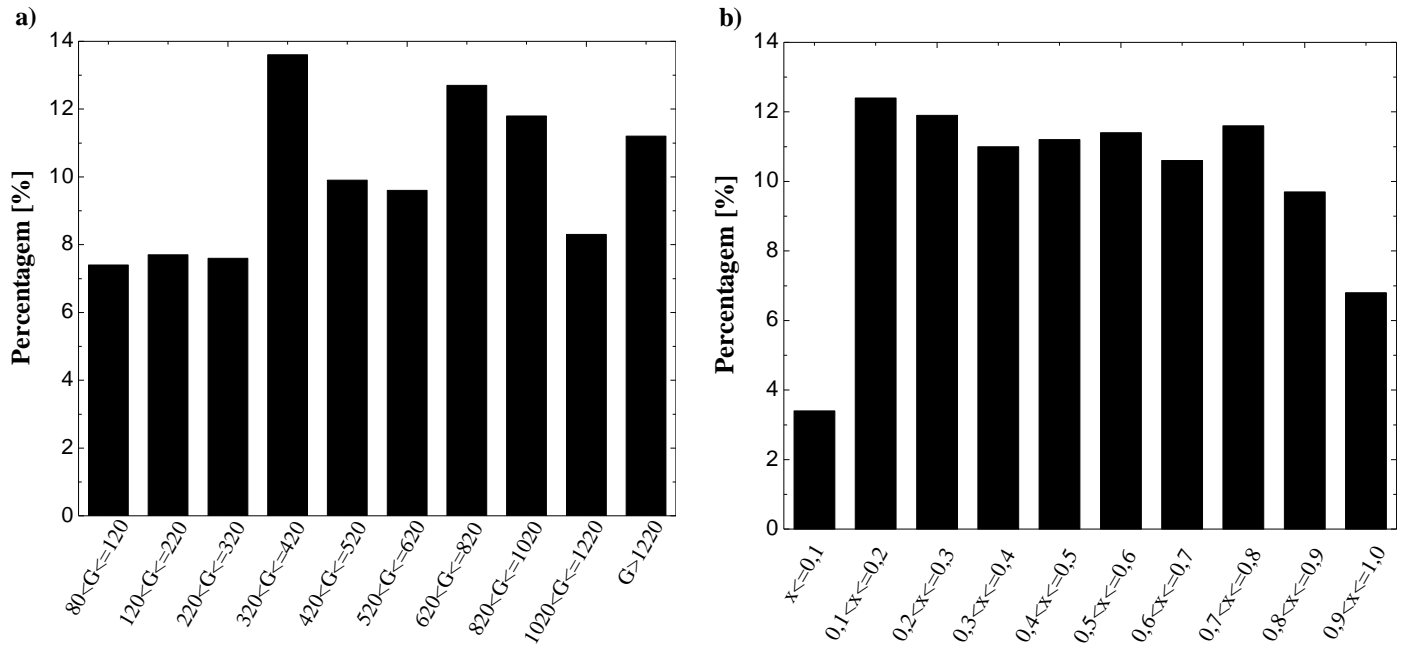

Figura 6.2. Distribuição do banco de dados experimental segundo as faixas de: a) velocidades mássicas e b) títulos de vapor.

A Figura 6.3 ilustra a distribuição dos resultados experimentais de acordo a faixa do gradiente de perda de pressão. Nesta figura nota-se que a maior parcela dos dados concentra-se em valores inferiores a $150 \mathrm{kPa} / \mathrm{m}$. Valores superiores a $400 \mathrm{kPa} / \mathrm{m}$ também são observados correspondendo a parcela aproximada de $7 \%$ dos dados. Tais resultados correspondem a condições de elevada velocidade mássica e as seções quadrada e triangular para o refrigerante R134a.

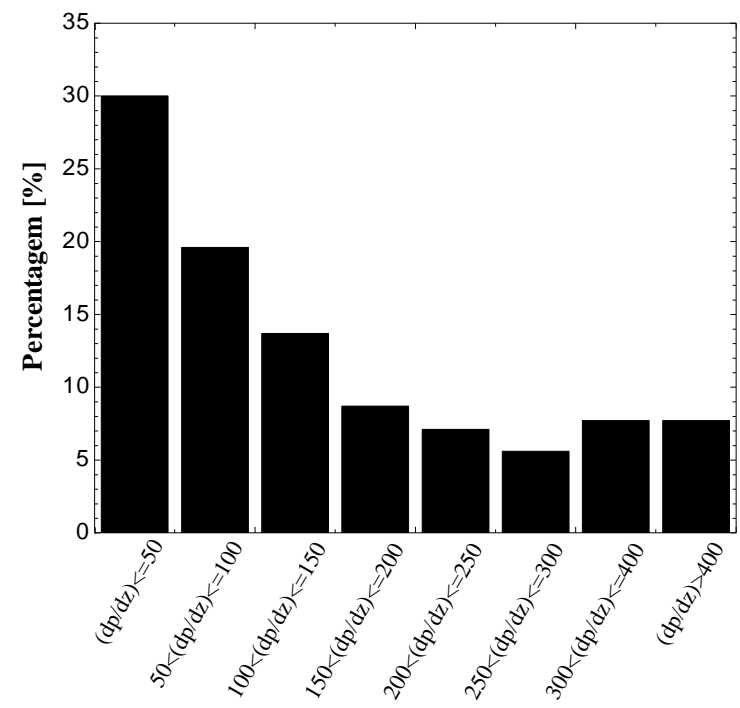

Figura 6.3. Distribuição do banco de dados experimental segundo os resultados de gradiente de pressão. 
A Figura 6.4 ilustra a distribuição dos regimes de escoamento do banco de dados experimental baseado no número de Reynolds das fases. Considerando transição entre regime laminar e turbulento em número de Reynolds igual a 2000, observa-se que 937 dados correspondem à região líquido-laminar/gás-turbulento, 499 dados à região líquidoturbulento/gás-turbulento e apenas 32 à região gás-laminar/líquido-laminar-outurbulento.

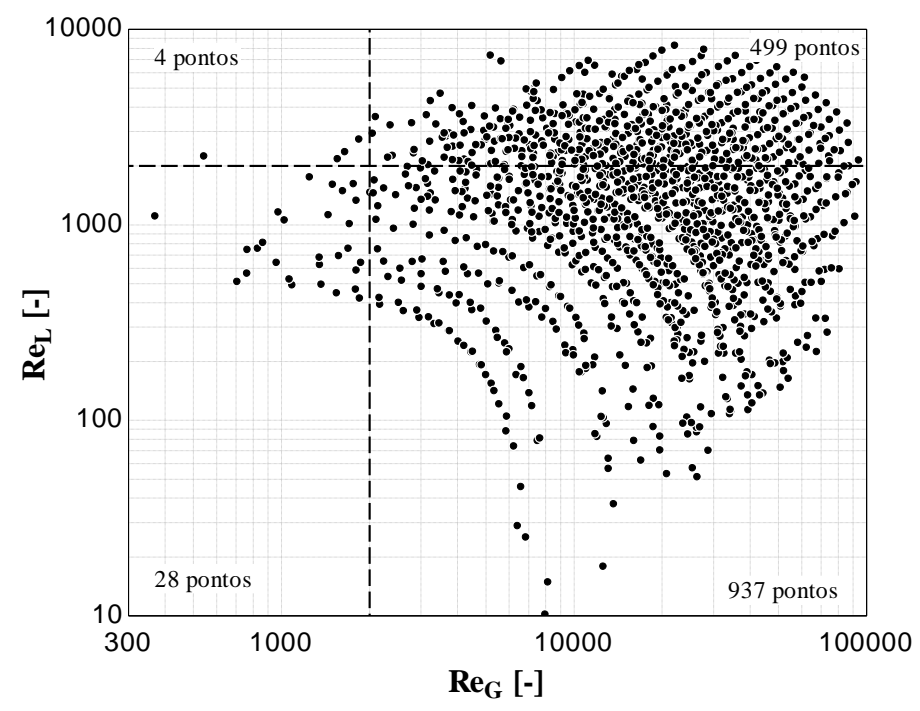

Figura 6.4. Distribuição dos regimes de escoamento do banco de dados experimental baseado no número de Reynolds das fases separadas.

\subsection{Análise paramétrica dos resultados experimentais}

Esta seção apresenta a análise paramétrica dos resultados experimentais, identificando os efeitos na perda de pressão da velocidade mássica, título de vapor, temperatura de saturação, fluido refrigerante e geometria da seção transversal.

\subsubsection{Efeitos da velocidade mássica e título de vapor}

A Figura 6.5 ilustra resultados de perda de pressão por atrito levantados para escoamento bifásico. Nota-se nesta figura que o gradiente de perda de pressão se eleva com o incremento da velocidade mássica. Também identifica-se que o gradiente da perda de pressão passa por um máximo com o incremento do título de vapor a partir do qual seu valor decresce drasticamente. Este pico desloca-se para títulos de vapor inferiores com o incremento da velocidade mássica, comportamento não constatado para a geometria triangular (ver Figura 6.5c). 
a)

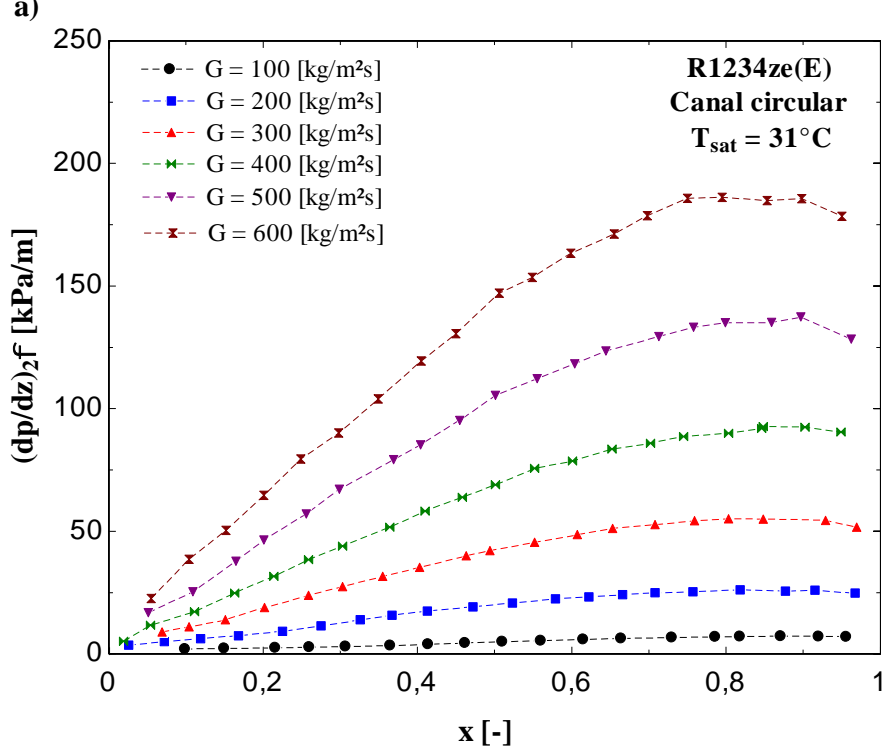

b)

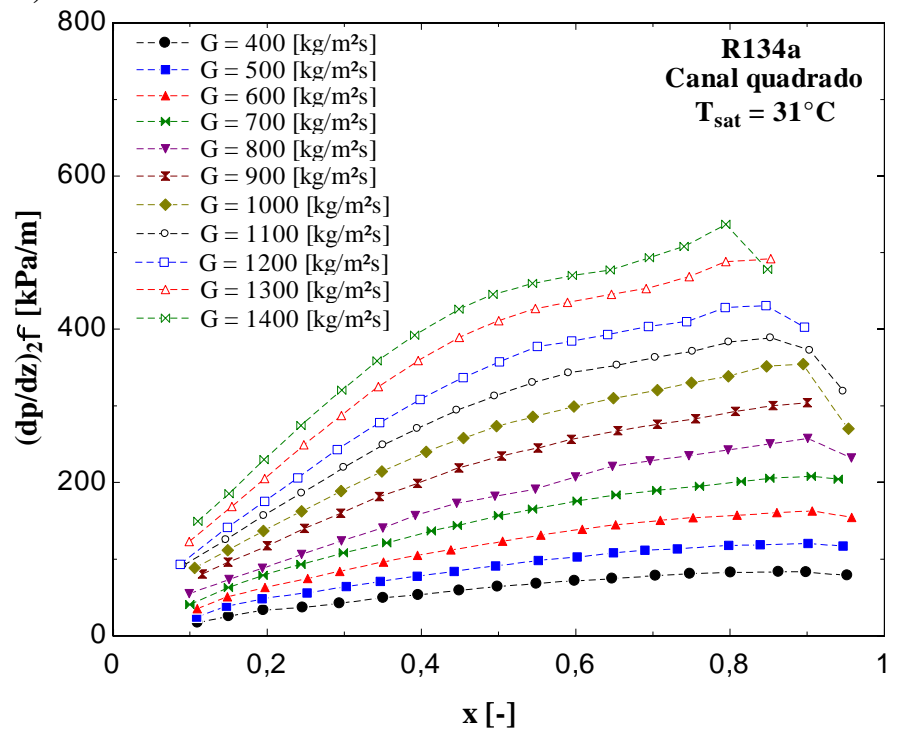

c)

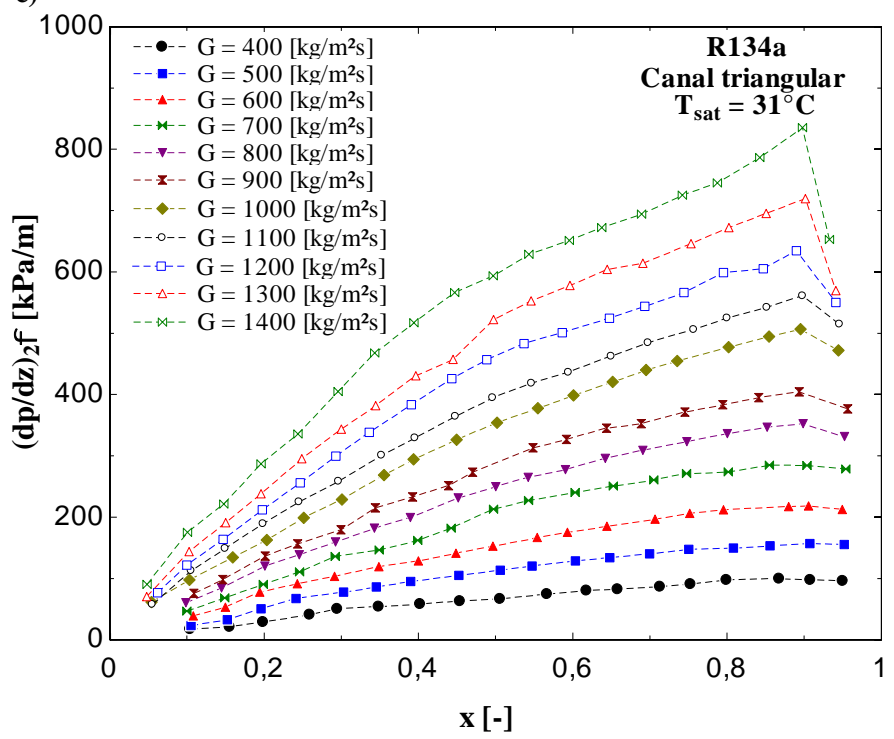

Figura 6.5. Ilustração do efeito da velocidade mássica no gradiente da perda de pressao. 


\subsubsection{Efeito da temperatura de saturação}

Conforme ilustrado na Figura 6.6, constata-se a redução da perda de pressão com o incremento da temperatura de saturação. Tal comportamento decorre do fato do volume específico da fase vapor decrescer com o incremento da temperatura de saturação, resultando no decréscimo da velocidade superficial da mistura. Este comportamento foi observado para todos os fluidos e geometrias avaliadas.

a)

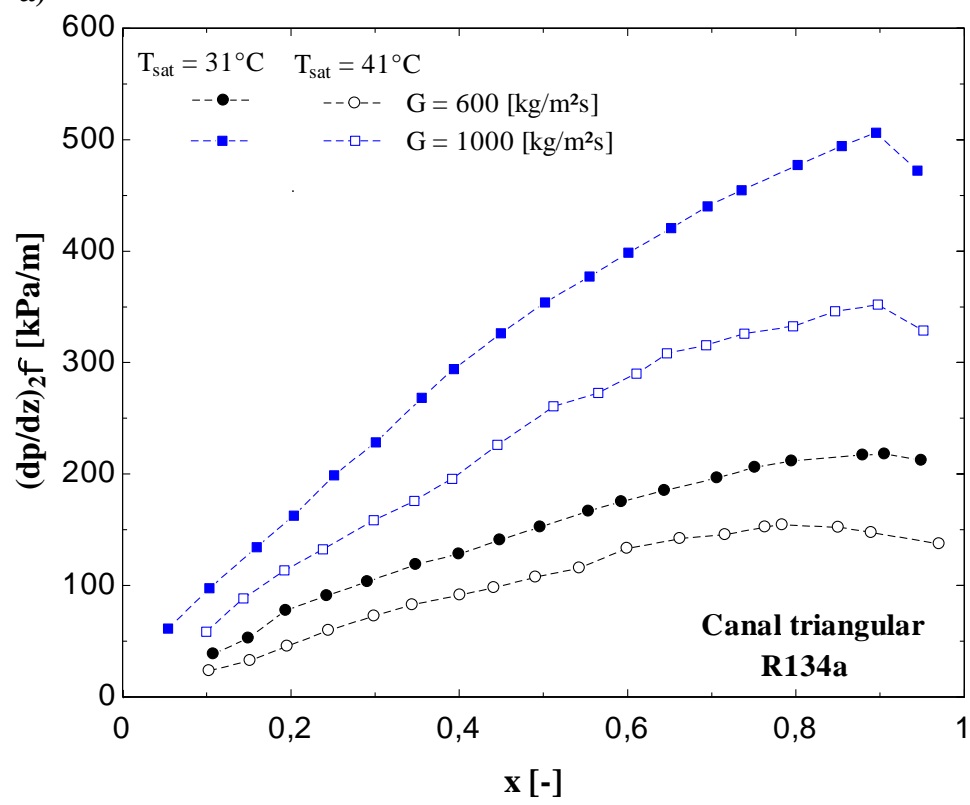

b)

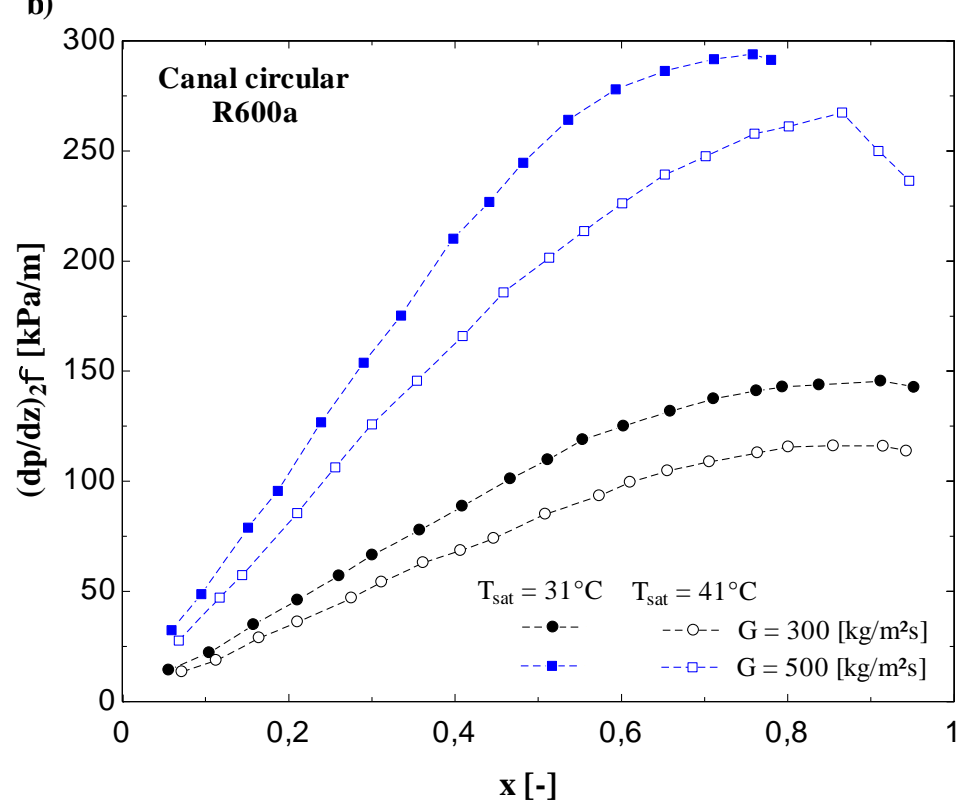

Figura 6.6. Ilustrações do efeito da temperatura de saturação no gradiente da perda de pressão. 


\subsubsection{Efeito do fluido de trabalho}

A Figura 6.7 ilustra resultados para a perda de pressão por atrito para os refrigerantes R134a, R1234ze(E), R1234yf e R600a (isobutano). Segundo esta figura, os fluidos R1234yf e R134a proporcionam gradientes de pressão próximos e inferiores ao R1234ze(E) e o R600a. O isobutano (R600a) apresenta gradientes de pressão até 200\% superiores aos demais fluidos.
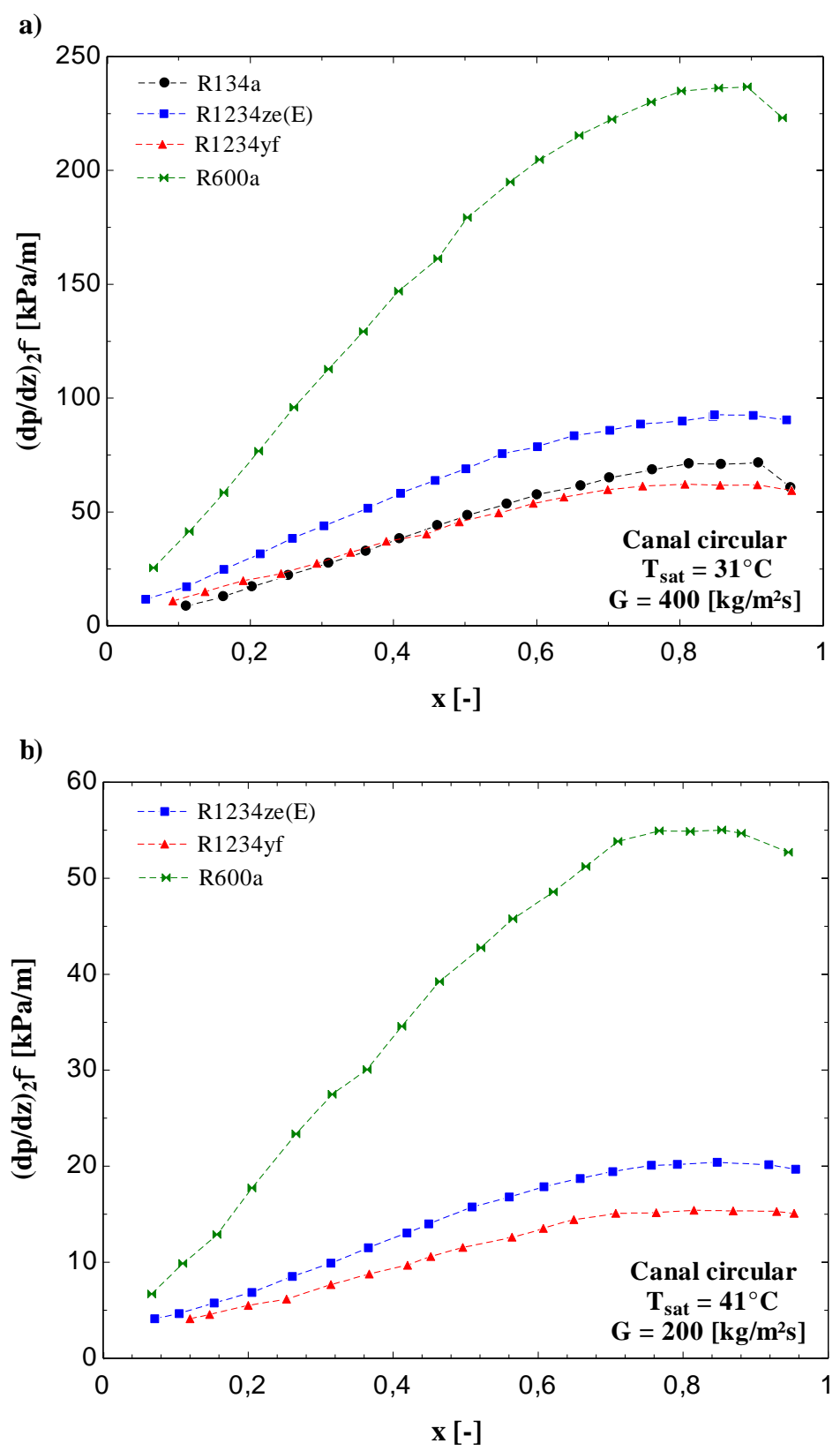

Figura 6.7. Ilustraçoes do efeito do fluido no gradiente da perda de pressao bifasica num tubo circular, $D$ $=1,1 \mathrm{~mm}$. 
Tal diferença entre o isobutano e os demais fluidos está relacionado ao fato do volume específico da fase vapor do hidrocarboneto ser no mínimo 3 vezes superior ao dos fluidos R134a, R1234ze(E) e R1234yf. Isto implica em uma velocidade da mistura tambem superior para o R600a. A Tabela 6.2 mostra a velocidade in situ da fase vapor estimadas para as condições experimentais ilustradas na Figura 6.7. Na estimativa da velocidade da fase vapor, utilizou-se a correlação de Kanizawa e Ribatski (2015) para a determinação da fração de vazio superficial. Como constatado na Tabela 6.2, a velocidade da fase vapor do isobutano é entre 3 a 3,7 vezes superior a do R134, implicando na perda de pressão superior.

Tabela 6.2. Velocidade in situ da fase gás para as condiçoes experimentais ilustradas na Figura 6.7.

\begin{tabular}{c|c|c|cccc}
\hline \multirow{2}{*}{$\boldsymbol{G}\left[\mathbf{k g} / \mathbf{m}^{2} \mathbf{s}\right]$} & \multirow{2}{*}{$\boldsymbol{T}_{\text {sat }}\left[{ }^{\circ} \mathbf{C}\right]$} & \multirow{2}{*}[-]{} & \multicolumn{5}{|c}{$\mathbf{U}_{\mathbf{G}}[\mathbf{m} / \mathbf{s}]$} \\
\cline { 4 - 7 } & & & $\mathbf{R 1 3 4 a}$ & $\mathbf{R 1 2 3 4 z e}(\mathbf{E})$ & $\mathbf{R 1 2 3 4 y f}$ & $\mathbf{R 6 0 0 a}$ \\
\hline 400 & 31 & 0,05 & 0,87 & 1,06 & 0,80 & 2,74 \\
400 & 31 & 0,2 & 2,57 & 3,11 & 2,28 & 8,68 \\
400 & 31 & 0,4 & 4,66 & 5,64 & 4,08 & 16,16 \\
400 & 31 & 0,6 & 6,66 & 8,06 & 5,80 & 23,43 \\
400 & 31 & 0,8 & 8,59 & 10,39 & 7,44 & 30,51 \\
400 & 31 & 0,95 & 9,96 & 12,04 & 8,59 & 35,63 \\
\hline \multirow{2}{*}{$\boldsymbol{G}\left[\mathbf{k g} / \mathbf{m}^{2} \mathbf{s}\right]$} & \multirow{2}{*}{$\boldsymbol{T}_{\text {sat }}\left[{ }^{\mathbf{C}} \mathbf{C}\right]$} & $\boldsymbol{x}[-]$ & \multicolumn{4}{|c}{$\mathbf{u G}[\mathbf{m} / \mathbf{s}]$} \\
\hline 200 & 41 & 0,05 & 0,37 & 0,45 & 0,35 & 1,16 \\
200 & 41 & 0,2 & 1,03 & 1,24 & 0,93 & 3,48 \\
200 & 41 & 0,4 & 1,81 & 2,19 & 1,62 & 6,36 \\
200 & 41 & 0,6 & 2,56 & 3,09 & 2,26 & 9,13 \\
200 & 41 & 0,8 & 3,26 & 3,94 & 2,86 & 11,81 \\
200 & 41 & 0,95 & 3,75 & 4,54 & 3,28 & 13,72 \\
\hline
\end{tabular}

Uma análise comparativa detalhada sobre o desempenho dos fluidos encontra-se no Capítulo 7 e inclui considerações sobre o coeficiente de transferência de calor.

\subsubsection{Efeito da geometria da seção transversal}

A Figura 6.8 ilustra o efeito da geometria da seção transversal do canal no gradiente da perda de pressão. Segundo esta figura para uma mesma velocidade mássica, o gradiente de pressão para o canal triangular é superior ao quadrado, o qual, por sua vez, 
é superior ao gradiente do canal circular. Um dos fatores a este resultado deve-se ao fato dos canais no presente estudo possuírem perímetros externos próximos, resultando desta forma na redução da área de seção transversal do escoamento segundo a seguinte ordem decrescente: circular, quadrado e triangular. Quantitativamente, o canal circular apresenta uma área transversal $12 \%$ e $31 \%$ superior aos canais quadrado e triangular, respectivamente.

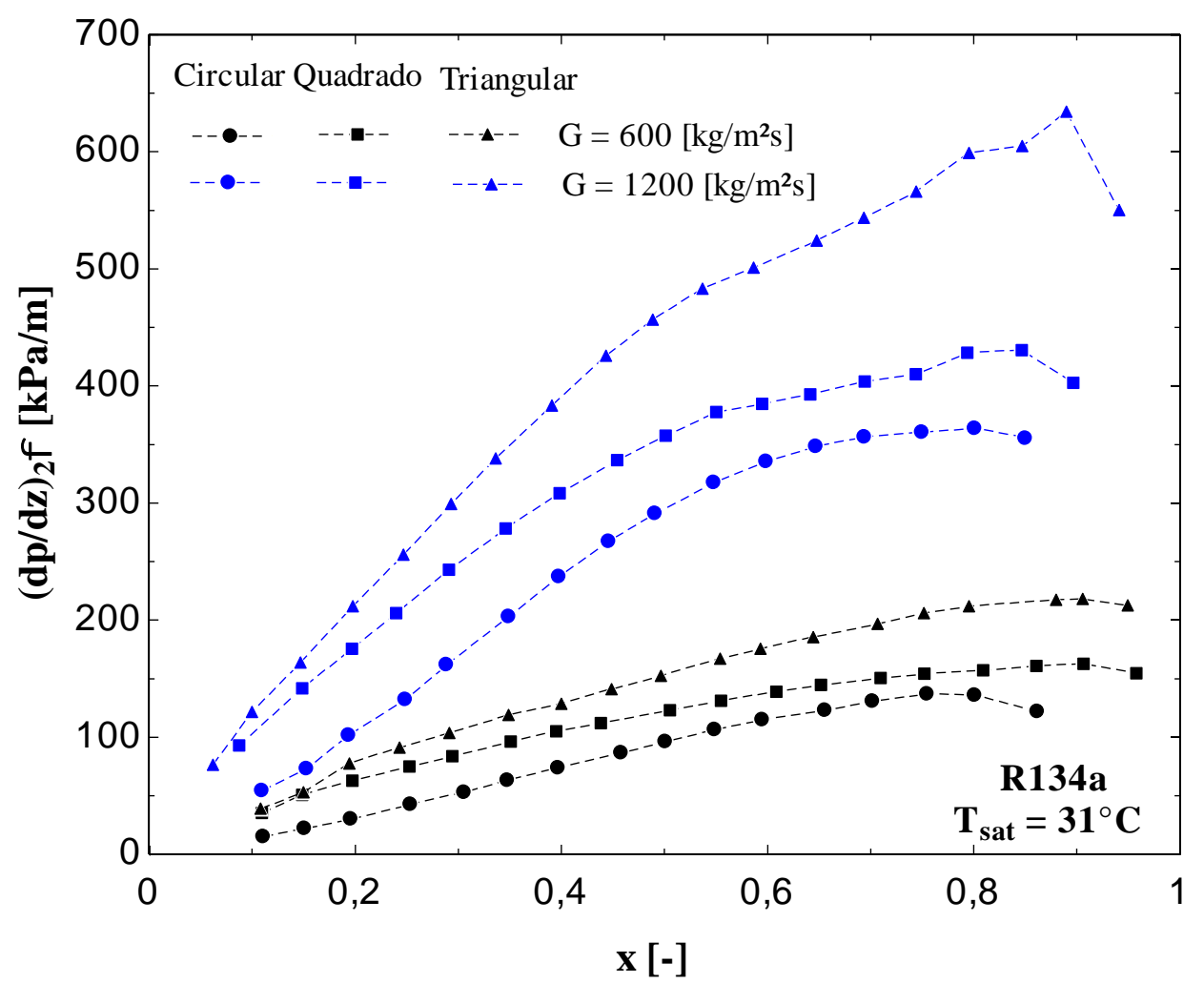

Figura 6.8. Ilustração do efeito da geometria da seção transversal no gradiente da perda de pressao bifasica.

A Figura 6.9 ilustra a variação com o título de vapor da relação entre a perda de pressão experimental para canais não-circulares e circulares para as mesmas condições experimentais. No geral, segundo a figura, a relação $(\mathrm{dp} / \mathrm{dz})_{\text {não-cird }} /(\mathrm{dp} / \mathrm{dz})_{\text {circ }}$ decresce com o acréscimo da velocidade mássica, apresentando valor mínimo para títulos de vapor próximos a 0,7 , para títulos de vapor superiores, ocorre o incremento desta relação com acréscimos do título de vapor.

Uma discussão mais detalhada sobre o efeito da geometria no desempenho global de um dissipador de calor baseado em multi-microcanais encontra-se no Capítulo 7 e 
inclui considerações sobre o coeficiente de transferência de calor, perda de pressão e o fator de empacotamento dos canais.

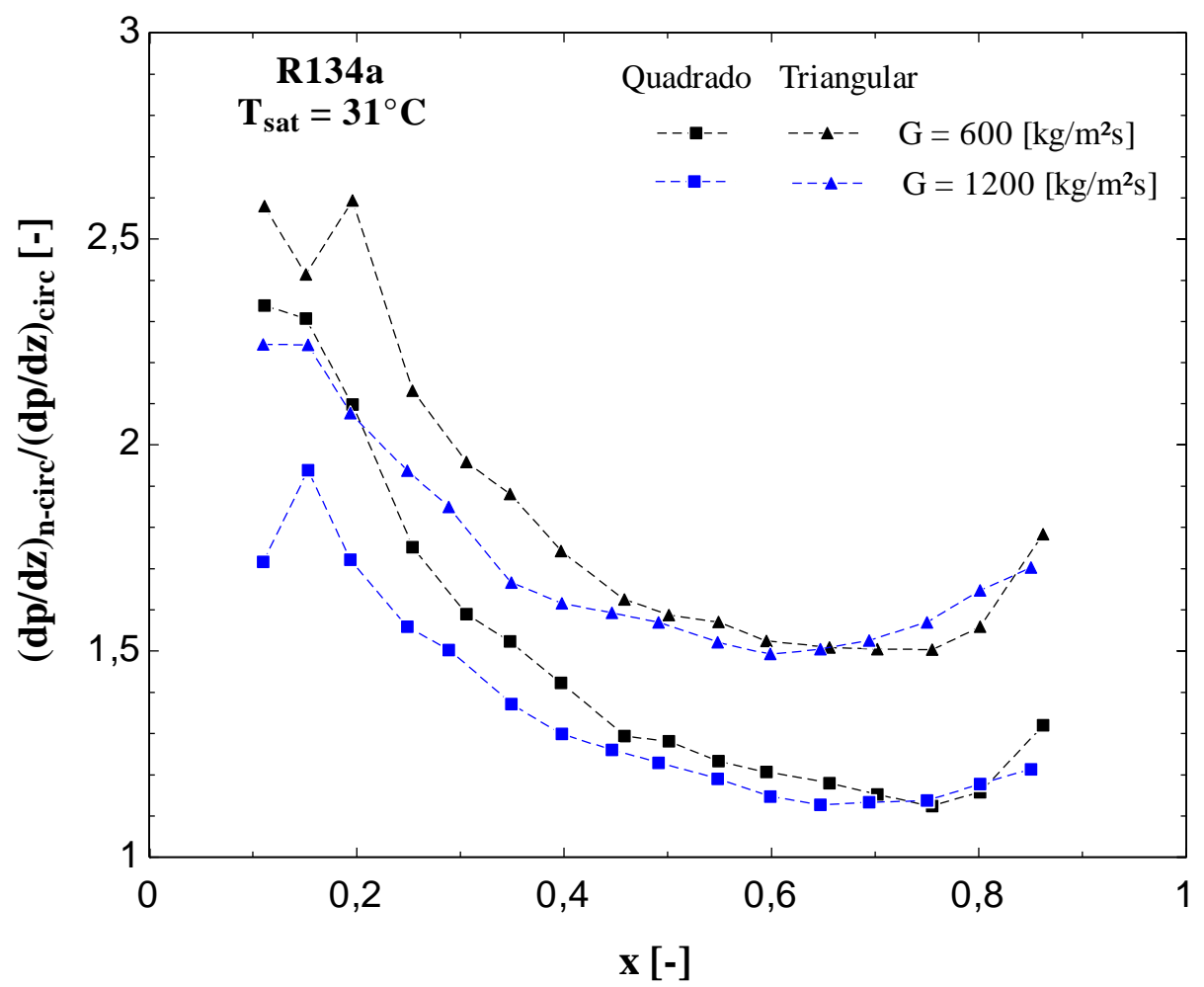

Figura 6.9. Efeito da geometria da seção transversal no gradiente da perda de pressao bifasica.

\subsection{Comparação com métodos de previsão da literatura}

Neste item, os métodos de previsão da literatura descritos no Capítulo 3 são comparados ao banco de dados experimental para o gradiente da perda de pressão obtidos no presente estudo. Esta avaliação envolve uma análise comparativa de tendências e comportamento considerando os seguintes parâmetros estatísticos: o erro absoluto médio (EMA) e a parcela de dados previsto com erro dentro de uma determinada faixa.

É importante mencionar que a avaliação dos métodos de previsão foi realizada considerando os seguintes aspectos:

Adotou-se como dimensão característica para o cálculo da perda de pressão monofásica aquela recomendada pelos autores originais. No caso de métodos que não explicitam o uso do diâmetro equivalente ou hidráulico e que foram desenvolvidos apenas com resultados para seções circulares, optou-se pelo uso do diâmetro equivalente com base em 
aspectos mencionados e discutidos no item de validação dos resultados experimentais mediante resultados para escoamentos monofásicos (Itens 5.5.2 e 5.5.3).

Para métodos que não indicam o número de Reynolds de transição considerou-se regime turbulento para números de Reynolds superiores a 3000, uma ponderação linear entre laminar e turbulento para números de Reynolds entre 2300 e 3000 e regime laminar para Reynolds inferiores a 2300. Tais valores foram adotados com base nos resultados obtidos para escoamento monofásico descritos no Item 5.5.

\subsubsection{Avaliação estatística dos métodos de previsão}

A Tabela 6.2 apresenta os resultados para o erro absoluto médio e a parcela dos dados previsto com erro entre $\pm 20 \%$ levantados a partir de comparações entre os dados experimentais e métodos de previsão da literatura descritos no Capítulo 3. Nesta tabela os resultados das comparações são apresentados para cada par fluido/geometria e para a totalidade do banco de dados.

Considerando nesta análise a base de dados completa, Müller-Steinhagen e Heck (1986) proporcionou as melhores previsões, fornecendo um erro absoluto médio de 18,7\%. Friedel (1981), Sun e Mishima (2009b) e Del Col et al. (2013) também proporcionaram resultados razoáveis, prevendo 58,2\%, 53,3\% e 63,8\% da base de dados respectivamente dentro da margem de erro $\pm 20 \%$. O modelo homogêneo, com a viscosidade da mistura dada por Cicchitti et al. (1960), e o método proposto por Kim e Mudawar (2012) preveem satisfatoriamente o banco de dados, resultando em um erro absoluto médio de aproximadamente $20 \%$. Vale destacar que o desempenho dos métodos de Müller-Steinhagen e Heck (1986), Kim e Mudawar (2012) e Sun e Mishima (2009b) também foram indicados como satisfatórios por Kim e Mudawar (2014), com base na comparação com um banco de dados da literatura contendo 7115 resultados experimentais. Os demais métodos de previsão da literatura proporcionaram EMA superiores a $25 \%$ e $\eta$ inferiores a $45 \%$. 
Tabela 6.3. Erro médio absoluto e parcela dos dados com previsões com erro entre $\pm 20 \%$ do resultado experimental.*

\begin{tabular}{|c|c|c|c|c|c|c|c|c|}
\hline \multirow[t]{2}{*}{ Autor (es) } & \multirow{2}{*}{$\begin{array}{c}\text { Fluido } \\
\text { Geometria } \\
\text { \#Dados }\end{array}$} & $\begin{array}{l}\text { R134a } \\
\text { Circular }\end{array}$ & $\begin{array}{c}\text { R134a } \\
\text { Quadrada }\end{array}$ & $\begin{array}{c}\mathrm{R} 134 \mathrm{a} \\
\text { Triangular }\end{array}$ & $\begin{array}{l}\text { R1234ze }(\mathrm{E}) \\
\text { Circular }\end{array}$ & $\begin{array}{l}\text { R1234yf } \\
\text { Circular }\end{array}$ & $\begin{array}{l}\text { R600a } \\
\text { Circular }\end{array}$ & Total \\
\hline & & 253 & 295 & 365 & 229 & 140 & 186 & 1468 \\
\hline \multicolumn{9}{|c|}{ Métodos baseados no modelo homogêneo } \\
\hline \multirow{2}{*}{ McAdams (1942) } & EMA & $33,1 \%$ & $30,9 \%$ & $20,2 \%$ & $45,6 \%$ & $50,6 \%$ & $46,0 \%$ & $34,7 \%$ \\
\hline & $\eta$ & $18,2 \%$ & $11,2 \%$ & $43,0 \%$ & $1,3 \%$ & $0,0 \%$ & $1,1 \%$ & $16,4 \%$ \\
\hline \multirow{2}{*}{ Cicchitti et al. (1960) } & EMA & $18,7 \%$ & $10,7 \%$ & $9,9 \%$ & $31,9 \%$ & $38,5 \%$ & $28,1 \%$ & $20,0 \%$ \\
\hline & $\eta$ & $54,5 \%$ & $89,2 \%$ & $90,7 \%$ & $8,7 \%$ & $0,7 \%$ & $16,7 \%$ & $53,4 \%$ \\
\hline \multirow{2}{*}{ Owens (1961) } & EMA & $14,5 \%$ & $19,7 \%$ & $28,7 \%$ & $28,6 \%$ & $25,5 \%$ & $19,1 \%$ & $24,9 \%$ \\
\hline & $\eta$ & $75,1 \%$ & $62,7 \%$ & $37,3 \%$ & $33,6 \%$ & $32,1 \%$ & $65,6 \%$ & $51,4 \%$ \\
\hline \multirow{2}{*}{ Dukler et al. (1964) } & EMA & $36,2 \%$ & $34,9 \%$ & $23,7 \%$ & $49,2 \%$ & $52,7 \%$ & $50,3 \%$ & $38,2 \%$ \\
\hline & $\eta$ & $14,6 \%$ & $7,1 \%$ & $29,9 \%$ & $0,4 \%$ & $0,0 \%$ & $0,0 \%$ & $11,4 \%$ \\
\hline \multirow{2}{*}{$\begin{array}{l}\text { Beattie e Whalley } \\
\text { (1982) }\end{array}$} & EMA & $29,9 \%$ & $25,2 \%$ & $16,4 \%$ & $43,0 \%$ & $46,4 \%$ & $43,3 \%$ & $30,9 \%$ \\
\hline & $\eta$ & $23,3 \%$ & $24,1 \%$ & $70,7 \%$ & $1,3 \%$ & $0,7 \%$ & $5,9 \%$ & $27,5 \%$ \\
\hline \multirow{2}{*}{ Lin et al. (1991) } & EMA & $40,5 \%$ & $39,3 \%$ & $28,1 \%$ & $52,0 \%$ & $55,8 \%$ & $53,2 \%$ & $42,1 \%$ \\
\hline & $\eta$ & $5,5 \%$ & $4,7 \%$ & $17,8 \%$ & $0,0 \%$ & $0,0 \%$ & $0,0 \%$ & $6,3 \%$ \\
\hline \multirow{2}{*}{ Garcia et al. (2003) } & EMA & $41,4 \%$ & $41,0 \%$ & $30,2 \%$ & $55,7 \%$ & $56,7 \%$ & $56,7 \%$ & $44,2 \%$ \\
\hline & $\eta$ & $11,1 \%$ & $2,0 \%$ & $14,0 \%$ & $0,4 \%$ & $0,0 \%$ & $0,0 \%$ & $5,9 \%$ \\
\hline \multirow{2}{*}{$\begin{array}{l}\text { Awad e Muzychka } \\
(2010)\end{array}$} & EMA & $28,1 \%$ & $23,6 \%$ & $14,3 \%$ & $40,8 \%$ & $46,1 \%$ & $40,2 \%$ & $29,0 \%$ \\
\hline & $\eta$ & $26,9 \%$ & $28,1 \%$ & $78,9 \%$ & $1,3 \%$ & $0,0 \%$ & $5,9 \%$ & $30,9 \%$ \\
\hline \multicolumn{9}{|c|}{ Métodos baseados em multiplicadores bifásicos } \\
\hline \multirow{2}{*}{$\begin{array}{l}\text { Lockhart e Martinelli } \\
\text { (1949) }\end{array}$} & EMA & $100,2 \%$ & $69,7 \%$ & $95,9 \%$ & $30,2 \%$ & $29,0 \%$ & $31,6 \%$ & $66,6 \%$ \\
\hline & $\eta$ & $36,0 \%$ & $35,9 \%$ & $1,9 \%$ & $65,5 \%$ & $57,9 \%$ & $41,9 \%$ & $34,9 \%$ \\
\hline \multirow{2}{*}{ Chisholm (1973) } & EMA & $36,3 \%$ & $26,1 \%$ & $51,2 \%$ & $43,1 \%$ & $31,9 \%$ & $47,7 \%$ & $40,0 \%$ \\
\hline & $\eta$ & $56,5 \%$ & $60,3 \%$ & $35,1 \%$ & $32,3 \%$ & $37,1 \%$ & $34,4 \%$ & $43,5 \%$ \\
\hline \multirow{2}{*}{ Friedel (1979) } & EMA & $17,7 \%$ & $13,2 \%$ & $25,6 \%$ & $25,5 \%$ & $19,9 \%$ & $21,3 \%$ & $20,7 \%$ \\
\hline & $\eta$ & $77,9 \%$ & $75,6 \%$ & $40,0 \%$ & $59,4 \%$ & $52,1 \%$ & $43,0 \%$ & $58,2 \%$ \\
\hline \multirow{2}{*}{ Grönnerud (1979) } & EMA & $58,7 \%$ & $71,7 \%$ & $85,1 \%$ & $49,8 \%$ & $38,0 \%$ & $42,0 \%$ & $62,4 \%$ \\
\hline & $\eta$ & $9,1 \%$ & $24,4 \%$ & $15,1 \%$ & $28,4 \%$ & $35,0 \%$ & $33,9 \%$ & $22,3 \%$ \\
\hline \multirow{2}{*}{$\begin{array}{l}\text { Jung e Radermacher } \\
\text { (1989) }\end{array}$} & EMA & $80,6 \%$ & $76,2 \%$ & $98,0 \%$ & $47,2 \%$ & $46,9 \%$ & $35,1 \%$ & $69,8 \%$ \\
\hline & $\eta$ & $1,6 \%$ & $11,9 \%$ & $2,7 \%$ & $30,1 \%$ & $28,6 \%$ & $32,3 \%$ & $14,9 \%$ \\
\hline \multirow{2}{*}{$\begin{array}{l}\text { Mishima e Hibiki } \\
\text { (1996) }\end{array}$} & EMA & $64,7 \%$ & $60,7 \%$ & $53,2 \%$ & $68,2 \%$ & $69,9 \%$ & $70,4 \%$ & $62,8 \%$ \\
\hline & $\eta$ & $0,0 \%$ & $2,7 \%$ & $4,4 \%$ & $0,0 \%$ & $0,0 \%$ & $0,0 \%$ & $1,6 \%$ \\
\hline \multirow{2}{*}{ Tran et al. (2000) } & EMA & $139,5 \%$ & $172,4 \%$ & $269,7 \%$ & $98,8 \%$ & $73,4 \%$ & $139,1 \%$ & $165,8 \%$ \\
\hline & $\eta$ & $0,0 \%$ & $0,0 \%$ & $0,0 \%$ & $0,4 \%$ & $4,3 \%$ & $0,0 \%$ & $0,5 \%$ \\
\hline \multirow{2}{*}{ Zhang e Webb (2001) } & EMA & $17,5 \%$ & $15,7 \%$ & $25,6 \%$ & $25,4 \%$ & $27,9 \%$ & $23,8 \%$ & $22,2 \%$ \\
\hline & $\eta$ & $75,9 \%$ & $72,2 \%$ & $38,6 \%$ & $51,5 \%$ & $32,1 \%$ & $55,9 \%$ & $55,4 \%$ \\
\hline \multirow{2}{*}{ Lee e Lee (2001a) } & EMA & $127,9 \%$ & $100,1 \%$ & $124,9 \%$ & $29,8 \%$ & $35,2 \%$ & $23,6 \%$ & $84,2 \%$ \\
\hline & $\eta$ & $2,4 \%$ & $1,0 \%$ & $0,0 \%$ & $42,8 \%$ & $33,6 \%$ & $60,8 \%$ & $18,2 \%$ \\
\hline
\end{tabular}

*Números em negrito indicam um EMA inferior a $20 \%$ ou um $\eta$ superior a $80 \%$.

**Números em vermelho indicam o melhor resultado de EMA e $\eta$ para cada banco de dados. 
Tabela 6.2 (continuação). Erro médio absoluto e parcela dos dados com previsões com erro entre $\pm 20 \%$ do resultado experimental.

\begin{tabular}{|c|c|c|c|c|c|c|c|c|}
\hline \multirow[t]{2}{*}{ Autor (es) } & \multirow{2}{*}{$\begin{array}{c}\text { Fluido } \\
\text { Geometria } \\
\text { \#Dados }\end{array}$} & $\begin{array}{l}\text { R134a } \\
\text { Circular }\end{array}$ & $\begin{array}{l}\text { R134a } \\
\text { Quadrado }\end{array}$ & $\begin{array}{l}\mathrm{R} 134 \mathrm{a} \\
\text { Triangular }\end{array}$ & $\begin{array}{l}\text { R1234ze(E) } \\
\text { Circular }\end{array}$ & $\begin{array}{l}\text { R1234yf } \\
\text { Circular }\end{array}$ & $\begin{array}{c}\text { R600a } \\
\text { Circular }\end{array}$ & Total \\
\hline & & 253 & 295 & 365 & 229 & 140 & 186 & 1468 \\
\hline \multirow{2}{*}{ Yu et al. (2002) } & EMA & $138,6 \%$ & $243,7 \%$ & $260,7 \%$ & $163,3 \%$ & $130,5 \%$ & $170,4 \%$ & $197,2 \%$ \\
\hline & $\eta$ & $15,4 \%$ & $10,2 \%$ & $10,4 \%$ & $12,2 \%$ & $12,9 \%$ & $11,8 \%$ & $11,9 \%$ \\
\hline \multirow{2}{*}{$\begin{array}{l}\text { Lee e Mudawar } \\
\text { (2005a) }\end{array}$} & EMA & $73,4 \%$ & $87,8 \%$ & $129,1 \%$ & $39,5 \%$ & $45,5 \%$ & $32,7 \%$ & $77,0 \%$ \\
\hline & $\eta$ & $0,4 \%$ & $0,0 \%$ & $0,0 \%$ & $23,6 \%$ & $22,1 \%$ & $43,5 \%$ & $11,4 \%$ \\
\hline \multirow{2}{*}{ Hwang e Kim (2006) } & EMA & $111,3 \%$ & $63,8 \%$ & $48,2 \%$ & $18,4 \%$ & $30,2 \%$ & $17,3 \%$ & $51,9 \%$ \\
\hline & $\eta$ & $0,0 \%$ & $11,5 \%$ & $13,2 \%$ & $60,7 \%$ & $31,4 \%$ & $64,5 \%$ & $26,2 \%$ \\
\hline \multirow{2}{*}{$\begin{array}{l}\text { Sun e Mishima } \\
(2009 b)\end{array}$} & EMA & $20,7 \%$ & $12,1 \%$ & $11,6 \%$ & $27,8 \%$ & $28,5 \%$ & $29,5 \%$ & $19,7 \%$ \\
\hline & $\eta$ & $49,4 \%$ & $82,4 \%$ & $83,0 \%$ & $18,8 \%$ & $21,4 \%$ & $21,0 \%$ & $53,3 \%$ \\
\hline \multirow{2}{*}{ Zhang et al. (2010) } & EMA & $33,0 \%$ & $37,3 \%$ & $30,9 \%$ & $43,3 \%$ & $39,4 \%$ & $56,4 \%$ & $38,9 \%$ \\
\hline & $\eta$ & $17,0 \%$ & $8,5 \%$ & $20,0 \%$ & $4,8 \%$ & $5,0 \%$ & $0,0 \%$ & $10,8 \%$ \\
\hline \multirow{2}{*}{ Pamitran et al. (2010) } & EMA & $290,2 \%$ & $229,9 \%$ & $220,3 \%$ & $120,1 \%$ & $116,8 \%$ & $159,7 \%$ & $201,1 \%$ \\
\hline & $\eta$ & $0,0 \%$ & $1,0 \%$ & $0,0 \%$ & $6,6 \%$ & $5,0 \%$ & $2,7 \%$ & $2,0 \%$ \\
\hline \multirow{2}{*}{ Li e Wu (2011) } & EMA & $45,2 \%$ & $40,4 \%$ & $47,4 \%$ & $29,7 \%$ & $25,7 \%$ & $20,1 \%$ & $37,2 \%$ \\
\hline & $\eta$ & $17,4 \%$ & $25,1 \%$ & $14,0 \%$ & $59,0 \%$ & $54,3 \%$ & $68,8 \%$ & $34,9 \%$ \\
\hline \multirow{2}{*}{$\begin{array}{l}\text { Kim e Mudawar } \\
\text { (2012) }\end{array}$} & EMA & $18,5 \%$ & $10,6 \%$ & $16,0 \%$ & $28,7 \%$ & $30,9 \%$ & $26,6 \%$ & $20,0 \%$ \\
\hline & $\eta$ & $68,8 \%$ & $83,4 \%$ & $69,9 \%$ & $7,0 \%$ & $6,4 \%$ & $14,5 \%$ & $49,5 \%$ \\
\hline \multirow{2}{*}{ Del Col et al. (2013) } & EMA & $18,1 \%$ & $11,0 \%$ & $56,0 \%$ & $14,2 \%$ & $22,6 \%$ & $11,3 \%$ & $23,1 \%$ \\
\hline & $\eta$ & $79,8 \%$ & $87,8 \%$ & $0,3 \%$ & $80,8 \%$ & $36,4 \%$ & $94,1 \%$ & $63,8 \%$ \\
\hline \multicolumn{9}{|c|}{ Métodos estritamente empíricos } \\
\hline \multirow{2}{*}{$\begin{array}{l}\text { Muller-Steinhagen e } \\
\text { Heck (1986) }\end{array}$} & EMA & $13,6 \%$ & $14,3 \%$ & $21,9 \%$ & $19,0 \%$ & $26,1 \%$ & $20,4 \%$ & $18,7 \%$ \\
\hline & $\eta$ & $81,0 \%$ & $76,3 \%$ & $53,4 \%$ & $44,1 \%$ & $25,0 \%$ & $41,4 \%$ & $57,1 \%$ \\
\hline \multirow{2}{*}{ Xu e Fang (2012) } & EMA & $69,3 \%$ & $91,8 \%$ & $183,1 \%$ & $32,5 \%$ & $10,7 \%$ & $80,8 \%$ & $92,3 \%$ \\
\hline & $\eta$ & $2,4 \%$ & $0,0 \%$ & $0,0 \%$ & $13,5 \%$ & $83,6 \%$ & $0,5 \%$ & $10,6 \%$ \\
\hline \multirow{2}{*}{$\begin{array}{l}\text { Da Silva e Ribatski } \\
\text { (2013) }\end{array}$} & EMA & $23,6 \%$ & $16,7 \%$ & $10,0 \%$ & $33,8 \%$ & $39,8 \%$ & $34,7 \%$ & $25,4 \%$ \\
\hline & $\eta$ & $76,8 \%$ & $67,8 \%$ & $\mathbf{8 1 , 8 \%}$ & $7,4 \%$ & $0,7 \%$ & $7,5 \%$ & $45,1 \%$ \\
\hline \multicolumn{9}{|c|}{ Métodos baseados em análises fenomenológicas } \\
\hline \multirow{2}{*}{$\begin{array}{l}\text { Cioncolini et al. } \\
(2009)\end{array}$} & EMA & $41,4 \%$ & $39,2 \%$ & $33,3 \%$ & $45,2 \%$ & $39,0 \%$ & $49,1 \%$ & $40,3 \%$ \\
\hline & $\eta$ & $18,2 \%$ & $37,6 \%$ & $43,8 \%$ & $19,2 \%$ & $33,6 \%$ & $10,8 \%$ & $29,2 \%$ \\
\hline
\end{tabular}

*Números em negrita indicam um EMA inferior a $20 \%$ ou um $\eta$ superior a $80 \%$.

**Números em vermelho indicam o melhor resultado para cada banco de dados

O modelo homogêneo com a viscosidade dada por Cicchitti et al. (1960) forneceu previsões razoáveis dos dados do fluido R134a independentemente da geometria. Este resultado não é surpreendente, considerando que vários autores reportaram que o modelo homogêneo com a viscosidade bifásica dada por Cichitti et al. (1960) fornece previsões razoáveis de seus bancos de dados, na sua maioria compostos por dados experimentais para o refrigerante R134a (ver RIBATSKI; WOJTAN; THOME, 2006 e FELCAR; RIBATSKI, 2008). Por outro lado, segundo o presente estudo o modelo não fornece 
previsões satisfatórias para os fluidos refrigerantes com reduzido GWP (R1234ze(E), R1234yf) e o isobutano (R600a), resultando em valores de $\eta$ inferiores a 20\%. A Figura 6.10 ilustra a comparação dos dados experimentais com o modelo homogêneo utilizando a viscosidade da mistura dada por Cicchitti et al. (1960). Como ilustrado na figura, o modelo homogêneo com a viscosidade da mistura dada por Cicchitti et al. (1960) fornece previsões satisfatórias apenas para o R134a, no entanto, vale mencionar que o modelo sobrestima a maior parte dos resultados experimentais do R134a, especialmente para gradientes da perda de pressão superiores a $300 \mathrm{kPa} / \mathrm{m}$.

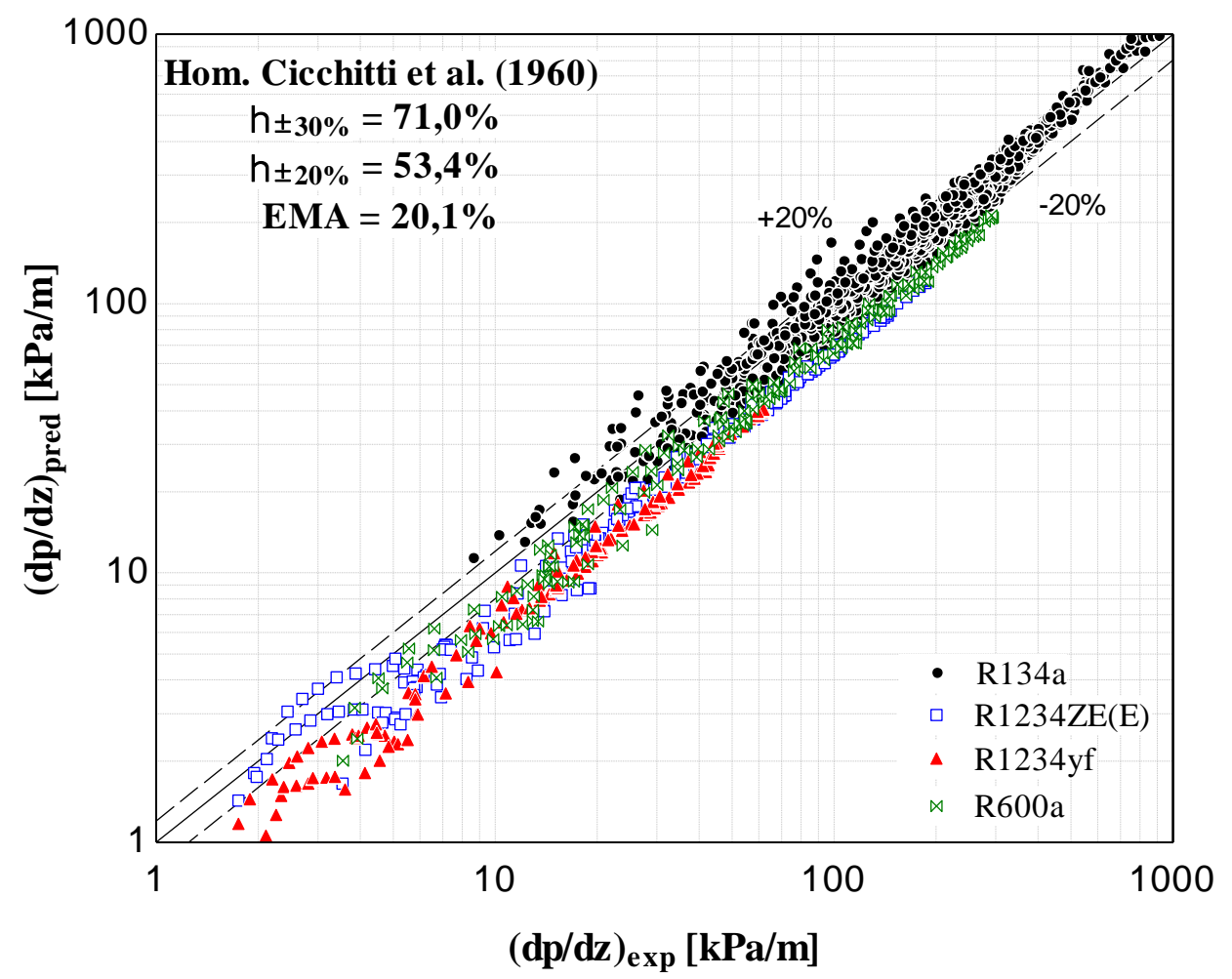

Figura 6.10. Comparação dos dados experimentais do gradiente da perda de pressao com o modelo homogenêo com a viscosidade da mistura dada por Cicchitti et al. (1960).

Sun e Mishima (2009b) e Kim e Mudawar (2012) fornecem previsões satisfatórias dos resultados do R134a, proporcionando valores de EMA inferiores a 20\% independentemente da geometria. Entretanto, previsões insatisfatórias se verificam para os fluidos R1234ze(E), R1234yf e R600a conforme ilustrado na Figura 6.11. Este resultado não surpreende devido ao fato destes métodos não incluírem em seus desenvolvimentos resultados experimentais para estes refrigerantes, conforme indicado na Tabela 3.3. 
a)

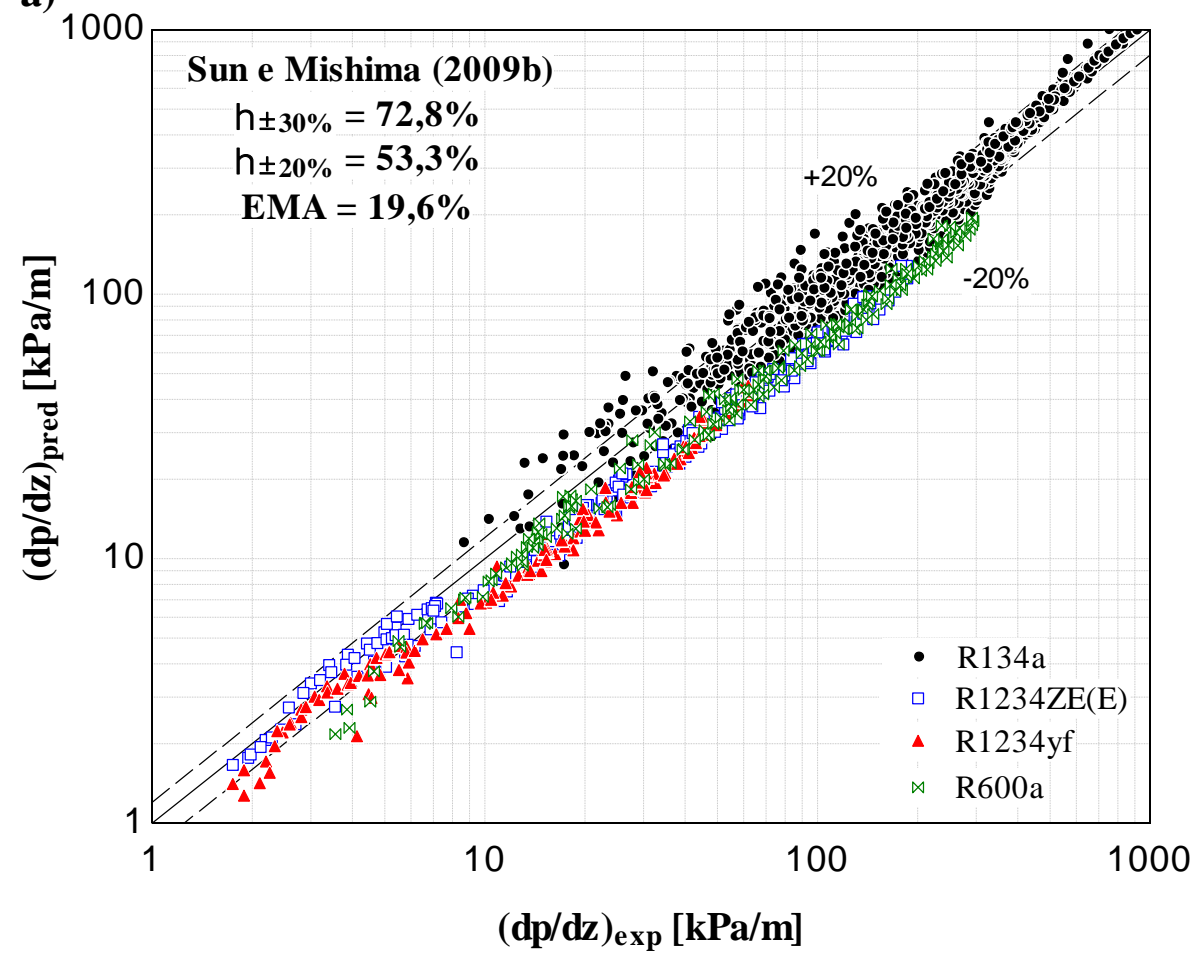

b)

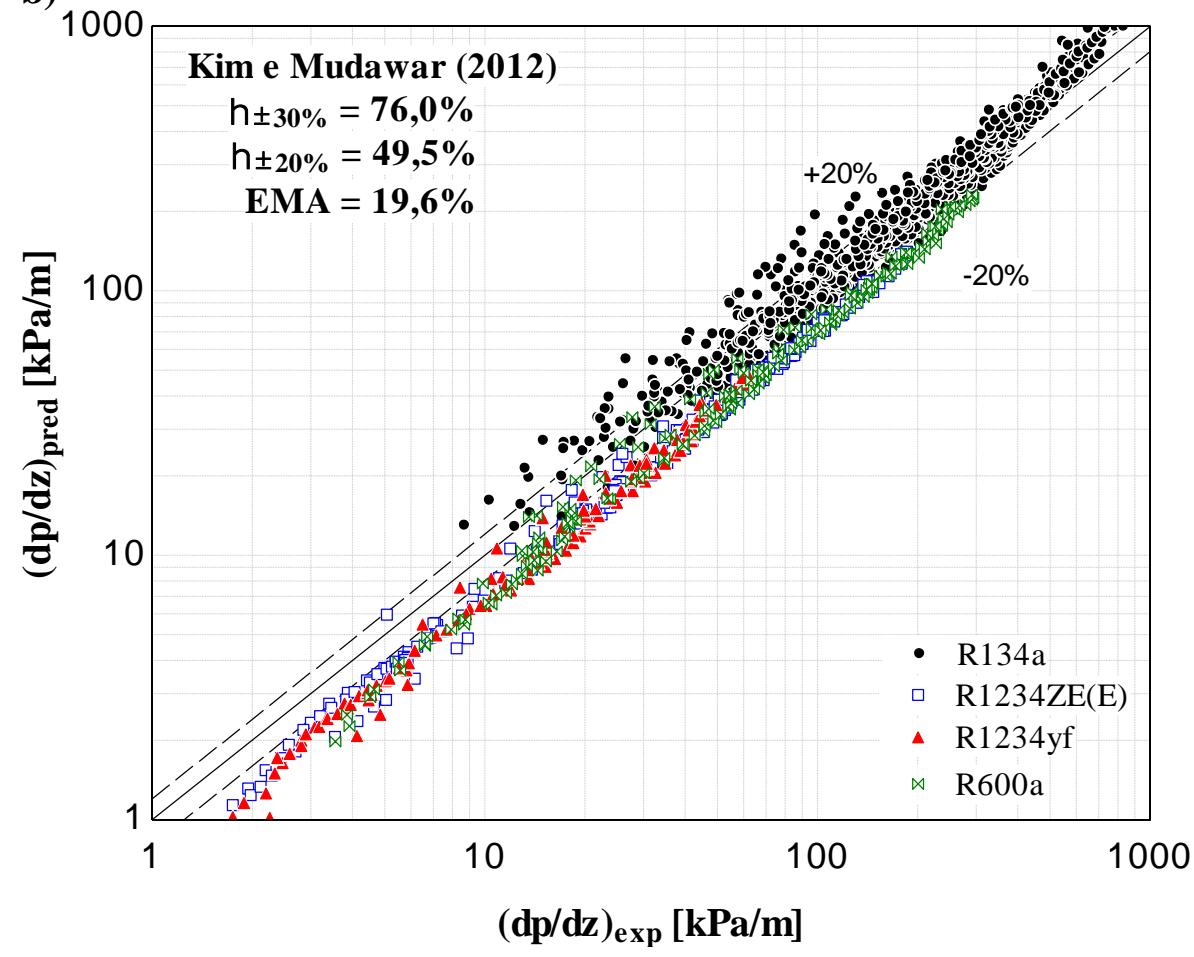

Figura 6.11. Comparação dos dados experimentais do gradiente da perda de pressão com os métodos de a) Sun e Mishima (2009b) e b) Kim e Mudawar (2012).

Os métodos de Friedel (1979) e Del Col et al. (2013) proporcionam previsões satisfatórias para o fluido R134a para as geometrias circular e quadrada. Por outro lado, o método de Del Col et al. (2013) proporciona previsões insatisfatórias para a geometria 
triangular. Conforme discutido na Seção 3.3, este método incorpora efeitos de rugosidade relativa e foi proposto baseado em Friedel (1979) para canais de dimensões reduzidas. Tanto Friedel (1979) como Del Col et al. (2013) proporcionam previsões similares para as geometrias circular e quadrada com o fluido R134a e R1234yf. No entanto, este último apresenta erros em relação aos resultados experimentais substancialmente inferiores aos constatados para o método de Friedel (1979) para os fluidos R1234ze(E) e R600a. A Figura 6.12 ilustra a comparação dos dados experimentais com as previsões proporcionadas pelo método de Del Col et al. (2013). Segundo esta figura, o método sobrestima parcela significativa dos dados para R134a (principalmente para a geometria triangular) e subestima os dados para R2343yf.

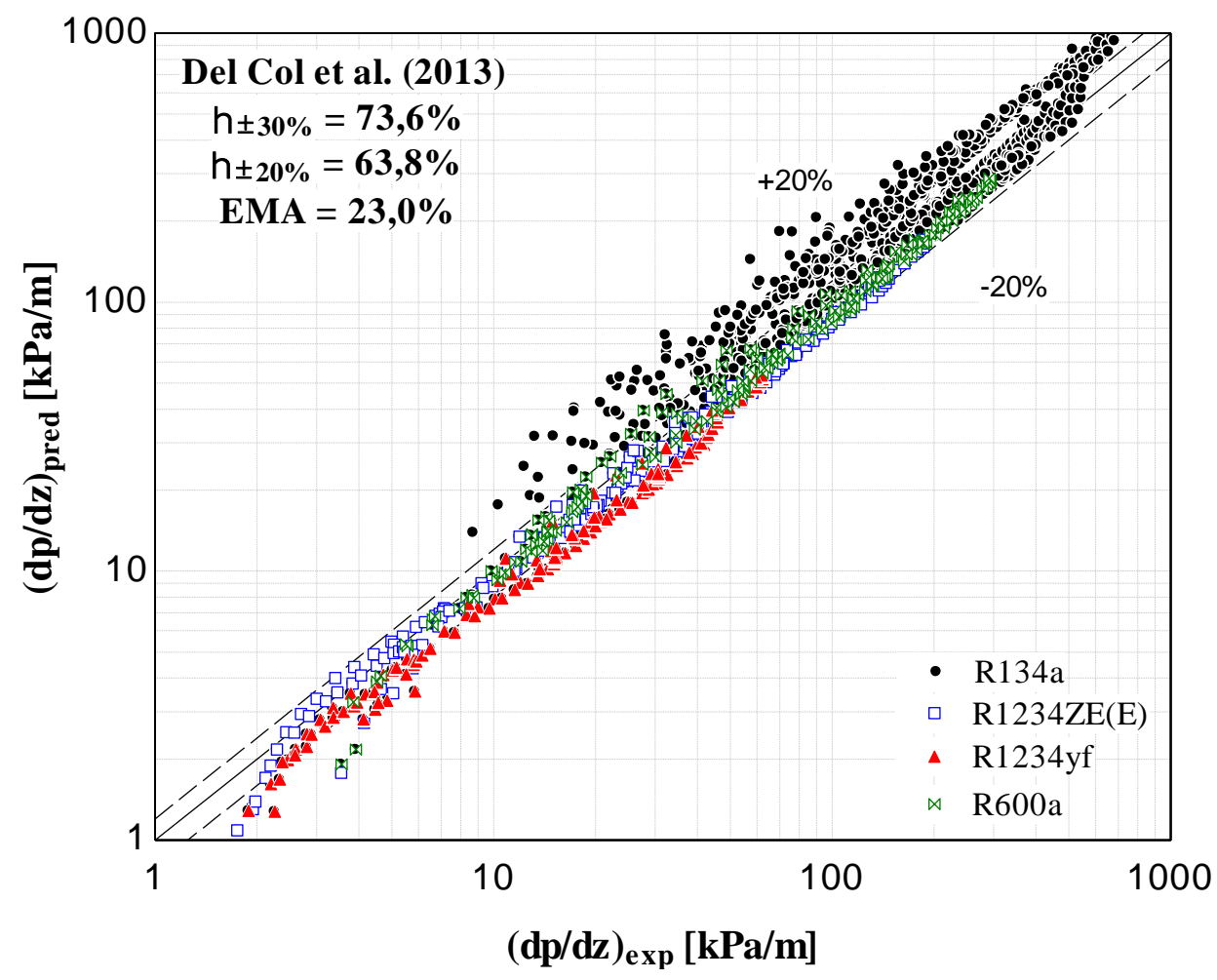

Figura 6.12. Comparação dos dados experimentais do gradiente da perda de pressão com o método de Del Col et al. (2013).

O método de Müller-Steinhagen e Heck(1986) prevê satisfatoriamente os resultados experimentais para as seçoes circular e quadrada com os fluidos R134a, R1234ze(E) e R600a, proporcionando valores de EMA inferiores a 21\%. No entanto, desvios elevados são constatados para os fluidos R1234yf, em seção circular, e R134a, em seção triangular, resultando em valores de EMA de 26,1 e 21,9\%, respectivamente. Na Figura 6.13 observa-se que o método de Müller-Steinhagen e Heck (1986) 
proporciona melhores resultados para a faixa de gradiente de perda de pressão entre $50 \mathrm{e}$ $300 \mathrm{kPa} / \mathrm{m}$.

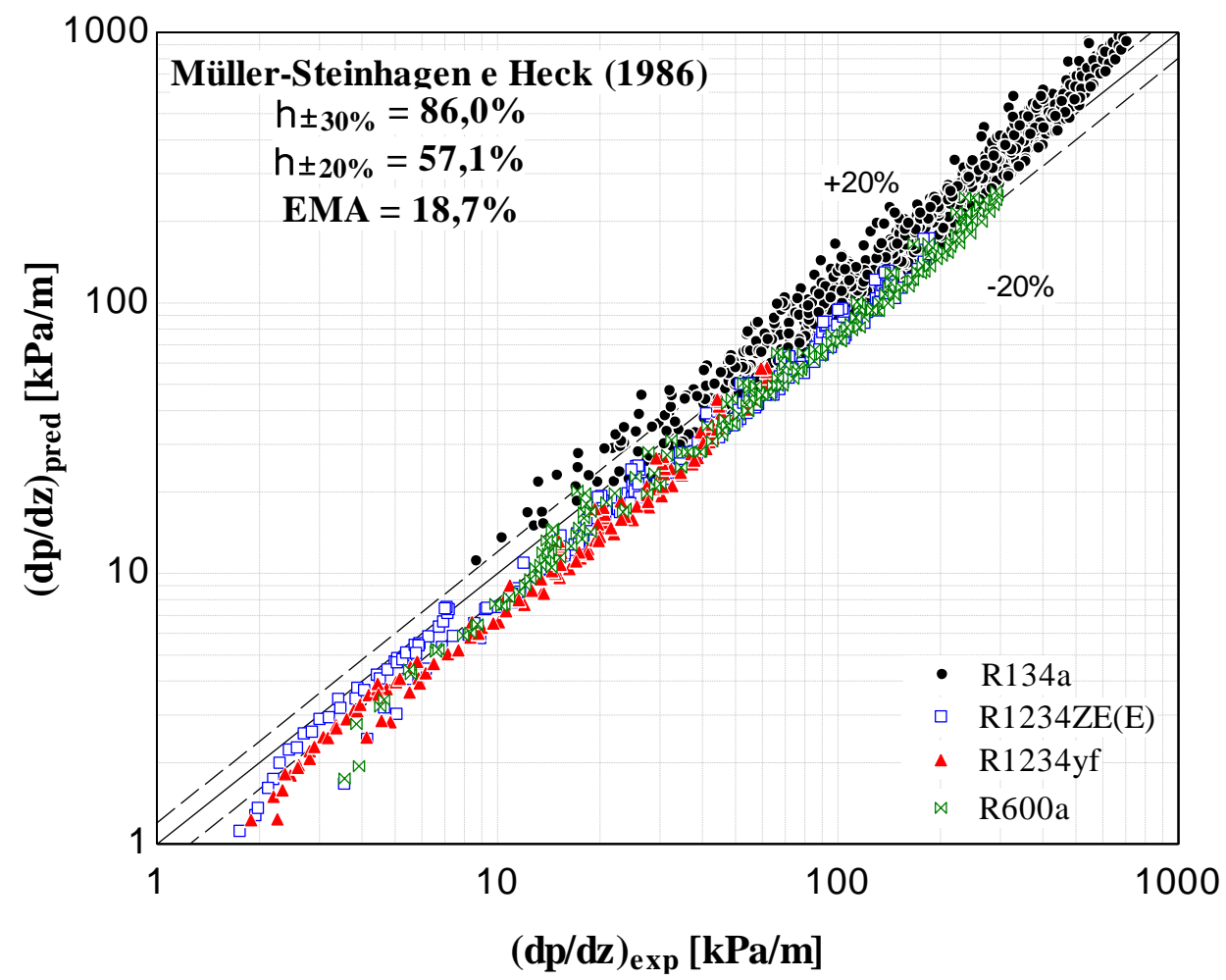

Figura 6.13. Comparação dos dados experimentais do gradiente da perda de pressão com o método de Müller-Steinhagen e Heck (1986).

O modelo homogêneo com a viscosidade bifásica dada por Owens (1961) proporciona resultados satisfatórios para os fluido R134a (geometrias circular e quadrada) e R600a. Por outro lado, as previsões da perda de pressão com as viscosidades dadas por Beattie e Walley (1982) e Awad e Muzychka (2010) são satisfatórias apenas para o R134 e geometria triangular. Já as previsões com a viscosidade da mistura dada por McAdams (1942), Dukler et al. (1964), Lin et al. (1991) e Garcia et al. (2003) são insatisfatórias independentemente da geometria da seção transversal e do fluido.

Para o método de Zhang et al. (2010), constatam-se desvios elevados em relação aos dados experimentais independentemente do fluido e geometria avaliada. Especula-se que parcela deste resultado relaciona-se ao fato da correlação não ser indicada para ambas as fases turbulentas, condição que caracteriza $34 \%$ do banco de dados levantado neste estudo (ver Figura 6.4). Os métodos de Lockhart e Martinelli (1949), Chisholm (1973), Grönnerud (1979), Jung e Radermacher (1989), Mishima e Hibiki (1996), Tran et al. (2000), Lee e Lee (2001), Yu et al. (2002), Lee e Mudawar (2005), Pamitran et al. (2010) 
e Li e Wu (2011) não fornecem previsões satisfatórias independentemente da geometria e fluido.

Xu e Fang (2012) proporciona resultados razoáveis para o R1234yf e Da Silva e Ribatski (2013) prevê satisfatoriamente os resultados do R134a, independentemente da geometria. O modelo fenomenológico para padrão anular desenvolvido por Cioncolini et al. (2009) não se mostrou adequado para a previsão dos bancos de dados obtido neste estudo, resultando em erros absolutos médios superiores a $33 \%$.

\subsubsection{Avaliação de tendências dos métodos de previsão}

Neste item são contrastadas as tendências dos resultados experimentais levantados neste estudo com 8 métodos da literatura para estimativa da perda de pressão por atrito. Os métodos foram escolhidos considerando os seguintes fatores: $i$ ) proporcionar melhores previsões segundo parâmetros estatísticos com base na análise apresentada na seção anterior, ii) métodos de previsão de perda de pressão mais frequentemente citados na literatura.

A Figura 6.14 ilustra as tendências dos métodos da literatura comparados aos dados experimentais para o fluido R134a. Conforme indicado na Figura 6.14a, para os dados experimentais obtidos para a geometria quadrada, Sun e Mishima (2009b) e o modelo homogêneo com a viscosidade da mistura dada por Cicchitti et al. (1960) capturam razoavelmente a tendência dos dados experimentais. Os métodos de Friedel (1979), Müller-Steinhagen e Heck (1986), Kim e Mudawar (2012) e Del Col et al. (2013) capturam a tendência dos dados experimentais para títulos de vapor reduzidos e intermediários.

Já para a geometria triangular, conforme a Figura 6.14b, Sun e Mishima (2009b), Müller-Steinhagen e Heck (1986) e o modelo homogêneo com a viscosidade da mistura dada por Cicchitti et al. (1960) capturam razoavelmente a tendência dos dados experimentais. 
a)

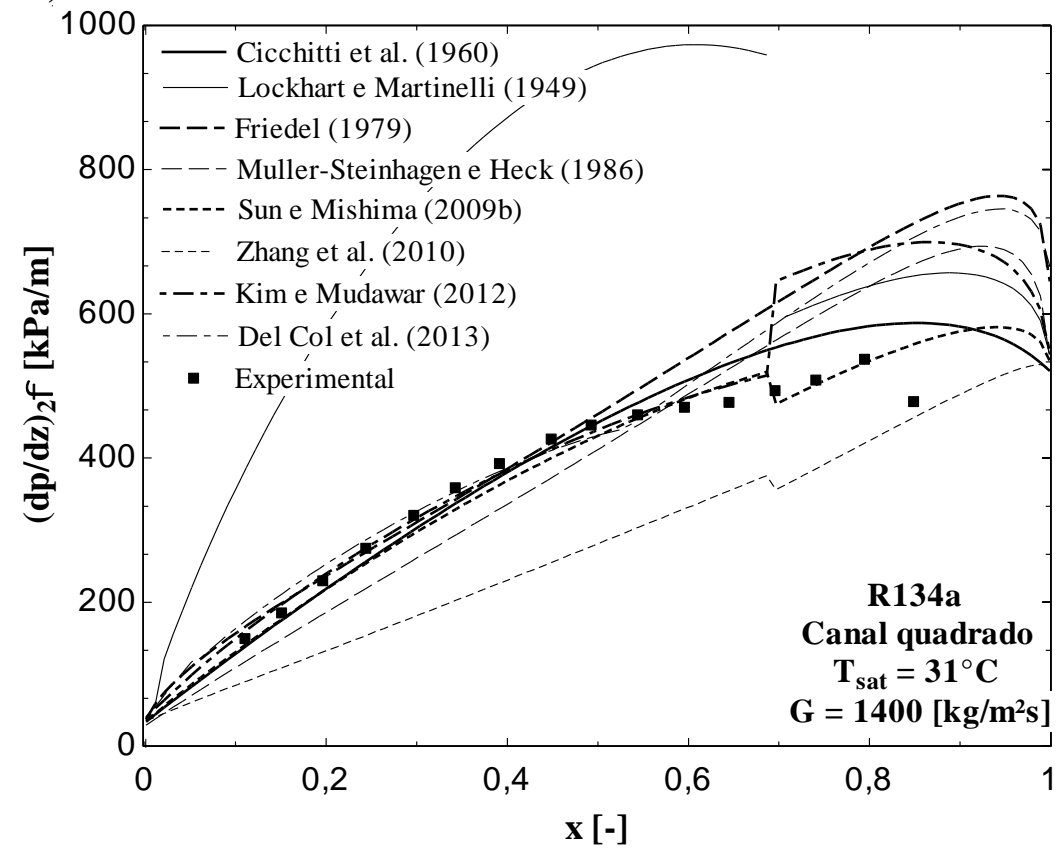

b)

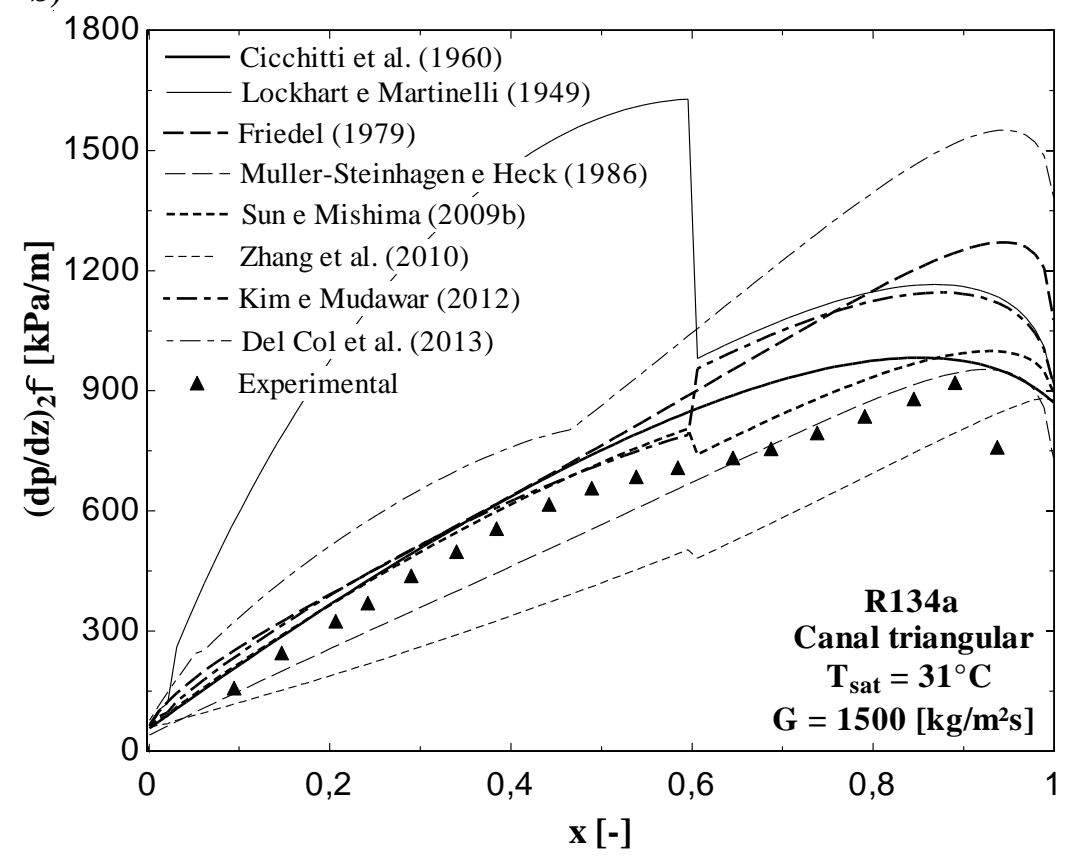

Figura 6.14. Comparação das tendências da perda de pressão de acordo aos métodos de previsão da literatura e dados experimentais para o fluido R134a, a) canal quadrado e b) canal triangular.

Para o fluido R1234ze(E) e R600a, observa-se na Figura 6.15 que os métodos que melhor capturam a tendência da perda de pressão experimental são Friedel (1979), Müller-Steinhagen e Heck (1986) e Del Col et al. (2013). Os demais métodos não proporcionam previsões satisfatórias das tendências dos resultados experimentais para estes fluidos. 
a)

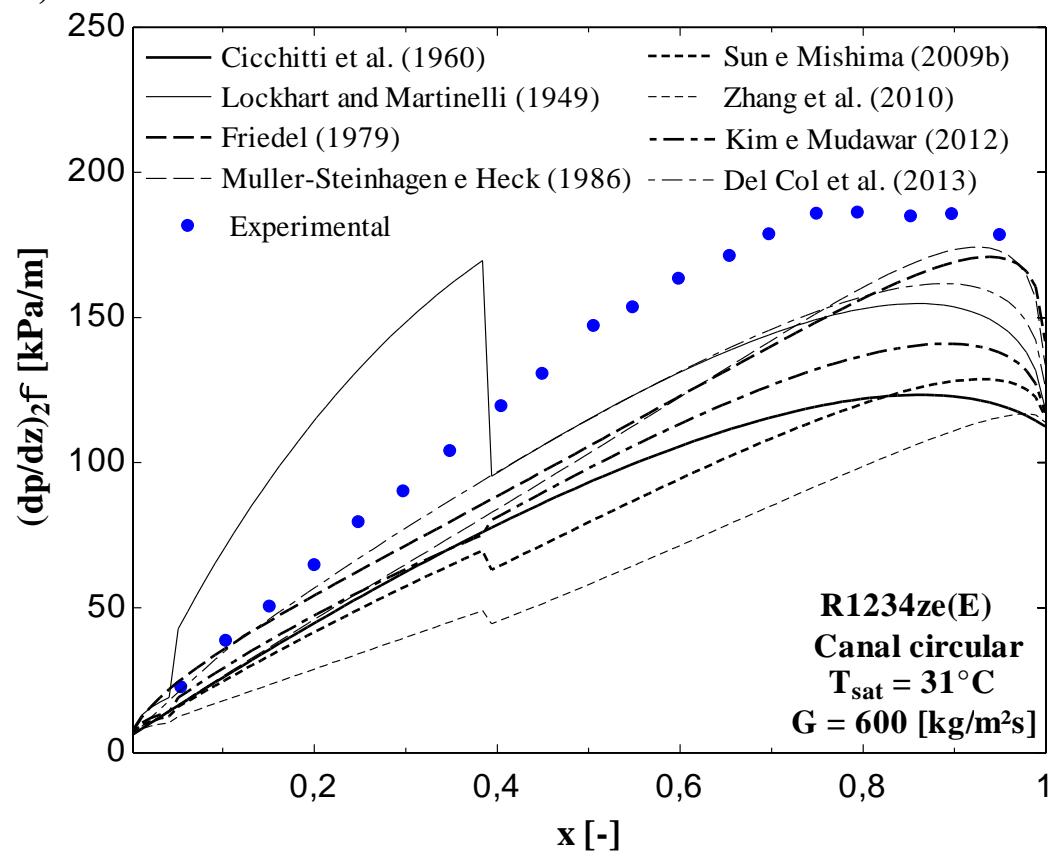

b)

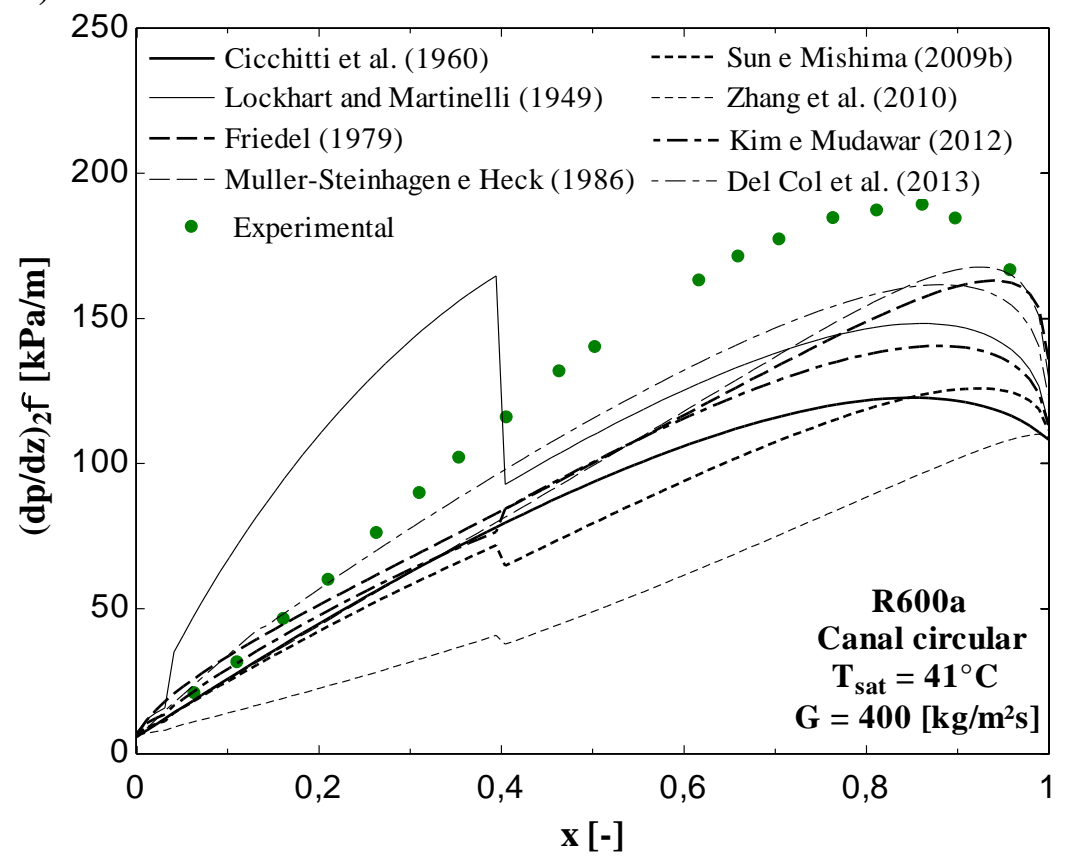

Figura 6.15. Comparação das tendências da perda de pressão de acordo aos métodos de previsão da literatura e dados experimentais para o fluido a) R1234ze(E) e b) R600a.

A tendência dos resultados experimentais para o fluido R1234yf foram capturados razoavelmente pelos métodos de Friedel (1979) e Müller-Steinhagen e Heck (1986), como ilustrado na Figura 6.16. O método de Lockhart e Martinelli (1949) também captura razoavelmente a tendência dos dados experimentais para títulos de vapor superiores a 0,3 . 


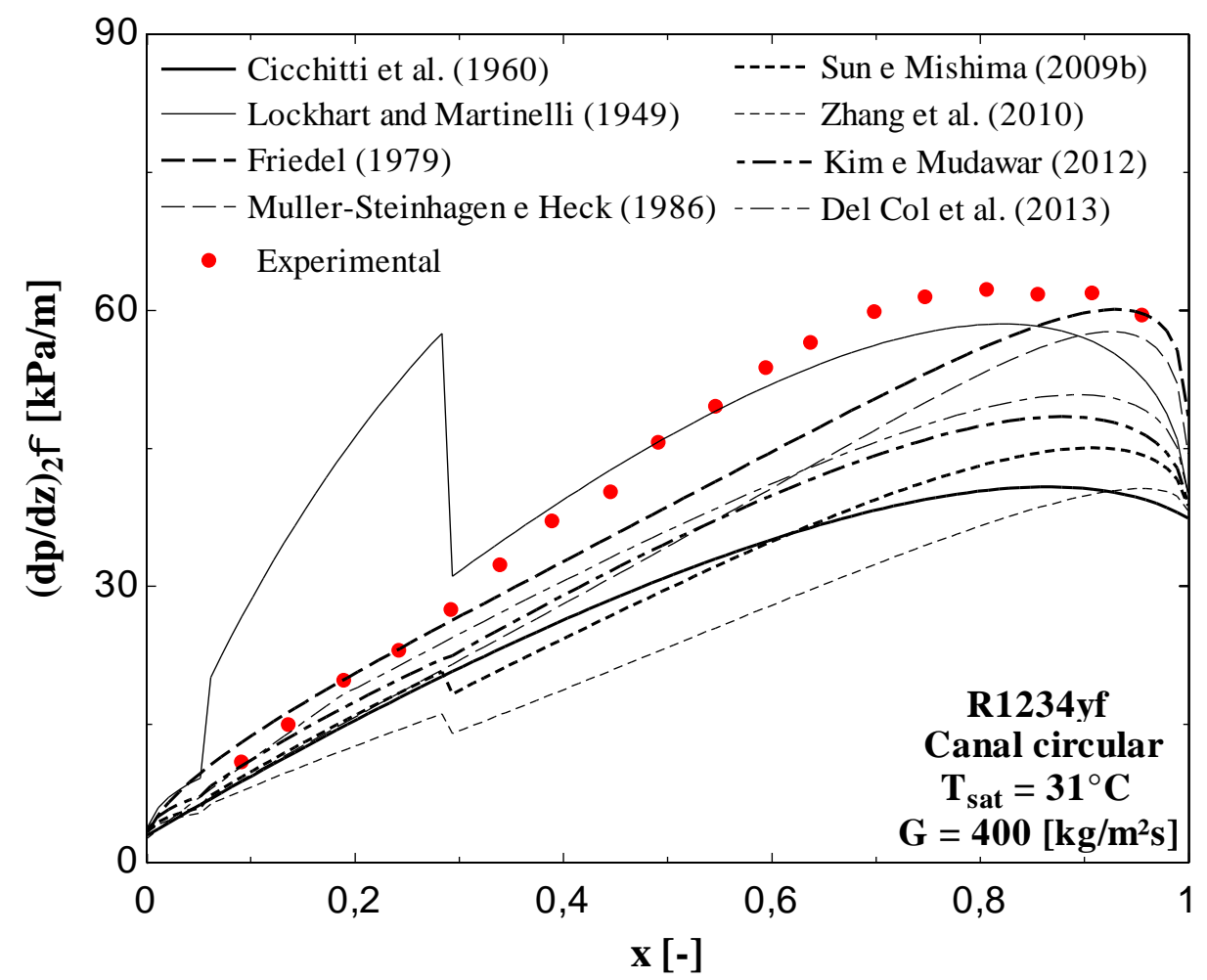

Figura 6.16. Comparação das tendências da perda de pressão de acordo aos métodos de previsão da literatura e dados experimentais para o fluido R1234yf.,

A partir dos parâmetros estatísticos e da análise de tendências dos métodos de previsão da literatura é possível extrair as seguintes conclusões:

A maioria dos métodos avaliados não proporciona previsões satisfatórias dos resultados experimentais para os fluidos R1234ze(E), R1234yf e isobutano e para o canal com seção transversal triangular;

Os métodos que forneceram as melhores previsões segundo apenas parâmetros estatísticos são Friedel (1979), Sun e Mishima (2009b), Kim e Mudawar (2012), Del Col et al. (2013), Müller-Steinhagen e Heck (1986) e o modelo homogêneo com a viscosidade dada por Cicchitti et al. (1960);

$>$ O modelo homogêneo com a viscosidade dada por Cicchitti et al. (1960), Sun e Mishima (2009b) e Kim e Mudawar (2012) capturam razoavelmente as tendências experimentais dos resultados para o fluido R134a;

Friedel (1979), Del Col et al. (2013) e Muller Steinhagen e Heck (1986) capturam as tendências dos dados experimentais apresentadas pelos fluidos R1234ze(E) e R600a; 
Os métodos de Del Col et al. (2013) e Müller-Steinhagen e Heck (1986) não preveem satisfatoriamente dados para a seção triangular (R134a) e para o fluido R1234yf.

\subsection{Proposição de um método para a previsão da perda de pressão}

Como observado e discutido na seção anterior, os métodos de previsão disponíveis não contemplam satisfatoriamente a ampla faixa de condições experimentais avaliadas no presente estudo. Por tanto, optou-se pelo desenvolvimento de um novo método de previsão da perda de pressão por atrito, o qual encontra-se descrito no presente item.

\subsubsection{Descrição do método proposto}

O método proposto se aplica à previsão da perda de pressão devido a efeitos de atrito durante escoamentos bifásicos em canais de reduzido diâmetro. Seu desenvolvimento toma por base o método de Müller-Steinhagen e Heck (1986) devido aos seguintes aspectos:

O procedimento proposto por estes autores é relativamente simples e de fácil implementação em programas computacionais de simulação de trocadores de calor. Além disso, uma vez implementado, não apresenta problemas de convergência devido a descontinuidades e resulta em gradientes de pressão correspondentes a escoamentos monofásicos para títulos de vapor iguais a 0 e 1 ;

D Este método se baseia em um banco de dados experimental amplo e proporcionou previsões razoáveis de resultados independentes segundo estudos da literatura que o compararam a bancos de dados extensos, conforme indicado por Ribatski et al. (2006), Felcar e Ribatski (2008), Revellin e Thome (2007), Cioncolini et al. (2009), Xu e Fang (2012), Xu et al. (2012) e Kim e Mudawar (2014);

Conforme indicado no item anterior, o método de Müller-Steinhagen e Heck (1986) proporcionou as melhores previsões dos dados levantados neste estudo, resultando em um EMA de $18,7 \%$ e prevendo $86 \%$ dos dados com desvios entre $\pm 30 \%$. 
O método de Müller-Steinhagen e Heck (1986) é dado pelas seguintes equações:

$$
\begin{aligned}
& \left(\frac{d p}{d z}\right)_{2 \phi}=F \cdot(1-x)^{1 / \lambda}+\left(\frac{d p}{d z}\right)_{G 0} \cdot x^{\lambda} \\
& F=\left(\frac{d p}{d z}\right)_{L 0}+\omega \cdot\left(\left(\frac{d p}{d z}\right)_{G 0}-\left(\frac{d p}{d z}\right)_{L 0}\right) \cdot x
\end{aligned}
$$

onde os coeficientes $\omega$ e $\lambda$ foram ajustados pelos autores como iguais a 3 e 2 , respectivamente, através dá análise de regressão de um banco de dados contendo 9313 resultados experimentais.

No desenvolvimento do novo método, inicialmente, a partir da base de dados levantada neste estudo contendo 1468 resultados experimentais envolvendo 4 fluidos (R134a, R1234ze(E), R1234yf e R600a), 3 geometrias da seção transversal (circular, quadrada e triangular) e velocidade mássicas entre 100 e $1600 \mathrm{~kg} / \mathrm{m}^{2} \mathrm{~s}$ determinou-se valores de $\omega$ e $\lambda$ para cada curva de $d p / d z$ vs. $x$ correspondente a uma condição experimental caracterizada por velocidade mássica, temperatura de saturação, fluido e geometria da seção transversal. Os coeficientes foram ajustados com base no método dos mínimos quadrados, utilizando a função nlinfit do programa MATLAB. Através desta análise constatou-se que $\omega$ decresce com o aumento da velocidade mássica, enquanto $\lambda$ varia apenas marginalmente. Com base neste fato, optou-se por adotar um valor de $\lambda$ constante e para correlacionar o valor de $\omega$, analisou-se números adimensionais que incluíssem efeitos inerciais através da velocidade mássica de forma a correlacionar tal expoente. Entre os números adimensionais avaliados, o número de Reynolds da mistura escoando como gás foi o que proporcionou as melhores previsões dos dados experimentais.

A Figura 6.17 ilustra os valores de $\omega$ obtidos em função do $R e_{G 0}$. 


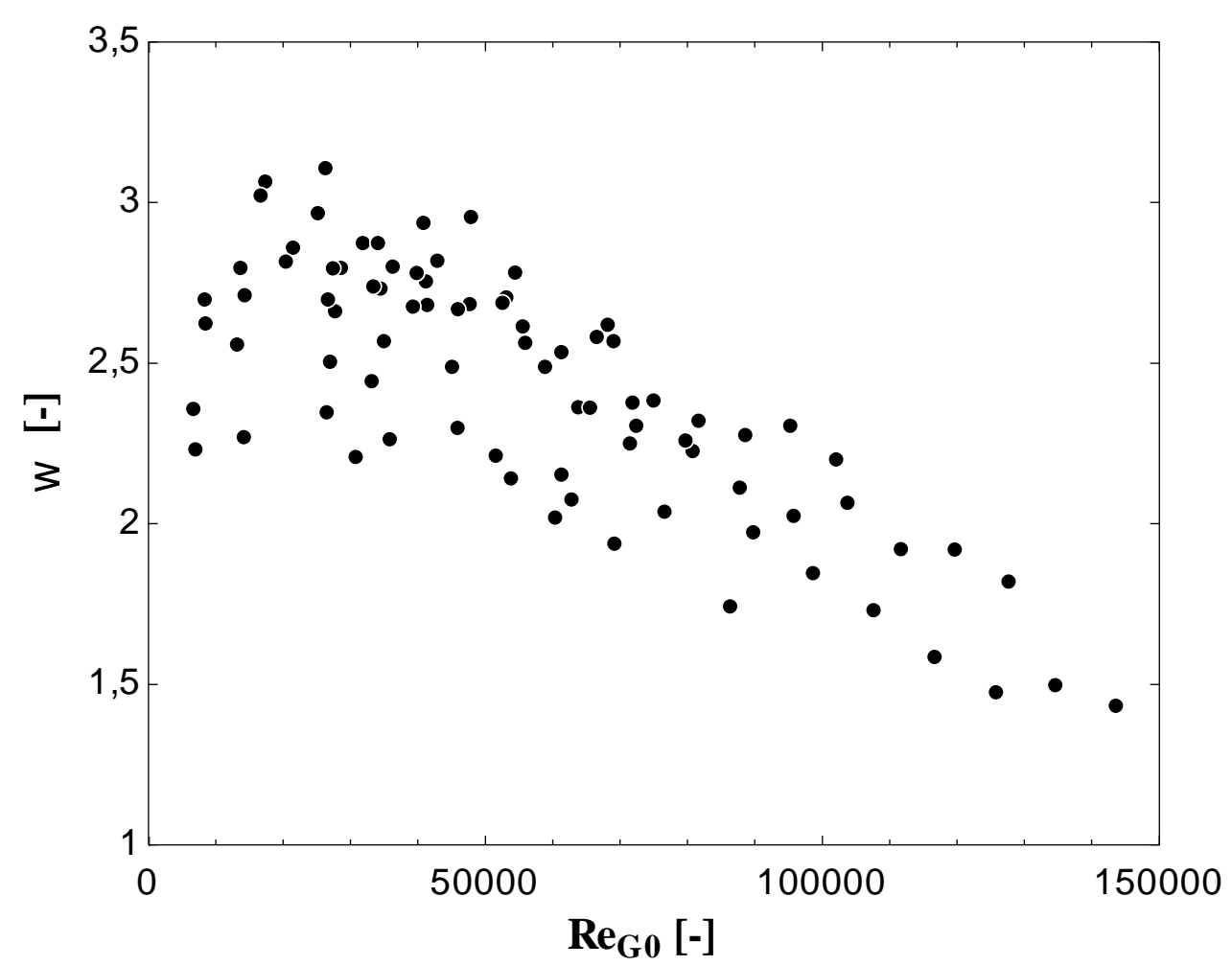

Figura 6.17. Coeficiente $\omega$ ideal em funçao do número de Reynolds da mistura escoando como a fase gasosa.

A partir do comportamento de $\omega$ com $\operatorname{Re}_{G 0}$ ilustrado na Figura 6.17, adotou-se a seguinte relação para a previsão deste coeficiente:

$\omega=a \cdot e^{b \cdot \operatorname{Re}_{G 0} / 1000}$

onde o número de Reynolds é calculado adotando-se o diâmetro equivalente como dimensão característica para canais não-circulares. Tal opção se deu com base na discussão e análise apresentada na seção 5.5. Os parâmetros a, b e $\lambda$ foram ajustados usando a função de mínimos quadrados para equações não-lineares do MATLAB R2010a, nlinfit. Através deste ajuste, os valores encontrados foram 3,013, -0,000004637 e 2,31, respectivamente.

O fluxograma apresentado na Figura 6.18 ilustra de forma esquemática o procedimento de implementação do método proposto. 


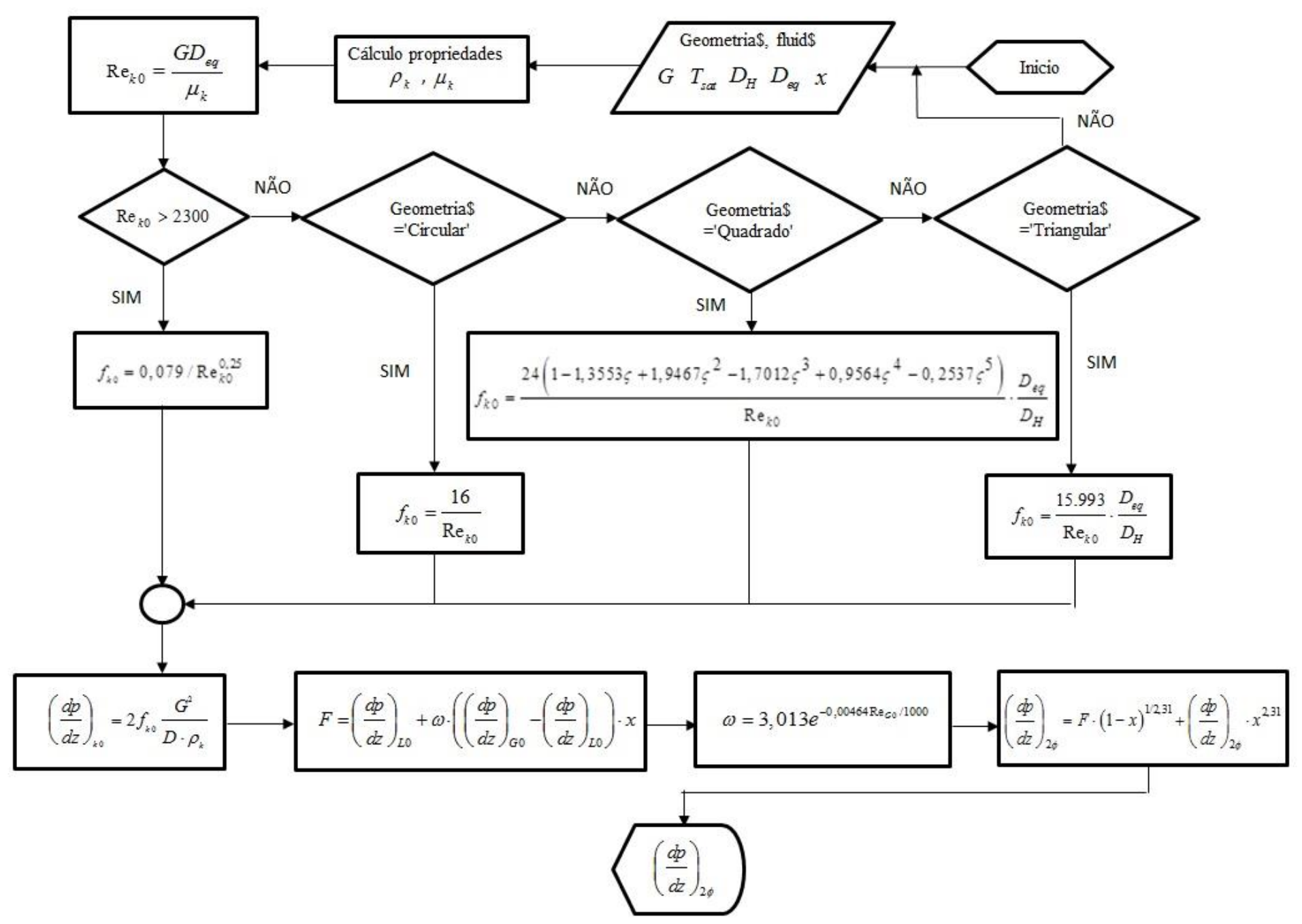

Figura 6.18. Fluxograma para a implementação do método proposto para perda de pressão. 


\subsubsection{Comparação com o banco de dados utilizado em seu desenvolvimento}

A Tabela 6.4 apresenta os parâmetros estatísticos resultantes das comparações do método com os dados segregados segundo fluido e geometria. Na comparação com a totalidade dos dados levantados, observa-se que o método proposto proporciona um EMA de $10,2 \%$ e prevê $97,1 \%$ e $89,2 \%$ dos dados com erro entre $\pm 30 \%$ e $\pm 20 \%$, respectivamente. Estes resultados permitem concluir que o método proposto proporciona, para o presente banco de dados, melhores previsões que os métodos disponíveis na literatura.

Tabela 6.4. Parámetros estatísticos da comparação entre o método proposto e dados experimentais.

\begin{tabular}{|c|c|c|c|c|c|c|}
\hline $\begin{array}{c}\text { Base de } \\
\text { dados }\end{array}$ & Geometria & \#Dados & EMA & MRE & $\eta \mathbf{3 0 \%}$ & $\eta 20 \%$ \\
\hline $\mathrm{R} 134 \mathrm{a}$ & Circular & 253 & $11,4 \%$ & $4,0 \%$ & $90,9 \%$ & $85,0 \%$ \\
\hline $\mathrm{R} 134 \mathrm{a}$ & Quadrado & 295 & $11,9 \%$ & $-7,0 \%$ & $99,0 \%$ & $80,0 \%$ \\
\hline $\mathrm{R} 134 \mathrm{a}$ & Triangular & 365 & $9,7 \%$ & $-5,7 \%$ & $98,9 \%$ & $93,7 \%$ \\
\hline $\mathrm{R} 1234 \mathrm{ze}(\mathrm{E})$ & Circular & 229 & $8,0 \%$ & $-1,0 \%$ & $97,4 \%$ & $91,3 \%$ \\
\hline R1234yf & Circular & 140 & $10,7 \%$ & $-9,7 \%$ & $\mathbf{9 7 , 9 \%}$ & $92,9 \%$ \\
\hline R600a & Circular & 186 & $9,3 \%$ & $-6,5 \%$ & $98,9 \%$ & $\mathbf{9 7 , 8 \%}$ \\
\hline Total & & 1468 & $10,2 \%$ & $-4,0 \%$ & $97,2 \%$ & $89,2 \%$ \\
\hline
\end{tabular}

O fato do método proposto proporcionar as melhores previsões é corroborado através da comparação das Figuras 6.10 a 6.13 com a Figura 6.19, notando-se que ao contrário dos métodos da literatura, o método proposto neste estudo não apresenta desvios significativos em relação aos dados experimentais para condições específicas. 


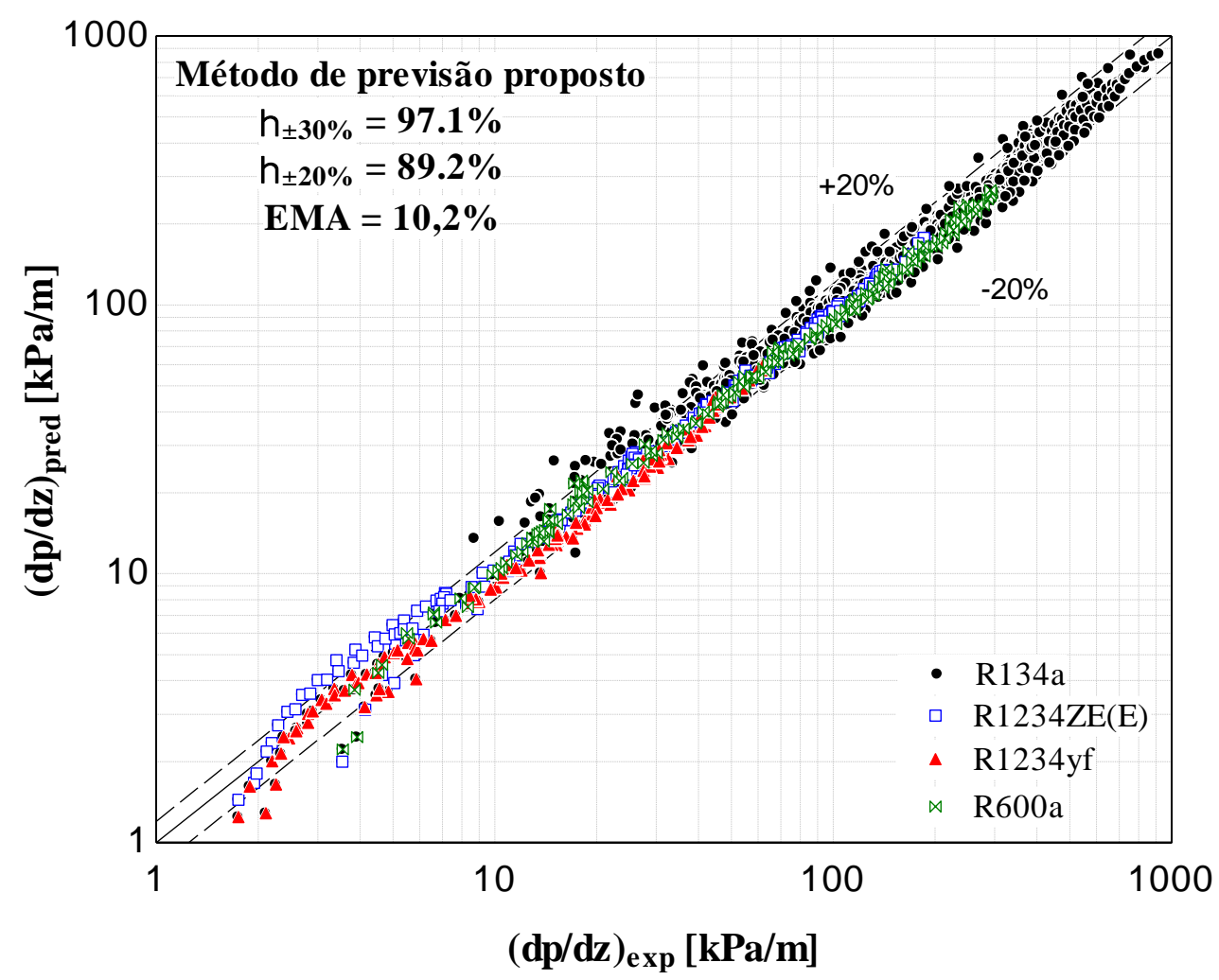

Figura 6.19. Comparação do banco de dados experimental com o método de previsão proposto no presente estudo.

As Figuras 6.20 a 6.23 ilustram avaliações comparativas do novo método e aqueles da literatura propostos por Müller-Steinhagen e Heck (1986), Kim e Mudawar (2012) e Del Col et al. (2013), que apresentaram as melhores previsões dos resultados levantados neste estudo. Nestas figuras as comparações são efetuadas com o banco de dados segregado de acordo com o fluido de trabalho, geometria da seção transversal, faixas de títulos de vapor, faixas de velocidades mássicas e gradiente da perda de pressão.

Na Figura 6.20 constata-se que o método proposto prevê razoavelmente os resultados experimentais para os quatro fluidos avaliados neste estudo com parcelas superiores a $84 \%$ dos dados previstos com erro entre $\pm 20 \%$. Pode-se observar também, que o método proposto proporciona melhores previsões que os métodos da literatura para os 4 fluidos, destacando o valor de $\eta_{ \pm 20 \%}$ significativamente superior para o R1234yf. No caso do isobutano, verifica-se que as alterações implementadas neste estudo ao procedimento inicialmente proposto por Müller-Steinhagen e Heck (1986), permitem elevar o valor de $\eta_{20 \%}$ de cerca de $40 \%$ para aproximadamente $100 \%$. 


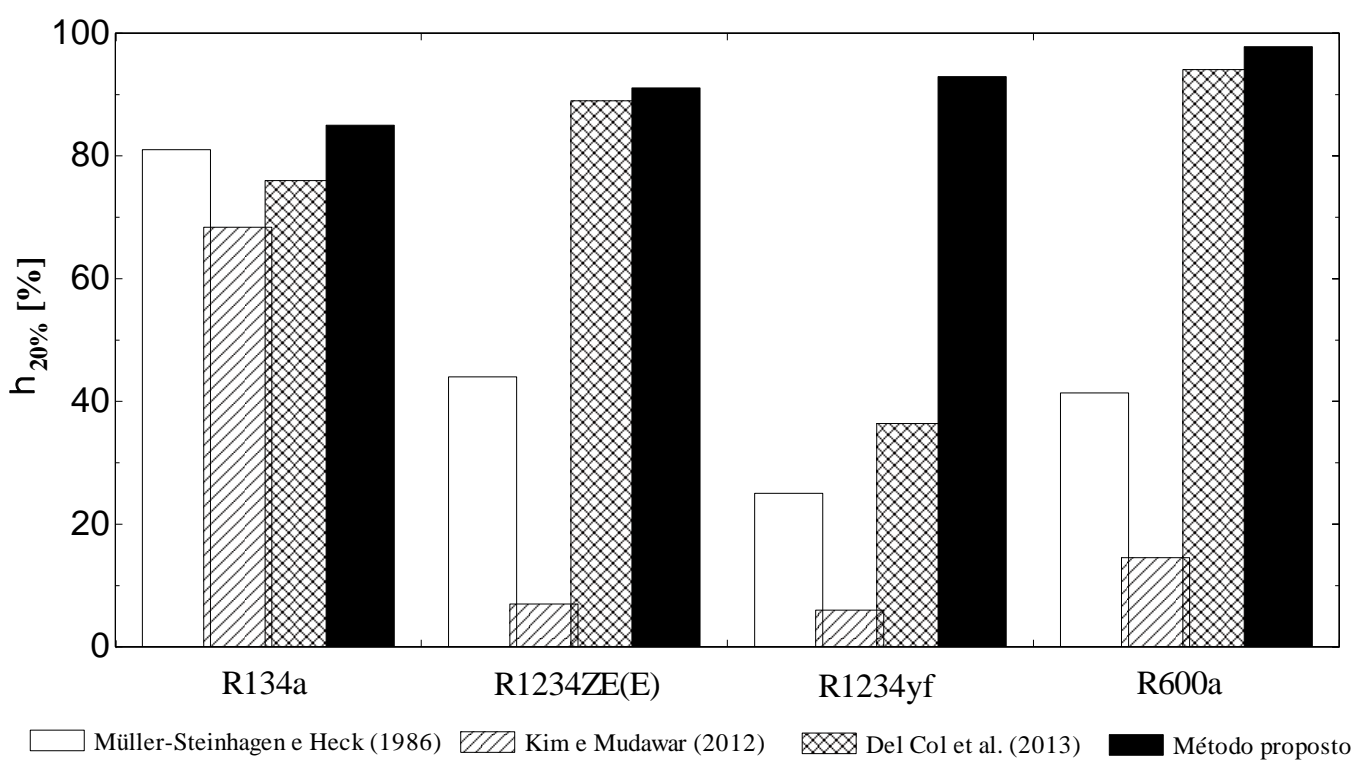

Figura 6.20. Parcela dos dados experimentais previstos segundo métodos da literatura com erro inferior a $20 \%$ de acordo com o fluido de trabalho.

Conforme ilustrado na Figura 6.21, o método proposto prevê razoavelmente os resultados experimentais com uma parcela superior a $80 \%$ dos dados dentro da faixa de $\pm 20 \%$ independentemente da geometria da seção transversal. Ressalta-se o fato do método proposto melhorar significativamente as previsões para a geometria triangular.

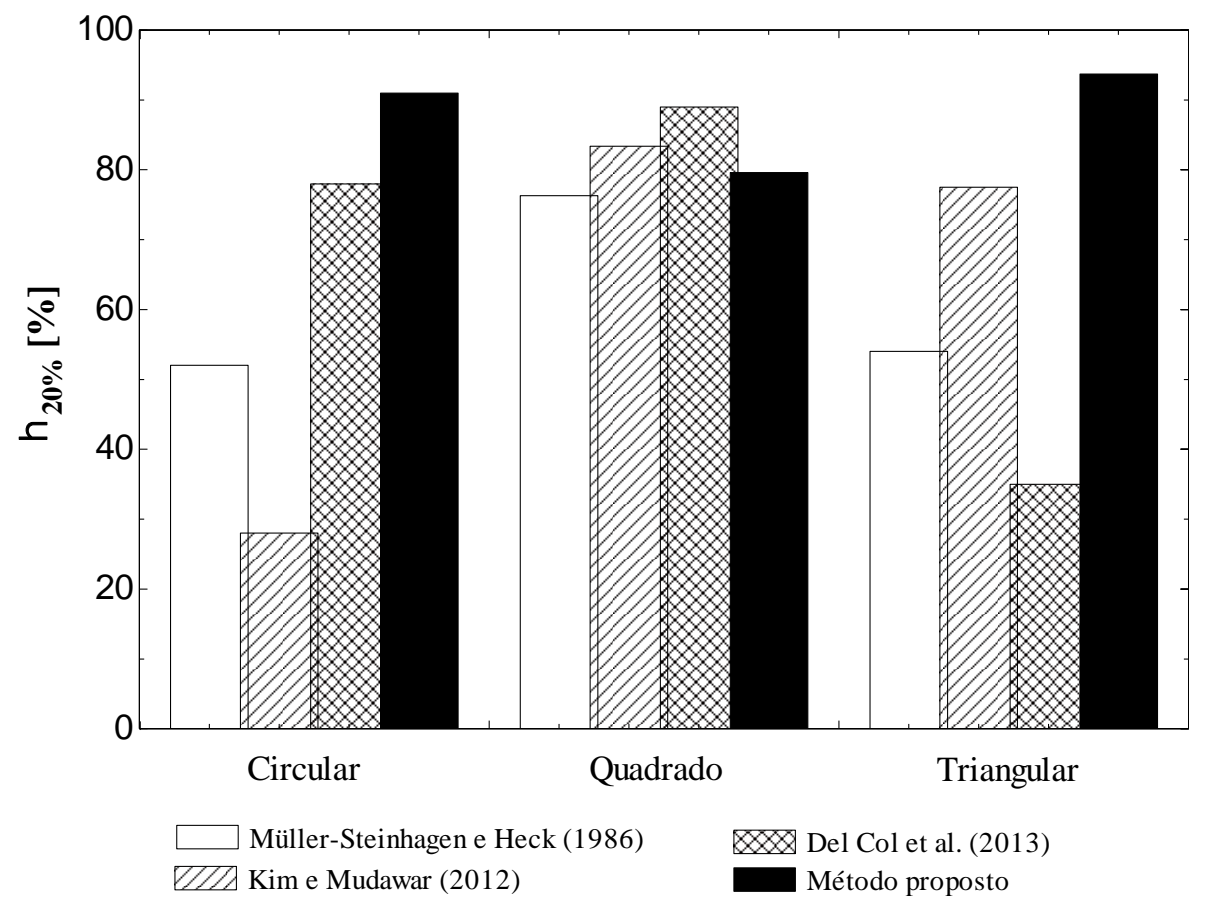

Figura 6.21. Parcela dos dados experimentais previstos segundo métodos da literatura com erro inferior a $20 \%$ de acordo com a geometria da seção transversal da tubulação. 
Segundo as Figuras 6.22 e 6.23, o novo método prevê, em relação aos demais, parcelas superiores dos dados com erros inferiores a $\pm 20 \%$, independentemente da faixa de título de vapor, velocidade mássica e perda de pressão.
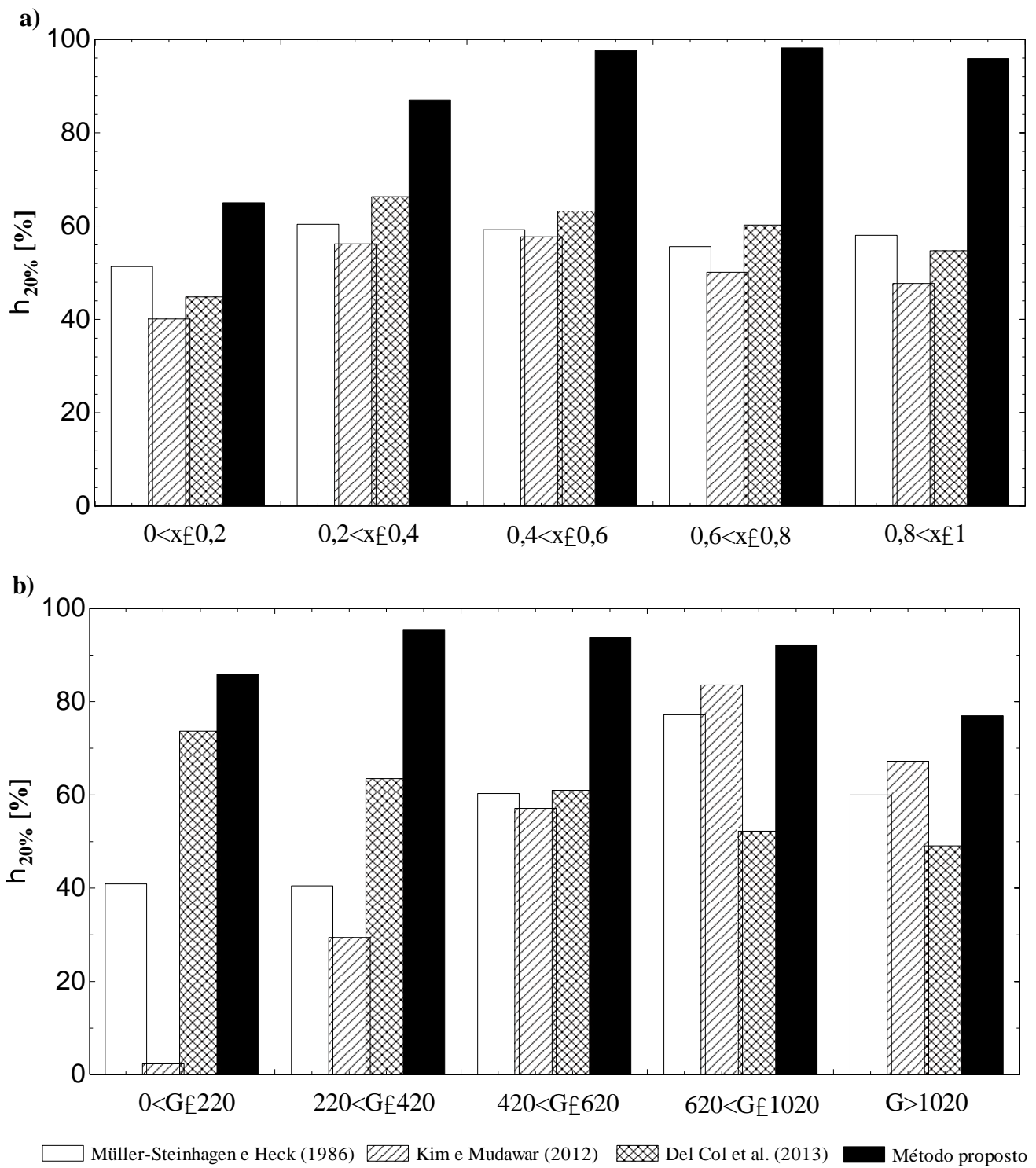

Figura 6.22. Parcela dos dados experimentais previstos segundo métodos da literatura com erro inferior a $20 \%$ de acordo com a) a faixa de título de vapor, b) faixa de velocidade mássica.

A Figura 6.22a ilustra que, embora satisfatórias, piores previsões se verificam para títulos de vapor inferiores a 0,2 resultando em um valor de $\eta_{20 \%}$ de aproximadamente $70 \%$. Ainda assim, o método proposto obteve melhores previsões para esta faixa de títulos de vapor quando comparados as previsões de Müller-Steinhagen e Heck (1986), Kim e Mudawar (2012) e Del Col et al. (2013). Vale mencionar que para valores de título vapor reduzidos as incertezas nas medidas experimentais são superiores. Por outro lado, conforme ilustra a Figura 6.20b, destaca-se o fato do método proposto não apresentar 
diferenças significativas no valor de $\eta_{ \pm 20 \%}$ com alterações na faixa de velocidades mássicas, prevendo parcelas superiores a $78 \%$ dos dados com desvios entre $\pm 20 \%$.

Na Figura 6.23 observa-se que o método proposto fornece melhores previsões que os métodos da literatura independentemente da faixa de gradientes de pressão avaliada.

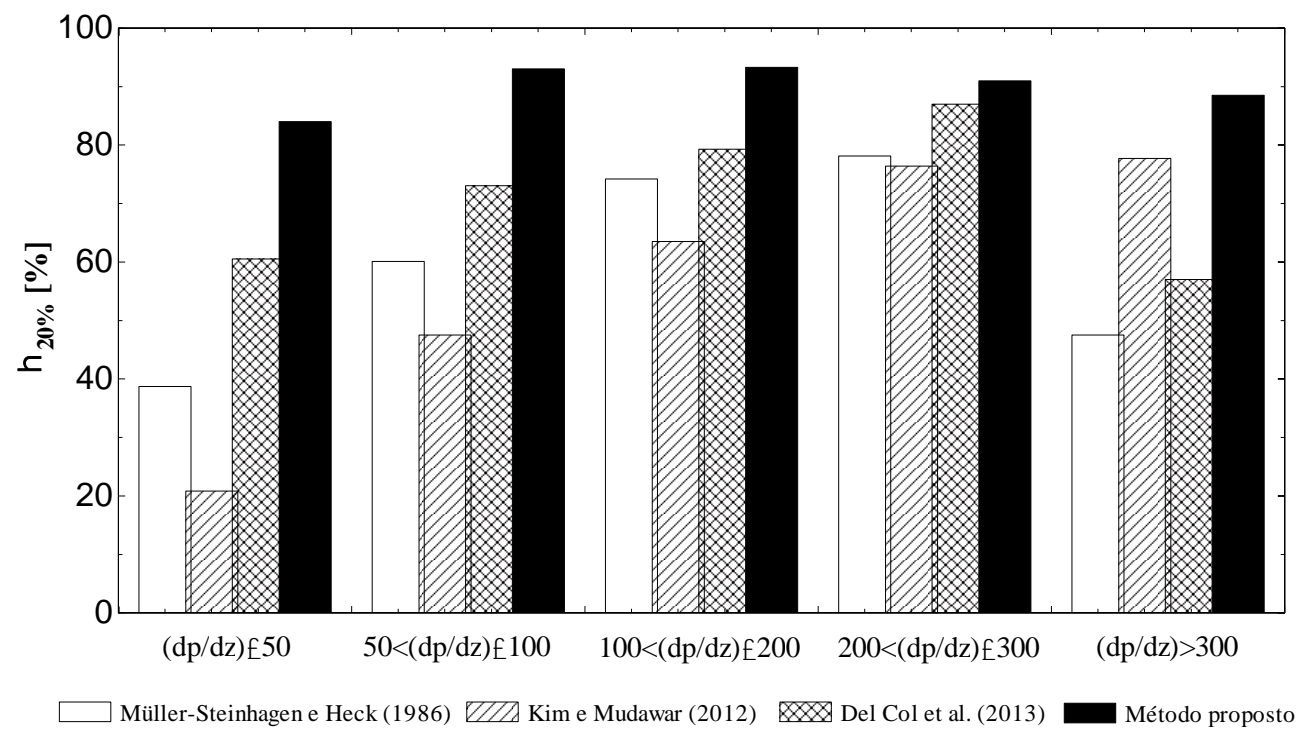

Figura 6.23. Parcela dos dados experimentais previstos segundo métodos da literatura com erro inferior a $20 \%$ de acordo à faixa do gradiente da perda de pressão.

\subsubsection{Análise paramétrica das tendências fornecidas pelo novo método}

Um método preditivo, além de prever satisfatoriamente os resultados experimentais segundo parâmetros médios estatísticos, deve capturar as tendências dos dados com a variação das condições experimentais. Buscando verificar o desempenho do método proposto em relação a este aspecto, o presente item ilustra comparações das tendências fornecidas pelos resultados experimentais e o método proposto com a variação da velocidade mássica, temperatura de saturação, fluido refrigerante e geometria da seção de testes.

A Figura 6.24 ilustra o efeito da velocidade mássica na perda de pressão bifásica. Nela constata-se o incremento da perda de pressão com o acréscimo da velocidade mássica, comportamento análogo ao verificado através da análise dos resultados experimentais. 


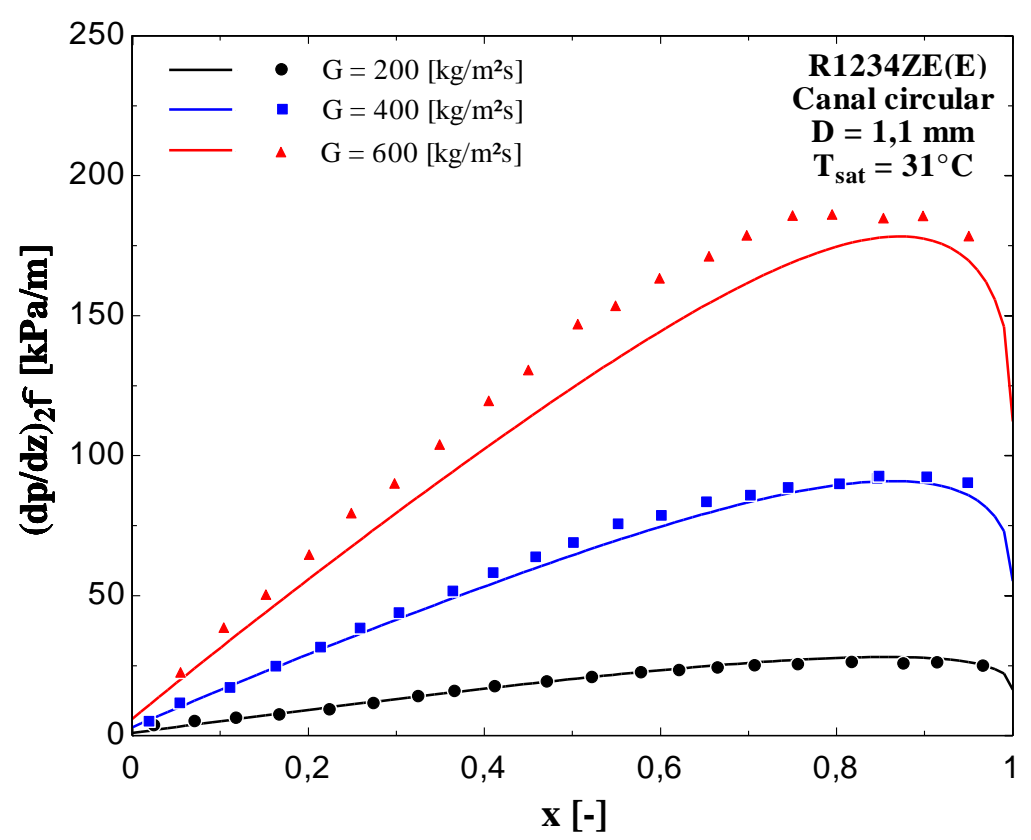

Figura 6.24. Efeito da velocidade mássica no gradiente da perda de pressão previsto pelo método proposto no presente estudo.

A análise da Figura 6.25, permite concluir também que o método proposto prevê adequadamente o comportamento da perda de pressão com o acréscimo da temperatura de saturação. Para o isobutano observa-se desvios superiores entre o método e os dados experimentais para a velocidade mássica de $400 \mathrm{~kg} / \mathrm{m}^{2} \mathrm{~s}$.

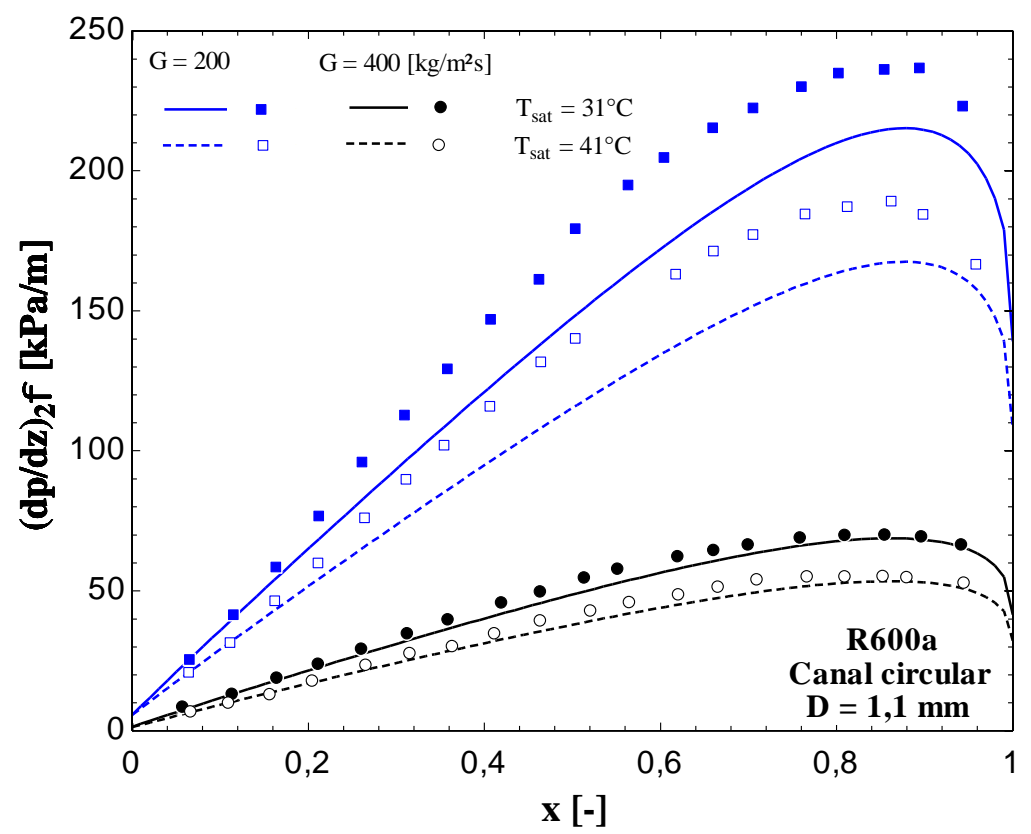

Figura 6.25. Efeito da temperatura de saturação no gradiente da perda de pressão previsto pelo método proposto no presente estudo. 
A Figura 6.26 ilustra o efeito do fluido e do diâmetro equivalente do canal no gradiente da perda de pressão previsto pelo método proposto. Como ilustrado na figura, o método proposto captura ambos os efeitos, fornecendo resultados aproximadamente coincidentes com os dados experimentais.
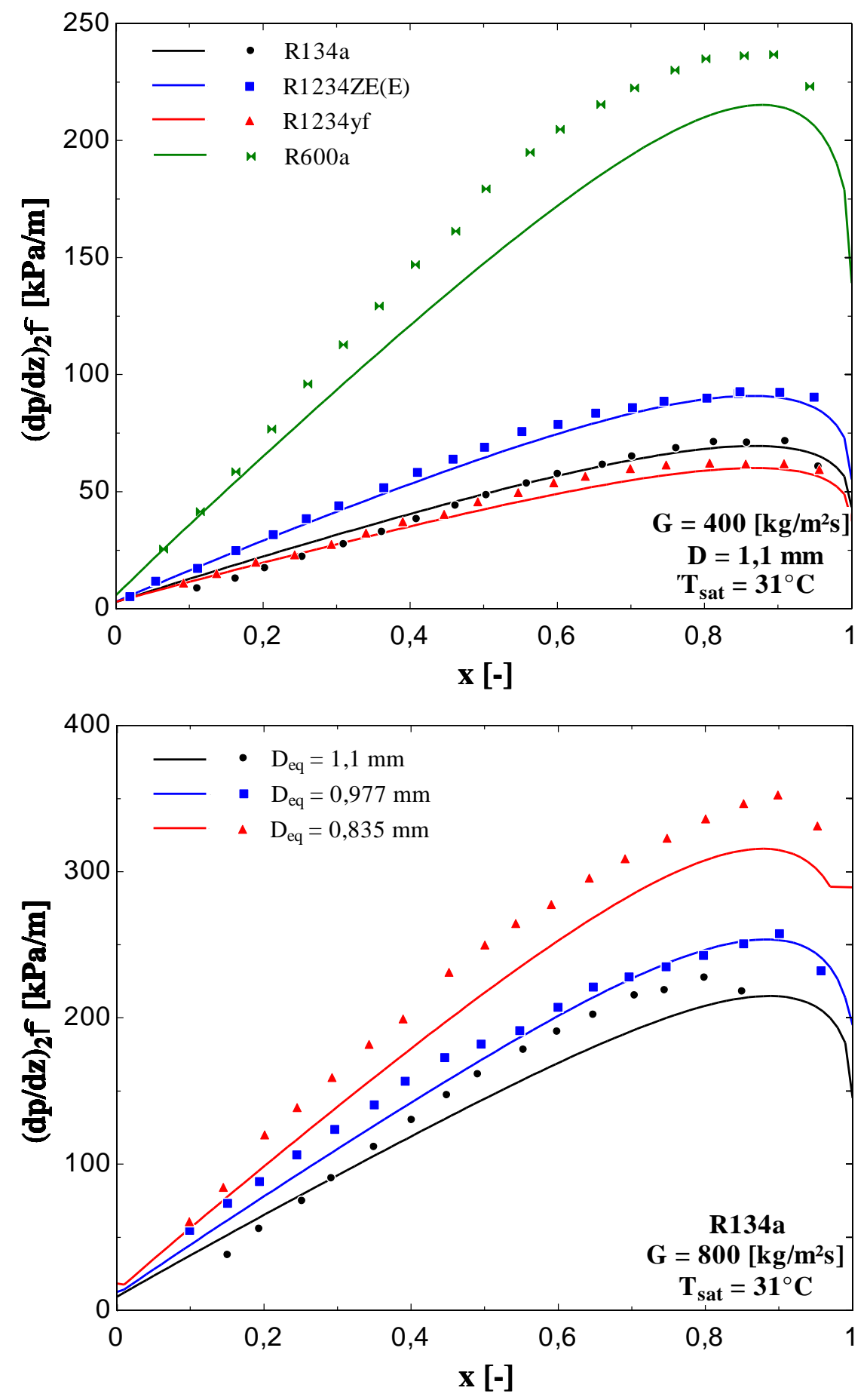

Figura 6.26. Efeito do fluido de trabalho e do diametro no gradiente da perda de pressão previsto pelo método proposto no presente estudo. 


\subsubsection{Comparação do novo método com dados da literatura}

Neste item, estimativas através do método proposto são comparadas com bancos de dados independentes levantados na literatura para escoamentos adiabáticos, canais únicos, seção circular e quadrada e os fluidos R1234yf, R1234ze(E), $\mathrm{CO}_{2}$ e propano. Não verificou-se na literatura analisada dados adicionais de perda de pressão em condições adiabáticas para outras geometrias de seção transversal conforme destacado a partir da análise da Tabela 3.6. Dados de perda de pressão para multicanais com seção transversal triangular ocorrem na literatura, entretanto, comparações entre estes dados e o método proposto no presente estudo não são adequadas, pois conforme já indicado no Item 3.3.2 comportamentos distintos do escoamento verificam-se em configurações de canais únicos e multicanais.

A Tabela 6.5 ilustra o erro absoluto médio e a parcela de dados prevista com desvios entre $\pm 30 \%$. De uma maneira geral, a partir desta tabela, concluiu-se que o método proposto fornece também previsões satisfatórias quando aplicado a resultados experimentais independentes.

Tabela 6.5. Erro médio absoluto e porcentagem de previsões dentro do $\pm 30 \%$ resultante da comparação entre o método proposto e o banco de dados da literatura.

\begin{tabular}{c|c|c|c|ccc}
\hline Autor (es) & $\begin{array}{c}\text { Fluido } \\
\text { Dimensões }\end{array}$ & Geometria & $\begin{array}{c}\# \\
\text { Pontos }\end{array}$ & EMA & $\boldsymbol{\eta}_{\mathbf{3 0} \%}$ & $\boldsymbol{\eta}_{\mathbf{2 0} \%}$ \\
\hline Del Col et al. (2013) & $\begin{array}{c}\mathrm{R} 1234 \mathrm{yf} \\
\mathrm{D}_{\text {eq }}=1.388 \\
\mathrm{~mm}\end{array}$ \\
$\begin{array}{c}\mathrm{R} 1234 \mathrm{ze}(\mathrm{E}) \\
\mathrm{D}=0,96 \mathrm{~mm}\end{array}$ & Quadrado & 42 & $\mathbf{1 6 , 1}$ & $88,7 \%$ & $64, \%$ \\
$\begin{array}{c}\mathrm{CO}_{2} \\
\text { Del Col et al. (2015) }\end{array}$ & Circular & 55 & $\mathbf{1 5 , 1 \%}$ & $\mathbf{9 0 , 4 \%}$ & $75,0 \%$ \\
$\begin{array}{c}\text { Ducoulombier et al. } \\
\text { (2011) } \\
\text { Propano } \\
\text { Del Col et al. (2014) }\end{array}$ & Circular & 285 & $\mathbf{1 2 , 7 \%}$ & $89,3 \%$ & $78,6 \%$ \\
\hline Total & 48 & $\mathbf{7 , 2 \%}$ & $\mathbf{1 0 0 \%}$ & $\mathbf{9 5 , 8 \%}$ \\
\hline
\end{tabular}

Segundo a Tabela 6.5, o método proposto proporciona resultados satisfatórios para o banco de dados de Del Col et al (2013) para o fluido propano, proporcionando um erro absoluto médio de 7,2\%. Para os fluidos $\mathrm{CO}_{2}$ e R1234ze(E), o método também proporciona previsões adequadas, obtendo EMAs de 12,7 e $15,1 \%$, respectivamente. É importante mencionar o fato do método proposto ter proporcionado previsões satisfatórias 
para os fluidos $\mathrm{CO}_{2}$ e propano, os quais não estão inclusos no banco de dados utilizado em seu desenvolvimento. Além disso, os dados para o $\mathrm{CO}_{2}$ foram obtidos em pressões reduzidas significativamente superiores em relação aos demais fluidos. Isto implica o método capturar diferentes comportamentos e padrões de escoamento para um mesmo título de vapor devido a inferiores velocidades de escorregamento entre as fases como resultado do decréscimo da razão de $v_{G} / v_{L}$ para este fluido em relação aos demais. 


\section{CAPÍTULO 7 - RESULTADOS PARA COEFICIENTE DE TRANSFERÊNCIA DE CALOR E DESENVOLVIMENTO DE UM MÉTODO DE PREVISÃO}

\subsection{Introdução}

Inicialmente, este capítulo descreve e caracteriza o banco de dados levantado neste estudo para o coeficiente de transferência de calor através do mecanismo da ebulição convectiva. Segue, uma análise detalhada do comportamento do coeficiente de transferência de calor com a variação do fluxo de calor, velocidade mássica, temperatura de saturação, geometria da seção transversal e fluido de trabalho. Posteriormente, apresenta-se uma análise global do efeito da geometria e do fluido num dissipador de calor. Subsequentemente, os métodos de previsão da literatura são comparados ao banco de dados experimental. Esta comparação foi realizada mediante avaliação de parâmetros estatísticos e da análise do comportamento do coeficiente de transferência de calor com o acréscimo do título de vapor. Finalmente, o capítulo apresenta o desenvolvimento de um método para a previsão do coeficiente de transferência de calor, o qual é comparado com o banco de dados experimental levantado neste estudo e resultados independentes coletados na literatura.

\subsection{Descrição e caracterização do presente banco de dados experimental}

A Tabela 7.1 descreve as condições experimentais do banco de dados levantado no presente estudo para o coeficiente de transferência de calor local. Obteve-se 4580 resultados, envolvendo 4 fluidos refrigerantes (R134a, R1234ze(E), R1234yf e R600a), canais com seções transversais circular, quadrada e triangular, correspondendo, respectivamente, a diâmetros equivalentes de 1,1, 0,977 e 0,835 mm. O banco de dados experimental envolve fluxos de calor de 15 a $145 \mathrm{~kW} / \mathrm{m}^{2}$, velocidades mássicas de $100 \mathrm{a}$ $800 \mathrm{~kg} / \mathrm{m}^{2} \mathrm{~s}$, temperaturas de saturação de 31 e $41{ }^{\circ} \mathrm{C}$ e títulos de vapor até 0,93 . Neste estudo foram constatados para ebulição convectiva coeficientes de transferência de calor de até $31,41 \mathrm{~kW} / \mathrm{m}^{2} \mathrm{~K}$. 
Tabela 7.1. Condições experimentais do banco de dados para o CTC levantados neste estudo.

\begin{tabular}{|c|c|c|c|c|c|c|}
\hline Fluido & & R134a & & R1234ze(E) & R1234yf & R600a \\
\hline Geometria & Circular & Quadrado & Triangular & Circular & Circular & Circular \\
\hline $\mathrm{D}_{\mathrm{eq}}[\mathrm{mm}]$ & 1,1 & 0,977 & 0,835 & 1,1 & 1,1 & 1,1 \\
\hline$\phi\left[\mathrm{kW} / \mathrm{m}^{2}\right]$ & $15-85$ & $15-75$ & $15-65$ & $15-95$ & $15-55$ & $15-145$ \\
\hline $\mathrm{G}\left[\mathrm{kg} / \mathrm{m}^{2} \mathrm{~s}\right]$ & $200-800$ & $200-700$ & $200-600$ & $100-500$ & $100-400$ & $200-500$ \\
\hline $\mathrm{T}_{\text {sat }}\left[{ }^{\circ} \mathrm{C}\right]$ & $31-41$ & $31-41$ & $31-41$ & $31-41$ & $31-41$ & $31-41$ \\
\hline$x[-]$ & $0-0.91$ & $0-0,92$ & $0-0,91$ & $0-0,91$ & $0-0.91$ & $0-0.93$ \\
\hline $\mathrm{h}\left[\mathrm{kW} / \mathrm{m}^{2} \mathrm{C}\right]$ & $\begin{array}{c}4,73- \\
21,3\end{array}$ & $4,06-15,2$ & $4,86-16,6$ & $3,26-17,31$ & $4,24-14,42$ & $\begin{array}{l}2,55- \\
32,41\end{array}$ \\
\hline $\mathrm{N}^{\circ}$ de dados & 772 & 753 & 418 & 847 & 475 & 1315 \\
\hline
\end{tabular}

A Figura 7.1 ilustra as parcelas de dados correspondentes às distintas condições experimentais. De acordo com ela, parcela aproximada de $75 \%$ dos dados obtidos corresponde a seção transversal circular, com as geometrias quadrada e triangular, condizendo, respectivamente, a 15 e $10 \%$ dos resultados. Devido a limitações de disponibilidade de fluido, dificultando o levantamento de resultados para faixas de condições mais abrangentes, parcelas inferiores a $20 \%$ dos dados correspondem aos fluidos R1234ze(E) e R1234yf. Parcelas próximas a 40 e $30 \%$ dos resultados foram levantados para os refrigerantes R134a e R600a, respectivamente. Vale mencionar ainda que cerca de $60 \%$ dos dados correspondem a temperatura de saturação próxima a $31^{\circ} \mathrm{C}$, enquanto aproximadamente $40 \%$ para temperatura de saturação de $41^{\circ} \mathrm{C}$.
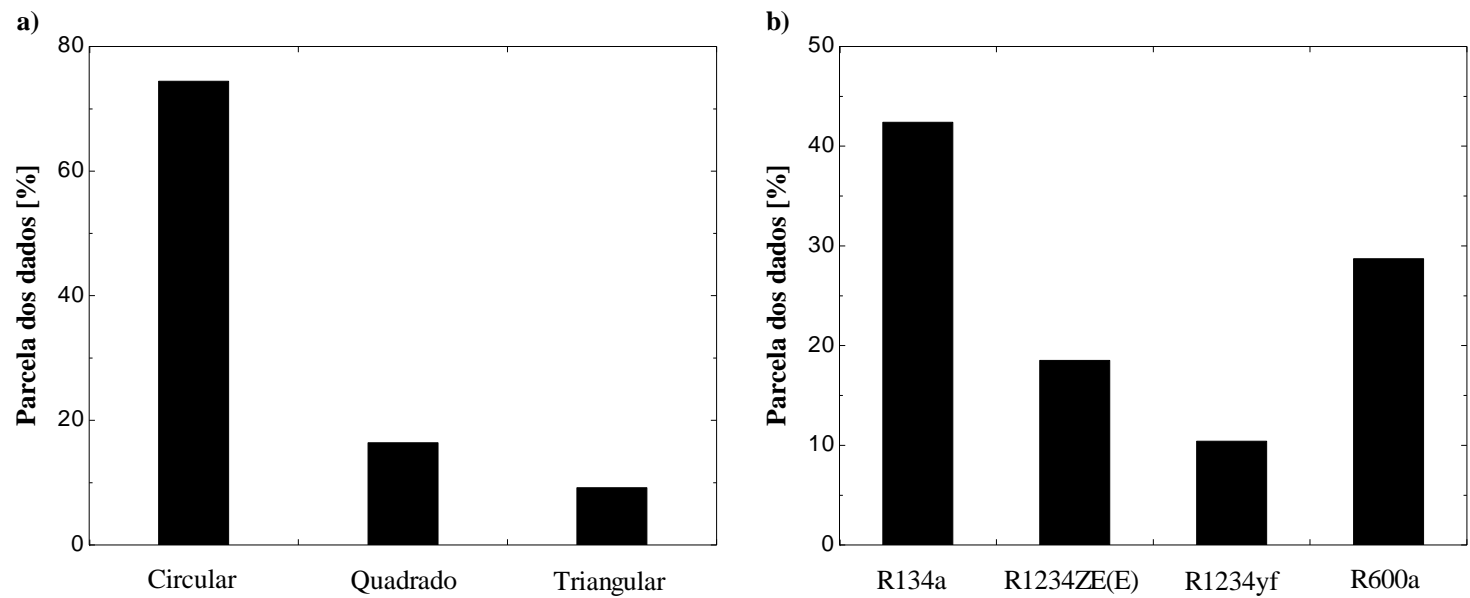

Figura 7.1. Distribuição do banco de dados experimental correspondente a: a) geometria da seção transversal, b) fluido de trabalho. 
Na Figura 7.2a constata-se que aproximadamente $80 \%$ dos dados levantados corresponde a velocidades mássicas entre 300 e $600 \mathrm{~kg} / \mathrm{m}^{2} \mathrm{~s}$. Parcelas de 15 e $5 \%$ condizem a velocidades mássicas inferiores a $220 \mathrm{~kg} / \mathrm{m}^{2} \mathrm{~s}$ e superiores a $620 \mathrm{~kg} / \mathrm{m}^{2} \mathrm{~s}$, respectivamente. Segundo a Figura 7.2b, 33\% dos dados estão relacionados a fluxos de calor reduzidos $\left(15-25 \mathrm{~kW} / \mathrm{m}^{2}\right), 40 \%$ a fluxos de calor intermediários $\left(35-55 \mathrm{~kW} / \mathrm{m}^{2}\right) \mathrm{e}$ $27 \%$ a fluxos de calor elevados $\left(>55 \mathrm{~kW} / \mathrm{m}^{2}\right)$. Na Figura $7.2 \mathrm{c}$, nota-se a predominância de resultados experimentais $(\sim 90 \%)$ para títulos de vapor entre 0,1 e 0,9. Também, constata-se número razoável de dados experimentais correspondendo a títulos de vapor inferiores a 0,1 e apenas $0,5 \%$ para títulos de vapor superiores a 0,9 . $\mathrm{O}$ reduzido número de resultados para $x>0,9$ está relacionado a restrições no aparato experimental de forma a evitar danos na seção de testes em condições próximas ao fluxo de secagem de parede. Razão similar está relacionada à ausência de dados para $x_{\text {sai }}>0,95$.
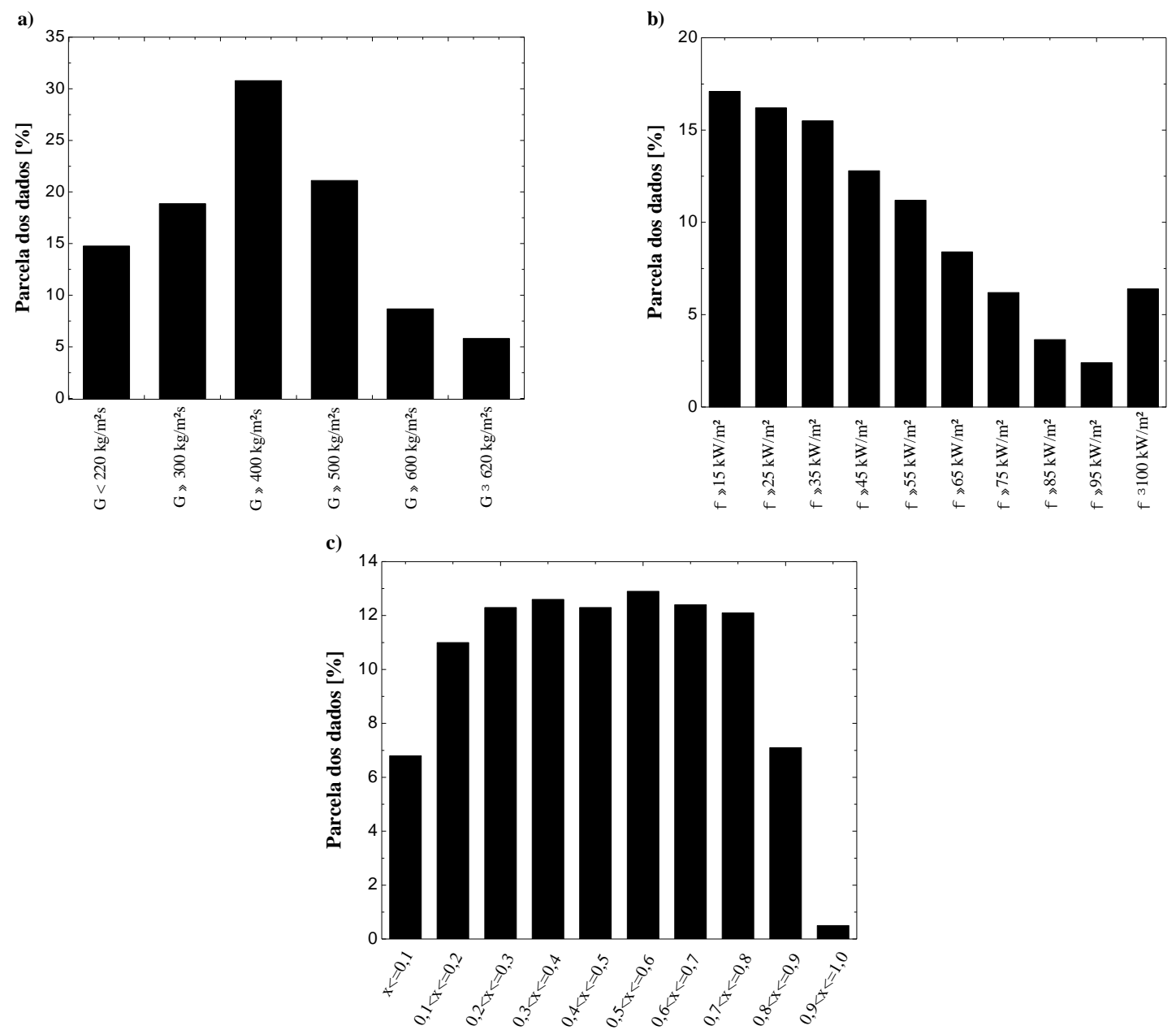

Figura 7.2. Distribuição do banco de dados experimental segundo as faixas de: a) velocidades mássicas, b) fluxos de calor, c) títulos de vapor. 
A Figura 7.3 ilustra a distribuição dos resultados experimentais segundo faixas do coeficiente de transferência de calor. Nesta figura nota-se que a maior parcela dos dados concentra-se em valores entre 5 e $20 \mathrm{~kW} / \mathrm{m}^{2} \mathrm{~K}$. Valores superiores a $20 \mathrm{~kW} / \mathrm{m}^{2} \mathrm{~K}$ também são observados, entretanto para uma parcela de apenas $6 \%$ dos dados. Estes valores ocorreram para condições de título de vapor elevado e, em sua maioria, para o refrigerante R600a. Já, coeficientes de transferência de calor inferiores a $5 \mathrm{~kW} / \mathrm{m}^{2} \mathrm{~K}$ estão relacionados a condições de fluxos de calor e títulos de vapor reduzidos e correspondem majoritariamente a resultados para o isobutano.

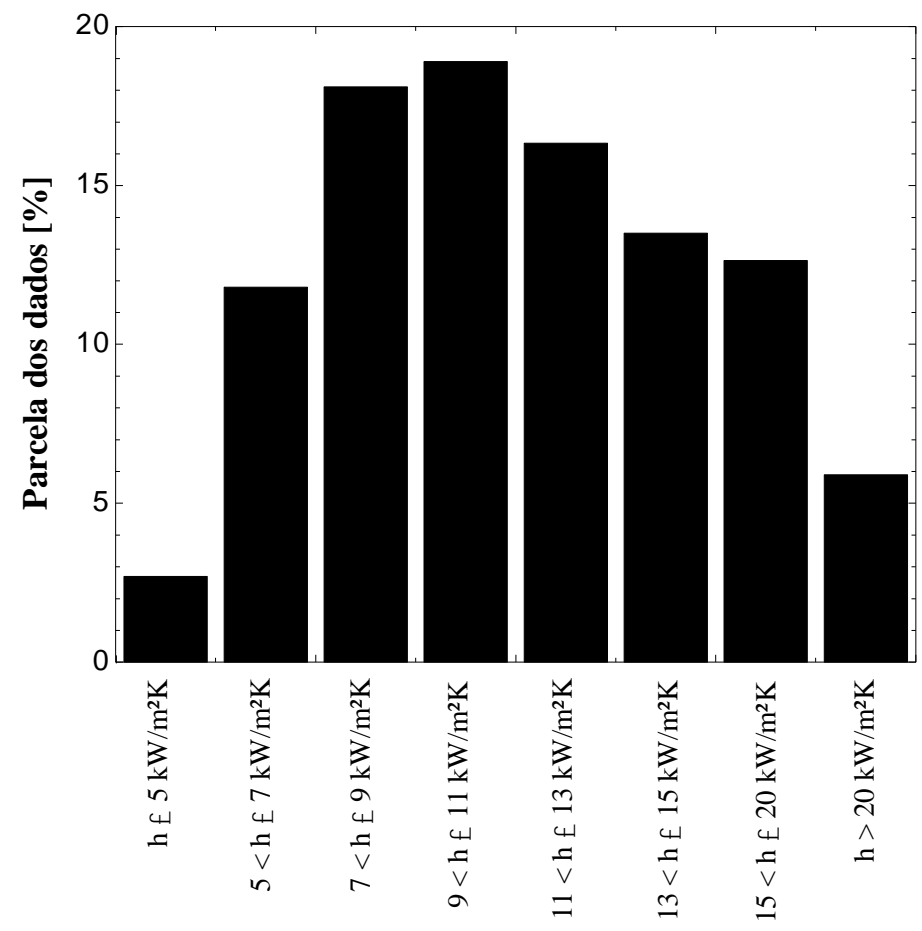

Figura 7.3. Distribuição do banco de dados segundo as faixas de coeficientes de transferência de calor.

A Figura 7.4 ilustra a distribuição dos dados experimentais segundo os regimes de escoamento caracterizado pela parcela de vazão correspondente a cada fase. Considerando a transição entre regime laminar e turbulento ocorrendo para número de Reynolds igual a 2000, constata-se que 3347 dados experimentais correspondem aos regimes líquido-laminar/gás-turbulento, 1084 estão relacionados a líquidoturbulento/gás-turbulento e apenas 150 dados correspondem a fase gás segundo o regime laminar. 


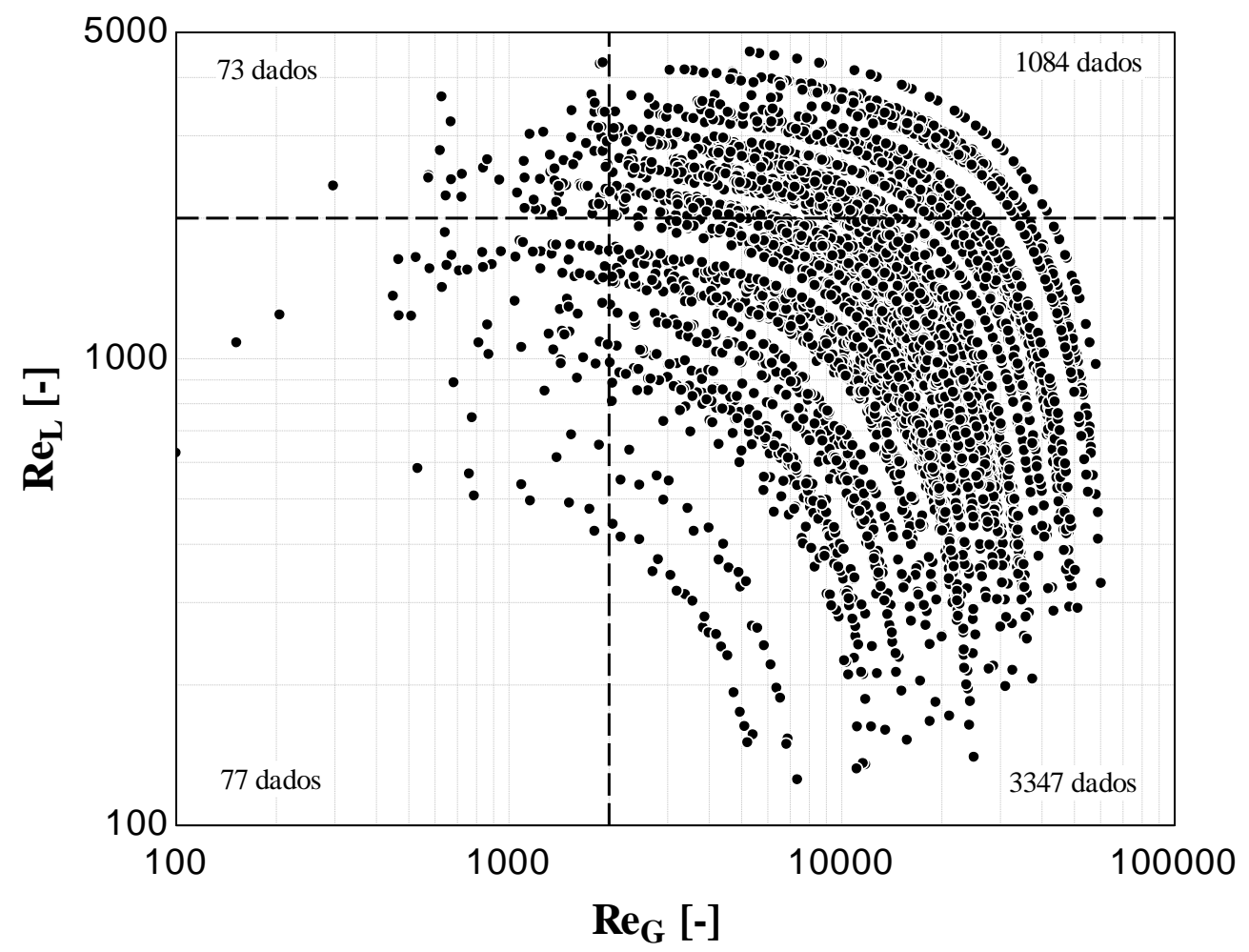

Figura 7.4. Distribuição do banco de dados experimental segundo regimes de escoamento baseado no número de Reynolds das fases separadas.

\subsection{Análise paramétrica dos resultados experimentais}

Esta seção apresenta a análise paramétrica dos resultados experimentais identificando os efeitos de fluxo de calor, velocidade mássica, temperatura de saturação, geometria da seção transversal e fluido no comportamento do coeficiente de transferência de calor com a variação do título de vapor.

\subsubsection{Efeito do fluxo de calor e título de vapor}

A Figura 7.5 ilustra o efeito do fluxo de calor no comportamento do coeficiente de transferência de calor com o acréscimo do título de vapor. De maneira geral, observase que o CTC se eleva com a elevação do fluxo de calor em condições em que predominam efeitos de ebulição nucleada, correspondentes a títulos de vapor reduzidos e intermediários. Já para títulos de vapor elevados, condição em que predominam efeitos convectivos, o coeficiente de transferência de calor torna-se independente do fluxo de calor. 


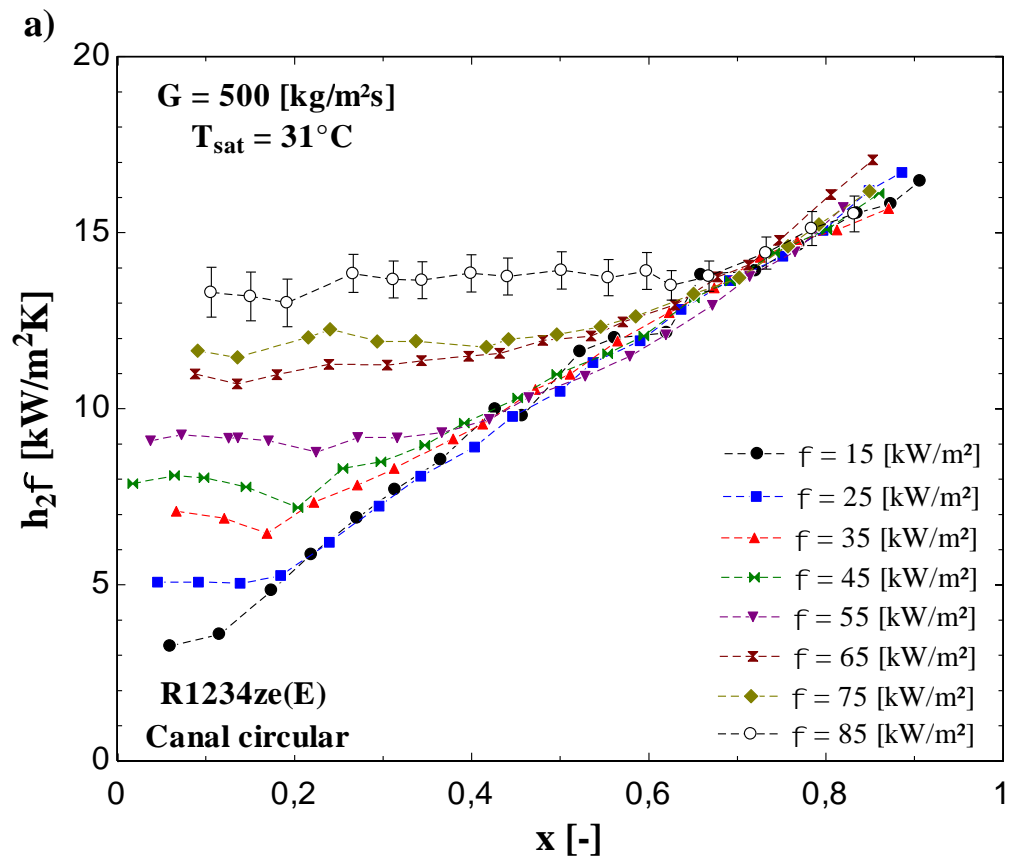

b)

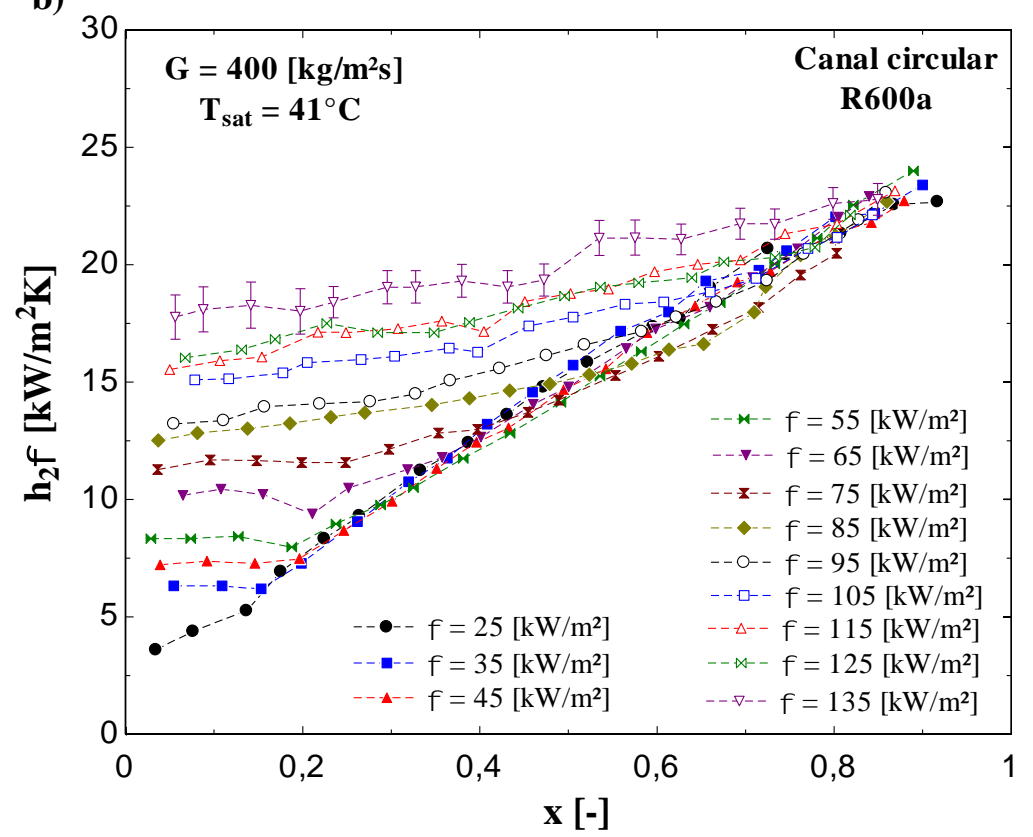

Figura 7.5. Ilustrações do efeito do fluxo de calor no CTC para ebulição convectiva dos fluidos: a) R1234ze(E) e b) R600a.

Segundo a Figura 7.5a, no caso do R1234ze(E), observa-se a partir de títulos de vapor superiores a 0,4, a predominância de efeitos convectivos para fluxos de calor inferiores $65 \mathrm{~kW} / \mathrm{m}^{2}$ caracterizados pelo aumento do CTC com o título de vapor combinado a um efeito marginal do fluxo de calor. Enquanto que para o R600a, considerando comportamentos similares, observa-se a predominância de efeitos convectivos para fluxos de calor inferiores a $95 \mathrm{~kW} / \mathrm{m}^{2}$, a partir de títulos de vapor superiores a 0,4 . 


\subsubsection{Efeito da velocidade mássica}

A Figura 7.6 ilustra o efeito da velocidade mássica no comportamento do coeficiente de transferência de calor para diferentes condições experimentais.

a)

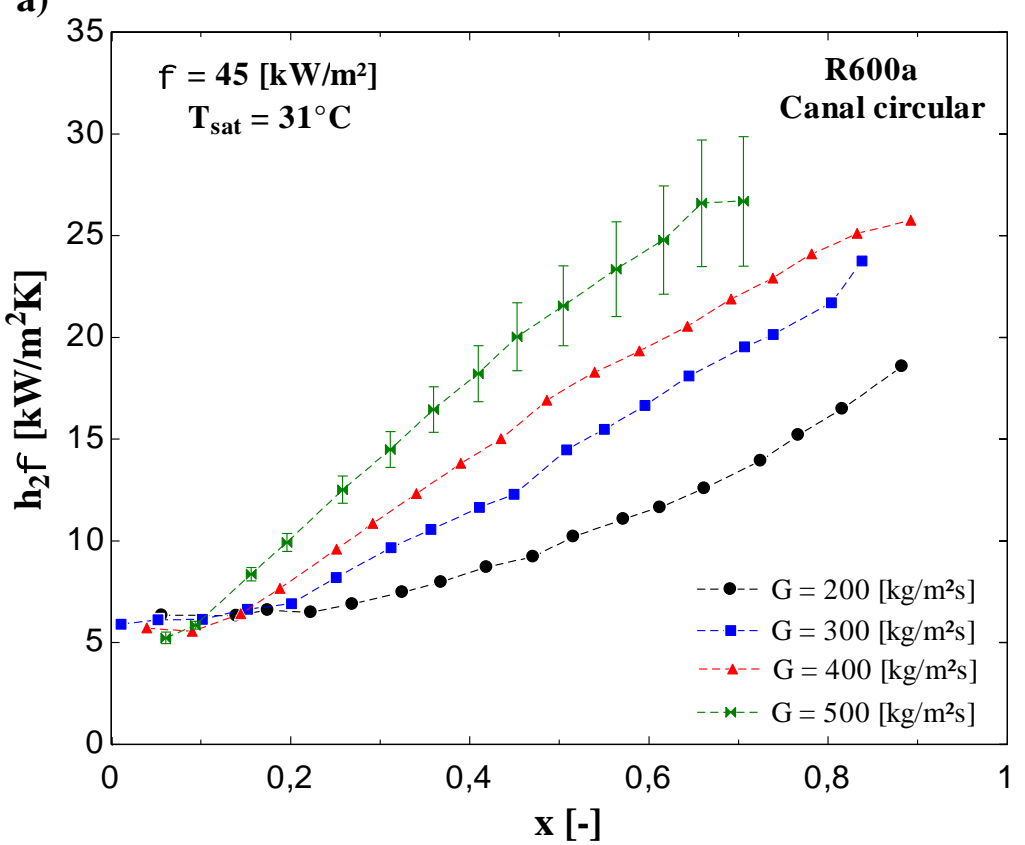

b)

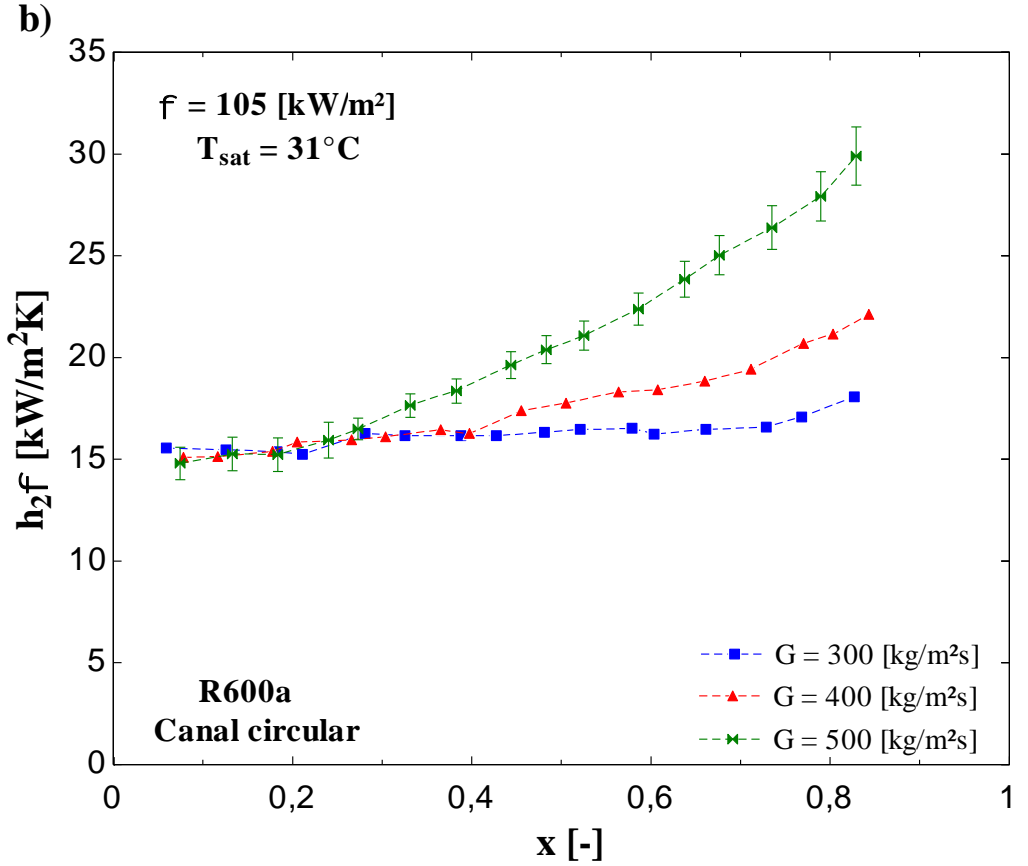

Figura 7.6. Ilustrações do efeito da velocidade massica no CTC durante a ebulição convectiva do R600a.

Segundo a figura, o coeficiente de transferência de calor se eleva com o acréscimo da velocidade mássica para a faixa de títulos de vapor onde predominam os efeitos 
convectivos. Já para títulos de vapor onde se observa a predominância dos efeitos de ebulição nucleada, o coeficiente de transferência de calor mostra-se independente da velocidade mássica.

\subsubsection{Efeito da temperatura de saturação}

A Figura 7.7 ilustra um aumento do coeficiente de transferência de calor se eleva entre 5 a $15 \%$ com o incremento da temperatura de saturação de 31 a $41^{\circ} \mathrm{C}$ para o R134 numa geometria circular.

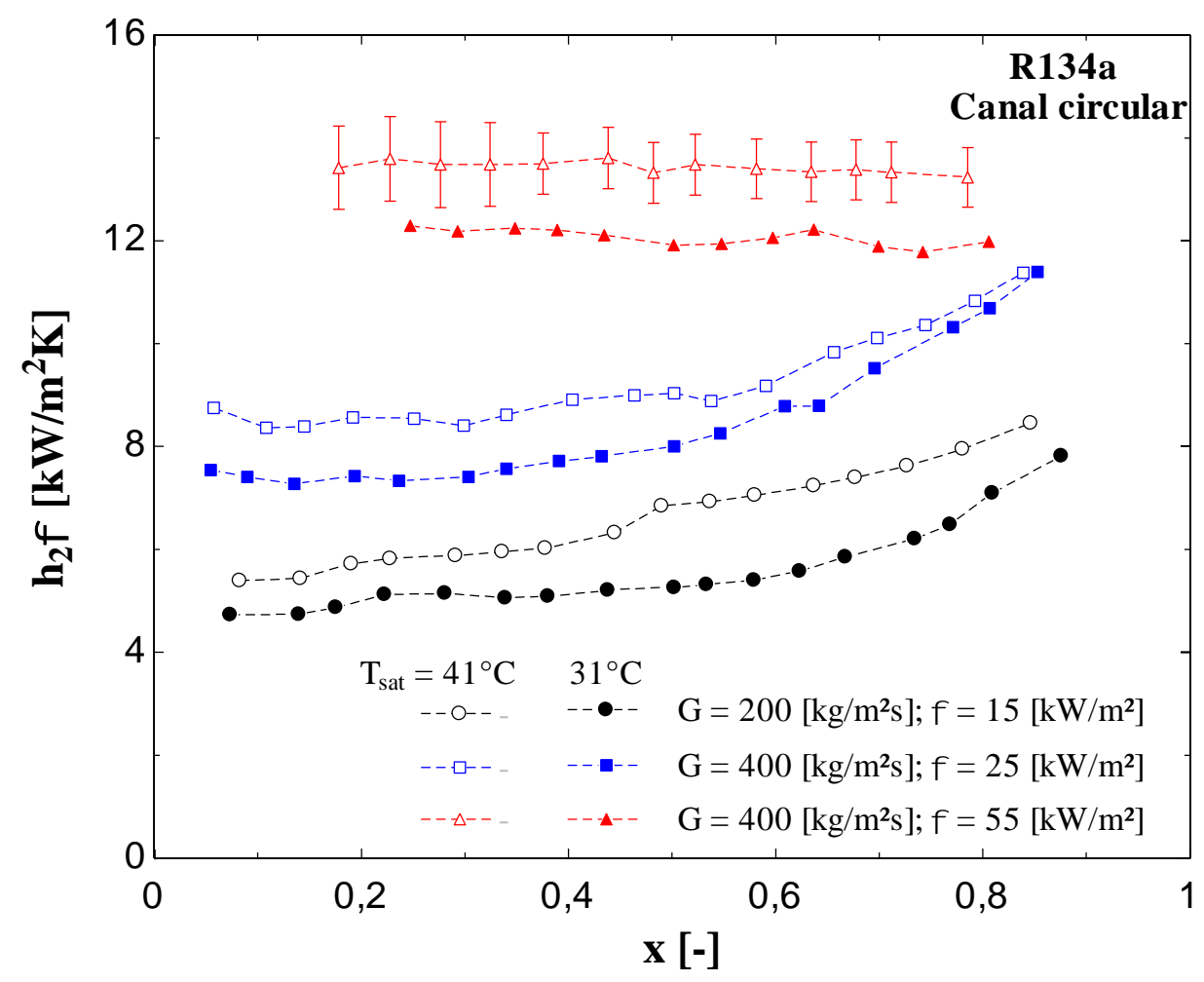

Figura 7.7. Ilustração do efeito da temperatura de saturação no CTC para a ebulição convectiva do R134a.

Para o fluido isobutano, segundo a Figura 7.8, o coeficiente de transferência de calor com o acréscimo da temperatura de saturação de 31 para $41^{\circ} \mathrm{C}$, eleva-se sob condições de títulos de vapor reduzido e decresce para títulos de vapor elevados. O incremento do fluxo de calor posterga para títulos de vapor superiores a região em que predominam efeitos de ebulição nucleada. Isto faz com que na Figura 7.8 o cruzamento das curvas para condições similares (exceto por $\mathrm{T}_{\mathrm{sat}}$ ) ocorra em títulos de vapor superiores. Por outro lado, com o acréscimo da velocidade mássica o cruzamento das curvas para condições similares (exceto por $\mathrm{T}_{\text {sat }}$ ) ocorre para títulos de vapor inferiores. 


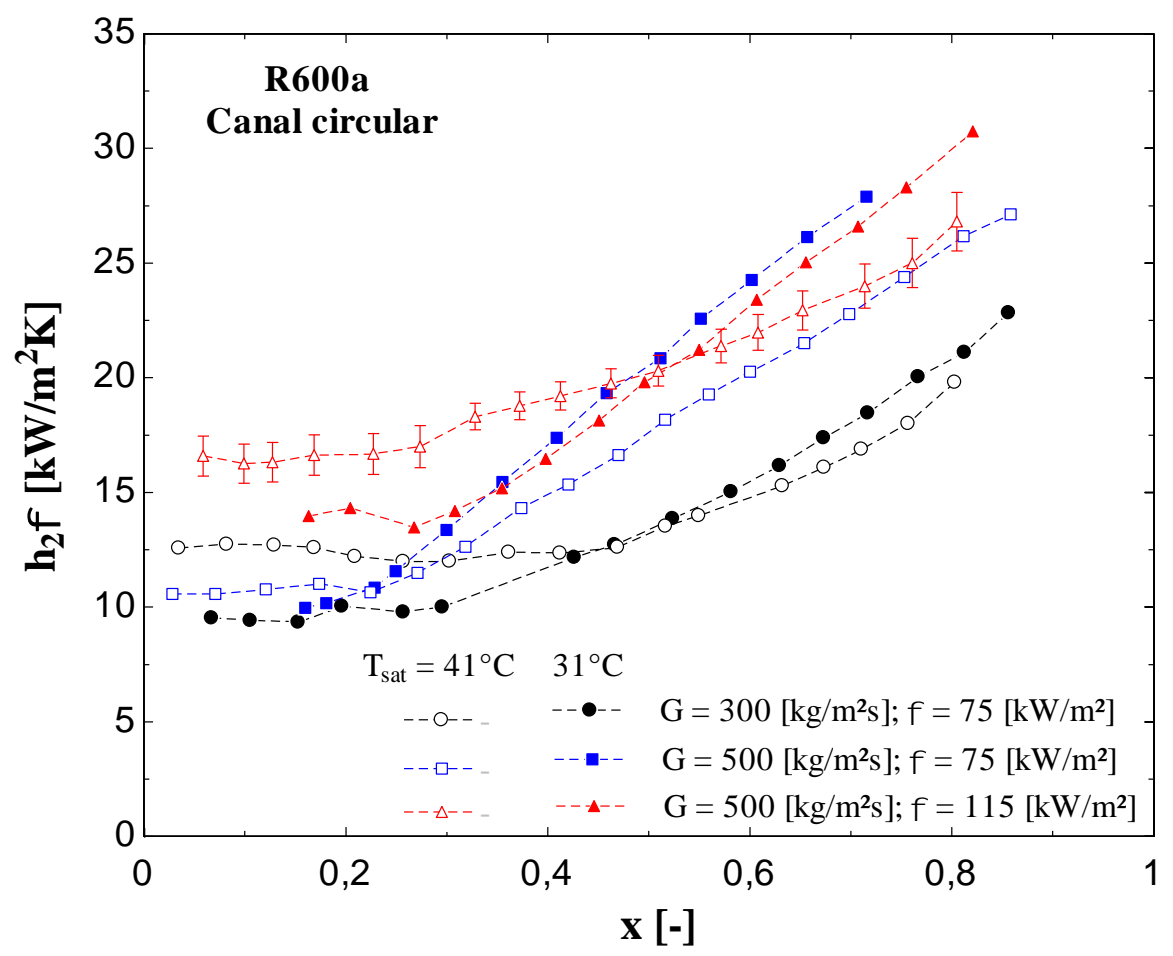

Figura 7.8. Ilustração do efeito da temperatura de saturação no CTC durante a ebulição convectiva do R600a.

\subsubsection{Efeito do fluido de trabalho}

As Figuras 7.9 e 7.10 ilustram comparações entre os coeficientes de transferência de calor proporcionados pelos fluidos R134a, R1234ze(E), R1234yf e R600a para temperaturas de saturação de 31 e $41^{\circ} \mathrm{C}$, respectivamente.

Segundo a Figura 7.9, o coeficiente de transferência de calor do R134a e do R1234yf apresentam resultados próximos e tendências similares. Além disso, constata-se que para fluxos de calor reduzidos $\left(15 \mathrm{~kW} / \mathrm{m}^{2}\right)$ o coeficiente de transferência de calor do R134a é 2-10\% superior ao do R1234yf, enquanto que para fluxos de calor elevados (45 $\mathrm{kW} / \mathrm{m}^{2}$ ) o CTC do R1234yf é 6-10 \% superior ao coeficiente de transferência de calor do R134a. Para títulos de vapor reduzidos, o valor do coeficiente de transferência de calor para o R1234ze(E) é inferior aos do R134a e r1234yf, comportamento que se acentua com o acréscimo do fluxo de calor (ver Fig. 7.9b). 

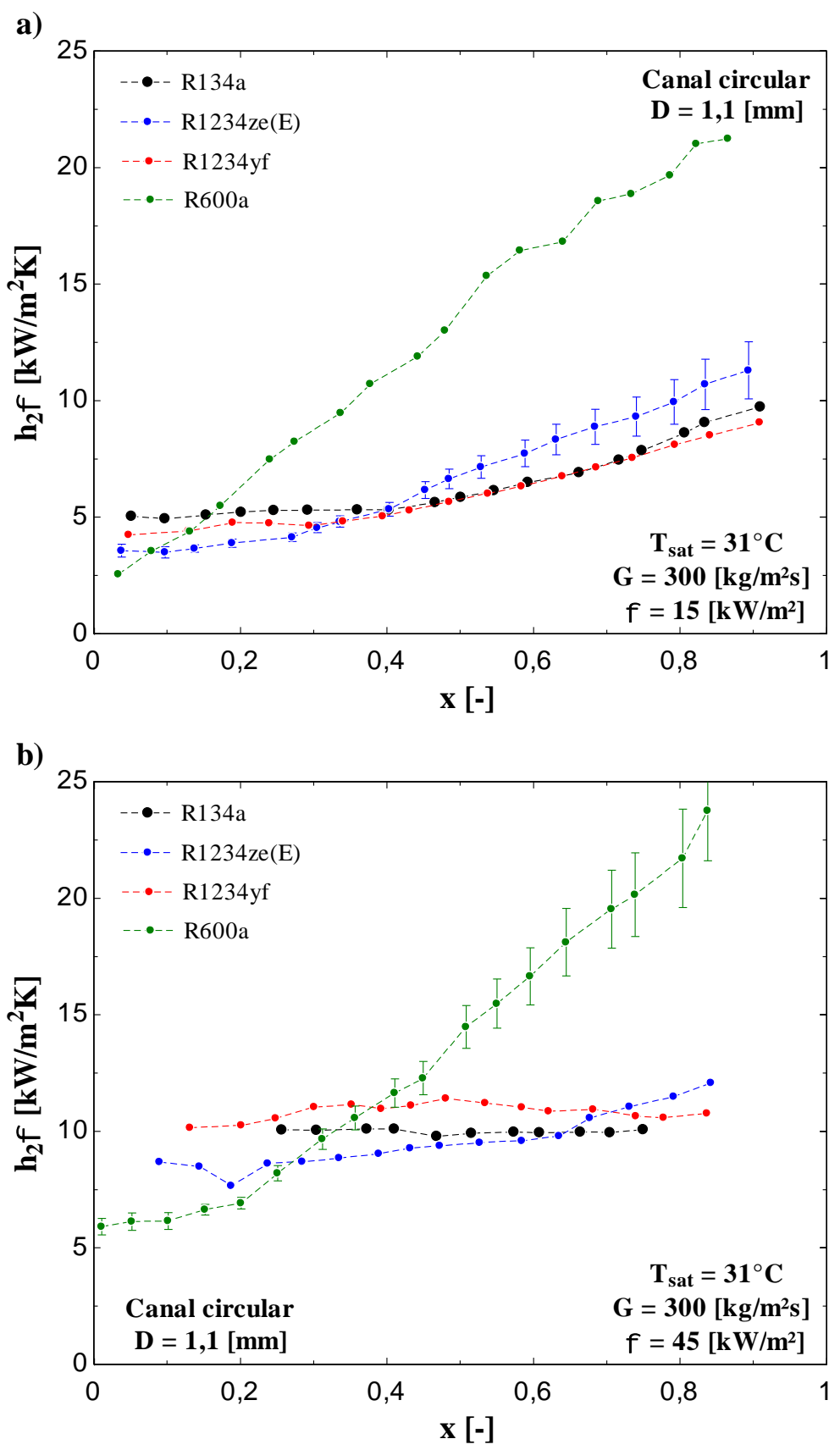

Figura 7.9. Ilustração do efeito do fluido no CTC durante a ebulição convectiva para $T_{\text {sat }}=31^{\circ} \mathrm{C}$.

Na Figura 7.9 observa-se também que para títulos de vapor elevados o coeficiente de transferência de calor para o fluido R1234ze(E) é superior ao CTC do R134a. O CTC do R600a (isobutano), embora com CTCs inferiores ao R134a e aos HFOs em títulos de vapor inferiores a 0,2 , eleva-se significativamente com o incremento do título de vapor, alcançando valores até $120 \%$ superiores aos demais para $x>0,8$. Tal comportamento está relacionado à predominância de efeitos convectivos para o R600a devido a seu volume específico da fase vapor ser no mínimo 4 vezes superior aos demais refrigerantes conforme indicado na Tabela 5.6. Tal fato implica em uma maior aceleração do 
escoamento durante o processo de evaporação intensificando progressivamente a transferência de calor através da redução da espessura do filme líquido e, consequentemente, suprimindo efeitos de ebulição nucleada através do incremento do gradiente de temperaturas junto a superfície aquecida. Para fluxos de calor reduzidos $\approx 15$ $\mathrm{kW} / \mathrm{m}^{2}$ ) e títulos de vapor superiores a 0,3 , o mecanismo de transferência de calor dominante parece estar relacionado a efeitos convectivos para todos os fluidos avaliados. Com o acréscimo do fluxo de calor $\left(45 \mathrm{~kW} / \mathrm{m}^{2}\right)$, mantendo constante a temperatura de saturação, o mecanismo de transferência de calor dominante para os fluidos R134a, R1234yf e R1234ze(E) passa a estar relacionado a efeitos de ebulição nucleada. Porém, para o isobutano (R600a) efeitos convectivos se mantem como mecanismo dominante. Vale destacar que os comportamentos observado neste estudo para o isobutano distinguem-se significativamente dos resultados de Copetti et al. (2013). Estes autores reportaram o decréscimo do CTC a partir de títulos de vapor intermediários, conforme descrito no Capitulo 4.

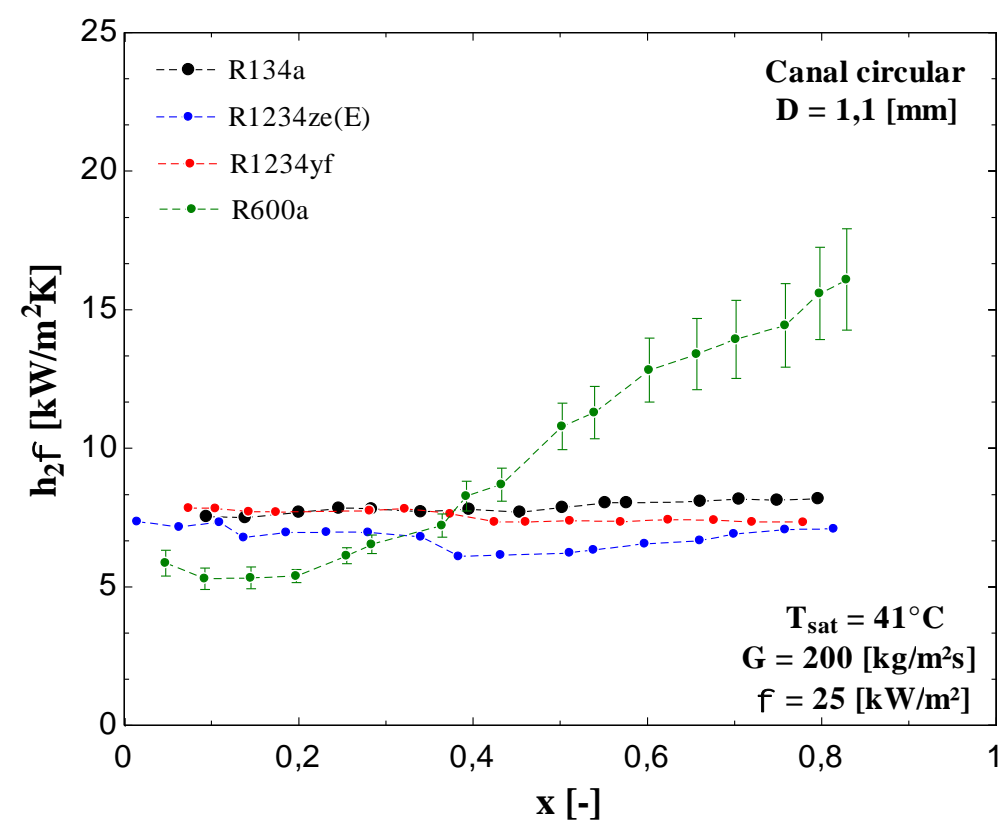

Figura 7.10. Ilustração do efeito do fluido no CTC durante a ebulição convectiva para $T_{\text {sat }}=41^{\circ} \mathrm{C}$.

Resultados para os fluidos R134a, R1234ze(E) e R1234yf, segundo a Figura 7.10, indicam a predominância dos efeitos de ebulição nucleada para uma temperatura de saturação de $41^{\circ} \mathrm{C}$. Enquanto que para o isobutano, o mecanismo de transferência de calor dominante continua relacionado a efeitos convectivos para títulos de vapor superiores a 0,2. Observa-se também nesta figura que o CTC para o R1234ze(E) é inferior ao CTC dos fluidos R134a e R1234yf, independentemente do título de vapor. 


\subsubsection{Efeito da geometria da seção transversal}

As Figuras 7.11 a 7.13 ilustram o efeito da geometria da seção transversal do canal no coeficiente de transferência de calor para o fluido R134a e diferentes condições de temperatura de saturação, velocidade mássica e fluxo de calor.
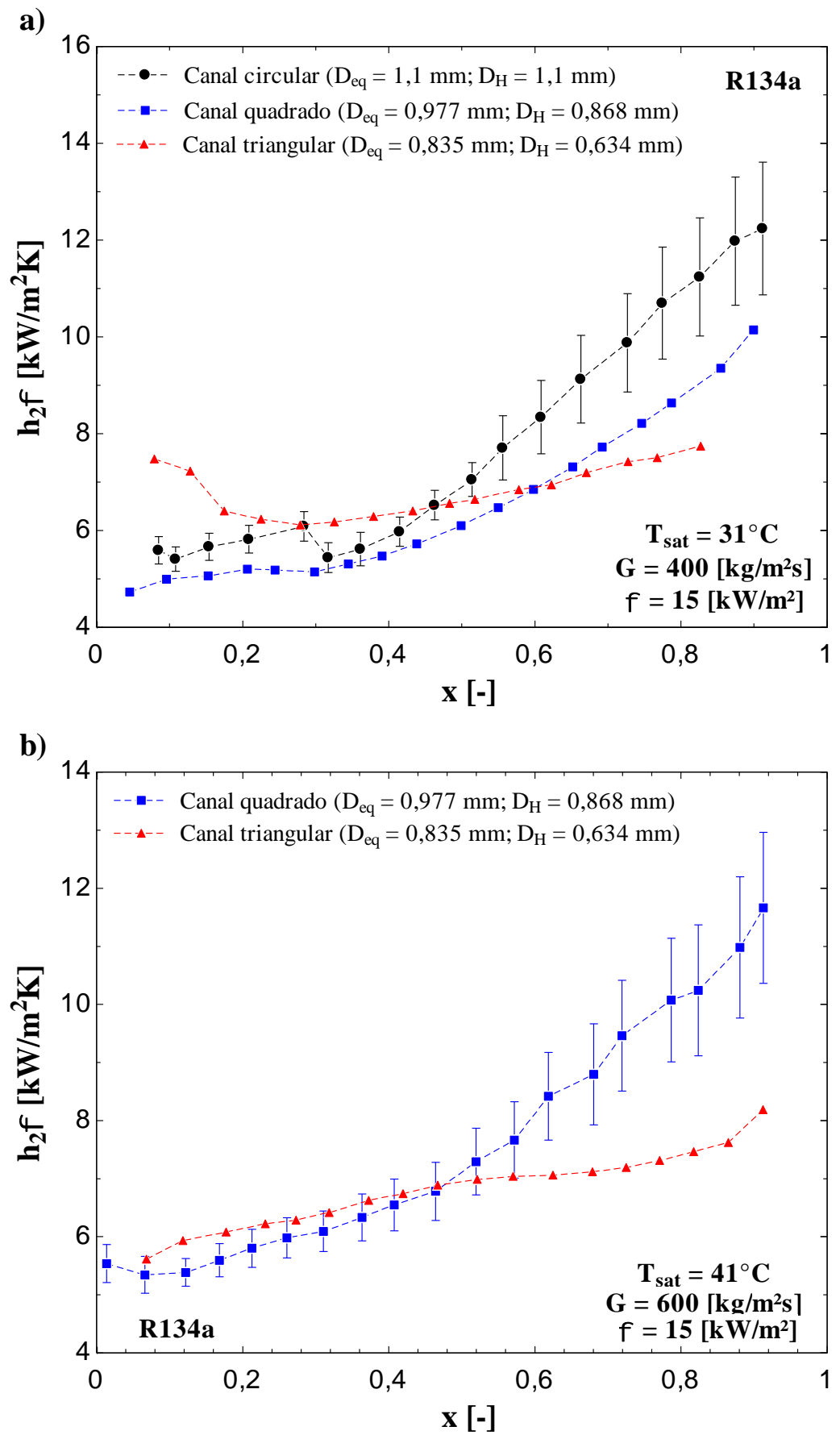

Figura 7.11. Ilustração do efeito da geometria da seção transversal do canal no CTC durante a ebulição convectiva em condiçoes de fluxos de calor reduzidos. 
Segundo a Figura 7.11, o coeficiente de transferência de calor para canais circulares $\left(D_{e q}=1,1 \mathrm{~mm}\right)$ é superior ao observado para canais não-circulares em fluxos de calor reduzidos $\left(15 \mathrm{~kW} / \mathrm{m}^{2}\right)$ e títulos de vapor intermediários e elevados. Também verifica-se para tal condição que o CTC para o canal quadrado $\left(D_{e q}=0,977 \mathrm{~mm}\right)$ é superior ao do canal triangular $\left(D_{e q}=0,835 \mathrm{~mm}\right)$. Já, para títulos de vapor reduzidos, o coeficiente de transferência de calor para as diferentes seções transversais são próximas. É importante mencionar que tais diferenças de comportamentos entre as geometrias avaliadas não decorrem de diferenças na dimensão da seção transversal do canal, pois variações do diâmetro de microcanais com seção transversal circular superiores às variações de diâmetro equivalente no presente estudo resultaram em alterações desprezíveis no CTC segundo resultados apresentados em Kanizawa et al. (2016).

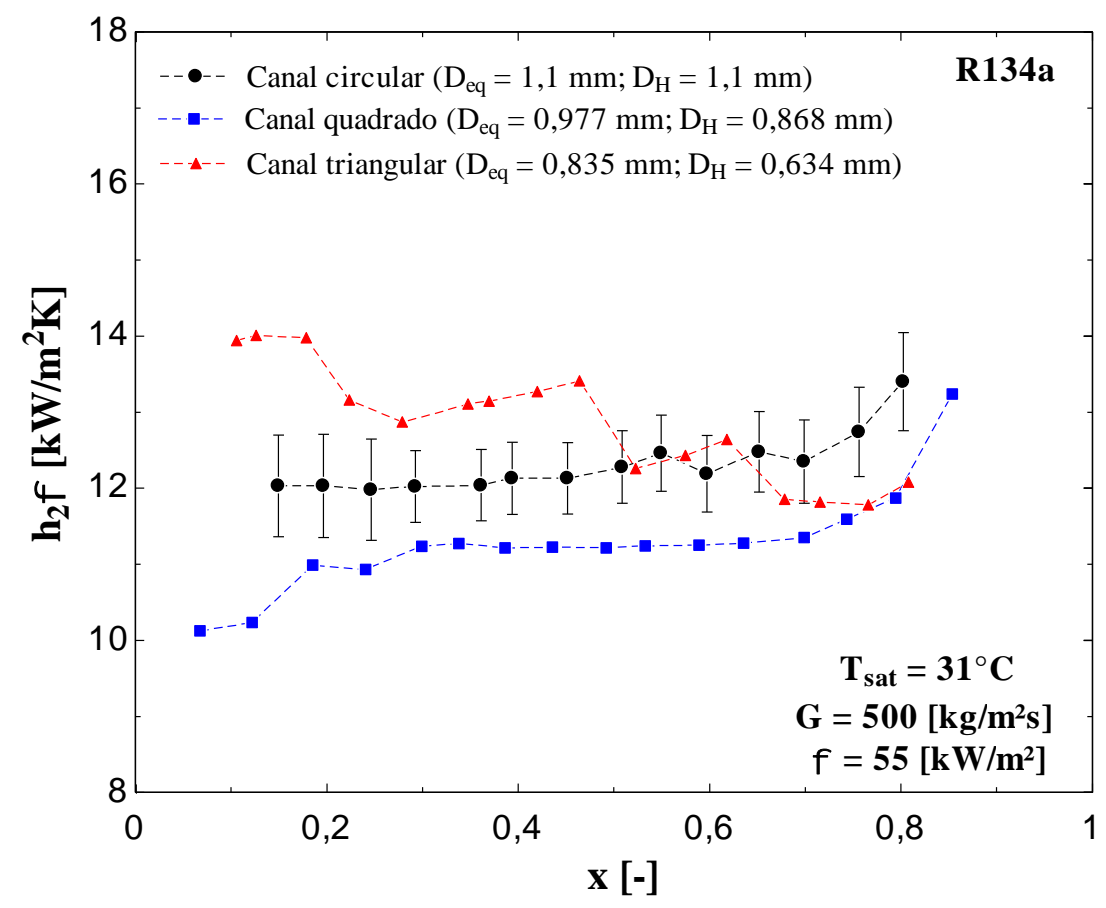

Figura 7.12. Ilustração do efeito da geometria da seção transversal do canal no CTC durante a ebulição convectiva para o R134a, $\mathrm{G}=500 \mathrm{~kg} / \mathrm{m}^{2} \mathrm{~s}, \mathrm{~T}_{\mathrm{sat}}=31^{\circ} \mathrm{C}$ e $\phi=55 \mathrm{~kW} / \mathrm{m}^{2}$.

Já segundo a Figura 7.12, para fluxos de calor superiores em relação à Figura 7.11, o coeficiente de transferência de calor em canais triangulares é superior ao CTC para canais circulares e quadrados sob condições de títulos de vapor reduzidos e intermediários. Verifica-se também que efeitos de supressão de nucleação de bolhas se intensificam para o canal triangular resultando no decréscimo do coeficiente de transferência de calor com o incremento do título de vapor, de forma que em títulos de vapor superiores a aproximadamente 0,6 , o CTC para a seção circular torna-se superior. 
Já a Figura 7.13 ilustra o comportamento contrario ao indicado na Figura 7.12, neste caso verifica-se o incremento do coeficiente de transferência de calor com o aumento do titulo de vapor para o canal triangular e uma temperatura de saturação de $41^{\circ} \mathrm{C}$. Tal comportamento se justifica pois com o incremento de $T_{\text {sat }}$ efeitos de ebulição nucleada se intensificam e a supressão da ebulição nucleada decresce com a redução do volume especifico da fase vapor. Estes efeitos combinados implicam, na Figura 7.13, em um CTC para a geometria triangular superior às demais independentemente do título de vapor.

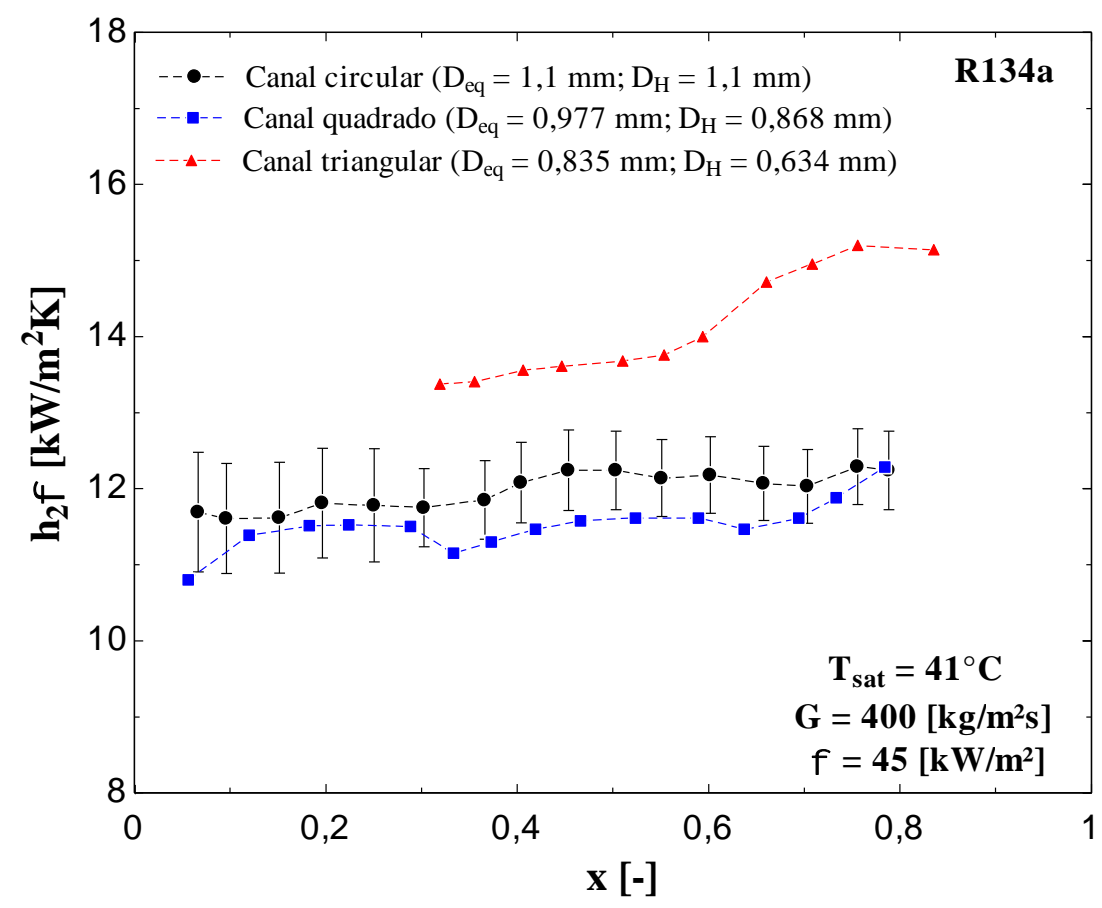

Figura 7.13. Ilustração do efeito da geometria da seção transversal do canal no CTC durante a ebulição convectiva do $\mathrm{R} 134 \mathrm{a}, \mathrm{T}_{\mathrm{sat}}=41^{\circ} \mathrm{C}, \mathrm{G}=400 \mathrm{~kg} / \mathrm{m}^{2} \mathrm{~s}$ e $\phi=45 \mathrm{~kW} / \mathrm{m}^{2}$.

De uma maneira geral, os comportamentos indicados nas Figuras 7.11 a 7.13 para o canal triangular indicam a predominância para esta geometria de efeitos de ebulição nucleada ainda que para fluxos de calor reduzidos. Este desempenho pode estar relacionado ao fato deste canal apresentar rugosidade significativamente superior as geometrias quadrado e circular. De acordo com a Tabela 5.3, a rugosidade do canal triangular é $1,78 \mu \mathrm{m}$, o dobro da rugosidade do canal quadrado $(0,85 \mu \mathrm{m})$ e mais de 6 vezes superior à rugosidade do canal circular $(0,29 \mu \mathrm{m})$. Tal característica superficial contribui no incremento do número de núcleos ativos para o canal triangular, favorecendo assim, o predomínio dos efeitos de ebulição nucleada. 


\subsection{Comparação com métodos de previsão da literatura}

Neste item os métodos de previsão da literatura descritos no Capítulo 4 são comparados ao banco de dados experimental para o CTC obtidos no presente estudo. Esta avaliação considera parâmetros estatísticos como o erro absoluto médio (EMA) e a parcela dos dados previsto com desvios dentro de uma determinada margem, além disso, envolve uma análise de tendências de comportamento.

É importante mencionar que a avaliação dos métodos de previsão foi realizada considerando os seguintes aspectos:

Adotou-se como dimensão característica para o cálculo do Nusselt monofásico, dos números de Reynolds das fases e dos demais adimensionais aquele recomendado pelos autores do trabalho original. No caso de métodos que não explicitam o uso do diâmetro equivalente ou hidráulico e que foram desenvolvidos apenas com resultados para seções circulares, optou-se pelo uso do diâmetro equivalente como dimensão característica com base nos aspectos discutidos e apontados na seção de validação dos resultados experimentais para escoamento monofásico (Seções 5.5.2 e 5.5.3);

Para métodos baseados no número de confinamento, para as previsões em canais quadrado e triangular optou-se por utilizar a definição apresentada na Seção 2.3. Desta maneira, para polígonos regulares (canal quadrado e triangular equilátero) utilizou-se o diâmetro hidráulico;

Para os métodos que não indicam o número de Reynolds de transição considerou-se no cálculo do CTC monofásico regime turbulento para $R e \geq 3000$, ponderação linear entre laminar e turbulento para $2300<R e<3000 \mathrm{e}$ regime laminar para $R e \leq 2300$. Tais valores foram adotados com base nos resultados obtidos para escoamento monofásico descritos na Seção 5.5.

\subsubsection{Avaliação estatística dos métodos de previsão}

A Tabela 7.2 apresenta os parâmetros estatísticos levantados a partir de comparações entre os dados experimentais e os métodos de previsão da literatura. Nesta tabela, os resultados das comparações são apresentados para cada combinação fluido/geometria e para a totalidade dos dados. 
Tabela 7.2. Erro médio absoluto e parcela das previsões com erro entre $\pm 30 \%$ do resultado experimental.*

\begin{tabular}{|c|c|c|c|c|c|c|c|c|}
\hline \multirow[t]{2}{*}{ Autor (es) } & \multirow{2}{*}{$\begin{array}{c}\text { Fluido } \\
\text { Geometria } \\
\text { \#Dados }\end{array}$} & $\begin{array}{l}\text { R134a } \\
\text { Circular }\end{array}$ & $\begin{array}{c}\text { R134a } \\
\text { Quadrado }\end{array}$ & $\begin{array}{l}\mathrm{R} 134 \mathrm{a} \\
\text { Triangular }\end{array}$ & $\begin{array}{l}\text { R1234ze } \\
\text { Circular }\end{array}$ & $\begin{array}{l}\text { R1234yf } \\
\text { Circular }\end{array}$ & $\begin{array}{l}\text { R600a } \\
\text { Circular }\end{array}$ & Total \\
\hline & & 772 & 753 & 418 & 84 & 475 & 1315 & 4580 \\
\hline \multicolumn{9}{|c|}{ Modelos de previsão estritamente empíricos } \\
\hline \multirow{2}{*}{$\begin{array}{l}\text { Lazareck e Black } \\
\text { (1982) }\end{array}$} & EMA & $22,1 \%$ & $15,0 \%$ & $21,8 \%$ & $20,4 \%$ & $17,6 \%$ & $28,3 \%$ & $21,9 \%$ \\
\hline & $\eta$ & $75,6 \%$ & $\mathbf{8 5 , 7 \%}$ & $72,5 \%$ & $76,6 \%$ & $\mathbf{8 8 , 0 \%}$ & $59,8 \%$ & $73,9 \%$ \\
\hline \multirow{2}{*}{ Tran et al. (1996) } & EMA & $43,2 \%$ & $41,9 \%$ & $51,5 \%$ & $31,4 \%$ & $11,8 \%$ & $55,7 \%$ & $41,9 \%$ \\
\hline & $\eta$ & $6,7 \%$ & $4,4 \%$ & $0,0 \%$ & $59,6 \%$ & $94,5 \%$ & $4,3 \%$ & $23,9 \%$ \\
\hline \multirow{2}{*}{$\begin{array}{l}\text { Kew e Cornwell } \\
\text { (1997) }\end{array}$} & EMA & $16,4 \%$ & $12,3 \%$ & $15,1 \%$ & $15,9 \%$ & $10,2 \%$ & $24,2 \%$ & $17,1 \%$ \\
\hline & $\eta$ & $82,9 \%$ & $92,3 \%$ & $90,2 \%$ & $83,7 \%$ & $96,6 \%$ & $67,1 \%$ & $82,1 \%$ \\
\hline \multirow{2}{*}{ Warrier et al. (2002) } & EMA & $62,6 \%$ & $60,2 \%$ & $53,9 \%$ & $64,5 \%$ & $63,2 \%$ & $60,0 \%$ & $63,2 \%$ \\
\hline & $\eta$ & $7,8 \%$ & $12,5 \%$ & $2,9 \%$ & $6,4 \%$ & $3,6 \%$ & $11,4 \%$ & $8,4 \%$ \\
\hline \multirow{2}{*}{$\begin{array}{l}\text { Kandlikar e Balasu- } \\
\text { bramanian (2004) }\end{array}$} & EMA & $50,7 \%$ & $44,7 \%$ & $56,5 \%$ & $56,7 \%$ & $59,5 \%$ & $46,8 \%$ & $51,1 \%$ \\
\hline & $\eta$ & $8,8 \%$ & $20,7 \%$ & $6,9 \%$ & $5,2 \%$ & $1,5 \%$ & $22,6 \%$ & $13,1 \%$ \\
\hline \multirow{2}{*}{$\begin{array}{l}\text { Sun e Mishima } \\
(2009 a)\end{array}$} & EMA & $11,6 \%$ & $11,7 \%$ & $9,2 \%$ & $15,5 \%$ & $8,0 \%$ & $27,3 \%$ & $16,3 \%$ \\
\hline & $\eta$ & $86,8 \%$ & $94,0 \%$ & $98,3 \%$ & $\mathbf{8 3 , 9 \%}$ & $\mathbf{9 7 , 3 \%}$ & $59,1 \%$ & $81,7 \%$ \\
\hline \multirow{2}{*}{ Li e Wu (2010) } & EMA & $23,9 \%$ & $20,7 \%$ & $16,3 \%$ & $26,8 \%$ & $20,6 \%$ & $48,9 \%$ & $30,1 \%$ \\
\hline & $\eta$ & $70,6 \%$ & $76,5 \%$ & $90,7 \%$ & $60,0 \%$ & $77,3 \%$ & $18,9 \%$ & $57,3 \%$ \\
\hline \multirow{2}{*}{ Basu et al. (2011) } & EMA & & & & & & $28,2 \%$ & $21,4 \%$ \\
\hline & $\eta$ & $80,6 \%$ & $84,5 \%$ & $44,3 \%$ & $\mathbf{8 1 , 7 \%}$ & $\mathbf{9 7 , 3 \%}$ & $58,3 \%$ & $73,3 \%$ \\
\hline \multirow{2}{*}{ Oh e Son (2011) } & EMA & $46,7 \%$ & $39,5 \%$ & $41,4 \%$ & $55,0 \%$ & $62,4 \%$ & $49,7 \%$ & $49,1 \%$ \\
\hline & $\eta$ & $27,8 \%$ & $40,1 \%$ & $36,4 \%$ & $7,9 \%$ & $4,2 \%$ & $0,0 \%$ & $16,5 \%$ \\
\hline \multicolumn{9}{|c|}{ Modelos de previsão baseados na superposição de efeitos } \\
\hline \multirow{2}{*}{ Chen (1966) } & EMA & $16,9 \%$ & $10,8 \%$ & $18,8 \%$ & $20,8 \%$ & $22,5 \%$ & $26,6 \%$ & $20,7 \%$ \\
\hline & $\eta$ & $90,5 \%$ & $98,3 \%$ & $\mathbf{8 2 , 3 \%}$ & $77,4 \%$ & $74,1 \%$ & $57,7 \%$ & $77,5 \%$ \\
\hline \multirow{2}{*}{$\begin{array}{l}\text { Liu e Winterton } \\
\text { (1991) }\end{array}$} & EMA & & $18,7 \%$ & $24,6 \%$ & $28,8 \%$ & $32,7 \%$ & $22,2 \%$ & $25,1 \%$ \\
\hline & $\eta$ & $58,4 \%$ & $93,2 \%$ & $56,2 \%$ & $53,0 \%$ & $25,1 \%$ & $69,4 \%$ & $62,6 \%$ \\
\hline \multirow{2}{*}{ Zhang et al. (2004) } & EMA & $21,1 \%$ & & $5 \%$ & & $7 \%$ & $31,4 \%$ & $24,9 \%$ \\
\hline & $\eta$ & $81,7 \%$ & $92,4 \%$ & $68,7 \%$ & $61,9 \%$ & $63,2 \%$ & $50,5 \%$ & $67,6 \%$ \\
\hline \multirow{2}{*}{ Saitoh et al. (2007) } & EMA & $22,1 \%$ & $14,6 \%$ & $25,6 \%$ & $18,4 \%$ & $15,8 \%$ & $31,5 \%$ & $22,6 \%$ \\
\hline & $\eta$ & $80,6 \%$ & $85,1 \%$ & $68,2 \%$ & $79,5 \%$ & $88,6 \%$ & $54,5 \%$ & $73,4 \%$ \\
\hline \multirow{2}{*}{ Berstch et al. (2009) } & EMA & $39,2 \%$ & $33,1 \%$ & $37,6 \%$ & $38,5 \%$ & $35,7 \%$ & $39,5 \%$ & $37,7 \%$ \\
\hline & $\eta$ & $15,2 \%$ & $43,0 \%$ & $23,2 \%$ & $26,6 \%$ & $28,8 \%$ & $39,0 \%$ & $30,7 \%$ \\
\hline \multirow{2}{*}{ Oh et al. (2011) } & EMA & $55,1 \%$ & $53,7 \%$ & $60,4 \%$ & $56,9 \%$ & $56,7 \%$ & $48,2 \%$ & $53,9 \%$ \\
\hline & $\eta$ & $0,3 \%$ & $0,3 \%$ & $0,5 \%$ & $0,6 \%$ & $0,0 \%$ & $11,3 \%$ & $3,5 \%$ \\
\hline \multirow{2}{*}{$\begin{array}{l}\text { Kim e Mudawar } \\
\text { (2013a) }\end{array}$} & EMA & $11,0 \%$ & $8,4 \%$ & $12,9 \%$ & $13,2 \%$ & $10,0 \%$ & $23,8 \%$ & $14,7 \%$ \\
\hline & $\eta$ & $94,8 \%$ & $100,0 \%$ & $92,8 \%$ & $88,0 \%$ & $96,8 \%$ & $62,9 \%$ & $85,3 \%$ \\
\hline \multirow{2}{*}{$\begin{array}{l}\text { Mahmoud e } \\
\text { Karayiannis (2013) }\end{array}$} & EMA & $23,9 \%$ & $19,2 \%$ & $27,3 \%$ & $25,9 \%$ & $22,3 \%$ & $29,2 \%$ & $25,4 \%$ \\
\hline & $\eta$ & $68,4 \%$ & $85,4 \%$ & $55,7 \%$ & $65,9 \%$ & $81,9 \%$ & $57,0 \%$ & $67,4 \%$ \\
\hline \multirow{2}{*}{$\begin{array}{l}\text { Kanizawa et al. } \\
\text { (2016) }\end{array}$} & EMA & $18,4 \%$ & $7,1 \%$ & $14,5 \%$ & $13,2 \%$ & $16,7 \%$ & $22,8 \%$ & $16,3 \%$ \\
\hline & $\eta$ & $90,0 \%$ & $100 \%$ & $95,7 \%$ & $90,8 \%$ & $98,7 \%$ & $65,7 \%$ & $86,1 \%$ \\
\hline
\end{tabular}

*Números em negrito indicam um EMA inferior a $20 \%$ ou um $\eta$ superior a $80 \%$.

**Números em vermelho indicam o melhor resultado de EMA e $\eta$ para cada banco de dados 
Tabela 7.2 (continuação). Erro médio absoluto e parcela de previsoes com erro entre $\pm 20 \%$ do resutlado experimental.

\begin{tabular}{|c|c|c|c|c|c|c|c|c|}
\hline \multirow[t]{2}{*}{ Autor (es) } & \multirow{2}{*}{$\begin{array}{c}\text { Fluido } \\
\text { Geometria } \\
\text { \#Dados }\end{array}$} & $\begin{array}{l}\text { R134a } \\
\text { Circular }\end{array}$ & $\begin{array}{l}\text { R134a } \\
\text { Quadrado }\end{array}$ & $\begin{array}{l}\mathrm{R} 134 \mathrm{a} \\
\text { Triangular }\end{array}$ & $\begin{array}{l}\text { R1234ze } \\
\text { Circular }\end{array}$ & $\begin{array}{l}\text { R1234yf } \\
\text { Circular }\end{array}$ & $\begin{array}{l}\text { R600a } \\
\text { Circular }\end{array}$ & Total \\
\hline & & 772 & 753 & 418 & 847 & 475 & 1315 & 4580 \\
\hline \multicolumn{9}{|c|}{ Modelos de previsão baseados em aspectos fenomenológicos } \\
\hline \multirow{2}{*}{ Thome et al. (2004) } & EMA & $20,5 \%$ & $22,7 \%$ & $30,2 \%$ & $25,6 \%$ & $30,3 \%$ & $41,2 \%$ & $29,7 \%$ \\
\hline & $\eta$ & $76,7 \%$ & $71,8 \%$ & $48,3 \%$ & $65,2 \%$ & $49,9 \%$ & $36,1 \%$ & $56,7 \%$ \\
\hline \multirow{2}{*}{$\begin{array}{l}\text { Cioncolini e Thome } \\
\text { (2009) }\end{array}$} & EMA & $38,8 \%$ & $44,2 \%$ & $56,0 \%$ & $44,5 \%$ & $53,1 \%$ & $41,2 \%$ & $44,5 \%$ \\
\hline & $\eta$ & $10,5 \%$ & $7,6 \%$ & $3,8 \%$ & $8,1 \%$ & $2,1 \%$ & $2,9 \%$ & $5,9 \%$ \\
\hline \multirow{2}{*}{$\begin{array}{l}\text { Costa-Patry e Thome } \\
\text { (2012) }\end{array}$} & EMA & $39,1 \%$ & $40,9 \%$ & $55,0 \%$ & $41,8 \%$ & $51,5 \%$ & $40,9 \%$ & $43,2 \%$ \\
\hline & $\eta$ & $10,9 \%$ & $10,1 \%$ & $3,8 \%$ & $10,2 \%$ & $2,1 \%$ & $3,9 \%$ & $7,1 \%$ \\
\hline
\end{tabular}

*Números em negrito indicam um EMA inferior a $20 \%$ ou um $\eta$ superior a $80 \%$.

**Números em vermelho indicam o melhor resultado de EMA e $\eta$ para cada banco de dados

Para as comparações envolvendo o banco de dados completo, os modelos de Kanizawa et al. (2016) e Kim e Mudawar (2013a) forneceram as melhores previsões. Kanizawa et al. (2016) obteve um EMA de 16,3\% e previu $86,1 \%$ dos dados com erro entre $\pm 30 \%$. Já Kim e Mudawar (2013a) obteve um EMA de $14.7 \%$ e previu 85,3\% dos resultados com desvios dentro da faixa $\pm 30 \%$. Kew e Cornwell (1997) e Sun e Mishima (2009a) também proporcionaram previsões razoáveis do banco de dados, resultando respectivamente em 82,1 e $81,7 \%$ dos dados previstos com erro entre $\pm 30 \%$. Os métodos desenvolvidos para ebulição convectiva em micro-escala de Zhang et al. (2004), Saitoh et al. (2007) e Mahmoud e Karayiannis (2013) proporcionaram erros absolutos médios de 25\%. Lazarek e Black (1982), Basu et al. (2011) e os métodos desenvolvidos para canais convencionais de Chen (1963) e Liu e Winterton (1991) preveem razoavelmente o banco de dados resultando em erros absolutos médios entre 20 e 25\%. Tran et al. (1996), Warrier et al. (2002), Kandlikar e Balasubramanian (2004), Li e Wu (2011), Oh e Son (2011), Bertsch et al. (2009), Oh et al. (2011) e Thome et al. (2004) forneceram erros médio absolutos superiores a $30 \%$ e uma parcela inferior a $60 \%$ dos dados com desvios dentro da faixa $\pm 30 \%$.

Apesar de desenvolvido com base em dados para escoamentos verticais do R113, o método de Lazarek e Black (1982) forneceu previsões razoáveis dos dados experimentais do R134a, para o canal de seção transversal quadrada, e do fluido R1234yf. Kew e Cornwell (1997), método cujo desenvolvimento se baseou em Lazarek e Black (1982), forneceu previsões satisfatórias para os fluidos R1234ze(E), R1234yf e R134a, independentemente da geometria da seção transversal. No entanto, por ser um método 
que se baseia no predomínio de efeitos de ebulição nucleada, não prevê satisfatoriamente resultados do isobutano, para o qual prevalecem efeitos convectivos. Por outro lado, é importante notar que o método de Kew e Cornwell (1997) prevê majoritariamente valores inferiores aos experimentais como observado na Figura 7.14.

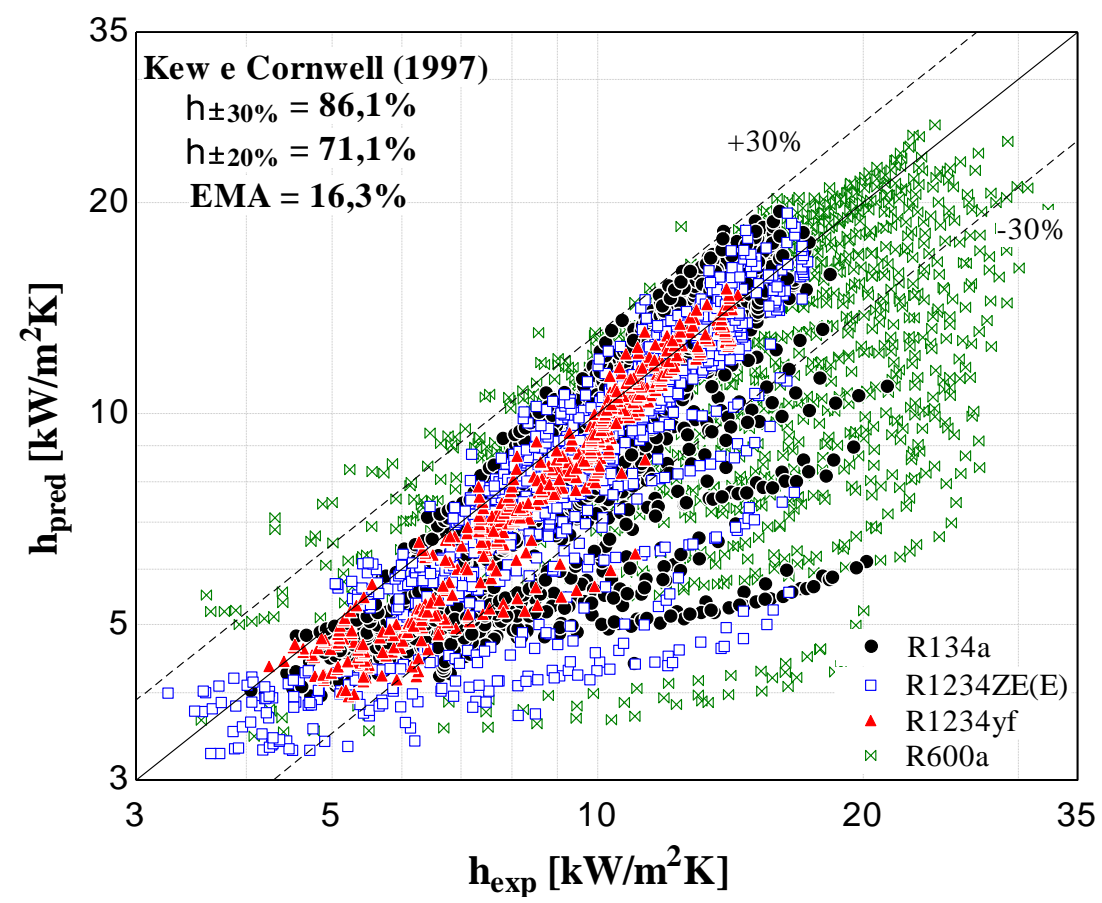

Figura 7.14. Comparação dos dados experimentais de CTC com o método de previsão de Kew e Cornwell (1997).

O método de Basu et al. (2011), que se baseia em um banco de dados contendo mais de 3000 resultados experimentais para R134a, prevê satisfatoriamente os dados das geometrias de seção circular e quadrada. Este método também apresenta previsões razoáveis dos resultados experimentais dos fluidos R1234ze(E) e R1234yf. O método de Li e Wu (2011) proporciona resultados satisfatórios para o fluido R134a, independentemente da geometria, e para o fluido R1234ze(E). Tran et al. (1996) prevê satisfatoriamente os resultados para o fluido R1234yf. Thome et al. (2014) apresenta previsões razoáveis apenas para a geometria circular com o fluido R134a. Berstch et al. (2009), apesar de ter alcançado as melhores previsões do banco de dados levantado na literatura, conforme indicado no Item 4.3, fornece previsões insatisfatórias do banco de dados do presente estudo. Resultado provavelmente devido ao fato deste método proporcionar melhores resultados para faixas de títulos de vapor reduzidas que caracterizam o banco de dados da literatura. Warrier et al. (2002), Kandlikar e 
Balasubramanian (2004), Oh e Son (2011) e Oh et al. (2011) forneceram previsões insatisfatórias independentemente da geometria e do fluido de trabalho.

O método de Chen (1963) implica em previsões satisfatórias para o R134a independentemente da geometria da seção transversal. Liu e Winterton (1991) prevê satisfatoriamente os dados para a geometria quadrada. Apesar de não recomendado para as demais condições, é importante ressaltar que o método de Liu e Winterton (1991) mostrou-se o mais adequado para o R600a resultando em um erro médio absoluto de $22,2 \%$ e uma parcela de $69,4 \%$ dos dados com erro entre $\pm 30 \%$.

O procedimento proposto por Zhang et al. (2004) para o cálculo de CTC proporcionou previsões razoáveis dos resultados experimentais para as geometrias de seção transversal circular e quadrada com o fluido R134a. Saitoh et al. (2007), além de fornecer previsões satisfatórias para as geometrias circular e quadrada do R134a, mostrou-se adequado para a previsão do CTC com o fluido R1234yf. Este resultado provavelmente é explicado pelo fato das propriedades do R1234yf serem próximas as do R134a, conforme indicado na Tabela 5.6.

O método de Mahmoud e Karayiannis (2013) proporciona previsões satisfatórias dos resultados do R134a para a geometria quadrada e para o fluido R1234yf, no entanto, não prevê adequadamente os dados para R1234ze(E), R600a e resultados para as seções circular e triangular com o R134a. Considerando que este método se baseia em mais de 5000 dados experimentais para o R134a, abrangendo ampla faixa de diâmetros, incluindo o utilizado no presente estudo $(1.1 \mathrm{~mm})$, é curioso o fato do método não proporcionar previsões satisfatórias para o R134a na geometria circular.

Os métodos de Sun e Mishima (2009a) e Kim e Mudawar (2013a) proporcionaram previsões satisfatórias para as três geometrias e para os fluidos R134a, R1234ze(E) e R1234yf. Entretanto, ambos os métodos proporcionam resultados insatisfatórios para o R600a, provavelmente devido ao fato que nenhum destes métodos considera o R600a no banco de dados utilizado no seu desenvolvimento. A Figura 7.15 ilustra uma comparação dos resultados experimentais com os métodos de Sun e Mishima (2009a) e Kim e Mudawar (2013a). Conforme ilustrado, estes métodos subestimam parcela significativa de dados experimentais independentemente do fluido de trabalho e a faixa de coeficiente de transferência de calor. 

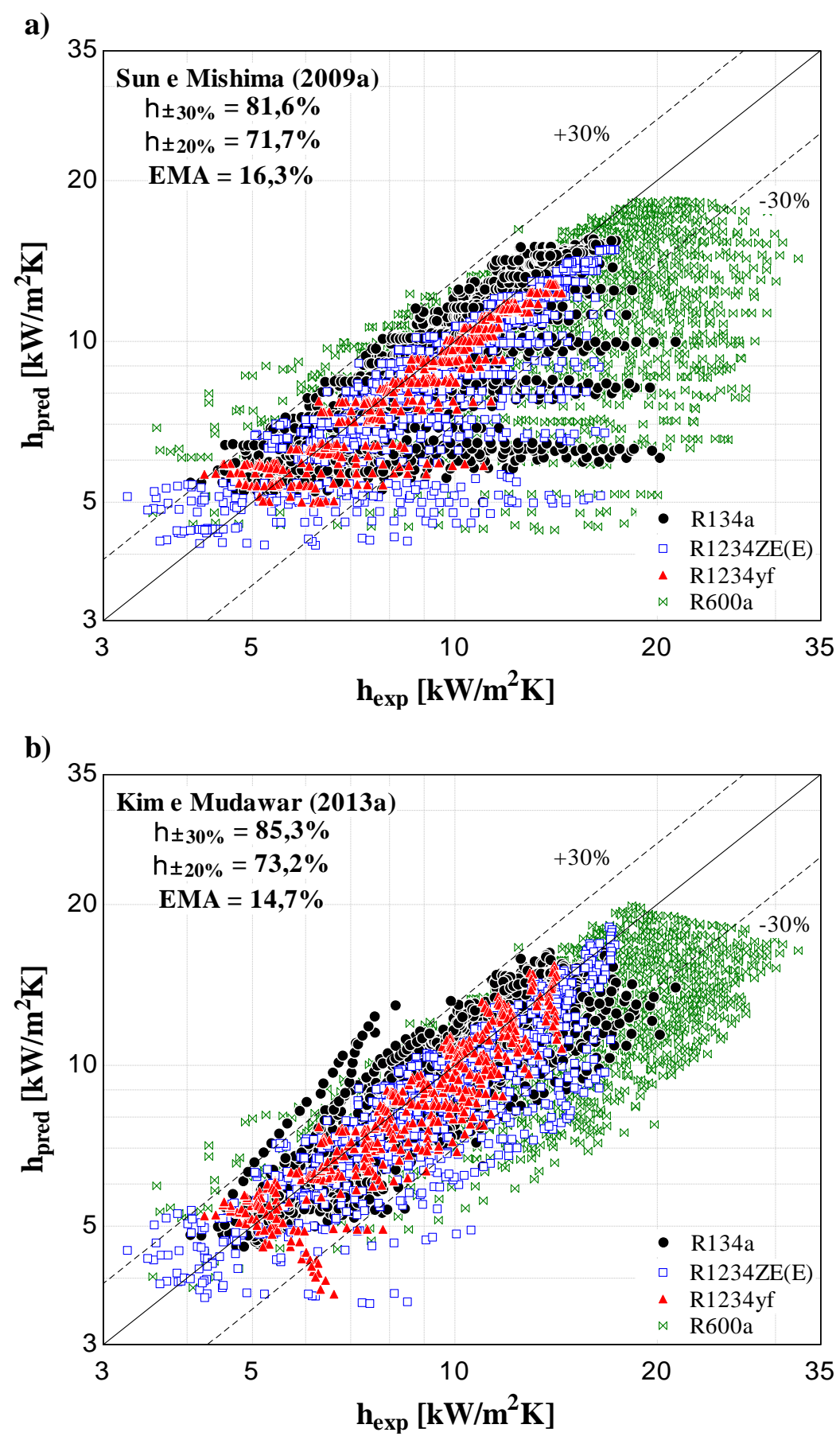

Figura 7.15. Comparação dos dados experimentais de CTC com o método de previsão de: a) Sun e Mishima (2009b), b) Kim e Mudawar (2013a).

O método de Kanizawa et al. (2016) proporciona resultados satisfatórios para os fluidos R134a, R1234ZE(E) e R1234yf, prevendo parcelas superiores a 90\% dos dados com desvios entre $\pm 30 \%$. A Figura 7.16a ilustra uma comparação das previsões fornecidas pelo método de Kanizawa et al. (2016) para o fluido R134a, com os dados experimentais segregados de acordo com a seção transversal do canal. Conforme ilustrado na figura, o método subestima parcela significativa dos dados experimentais, 
independentemente da geometria da seção transversal. Também pode-se mencionar que o método falha na previsão de uma parcela dos dados experimentais para geometria circular para valores experimentais de CTC superiores a $10 \mathrm{~kW} / \mathrm{m}^{2} \mathrm{~K}$, apresentando desvios superiores a $30 \%$.
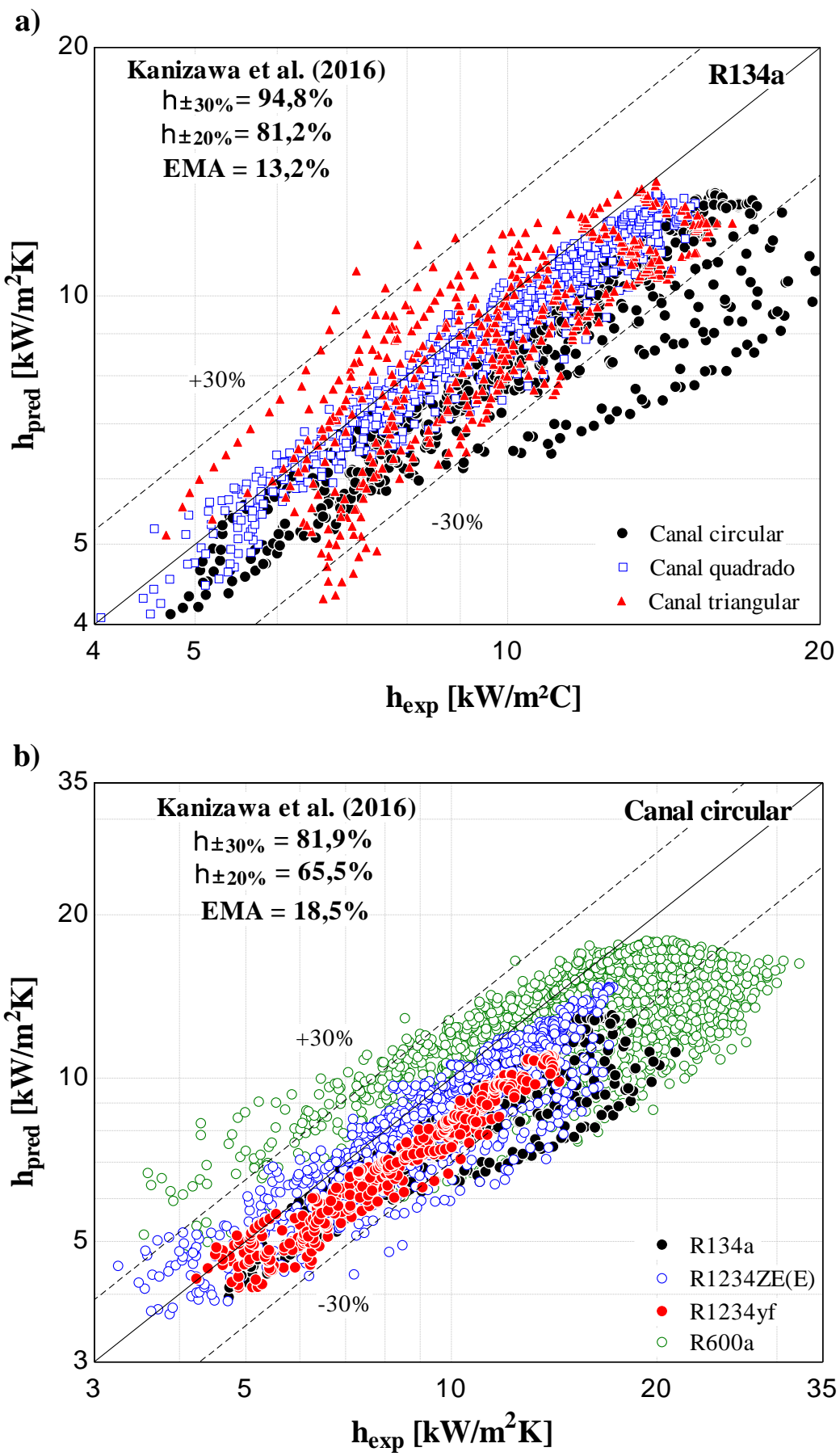

Figura 7.16. Comparação dos dados experimentais de CTC com o método de previsão de Kanizawa et al. (2016) segregados por a) geometria da seçao transversal, b) fluido de trabalho. 
A Figura 7.16b ilustra comparações do método de Kanizawa et al. (2016) com os dados segregados de acordo com fluido de trabalho, para o canal circular. Segundo esta figura, o método subestima parcela significativa dos dados para os fluidos R1234ze(E) e o R1234yf. Por outro lado, para o fluido R600a, observa-se que o método sobrestima a maioria dos valores experimentais para coeficientes de transferência de calor inferiores a $8 \mathrm{~kW} / \mathrm{m}^{2} \mathrm{~K}$ e subestima os valores experimentais de CTC superiores a $10 \mathrm{~kW} / \mathrm{m}^{2} \mathrm{~K}$. Este resultado pode estar relacionado ao fato dos autores terem utilizado no desenvolvimento do método os dados para o isobutano apresentados por Copetti et al. (2013), cujos comportamentos os quais diferem significativamente dos resultados do presente estudo, conforme já mencionado no Item 7.3.4.

\subsubsection{Avaliação de tendências dos métodos de previsão}

As Figuras 7.17 e 7.18 ilustram comparações entre as tendências dos resultados experimentais e aquelas fornecidas pelos métodos de previsão que obtiveram melhor desempenho com base na análise estatística. Segundo a Figura 7.17, para o canal quadrado e o fluido R134a, os métodos de Chen (1963) e Kanizawa et al. (2016) capturam satisfatoriamente a tendência do CTC com o acréscimo do título de vapor.

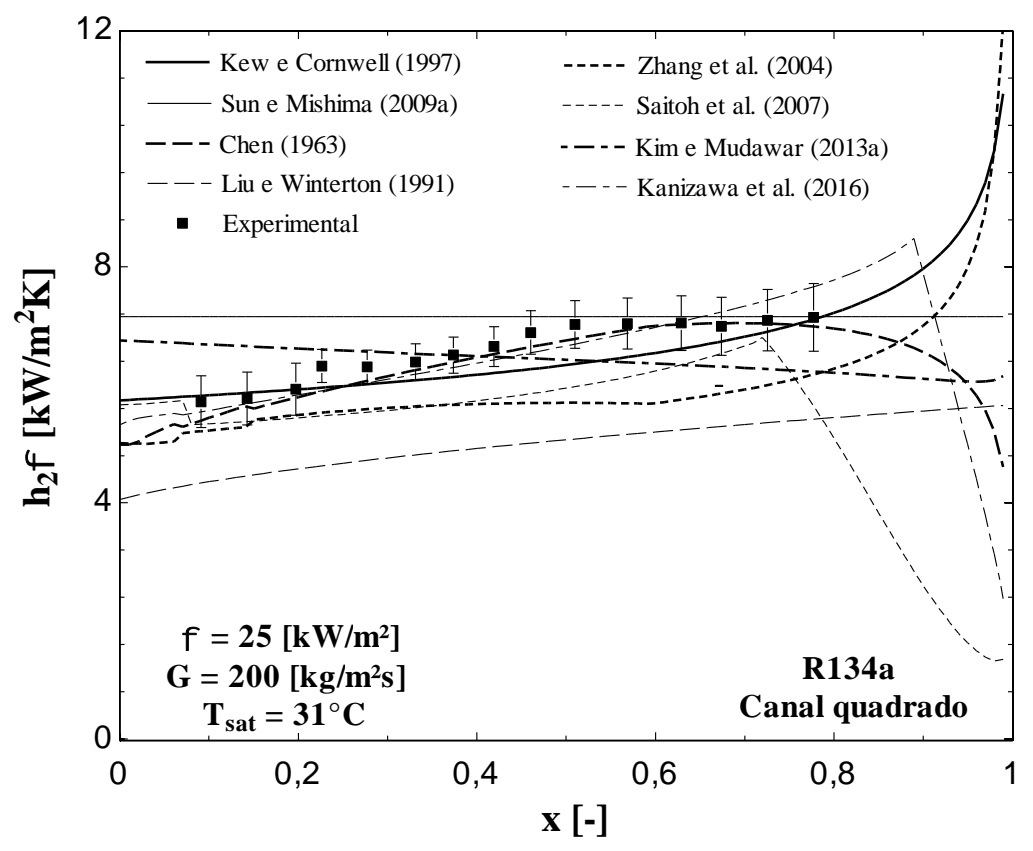

Figura 7.17. Comparação das tendencias do CTC de acordo com os métodos de previsão da literatura e dados experimentais para o fluido R134a na geometria quadrada. 
Por outro lado, segundo a Figura 7.18, nenhum dos métodos de previsão indica para a geometria triangular o decréscimo do coeficiente de transferência de calor com o incremento do título de vapor conforme comportamentos dos resultados experimentais. No entanto, constata-se que os métodos de Sun e Mishima (2009b) e Kim e Mudawar (2013a) preveem a tendência dos resultados experimentais para títulos de vapor inferiores a 0,5 , caso se considere a barra de incertezas.

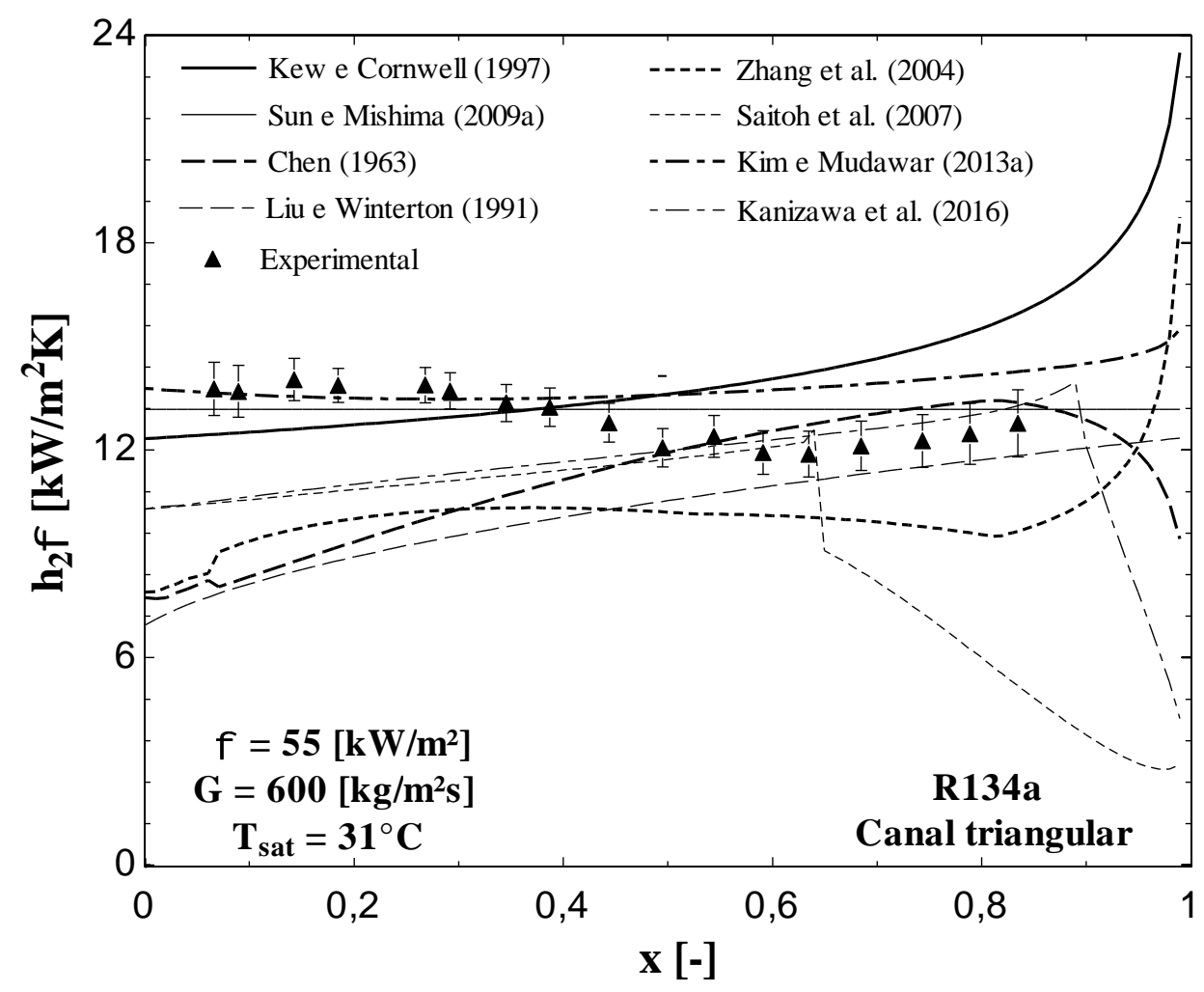

Figura 7.18. Comparação das tendencias do CTC de acordo aos métodos de previsão da literatura e dados experimentais para o fluido R134a.

Segundo a Figura 7.19, nenhum dos métodos da literatura captura o comportamento do coeficiente de transferência de calor para o R1234ze(E) em condições de títulos de vapor superiores a 0,4 independentemente das condições de fluxo de calor e velocidade mássica avaliadas. Já, para títulos de vapor inferiores a 0,4, observa-se que os métodos de Sun e Mishima (2009a), Kim e Mudawar (2013a) e Kanizawa et al. (2016) capturam razoavelmente a tendência dos resultados experimentais ilustrados nesta figura. 

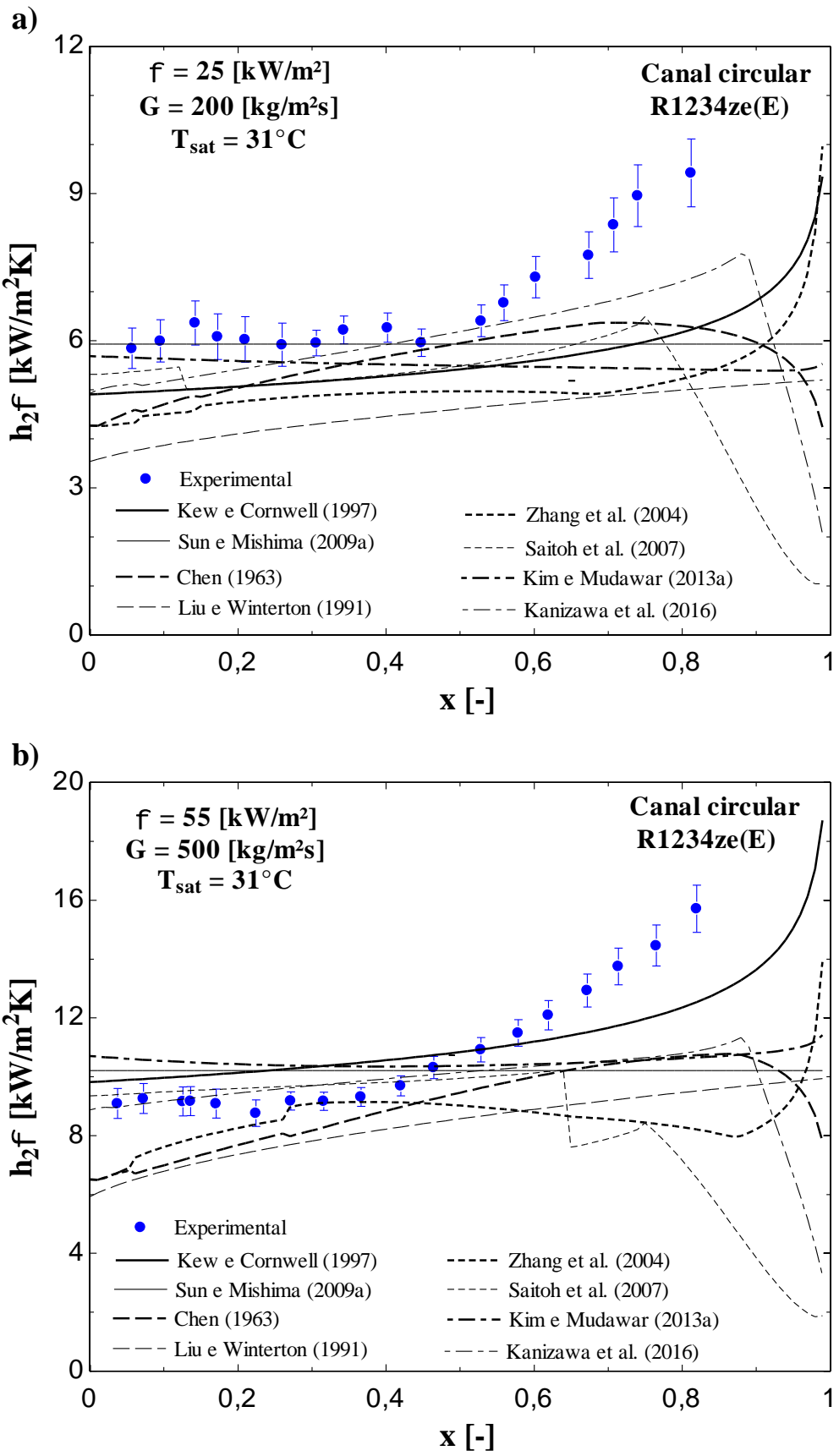

Figura 7.19. Comparação das tendencias do CTC de acordo aos métodos de previsão da literatura e dados experimentais para o fluido R1234ze(E).

Segundo a Figura 7.20b, apenas o método de Sun e Mishima (2009a) captura satisfatoriamente a tendência dos dados experimentais para o fluido R1234yf para uma temperatura de saturação de $41^{\circ} \mathrm{C}$. Já, para $T_{\text {sat }}=31^{\circ} \mathrm{C}$ (ver Fig. 7.20a), Saitoh et al. (2007) e Kanizawa et al. (2016) capturam satisfatoriamente os comportamentos dos resultados experimentais para títulos de vapor inferiores a 0,4. Porém, nenhum dos métodos captura adequadamente a predominância dos efeitos convectivos e o decorrente significativo aumento do coeficiente de transferência de calor com o título de vapor. 

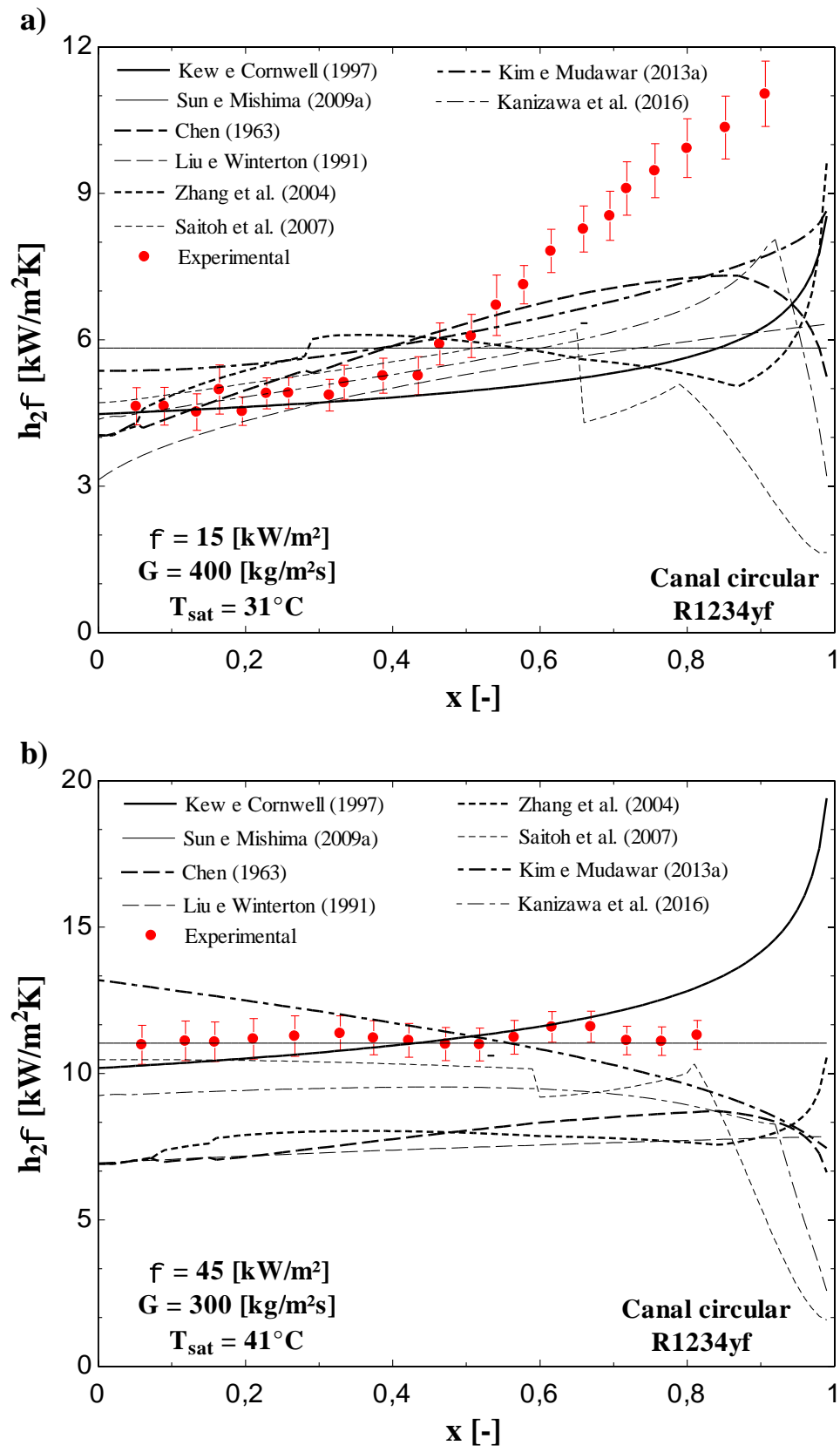

Figura 7.20. Comparação das tendencias do CTC de acordo aos métodos de previsão da literatura e dados experimentais para o fluido R1234yf.

A Figura 7.21 ilustra a evolução do CTC com o acréscimo do título de vapor de acordo com os métodos de previsão e aos dados experimentais para o isobutano. Segundo esta figura, o método de Kew e Corwell (1997) captura razoavelmente a tendência dos dados experimentais para uma temperatura de saturação de $41^{\circ} \mathrm{C}$, entretanto para $T_{\text {sat }}=$ $31^{\circ} \mathrm{C}$, subestima o CTC para títulos de vapor superiores a 0,5 . De uma maneira geral conclui-se que condições em qual predominam efeitos convectivos, os métodos existentes não proporcionam previsões razoáveis das tendências verificadas através dos dados experimentais para este hidrocarboneto. 
a)

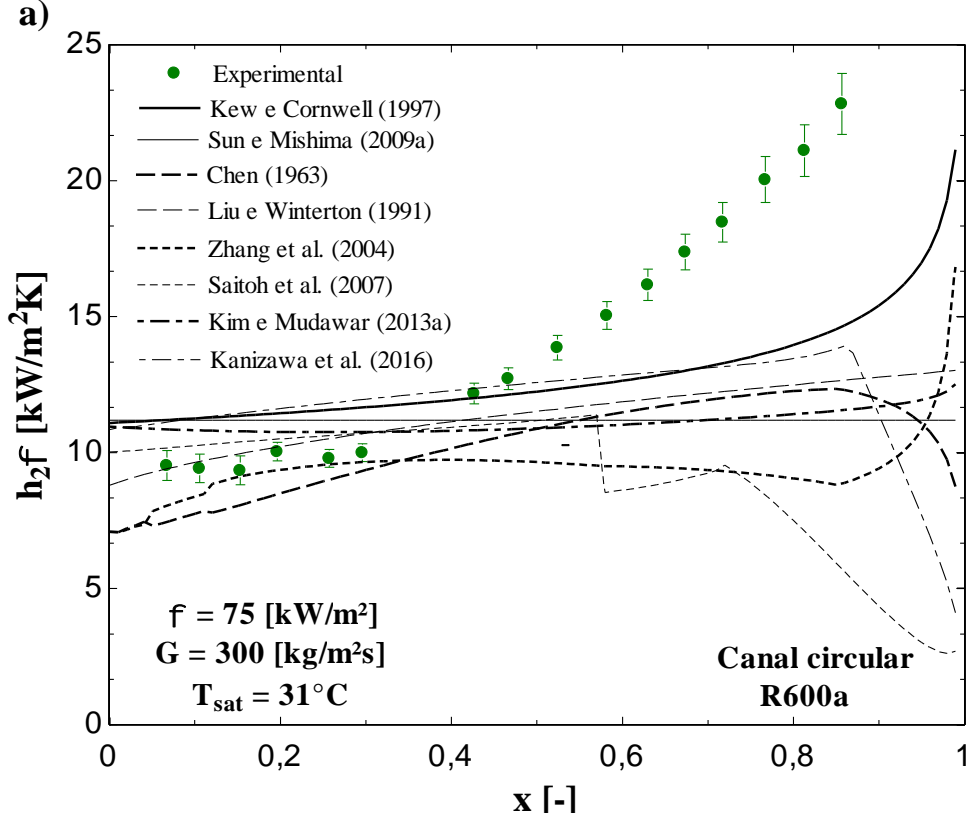

b)

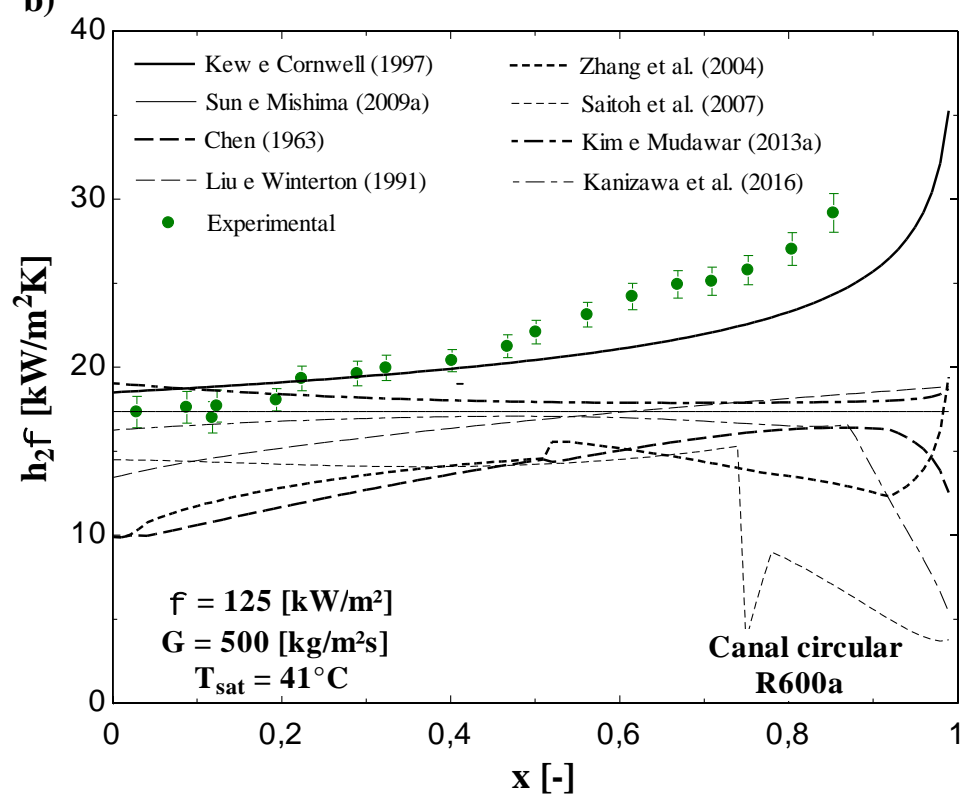

Figura 7.21. Comparação das tendencias do CTC de acordo aos métodos de previsão da literatura e dados experimentais para o fluido isobutano.

A partir da avaliação estatística e da análise de tendências dos métodos de previsão da literatura em relação aos resultados experimentais, extrai-se as seguintes conclusões:

Os métodos que forneceram as melhores previsões segundo apenas parâmetros estatísticos são os desenvolvidos por Kew e Cornwell (1997), Sun e Mishima (2009a), Kim e Mudawar (2013a) e Kanizawa et al. (2016); O método de Kew e Cornwell (1997), apesar de fornecer um erro médio relativo de apenas $17,1 \%$ em relação a totalidade dos dados, as tendências 
de seus resultados para o coeficiente de transferência de calor não se alteram com o acréscimo do título de vapor independentemente da condição experimental de fluido, velocidade mássica, fluxo de calor e temperatura de saturação. Tal comportamento não é corroborado pelos dados experimentais;

O método de Sun e Mishima (2009a) proporciona resultados estatísticos satisfatórios para os dados dos fluidos R1234ze(E), R134a e R1234yf, entretanto, apenas captura corretamente as tendências de resultados experimentais para os quais predominam efeitos de ebulição nucleada;

> Os métodos de Kim e Mudawar (2013a) e Kanizawa et al. (2016), proporcionam no geral previsões estatísticas satisfatórias do coeficiente de transferência de calor para os fluidos R134a, R1234ze(E) e R1234yf. Entretanto, estes métodos apenas capturam satisfatoriamente as tendências do CTC com o acréscimo do título de vapor para títulos de vapor reduzidos e intermediários;

$>$ Apesar dos métodos de Kim e Mudawar (2013a), Sun e Mishima (2009a) e Kanizawa et al. (2016) proporcionarem resultados estatísticos satisfatórios, observou-se que nenhum deles captura as tendências dos dados experimentais para a geometria triangular;

Verificou-se também que os métodos analisados não proporcionam resultados satisfatórios para o isobutano. Já que nenhum deles captura o grau de intensificação dos efeitos convectivos observado para este fluido para a maioria de condições experimentais.

\subsection{Desenvolvimento de um método de previsão do CTC}

Conforme destacado na seção anterior, os métodos de previsão disponíveis não contemplam satisfatoriamente a ampla faixa de condições experimentais avaliadas no presente estudo. Por tanto, optou-se por ajustar os coeficientes do método proposto por Kanizawa et al. (2016), com base no banco de dados levantado neste estudo, conforme procedimento descrito deste item: 


\subsubsection{Descrição do método proposto}

Este item apresenta a descrição do método desenvolvido no presente estudo para a previsão do CTC durante a ebulição convectiva em canais de dimensões reduzidas e seções transversais circulares e quadradas. A distinção de comportamentos em relação as demais geometrias, rugosidade superficial significativamente superior combinadas a um banco de dados baseado em resultados para um único refrigerante fez com que se opta-se pela não inclusão de resultados para a seção triangular no banco de dados utilizados no ajuste do modelo.

Neste contexto deve-se destacar o fato de tanto o aprisionamento de líquido superaquecido nos cantos, como a rugosidade superficial elevada, poderem estar relacionados à intensificação de efeitos de ebulição nucleada para a geometria triangular. Desta forma, a incorporação ao método de apenas um destes efeitos poderia ser mecanisticamente inadequada considerando resultados para apenas o fluido R134a e uma única rugosidade superficial. Assim, para seções transversais triangulares, recomenda-se o método de Kanizawa et al. (2016) já que este método obteve previsões estatisticamente satisfatórias para esta geometria conforme resultados indicados na Tabela 7.2. Vale mencionar, que o uso do diâmetro equivalente para os dados para canais triangulares foi exaustivamente analisado, entretanto, não foi suficiente para capturar adequadamente o efeito da geometria no CTC.

Conforme indicado na seção anterior, o método proposto por Kanizawa et al. (2016) prevê satisfatoriamente os resultados dos fluidos R134a, R1234ze(E) e R1234yf. No entanto, o método não é adequado para a previsão do CTC do refrigerante R600a, para o qual predominam efeitos convectivos. Por outro lado, verificou-se no presente estudo que a transição entre o predomínio de efeitos de ebulição para efeitos convectivos ocorre de forma mais abrupta do que o previsto apenas pela composição linear destes efeitos. Desta forma, no presente estudo optou-se pelo ajuste do método de Kanizawa et al. (2016) através de um expoente assimptótico igual a 2, conforme recomendado por Liu e Winterton (1991). Assim, no método proposto neste estudo o CTC bifásico durante a ebulição convectiva em canais de diâmetro reduzido para condições de títulos de vapor inferiores à secagem de parede é dado por: 


$$
h_{2 \phi}=\left[\left(F \cdot h_{L}\right)^{2}+\left(S \cdot h_{e n}\right)^{2}\right]^{0,5}
$$

No caso de títulos de vapor superiores à secagem de parede $\left(x>x_{\text {secagem }}\right)$, optou-se em adotar o método proposto por Kanizawa et al. (2016) dado pelas Eqs. 4.20 a 4.24. Optou-se por manter este procedimento pois ele capturou satisfatoriamente os dados experimentais deste estudo e também devido à ausência na literatura de um banco de dados abrangente visando a caracterização do CTC em condições pós-secagem de parede.

Para o cálculo do coeficiente de transferência de calor por ebulição nucleada na Eq. 7.1, de forma análoga a Kanizawa et al. (2016), adotou-se o modelo de Stephan e Abdelsalam (1980). Já para o cálculo do CTC por ebulição convectiva, adotou-se a correlação de Dittus-Boelter, independentemente do número de Reynolds.

Para a estimativa do fator de intensificação dos efeitos de ebulição convectiva manteve-se a forma da correlação proposta por Kanizawa et al. (2016), dada pela seguinte relação:

$$
F=1+\frac{c_{f, 1} X_{t x}^{c_{f, 2}}}{\left(1+W e_{u G}^{c_{f, 3}}\right)}
$$

Para a estimativa do fator de supressão de efeitos de ebulição nucleada mantevese a forma de Kanizawa et al. (2016), que inclui o número de Bond, no intuito de capturar efeitos de confinamento do processo de ebulição com a redução do diâmetro. $\mathrm{O}$ fator de supressão é dado por:

$$
S=\frac{c_{s, 1} B d^{c_{s, 2}}}{\left(1+c_{s, 3}\left(10^{-4} \operatorname{Re}_{L} F^{1,25}\right)^{c_{s, 4}}\right.}
$$

Os coeficientes $c_{f, 1}, c_{f, 2}, c_{f, 3}, c_{s, 1}, c_{s, 2}, c_{s, 3}$ e $c_{s, 4}$ foram ajustados usando o método dos mínimos quadrados para equações não lineares (nlinfit) através do programa MATLAB 2010a. Através deste procedimento, valores de $c_{f, 1}, c_{f, 2}, c_{f, 3}, c_{s, 1}, c_{s, 2}, c_{s, 3}$ e $c_{s, 4}$ iguais a 2,55, -1,04, -0,194, 1,427, 0,032, 0,1086 e 0,981 foram obtidos.

A Figura 7.22 apresenta um fluxograma indicando o procedimento de implementação do método proposto neste estudo. 


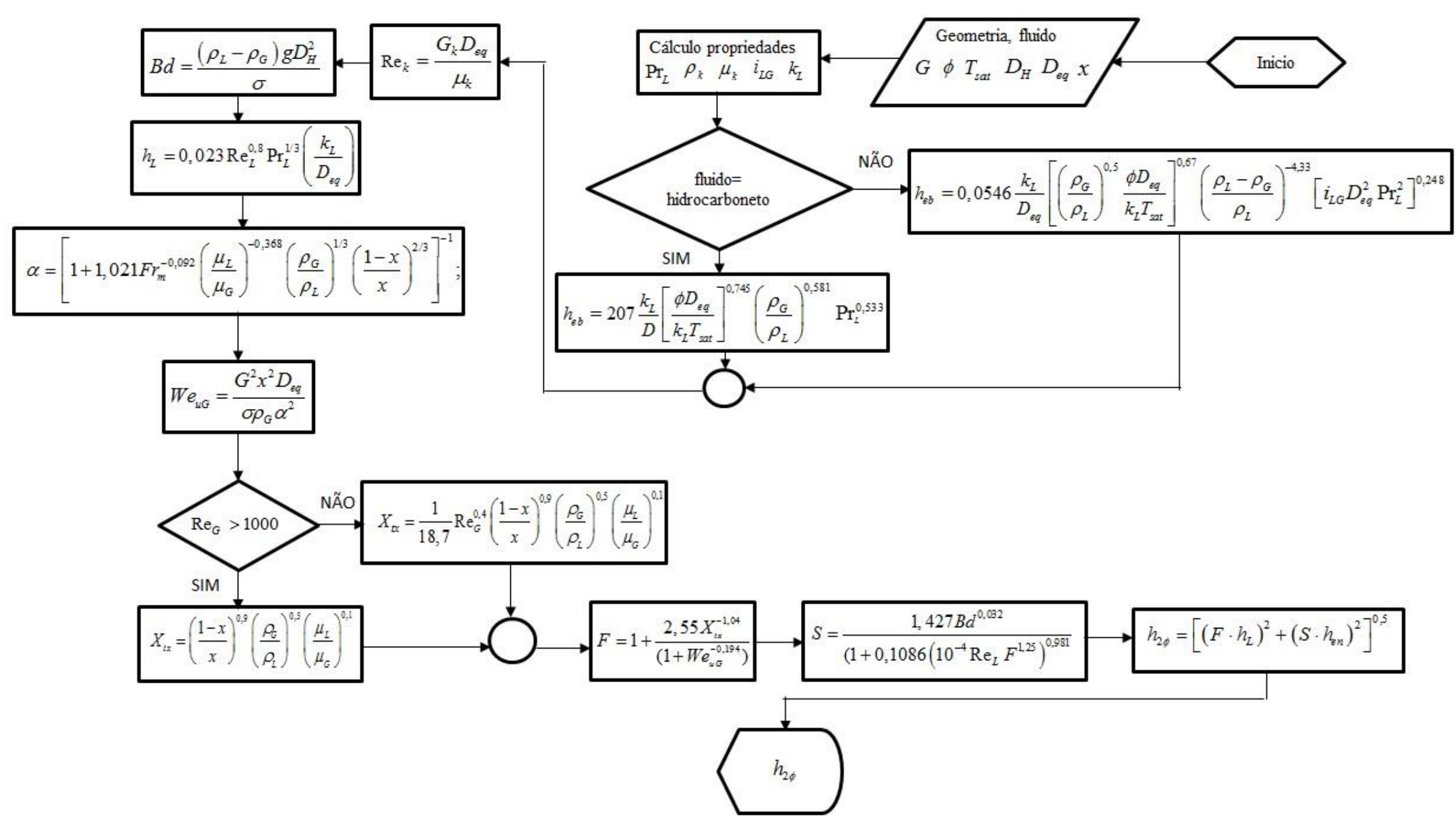

Figura 7.22. Fluxograma para a implementação do método proposto para coeficiente de transferencia de calor pré-secagem de parede. 


\subsubsection{Comparação do novo método com o banco de dados experimental}

A Tabela 7.3 apresenta os parâmetros estatísticos resultantes da comparação entre o método desenvolvido neste estudo e o banco de dados utilizado em sua formulação. Observa-se na tabela, que o método desenvolvido proporciona resultados satisfatórios independentemente do fluido e geometria da seção com erros absolutos médios inferiores a $14.1 \%$.

Tabela 7.3. Parâmetros estatísticos resultantes da comparação do método desenvolvido e o banco de dados experimental levantado no presente estudo.

\begin{tabular}{c|c|c|ccc}
\hline Fluido & Geometria & $\begin{array}{c}\text { Número } \\
\text { de dados }\end{array}$ & EMA & $\boldsymbol{\eta}_{30 \%}$ & $\boldsymbol{\eta}_{20 \%}$ \\
\hline R134a & Circular & 772 & $\mathbf{9 , 8 \%}$ & $\mathbf{1 0 0 \%}$ & $\mathbf{9 5 , 9 \%}$ \\
R134a & Quadrado & 753 & $\mathbf{1 2 , 3 \%}$ & $\mathbf{8 8 , 6 \%}$ & $\mathbf{7 9 , 2 \%}$ \\
R1234ze(E) & Circular & 847 & $\mathbf{8 , 8 \%}$ & $\mathbf{9 7 , 8 \%}$ & $\mathbf{9 2 , 1 \%}$ \\
R1234yf & Circular & 475 & $\mathbf{1 0 , 8 \%}$ & $\mathbf{9 7 , 9 \%}$ & $\mathbf{8 6 , 1 \%}$ \\
R600a & Circular & 1315 & $\mathbf{1 4 , 1 \%}$ & $\mathbf{9 6 , 0 \%}$ & $\mathbf{7 5 , 7 \%}$ \\
\hline Total & & 3409 & $\mathbf{1 1 , 3 \%}$ & $\mathbf{9 7 , 5 \%}$ & $\mathbf{8 5 , 3 \%}$ \\
\hline
\end{tabular}

*Números em negrito indicam um EMA inferior a $20 \%, \eta_{30 \%}$ e $\eta_{20 \%}$ superior a $80 \%$ e $70 \%$, respectivamente.

A Figura 7.23a apresenta uma comparação entre os resultados estimados através do método proposto no presente estudo e o banco de dados experimental segregados de acordo com o fluido de trabalho. Como observado na figura, o novo método proporciona previsões satisfatórias independentemente do fluido e da faixa de valores de coeficiente de transferência de calor. A Figura 7.23b ilustra a comparação das previsões fornecidas pelo método proposto para o fluido R134a, com os dados segregados de acordo com a geometria da seção transversal adotando-se Kanizawa et al. (2016) para a seção triangular. Conforme ilustrado na figura, o método prevê satisfatoriamente os dados experimentais para a seção circular independentemente da faixa do coeficiente de transferência de calor. Observa-se também que o método proposto sobrestima uma parcela dos dados experimentais para a geometria quadrada para CTCs superiores a 8 kW/m²K, já Kanizawa et al. (2016), para a seção transversal triangular, proporciona previsões uniformemente distribuídas independentemente da faixa de coeficiente de transferência de calor. 

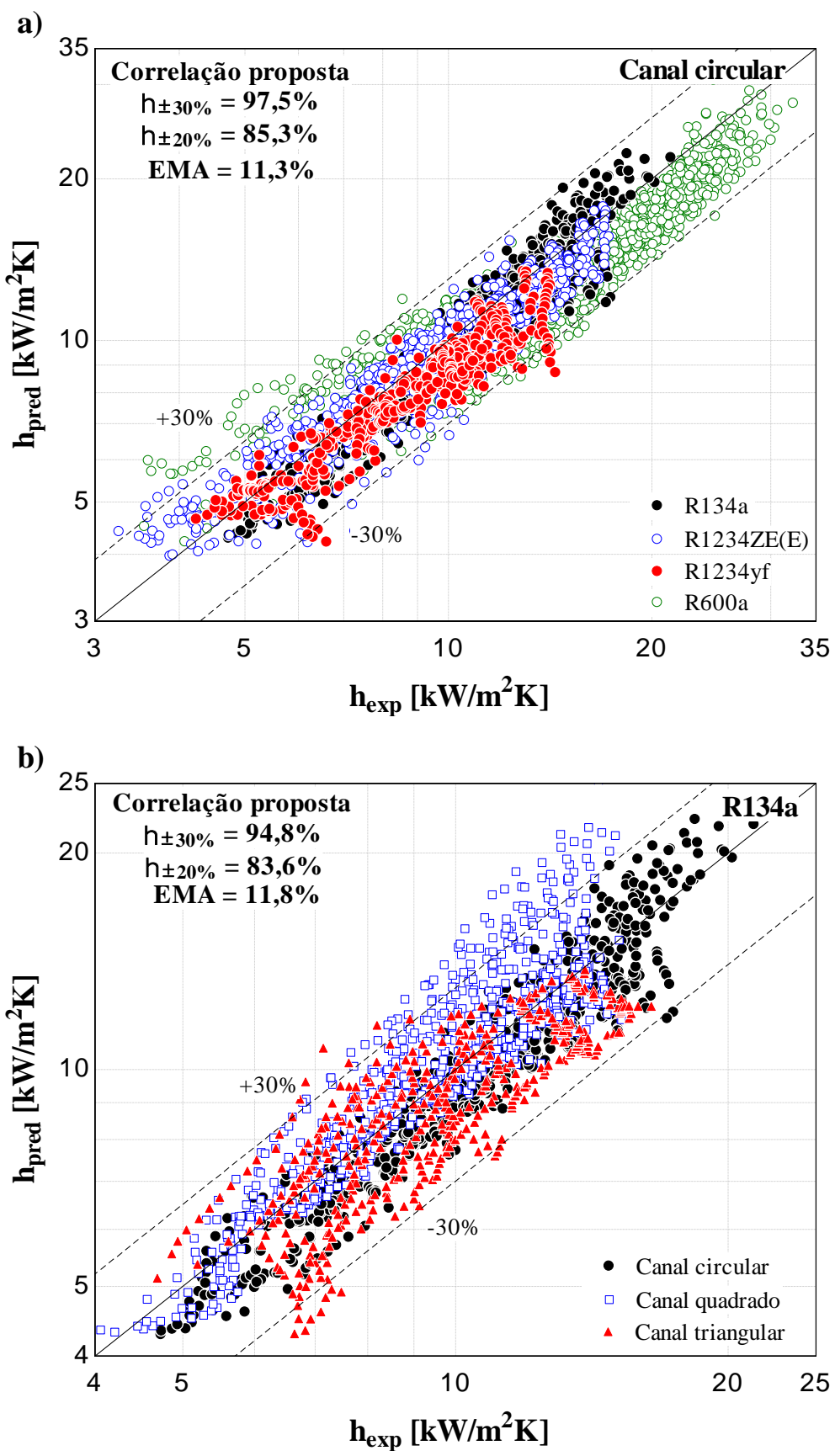

Figura 7.23. Comparação dos dados experimentais de CTC com o método de previsão proposto segregados por fluido para um canal circular.

As Figuras 7.24 a 7.27 ilustram avaliações comparativas do novo método em relação aos métodos da literatura de Sun e Mishima (2009a), Kim e Mudawar (2013a) e Kanizawa et al. (2016), os quais proporcionaram as melhores previsões do banco de dados levantado no presente estudo. Nestas figuras são apresentadas as parcelas de dados previstos com erros inferiores a $\pm 20 \%$ com os resultados segregados de acordo com o fluido refrigerante, geometria da seção de testes e as faixas de fluxo de calor, velocidade mássica, título de vapor e coeficiente de transferência de calor. 


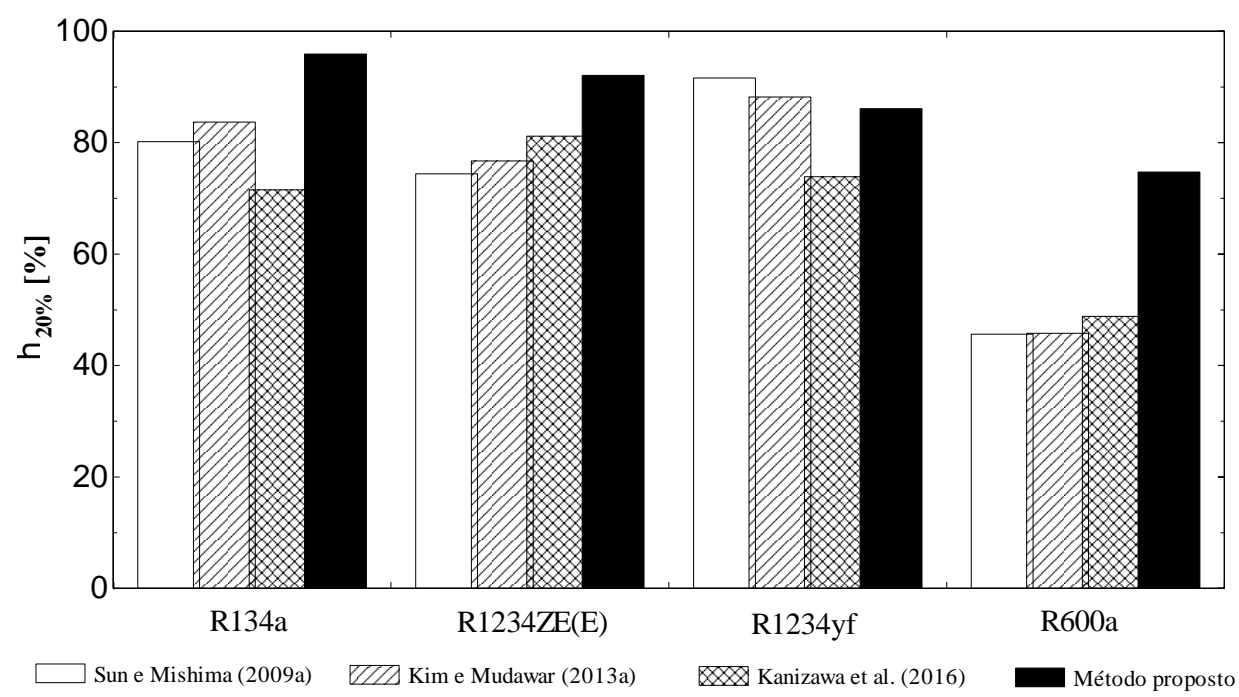

Figura 7.24. Parcela dos dados experimentais previstos com erro inferior a $\pm 20 \%$ segundo métodos da literatura e o proposto neste estudo de acordo ao fluido de trabalho.

Na Figura 7.24 constata-se que o método proposto prevê razoavelmente os resultados experimentais para os quatro fluidos avaliados neste estudo com parcelas superiores a $80 \%$ dos dados com erro entre $\pm 20 \%$. Pode-se observar também, que o método proposto proporciona melhores previsões que o método de Kanizawa et al. (2016) no qual é baseado. É importante mencionar ainda, que o método proposto melhora significativamente as previsões para o fluido R600a, considerando que os métodos da literatura previram para este fluido parcelas inferiores a 50\% dos resultados com erros entre $\pm 20 \%$.

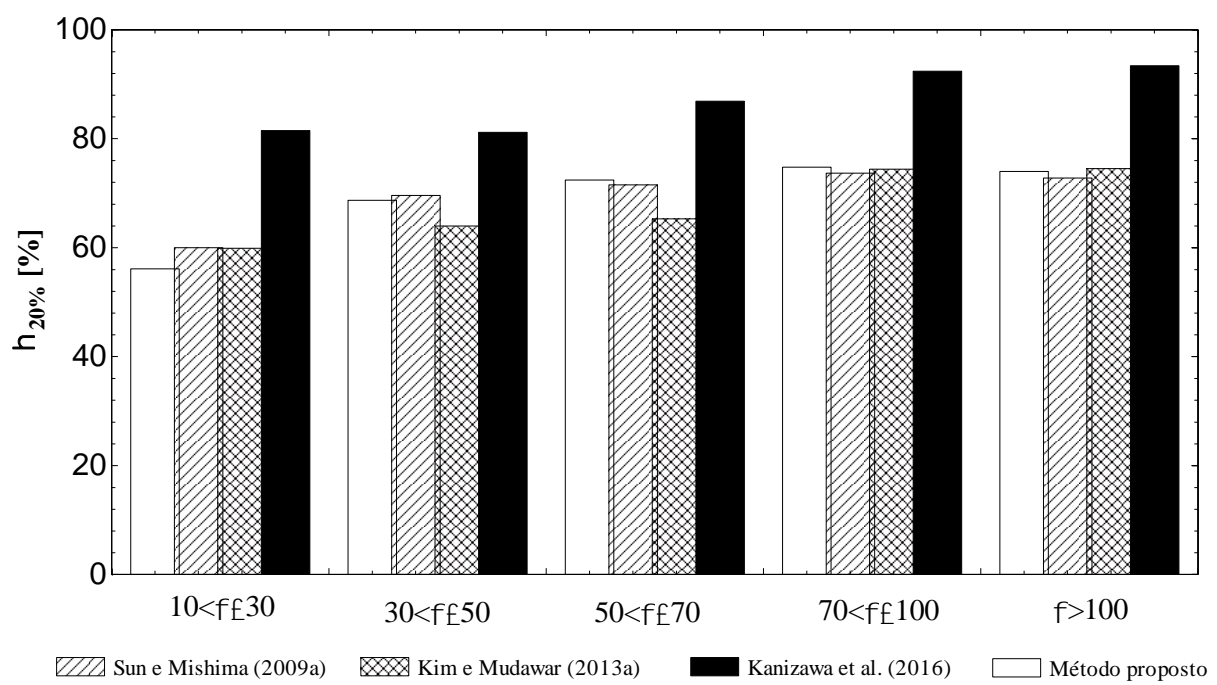

Figura 7.25. Parcela dos dados experimentais previstos com erro inferior a $\pm 30 \%$ segundo métodos da literatura e o proposto neste estudo de acordo à faixa de fluxo de calor $\left(\mathrm{kW} / \mathrm{m}^{2}\right)$. 
Conforme ilustrado nas Figuras 7.25 a 7.27, o método proposto prevê parcelas superiores dos dados com erros inferiores a $\pm 20 \%$ independentemente das faixas de fluxo de calor, título de vapor, velocidade mássica e coeficiente de transferência de calor.
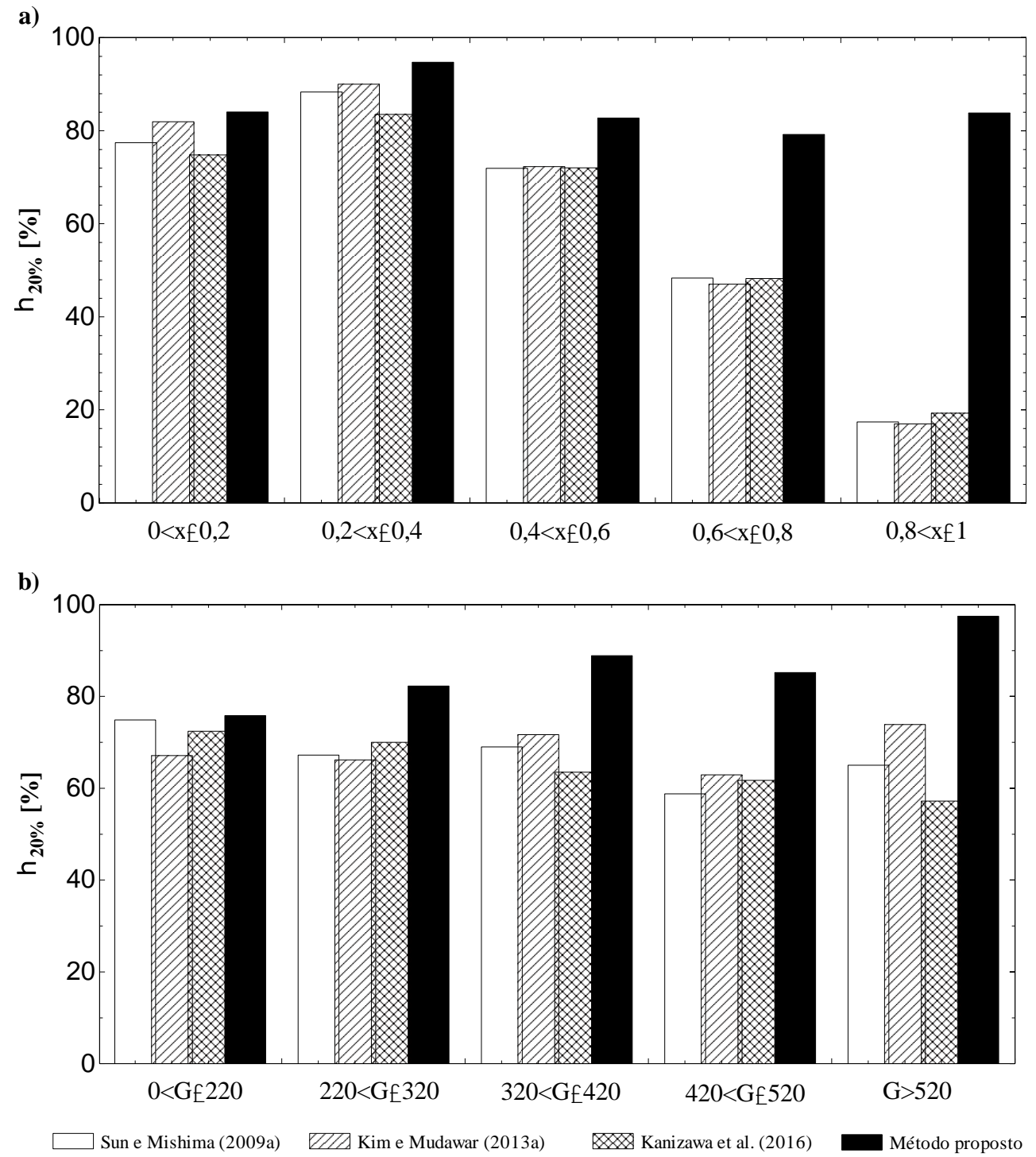

Figura 7.26. Parcela dos dados experimentais previstos com erro menor a $\pm 30 \%$ segundo métodos da literatura e o proposto neste estudo de acordo à faixa: a) título de vapor, b) velocidade mássica $\left(\mathrm{kg} / \mathrm{m}^{2} \mathrm{~s}\right)$.

Ressalta-se o resultado ilustrado na Figura 7.26a, segundo a qual o novo método ao contrário dos demais, não apresenta diferenças significativas na fração de dados com a mudança da faixa de títulos de vapor, prevendo parcelas superiores a $80 \%$ dos resultados dentro de uma margem de erro de $\pm 20 \%$. É importante também mencionar que o novo método melhora significativamente as previsões em relação aos da literatura para títulos de vapor superiores a 0,8 , faixa na qual os métodos atualmente disponíveis literatura previram parcelas inferiores a $25 \%$ dos dados com desvios entre $\pm 20 \%$. Este resultado 
explica-se pelo fato dos métodos da literatura não preverem satisfatoriamente a predominância dos efeitos convectivos para títulos superiores a 0,4 , especialmente para $\mathrm{o}$ isobutano (ver Fig. 7.21).

Segundo a Figura 7.26b, os métodos da literatura previram parcelas entre 55 e $75 \%$ dos dados com erro entre $\pm 20 \%$, enquanto, o método proposto proporcionou $\eta_{ \pm 20 \%}$ superiores a estes valores independentemente da velocidade mássica. Vale ressaltar que o método proposto apresenta previsões significativamente melhores para velocidade mássicas superiores a $520 \mathrm{~kg} / \mathrm{m}^{2} \mathrm{~s}$, correspondendo em sua maioria a resultados para o R134a conforme indicado na Tabela 7.1.

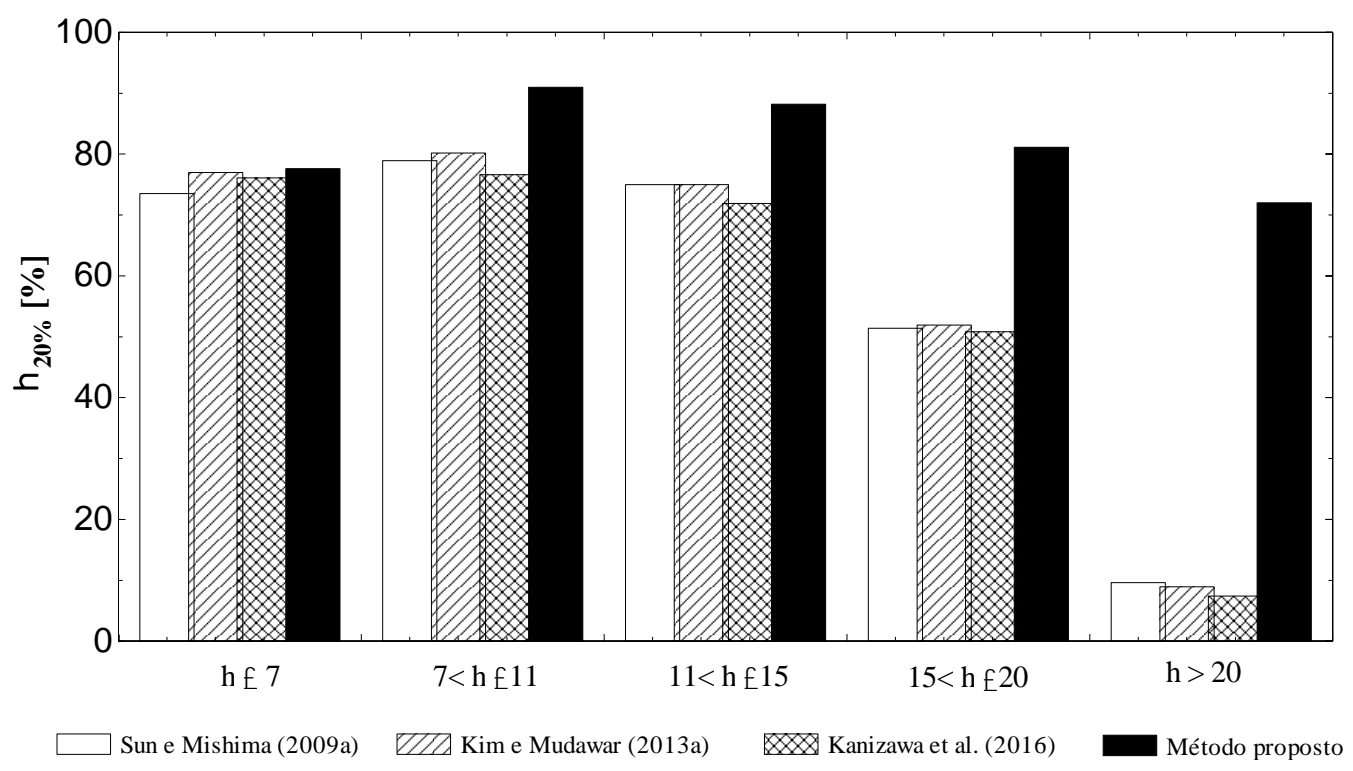

Figura 7.27. Parcela dos dados experimentais previstos com erro inferior a $\pm 20 \%$ segundo métodos da literatura e o proposto de acordo à faixa de coeficiente de transferência de calor $\left(\mathrm{kW} / \mathrm{m}^{2} \mathrm{~K}\right)$.

A Figura 7.30 ilustra a parcela de dados experimentais segregado de acordo à faixa de coeficiente de transferência de calor previstos com erro inferior a $\pm 20 \%$ segundo os métodos da literatura e o proposto neste estudo. Como ilustra a figura, os métodos de Sun e Mishima (2009a), Kim e Mudawar (2013a) e Kanizawa et al. (2016) proporcionam previsões razoáveis para coeficientes de transferência de calor inferiores a $15 \mathrm{~kW} / \mathrm{m}^{2} \mathrm{~K}$, mas proporcionam resultados insatisfatórios para CTCs superiores a $15 \mathrm{~kW} / \mathrm{m}^{2} \mathrm{~K}$. Por outro lado, o novo método apresenta previsões razoáveis independentemente da faixa de coeficiente de transferência de calor, melhorando em $800 \%$ a parcela de dados previstos com desvios entre $\pm 20 \%$ para CTCs superiores a $20 \mathrm{~kW} / \mathrm{m}^{2} \mathrm{~K}$, correspondendo aos dados experimentais para títulos elevados e o fluido R600a. 


\subsubsection{Análise paramétrica das tendências fornecidas pelo método}

As Figuras 7.28 e 7.29 ilustram o efeito do fluxo de calor no comportamento do coeficiente de transferência de calor com a variação do título de vapor segundo o método proposto e dados experimentais para os fluidos R1234ze(E) e R600a, respectivamente.

Como constata-se nas figuras, para condições de escoamento pré-secagem de parede, o método prevê o incremento do CTC com o acréscimo do fluxo de calor. Para o fluido R1234ze(E), o método prevê satisfatoriamente o incremento do coeficiente de transferência de calor com o aumento do fluxo de calor e captura seu comportamento com a variação do título de vapor. Para o fluido R600a, o método proposto também captura o efeito do acréscimo do CTC com o fluxo de calor, embora apresenta maiores divergências em relação aos resultados experimentais para fluxos de calor elevados.

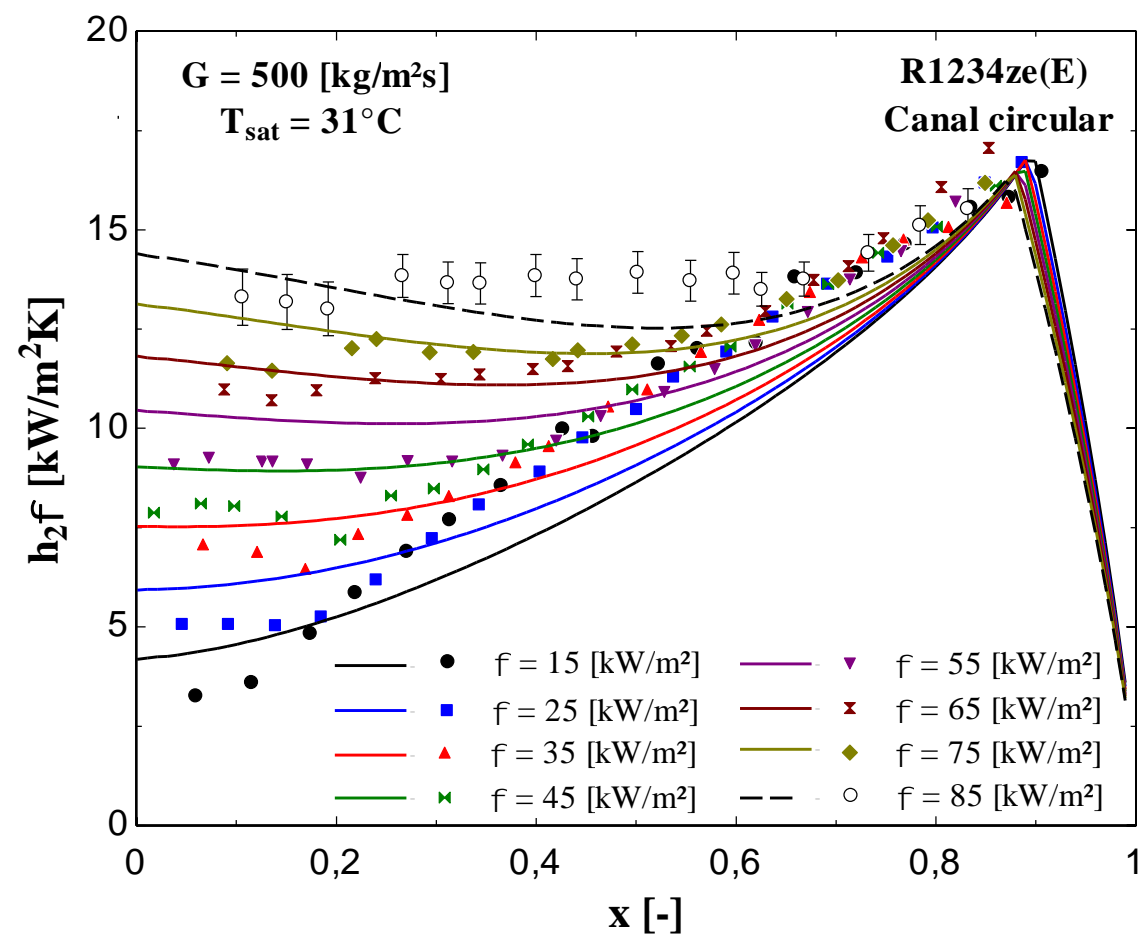

Figura 7.28. Comparação do efeito do fluxo de calor no comportamento do CTC com o acréscimo de $\mathrm{x}$ segundo o método proposto e os dados experimentais, R1234ze(E). 


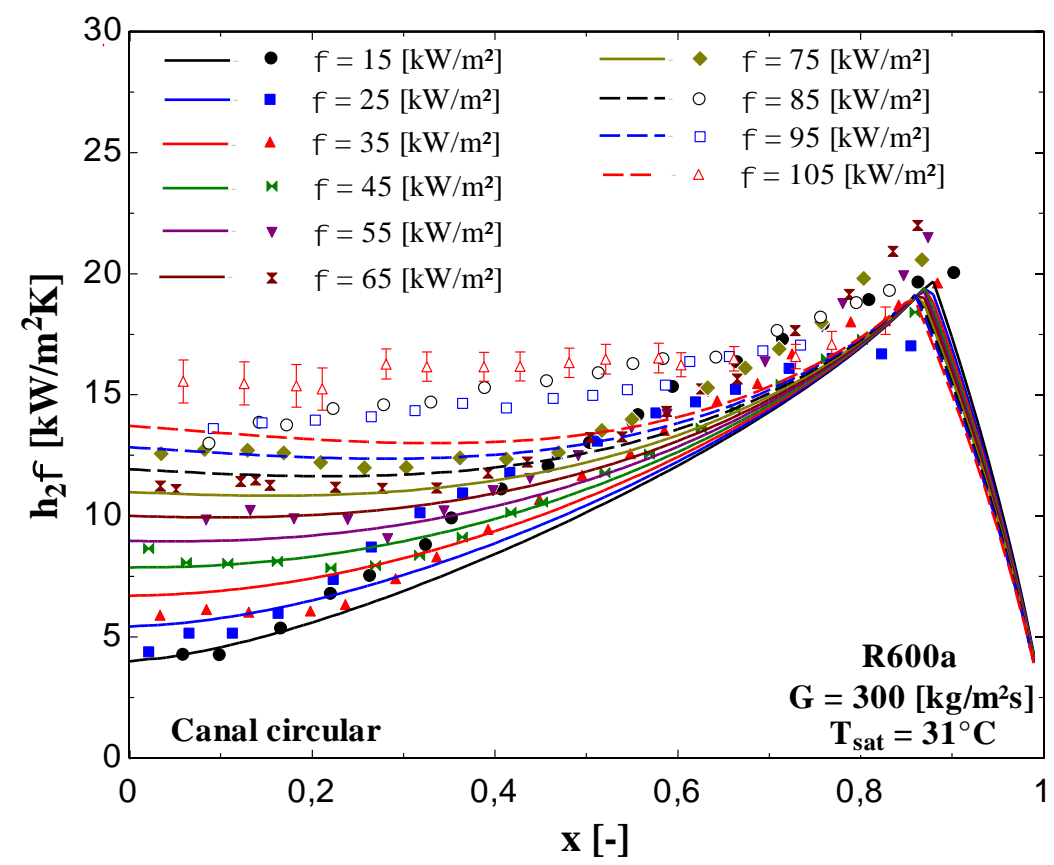

Figura 7.29. Comparação do efeito do fluxo de calor no comportamento do CTC com o acréscimo de x segundo o método proposto e os dados experimentais, R600a.

As Figuras 7.30 e 7.31 ilustram o efeito da velocidade mássica no comportamento do CTC com o acréscimo do título de vapor segundo os resultados experimentais e previsões fornecidas pelo método proposto.

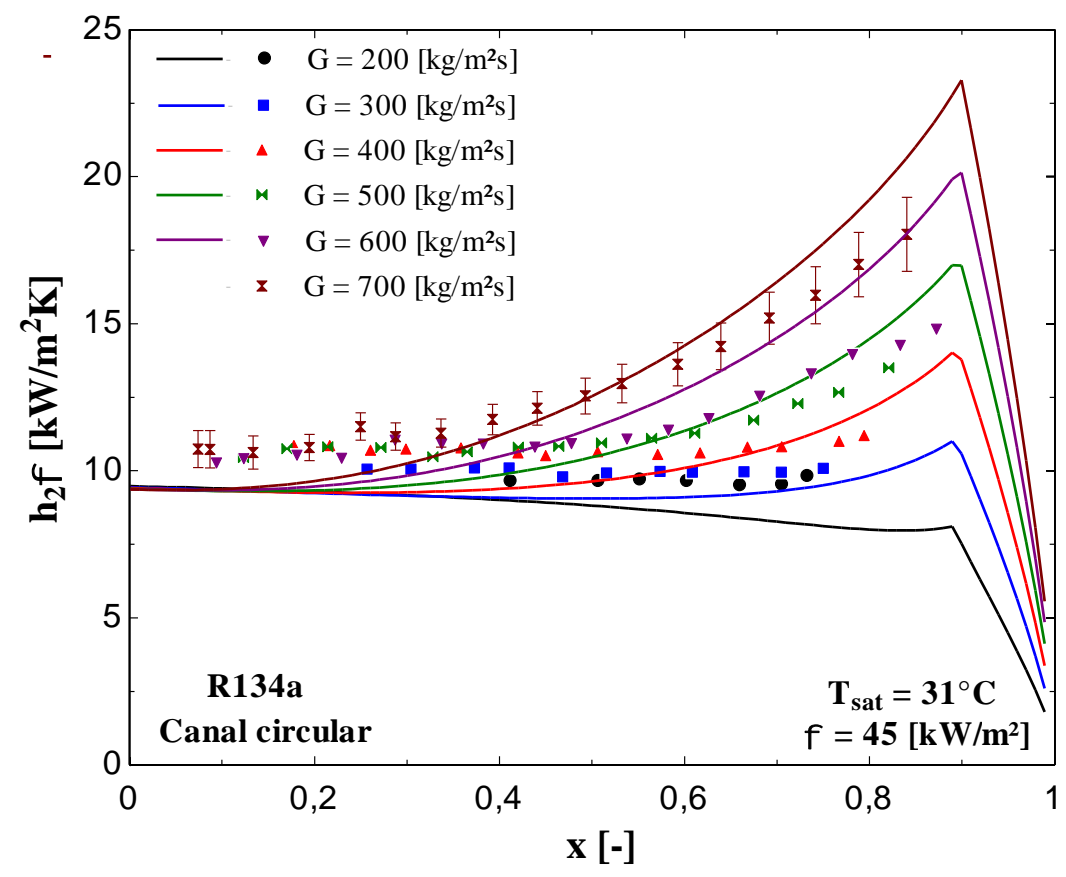

Figura 7.30. Comparação do efeito da velocidade mássica no comportamento do CTC com o acréscimo de $\mathrm{x}$ segundo o método proposto e os dados experimentais, R134a. 
De acordo com a Figura 7.31, o método proposto prevê satisfatoriamente o comportamento do coeficiente de transferência de calor com o acréscimo da velocidade mássica para o fluido R134a. Por outro lado, para o fluido R1234yf, o novo método prevê satisfatoriamente apenas os resultados experimentais para velocidades mássicas iguais a 300 e $400 \mathrm{~kg} / \mathrm{m}^{2} \mathrm{~s}$. O método proporciona valores inferiores aos experimentais para velocidades mássicas de 100 e $200 \mathrm{~kg} / \mathrm{m}^{2} \mathrm{~s}$, comportamento que se acentua para títulos de vapor elevados.

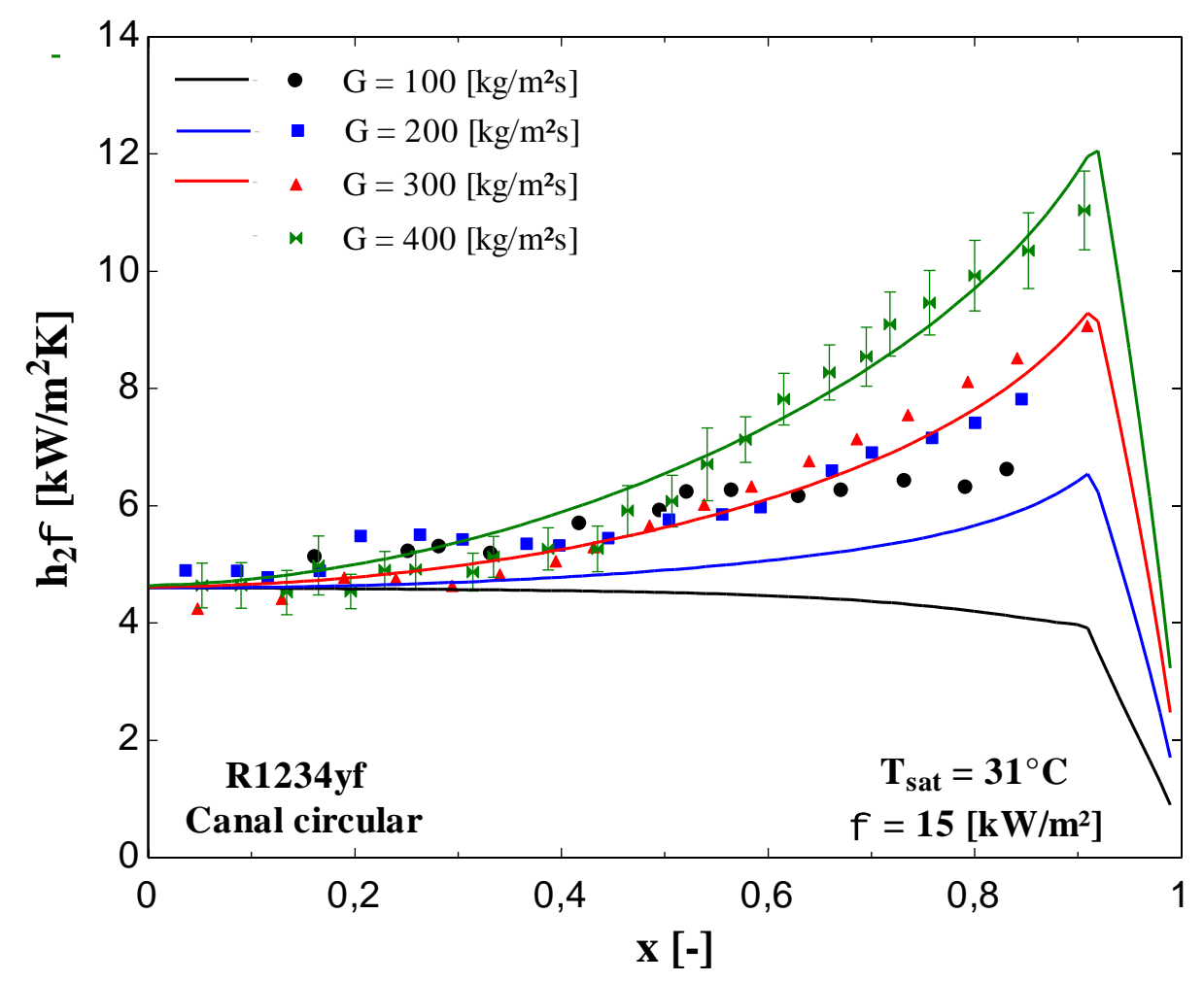

Figura 7.31. Comparação do efeito da velocidade mássica no comportamento do CTC com o acréscimo de $\mathrm{x}$ segundo o método proposto e os dados experimentais, R1234yf.

Através da análise das Figuras 7.32 e 7.33, constata-se que o novo método proposto captura adequadamente o efeito da temperatura de saturação no comportamento do coeficiente de transferência de calor. No geral, segundo estas figuras, as previsões proporcionadas pelo novo método e os resultados experimentais coincidem razoavelmente. Observa-se que para títulos de vapor inferiores a 0,4 - 0,6, dependendo do fluido e de condições de fluxo de calor, o método proposto neste estudo prevê o incremento do coeficiente de transferência de calor com a elevação da temperatura de saturação. Por outro lado, para títulos de vapor elevados o método prevê o decréscimo do CTC com o acréscimo da temperatura de saturação. 


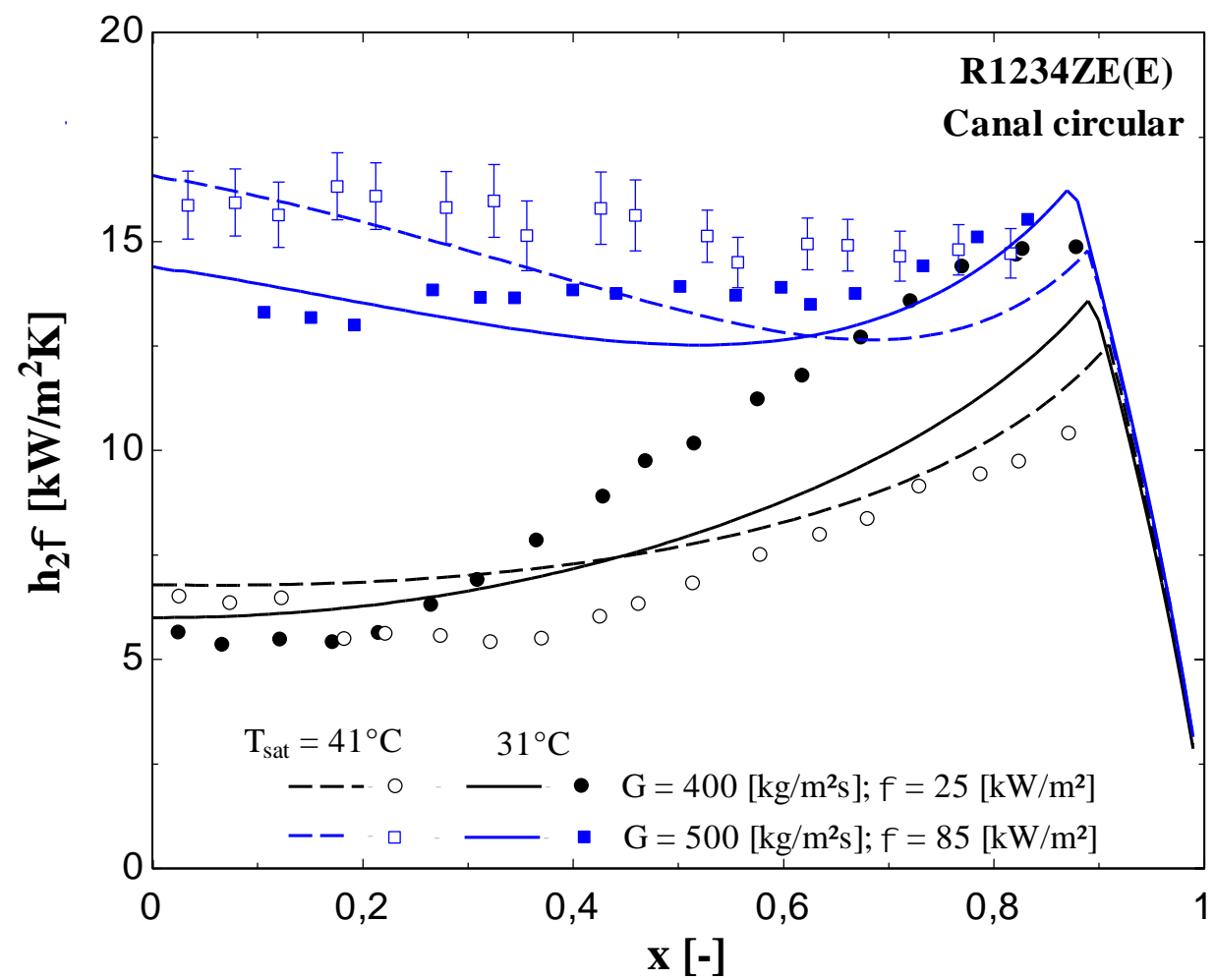

Figura 7.32. Comparação do efeito da temperatura de saturação no comportamento do CTC com o acréscimo de $\mathrm{x}$ segundo o método proposto e os dados experimentais, R1234ze(E).

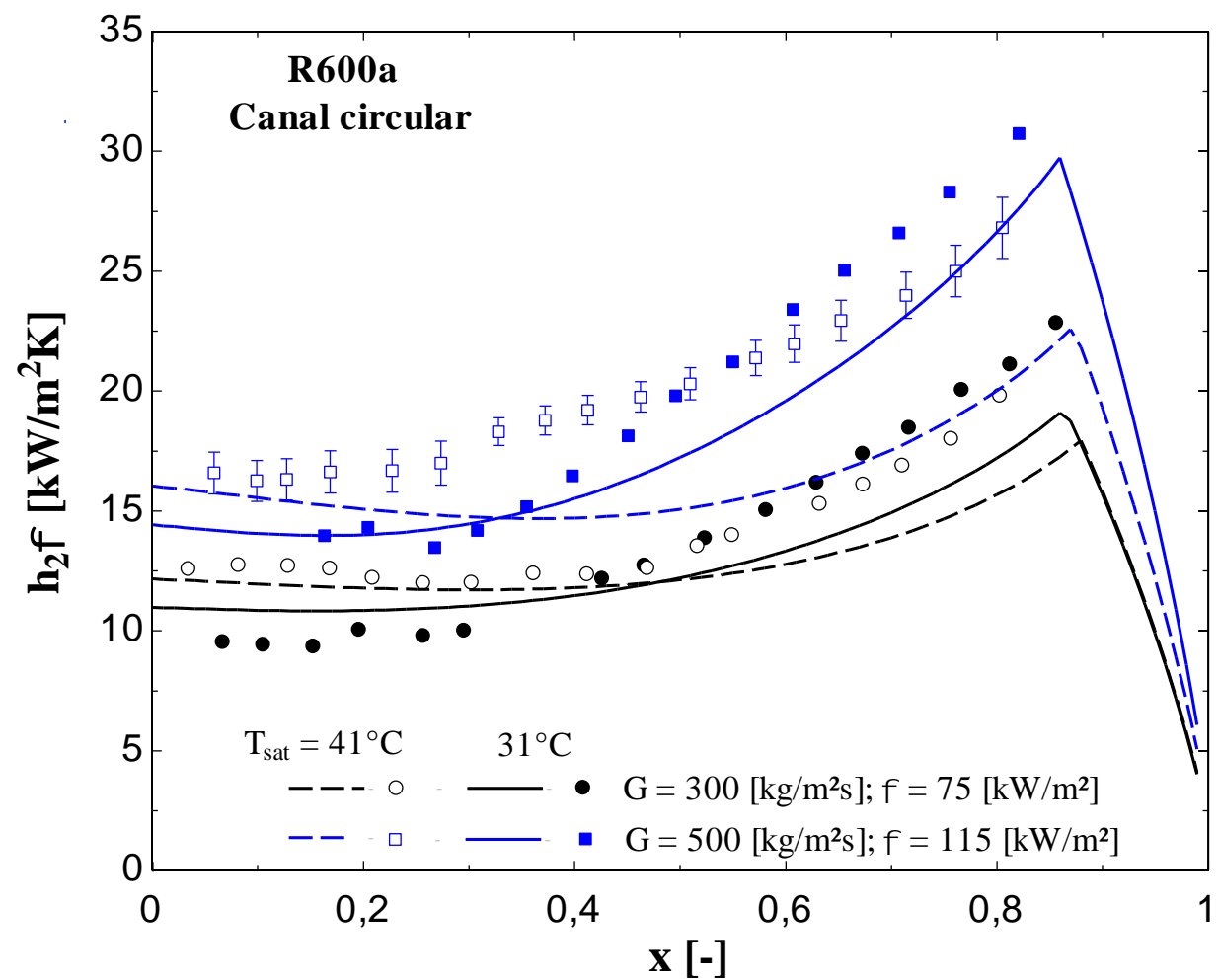

Figura 7.33. Comparação do efeito da temperatura de saturação no comportamento do CTC com o acréscimo de x segundo o método proposto e os dados experimentais, R600a. 
Para o fluido R1234ze(E), conforme ilustra a Figura 7.32, divergências superiores entre os dados experimentais e os valores calculados se verificam para o fluxo de calor de $25 \mathrm{~kW} / \mathrm{m}^{2}$ e temperatura de saturação de $31^{\circ} \mathrm{C}$. Por outro lado, para o fluido isobutano (ver Fig. 7.33), a maior divergência entre resultados experimentais e os previstos pelo método são para condições de fluxo de calor elevado $\left(115 \mathrm{~kW} / \mathrm{m}^{2}\right)$ e temperatura de saturação de $41^{\circ} \mathrm{C}$.

De uma maneira geral, segundo as Figuras 7.34 e 7.35, o método proposto captura adequadamente o efeito do fluido de trabalho no comportamento do coeficiente de transferência de calor. Observa-se também que o título de vapor para qual o CTC experimental do isobutano supera ao coeficiente de transferência de calor dos fluidos R134a, R1234ze(E) e R1234yf é previsto satisfatoriamente pelo novo método. Pode-se observar ainda nas Figuras 7.34 e 7.35, que o método proposto apresenta divergências superiores em relação aos dados experimentais para o isobutano com temperatura de saturação de $31^{\circ} \mathrm{C}$ e para os fluidos R134a e R1234yf com temperatura de saturação de $41^{\circ} \mathrm{C}$. É importante também notar que o método proposto proporciona tendências similares para os fluidos R134a e R1234ze(E), com o primeiro apresentando resultados $4 \%$ superiores ao do R134a.

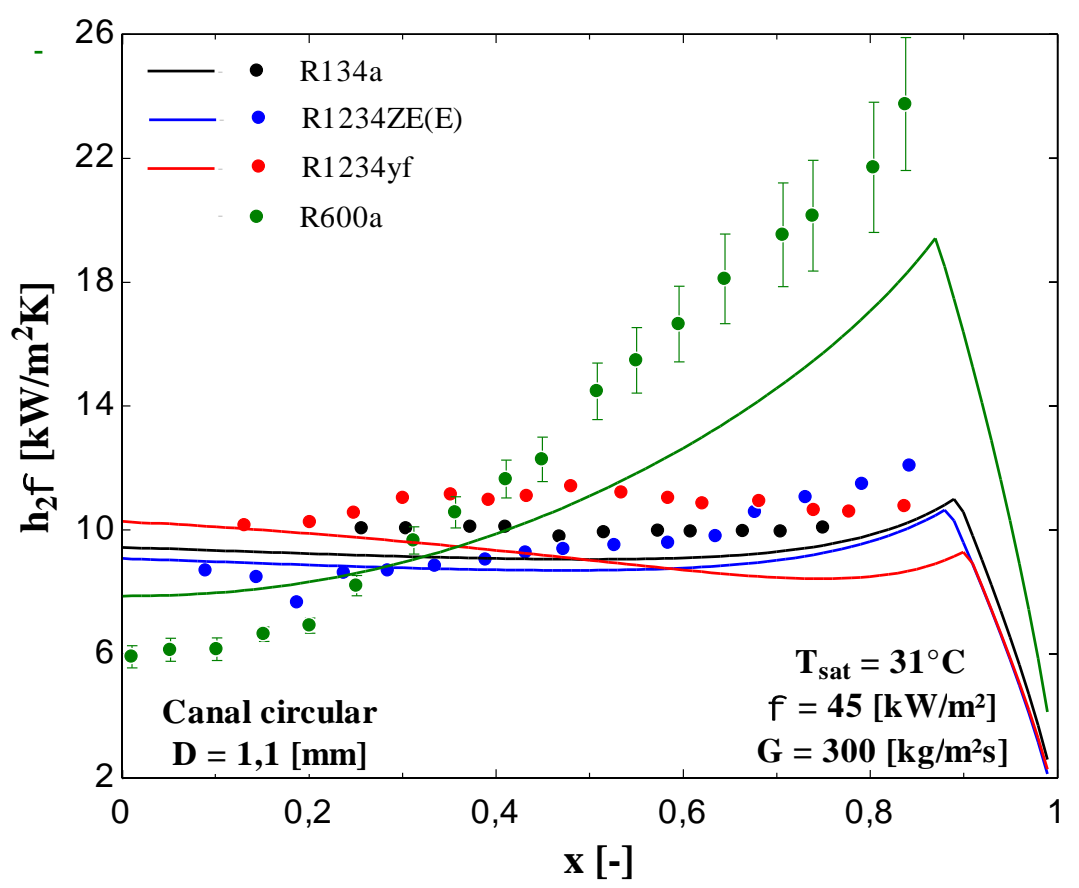

Figura 7.34. Comparação do efeito do fluido no comportamento do CTC com o acréscimo de x segundo o método proposto e os dados experimentais, $\mathrm{T}_{\mathrm{sat}}=31^{\circ} \mathrm{C}$. 


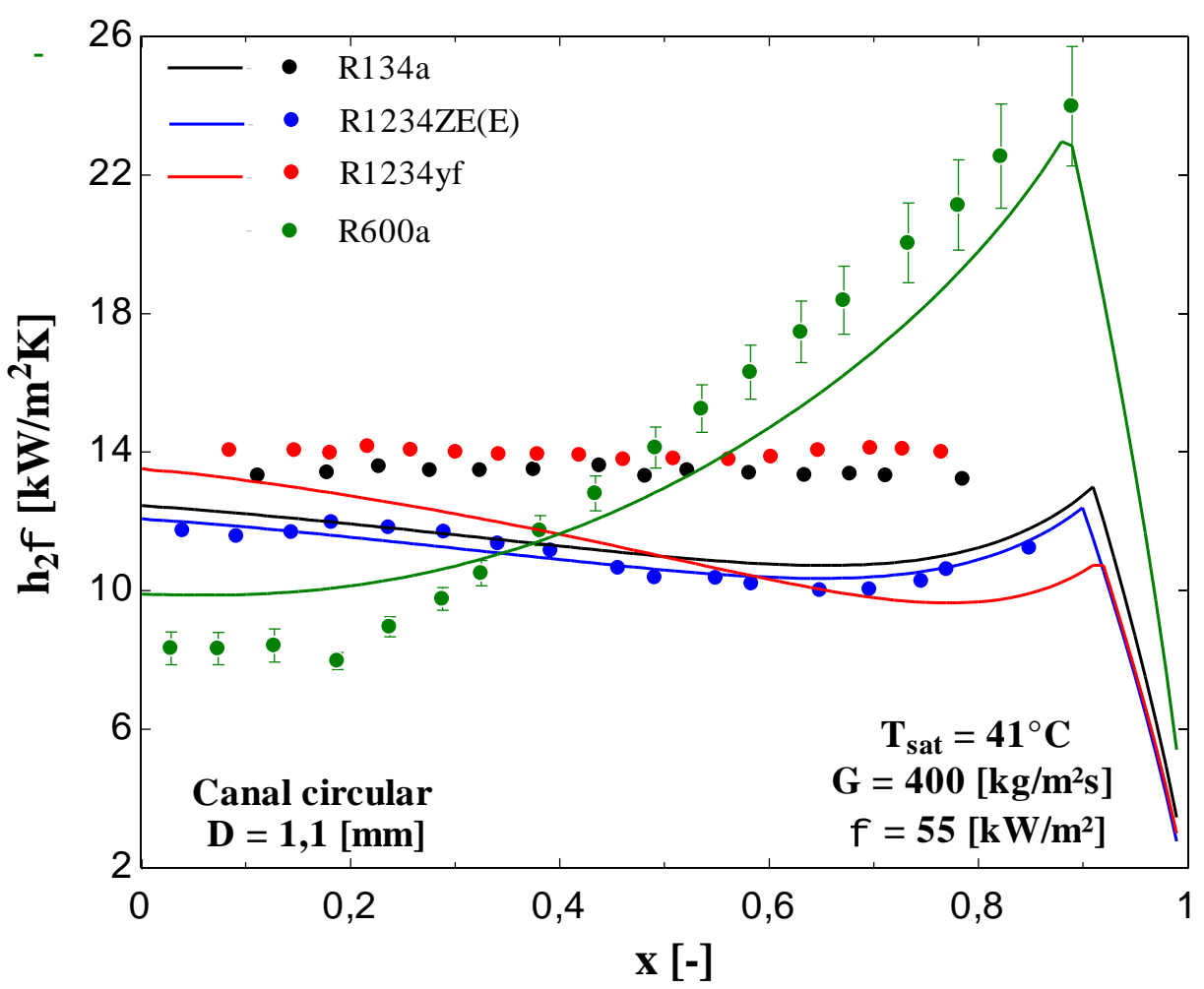

Figura 7.35. Comparação do efeito do fluido no comportamento do CTC com o acréscimo de $\mathrm{x}$ segundo o método proposto e os dados experimentais, $\mathrm{T}_{\mathrm{sat}}=41^{\circ} \mathrm{C}$.

\subsubsection{Comparação do método proposto com dados independentes da literatura}

Neste item, estimativas a partir do método proposto são comparadas com dados independentes coletados na literatura. Vale mencionar que não se verificou na bibliografia analisada dados para o R1234ze(E) em canais únicos de diâmetro reduzido, conforme já destacado no Item 4.3.

A Tabela 7.5 ilustra o erro absoluto médio e a parcela de dados prevista com desvios entre $\pm 30 \%$. O método proposto fornece previsões satisfatórias para os bancos de dados de Tibiriçá e Ribatski (2010), Anwar et al. (2015) e os dados para o fluido R134a de Kanizawa et al. (2016). No entanto, falha na previsão dos bancos de dados de Li et al. (2012), Del Col et al. (2013), Copetti et al. (2013) e Choi et al. (2014). Especula-se que o motivo pelo qual o método não prevê satisfatoriamente os dados para o propano de Choi et al. (2014) e para o isobutano de Copetti et al. (2013) é o comportamento pouco comum do CTC reportado por estes autores, segundo os quais o CTC decresce a partir de títulos de vapor entre 0,3 e 0,4 , como destacado no Item 4.4 . 
Tabela 7.4. Parâmetros estatísticos resultantes da comparação do método desenvolvido e dados independentes levantados na literatura.

\begin{tabular}{c|c|c|c|cc}
\hline Autor(es) & Fluido & D[mm] & \#Dados & EMA & $\boldsymbol{\eta}_{\mathbf{3 0} \%}$ \\
\hline $\begin{array}{c}\text { Tibiriça e Ribatski } \\
\text { (2010) }\end{array}$ & R134a & 2,32 & 1334 & $\mathbf{1 6 , 0 \%}$ & $\mathbf{8 9 , 6 \%}$ \\
Li et al. (2012) & R1234fa & 2,32 & 322 & $22,9 \%$ & $72,7 \%$ \\
& R32 & 2 & 72 & $31,7 \%$ & $60,0 \%$ \\
Del Col et al. (2013) & R1234yf & 0,96 & 116 & $44,1 \%$ & $0,0 \%$ \\
Copetti et al. (2013) & R600a & 2,6 & 63 & $27,6 \%$ & $58,7 \%$ \\
& R290 & 1,$5 ; 3$ & 147 & $340,2 \%$ & $2,7 \%$ \\
Choi et al. (2014) & R1234yf & 1,$5 ; 3$ & 161 & $55,4 \%$ & $66,2 \%$ \\
& R1234yf & 1,6 & 200 & $23,1 \%$ & $\mathbf{8 9 , 5 \%}$ \\
Anwar et al. (2015) & R134a & 0,38 & 23 & $\mathbf{1 1 , 9 \%}$ & $\mathbf{9 1 , 3 \%}$ \\
\hline Kanizawa et al. (2016) & R245fa & 0,38 & 25 & $35,4 \%$ & $64,0 \%$ \\
\hline
\end{tabular}

*Números em negrito indicam um EMA inferior a $20 \%$ e $\eta_{30 \%}$ superior a $80 \%$.

A Figura 7.39 ilustra a comparação do efeito do diâmetro no comportamento do coeficiente de transferência de calor com o acréscimo do título de vapor segundo o método proposto e dados experimentais do presente estudo para diâmetro $1,1 \mathrm{~mm}$, os dados de Tibiriçá e Ribatski (2010) e Kanizawa et al. (2016) para os diâmetros de 2,32 e $0,38 \mathrm{~mm}$, respectivamente.

Como observado na figura, o coeficiente de transferência de calor previsto pelo método proposto se eleva com o decréscimo do diâmetro do canal. Este comportamento coincide ao observado na maioria dos estudos experimentais para microcanais, conforme destacado por Ribatski (2013). Por outro lado, apesar dos dados para diâmetros de 0,38 e 2,32 mm não terem sido incorporados ao banco de dados do presente estudo para o ajuste dos coeficientes empíricos, o método proposto captura qualitativamente o comportamento destes resutlados experimentais. 

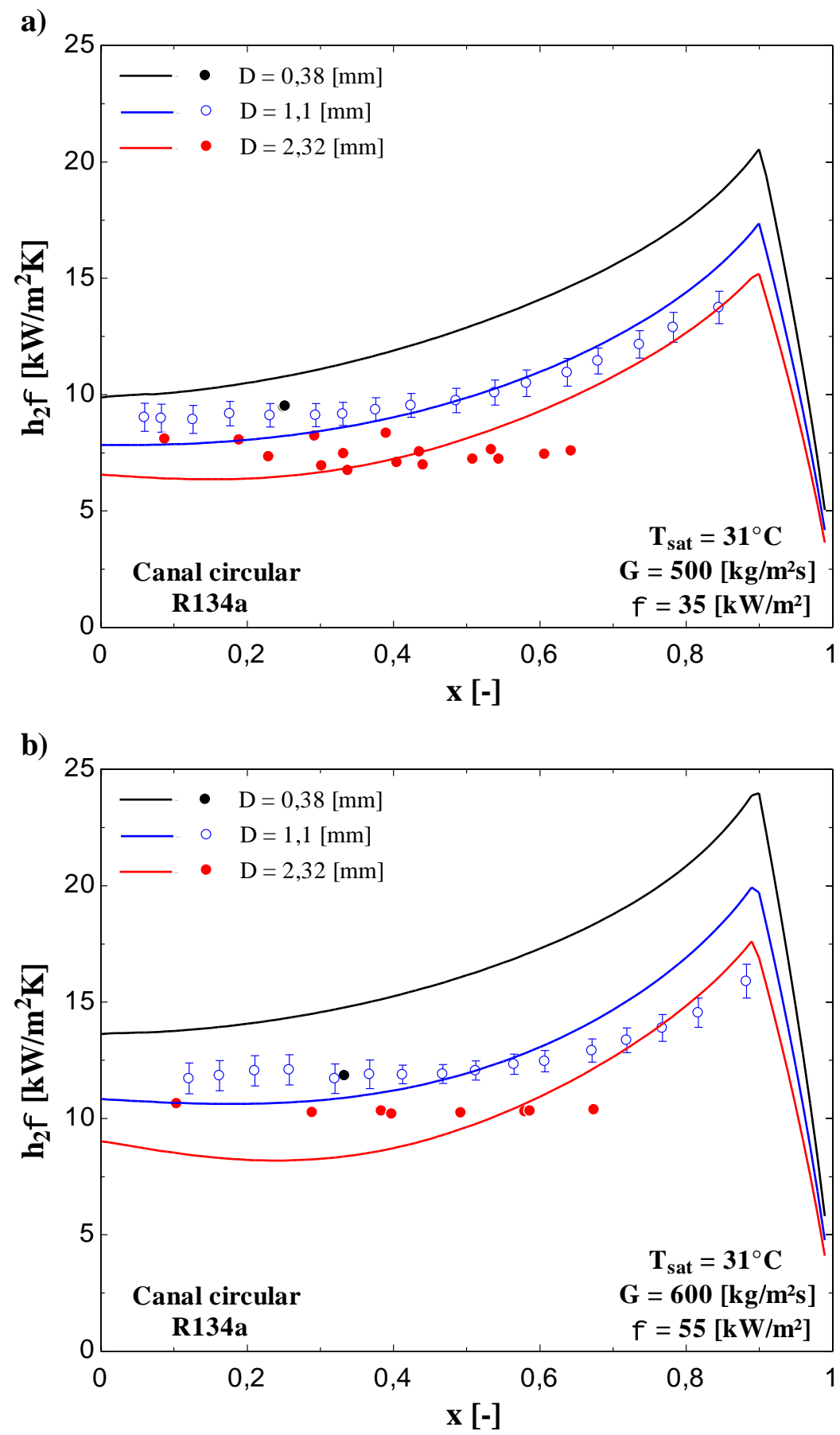

Figura 7.36. Comparação do efeito do diametro no comportamento do CTC com o acréscimo de $x$ segundo o método proposto e dados experimentais do presente estudo, de Tibiriçá e Ribatski (2010) e Kanizawa et al. (2016).

\subsection{Análise global do efeito da geometria}

A avaliação adequada do efeito da geometria do canal em termos de aplicações em trocadores e dissipadores de calor deve incorporar além do coeficiente de transferência de calor, e a potência de bombeamento, um índice de empacotamento de 
canais, relacionando a área efetiva de contato do fluido refrigerante com a superfície aquecida e o volume do dispositivo. Neste estudo tal avaliação se dá a partir da razão entre o calor dissipado por unidade de potência de bombeamento para canais nãocirculares e circular, segundo a seguinte equação:

$$
\xi_{\text {geometria }}=\frac{Q_{\text {diss,n-circ }} / P_{\text {bomb,n-circ }}}{Q_{\text {diss,circ }} / P_{\text {bomb,circ }}}
$$

No presente estudo manteve-se o perímetro dos canais aproximadamente constantes através do processo de conformação das seções de testes não-circulares, a partir de tubos com dimensões similares. Desta forma, mantem-se a área de transferência de calor para as geometrias avaliadas. Neste contexto, a Figura 7.37 ilustra esquematicamente possíveis distribuições de canais. Nela constata-se que a configuração triangular proporcionou uma área de contato entre o fluido e a superfície superior às demais configurações contando com 19 canais, enquanto as geometrias circular e quadrada com 11 e 14 canais, respectivamente. Na elaboração destas figuras adotou-se uma distancia entre canais de $200 \mu \mathrm{m}$, correspondendo a uma eficiência de aleta aproximada para o caso crítico correspondendo a seção triangular de $80 \%$.

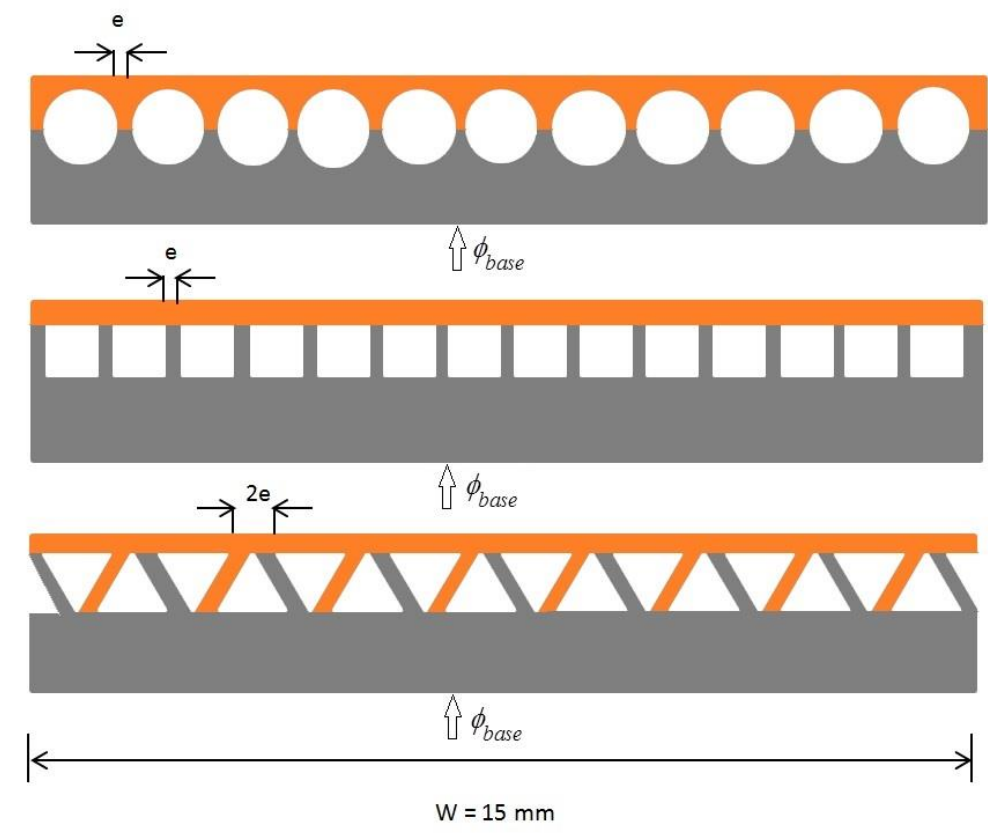

Figura 7.37. Configuração geometrica dos microtrocadores para seçoes circular, quadrada e triangular. 
Para avaliar o parâmetro global de desempenho definido através da Eq. 7.4, considerando dissipadores com as geometrias ilustras na Figura 7.37, efetuou-se um processo iterativo baseado na média aritmética dos coeficientes locais considerando 10 elementos discretos ao longo do comprimento do dissipador. Neste procedimento os valores do coeficiente de calor locais são estimados através do método de previsão proposto na anterior seção. Assim, o calor dissipado total, é dado por:

$$
Q_{\text {diss }}=\bar{h} \cdot A_{\text {troca, }, \text { total }} \cdot\left(\bar{T}_{p}-\bar{T}_{\text {sat }}\right)
$$

A potência de bombeamento na Eq. 7.4 é calculada através do produto entre a perda de pressão bifásica e o fluxo volumétrico do líquido subresfriado na entrada do dissipador segundo a seguinte equação:

$$
P_{b o m b}=\Delta p_{2 \phi} \cdot \frac{\dot{m}}{\rho_{\text {sub }}}
$$

onde a perda de pressão bifásica é estimado através de um processo iterativo considerando a soma da perda de pressão em 10 elementos discretos compreendendo ao dissipador de calor. A perda de pressão por atrito correspondente a cada elemento foi calculada segundo o método de previsão desenvolvido no presente estudo, cuja descrição encontra-se no Capitulo 6. A estimativa da componente da perda de pressão aceleracional para cada elemento se deu através da Eq. 5.24, com a fração de vazio superficial segundo o modelo de Kanizawa e Ribatski (2015). Nessa simulações adotou-se um título de vapor de entrada de 0,2, considerando-se restrições na entrada de cada canal conforme sugerido por Szczukiewicz (2012) para minimizar efeitos de propagação de instabilidades térmicas.

A Figura 7.38 ilustra valores do fator de desempenho da geometria da seção transversal para duas condições experimentais mantendo a vazão mássica total, o título de vapor na entrada e a temperatura de saturação constantes. O fator de desempenho foi avaliado para vazões mássicas intermediárias e elevadas e temperaturas de saturação de 31 e $41^{\circ} \mathrm{C}$. Segundo esta figura, o desempenho do dissipador de calor segundo o parâmetro global definida através da Eq. 7.4 para os canais com os canais triangulares é entre 20 a 40\% superior ao dissipador de calor baseado em canais circulares. Observa-se também que para uma vazão mássica intermediária e temperatura de saturação de $41^{\circ} \mathrm{C}$, o desempenho do dissipador de calor baseado em canais triangulares se eleva com o acréscimo de $\Delta T$ até $3,5^{\circ} \mathrm{C}$, posteriormente, este decresce com acréscimos adicionais de 
$\Delta T$. Já, para vazões mássicas superiores e a mesma temperatura de saturação, o desempenho se eleva até superaquecimentos ainda superiores. Constata-se também que o desempenho dos dissipadores de calor baseados em canais triangulares apresenta desempenho superior para temperatura de saturação de $41^{\circ} \mathrm{C}$ até um $\Delta T$ de $5,5^{\circ} \mathrm{C}$, a partir do qual, o desempenho para temperatura de saturação de $31^{\circ} \mathrm{C}$ torna-se superior. $\mathrm{O}$ dissipador de calor com canais quadrados apresenta desempenho entre 5 e $12 \%$ superior em relação ao com canais circulares, independentemente da condição experimental. $\mathrm{O}$ desempenho do dissipador de calor contendo canais com seção transversal quadrada varia apenas marginalmente com o aumento da velocidade mássica ou da temperatura de saturação.

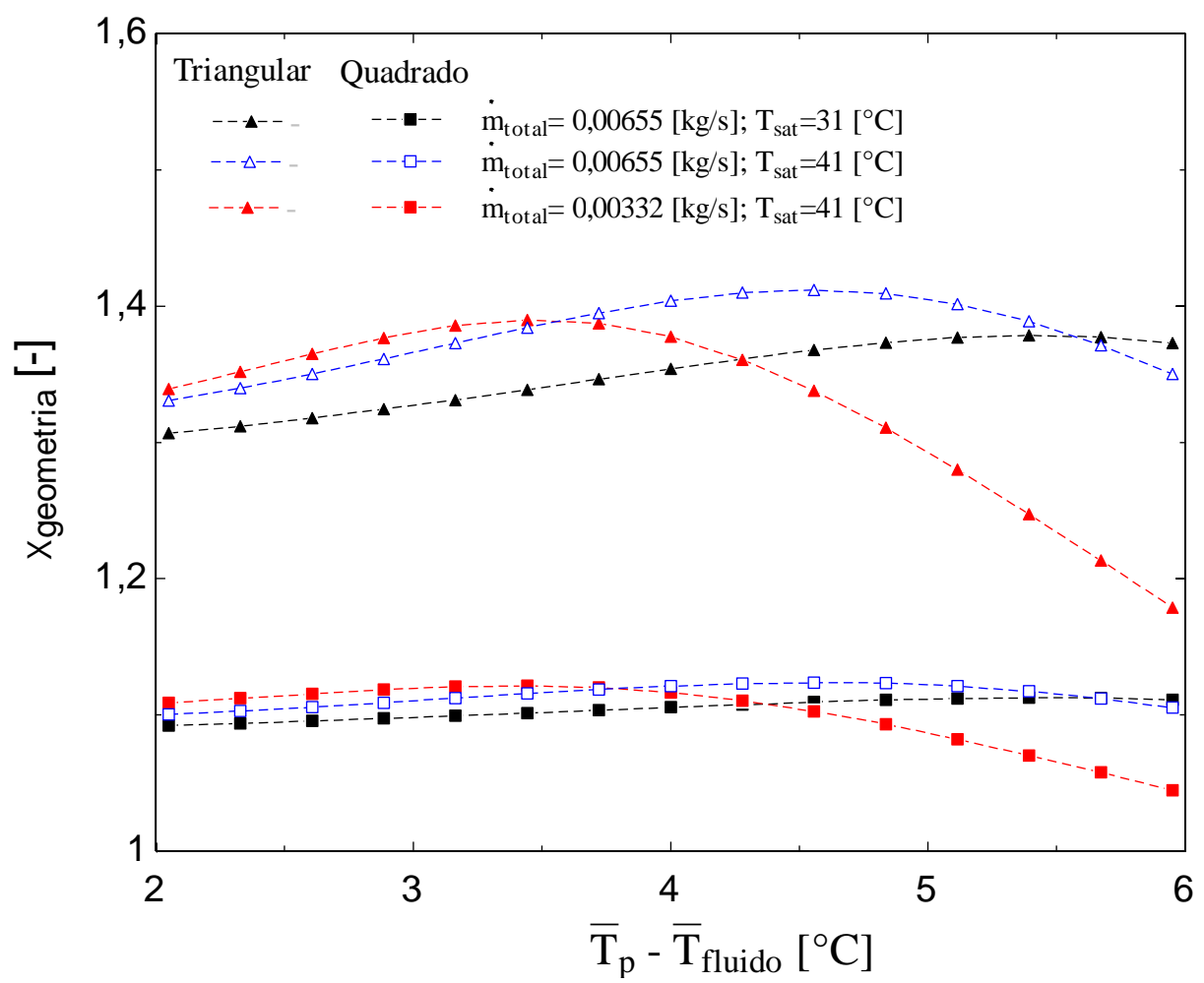

Figura 7.38. Fator de desempenho para as geometria de seção transversal avaliadas neste estudo, considerando as configuraçoes ilustradas na Figura 7.37.

A Tabela 7.5 ilustra os demais parâmetros calculados para as simulações ilustradas na Figura 7.38 considerando uma condição operacional específica. Nesta tabela, constatase que o dissipador de calor baseado em canais triangulares apresenta fluxo de calor na base (footprint) e coeficiente de transferência de calor médio superiores aos dissipadores baseados em canais circulares e quadrados. Desta forma, dissipa uma potência de 34,47 W, cerca de $80 \%$ superior ao calor dissipado pela configuração com canais circulares. 
Observa-se também que a potência de bombeamento para o dissipador com canais triangulares é cerca de $30 \%$ superior à potência do dissipador baseado em canais circulares. Isto resulta em um desempenho global para a geometria triangular $35 \%$ superior ao desempenho da geometria circular. Por outro lado, o dissipador de calor baseado em canais quadrados apresenta um desempenho de apenas $11 \%$ superior à geometria circular, segundo o parâmetro definido pela Eq. 7.4.

Tabela 7.5. Valores do calor dissipado e da potência de bombeamento para os disspadores de calor nãocirculares comparados ao circular, $x_{i n}=0,20, \Delta T=4^{\circ} \mathrm{C}, m_{\text {total }}=0,00655 \mathrm{~kg} / \mathrm{s}$

\begin{tabular}{c|c|c|c}
\hline & Circular & Quadrado & Triangular \\
\hline$\dot{m}_{\text {total }}[\mathrm{kg} / \mathrm{s}]$ & 0,00655 & 0,00655 & 0,00655 \\
$G\left[\mathrm{~kg} / \mathrm{m}^{2} \mathrm{~s}\right]$ & 626,6 & 626,8 & 600 \\
$\Delta T\left[{ }^{\circ} \mathrm{C}\right]$ & 4 & 4 & 4 \\
$\mathrm{x}_{\text {in }}[-]$ & 0,2 & 0,2 & 0,2 \\
$\mathrm{x}_{\text {out }}[-]$ & 0,216 & 0,222 & 0,231 \\
$\phi\left[\mathrm{kW} / \mathrm{m}^{2}\right]$ & 31,83 & 33,6 & 35 \\
$\phi_{\text {footprint }}\left[\mathrm{kW} / \mathrm{m}^{2}\right]$ & 80,66 & 108,3 & 153,2 \\
$\bar{h}\left[\mathrm{~kW} / \mathrm{m}^{2} .{ }^{\circ} \mathrm{C}\right]$ & 7,982 & 8,424 & 8,78 \\
$Q_{\text {diss }}[\mathrm{W}]$ & 18,15 & 24,38 & 34,47 \\
$d p[\mathrm{~Pa}]$ & 756 & 918,5 & 1061 \\
$\rho_{\text {sub }}\left[\mathrm{kg} / \mathrm{m}^{3}\right]$ & 1227 & 1227 & 1227 \\
$\mathrm{P}_{\text {bomb }}[\mathrm{W}]$ & 0,004165 & 0,004905 & 0,005665 \\
$\xi[-]$ & 1 & 1,105 & 1,35 \\
\hline
\end{tabular}





\section{CAPÍTULO 8 - CONCLUSÕES E RECOMENDAÇÕES}

O presente trabalho trata de um estudo teórico-experimental sobre a perda de pressão e o coeficiente de transferência de calor durante a ebulição convectiva no interior de canais únicos de dimensões reduzidas. Este estudo envolveu ampla revisão da literatura e o levantamento experimental de um banco de dados extenso. Com base nos resultados obtidos, métodos de previsão da perda de pressão por atrito e do coeficiente de transferência de calor foram propostos. A partir deste estudo realizado, o presente capítulo apresenta as conclusões e recomendações para trabalhos futuros.

\subsection{Conclusões}

A partir do presente estudo as seguintes conclusões são apresentadas:

Concluiu-se que o diâmetro hidráulico é amplamente adotado como dimensão característica pelos estudos da literatura para escoamentos turbulentos monofásicos. No entanto, verificou-se que as correlações para perda de pressão e coeficiente de transferência de calor monofásico, propostas com base em resultados para canais circulares, preveem adequadamente os resultados experimentais levantados no presente estudo quando adota-se o diâmetro equivalente como dimensão característica;

A partir da análise paramétrica dos resultados experimentais, concluiu-se que o gradiente de perda de pressão por atrito do R600a é superior aos demais fluidos ensaiados. Além disso, verificou-se que o gradiente de perda de pressão do R1234ze(E) é superior ao R134a e R1234yf, fluidos que apresentam gradientes da perda de pressão próximos para títulos de vapor reduzidos e intermediários;

O gradiente da perda de pressão por atrito se eleva com o acréscimo da velocidade mássica e com a redução da temperatura de saturação. O gradiente da perda de pressão apresenta um pico em títulos de vapor elevados, o qual passa a ocorrer para títulos de vapor inferiores com o incremento da velocidade mássica para as geometrias circular e quadrada; 
Para condições experimentais similares constatou-se gradientes da perda de pressão superiores para a geometria triangular quando comparado aos canais quadrado e circular. De uma forma geral, para uma mesma condição experimental, a razão entre a perda de pressão para canais não-circulares e circulares decresce com o aumento da velocidade mássica, exceto para uma faixa reduzida de títulos de vapor próximas ao pico do gradiente da perda de pressão;

No geral, os métodos de previsão de Del Col et al. (2013), MüllerSteinhagen e Heck (1986), Friedel (1979), Sun e Mishima (2009b) e Kim e Mudawar (2012) proporcionam previsões estatisticamente satisfatórias dos resultados de perda de pressão. No entanto, estes métodos falham na previsão das tendências com a variação do título de vapor para determinadas condições de fluido e geometria;

Um novo método de previsão baseado em Müller-Steinhagen e Heck (1986) foi desenvolvido neste estudo. O método proposto adota o diâmetro equivalente como a dimensão característica de canais não-circulares e proporciona previsões satisfatórias do banco de dados usado no seu desenvolvimento, prevendo $97,1 \%$ e $89,2 \%$ dos dados experimentais dentro de uma margem de erro de \pm 30 e $\pm 20 \%$, respectivamente. Além disso, o método proposto captura adequadamente as tendências dos dados experimentais;

$>\mathrm{O}$ método proposto também prevê satisfatoriamente resultados da literatura de Ducoulombier et al. (2011), Del Col et al. (2015) e Del Col et al. (2014) para os fluidos $\mathrm{CO}_{2}$, R1234ze(E) e propano, respectivamente;

Com base no extenso banco de dados para o coeficiente de transferência de calor levantado neste estudo, verificou-se que o coeficiente de transferência de calor se eleva com o acréscimo do fluxo de calor em condições em que predominam efeitos de ebulição nucleada, correspondendo a títulos de vapor reduzidos e intermediários. Já, para títulos de vapor elevados, condição em que predominam os efeitos convectivos, o coeficiente de transferência de calor torna-se independente do fluxo de calor. Notou-se também que o coeficiente de transferência de calor se eleva com o acréscimo da velocidade mássica para títulos de vapor em que predominam os efeitos convectivos., com este efeito tornando-se 
desprezível para títulos de vapor correspondentes à predominância de efeitos de ebulição nucleada;

Para os fluidos R134a, R1234ze(E) e R1234yf, o coeficiente de transferência de calor se eleva com o acréscimo da temperatura de saturação. Já para o R600a, o coeficiente de transferência e calor se eleva com o acréscimo da temperatura de saturação para condições de títulos de vapor reduzido e decresce para títulos de vapor elevados. O coeficiente de transferência de calor do R134a e do R1234yf apresentam resultados próximos e tendências similares. Para títulos de vapor reduzidos, o valor do coeficiente de transferência de calor do R1234ze(E) apresenta valores inferiores aos do R134a, comportamento que se acentua com o acréscimo do fluxo de calor;

Observou-se coeficientes de transferência de calor para o R600a inferiores aos refrigerantes R134a, R1234ze(E) e R1234yf para títulos de vapor inferiores a 0,2. Entretanto, o CTC para o R600a se eleva drasticamente com o incremento do título de vapor alcançando valores de até $120 \%$ superiores aos demais fluidos para títulos de vapor superiores a 0,8. Tal comportamento está relacionado à predominância de efeitos convectivos para o R600a, pois seu volume específico da fase vapor é no mínimo 4 vezes superior aos demais refrigerantes;

$>$ Os comportamentos observados para o coeficiente de transferência de calor para o canal triangular sugerem a predominância de efeitos de ebulição nucleada, independentemente do fluxo de calor. Especula-se que este fato está relacionado à elevada rugosidade superficial do canal triangular $(1,78 \mu \mathrm{m})$;

$>$ Para fluxos de calor reduzidos, verificou-se coeficientes de transferência de calor para canais circulares superiores. Por outro lado, para fluxos de calor elevados, o CTC em canais triangulares é superior ao coeficiente de transferência de calor para canais circulares e quadrados para títulos de vapor reduzidos e intermediários;

A partir da análise do parâmetro global do efeito da geometria, baseado na razão entre o calor dissipado $(\bar{h} \cdot A \cdot \Delta T)$ e a potência de bombeamento ( $\left.\Delta p \cdot \dot{m} / \rho_{\text {sub }}\right)$, concluiu-se que dissipadores de calor com canais de seção 
transversal triangular apresentam desempenho superior as configurações contendo canais circulares e quadrados. Já o canal com geometria de seção quadrada, embora com desempenho inferior ao triangular, apresenta um parâmetro global de eficiência 20\% superior a geometria circular;

Os métodos de Kanizawa et al. (2016), Kim e Mudawar (2013a) forneceram as melhores previsões dos resultados levantados no presente estudo. Kew e Cornwell (1997) e Sun e Mishima (2009a) também proporcionaram previsões razoáveis do banco de dados. Nenhum dos métodos analisados proporciona resultados satisfatórios para o isobutano, já que não capturam o grau de intensificação de efeitos convectivos observada para este fluido para a maioria de condições experimentais;

$>$ De uma forma geral, os métodos de Kim e Mudawar (2013a) e Kanizawa et al. (2016), proporcionam valores de $\eta_{30 \%}$ satisfatórios referente a previsão do coeficiente de transferência de calor dos fluidos R134a, R1234ze(E) e R1234yf. Entretanto, estes métodos apenas capturam satisfatoriamente as tendências do CTC com o acréscimo do título de vapor para títulos de vapor reduzidos e intermediários;

$>$ Nenhum dos métodos captura adequadamente a predominância dos efeitos de ebulição nucleada nos resultados experimentais para canais triangulares. Comportamento que supõe-se decorrente do aprisionamento de líquido superaquecido nos cantos e de sua elevada rugosidade superficial;

$>$ Propõe-se um novo método de previsão para o CTC para canais circulares e quadrados baseado em Kanizawa et al. (2016) foi proposto. Este novo método proporciona predições satisfatórias do banco de dados usado no seu desenvolvimento, prevendo $97,5 \%$ e $85,3 \%$ dos dados dentro de uma margem de erro de \pm 30 e $\pm 20 \%$, respectivamente. Além disso, o método proposto captura adequadamente as tendências dos dados experimentais;

$>$ Para a previsão do coeficiente de calor em canais triangulares, recomendase o método de Kanizawa et al. (2016) já que este método proporcionou, segundo os parâmetros estatísticos o em sua análise, resultados satisfatórios;

O método proposto neste estudo também prevê satisfatoriamente resultados independentes da literatura de Tibiriçá e Ribatski (2010), para 
o R134a e R245fa com diâmetro 2,32 mm, Li et al. ((2012) para o R1234yf e diâmetro de 2 mm, Anwar et al. (2015) para R1234yf e diâmetro 1,6 mm e Kanizawa e Ribatski (2016) para R134a e R245fa e diâmetro de 0,38 $\mathrm{mm}$.

\subsection{Recomendações para trabalhos futuros}

O presente estudo envolveu uma análise ampla da perda de pressão e o coeficiente de transferência de calor em um canal de diâmetro reduzido. Entretanto, diversos temas não explorados, ou não aprofundados, podem ser considerados para trabalhos futuros, entre os quais se destacam:

Realização de ensaios para perda de pressão e coeficiente de transferência de calor em canais únicos para os fluidos propano (R290) e propileno (R1270). Resultados para estes fluidos ampliariam as faixas de condições experimentais dos bancos de dados analisados neste estudo ao incluírem refrigerantes naturais com elevado potencial de aplicaçao;

Realização de ensaios para ebulição convectiva para diversos diâmetros do canal, especialmente dimensões inferiores a $1 \mathrm{~mm}$, já que dissipadores de calor baseados em multimicrocanais apresentam diâmetros hidráulicos inferiores $500 \mu \mathrm{m}$;

$>$ Realização de ensaios para novas geometrias de canais (retangulares com diversos fatores de forma, triangulares, semicirculares e trapezoidais), pois estas são outras configurações de seções transversais verificadas em dissipadores de calor baseadas em microcanais;

Investigação do título de secagem de parede e sua dependência com o fluxo de calor, velocidade mássica e temperatura de saturação, já que estes dados experimentais não se verificam na literatura;

Experimentos com visualização do padrão de escoamento e efeitos dos cantos no aprisionamento de líquido, especialmente para canais com seção transversal triangular. Estas visualizações devem ser realizadas preferencialmente para condições diabáticas, de forma a possibilitar a investigação dos mecanismos durante o processo de mudança de fase em um dissipador de calor; 
Estudos sobre o efeito da rugosidade superficial do canal no coeficiente de transferência de calor bifásico durante a ebulição convectiva, pois, embora tema relevante, pouca atenção foi dada a ele;

Resultados experimentais para a fração de vazio em canais de reduzida dimensão são raros na literatura, portanto, recomenda-se o levantamento de dados experimentais para a fração de vazio em canais de diâmetro reduzido com o intuito de desenvolver um método de previsão que proporcione resultados satisfatórios para condições experimentais mais abrangentes. 


\section{REFERÊNCIAS}

ABDELALL, F. F. et al. (2005). Pressure drop caused by abrupt flow area changes in small channels. Experimental Thermal and Fluid Science, v. 29, n. 4, p. 425-434.

ABERNETHY, R. B. et al. (1973). Handbook uncertainty in gas turbine measurements. Arnold Eng ed. [s.n.]Tennessee.

AHMED, S.; BRUNDRETT, E. (1971). Characteristic lenght for non-circular ducts. Int. J. Heat Mass Transfer, v. 14, p. 157-159.

ALTEMANI, C. A. C.; SPARROW, E. M. (1980). Turbulent Heat Transfer and Fluid Flow in an Unsymmetrically Heated Triangular Duct. Journal of Heat Transfer, v. 102, n. 4, p. 590-597.

ANWAR, Z.; PALM, B.; KHODABANDEH, R. (2015). Flow boiling heat transfer, pressure drop and dryout characteristics of R1234yf: Experimental results and predictions. Experimental Thermal and Fluid Science, v. 66, p. 137-149.

AWAD, M. M.; MUZYCHKA, Y. S. (2010). Two-Phase Flow Modeling in Microchannels and Minichannels. Heat Transfer Engineering, v. 31, n. 13, p. 10231033.

BAHRAMI, M.; YOVANOVICH, M. M.; CULHAM, J. R. (2006). Pressure Drop of Fully-Developed, Laminar Flow in Microchannels of Arbitrary Cross-Section. Journal of Fluids Engineering, v. 128, n. 5, p. 1036.

BANDOPADHAYAY, P. C.; AMBROSE, C. W. (1980). A generalised lenght dimension for non-circular ducts. Letters in Heat and Mass Transfer, v. 7, p. 323-328.

BARBIERI, P. E. L. (2005). Estudo teorico-experimental da ebulicao convectiva do refrigerante R134a em tubos lisos. Tese Doutorado, Universidade de Sao Paulo, Sao Carlos. .

BAROCZY, C. J. (1966). A systematic correlation for two-phase pressure drop. Chem. Engng. Prog. Symp. Ser., v. 62, n. 44, p. 232-249.

BASU, S. et al. (2011). Flow Boiling of R134a in Circular Microtubes-Part I: Study of Heat Transfer Characteristics. Journal of Heat Transfer, v. 133, n. 51502, p. 1-9.

BEATTIE, D.R.H., WHALLEY, P. B. (1982). A simple two-phase frictional pressure drop calculation method. International Journal of Multiphase Flow, v. 8, n. 1, p. 8387.

BERTSCH, S. S.; GROLL, E. A.; GARIMELLA, S. V. (2009). A composite heat transfer correlation for saturated flow boiling in small channels. International Journal of Heat and Mass Transfer, v. 52, n. 7-8, p. 2110-2118.

BLASIUS, H. (1913). Das ahnlichkeitsgesetz bei reibungsvorg/ingen in fltissigkeiten. Forschg. Arb. Ing. Wes., v. 131. 
CALM, J. M. (2008). The next generation of refrigerants - Historical review, considerations, and outlook. International Journal of Refrigeration, v. 31, n. 7, p. $1123-1133$.

CAVALLINI, A. et al. (2009). Frictional pressure drop during vapour-liquid flow in minichannels: Modelling and experimental evaluation. International Journal of Heat and Fluid Flow, v. 30, n. 1, p. 131-139.

CHALFI, T. Y.; GHIAASIAAN, S. M. (2008). Pressure drop caused by flow area changes in capillaries under low flow conditions. International Journal of Multiphase Flow, v. 34, n. 1, p. 2-12.

CHANDRUPATLA, A. R.; SASTRI, V. M. K. (1977). Laminar forced convection heat transfer of a non-newtonian fluid in a square duct. International Journal of Heat and Mass Transfer, v. 20, n. 12, p. 1315-1324.

CHEN, I. Y. et al. (2007). Two-phase frictional pressure drop in small rectangular channels. Experimental Thermal and Fluid Science, v. 32, n. 1, p. 60-66.

CHEN, I. Y. et al. (2010). Two-Phase Flow Across Small Sudden Expansions and Contractions. Heat Transfer Engineering, v. 31, n. 4, p. 298-309.

CHEN, J. C. (1966). Correlation for boiling heat transfer to saturated fluids in convective flow. Industrial \& Engineering Chemistry Process Design and Development, v. 5, n. 3, p. 322-329.

CHISHOLM, D. et al. (1967). LOCKHART-MARTINELLI BASIS FOR THE CORRELATION FLOW FOR TWO-PHASE. v. 10, n. 18, p. 1767-1778.

CHISHOLM, D. (1973). Pressure gradients due to friction during the flow of evaporating two-phase mixtures in smooth tubes and channels. International Journal of Heat and Mass Transfer, v. 16, n. 2, p. 347-358.

CHOI, K. et al. (2014). Comparison of heat transfer coefficient during evaporation of natural refrigerants and R-1234yf in horizontal small tube. International Journal of Refrigeration, v. 41, p. 210-218.

CHOW, V. TE. (1959). Open-channel hydraulics.

CICCHITTI, A.; LOMBARDI, C.; SILVESTRI, M. (1960). Two-phase cooling experiments: pressure drop, heat transfer and burnout measurements. Energia Nucleare, v. 7 , p. $417-425$.

CIONCOLINI, A.; THOME, J. R. (2011). Algebraic turbulence modeling in adiabatic and evaporating annular two-phase flow. International Journal of Heat and Fluid Flow, v. 32, n. 4, p. 805-817.

CIONCOLINI, A.; THOME, J. R.; LOMBARDI, C. (2009). Unified macro-to-microscale method to predict two-phase frictional pressure drops of annular flows. International Journal of Multiphase Flow, v. 35, n. 12, p. 1138-1148.

CLAIBORNE, H. C. (1952). A critical review of the literature on pressure drop in noncircular ducts and annuli. Technical Information Service, Oak Ridge National 
Laboratory. Oak Ridge, Tennessee. Disponível em: $\langle$ https://books.google.com.br/books?id=9DpYAAAAYAAJ $>$.

COLLIER, J. G.; THOME, J. R. (1996). Convective boiling and condensation. [s.n.]New York.

CONSOLINI, L. et al. (2007). Heat Transfer in Confined Forced-Flow Boiling. Heat Transfer Engineering, v. 28, n. 10, p. 826-833.

COOPER, M. G. (1984). Heat Flow Rates in Saturated Nucleate Pool Boiling-A WideRanging Examination Using Reduced Properties. In: TRANSFER, J. P. H. AND T. F. I. B. T.-A. IN H. (Ed.). . Elsevier. . v. Volume 16p. 157-239.

COPETTI, J. B.; MACAGNAN, M. H.; ZINANI, F. (2013). Experimental study on R600a boiling in $2.6 \mathrm{~mm}$ tube. International Journal of Refrigeration, v. 36, n. 2, p. 325334.

COSTA-PATRY, E.; OLIVIER, J.; THOME, J. R. (2012). MICRO-EVAPORATOR AND FLOW PATTERN-BASED PREDICTION METHOD FOR FLOW BOILING IN. v. 013002.

DA RIVA, E. et al. (2012). The importance of turbulence during condensation in a horizontal circular minichannel. International Journal of Heat and Mass Transfer, $v$. 55 , n. $13-14$, p. 3470-3481.

DA SILVA, J. D. (2012). Estudo teorico-experimental da perda de pressao durante a ebulicao convectiva de refrigerantes halogenados no interior de microcanais circulares. Tese (Mestrado) - Universidade de Sao Paulo. .

DA SILVA, J. D.; RIBATSKI, G. (2013). Two-phase frictional pressure drop of halocarbon refrigerants inside small diameter tubes: data analysis and the proposition of a new frictional pressure drop correlation. In: $8 \mathrm{TH}$ INTERNATIONAL CONFERENCE ON MULTIPHASE FLOW. Proceedings... JejuKorea.

DEL COL, D. et al. (2013). Experiments and updated model for two phase frictional pressure drop inside minichannels. International Journal of Heat and Mass Transfer, v. 67 , p. $326-337$.

DEL COL, D. et al. (2015). Condensation heat transfer and two-phase frictional pressure drop in a single minichannel with $\mathrm{R} 1234 \mathrm{ze}(\mathrm{E})$ and other refrigerants. International Journal of Refrigeration, v. 50, n. 842, p. 87-103.

DEL COL, D.; BORTOLATO, M.; BORTOLIN, S. (2014). Comprehensive experimental investigation of two-phase heat transfer and pressure drop with propane in a minichannel. International Journal of Refrigeration, v. 47, p. 66-84.

DÍAZ, M. C.; SCHMIDT, J. (2007). Experimental investigation of transient boiling heat transfer in microchannels. International Journal of Heat and Fluid Flow, v. 28, n. 1, p. $95-102$.

DUAN, Z.; YOVANOVICH, M. M.; MUZYCHKA, Y. S. (2012). Pressure Drop for Fully Developed Turbulent Flow in Circular and Noncircular Ducts. Journal of Fluids 
Engineering, v. 134, n. 6, p. 061201.

DUCOULOMBIER, M. et al. (2011). Carbon dioxide flow boiling in a single microchannel - Part I: Pressure drops. Experimental Thermal and Fluid Science, v. 35, n. 4, p. 581-596.

DUKLER, A. E.; WICKS, M.; CLEAVELAND, R. G. (1964). Pressure drop and hold up in two-phase flow. AIChE Journal, v. 10, p. 38-51.

FELCAR, H. O. M.; RIBATSKI, G. (2008). Avaliação de métodos preditivos para perda de carga durante o escoamento bifásico e a ebulição convectiva em microcanais. In: $1^{\circ}$ ENCONTRO BRASILEIRO SOBRE EBULIÇÃO, CONDENSAÇÃO E ESCOAMENTO MULTIFÁSICO LÍQUIDO-GÁS. Proceedings... Florianópolis.

FOSTER, H. K.; ZUBER, N. (1955). Bubble dynamics and boiling heat transfer. AIChE Journal, v. 1, p. 531-535.

FRIEDEL, L. (1979). Pressure drop during gas/vapor-liquid flow pipes. International Chemical Engineering,

FU, B.-R.; LEE, C.-Y.; PAN, C. (2013). The effect of aspect ratio on flow boiling heat transfer of HFE-7100 in a microchannel heat sink. International Journal of Heat and Mass Transfer, v. 58, n. 1-2, p. 53-61.

GAN, Y.; XU, J.; YAN, Y. (2015). An experimental study of two-phase pressure drop of acetone in triangular silicon micro-channels. Applied Thermal Engineering, v. 80, p. 76-86.

GARCÍA, F. et al. (2003). Power law and composite power law friction factor correlations for laminar and turbulent gas-liquid flow in horizontal pipelines. International Journal of Multiphase Flow, v. 29, n. 10, p. 1605-1624.

GEIGER, G. E. (1964). Sudden contraction losses in single and two-phase flow. PhD Thesis, University of Pittsburg, Pittsburg, PA. .

GNIELINSKI, V. (1976). New equations for heat and mass transfer in turbulent flow in pipes and channels. Int. Chemical Engineering, p. 359-368.

GRÖNNERUD, R. (1979). Investigation of liquid hold-up, flow-resistance and heat transfer in circulation type evaporators. Part IV: Two-phase flow resistance in boiling refrigerants. Bulletin de L'institut International Du Froid - Bulletin of the International Journal of Refrigeration, v. 1972, n. 1, p. 127-138.

HARIRCHIAN, T.; GARIMELLA, S. V. (2012). Flow regime-based modeling of heat transfer and pressure drop in microchannel flow boiling. International Journal of Heat and Mass Transfer, v. 55, n. 4, p. 1246-1260.

HAUSEN, H. (1943). Darstellung des Wärmeüberganges in rohren durch verallgemeinerte potenzbeziehungen. Z. VDI. Beiheft Verfahrenstechnick, v. 4, p. 91102.

HETSRONI, G. et al. (2005). Explosive boiling of water in parallel micro-channels. International Journal of Multiphase Flow, v. 31, n. 4, p. 371-392. 
HWANG, Y. W.; KIM, M. S. (2006). The pressure drop in microtubes and the correlation development. International Journal of Heat and Mass Transfer, v. 49, n. 11-12, p. 1804-1812.

IDE, H.; FUKANO, T. (2005). Experimental research on the correlations of holdup and frictional pressure drop in air-water two-phase flow in a capillary rectangular channel. Experimental Thermal and Fluid Science, v. 29, n. 7, p. 833-841.

JONES JR., O. C. (1976). An Improvement in the Calculation of Turbulent Friction in Rectangular Ducts. Journal of Fluids Engineering,

JUNG, D. S.; RADERMACHER, R. (1989). Prediction of pressure drop during horizontal annular flow boiling of pure and mixed refrigerants. International Journal of Heat and Mass Transfer, v. 32, n. 12, p. 2435-2446.

KAEW-ON, J.; SAKAMATAPAN, K.; WONGWISES, S. (2011). Flow boiling heat transfer of R134a in the multiport minichannel heat exchangers. Experimental Thermal and Fluid Science, v. 35, n. 2, p. 364-374.

KANDLIKAR, S. G. (1990). A General Correlation for Saturated Two-Phase Flow Boiling Heat Transfer Inside Horizontal and Vertical Tubes. Journal of Heat Transfer, v. 112, n. 1, p. 219.

KANDLIKAR, S. G. (1991). A Model for Correlating Flow Boiling Heat Transfer in Augmented Tubes and Compact Evaporators. Journal of Heat Transfer, v. 113, n. November, p. 966.

KANDLIKAR, S. G.; BALASUBRAMANIAN, P. (2004). An Extension of the Flow Boiling Correlation to Transition, Laminar, and Deep Laminar Flows in Minichannels and Microchannels. Heat Transfer Engineering, v. 25, n. 3, p. 86-93.

KANDLIKAR, S. G.; STUMM, B. J. (1995). A control volume approach for investigation forces on a departing bubble under subcooled flow boiling. J. Heat transfer, v. 117, p. 990-997.

KANIZAWA, F. T.; RIBATSKI, G. (2015). A new void fraction predictive method based on the minimum energy dissipation. Journal Braz. Soc. Mech. Sci. Eng.,

KANIZAWA, F. T.; TIBIRIÇÁ, C. B.; RIBATSKI, G. (2015). Heat transfer during convective flow boiling inside micro-scale channels. International Journal of Heat and Mass Transfer, p. In Press.

KANIZAWA, F. T.; TIBIRIÇÁ, C. B.; RIBATSKI, G. (2016). Heat transfer during convective flow boiling inside micro-scale channels. International Journal of Heat and Mass Transfer, v. 93, p. 566-583.

KASZA, K. E.; DIDASCALOU, T.; WAMBSGANSS, M. W. (1997). Microscale flow visualization of nucleate boiling in small channels: mechanisms influencing heat transfer. In: CONFERENCE HEAT EXCHANGERS FOR THE PROCESS INDUSTRIES. Proceedings...

KAWAHARA, A.; CHUNG, P. M.-Y.; KAWAJI, M. (2002). Investigation of two-phase flow pattern, void fraction and pressure drop in a microchannel. International Journal 
of Multiphase Flow, v. 28, n. 9, p. 1411-1435.

KAYS, W. M. (1950). Loss Coefficients for Abrupt Changes in Flow Cross Section with Low Reynolds Number Flow in Single and Multiple Tube Systems. Stanford University. Dept. of Mechanical Engineering. Navy, United States.

KEW, P. A.; CORNWELL, K. (1997). Correlations for the prediction of boiling heat transfer in small-diameter channels. Applied Thermal Engineering, v. 17, n. 8-10, p. $705-715$.

KIM, S. M.; MUDAWAR, I. (2013a). Universal approach to predicting saturated flow boiling heat transfer in mini/micro-channels - Part II. Two-phase heat transfer coefficient. International Journal of Heat and Mass Transfer, v. 64, p. 1239-1256.

KIM, S. M.; MUDAWAR, I. (2013b). Universal approach to predicting saturated flow boiling heat transfer in mini/micro-channels - Part I. Dryout incipience quality. International Journal of Heat and Mass Transfer, v. 64, p. 1226-1238.

KIM, S.-M.; MUDAWAR, I. (2012). Universal approach to predicting two-phase frictional pressure drop for adiabatic and condensing mini/micro-channel flows. International Journal of Heat and Mass Transfer, v. 55, n. 11-12, p. 3246-3261.

KUTATELADZE, S. S. (1961). Boiling heat transfer. International Journal of Heat and Mass Transfer, v. 4, p. 31-45.

LAZAREK, G. M.; BLACK, S. H. (1982). Evaporative heat transfer, pressure drop and critical heat flux in a small vertical tube with R-113. International Journal of Heat and Mass Transfer, v. 25, n. 7, p. 945-960.

LEÃO, H. L. S. L.; DO NASCIMENTO, F. J.; RIBATSKI, G. (2014). Flow boiling heat transfer of R407C in a microchannels based heat spreader. Experimental Thermal and Fluid Science, v. 59, p. 140-151.

LEE, H. J.; LEE, S. Y. (2001a). Pressure drop correlations for two-phase flow within horizontal rectangular channels with small heights. International Journal of Multiphase Flow, v. 27, p. 783-796.

LEE, H. J.; LEE, S. Y. (2001b). Heat transfer correlation for boiling flows in small rectangular horizontal channels with low aspect ratios. International Journal of Multiphase Flow, v. 27, p. 2043-2062.

LEE, J.; MUDAWAR, I. (2005a). Two-phase flow in high-heat-flux micro-channel heat sink for refrigeration cooling applications: Part I-pressure drop characteristics. International Journal of Heat and Mass Transfer, v. 48, n. 5, p. 928-940.

LEE, J.; MUDAWAR, I. (2005b). Two-phase flow in high-heat-flux micro-channel heat sink for refrigeration cooling applications: Part II-heat transfer characteristics. International Journal of Heat and Mass Transfer, v. 48, n. 5, p. 941-955.

LI, M.; DANG, C.; HIHARA, E. (2012). Flow boiling heat transfer of HFO1234yf and R32 refrigerant mixtures in a smooth horizontal tube: Part I. Experimental investigation. International Journal of Heat and Mass Transfer, v. 55, n. 13-14, p. 3437-3446. 
LI, W.; WU, Z. (2010). A general correlation for evaporative heat transfer in micro/minichannels. International Journal of Heat and Mass Transfer, v. 53, n. 9-10, p. 17781787.

LI, W.; WU, Z. (2011). Generalized adiabatic pressure drop correlations in evaporative micro/mini-channels. Experimental Thermal and Fluid Science, v. 35, n. 6, p. 866872.

LIN, S. et al. (1991). Local frictional pressure drop during vaporization of R-12 through capillary tubes. International Journal of Multiphase Flow, v. 17, n. 1, p. 95-102.

LIU, Z.; WINTERTON, R. H. S. (1991). A general correlation for saturated and subcooled flow boiling in tubes and annuli , based on a nucleate pool boiling equation. Int. J. Heat Mass Transfer, v. 34, n. 11, p. 2759-2766.

LOCKHART, R. W.; MARTINELLI, R. C. (1949). Proposed correlation of data for isothermal two-phase two component flow in pipes. Chem. Eng. Prog., v. 45, n. 1, p. 39. LÓPEZ-BELCHÍ, A. et al. (2014). Experimental condensing two-phase frictional pressure drop inside mini-channels. Comparisons and new model development. International Journal of Heat and Mass Transfer, v. 75, p. 581-591.

MAHMOUD, M. M.; KARAYIANNIS, T. G. (2013). Heat transfer correlation for flow boiling in small to micro tubes. International Journal of Heat and Mass Transfer, $v$. 66 , p. 553-574.

MARKAL, B.; AYDIN, O.; AVCI, M. (2016a). Effect of aspect ratio on saturated flow boiling in microchannels. International Journal of Heat and Mass Transfer, v. 93, p. $130-143$.

MARKAL, B.; AYDIN, O.; AVCI, M. (2016b). An experimental investigation of saturated flow boiling heat transfer and pressure drop in square microchannels. International Journal of Refrigeration, n. 2016.

MAURO, A. W. et al. (2007). Comparison of experimental pressure drop data for two phase flows to prediction methods using a general model. International Journal of Refrigeration, v. 30, n. 8, p. 1358-1367.

MCADAMS, W. H.; WOODS, W. K.; HEROMAN, L. C. (1942). Vaporization inside horizontal tubes-II-benzene-oil mixtures. ASME Trans., v. 64, p. 193.

MISHIMA, K.; HIBIKI, T. (1996). Some characteristics of air-water two-phase flow in small diameter vertical tubes. International Journal of Multiphase Flow,

MORENO QUIBÉN, J.; THOME, J. R. (2007). Flow pattern based two-phase frictional pressure drop model for horizontal tubes, Part II: New phenomenological model. International Journal of Heat and Fluid Flow, v. 28, n. 5, p. 1060-1072.

MORTADA, S. et al. (2012). Boiling heat transfer and pressure drop of R-134a and R$1234 \mathrm{yf}$ in minichannels for low mass fluxes. International Journal of Refrigeration, $\mathrm{v}$. 35, n. 4, p. 962-973.

MOTA-BABILONI, A. et al. (2014). Drop-in energy performance evaluation of R1234yf 
and R1234ze(E) in a vapor compression system as R134a replacements. Applied Thermal Engineering, v. 71, n. 1, p. 259-265.

MÜLLER-STEINHAGEN, H.; HECK, K. (1986). A simple friction pressure drop correlation for two-phase flow in pipes. Chemical Engineering and Processing: Process Intensification, v. 20, n. 6, p. 297-308.

OH, H. K.; SON, C. H. (2011). Evaporation flow pattern and heat transfer of R-22 and R-134a in small diameter tubes. Heat and Mass Transfer/Waerme- und Stoffuebertragung, v. 47, n. 6, p. 703-717.

OH, J. T. et al. (2011). Experimental investigation on two-phase flow boiling heat transfer of five refrigerants in horizontal small tubes of $0.5,1.5$ and $3.0 \mathrm{~mm}$ inner diameters. International Journal of Heat and Mass Transfer, v. 54, n. 9-10, p. 2080-2088.

OWENS, W. L. (1961). Two-phase pressure gradient. [s.n.]New York.

PAMITRAN, A. S. et al. (2011). Evaporation heat transfer coefficient in single circular small tubes for flow natural refrigerants of $\mathrm{C} 3 \mathrm{H} 8, \mathrm{NH} 3$, and $\mathrm{CO} 2$. International Journal of Multiphase Flow, v. 37, n. 7, p. 794-801.

PAMITRAN, A. S. et al. (2010). Characteristics of two-phase flow pattern transitions and pressure drop of five refrigerants in horizontal circular small tubes. International Journal of Refrigeration, v. 33, n. 3, p. 578-588.

PETUKHOV, B. S.; POPOV, V. N. (1963). Theoretical calculation of heat exchanger in turbulent flow in tubes of an incompressible fluid with variable physical properties. High Temp., v. 1, n. 1, p. 69-83.

QU, W.; MUDAWAR, I. (2003). Measurement and prediction of pressure drop in twophase micro-channel heat sinks. International Journal of Heat and Mass Transfer, v. 46 , n. 15 , p. 2737-2753.

REVELLIN, R.; HABERSCHILL, P. (2009). Prediction of frictional pressure drop during flow boiling of refrigerants in horizontal tubes: Comparison to an experimental database. International Journal of Refrigeration, v. 32, n. 3, p. 487-497.

REVELLIN, R.; THOME, J. R. (2007). Adiabatic two-phase frictional pressure drops in microchannels. Experimental Thermal and Fluid Science, v. 31, n. 7, p. 673-685.

RIBATSKI, G. (2013). A Critical Overview on the Recent Literature Concerning Flow Boiling and Two-Phase Flows Inside Micro-Scale Channels. Experimental Heat Transfer, v. 26, n. 2-3, p. 198-246.

RIBATSKI, G.; WOJTAN, L.; THOME, J. R. (2006). An analysis of experimental data and prediction methods for two-phase frictional pressure drop and flow boiling heat transfer in micro-scale channels. Experimental Thermal and Fluid Science, v. 31, n. 1, p. 1-19.

ROHSENOW, W. N. (1952). A method of correlating heat transfer data for surface boiling liquids. Journal of Heat Transfer, p. 969-976.

ROUHANI, S. .; AXELSSON, E. (1970). Calculation of void volume fraction in the 
subcooled and quality boiling regions. International Journal of Heat and Mass Transfer, v. 13, n. 2, p. 383-393.

SAITOH, S. et al. (2011). Boiling heat transfer of HFO-1234yf flowing in a smooth small-diameter horizontal tube. International Journal of Refrigeration, v. 34, n. 8, p. 1846-1853.

SAITOH, S.; DAIGUJI, H.; HIHARA, E. (2007). Correlation for boiling heat transfer of $\mathrm{R}-134 \mathrm{a}$ in horizontal tubes including effect of tube diameter. International Journal of Heat and Mass Transfer, v. 50, n. 25-26, p. 5215-5225.

SEMPÉRTEGUI-TAPIA, D.; DE OLIVEIRA ALVES, J.; RIBATSKI, G. (2013). TwoPhase flow characteristics during convective boiling of halocarbon refrigerants inside horizontal small-diameter tubes. Heat Transfer Engineering, v. 34, n. 13, p. 1073-1087.

SHAH, R. K. (1975). Laminar flow friction and forced convection heat transfer in ducts of arbitrary geometry. International Journal of Heat and Mass Transfer, v. 18, n. 7-8, p. 849-862.

SHAH, R. K.; LONDON, A. L. (1978). Laminar flow forced convection in ducts. Adv. Heat Transfer Supplement 1. Academic P ed. [s.n.]New York.

SIEGEL, R.; SPARROW, E. M.; HALLMAN, T. M. (1958). Steady laminar heat transfer in a circular tube with prescribed wall heat flux. Applied Scientific Research, Section A, v. 7, n. 5, p. 386-392.

SILVESTRI, M. et al. (1963). A research program in two-phase flo

SOBIERSKA, E. et al. (2006). Experimental results of flow boiling of water in a vertical microchannel. Experimental Thermal and Fluid Science, v. 31, n. 2, p. 111-119.

SOUPREMANIEN, U. et al. (2011). Influence of the aspect ratio on boiling flows in rectangular mini-channels. Experimental Thermal and Fluid Science, v. 35, n. 5, p. 797-809.

STEINKE, M. E.; KANDLIKAR, S. G. (2004). An Experimental Investigation of Flow Boiling Characteristics of Water in Parallel Microchannels. Journal of Heat Transfer, v. 126 , n. 4 , p. 518.

STEPHAN, K.; ABDELSALAM, M. (1980). Heat-transfer correlations for natural convection boiling. International Journal of Heat and Mass Transfer, v. 23, n. 1, p. 73-87.

SUN, L.; MISHIMA, K. (2009a). An evaluation of prediction methods for saturated flow boiling heat transfer in mini-channels. International Journal of Heat and Mass Transfer, v. 52, n. 23-24, p. 5323-5329.

SUN, L.; MISHIMA, K. (2009b). Evaluation analysis of prediction methods for twophase flow pressure drop in mini-channels. International Journal of Multiphase Flow, v. 35, n. 1, p. 47-54.

TAYLOR, B. N.; KUYATT, C. E. (1994). Guidelines for Evaluating and Expressing the Uncertainty of NIST Measurement Results. NIST Technical Note, n. 1297, p. 25. 
THOME, J. R. et al. (2008). Flow boiling of ammonia and hydrocarbons: A state-of-theart review. International Journal of Refrigeration, v. 31, n. 4, p. 603-620.

THOME, J. R.; DUPONT, V.; JACOBI, A. M. (2004). Heat transfer model for evaporation in microchannels. Part I: presentation of the model. International Journal of Heat and Mass Transfer, v. 47, n. 14-16, p. 3375-3385.

TIBIRIÇÁ, C. B. (2011). Estudo teorico-experimental da transferencia de calor e do fluxo critico durante a ebulicao convectiva no interior de microcanais. Thesis $\mathrm{PhD}$ Universidade de São Paulo, USP. .

TIBIRIÇÁ, C. B.; RIBATSKI, G. (2010). Flow boiling heat transfer of R134a and R245fa in a $2.3 \mathrm{~mm}$ tube. International Journal of Heat and Mass Transfer, v. 53, n. 11-12, p. 2459-2468.

TIBIRIÇÁ, C. B.; RIBATSKI, G. (2013). Flow boiling in micro-scale channels Synthesized literature review. International Journal of Refrigeration, v. 36, n. 2, p. 301-324.

TIBIRIÇÁ, C. B.; RIBATSKI, G. (2014). Flow patterns and bubble departure fundamental characteristics during flow boiling in microscale channels. Experimental Thermal and Fluid Science,

TRAN, T. N. et al. (2000). Two-phase pressure drop of refrigerants during flow boiling in small channels: an experimental investigation and correlation development. International Journal of Multiphase Flow, v. 26, p. 1739-1754.

TRAN, T. N.; WAMBSGANSS, M. W.; FRANCE, D. M. (1996). Small circular- and rectangular-channel boiling with two refrigerants. International Journal of Multiphase Flow, v. 22, n. 3, p. 485-498.

URSENBACHER, T.; WOJTAN, L.; THOME, J. R. (2004). Interfacial measurements in stratified types of flow. Part I: New optical measurement technique and dry angle measurements. International Journal of Multiphase Flow, v. 30, n. 2, p. 107-124.

WARRIER, G. R.; DHIR, V. K.; MOMODA, L. A. (2002). Heat transfer and pressure drop in narrow rectangular channels. Experimental Thermal and Fluid Science, v. 26, n. 1, p. 53-64.

WOJTAN, L.; URSENBACHER, T.; THOME, J. R. (2005). Investigation of flow boiling in horizontal tubes: Part II-Development of a new heat transfer model for stratifiedwavy, dryout and mist flow regimes. International Journal of Heat and Mass Transfer, v. 48, n. 14, p. 2970-2985.

WOLDESEMAYAT, M. A.; GHAJAR, A. J. (2007). Comparison of void fraction correlations for different flow patterns in horizontal and upward inclined pipes. International Journal of Multiphase Flow, v. 33, n. 4, p. 347-370.

WONG, T. N.; OOI, K. T. (1995). Refrigerant flow in capillary tube: An assessment of the two-phase viscosity correlations on model prediction. Int. Comm. Heat Mass Transfer, v. 22, n. 4, p. 595-604.

XU, Y.; FANG, X. (2012). A new correlation of two-phase frictional pressure drop for 
evaporating flow in pipes. International Journal of Refrigeration, v. 35, n. 7, p. 20392050.

YU, W. et al. (2002). Two-phase pressure drop, boiling heat transfer, and critical heat flux to water in a small-diameter horizontal tube. International Journal of Multiphase Flow, v. 28, n. 6, p. 927-941.

ZHANG, M.; WEBB, R. L. (2001). Correlation of two-phase friction for refrigerants in small-diameter tubes. Experimental Thermal and Fluid Science, v. 25, n. 3-4, p. 131139.

ZHANG, W. et al. (2006). Correlation of critical heat flux for flow boiling of water in mini-channels. International Journal of Heat and Mass Transfer, v. 49, n. 5-6, p. 1058-1072.

ZHANG, W.; HIBIKI, T.; MISHIMA, K. (2004). Correlation for flow boiling heat transfer in mini-channels. International Journal of Heat and Mass Transfer, v. 47, n. 26, p. 5749-5763.

ZHANG, W.; HIBIKI, T.; MISHIMA, K. (2010). International Journal of Heat and Mass Transfer Correlations of two-phase frictional pressure drop and void fraction in minichannel. International Journal of Heat and Mass Transfer, v. 53, n. 1-3, p. 453-465.

ZIVI, S. M. (1964). Estimation of Steady-State Steam Void-Fraction by Means of the Principle of Minimum Entropy Production. Journal of Heat Transfer, v. 86, n. 247-252. 


\section{APÊNDICE A - ESCOAMENTO MONOFÁSICO}

Neste item são apresentados correlações para a perda de pressão e o coeficiente de transferência de calor em escoamento monofásico.

\section{A.1 Perda de pressão}

Geralmente a perda de pressão para escoamento bifásico é estimado como uma função das perdas de pressão por atrito para o escoamento monofásico correspondente. Desta forma, visando embasar discussões futuras este item trata de uma revisão da literatura sobre a perda de pressão por atrito em escoamentos monofásicos.

Considerando um escoamento em regime permanente no interior de um duto, como ilustrado na Figura A.1, quando o fluido entra em contato com a superfície, efeitos viscosos promovem o desenvolvimento de uma camada limite. Esta região finaliza com o estabelecimento de um perfil de velocidades que se mantém ao longo do comprimento do duto. A partir deste ponto, diz-se que o escoamento encontra-se completamente desenvolvido e a distância a partir da seção de entrada até esta posição é denominada de comprimento de desenvolvimento hidrodinâmico.

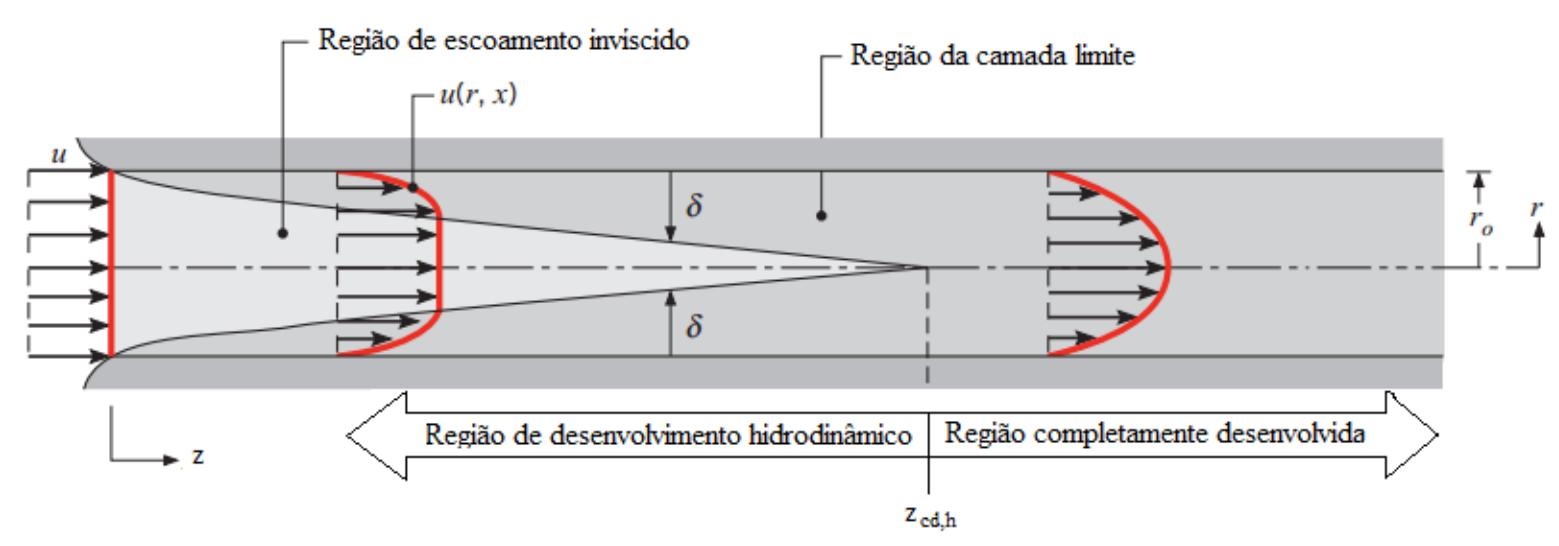

Figura A.1.- Desenvolvimento da camada limite laminar num tubo circular, Incropera et al. (1990).

$\mathrm{Na}$ região completamente desenvolvida tem-se um perfil de velocidade plenamente desenvolvido, cuja forma depende do regime de escoamento. Para escoamento laminar verifica-se um perfil de velocidade parabólico, conforme ilustrado 
Figura A.1, e para escoamento turbulento o perfil de velocidade se achata devido a efeitos de mistura turbulenta na direção radial.

O regime de escoamento é determinado pelo número de Reynolds. Geralmente, para $\operatorname{Re}<2300$ assume-se escoamento laminar, para números de Reynolds entre 2300 e 10.000 considera-se que o escoamento se encontra em transição e para Re superiores a 10.000 verifica-se o escoamento turbulento.

No escoamento laminar, o comprimento de desenvolvimento hidrodinâmico para canais circulares de acordo a Kays e Crawford (1993) pode ser estimado pela seguinte expressão:

$\left(\frac{z_{c d, h}}{D}\right)_{\text {lam }} \approx 0,05 \cdot \operatorname{Re}_{D}$

Para escoamento turbulento o comprimento de desenvolvimento hidrodinâmico segundo Kays e Crawford (1993) é dado por:

$10 \leq\left(\frac{z_{c d, h}}{D}\right)_{\text {turb }} \leq 60$

Uma vez o escoamento encontrando plenamente desenvolvido, o fator de atrito tipo Fanning é calculado de acordo a geometria do canal e o regime do escoamento como descrito a seguir:

\section{A.1.1 Fator de atrito em tubo circulares}

\section{Regime Laminar}

Deduzida a partir da lei de Poiseville e da relação da tensão cisalhante na parede do tudo com o gradiente de pressão, o fator de atrito em tubos circulares para um escoamento laminar e completamente desenvolvido é uma função do número de Reynolds como indica a seguinte equação:

$$
f=\frac{16}{\operatorname{Re}}
$$




\section{Regime Turbulento}

No caso de escoamento turbulento o fator de atrito tipo Fanning é função do número de Reynolds e da rugosidade relativa. Ele é calculado a partir de correlações empíricas, sendo a mais comum Blasius. A Tabela A.1 apresenta correlações para o fator de atrito em regime turbulento para escoamento completamente desenvolvido.

Tabela A.1.- Fator de atrito turbulento para escoamento plenamente desenvolvido.

\begin{tabular}{|c|c|c|}
\hline Autores & Correlação & Observações \\
\hline Blasius (1913) & $f=\frac{0,079}{\operatorname{Re}^{0,25}}$ & $\mathrm{p} / \operatorname{Re} 4 \times 10^{3}$ a $10^{5}$ \\
\hline Nikuradse (1932) & $\begin{array}{l}f=0,0008+0,0553 \cdot \operatorname{Re}^{-0,237} \\
\frac{1}{\sqrt{f}}=3,48-1,737 \cdot \ln \left(\frac{\varepsilon}{D}\right)\end{array}$ & $\mathrm{p} / \operatorname{Re} 10^{5}$ a $10^{7}$ \\
\hline Colebrook (1939) & $\frac{1}{\sqrt{f}}=4 \cdot \log \left[\frac{\varepsilon / D}{3,7}+\frac{1,255}{\operatorname{Re} f^{0,5}}\right]$ & - \\
\hline McAdams (1954) & $\begin{array}{r}f=\frac{0,046}{\operatorname{Re}^{0,2}} \\
f=\frac{0,036}{\operatorname{Re}^{0,1818}}\end{array}$ & $\begin{array}{l}\mathrm{p} / \operatorname{Re} 3 \times 10^{4} \text { a } 10^{6} \\
\mathrm{p} / \operatorname{Re} 4 \times 10^{4} \text { a } 10^{7}\end{array}$ \\
\hline Chen (1959) & $\frac{1}{\sqrt{f}}=-2 \cdot \log \left[\frac{\varepsilon / D}{3,7065}-\frac{5,0452}{\operatorname{Re}} \cdot \log \left(\frac{(\varepsilon / D)^{1,1098}}{2,8257}+\frac{5,8506}{\mathrm{Re}^{0,8981}}\right)\right]$ & $\mathrm{p} / \operatorname{Re} 4 \times 10^{3}$ a $10^{8}$ \\
\hline $\begin{array}{l}\text { Swamee e Jain } \\
\quad(1976)\end{array}$ & $\frac{1}{\sqrt{f}}=3,4769-1,7372 \cdot \ln \left(\frac{\varepsilon}{D}+\frac{42,48}{\operatorname{Re}^{0,9}}\right)$ & $\mathrm{p} / \operatorname{Re} 4 \times 10^{3}$ a $10^{8}$ \\
\hline Churchill (1977) & $\begin{array}{c}f=2\left[\left(\frac{8}{\mathrm{Re}}\right)^{12}+\frac{1}{(A+B)^{3 / 2}}\right]^{1 / 12} \\
A=\left\{2,457 \ln \left[\left(\frac{7}{\operatorname{Re}}\right)^{0.9}+0,27 \frac{\varepsilon}{D}\right]^{-1}\right\}^{16}, B=\left(\frac{37530}{\mathrm{Re}}\right)^{16}\end{array}$ & $\begin{array}{l}\text { Aplica a regime } \\
\text { laminar, transição e } \\
\text { turbulento. }\end{array}$ \\
\hline Round (1980) & $\frac{1}{\sqrt{f}}=4,2146-1,5635 \cdot \ln \left(\frac{\varepsilon}{D}+\frac{96,2963}{\operatorname{Re}}\right)$ & $\begin{array}{l}\text { Resultados } \\
\text { similares ao } \\
\text { Diagrama de } \\
\text { Moody* }\end{array}$ \\
\hline $\begin{array}{l}\text { Bhatti e Shah } \\
\text { (1987) }\end{array}$ & $f=0,0366 \cdot \operatorname{Re}^{-0,1818} f=0,00128+0,1143 \cdot \operatorname{Re}^{-0,311}$ & $\begin{array}{l}\mathrm{p} / \operatorname{Re} 4 \times 10^{4} \text { a } 10^{7} \\
\mathrm{p} / \operatorname{Re} 4 \times 10^{3} \text { a } 10^{7}\end{array}$ \\
\hline
\end{tabular}

*Gráfico com base a resultados experimentais proposto em 1944 para o calculo do fator de atrito em função do número de Reynolds e a rugosidade relativa 


\section{A.1.2 Fator de atrito em dutos retangulares}

\section{Regime Laminar}

O fator de atrito para escoamento plenamente desenvolvido em tubulações retangulares, segundo Rohsenow et al. (1998), é dado pela seguinte equação empírica:

$$
f \cdot \operatorname{Re}=24 \cdot\left(1-1,3553 \zeta+1,9467 \zeta^{2}-1,7012 \zeta^{3}+0,9564 \zeta^{4}-0,2537 \zeta^{5}\right)
$$

\section{Regime Turbulento}

Geralmente, o diâmetro do tubo circular é substituído pelo diâmetro hidráulico nas correlações para diâmetro circular.

\section{A.1.3 Fator de atrito em dutos triangulares}

\section{Regime Laminar}

O fator de atrito para escoamento plenamente desenvolvido em canais triangulares equiláteros segundo Rohsenow et al. (1998) é dado pela seguinte equação:

$$
f=\frac{13,333}{\operatorname{Re}}
$$

\section{Regime Turbulento}

Rohsenow et al. (1998) propõe a seguinte equação empírica para o cálculo do fator de atrito em canais triangulares equiláteros para escoamento desenvolvido:

$$
f=\frac{0,0425}{\operatorname{Re}^{0,2}}
$$

\section{A.2 Coeficiente de transferência de calor}

Métodos para determinação do CTC através do mecanismo de convecção forçada no interior de canais apresentam como parâmetros além das propriedades de transporte e velocidade do fluido: o regime do escoamento, a geometria da tubulação, o comprimento de desenvolvimento térmico e hidrodinâmico e a forma de aquecimento imposta. 
De maneira análoga à camada limite hidrodinâmica, perante uma condição de aquecimento da superfície do duto ocorre o desenvolvimento de uma camada limite térmica. A distância compreendendo a entrada do duto e o estabelecimento de escoamento completamente termicamente desenvolvido para escoamento laminar segundo Kays e Crawford (1993) é dada pela seguinte equação:

$$
\left(\frac{z_{c d, t}}{D}\right)_{\text {lam }} \approx 0,05 \cdot \operatorname{Re}_{D} \cdot \operatorname{Pr}
$$

Para escoamento turbulento Kays e Crawford (1993) propõem um comprimento de desenvolvimento térmico independente do número de Prandtl e do número de Reynolds, dado por:

$$
\left(\frac{z_{c d, t}}{D}\right)_{\text {turb }} \approx 60
$$

O cálculo do número de Nusselt para escoamento plenamente desenvolvido é função da geometria do canal e regime de escoamento.

\section{A.2.1 Tubos circulares}

\section{Regime laminar}

Em escoamento monofásico em canais circulares, em regime laminar termicamente desenvolvido e fluxo de calor uniforme, o número de Nusselt é dado pela seguinte equação:

$$
N u_{D}=4,364
$$

\section{Regime Turbulento}

$\mathrm{Na}$ Tabela A. são apresentadas as correlações existentes para o cálculo do coeficiente de transferência de calor monofásico para escoamento turbulento plenamente desenvolvido. A tabela foi extraída do handbook de Rohsenow et al. (1998). 
Tabela A.2.- Correlações para o cálculo do número de Nusselt monofásico para regime turbulento desenvolvido num canal circular, Rohsenow et al. (1998)

\begin{tabular}{|c|c|c|}
\hline Autores & Correlação & Faixa de aplicação \\
\hline $\begin{array}{l}\text { Dittus e Boelter } \\
\quad(1930)\end{array}$ & $N u_{D}=0,023 \operatorname{Re}_{D}^{0,8} \operatorname{Pr}^{0,4}$ & $\begin{array}{c}0,6 \leq \operatorname{Pr} \leq 160 \\
\operatorname{Re}_{D} \geq 10000\end{array}$ \\
\hline Sieder e Tate (1936) & $N u_{D}=0,027 \operatorname{Re}_{D}^{0,8} \operatorname{Pr}^{1 / 3}\left(\frac{\mu}{\mu_{w}}\right)^{0,14}$ & $\begin{array}{c}0,7 \leq \operatorname{Pr} \leq 16.700 \\
10^{4} \leq \operatorname{Re}_{D}\end{array}$ \\
\hline & $N u_{D}=\frac{(f / 2) \operatorname{Re}_{D} \operatorname{Pr}}{(5 \operatorname{Pr}+1)]}$ & $\begin{aligned} & 0,5 \leq \operatorname{Pr} \leq 10 \\
& 10^{4}<\operatorname{Pe}<5 \times 10^{6}\end{aligned}$ \\
\hline von Karman (1939) & $1+5(f / 2)^{1 / 2}\left[\operatorname{Pr}-1+\ln \left(\frac{5 \operatorname{Pr}+1}{6}\right)\right]$ & $10^{4} \leq \operatorname{Re}_{D} \leq 5 \times 10^{\circ}$ \\
\hline Prandtl (1944) & $N u_{D}=\frac{(f / 2) \operatorname{Re}_{D} \operatorname{Pr}}{1+8,7(f / 2)^{1 / 2}(\operatorname{Pr}-1)}$ & $\begin{array}{c}0,5 \leq \operatorname{Pr} \leq 5 \\
10^{4} \leq \operatorname{Re}_{D} \leq 5 \times 10^{6}\end{array}$ \\
\hline $\begin{array}{l}\text { Drexel e McAdams } \\
\quad(1945)\end{array}$ & $N u_{D}=0,023 \operatorname{Re}_{D}^{0,8} \operatorname{Pr}^{0,4}$ & $\begin{array}{c}\operatorname{Pr} \leq 7 \\
10^{4} \leq \operatorname{Re}_{D} \leq 5 \times 10^{6}\end{array}$ \\
\hline $\begin{array}{l}\text { Friend e Metzner } \\
\qquad(1958)\end{array}$ & $N u_{D}=\frac{(f / 2) \operatorname{Re}_{D} \operatorname{Pr}}{1,2+11,8(f / 2)^{1 / 2}(\operatorname{Pr}-1) \operatorname{Pr}^{-1 / 3}}$ & $\begin{array}{c}50 \leq \operatorname{Pr} \leq 600 \\
10^{4} \leq \operatorname{Re}_{D} \leq 5 \times 10^{6}\end{array}$ \\
\hline $\begin{array}{l}\text { Petukhov e Kirillov } \\
\text { (1958) }\end{array}$ & $\begin{array}{c}N u_{D}=\frac{(f / 2) \operatorname{Re}_{D} \operatorname{Pr}}{C+12,7(f / 2)^{1 / 2}\left(\operatorname{Pr}^{2 / 3}-1\right)} \\
C=1,07+900 / \operatorname{Re}_{D}-[0,63 /(1+10 \operatorname{Pr})]\end{array}$ & $\begin{aligned} 0,5 & \leq \operatorname{Pr} \leq 10^{6} \\
10^{4} \leq \operatorname{Re}_{D} & \leq 5 \times 10^{6}\end{aligned}$ \\
\hline $\begin{array}{l}\text { Dipprey e Sabersky } \\
\quad(1963)\end{array}$ & $N u_{D}=\frac{\operatorname{Re}_{D} \operatorname{Pr} \sqrt{f / 2}}{1+\sqrt{f / 2}\left[5,19 \operatorname{Re}_{\varepsilon}^{0,2} \operatorname{Pr}^{0,44}-8,48\right]}$ & $\begin{array}{l}0,0024 \leq \varepsilon / D_{H} \leq 0,049 \\
1,2 \leq \operatorname{Pr} \leq 5,94 \\
1,4 \times 10^{4} \leq \operatorname{Re}_{D} \leq 5 \times 10^{5}\end{array}$ \\
\hline Colburn (1964) & $\begin{array}{l}N u_{D}=(f / 2) \operatorname{Re}_{D} \operatorname{Pr}^{1 / 3} \\
N u_{D}=0,023 \operatorname{Re}_{D}^{0,8} \operatorname{Pr}^{1 / 3}\end{array}$ & $\begin{array}{c}0,5 \leq \operatorname{Pr} \leq 3 \\
10^{4} \leq \operatorname{Re}_{D} \leq 10^{5}\end{array}$ \\
\hline Gowen e Smith & $\operatorname{Re}_{D} \operatorname{Pr} \sqrt{f / 2}$ & $0,0021 \leq \varepsilon / D_{H} \leq 0,095$ \\
\hline (1968) & $4,5+\left[0,155 \cdot\left(\operatorname{Re}_{D} \sqrt{f / 2}\right)^{0,54}+\sqrt{2 / f}\right] \cdot \sqrt{\operatorname{Pr}}$ & $10^{4} \leq \operatorname{Re}_{D} \leq 5 \times 10^{4}$ \\
\hline Webb (1971) & $N u_{D}=\frac{(f / 2) \operatorname{Re}_{D} \operatorname{Pr}}{1,07+9(f / 2)^{1 / 2}(\operatorname{Pr}-1) \operatorname{Pr}^{1 / 4}}$ & $\begin{array}{l}0,5 \leq \operatorname{Pr} \leq 100 \\
10^{4} \leq \operatorname{Re}_{D} \leq 5 \times 10^{t}\end{array}$ \\
\hline Gnielinski (1976) & $N u_{D}=\frac{(f / 8)\left(\mathrm{Re}_{D}-1000\right) \operatorname{Pr}}{1+12,7(f / 8)^{1 / 2}\left(\operatorname{Pr}^{2 / 3}-1\right)}$ & $\begin{array}{l}0,5 \leq \operatorname{Pr} \leq 2000 \\
2300 \leq \operatorname{Re}_{D} \leq 5 \times 10^{6}\end{array}$ \\
\hline
\end{tabular}


Tabela A.2 (continuação).- Correlações para o cálculo do número de Nusselt monofásico para regime turbulento desenvolvido num canal circular, Rohsenow et al. (1998)

\begin{tabular}{|c|c|c|}
\hline Autores & Correlação & Faixa de aplicação \\
\hline Sandall et al. (1980) & $\begin{array}{c}N u_{D}=\frac{(f / 2)^{1 / 2} \operatorname{Re}_{D} \operatorname{Pr}}{12,48 \operatorname{Pr}^{2 / 3}-7,853 \operatorname{Pr}^{1 / 3}+3,613 \ln (\operatorname{Pr})+5,8+C} \\
C=2,78 \ln \left(\frac{\sqrt{f / 2}}{45} \cdot \operatorname{Re}_{D}\right)\end{array}$ & $\begin{array}{c}0,5 \leq \operatorname{Pr} \leq 2000 \\
10^{4} \leq \operatorname{Re}_{D} \leq 5 \times 10^{6}\end{array}$ \\
\hline Bhatti e Shah (1987) & $N u_{D}=\frac{\operatorname{Re}_{D} \operatorname{Pr}(f / 2)}{1+\sqrt{f / 2}\left[4,5 \operatorname{Re}_{\varepsilon}^{0,2} \operatorname{Pr}^{0,5}-8,48\right]}$ & $\begin{array}{c}0,002 \leq \varepsilon / D_{H} \leq 0,05 \\
0,5 \leq \operatorname{Pr} \leq 10 \\
\operatorname{Re}_{D}>10^{4}\end{array}$ \\
\hline Bhatti e Shah (1987) & $N u_{D}=\frac{\left(\operatorname{Re}_{D}-1000\right) \operatorname{Pr}(f / 2)}{1+\sqrt{f / 2}\left[\left(17,42-13,77 \operatorname{Pr}_{L}^{0,8}\right) \operatorname{Re}_{\varepsilon}^{0,5}-8,48\right]}$ & $\begin{array}{c}0,002 \leq \varepsilon / D_{H} \leq 0,05 \\
0,5 \leq \operatorname{Pr} \leq 5000 \\
\operatorname{Re}_{D}>2300\end{array}$ \\
\hline
\end{tabular}

Rohsenow et al. (1998) recomendam o uso das equações de Gnielinski (1976) ou Bhatti e Shah (1987).

\section{A.2.2 Dutos retangulares}

\section{Regime laminar}

O número de Nusselt para escoamento laminar plenamente desenvolvido num canal retangular, para fluxo de calor uniforme nas 4 faces, de acordo com Rohsenow et al. (1998) pode ser calculado mediante a seguinte equação:

$$
N u=8,235 \cdot\left(1-2,0421 \zeta+3,0853 \zeta^{2}-2,4765 \zeta^{3}+1,0578 \zeta^{4}+0,1861 \zeta^{5}\right) \quad \text { A. } 10
$$

Para o cálculo do número de Nusselt com uma ou mais facs isoladas termicamente, o Nusselt é dado pela Tabela A.3. 
Tabela A.3.- Número de Nusselt para escoamento laminar desenvolvido em canais retangulares, Rohsenow et al. (1998).

\begin{tabular}{|c|c|c|c|c|c|}
\hline$\zeta$ & $\mathbf{N u}$ & $\mathrm{Nu}$ & $\mathrm{Nu}$ & $\begin{array}{c}\text { NIIIII/ } \\
\mathrm{Nu}\end{array}$ & गाIाII। \\
\hline 0 & 8,235 & 8,235 & 8,235 & 0 & 5,385 \\
\hline 0,1 & 6,785 & 6,939 & 7,248 & 0,538 & 4,410 \\
\hline 0,2 & 5,738 & 6,072 & 6,561 & 0,964 & 3,914 \\
\hline 0,3 & 4,99 & 5,393 & 5,997 & 1,312 & 5,538 \\
\hline 0,4 & 4,472 & 4,885 & 5,555 & 1,604 & 3,279 \\
\hline 0,5 & 4,123 & 4,505 & 5,203 & 1,854 & 3,104 \\
\hline 0,6 & 3,895 & - & - & - & 2,987 \\
\hline 0,7 & 3,75 & 3,991 & 4,662 & 2,263 & 2,911 \\
\hline 0,8 & 3,664 & - & - & - & 2,866 \\
\hline 0,9 & 3,62 & - & - & - & 2,843 \\
\hline 1 & 3,608 & 3,556 & 4,094 & 2,712 & 2,836 \\
\hline 2 & 4,123 & 3,146 & 2,947 & 3,539 & 2,911 \\
\hline 2,5 & 4,472 & 3,169 & 2,598 & 3,777 & 3,279 \\
\hline 5 & 5,738 & 3,639 & 1,664 & 4,411 & 3,914 \\
\hline 10 & 6,785 & 4,252 & 0,975 & 4,851 & 4,410 \\
\hline$\infty$ & 8,235 & 5,385 & 0 & 5,385 & 5,385 \\
\hline
\end{tabular}

\section{Regime Turbulento}

Rohsenow et al. (1998) recomendam o uso das correlações para tubos circulares substituindo o diâmetro do tubo circular pelo diâmetro hidráulico do tubo retangular ou pelo seguinte modificação do diâmetro:

$$
D_{t r}=\frac{2}{3} \cdot D_{H}+\frac{11}{24} \cdot \zeta \cdot(2-\zeta)
$$

Onde $\zeta$ é o fator de forma do canal retangular. 


\section{A.2.3 Dutos triangulares}

\section{Regime Laminar}

De acordo a Rohsenow et al. (1998), o número de Nusselt para um escoamento laminar num canal triangular equilátero totalmente desenvolvido é:

$N u=3,111$

\section{Regime Turbulento}

Altemani e Sparrow (1980) apud Rohsenow et al. (1998) realizaram testes de transferência de calor para um escoamento plenamente desenvolvido num canal triangular equilátero. Eles encontraram que o número de Nusselt independe do Prandtl como indicado a continuação:

$N u=0,019 \cdot \operatorname{Re}^{0,781}$ 


\section{APÊNDICE B - DADOS EXPERIMENTAIS}

Neste apêndice são apresentados os dados obtidos no presente estudo para perda de pressao bifasica em condicoes adiabáticas e para o coeficiente de transfêrencia de calor local. Os diâmetros equivalente e hidráulico sao dados a seguir para cada geometría:

Tubo circular: $\mathrm{D}_{\mathrm{eq}}=1,1 \mathrm{~mm} ; \mathrm{D}_{\mathrm{H}}=1,1 \mathrm{~mm} ; \mathrm{Ra}=0,29 \mu \mathrm{m}$.

Canal quadrado: $\mathrm{D}_{\mathrm{eq}}=0.977 \mathrm{~mm} ; \mathrm{D}_{\mathrm{H}}=0.868 \mathrm{~mm} ; \mathrm{Ra}=0,84 \mu \mathrm{m}$.

Canal triangular: $\mathrm{D}_{\mathrm{eq}}=0.835 \mathrm{~mm} ; \mathrm{D}_{\mathrm{H}}=0.634 \mathrm{~mm} ; \mathrm{Ra}=1,78 \mu \mathrm{m}$.

\section{B.1 Perda de pressao adiabatica}

As Tabelas B.1 a B6 apresentam os resultados experimentais para o gradiente de pressao bifásica $(\mathrm{em} \mathrm{kPa} / \mathrm{m}]$. Estes resultados experimentais encontram-se segregados por fluido e geometría.

Tabela B.1. R134a, geometría circular.

\begin{tabular}{|c|c|c|c|}
\hline $\boldsymbol{T}_{\text {sat }}[\boldsymbol{C}]$ & $\boldsymbol{G}\left[\mathbf{k g} / \boldsymbol{m}^{2} \boldsymbol{s}\right]$ & $\boldsymbol{x}[-]$ & $(\boldsymbol{d p} / \mathbf{d} \boldsymbol{z})_{\boldsymbol{f}}$ \\
\hline 31.0 & 395.7 & 0.111 & 8.701 \\
\hline 31.0 & 396.7 & 0.163 & 12.86 \\
\hline 31.2 & 405.1 & 0.203 & 17.24 \\
\hline 31.2 & 400.9 & 0.254 & 22.14 \\
\hline 31.0 & 400.9 & 0.31 & 27.57 \\
\hline 31.0 & 398.8 & 0.362 & 32.75 \\
\hline 31.2 & 402 & 0.409 & 38.23 \\
\hline 31.2 & 403 & 0.462 & 44 \\
\hline 31.0 & 403 & 0.504 & 48.51 \\
\hline 31.0 & 400.9 & 0.559 & 53.48 \\
\hline 31.2 & 403 & 0.601 & 57.54 \\
\hline 31.2 & 397.8 & 0.662 & 61.54 \\
\hline 31.0 & 402 & 0.702 & 65.06 \\
\hline 31.0 & 398.8 & 0.762 & 68.58 \\
\hline 31.2 & 399.9 & 0.813 & 71.15 \\
\hline 31.2 & 397.8 & 0.858 & 70.87 \\
\hline 31.0 & 399.9 & 0.91 & 71.62 \\
\hline 31.0 & 402 & 0.955 & 60.7 \\
\hline 31.2 & 503 & 0.081 & 10.36 \\
\hline 31.2 & 501.9 & 0.111 & 13.6 \\
\hline 31.1 & 498.8 & 0.158 & 19.78 \\
\hline 31.2 & 495.6 & 0.211 & 28.12 \\
\hline 31.1 & 501.9 & 0.255 & 36.66 \\
\hline 31.2 & 499.8 & 0.314 & 46.35 \\
\hline 31.0 & 500.9 & 0.363 & 55.08 \\
\hline 31.1 & 500.9 & 0.41 & 63.01 \\
\hline
\end{tabular}

\begin{tabular}{|c|c|c|c|}
\hline$T_{\text {sat }}[C]$ & $G\left[\mathrm{~kg} / \mathrm{m}^{2} \mathrm{~s}\right]$ & $x[-]$ & $(d p / d z)_{f}$ \\
\hline 31.2 & 500.9 & 0.453 & 70.09 \\
\hline 31.1 & 500.9 & 0.5 & 77.41 \\
\hline 31.0 & 497.7 & 0.577 & 85.31 \\
\hline 31.0 & 499.8 & 0.593 & 91.33 \\
\hline 31.2 & 497.7 & 0.657 & 98.45 \\
\hline 31.2 & 498.8 & 0.703 & 103.3 \\
\hline 31.0 & 501.9 & 0.757 & 108.1 \\
\hline 31.1 & 499.8 & 0.803 & 110.3 \\
\hline 31.2 & 499.4 & 0.857 & 107.9 \\
\hline 31.1 & 501 & 0.904 & 98.34 \\
\hline 31.0 & 501.4 & 0.951 & 82.2 \\
\hline 31.0 & 600 & 0.111 & 15.05 \\
\hline 31.2 & 598.7 & 0.151 & 21.92 \\
\hline 31.2 & 599.8 & 0.196 & 29.92 \\
\hline 31.1 & 599.6 & 0.254 & 42.7 \\
\hline 31.2 & 600.9 & 0.306 & 52.78 \\
\hline 31.1 & 600.3 & 0.348 & 63.15 \\
\hline 31.1 & 600.5 & 0.397 & 73.75 \\
\hline 31.1 & 599.5 & 0.458 & 86.66 \\
\hline 31.1 & 601.1 & 0.501 & 96.1 \\
\hline 31.0 & 600.2 & 0.549 & 106.3 \\
\hline 30.9 & 601.1 & 0.595 & 115 \\
\hline 30.9 & 600 & 0.656 & 122.8 \\
\hline 30.9 & 599.2 & 0.702 & 130.7 \\
\hline 31.0 & 599.3 & 0.755 & 137.1 \\
\hline 30.9 & 598.7 & 0.801 & 135.8 \\
\hline 30.9 & 597.9 & 0.862 & 121.8 \\
\hline 31.2 & 700.4 & 0.154 & 26.19 \\
\hline 31.0 & 700.4 & 0.197 & 38.62 \\
\hline
\end{tabular}




\begin{tabular}{|c|c|c|c|}
\hline$T_{\text {sat }}[C]$ & $G\left[\mathrm{~kg} / \mathrm{m}^{2} \mathrm{~s}\right]$ & $x[-]$ & $(d p / d z)_{f}$ \\
\hline 31.0 & 700.6 & 0.249 & 53.31 \\
\hline 31.2 & 700.7 & 0.302 & 68.54 \\
\hline 31.2 & 700.7 & 0.354 & 81.32 \\
\hline 31.2 & 698.3 & 0.407 & 94.71 \\
\hline 31.1 & 698.8 & 0.45 & 107.9 \\
\hline 31.2 & 700.2 & 0.499 & 121.4 \\
\hline 31.1 & 699.8 & 0.553 & 134.7 \\
\hline 31.1 & 700.3 & 0.594 & 144.8 \\
\hline 31.2 & 699.2 & 0.652 & 157 \\
\hline 31.1 & 699.6 & 0.698 & 165.5 \\
\hline 31.1 & 700.1 & 0.753 & 175.1 \\
\hline 31.1 & 698.5 & 0.8 & 181.6 \\
\hline 31.0 & 701.4 & 0.847 & 172.5 \\
\hline 30.9 & 699.4 & 0.909 & 167.4 \\
\hline 31.2 & 797.8 & 0.151 & 37.97 \\
\hline 31.0 & 799.7 & 0.194 & 55.73 \\
\hline 31.2 & 798.3 & 0.252 & 74.86 \\
\hline 31.1 & 799.9 & 0.292 & 90.39 \\
\hline 31.2 & 800.3 & 0.35 & 111.8 \\
\hline 31.2 & 799.6 & 0.401 & 130.3 \\
\hline 31.2 & 799 & 0.449 & 147.3 \\
\hline 31.1 & 800.3 & 0.491 & 161.6 \\
\hline 31.2 & 799.9 & 0.553 & 178.2 \\
\hline 31.1 & 799.4 & 0.599 & 190.6 \\
\hline 31.1 & 799.8 & 0.648 & 202.1 \\
\hline 31.0 & 799.5 & 0.704 & 215.5 \\
\hline 31.0 & 799.4 & 0.745 & 218.9 \\
\hline 31.0 & 799.1 & 0.799 & 227.5 \\
\hline 31.0 & 795.9 & 0.85 & 218.1 \\
\hline 31.1 & 899.4 & 0.106 & 36.11 \\
\hline 31.2 & 901.1 & 0.152 & 52.71 \\
\hline 31.0 & 900.1 & 0.193 & 72.9 \\
\hline 31.2 & 900.2 & 0.258 & 96.5 \\
\hline 31.2 & 900.5 & 0.299 & 116.7 \\
\hline 31.1 & 899.5 & 0.349 & 144.4 \\
\hline 31.1 & 899.7 & 0.398 & 165.6 \\
\hline 31.1 & 900.4 & 0.435 & 182.2 \\
\hline 31.2 & 900.1 & 0.495 & 202.7 \\
\hline 31.2 & 899.7 & 0.554 & 219.5 \\
\hline 31.1 & 900.5 & 0.597 & 237.1 \\
\hline 31.1 & 900 & 0.654 & 251.2 \\
\hline 31.1 & 900 & 0.707 & 260.3 \\
\hline 31.1 & 900.3 & 0.755 & 265.6 \\
\hline 31.1 & 899.7 & 0.801 & 267.1 \\
\hline 31.1 & 900.9 & 0.846 & 265.9 \\
\hline 31.1 & 900.8 & 0.893 & 266.4 \\
\hline 31.2 & 1001 & 0.155 & 58.13 \\
\hline 31.1 & 1000 & 0.199 & 78.45 \\
\hline 31.1 & 1001 & 0.25 & 103.1 \\
\hline 31.2 & 1003 & 0.297 & 124.3 \\
\hline 31.1 & 1000 & 0.347 & 153.1 \\
\hline 31.1 & 1000 & 0.392 & 176.8 \\
\hline 31.1 & 1000 & 0.442 & 202.9 \\
\hline 31.2 & 1000 & 0.498 & 225.8 \\
\hline 31.2 & 999.7 & 0.55 & 246 \\
\hline 31.1 & 1000 & 0.595 & 262.2 \\
\hline 31.1 & 1000 & 0.653 & 277.3 \\
\hline
\end{tabular}

\begin{tabular}{|c|c|c|c|}
\hline$T_{\text {sat }}[C]$ & $G\left[\mathrm{~kg} / \mathrm{m}^{2} \mathrm{~s}\right]$ & $x[-]$ & $(d p / d z)_{f}$ \\
\hline 31.0 & 1001 & 0.69 & 290.6 \\
\hline 31.1 & 1002 & 0.75 & 298.9 \\
\hline 31.1 & 999.7 & 0.795 & 302.9 \\
\hline 31.2 & 999.4 & 0.857 & 307.7 \\
\hline 31.2 & 999.3 & 0.903 & 298 \\
\hline 31.2 & 1100 & 0.148 & 66.25 \\
\hline 31.1 & 1100 & 0.197 & 86.11 \\
\hline 31.0 & 1100 & 0.249 & 116.6 \\
\hline 31.2 & 1099 & 0.294 & 138 \\
\hline 31.0 & 1100 & 0.345 & 173.8 \\
\hline 31.1 & 1099 & 0.393 & 202.1 \\
\hline 31.1 & 1100 & 0.44 & 231.8 \\
\hline 31.1 & 1101 & 0.492 & 258.6 \\
\hline 31.1 & 1099 & 0.549 & 282.2 \\
\hline 31.0 & 1100 & 0.593 & 299.1 \\
\hline 31.0 & 1099 & 0.646 & 314.3 \\
\hline 31.0 & 1100 & 0.694 & 324.6 \\
\hline 31.0 & 1100 & 0.744 & 330.5 \\
\hline 31.1 & 1101 & 0.795 & 330.6 \\
\hline 31.2 & 1099 & 0.848 & 331.2 \\
\hline 31.2 & 1198 & 0.11 & 54.19 \\
\hline 31.2 & 1200 & 0.153 & 72.99 \\
\hline 31.2 & 1201 & 0.194 & 101.9 \\
\hline 31.1 & 1199 & 0.249 & 132 \\
\hline 31.2 & 1204 & 0.289 & 161.8 \\
\hline 31.2 & 1200 & 0.349 & 203 \\
\hline 31.1 & 1200 & 0.398 & 237.3 \\
\hline 31.1 & 1201 & 0.446 & 267.3 \\
\hline 31.2 & 1200 & 0.491 & 291 \\
\hline 31.2 & 1200 & 0.548 & 317.5 \\
\hline 31.2 & 1200 & 0.599 & 335.5 \\
\hline 31.2 & 1200 & 0.647 & 348.5 \\
\hline 31.2 & 1199 & 0.694 & 356.3 \\
\hline 31.2 & 1200 & 0.75 & 360.6 \\
\hline 31.1 & 1200 & 0.801 & 363.8 \\
\hline 31.2 & 1200 & 0.85 & 355.2 \\
\hline 31.1 & 1301 & 0.151 & 78.29 \\
\hline 31.1 & 1301 & 0.201 & 108.1 \\
\hline 31.2 & 1297 & 0.245 & 139.9 \\
\hline 31.1 & 1300 & 0.3 & 185.8 \\
\hline 31.1 & 1299 & 0.349 & 224.1 \\
\hline 31.1 & 1300 & 0.392 & 257 \\
\hline 31.2 & 1300 & 0.448 & 294.3 \\
\hline 31.2 & 1300 & 0.494 & 322.6 \\
\hline 31.0 & 1300 & 0.546 & 348.6 \\
\hline 31.0 & 1300 & 0.602 & 366.1 \\
\hline 31.0 & 1301 & 0.641 & 373.5 \\
\hline 31.1 & 1301 & 0.7 & 373 \\
\hline 31.2 & 1300 & 0.749 & 372.3 \\
\hline 31.1 & 1300 & 0.792 & 364.4 \\
\hline 31.1 & 1400 & 0.149 & 85.81 \\
\hline 31.1 & 1402 & 0.203 & 119.8 \\
\hline 31.1 & 1402 & 0.249 & 164.7 \\
\hline 31.1 & 1399 & 0.3 & 198.4 \\
\hline 31.1 & 1401 & 0.347 & 240.8 \\
\hline 31.1 & 1401 & 0.39 & 281.5 \\
\hline 31.2 & 1399 & 0.447 & 323.2 \\
\hline
\end{tabular}




\begin{tabular}{|c|c|c|c|}
\hline$T_{\text {sat }}[C]$ & $G\left[\mathrm{~kg} / \mathrm{m}^{2} \mathrm{~s}\right]$ & $x[-]$ & $(d p / d z)_{f}$ \\
\hline 31.0 & 1400 & 0.495 & 354.2 \\
\hline 31.1 & 1399 & 0.547 & 378.3 \\
\hline 31.0 & 1400 & 0.597 & 388.5 \\
\hline 31.1 & 1401 & 0.645 & 389 \\
\hline 31.1 & 1400 & 0.693 & 380.9 \\
\hline 31.1 & 1400 & 0.75 & 367 \\
\hline 31.1 & 1501 & 0.149 & 89.75 \\
\hline 31.1 & 1501 & 0.203 & 125.4 \\
\hline 31.2 & 1499 & 0.25 & 172 \\
\hline 31.2 & 1500 & 0.298 & 218.2 \\
\hline 31.1 & 1500 & 0.349 & 268.9 \\
\hline 31.1 & 1499 & 0.395 & 312 \\
\hline 31.1 & 1500 & 0.449 & 354.1 \\
\hline 31.1 & 1500 & 0.499 & 382.3 \\
\hline 31.1 & 1500 & 0.543 & 399.7 \\
\hline 31.1 & 1501 & 0.589 & 411.4 \\
\hline 31.1 & 1500 & 0.64 & 411.3 \\
\hline 31.0 & 1602 & 0.154 & 98.73 \\
\hline 31.2 & 1600 & 0.194 & 131.1 \\
\hline 31.1 & 1600 & 0.249 & 187.5 \\
\hline 31.1 & 1601 & 0.294 & 228.1 \\
\hline 31.1 & 1601 & 0.345 & 285.6 \\
\hline 31.2 & 1610 & 0.391 & 325.9 \\
\hline 31.2 & 1613 & 0.426 & 366.6 \\
\hline 41.1 & 598.7 & 0.152 & 18.67 \\
\hline 41.0 & 602.9 & 0.196 & 26.07 \\
\hline 41.0 & 602.9 & 0.249 & 34.2 \\
\hline 40.8 & 602.9 & 0.296 & 41.59 \\
\hline 41.1 & 598.7 & 0.359 & 50.77 \\
\hline 41.1 & 598.7 & 0.418 & 58.8 \\
\hline 41.1 & 601.9 & 0.446 & 64.29 \\
\hline 41.0 & 600.8 & 0.5 & 72.2 \\
\hline 40.9 & 598.7 & 0.566 & 80.06 \\
\hline 40.9 & 601.9 & 0.604 & 85.4 \\
\hline 40.9 & 598.7 & 0.65 & 90.42 \\
\hline 41.1 & 597.7 & 0.71 & 94.48 \\
\hline 40.9 & 600.8 & 0.76 & 99.68 \\
\hline 40.9 & 600.8 & 0.799 & 104.3 \\
\hline 41.1 & 605.1 & 0.844 & 95.65 \\
\hline 41.0 & 697.7 & 0.153 & 23.68 \\
\hline 41.0 & 697.7 & 0.195 & 33.28 \\
\hline 41.1 & 701.9 & 0.247 & 44.75 \\
\hline 41.1 & 700.8 & 0.303 & 54.33 \\
\hline
\end{tabular}

\begin{tabular}{|c|c|c|c|}
\hline $\left.\boldsymbol{T}_{\text {sat }} \boldsymbol{[ C}\right]$ & $\boldsymbol{G}\left[\mathbf{k g} \mathbf{m}^{\mathbf{2}} \boldsymbol{s}\right]$ & $\boldsymbol{x}[-]$ & $(\boldsymbol{d p} / \boldsymbol{d} \boldsymbol{z})_{\boldsymbol{f}}$ \\
\hline 41.0 & 701.9 & 0.35 & 63.79 \\
\hline 41.1 & 699.8 & 0.402 & 72.12 \\
\hline 41.0 & 700.8 & 0.442 & 81.1 \\
\hline 41.0 & 697.7 & 0.5 & 92.01 \\
\hline 41.0 & 700.8 & 0.55 & 101.8 \\
\hline 41.0 & 697.7 & 0.6 & 109.1 \\
\hline 41.0 & 699.8 & 0.651 & 116.2 \\
\hline 41.0 & 702.9 & 0.687 & 121.8 \\
\hline 41.0 & 699.8 & 0.752 & 127.5 \\
\hline 41.1 & 699.8 & 0.808 & 120.6 \\
\hline 41.2 & 702.9 & 0.849 & 113.4 \\
\hline 41.1 & 797.6 & 0.106 & 23.08 \\
\hline 41.0 & 797.6 & 0.157 & 32.09 \\
\hline 41.0 & 798.7 & 0.193 & 39.58 \\
\hline 41.0 & 801.8 & 0.248 & 54.89 \\
\hline 41.1 & 799.7 & 0.3 & 69.17 \\
\hline 41.0 & 799.7 & 0.346 & 76.34 \\
\hline 41.1 & 803.9 & 0.392 & 89.24 \\
\hline 40.9 & 800.8 & 0.45 & 104.1 \\
\hline 40.8 & 801.8 & 0.508 & 117.8 \\
\hline 40.8 & 799.7 & 0.552 & 126.7 \\
\hline 40.8 & 796.6 & 0.611 & 135.1 \\
\hline 40.9 & 797.6 & 0.654 & 146 \\
\hline 41.0 & 799.7 & 0.701 & 148.7 \\
\hline 41.0 & 798.7 & 0.753 & 145.6 \\
\hline 41.1 & 798.7 & 0.8 & 136 \\
\hline 41.0 & 997.5 & 0.113 & 26.64 \\
\hline 40.9 & 1007 & 0.156 & 41.49 \\
\hline 40.9 & 1001 & 0.199 & 57.86 \\
\hline 40.9 & 995.4 & 0.26 & 80.05 \\
\hline 41.0 & 997.5 & 0.296 & 88.17 \\
\hline 41.0 & 980.7 & 0.351 & 105.2 \\
\hline 41.2 & 1003 & 0.389 & 121.4 \\
\hline 41.0 & 998.6 & 0.449 & 145.3 \\
\hline 41.0 & 995.4 & 0.501 & 162.3 \\
\hline 41.1 & 1002 & 0.553 & 176.3 \\
\hline 41.1 & 998.6 & 0.603 & 185.1 \\
\hline 41.0 & 1001 & 0.65 & 192.5 \\
\hline 41.0 & 1001 & 0.706 & 201.5 \\
\hline 41.0 & 1001 & 0.746 & 204.7 \\
\hline 41.0 & 1002 & 0.812 & 189.9 \\
\hline & & & \\
\hline
\end{tabular}

Tabela B.2. R1234ze(E), geometría circular.

\begin{tabular}{|l|l|l|l|}
\hline $\boldsymbol{T}_{\text {sat }}[\boldsymbol{C}]$ & $\boldsymbol{G}\left[\mathbf{k g} / \boldsymbol{m}^{2} \boldsymbol{s}\right]$ & $\boldsymbol{x}[-]$ & $(\mathbf{d p} / \mathbf{d z})_{\boldsymbol{f}}$ \\
\hline 30.8 & 99.57 & 0.10 & 1.943 \\
\hline 30.9 & 101.3 & 0.15 & 2.194 \\
\hline 30.9 & 99.89 & 0.22 & 2.437 \\
\hline 30.9 & 99.59 & 0.26 & 2.698 \\
\hline 30.9 & 98.82 & 0.31 & 2.998 \\
\hline 30.8 & 100.2 & 0.37 & 3.405 \\
\hline 31.1 & 99.92 & 0.41 & 3.877 \\
\hline 31.2 & 101 & 0.46 & 4.418 \\
\hline 31.2 & 102.4 & 0.51 & 4.981 \\
\hline
\end{tabular}

\begin{tabular}{|l|l|l|l|}
\hline $\boldsymbol{T}_{\text {sat }}[\boldsymbol{C}]$ & $\boldsymbol{G}\left[\mathbf{k g} / \mathbf{m}^{2} \boldsymbol{s}\right]$ & $\boldsymbol{x}[-]$ & $(\boldsymbol{d p} / \mathbf{d z})_{\boldsymbol{f}}$ \\
\hline 31.1 & 100.5 & 0.56 & 5.394 \\
\hline 31.1 & 101.2 & 0.62 & 5.9 \\
\hline 31.1 & 100.3 & 0.66 & 6.267 \\
\hline 31.1 & 100 & 0.73 & 6.727 \\
\hline 31.1 & 98.86 & 0.79 & 6.915 \\
\hline 30.9 & 100.7 & 0.82 & 7.124 \\
\hline 30.9 & 100.1 & 0.87 & 7.191 \\
\hline 31.0 & 100.1 & 0.92 & 7.091 \\
\hline 31.0 & 100.2 & 0.96 & 7 \\
\hline 31.0 & 198.8 & 0.03 & 3.547 \\
\hline 31.0 & 199 & 0.07 & 5.041 \\
\hline
\end{tabular}




\begin{tabular}{|l|l|l|l|}
\hline $\boldsymbol{T}$ sat $\boldsymbol{[ C}]$ & $\boldsymbol{G}\left[\mathbf{k g} \boldsymbol{m}^{\mathbf{}} \boldsymbol{s}\right]$ & $\boldsymbol{x}[-\boldsymbol{l}$ & $\boldsymbol{( d \boldsymbol { p } / \boldsymbol { d } \boldsymbol { z } ) \boldsymbol { f }}$ \\
\hline 31.1 & 201 & 0.12 & 6.153 \\
\hline 31.0 & 201.4 & 0.17 & 7.39 \\
\hline 31.0 & 199.5 & 0.23 & 9.208 \\
\hline 30.9 & 199.9 & 0.28 & 11.41 \\
\hline 30.9 & 200.8 & 0.33 & 13.84 \\
\hline 30.9 & 202.7 & 0.37 & 15.68 \\
\hline 31.0 & 203.3 & 0.41 & 17.43 \\
\hline 31.0 & 199.8 & 0.47 & 19.08 \\
\hline 31.0 & 200.2 & 0.52 & 20.67 \\
\hline 31.0 & 199.8 & 0.58 & 22.41 \\
\hline 31.0 & 199.8 & 0.62 & 23.19 \\
\hline 31.0 & 200.1 & 0.67 & 24.09 \\
\hline 31.1 & 201 & 0.71 & 24.87 \\
\hline 31.0 & 200.5 & 0.76 & 25.29 \\
\hline 31.0 & 201.8 & 0.82 & 26.11 \\
\hline 31.1 & 200 & 0.88 & 25.51 \\
\hline 30.9 & 197.8 & 0.92 & 25.9 \\
\hline 31.1 & 197.8 & 0.97 & 24.72 \\
\hline 30.7 & 303.1 & 0.07 & 8.876 \\
\hline 30.8 & 300.9 & 0.10 & 11.04 \\
\hline 30.9 & 299.9 & 0.15 & 13.96 \\
\hline 30.9 & 299.9 & 0.20 & 18.86 \\
\hline 30.8 & 298.8 & 0.26 & 23.81 \\
\hline 30.9 & 297.8 & 0.30 & 27.35 \\
\hline 30.8 & 299.9 & 0.36 & 31.65 \\
\hline 30.8 & 299.9 & 0.40 & 35.3 \\
\hline 30.9 & 300.9 & 0.46 & 40.01 \\
\hline 30.9 & 300.9 & 0.49 & 42.08 \\
\hline 30.8 & 299.9 & 0.55 & 45.5 \\
\hline 30.9 & 300.9 & 0.61 & 48.59 \\
\hline 30.9 & 302 & 0.65 & 51.1 \\
\hline 31.0 & 299.9 & 0.71 & 52.73 \\
\hline 31.0 & 295.7 & 0.76 & 54.24 \\
\hline 31.0 & 298.8 & 0.80 & 55.08 \\
\hline 31.0 & 302 & 0.85 & 54.94 \\
\hline 31.0 & 294.6 & 0.93 & 54.35 \\
\hline 31.1 & 299.9 & 0.97 & 51.6 \\
\hline 31.1 & 399.9 & 0.02 & 5.073 \\
\hline 30.8 & 403 & 0.05 & 11.65 \\
\hline 30.9 & 399.9 & 0.11 & 17.11 \\
\hline 30.9 & 399.9 & 0.16 & 24.83 \\
\hline 30.9 & 393.5 & 0.21 & 31.55 \\
\hline 30.9 & 398.8 & 0.26 & 38.35 \\
\hline 30.9 & 399.9 & 0.30 & 43.87 \\
\hline 30.9 & 395.7 & 0.36 & 51.64 \\
\hline 30.9 & 399.9 & 0.41 & 58.23 \\
\hline 30.9 & 397.8 & 0.46 & 63.87 \\
\hline 30.9 & 399.9 & 0.50 & 68.91 \\
\hline 31.0 & 404.1 & 0.55 & 75.67 \\
\hline 31.0 & 398.8 & 0.60 & 78.61 \\
\hline 31.1 & 399.9 & 0.65 & 83.48 \\
\hline 31.1 & 396.7 & 0.70 & 85.84 \\
\hline 31.1 & 397.8 & 0.75 & 88.65 \\
\hline 31.1 & 397.8 & 0.80 & 89.92 \\
\hline 31.1 & 399.9 & 0.85 & 91.84 \\
\hline 30.9 & 400.9 & 0.85 & 92.63 \\
\hline 31.0 & 398.8 & 0.90 & 92.41 \\
\hline & & & \\
\hline
\end{tabular}

\begin{tabular}{|l|l|l|l|}
\hline $\left.\boldsymbol{T}_{\text {sat }} \boldsymbol{[ C}\right]$ & $\boldsymbol{G}\left[\mathbf{k g} \boldsymbol{m}^{\mathbf{2}} \boldsymbol{s}\right]$ & $\boldsymbol{x}[-\boldsymbol{]}$ & $(\boldsymbol{d} \boldsymbol{p} / \boldsymbol{d} \boldsymbol{z}) \boldsymbol{f}$ \\
\hline 31.0 & 399.9 & 0.95 & 90.39 \\
\hline 30.9 & 505.1 & 0.05 & 16.75 \\
\hline 30.9 & 494.6 & 0.11 & 25.24 \\
\hline 30.9 & 497.7 & 0.17 & 37.78 \\
\hline 30.9 & 507.2 & 0.20 & 46.39 \\
\hline 31.0 & 499.8 & 0.26 & 57.02 \\
\hline 31.0 & 505.1 & 0.30 & 67.18 \\
\hline 30.8 & 498.8 & 0.37 & 79.22 \\
\hline 30.8 & 494.6 & 0.40 & 85.17 \\
\hline 30.9 & 499.8 & 0.46 & 95.19 \\
\hline 30.9 & 503 & 0.50 & 105.4 \\
\hline 30.9 & 501.9 & 0.56 & 112.2 \\
\hline 30.9 & 498.8 & 0.60 & 118.3 \\
\hline 31.0 & 503 & 0.64 & 123.5 \\
\hline 31.0 & 496.7 & 0.71 & 129.3 \\
\hline 31.1 & 499.8 & 0.76 & 133.2 \\
\hline 31.1 & 499.8 & 0.80 & 135 \\
\hline 31.1 & 496.7 & 0.86 & 135.2 \\
\hline 31.1 & 505.1 & 0.90 & 137.4 \\
\hline 31.1 & 495.6 & 0.96 & 128.4 \\
\hline 30.9 & 600 & 0.06 & 22.59 \\
\hline 31.1 & 598.7 & 0.10 & 38.48 \\
\hline 31.1 & 599.8 & 0.15 & 50.38 \\
\hline 31.1 & 599.6 & 0.20 & 64.65 \\
\hline 31.1 & 600.9 & 0.25 & 79.47 \\
\hline 31.1 & 600.3 & 0.30 & 90.08 \\
\hline 31.1 & 600.5 & 0.35 & 104 \\
\hline 31.1 & 599.5 & 0.41 & 119.5 \\
\hline 31.0 & 601.1 & 0.45 & 130.6 \\
\hline 31.0 & 600.2 & 0.51 & 147 \\
\hline 30.8 & 601.1 & 0.55 & 153.5 \\
\hline 30.9 & 600 & 0.60 & 163.3 \\
\hline 30.9 & 599.2 & 0.66 & 171.2 \\
\hline 30.9 & 599.3 & 0.70 & 178.7 \\
\hline 30.9 & 598.7 & 0.75 & 185.8 \\
\hline 30.8 & 597.9 & 0.80 & 186.1 \\
\hline 30.8 & 597.9 & 0.85 & 184.8 \\
\hline 30.8 & 597.9 & 0.90 & 185.6 \\
\hline 30.8 & 597.9 & 0.95 & 178.4 \\
\hline 41.1 & 100.9 & 0.11 & 1.746 \\
\hline 41.1 & 99.38 & 0.16 & 1.979 \\
\hline 41.2 & 98.86 & 0.20 & 2.118 \\
\hline 41.2 & 100.5 & 0.26 & 2.287 \\
\hline 41.2 & 98.8 & 0.32 & 2.572 \\
\hline 41.2 & 100.2 & 0.37 & 2.844 \\
\hline 41.1 & 100.4 & 0.42 & 3.197 \\
\hline 41.1 & 100.1 & 0.46 & 3.457 \\
\hline 41.0 & 100.4 & 0.50 & 3.826 \\
\hline 41.0 & 100.4 & 0.55 & 4.051 \\
\hline 40.9 & 99.75 & 0.62 & 4.507 \\
\hline 40.9 & 101.4 & 0.65 & 4.756 \\
\hline 40.9 & 100.9 & 0.70 & 5.054 \\
\hline 40.9 & 100.1 & 0.73 & 5.25 \\
\hline 40.9 & 100.2 & 0.78 & 5.394 \\
\hline 40.9 & 99.33 & 0.86 & 5.705 \\
\hline 40.9 & 97.95 & 0.95 & 5.854 \\
\hline 40.9 & 99.46 & 0.99 & 5.759 \\
\hline & & & \\
\hline
\end{tabular}




\begin{tabular}{|l|l|l|l|}
\hline $\left.\boldsymbol{T}_{\text {sat }} \boldsymbol{[} \boldsymbol{C}\right]$ & $\boldsymbol{G}\left[\mathbf{k g} \boldsymbol{m}^{2} \boldsymbol{s}\right]$ & $\boldsymbol{x}[-\boldsymbol{]}$ & $(\boldsymbol{d} \boldsymbol{p} / \boldsymbol{d})_{\boldsymbol{f}}$ \\
\hline 40.6 & 199.7 & 0.07 & 4.132 \\
\hline 40.7 & 200.3 & 0.11 & 4.648 \\
\hline 40.8 & 200.7 & 0.15 & 5.756 \\
\hline 40.9 & 201 & 0.21 & 6.854 \\
\hline 40.9 & 201.2 & 0.26 & 8.531 \\
\hline 40.9 & 199 & 0.31 & 9.922 \\
\hline 40.9 & 198.7 & 0.37 & 11.51 \\
\hline 40.9 & 199.2 & 0.42 & 13.07 \\
\hline 40.9 & 200.2 & 0.45 & 14 \\
\hline 40.9 & 202.2 & 0.51 & 15.77 \\
\hline 40.9 & 200.6 & 0.56 & 16.82 \\
\hline 40.9 & 200.2 & 0.61 & 17.86 \\
\hline 40.9 & 199.7 & 0.66 & 18.74 \\
\hline 40.9 & 200.7 & 0.70 & 19.43 \\
\hline 40.9 & 200.3 & 0.76 & 20.1 \\
\hline 40.9 & 199.9 & 0.79 & 20.2 \\
\hline 40.9 & 199.7 & 0.85 & 20.42 \\
\hline 40.9 & 200.2 & 0.92 & 20.17 \\
\hline 40.8 & 200.2 & 0.96 & 19.69 \\
\hline 40.9 & 297.8 & 0.06 & 5.439 \\
\hline 40.9 & 299.9 & 0.10 & 8.236 \\
\hline 40.9 & 305.2 & 0.15 & 11.04 \\
\hline 40.9 & 305.2 & 0.20 & 14.33 \\
\hline 40.8 & 305.2 & 0.25 & 17.33 \\
\hline 40.9 & 302 & 0.29 & 19.68 \\
\hline 40.8 & 303.1 & 0.34 & 22.9 \\
\hline 40.8 & 303.1 & 0.40 & 26.07 \\
\hline 40.9 & 299.9 & 0.46 & 29.26 \\
\hline 40.9 & 299.9 & 0.51 & 31.84 \\
\hline 40.8 & 299.9 & 0.57 & 35.02 \\
\hline 40.8 & 298.8 & 0.61 & 36.68 \\
\hline 40.8 & 299.9 & 0.66 & 38.76 \\
\hline 40.8 & 295.7 & 0.73 & 40.32 \\
\hline 40.8 & 298.8 & 0.76 & 41.46 \\
\hline 40.9 & 303.1 & 0.79 & 42.07 \\
\hline 40.9 & 297.8 & 0.87 & 42.38 \\
\hline 40.6 & 298.8 & 0.90 & 42.28 \\
\hline 40.8 & 299.9 & 0.96 & 41.02 \\
\hline 40.9 & 399.9 & 0.06 & 9.298 \\
\hline 40.8 & 412.5 & 0.10 & 14.11 \\
\hline 40.8 & 407.2 & 0.15 & 18.6 \\
\hline 40.9 & 399.9 & 0.21 & 24.52 \\
\hline 40.9 & 399.9 & 0.26 & 29.5 \\
\hline 40.9 & 399.9 & 0.30 & 33.82 \\
\hline 41.0 & 396.7 & 0.36 & 40.1 \\
\hline 40.9 & 397.8 & 0.41 & 44.77 \\
\hline 40.9 & 399.9 & 0.46 & 49.22 \\
\hline & & & \\
\hline & & & \\
\hline
\end{tabular}

\begin{tabular}{|c|l|l|l|}
\hline $\boldsymbol{T}_{\text {sat }}[\boldsymbol{C} \boldsymbol{]}$ & $\boldsymbol{G} \boldsymbol{[ k \boldsymbol { g } / \boldsymbol { m } ^ { 2 } \boldsymbol { s } ]}$ & $\boldsymbol{x}[-\boldsymbol{]}$ & $(\boldsymbol{d p} / \boldsymbol{d})_{\boldsymbol{f}}$ \\
\hline 40.9 & 404.1 & 0.50 & 53.95 \\
\hline 40.9 & 404.1 & 0.55 & 58 \\
\hline 41.0 & 400.9 & 0.60 & 61.38 \\
\hline 40.9 & 397.8 & 0.65 & 63.88 \\
\hline 40.9 & 402 & 0.70 & 67.39 \\
\hline 40.9 & 404.1 & 0.75 & 69.63 \\
\hline 40.9 & 403 & 0.80 & 70.74 \\
\hline 40.9 & 402 & 0.86 & 71.95 \\
\hline 40.9 & 396.7 & 0.91 & 69.82 \\
\hline 40.9 & 396.7 & 0.97 & 67.91 \\
\hline 40.8 & 497.7 & 0.06 & 11.92 \\
\hline 40.8 & 497.7 & 0.10 & 18.23 \\
\hline 40.8 & 504 & 0.16 & 26.65 \\
\hline 40.8 & 494.6 & 0.21 & 34.28 \\
\hline 40.9 & 499.8 & 0.26 & 42.1 \\
\hline 40.8 & 501.9 & 0.30 & 49.09 \\
\hline 40.9 & 494.6 & 0.36 & 57.53 \\
\hline 40.9 & 505.1 & 0.39 & 63.66 \\
\hline 40.8 & 495.6 & 0.47 & 71.69 \\
\hline 40.9 & 500.9 & 0.51 & 78.01 \\
\hline 40.8 & 505.1 & 0.55 & 83.65 \\
\hline 40.8 & 501.9 & 0.59 & 88.17 \\
\hline 40.9 & 498.8 & 0.66 & 93.82 \\
\hline 40.9 & 505.1 & 0.69 & 97.34 \\
\hline 40.9 & 497.7 & 0.75 & 99.51 \\
\hline 40.9 & 503 & 0.80 & 103.4 \\
\hline 40.9 & 503 & 0.84 & 104.2 \\
\hline 40.9 & 498.8 & 0.91 & 102.9 \\
\hline 40.9 & 496.7 & 0.95 & 99.86 \\
\hline 40.9 & 600 & 0.05 & 15.31 \\
\hline 40.8 & 598.7 & 0.10 & 25.9 \\
\hline 41.0 & 599.8 & 0.15 & 34.31 \\
\hline 40.9 & 599.6 & 0.20 & 44.07 \\
\hline 40.9 & 600.9 & 0.26 & 56.91 \\
\hline 41.0 & 600.3 & 0.30 & 65.16 \\
\hline 40.9 & 600.5 & 0.35 & 73.46 \\
\hline 41.0 & 599.5 & 0.40 & 83.16 \\
\hline 41.0 & 601.1 & 0.45 & 93.46 \\
\hline 40.9 & 600.2 & 0.50 & 104.6 \\
\hline 41.0 & 601.1 & 0.55 & 113.3 \\
\hline 40.8 & 600 & 0.59 & 121.6 \\
\hline 40.8 & 599.2 & 0.65 & 130.9 \\
\hline 40.9 & 599.3 & 0.71 & 137.3 \\
\hline 41.0 & 598.7 & 0.76 & 140.5 \\
\hline 40.9 & 597.9 & 0.80 & 143.9 \\
\hline 40.9 & 597.9 & 0.86 & 142.9 \\
\hline 40.8 & 597.9 & 0.91 & 140.3 \\
\hline 41.0 & 597.9 & 0.95 & 137 \\
\hline & & & \\
\hline
\end{tabular}

Tabela B.3. R1234yf, geometría circular.

\begin{tabular}{|c|c|c|c|}
\hline $\boldsymbol{T}_{\text {sat }}[\boldsymbol{C}]$ & $\boldsymbol{G}\left[\mathbf{k g} / \boldsymbol{m}^{2} \boldsymbol{s}\right]$ & $\boldsymbol{x}[-]$ & $(\boldsymbol{d p} / \mathbf{d z})_{\boldsymbol{f}}$ \\
\hline 30.8 & 98.18 & 0.11 & 1.746 \\
\hline 31.0 & 100.4 & 0.15 & 1.887 \\
\hline
\end{tabular}

\begin{tabular}{|c|c|c|c|}
\hline $\boldsymbol{T}_{\text {sat }}[\boldsymbol{C}]$ & $\boldsymbol{G}\left[\mathbf{k g} / \mathbf{m}^{2} \boldsymbol{s}\right]$ & $\boldsymbol{x}[-]$ & $(\boldsymbol{d p} / \mathbf{d z})_{\boldsymbol{f}}$ \\
\hline 31.1 & 100.2 & 0.21 & 2.198 \\
\hline 31.1 & 100.1 & 0.27 & 2.467 \\
\hline 31.1 & 100.1 & 0.30 & 2.607 \\
\hline 31.2 & 99.91 & 0.35 & 2.805 \\
\hline
\end{tabular}




\begin{tabular}{|c|c|c|c|}
\hline$T_{\text {sat }}[C]$ & $G\left[\mathrm{~kg} / \mathrm{m}^{2} \mathrm{~s}\right]$ & $x[-]$ & $(d p / d z)_{f}$ \\
\hline 31.2 & 100.4 & 0.40 & 3.08 \\
\hline 31.3 & 99.23 & 0.46 & 3.356 \\
\hline 31.1 & 101.1 & 0.51 & 3.785 \\
\hline 31.0 & 101.1 & 0.57 & 4.527 \\
\hline 30.8 & 101.1 & 0.61 & 4.725 \\
\hline 30.8 & 100.2 & 0.66 & 5.032 \\
\hline 30.8 & 100.2 & 0.69 & 5.157 \\
\hline 30.8 & 101.1 & 0.75 & 5.554 \\
\hline 31.0 & 99.23 & 0.81 & 5.805 \\
\hline 30.9 & 96.39 & 0.89 & 5.802 \\
\hline 30.8 & 92.49 & 0.99 & 5.857 \\
\hline 30.9 & 202 & 0.10 & 4.842 \\
\hline 30.8 & 197.8 & 0.17 & 5.905 \\
\hline 30.9 & 202 & 0.22 & 7.144 \\
\hline 30.9 & 201 & 0.26 & 8.313 \\
\hline 30.9 & 202 & 0.30 & 10.1 \\
\hline 30.8 & 198.9 & 0.37 & 11.98 \\
\hline 31.0 & 198.9 & 0.42 & 13.57 \\
\hline 30.8 & 199.9 & 0.47 & 15.21 \\
\hline 30.8 & 199.9 & 0.51 & 16.26 \\
\hline 30.9 & 197.8 & 0.57 & 17.52 \\
\hline 31.0 & 199.9 & 0.61 & 18.46 \\
\hline 30.9 & 199.9 & 0.66 & 19.38 \\
\hline 30.9 & 201 & 0.72 & 20.06 \\
\hline 30.8 & 199.9 & 0.77 & 20.75 \\
\hline 30.9 & 201 & 0.80 & 20.71 \\
\hline 30.9 & 197.8 & 0.87 & 20.64 \\
\hline 30.9 & 202 & 0.90 & 20.47 \\
\hline 30.9 & 202 & 0.96 & 19.29 \\
\hline 30.8 & 299.9 & 0.11 & 8.997 \\
\hline 31.0 & 302 & 0.16 & 11.33 \\
\hline 30.9 & 298.8 & 0.21 & 14.8 \\
\hline 30.9 & 297.8 & 0.26 & 18.44 \\
\hline 30.9 & 302 & 0.31 & 21.97 \\
\hline 30.9 & 300.9 & 0.36 & 24.95 \\
\hline 31.0 & 297.8 & 0.42 & 27.85 \\
\hline 30.9 & 298.8 & 0.46 & 30.3 \\
\hline 30.9 & 299.9 & 0.51 & 32.61 \\
\hline 30.8 & 302 & 0.55 & 34.8 \\
\hline 30.8 & 299.9 & 0.62 & 37.27 \\
\hline 31.0 & 299.9 & 0.65 & 38.76 \\
\hline 30.9 & 305.2 & 0.69 & 40.79 \\
\hline 30.9 & 296.7 & 0.77 & 41.89 \\
\hline 30.9 & 299.9 & 0.82 & 42.59 \\
\hline 30.9 & 299.9 & 0.86 & 42.57 \\
\hline 30.9 & 303.1 & 0.90 & 42.57 \\
\hline 30.9 & 298.8 & 0.97 & 39.46 \\
\hline 30.8 & 399.9 & 0.09 & 10.87 \\
\hline 30.9 & 403 & 0.14 & 14.92 \\
\hline 31.0 & 399.9 & 0.19 & 19.73 \\
\hline 30.9 & 399.9 & 0.24 & 22.99 \\
\hline 30.9 & 393.5 & 0.29 & 27.42 \\
\hline 30.9 & 398.8 & 0.34 & 32.28 \\
\hline 30.9 & 399.9 & 0.39 & 37.05 \\
\hline 31.0 & 395.7 & 0.45 & 40.2 \\
\hline 30.9 & 399.9 & 0.49 & 45.57 \\
\hline 30.9 & 397.8 & 0.55 & 49.52 \\
\hline
\end{tabular}

\begin{tabular}{|c|c|c|c|}
\hline$T_{\text {sat }}[C]$ & $G\left[\mathrm{~kg} / \mathrm{m}^{2} \mathrm{~s}\right]$ & $x[-]$ & $(d p / d z)_{f}$ \\
\hline 30.9 & 399.9 & 0.60 & 53.72 \\
\hline 30.9 & 404.1 & 0.64 & 56.46 \\
\hline 30.9 & 398.8 & 0.70 & 59.81 \\
\hline 30.9 & 399.9 & 0.75 & 61.41 \\
\hline 30.9 & 396.7 & 0.81 & 62.2 \\
\hline 30.9 & 397.8 & 0.86 & 61.69 \\
\hline 30.8 & 397.8 & 0.91 & 61.84 \\
\hline 30.8 & 399.9 & 0.96 & 59.42 \\
\hline 40.8 & 101.1 & 0.10 & 1.885 \\
\hline 40.9 & 98.28 & 0.16 & 2.106 \\
\hline 41.0 & 99.23 & 0.23 & 2.255 \\
\hline 41.2 & 102.2 & 0.30 & 2.336 \\
\hline 41.2 & 103.1 & 0.35 & 2.378 \\
\hline 41.0 & 97.33 & 0.42 & 2.593 \\
\hline 41.2 & 97.33 & 0.46 & 2.803 \\
\hline 41.1 & 101.1 & 0.48 & 2.893 \\
\hline 41.1 & 101.1 & 0.52 & 3.18 \\
\hline 41.1 & 102.2 & 0.56 & 3.366 \\
\hline 41.1 & 97.33 & 0.67 & 3.601 \\
\hline 41.1 & 97.33 & 0.72 & 3.871 \\
\hline 41.1 & 96.39 & 0.79 & 3.955 \\
\hline 41.2 & 100.2 & 0.80 & 4.188 \\
\hline 41.1 & 100.2 & 0.86 & 4.436 \\
\hline 41.2 & 101.1 & 0.90 & 4.447 \\
\hline 41.1 & 99.23 & 0.98 & 4.467 \\
\hline 41.0 & 200 & 0.12 & 4.124 \\
\hline 41.1 & 199.9 & 0.15 & 4.56 \\
\hline 41.1 & 201 & 0.20 & 5.511 \\
\hline 41.0 & 197.8 & 0.25 & 6.16 \\
\hline 41.1 & 199.9 & 0.31 & 7.668 \\
\hline 41.0 & 201 & 0.37 & 8.778 \\
\hline 41.2 & 197.8 & 0.42 & 9.705 \\
\hline 41.1 & 202 & 0.45 & 10.6 \\
\hline 41.1 & 203.1 & 0.50 & 11.56 \\
\hline 40.8 & 197.8 & 0.56 & 12.61 \\
\hline 40.8 & 199.9 & 0.61 & 13.53 \\
\hline 40.9 & 202 & 0.65 & 14.43 \\
\hline 41.0 & 201 & 0.71 & 15.09 \\
\hline 41.1 & 199.9 & 0.76 & 15.18 \\
\hline 41.0 & 196.8 & 0.82 & 15.41 \\
\hline 41.0 & 197.8 & 0.87 & 15.34 \\
\hline 41.1 & 197.8 & 0.93 & 15.29 \\
\hline 41.0 & 201 & 0.95 & 15.11 \\
\hline 40.8 & 300.9 & 0.10 & 6.499 \\
\hline 40.9 & 304.1 & 0.16 & 8.411 \\
\hline 40.9 & 307.3 & 0.20 & 10.43 \\
\hline 40.8 & 298.8 & 0.27 & 13.42 \\
\hline 40.8 & 304.1 & 0.31 & 15.3 \\
\hline 40.8 & 300.9 & 0.36 & 17.36 \\
\hline 40.8 & 299.9 & 0.42 & 19.99 \\
\hline 40.8 & 299.9 & 0.46 & 21.55 \\
\hline 40.8 & 302 & 0.50 & 23.72 \\
\hline 40.8 & 297.8 & 0.57 & 25.66 \\
\hline 40.8 & 304.1 & 0.61 & 27.52 \\
\hline 40.8 & 298.8 & 0.66 & 28.69 \\
\hline 40.8 & 299.9 & 0.70 & 29.57 \\
\hline 40.9 & 302 & 0.74 & 30.79 \\
\hline
\end{tabular}




\begin{tabular}{|c|c|c|c|}
\hline $\boldsymbol{T}_{\text {sat }}[\boldsymbol{C}]$ & $\boldsymbol{G}\left[\mathbf{k g} / \boldsymbol{m}^{2} \boldsymbol{s}\right]$ & $\boldsymbol{x}[-]$ & $(\boldsymbol{d p} / \boldsymbol{d z})_{\boldsymbol{f}}$ \\
\hline 40.9 & 298.8 & 0.80 & 30.98 \\
\hline 41.0 & 295.7 & 0.87 & 30.52 \\
\hline 41.0 & 304.1 & 0.89 & 30.56 \\
\hline 41.1 & 303.1 & 0.96 & 29.25 \\
\hline 40.9 & 399.9 & 0.11 & 13.67 \\
\hline 40.8 & 399.9 & 0.17 & 17.01 \\
\hline 40.8 & 393.5 & 0.22 & 19.81 \\
\hline 40.8 & 398.8 & 0.27 & 23.11 \\
\hline 40.8 & 399.9 & 0.33 & 27.68 \\
\hline 40.8 & 395.7 & 0.39 & 30.63 \\
\hline
\end{tabular}

\begin{tabular}{|c|c|c|c|}
\hline $\boldsymbol{T}_{\text {sat }}[\boldsymbol{C}]$ & $\boldsymbol{G}\left[\mathbf{k g} / \boldsymbol{m}^{2} \boldsymbol{s}\right]$ & $\boldsymbol{x}[-]$ & $(\boldsymbol{d p} / \boldsymbol{d z})_{\boldsymbol{f}}$ \\
\hline 40.8 & 399.9 & 0.44 & 34.55 \\
\hline 40.8 & 397.8 & 0.50 & 37.88 \\
\hline 40.8 & 399.9 & 0.55 & 40.96 \\
\hline 40.9 & 404.1 & 0.60 & 43.05 \\
\hline 40.8 & 398.8 & 0.66 & 44.17 \\
\hline 40.9 & 399.9 & 0.72 & 45.91 \\
\hline 40.9 & 396.7 & 0.78 & 45.51 \\
\hline 41.0 & 397.8 & 0.83 & 44.72 \\
\hline 41.0 & 397.8 & 0.89 & 45 \\
\hline 41.1 & 399.9 & 0.93 & 44.15 \\
\hline
\end{tabular}

Tabela B.4. R600a, geometría circular.

\begin{tabular}{|c|c|c|c|}
\hline$T_{\text {sat }}[C]$ & $G\left[\mathrm{~kg} / \mathrm{m}^{2} \mathrm{~s}\right]$ & $x[-]$ & $(d p / d z)_{f}$ \\
\hline 31.1 & 100.7 & 0.06 & 3.915 \\
\hline 30.9 & 99.82 & 0.11 & 4.528 \\
\hline 30.8 & 99.38 & 0.16 & 5.571 \\
\hline 30.8 & 103.1 & 0.20 & 6.608 \\
\hline 30.7 & 100.2 & 0.26 & 8.658 \\
\hline 30.7 & 103.1 & 0.30 & 10.46 \\
\hline 31.1 & 100.2 & 0.37 & 11.58 \\
\hline 31.1 & 104.1 & 0.39 & 12.47 \\
\hline 30.9 & 98.28 & 0.48 & 14.41 \\
\hline 30.8 & 99.23 & 0.51 & 15.25 \\
\hline 30.9 & 99.23 & 0.57 & 16.46 \\
\hline 31.1 & 102.2 & 0.60 & 17.06 \\
\hline 31.1 & 98.28 & 0.69 & 17.35 \\
\hline 31.1 & 101.1 & 0.71 & 17.9 \\
\hline 31.1 & 99.23 & 0.77 & 17.93 \\
\hline 31.0 & 103.1 & 0.77 & 18.21 \\
\hline 30.9 & 97.33 & 0.89 & 18.21 \\
\hline 30.9 & 103.1 & 0.87 & 18.06 \\
\hline 30.9 & 103.1 & 0.92 & 17.15 \\
\hline 30.8 & 202 & 0.06 & 8.33 \\
\hline 30.9 & 201 & 0.11 & 13 \\
\hline 30.8 & 202 & 0.17 & 18.78 \\
\hline 30.8 & 199.9 & 0.21 & 23.79 \\
\hline 30.8 & 199.9 & 0.26 & 29.09 \\
\hline 30.8 & 199.9 & 0.31 & 34.55 \\
\hline 30.8 & 201 & 0.36 & 39.58 \\
\hline 30.9 & 199.9 & 0.42 & 45.57 \\
\hline 30.9 & 199.9 & 0.46 & 49.61 \\
\hline 30.9 & 202 & 0.51 & 54.59 \\
\hline 30.9 & 202 & 0.55 & 57.64 \\
\hline 30.9 & 199.9 & 0.62 & 62.16 \\
\hline 31.0 & 199.9 & 0.66 & 64.39 \\
\hline 31.2 & 201 & 0.70 & 66.4 \\
\hline 31.3 & 199.9 & 0.76 & 68.78 \\
\hline 31.2 & 198.9 & 0.81 & 69.76 \\
\hline 31.1 & 202 & 0.86 & 69.9 \\
\hline 31.0 & 201 & 0.90 & 69.17 \\
\hline 31.0 & 202 & 0.94 & 66.27 \\
\hline 30.9 & 298.8 & 0.06 & 14.32 \\
\hline 30.9 & 299.9 & 0.11 & 22.11 \\
\hline
\end{tabular}

\begin{tabular}{|c|c|c|c|}
\hline $\boldsymbol{T}_{\text {sat }} \boldsymbol{[ C} \boldsymbol{C}$ & $\boldsymbol{G}\left[\mathbf{k g} / \boldsymbol{m}^{2} \boldsymbol{s}\right]$ & $\boldsymbol{x}[-]$ & $(\boldsymbol{d p} / \mathbf{d z}) \boldsymbol{f}$ \\
\hline 31.0 & 303.1 & 0.16 & 34.86 \\
\hline 31.1 & 300.9 & 0.21 & 46.06 \\
\hline 31.1 & 302 & 0.26 & 57.13 \\
\hline 31.2 & 304.1 & 0.30 & 66.54 \\
\hline 31.1 & 299.9 & 0.36 & 77.86 \\
\hline 30.9 & 298.8 & 0.41 & 88.65 \\
\hline 30.9 & 299.9 & 0.47 & 101.1 \\
\hline 30.9 & 299.9 & 0.51 & 109.8 \\
\hline 30.8 & 306.2 & 0.55 & 119 \\
\hline 30.9 & 302 & 0.60 & 125.1 \\
\hline 31.0 & 299.9 & 0.66 & 131.9 \\
\hline 31.1 & 299.9 & 0.71 & 137.5 \\
\hline 31.0 & 297.8 & 0.76 & 141.1 \\
\hline 31.3 & 299.9 & 0.79 & 142.8 \\
\hline 31.0 & 304.1 & 0.84 & 143.8 \\
\hline 31.1 & 296.7 & 0.91 & 145.5 \\
\hline 31.0 & 299.9 & 0.95 & 142.7 \\
\hline 30.9 & 402 & 0.07 & 25.48 \\
\hline 30.9 & 398.8 & 0.12 & 41.37 \\
\hline 30.8 & 398.8 & 0.16 & 58.51 \\
\hline 30.9 & 396.7 & 0.21 & 76.68 \\
\hline 30.9 & 402 & 0.26 & 95.93 \\
\hline 30.9 & 399.9 & 0.31 & 112.7 \\
\hline 31.0 & 399.9 & 0.36 & 129.2 \\
\hline 31.1 & 403 & 0.41 & 147 \\
\hline 31.2 & 394.6 & 0.46 & 161.2 \\
\hline 30.5 & 400.9 & 0.50 & 179.3 \\
\hline 30.7 & 400.9 & 0.56 & 195 \\
\hline 30.8 & 402 & 0.60 & 204.8 \\
\hline 30.9 & 399.9 & 0.66 & 215.4 \\
\hline 30.9 & 399.9 & 0.71 & 222.5 \\
\hline 30.9 & 399.9 & 0.76 & 230.1 \\
\hline 30.9 & 403 & 0.80 & 234.9 \\
\hline 31.0 & 398.8 & 0.85 & 236.3 \\
\hline 31.0 & 399.9 & 0.89 & 236.8 \\
\hline 31.1 & 400.9 & 0.94 & 223.1 \\
\hline 30.8 & 499.8 & 0.06 & 32.38 \\
\hline 31.1 & 498.8 & 0.10 & 48.74 \\
\hline 31.1 & 501.9 & 0.15 & 78.91 \\
\hline 31.1 & 495.6 & 0.19 & 95.68 \\
\hline 31.2 & 499.8 & 0.24 & 126.8 \\
\hline 31.2 & 499.8 & 0.29 & 153.9 \\
\hline & & & \\
\hline
\end{tabular}




\begin{tabular}{|c|c|c|c|}
\hline$T_{\text {sat }}[C]$ & $G\left[\mathrm{~kg} / \mathrm{m}^{2} \mathrm{~s}\right]$ & $x[-]$ & $(d p / d z)_{f}$ \\
\hline 31.1 & 496.7 & 0.34 & 175.2 \\
\hline 31.0 & 500.9 & 0.40 & 210.2 \\
\hline 31.1 & 496.7 & 0.44 & 226.9 \\
\hline 31.1 & 496.7 & 0.48 & 244.7 \\
\hline 31.1 & 497.7 & 0.54 & 264.1 \\
\hline 31.1 & 493.5 & 0.59 & 277.9 \\
\hline 30.8 & 481.9 & 0.65 & 286.3 \\
\hline 31.0 & 472.5 & 0.71 & 291.7 \\
\hline 30.8 & 466.2 & 0.76 & 293.8 \\
\hline 31.2 & 471.4 & 0.78 & 291.3 \\
\hline 41.1 & 99.23 & 0.07 & 3.552 \\
\hline 41.0 & 99.23 & 0.13 & 3.847 \\
\hline 41.0 & 102.2 & 0.16 & 4.647 \\
\hline 41.0 & 99.23 & 0.23 & 5.502 \\
\hline 41.1 & 101.1 & 0.27 & 6.589 \\
\hline 41.1 & 101.1 & 0.32 & 7.927 \\
\hline 41.1 & 100.2 & 0.36 & 8.731 \\
\hline 41.0 & 101.1 & 0.42 & 10.25 \\
\hline 41.1 & 99.23 & 0.47 & 10.8 \\
\hline 41.1 & 99.23 & 0.53 & 12.04 \\
\hline 41.1 & 102.2 & 0.55 & 12.93 \\
\hline 41.1 & 103.1 & 0.59 & 13.36 \\
\hline 41.0 & 99.23 & 0.66 & 13.81 \\
\hline 41.1 & 96.39 & 0.74 & 14.08 \\
\hline 41.1 & 100.2 & 0.75 & 14.77 \\
\hline 41.1 & 99.23 & 0.80 & 14.39 \\
\hline 41.1 & 105 & 0.79 & 14.56 \\
\hline 41.1 & 99.23 & 0.90 & 14.46 \\
\hline 41.2 & 97.33 & 0.98 & 13.96 \\
\hline 40.9 & 198.9 & 0.07 & 6.715 \\
\hline 41.0 & 198.9 & 0.11 & 9.865 \\
\hline 41.0 & 199.9 & 0.16 & 12.9 \\
\hline 41.0 & 202 & 0.21 & 17.74 \\
\hline 40.9 & 202 & 0.27 & 23.37 \\
\hline 40.9 & 202 & 0.32 & 27.51 \\
\hline 40.9 & 196.8 & 0.36 & 30.08 \\
\hline 40.9 & 199.9 & 0.41 & 34.59 \\
\hline 40.8 & 202 & 0.46 & 39.25 \\
\hline 40.9 & 199.9 & 0.52 & 42.75 \\
\hline 40.9 & 202 & 0.57 & 45.78 \\
\hline 40.8 & 198.9 & 0.62 & 48.57 \\
\hline 40.8 & 198.9 & 0.67 & 51.21 \\
\hline 41.0 & 202 & 0.71 & 53.83 \\
\hline 40.9 & 199.9 & 0.77 & 54.95 \\
\hline 40.9 & 201 & 0.81 & 54.88 \\
\hline 41.0 & 199.9 & 0.85 & 55.02 \\
\hline 40.9 & 202 & 0.88 & 54.67 \\
\hline 40.9 & 202 & 0.95 & 52.7 \\
\hline 41.0 & 298.8 & 0.07 & 13.58 \\
\hline 41.0 & 300.9 & 0.11 & 18.76 \\
\hline 41.0 & 305.2 & 0.17 & 28.89 \\
\hline 40.9 & 300.9 & 0.21 & 36.11 \\
\hline
\end{tabular}

\begin{tabular}{|c|c|c|c|}
\hline$T_{\text {sat }}[C]$ & $G\left[\mathrm{~kg} / \mathrm{m}^{2} \mathrm{~s}\right]$ & $x[-]$ & $(d p / d z)_{f}$ \\
\hline 41.0 & 300.9 & 0.28 & 47.06 \\
\hline 41.1 & 304.1 & 0.31 & 54.33 \\
\hline 41.1 & 304.1 & 0.36 & 63.06 \\
\hline 41.1 & 299.9 & 0.41 & 68.61 \\
\hline 41.2 & 295.7 & 0.45 & 74.02 \\
\hline 41.1 & 300.9 & 0.51 & 85.12 \\
\hline 41.1 & 298.8 & 0.57 & 93.38 \\
\hline 41.2 & 302 & 0.61 & 99.52 \\
\hline 41.2 & 302 & 0.66 & 104.8 \\
\hline 41.1 & 300.9 & 0.71 & 108.9 \\
\hline 41.1 & 297.8 & 0.76 & 112.9 \\
\hline 41.2 & 302 & 0.80 & 115.6 \\
\hline 41.1 & 300.9 & 0.86 & 116.1 \\
\hline 41.1 & 295.7 & 0.92 & 115.9 \\
\hline 41.0 & 299.9 & 0.94 & 113.8 \\
\hline 41.0 & 399.9 & 0.06 & 20.9 \\
\hline 41.0 & 399.9 & 0.11 & 31.45 \\
\hline 41.1 & 400.9 & 0.16 & 46.4 \\
\hline 41.1 & 397.8 & 0.21 & 59.92 \\
\hline 41.1 & 399.9 & 0.26 & 76.1 \\
\hline 41.0 & 399.9 & 0.31 & 89.77 \\
\hline 41.2 & 399.9 & 0.35 & 102 \\
\hline 41.3 & 399.9 & 0.41 & 115.9 \\
\hline 41.1 & 402 & 0.46 & 131.7 \\
\hline 41.0 & 399.9 & 0.50 & 140.2 \\
\hline 40.9 & 398.8 & 0.62 & 163.1 \\
\hline 41.0 & 400.9 & 0.66 & 171.4 \\
\hline 40.8 & 398.8 & 0.71 & 177.2 \\
\hline 40.9 & 402 & 0.76 & 184.6 \\
\hline 41.0 & 399.9 & 0.81 & 187.2 \\
\hline 41.1 & 396.7 & 0.86 & 189.2 \\
\hline 41.2 & 399.9 & 0.90 & 184.4 \\
\hline 41.1 & 400.9 & 0.96 & 166.6 \\
\hline 41.1 & 498.8 & 0.07 & 27.72 \\
\hline 41.1 & 500.9 & 0.12 & 47.17 \\
\hline 41.1 & 497.7 & 0.14 & 57.36 \\
\hline 41.2 & 498.8 & 0.21 & 85.53 \\
\hline 41.1 & 503 & 0.26 & 106.3 \\
\hline 41.0 & 505.1 & 0.30 & 125.8 \\
\hline 40.9 & 500.9 & 0.35 & 145.6 \\
\hline 41.0 & 498.8 & 0.41 & 165.9 \\
\hline 41.1 & 503 & 0.46 & 185.8 \\
\hline 41.3 & 499.8 & 0.51 & 201.5 \\
\hline 41.0 & 498.8 & 0.56 & 213.6 \\
\hline 41.1 & 499.8 & 0.60 & 226.2 \\
\hline 41.1 & 503 & 0.65 & 239.2 \\
\hline 41.1 & 499.8 & 0.70 & 247.6 \\
\hline 41.2 & 500.9 & 0.76 & 257.8 \\
\hline 41.1 & 499.8 & 0.80 & 261.2 \\
\hline 41.2 & 498.8 & 0.87 & 267.5 \\
\hline 41.0 & 496.7 & 0.91 & 249.9 \\
\hline 41.1 & 498.8 & 0.95 & 236.4 \\
\hline
\end{tabular}


Tabela B.5. R134a, geometría quadrada

\begin{tabular}{|c|c|c|c|}
\hline$T_{\text {sat }}[C]$ & $G\left[\mathrm{~kg} / \mathrm{m}^{2} \mathrm{~s}\right]$ & $x[-]$ & $(d p / d z)_{f}$ \\
\hline 31.0 & 400.1 & 0.11 & 17.1 \\
\hline 31.0 & 401.3 & 0.15 & 25.46 \\
\hline 31.0 & 400 & 0.20 & 33.6 \\
\hline 30.9 & 400.1 & 0.25 & 37.05 \\
\hline 30.9 & 399.1 & 0.29 & 42.22 \\
\hline 30.9 & 399.9 & 0.35 & 49.33 \\
\hline 31.0 & 398.9 & 0.40 & 53.46 \\
\hline 30.9 & 400.8 & 0.45 & 59.04 \\
\hline 30.9 & 400.3 & 0.50 & 64.16 \\
\hline 31.0 & 400.4 & 0.55 & 68.05 \\
\hline 31.0 & 402.5 & 0.60 & 71.75 \\
\hline 31.0 & 399.8 & 0.65 & 74.82 \\
\hline 30.9 & 400.6 & 0.70 & 78.57 \\
\hline 30.9 & 401.6 & 0.75 & 81.04 \\
\hline 30.9 & 399.5 & 0.80 & 82.44 \\
\hline 31.0 & 399.7 & 0.86 & 83.44 \\
\hline 31.0 & 400.9 & 0.90 & 83.13 \\
\hline 31.0 & 400.6 & 0.95 & 79.04 \\
\hline 30.9 & 500.4 & 0.11 & 24.45 \\
\hline 30.9 & 499.9 & 0.15 & 38.44 \\
\hline 31.0 & 499.7 & 0.19 & 48.42 \\
\hline 31.0 & 501.2 & 0.25 & 55.71 \\
\hline 30.9 & 499.5 & 0.30 & 64.15 \\
\hline 30.9 & 500.9 & 0.35 & 70.82 \\
\hline 30.9 & 500.5 & 0.39 & 77.41 \\
\hline 31.0 & 501.5 & 0.44 & 83.78 \\
\hline 31.1 & 500.2 & 0.50 & 90.88 \\
\hline 31.0 & 500.1 & 0.55 & 98.36 \\
\hline 31.0 & 498.4 & 0.60 & 102.9 \\
\hline 30.9 & 500.1 & 0.65 & 108.2 \\
\hline 30.9 & 500.4 & 0.69 & 111.6 \\
\hline 31.1 & 499.6 & 0.73 & 113.3 \\
\hline 31.1 & 498.8 & 0.80 & 118 \\
\hline 31.0 & 501.2 & 0.84 & 118.8 \\
\hline 30.9 & 499 & 0.90 & 120.4 \\
\hline 30.8 & 499.8 & 0.95 & 117 \\
\hline 30.9 & 598.4 & 0.11 & 35.19 \\
\hline 31.0 & 598.6 & 0.15 & 50.56 \\
\hline 31.1 & 597.9 & 0.20 & 62.78 \\
\hline 31.0 & 597.3 & 0.25 & 74.79 \\
\hline 31.1 & 601.6 & 0.29 & 83.87 \\
\hline 31.0 & 600.1 & 0.35 & 96.22 \\
\hline 30.9 & 599.6 & 0.40 & 104.9 \\
\hline 31.1 & 601.5 & 0.44 & 112.1 \\
\hline 31.0 & 599.2 & 0.51 & 123.1 \\
\hline 31.1 & 600 & 0.55 & 131.1 \\
\hline 31.0 & 599.5 & 0.61 & 138.7 \\
\hline 31.1 & 601.4 & 0.65 & 144.8 \\
\hline 31.1 & 600 & 0.71 & 150.6 \\
\hline 31.0 & 598.1 & 0.75 & 154.1 \\
\hline 31.2 & 599.9 & 0.81 & 157.1 \\
\hline 31.0 & 600.1 & 0.86 & 160.7 \\
\hline 31.0 & 598 & 0.91 & 162.7 \\
\hline 31.0 & 599.8 & 0.96 & 154.5 \\
\hline
\end{tabular}

\begin{tabular}{|c|c|c|c|}
\hline$T_{\text {sat }}[C]$ & $G\left[\mathrm{~kg} / \mathrm{m}^{2} \mathrm{~s}\right]$ & $x[-]$ & $(d p / d z)_{f}$ \\
\hline 31.0 & 699.2 & 0.10 & 40.65 \\
\hline 31.0 & 699.9 & 0.15 & 62.76 \\
\hline 31.1 & 699.1 & 0.19 & 78.74 \\
\hline 31.0 & 701.8 & 0.24 & 93.17 \\
\hline 31.0 & 698.9 & 0.30 & 108.1 \\
\hline 31.2 & 699.3 & 0.36 & 121.3 \\
\hline 31.0 & 696.2 & 0.41 & 136.6 \\
\hline 31.2 & 698.3 & 0.45 & 143.8 \\
\hline 31.0 & 698.5 & 0.50 & 156.9 \\
\hline 31.0 & 701 & 0.54 & 165.4 \\
\hline 31.0 & 700.2 & 0.60 & 175.8 \\
\hline 31.1 & 700 & 0.65 & 183.7 \\
\hline 31.1 & 699.3 & 0.70 & 189.6 \\
\hline 31.1 & 698.4 & 0.76 & 194.9 \\
\hline 30.9 & 700.2 & 0.81 & 201.5 \\
\hline 31.0 & 708.4 & 0.85 & 205.5 \\
\hline 31.1 & 697.7 & 0.91 & 207.9 \\
\hline 30.7 & 701.9 & 0.94 & 204.3 \\
\hline 31.0 & 800.6 & 0.10 & 54.79 \\
\hline 31.1 & 799.9 & 0.15 & 73.28 \\
\hline 31.0 & 799.7 & 0.19 & 88.17 \\
\hline 31.1 & 800.7 & 0.24 & 106.3 \\
\hline 31.1 & 797.6 & 0.30 & 123.8 \\
\hline 31.2 & 798.3 & 0.35 & 140.6 \\
\hline 31.2 & 801.2 & 0.39 & 156.7 \\
\hline 31.1 & 801.4 & 0.45 & 172.9 \\
\hline 31.1 & 800.3 & 0.50 & 182 \\
\hline 31.1 & 799.2 & 0.55 & 191.2 \\
\hline 31.0 & 800 & 0.60 & 207.2 \\
\hline 31.0 & 799.7 & 0.65 & 221 \\
\hline 31.0 & 800.2 & 0.70 & 228 \\
\hline 31.1 & 800 & 0.75 & 234.9 \\
\hline 31.1 & 801.2 & 0.80 & 242.6 \\
\hline 31.0 & 800.3 & 0.85 & 250.6 \\
\hline 30.9 & 798.3 & 0.90 & 257.6 \\
\hline 30.7 & 798.3 & 0.96 & 232.2 \\
\hline 31.0 & 899.9 & 0.12 & 80.49 \\
\hline 30.9 & 901.2 & 0.15 & 96.19 \\
\hline 30.8 & 898.4 & 0.20 & 117.5 \\
\hline 31.0 & 898.3 & 0.25 & 140.2 \\
\hline 30.9 & 900 & 0.30 & 159.8 \\
\hline 30.9 & 900.8 & 0.35 & 181.5 \\
\hline 30.9 & 897.9 & 0.39 & 198.9 \\
\hline 31.0 & 901.3 & 0.45 & 218.9 \\
\hline 30.9 & 898.1 & 0.50 & 234.7 \\
\hline 31.0 & 899.6 & 0.55 & 244.9 \\
\hline 30.9 & 900.2 & 0.59 & 256.5 \\
\hline 31.0 & 899 & 0.65 & 267.5 \\
\hline 31.0 & 901.9 & 0.71 & 276 \\
\hline 31.0 & 900.3 & 0.76 & 283.3 \\
\hline 31.0 & 898.2 & 0.81 & 292.7 \\
\hline 31.0 & 899.9 & 0.86 & 300.2 \\
\hline 30.9 & 899.3 & 0.90 & 303.9 \\
\hline 31.0 & 1000 & 0.11 & 88.39 \\
\hline 31.0 & 1000 & 0.15 & 111.5 \\
\hline 30.9 & 1001 & 0.20 & 136.8 \\
\hline 31.2 & 1000 & 0.24 & 162.2 \\
\hline
\end{tabular}




\begin{tabular}{|c|c|c|c|}
\hline$T_{\text {sat }}[C]$ & $G\left[\mathrm{~kg} / \mathrm{m}^{2} \mathrm{~s}\right]$ & $x[-]$ & $(d p / d z)_{f}$ \\
\hline 31.0 & 998.5 & 0.30 & 188.9 \\
\hline 31.1 & 999.2 & 0.35 & 214.2 \\
\hline 31.0 & 998.4 & 0.41 & 239.9 \\
\hline 31.0 & 998 & 0.45 & 257.8 \\
\hline 31.0 & 1000 & 0.50 & 273.3 \\
\hline 31.1 & 998 & 0.54 & 285.8 \\
\hline 31.0 & 1000 & 0.60 & 299.2 \\
\hline 31.0 & 998.2 & 0.65 & 310 \\
\hline 31.1 & 1000 & 0.71 & 320.4 \\
\hline 31.0 & 1002 & 0.75 & 330.3 \\
\hline 31.1 & 1000 & 0.80 & 338.6 \\
\hline 31.0 & 998.8 & 0.85 & 351.5 \\
\hline 31.0 & 1001 & 0.89 & 354.5 \\
\hline 30.9 & 1001 & 0.95 & 270.1 \\
\hline 31.0 & 1099 & 0.09 & 92.07 \\
\hline 31.1 & 1094 & 0.15 & 125.6 \\
\hline 31.0 & 1104 & 0.20 & 156.9 \\
\hline 31.2 & 1100 & 0.25 & 186.2 \\
\hline 31.0 & 1099 & 0.30 & 219.7 \\
\hline 31.1 & 1101 & 0.35 & 249.3 \\
\hline 31.1 & 1099 & 0.39 & 270.4 \\
\hline 31.0 & 1101 & 0.45 & 294.4 \\
\hline 31.0 & 1099 & 0.50 & 313 \\
\hline 30.9 & 1102 & 0.54 & 330.4 \\
\hline 30.8 & 1101 & 0.59 & 343.1 \\
\hline 31.0 & 1099 & 0.65 & 353.1 \\
\hline 31.1 & 1098 & 0.70 & 363.1 \\
\hline 31.1 & 1101 & 0.75 & 371.3 \\
\hline 31.1 & 1099 & 0.80 & 383.3 \\
\hline 30.9 & 1099 & 0.85 & 388.8 \\
\hline 30.9 & 1100 & 0.90 & 372.4 \\
\hline 31.0 & 1099 & 0.95 & 319.4 \\
\hline 31.1 & 1204 & 0.09 & 93.02 \\
\hline 31.0 & 1201 & 0.15 & 141.5 \\
\hline 31.0 & 1201 & 0.20 & 175.4 \\
\hline 31.1 & 1200 & 0.24 & 205.8 \\
\hline 31.0 & 1200 & 0.29 & 243 \\
\hline 31.0 & 1199 & 0.35 & 278.3 \\
\hline 31.0 & 1200 & 0.40 & 308.2 \\
\hline 31.0 & 1200 & 0.45 & 336.8 \\
\hline 30.9 & 1200 & 0.50 & 357.6 \\
\hline 30.7 & 1201 & 0.55 & 377.8 \\
\hline 31.0 & 1201 & 0.59 & 384.6 \\
\hline 31.0 & 1199 & 0.64 & 392.9 \\
\hline 31.1 & 1201 & 0.69 & 403.8 \\
\hline 31.2 & 1200 & 0.74 & 410 \\
\hline 31.1 & 1201 & 0.79 & 428.3 \\
\hline 31.1 & 1200 & 0.85 & 430.7 \\
\hline 31.0 & 1201 & 0.90 & 402.7 \\
\hline 31.1 & 1299 & 0.10 & 122.8 \\
\hline 31.1 & 1298 & 0.15 & 168.4 \\
\hline 31.1 & 1301 & 0.20 & 205.2 \\
\hline 30.9 & 1300 & 0.25 & 249.1 \\
\hline 31.0 & 1301 & 0.30 & 287.3 \\
\hline 31.1 & 1301 & 0.34 & 325.2 \\
\hline 31.1 & 1300 & 0.40 & 359.3 \\
\hline 31.0 & 1301 & 0.45 & 389.4 \\
\hline
\end{tabular}

\begin{tabular}{|c|c|c|c|}
\hline$T_{\text {sat }}[C]$ & $G\left[\mathrm{~kg} / \mathrm{m}^{2} \mathrm{~s}\right]$ & $x[-]$ & $(d p / d z)_{f}$ \\
\hline 31.0 & 1300 & 0.50 & 411 \\
\hline 30.9 & 1300 & 0.55 & 427.2 \\
\hline 31.1 & 1300 & 0.59 & 435.2 \\
\hline 31.1 & 1301 & 0.65 & 445.6 \\
\hline 31.1 & 1302 & 0.69 & 453 \\
\hline 31.1 & 1299 & 0.75 & 468.4 \\
\hline 31.1 & 1300 & 0.79 & 488.2 \\
\hline 31.1 & 1299 & 0.85 & 492.1 \\
\hline 30.9 & 1400 & 0.11 & 149.4 \\
\hline 31.0 & 1400 & 0.15 & 185.3 \\
\hline 30.9 & 1399 & 0.20 & 229.9 \\
\hline 31.0 & 1399 & 0.24 & 274.5 \\
\hline 31.0 & 1397 & 0.30 & 320.6 \\
\hline 30.9 & 1400 & 0.34 & 358.6 \\
\hline 31.0 & 1399 & 0.39 & 392.3 \\
\hline 31.0 & 1399 & 0.45 & 426.4 \\
\hline 30.9 & 1398 & 0.49 & 445.6 \\
\hline 31.0 & 1398 & 0.54 & 459.9 \\
\hline 31.1 & 1400 & 0.60 & 470.1 \\
\hline 31.2 & 1399 & 0.64 & 477.2 \\
\hline 31.0 & 1401 & 0.70 & 493.3 \\
\hline 31.1 & 1401 & 0.74 & 507.9 \\
\hline 31.1 & 1400 & 0.79 & 537.1 \\
\hline 31.0 & 1400 & 0.85 & 478.3 \\
\hline 31.1 & 1502 & 0.05 & 98.97 \\
\hline 30.9 & 1498 & 0.10 & 154.6 \\
\hline 31.1 & 1493 & 0.15 & 205.2 \\
\hline 31.0 & 1501 & 0.20 & 262.5 \\
\hline 31.0 & 1500 & 0.25 & 318.7 \\
\hline 31.0 & 1501 & 0.29 & 356.9 \\
\hline 31.1 & 1500 & 0.34 & 401.8 \\
\hline 31.0 & 1500 & 0.39 & 438.8 \\
\hline 31.0 & 1499 & 0.44 & 469.5 \\
\hline 30.9 & 1500 & 0.49 & 492.5 \\
\hline 31.0 & 1500 & 0.54 & 505.4 \\
\hline 31.0 & 1500 & 0.60 & 514.4 \\
\hline 31.0 & 1497 & 0.66 & 525.4 \\
\hline 31.0 & 1500 & 0.71 & 543.8 \\
\hline 31.1 & 1498 & 0.76 & 570 \\
\hline 31.1 & 1500 & 0.80 & 593.5 \\
\hline 31.1 & 1602 & 0.05 & 105.9 \\
\hline 31.1 & 1593 & 0.10 & 171.1 \\
\hline 31.0 & 1602 & 0.15 & 234.5 \\
\hline 31.0 & 1598 & 0.19 & 284.7 \\
\hline 31.1 & 1600 & 0.24 & 341.8 \\
\hline 31.2 & 1601 & 0.29 & 390.2 \\
\hline 31.0 & 1598 & 0.35 & 445 \\
\hline 31.1 & 1601 & 0.39 & 482.4 \\
\hline 31.0 & 1598 & 0.44 & 514.4 \\
\hline 30.9 & 1597 & 0.49 & 535.8 \\
\hline 31.0 & 1598 & 0.54 & 544.6 \\
\hline 31.1 & 1601 & 0.58 & 546.7 \\
\hline 31.0 & 1598 & 0.64 & 558 \\
\hline 31.1 & 1601 & 0.69 & 577.5 \\
\hline 31.0 & 1600 & 0.74 & 610.3 \\
\hline 31.1 & 1599 & 0.79 & 546.6 \\
\hline 41.1 & 402.6 & 0.10 & 17.42 \\
\hline
\end{tabular}




\begin{tabular}{|c|c|c|c|}
\hline $\left.\boldsymbol{T}_{\text {sat }} \boldsymbol{[ C}\right]$ & $\boldsymbol{G}\left[\mathbf{k g} / \boldsymbol{m}^{2} \boldsymbol{s}\right]$ & $\boldsymbol{x}[-]$ & $(\boldsymbol{d p} / \mathbf{d} \boldsymbol{z}) \boldsymbol{f}$ \\
\hline 41.2 & 403.9 & 0.15 & 13.74 \\
\hline 41.1 & 399.9 & 0.20 & 23.57 \\
\hline 41.1 & 399.9 & 0.25 & 28.41 \\
\hline 41.1 & 401.3 & 0.31 & 30.33 \\
\hline 41.1 & 395.9 & 0.36 & 34.62 \\
\hline 41.2 & 399.9 & 0.41 & 31.6 \\
\hline 41.2 & 395.9 & 0.46 & 33.49 \\
\hline 41.1 & 397.3 & 0.51 & 42.06 \\
\hline 41.2 & 398.6 & 0.55 & 39.58 \\
\hline 41.2 & 397.3 & 0.61 & 46.95 \\
\hline 40.9 & 399.9 & 0.65 & 47.99 \\
\hline 40.9 & 399.9 & 0.71 & 48.54 \\
\hline 40.9 & 397.3 & 0.77 & 47.9 \\
\hline 41.0 & 398.6 & 0.82 & 48.33 \\
\hline 41.0 & 399.9 & 0.86 & 53.19 \\
\hline 41.0 & 395.9 & 0.92 & 54.39 \\
\hline 41.0 & 397.3 & 0.98 & 48.93 \\
\hline 41.2 & 599.9 & 0.10 & 22.96 \\
\hline 41.1 & 598.6 & 0.15 & 30.99 \\
\hline 41.1 & 603.9 & 0.19 & 45.28 \\
\hline 41.0 & 597.2 & 0.26 & 51.45 \\
\hline 41.1 & 599.9 & 0.30 & 58.07 \\
\hline 41.1 & 594.6 & 0.36 & 64.08 \\
\hline 40.9 & 606.6 & 0.40 & 71.85 \\
\hline 40.9 & 602.6 & 0.45 & 73.6 \\
\hline 41.0 & 595.9 & 0.50 & 88.07 \\
\hline 41.0 & 602.6 & 0.54 & 86.34 \\
\hline 40.9 & 597.2 & 0.60 & 91.6 \\
\hline 40.9 & 599.9 & 0.66 & 102.1 \\
\hline 40.9 & 598.6 & 0.72 & 106.4 \\
\hline 41.0 & 595.9 & 0.75 & 105.9 \\
\hline 41.0 & 602.6 & 0.79 & 107.2 \\
\hline 41.1 & 598.6 & 0.86 & 109.9 \\
\hline 41.1 & 602.6 & 0.91 & 109.3 \\
\hline 41.0 & 599.9 & 0.95 & 105.8 \\
\hline 41.0 & 802.5 & 0.11 & 40.54 \\
\hline & & & \\
\hline
\end{tabular}

\begin{tabular}{|c|c|c|c|}
\hline $\left.\boldsymbol{T}_{\text {sat }} \boldsymbol{[ C}\right]$ & $\boldsymbol{G}\left[\mathbf{k g} \boldsymbol{m}^{2} \boldsymbol{s}\right]$ & $\boldsymbol{x}[-]$ & $(\boldsymbol{d p} / \boldsymbol{d} \boldsymbol{z})_{\boldsymbol{f}}$ \\
\hline 41.2 & 801.2 & 0.16 & 57.98 \\
\hline 41.2 & 801.2 & 0.20 & 71.58 \\
\hline 41.2 & 802.5 & 0.24 & 79.03 \\
\hline 41.2 & 801.2 & 0.29 & 91.29 \\
\hline 41.2 & 799.9 & 0.34 & 99.31 \\
\hline 41.2 & 802.5 & 0.39 & 118.1 \\
\hline 41.0 & 801.2 & 0.45 & 124.2 \\
\hline 41.1 & 802.5 & 0.49 & 135.1 \\
\hline 41.0 & 801.2 & 0.55 & 143.8 \\
\hline 41.1 & 801.2 & 0.60 & 149.5 \\
\hline 41.1 & 795.9 & 0.66 & 154.7 \\
\hline 41.0 & 799.9 & 0.70 & 161.2 \\
\hline 41.0 & 795.9 & 0.75 & 163 \\
\hline 41.1 & 795.9 & 0.81 & 171.6 \\
\hline 41.0 & 803.8 & 0.85 & 174.6 \\
\hline 41.1 & 806.5 & 0.90 & 172.3 \\
\hline 41.1 & 799.9 & 0.95 & 142.8 \\
\hline 41.2 & 1002 & 0.10 & 54.88 \\
\hline 41.3 & 1001 & 0.15 & 80.93 \\
\hline 41.1 & 1000 & 0.19 & 94.27 \\
\hline 40.8 & 1000 & 0.25 & 115.1 \\
\hline 40.9 & 997.1 & 0.30 & 137.3 \\
\hline 41.0 & 1000 & 0.34 & 148.7 \\
\hline 41.0 & 1000 & 0.40 & 167 \\
\hline 41.0 & 997.1 & 0.45 & 182.3 \\
\hline 41.0 & 995.8 & 0.50 & 191.8 \\
\hline 40.9 & 998.5 & 0.55 & 204.6 \\
\hline 40.9 & 998.5 & 0.60 & 209.4 \\
\hline 40.9 & 998.5 & 0.65 & 221.4 \\
\hline 40.9 & 995.8 & 0.71 & 226.3 \\
\hline 40.9 & 995.8 & 0.76 & 234 \\
\hline 40.9 & 1006 & 0.80 & 235.8 \\
\hline 41.0 & 1005 & 0.85 & 249.9 \\
\hline 41.0 & 1001 & 0.91 & 221.7 \\
\hline & & & \\
\hline
\end{tabular}

Tabela B.6. R134a, geometría triangular.

\begin{tabular}{|c|c|c|c|}
\hline $\boldsymbol{T}_{\text {sat }}[\boldsymbol{C}]$ & $\boldsymbol{G}\left[\mathbf{k g} / \boldsymbol{m}^{2} \boldsymbol{s}\right]$ & $\boldsymbol{x}[-]$ & $(\boldsymbol{d p} / \mathbf{d z})_{\boldsymbol{f}}$ \\
\hline 31.0 & 397.1 & 0.10 & 17.06 \\
\hline 31.0 & 400.1 & 0.16 & 20.74 \\
\hline 31.0 & 396.9 & 0.20 & 28.6 \\
\hline 31.0 & 399.9 & 0.26 & 41.04 \\
\hline 31.0 & 403.3 & 0.30 & 50.08 \\
\hline 31.1 & 399.6 & 0.35 & 54.13 \\
\hline 31.0 & 400.5 & 0.40 & 58.14 \\
\hline 30.9 & 395.9 & 0.45 & 62.85 \\
\hline 30.9 & 400 & 0.51 & 66.38 \\
\hline 31.0 & 400.1 & 0.57 & 74.36 \\
\hline 31.0 & 399.9 & 0.62 & 80.17 \\
\hline 31.1 & 399.6 & 0.66 & 82.24 \\
\hline 31.1 & 399.1 & 0.71 & 86.44 \\
\hline 31.1 & 400.4 & 0.75 & 90.73 \\
\hline 30.9 & 401.8 & 0.80 & 97.33 \\
\hline 31.0 & 398 & 0.87 & 99.85 \\
\hline
\end{tabular}

\begin{tabular}{|c|c|c|c|}
\hline $\boldsymbol{T}_{\text {sat }}[\boldsymbol{C}]$ & $\boldsymbol{G}\left[\mathbf{k g} / \boldsymbol{m}^{2} \boldsymbol{s}\right]$ & $\boldsymbol{x}[-]$ & $(\boldsymbol{d p} / \mathbf{d z})_{\boldsymbol{f}}$ \\
\hline 31.0 & 399.8 & 0.91 & 97.54 \\
\hline 31.0 & 401.5 & 0.95 & 95.94 \\
\hline 31.0 & 501.3 & 0.11 & 23.19 \\
\hline 30.9 & 500.1 & 0.15 & 32.5 \\
\hline 30.9 & 499.3 & 0.20 & 50.47 \\
\hline 31.0 & 500.6 & 0.24 & 67.11 \\
\hline 31.1 & 498.1 & 0.30 & 77.43 \\
\hline 31.0 & 500.4 & 0.35 & 86.2 \\
\hline 30.9 & 503.2 & 0.39 & 95.1 \\
\hline 31.0 & 500.3 & 0.45 & 104.8 \\
\hline 31.0 & 499.1 & 0.51 & 113.4 \\
\hline 31.1 & 500.6 & 0.55 & 120.3 \\
\hline 31.1 & 500.7 & 0.60 & 128.7 \\
\hline 31.1 & 502.1 & 0.65 & 133.8 \\
\hline 31.0 & 500.3 & 0.70 & 139.9 \\
\hline 30.8 & 500.1 & 0.75 & 147.3 \\
\hline 30.8 & 496.7 & 0.81 & 149.7 \\
\hline 30.9 & 499.4 & 0.86 & 152.9 \\
\hline
\end{tabular}




\begin{tabular}{|c|c|c|c|}
\hline$T_{\text {sat }}[C]$ & $G\left[\mathrm{~kg} / \mathrm{m}^{2} \mathrm{~s}\right]$ & $x[-]$ & $(d p / d z)_{f}$ \\
\hline 30.9 & 500.8 & 0.91 & 157 \\
\hline 30.9 & 499.5 & 0.95 & 155.3 \\
\hline 30.9 & 598.9 & 0.11 & 38.82 \\
\hline 31.0 & 599.3 & 0.15 & 52.9 \\
\hline 31.1 & 600 & 0.19 & 77.6 \\
\hline 31.0 & 603.2 & 0.24 & 91 \\
\hline 31.0 & 600.4 & 0.29 & 103.4 \\
\hline 31.1 & 598.7 & 0.35 & 118.8 \\
\hline 31.0 & 601 & 0.40 & 128.5 \\
\hline 30.9 & 597.8 & 0.45 & 140.8 \\
\hline 31.0 & 597 & 0.50 & 152.5 \\
\hline 31.0 & 598.8 & 0.55 & 166.9 \\
\hline 31.1 & 600.3 & 0.59 & 175.3 \\
\hline 31.2 & 593.3 & 0.64 & 185.2 \\
\hline 30.9 & 597.3 & 0.71 & 196.7 \\
\hline 30.9 & 598.3 & 0.75 & 206.1 \\
\hline 31.0 & 600.3 & 0.80 & 211.7 \\
\hline 31.1 & 599.4 & 0.88 & 217.2 \\
\hline 31.1 & 599.9 & 0.91 & 218.1 \\
\hline 31.1 & 604 & 0.95 & 212.4 \\
\hline 31.0 & 699.2 & 0.10 & 46.51 \\
\hline 31.0 & 703.5 & 0.15 & 68.28 \\
\hline 31.0 & 699.8 & 0.20 & 90.2 \\
\hline 31.3 & 708.9 & 0.25 & 110.4 \\
\hline 31.3 & 701.6 & 0.29 & 135.6 \\
\hline 31.0 & 698 & 0.35 & 146.2 \\
\hline 31.1 & 694.3 & 0.40 & 162.2 \\
\hline 31.2 & 703.5 & 0.44 & 182 \\
\hline 31.4 & 699.8 & 0.50 & 213.1 \\
\hline 30.8 & 703.5 & 0.54 & 227.1 \\
\hline 30.9 & 699.8 & 0.60 & 240 \\
\hline 31.0 & 699.8 & 0.65 & 250.7 \\
\hline 31.1 & 698 & 0.71 & 260.4 \\
\hline 31.2 & 698 & 0.75 & 271.3 \\
\hline 31.3 & 698 & 0.80 & 273.6 \\
\hline 31.3 & 699.8 & 0.86 & 284.9 \\
\hline 31.3 & 698 & 0.90 & 284 \\
\hline 31.3 & 696.1 & 0.95 & 278.3 \\
\hline 31.0 & 802.6 & 0.10 & 60.53 \\
\hline 31.3 & 798.5 & 0.14 & 84.2 \\
\hline 31.4 & 799.6 & 0.20 & 119.9 \\
\hline 31.3 & 798.8 & 0.25 & 138.6 \\
\hline 31.2 & 798.9 & 0.29 & 159.2 \\
\hline 31.1 & 798.2 & 0.34 & 181.9 \\
\hline 31.1 & 795.8 & 0.39 & 199.3 \\
\hline 30.9 & 798.3 & 0.45 & 231.1 \\
\hline 30.9 & 799.6 & 0.50 & 249.8 \\
\hline 31.0 & 800.2 & 0.54 & 264.6 \\
\hline 31.1 & 795.8 & 0.59 & 277.6 \\
\hline 31.2 & 799.6 & 0.64 & 295.6 \\
\hline 31.2 & 798.5 & 0.69 & 308.7 \\
\hline 31.3 & 800.6 & 0.75 & 322.9 \\
\hline 31.3 & 799.7 & 0.80 & 336.1 \\
\hline 31.2 & 800.9 & 0.85 & 346.5 \\
\hline 31.1 & 798 & 0.90 & 352.3 \\
\hline 30.9 & 799.7 & 0.95 & 331.3 \\
\hline 31.0 & 896.6 & 0.11 & 75.53 \\
\hline
\end{tabular}

\begin{tabular}{|c|c|c|c|}
\hline$T_{\text {sat }}[C]$ & $G\left[\mathrm{~kg} / \mathrm{m}^{2} \mathrm{~s}\right]$ & $x[-]$ & $(d p / d z)_{f}$ \\
\hline 31.2 & 899 & 0.15 & 98.01 \\
\hline 31.1 & 899 & 0.20 & 136.5 \\
\hline 30.9 & 898.4 & 0.24 & 156.1 \\
\hline 31.0 & 883.2 & 0.30 & 179.3 \\
\hline 31.2 & 899 & 0.34 & 214.9 \\
\hline 31.3 & 900.3 & 0.39 & 232.8 \\
\hline 31.4 & 896.4 & 0.44 & 251.4 \\
\hline 31.0 & 897.8 & 0.47 & 273 \\
\hline 30.9 & 901.4 & 0.55 & 312.8 \\
\hline 31.0 & 899.5 & 0.59 & 326.8 \\
\hline 31.1 & 899.5 & 0.64 & 344.9 \\
\hline 31.2 & 899.9 & 0.69 & 352.6 \\
\hline 31.1 & 900.6 & 0.75 & 371.3 \\
\hline 31.2 & 899 & 0.79 & 383.1 \\
\hline 31.3 & 901.2 & 0.84 & 395.1 \\
\hline 31.4 & 899.9 & 0.89 & 404.3 \\
\hline 31.1 & 899.4 & 0.96 & 376.5 \\
\hline 30.8 & 999.5 & 0.05 & 61.27 \\
\hline 30.8 & 1001 & 0.10 & 97.56 \\
\hline 30.9 & 998 & 0.16 & 134.2 \\
\hline 31.2 & 999.2 & 0.20 & 162.7 \\
\hline 31.2 & 1007 & 0.25 & 198.8 \\
\hline 31.2 & 1002 & 0.30 & 228.6 \\
\hline 31.0 & 996.9 & 0.36 & 268.4 \\
\hline 30.9 & 1000 & 0.39 & 294.2 \\
\hline 30.9 & 1000 & 0.45 & 326.2 \\
\hline 30.9 & 999.1 & 0.50 & 354.1 \\
\hline 31.1 & 998.6 & 0.55 & 377.4 \\
\hline 31.3 & 1001 & 0.60 & 398.7 \\
\hline 31.1 & 1000 & 0.65 & 420.8 \\
\hline 30.9 & 999.6 & 0.70 & 440.1 \\
\hline 30.9 & 1004 & 0.74 & 454.6 \\
\hline 31.1 & 997.7 & 0.80 & 477.4 \\
\hline 31.1 & 1002 & 0.85 & 494.3 \\
\hline 31.1 & 999.6 & 0.90 & 506.3 \\
\hline 30.9 & 1000 & 0.94 & 472.2 \\
\hline 30.9 & 1097 & 0.06 & 57.51 \\
\hline 31.0 & 1098 & 0.11 & 112.9 \\
\hline 31.0 & 1099 & 0.15 & 148.9 \\
\hline 31.0 & 1100 & 0.20 & 189.5 \\
\hline 31.0 & 1100 & 0.25 & 225.1 \\
\hline 30.9 & 1100 & 0.30 & 258.6 \\
\hline 30.8 & 1097 & 0.35 & 300.8 \\
\hline 30.9 & 1099 & 0.40 & 329.4 \\
\hline 30.9 & 1101 & 0.45 & 364.5 \\
\hline 31.0 & 1101 & 0.50 & 394.8 \\
\hline 31.2 & 1101 & 0.55 & 418.2 \\
\hline 31.3 & 1097 & 0.59 & 436.4 \\
\hline 31.2 & 1097 & 0.65 & 462.7 \\
\hline 31.0 & 1099 & 0.70 & 484.6 \\
\hline 31.0 & 1100 & 0.76 & 506.2 \\
\hline 31.0 & 1100 & 0.80 & 525 \\
\hline 31.2 & 1101 & 0.85 & 542.2 \\
\hline 31.1 & 1100 & 0.90 & 561.1 \\
\hline 30.9 & 1099 & 0.95 & 515.2 \\
\hline 31.1 & 1200 & 0.06 & 76.49 \\
\hline 31.1 & 1202 & 0.10 & 121.6 \\
\hline
\end{tabular}




\begin{tabular}{|c|c|c|c|}
\hline$T_{\text {sat }}[C]$ & $G\left[\mathrm{~kg} / \mathrm{m}^{2} \mathrm{~s}\right]$ & $x[-]$ & $(d p / d z)_{f}$ \\
\hline 30.9 & 1202 & 0.15 & 163.7 \\
\hline 31.0 & 1201 & 0.20 & 211.7 \\
\hline 31.2 & 1201 & 0.25 & 255.7 \\
\hline 30.8 & 1198 & 0.29 & 299.3 \\
\hline 31.1 & 1199 & 0.34 & 338.2 \\
\hline 31.1 & 1200 & 0.39 & 383.3 \\
\hline 30.9 & 1199 & 0.44 & 425.8 \\
\hline 31.0 & 1201 & 0.49 & 456.6 \\
\hline 31.1 & 1200 & 0.54 & 483 \\
\hline 31.2 & 1202 & 0.59 & 500.9 \\
\hline 31.2 & 1201 & 0.65 & 524.2 \\
\hline 31.2 & 1203 & 0.69 & 543.6 \\
\hline 31.1 & 1200 & 0.74 & 566.1 \\
\hline 30.9 & 1200 & 0.80 & 599.1 \\
\hline 31.0 & 1188 & 0.85 & 604.9 \\
\hline 31.1 & 1200 & 0.89 & 634.5 \\
\hline 31.1 & 1201 & 0.94 & 550.2 \\
\hline 30.2 & 1301 & 0.05 & 70.3 \\
\hline 30.4 & 1301 & 0.10 & 143.8 \\
\hline 30.5 & 1299 & 0.15 & 191.1 \\
\hline 30.7 & 1306 & 0.20 & 238.2 \\
\hline 30.9 & 1301 & 0.25 & 295.1 \\
\hline 31.1 & 1301 & 0.30 & 343.7 \\
\hline 31.2 & 1299 & 0.34 & 381.7 \\
\hline 31.3 & 1300 & 0.40 & 430.5 \\
\hline 31.3 & 1301 & 0.45 & 457.4 \\
\hline 31.2 & 1301 & 0.50 & 522.5 \\
\hline 31.1 & 1299 & 0.55 & 552.8 \\
\hline 31.1 & 1298 & 0.60 & 578.1 \\
\hline 31.0 & 1302 & 0.64 & 604.1 \\
\hline 31.0 & 1300 & 0.69 & 613.8 \\
\hline 31.0 & 1300 & 0.75 & 645.8 \\
\hline 31.0 & 1299 & 0.80 & 672 \\
\hline 31.3 & 1299 & 0.85 & 695.3 \\
\hline 31.5 & 1298 & 0.90 & 719.4 \\
\hline 31.6 & 1299 & 0.94 & 569.6 \\
\hline 30.9 & 1404 & 0.05 & 90.13 \\
\hline 30.8 & 1400 & 0.10 & 175.4 \\
\hline 31.2 & 1401 & 0.15 & 221.2 \\
\hline 31.4 & 1407 & 0.20 & 286.7 \\
\hline 31.6 & 1397 & 0.24 & 335.7 \\
\hline 31.1 & 1400 & 0.30 & 404.7 \\
\hline 31.0 & 1401 & 0.34 & 467.8 \\
\hline 31.0 & 1400 & 0.39 & 517.3 \\
\hline 31.0 & 1400 & 0.45 & 566.5 \\
\hline 31.1 & 1399 & 0.50 & 593.6 \\
\hline 31.1 & 1398 & 0.54 & 628.8 \\
\hline 31.2 & 1400 & 0.60 & 651.3 \\
\hline 31.2 & 1400 & 0.64 & 672.4 \\
\hline 31.3 & 1399 & 0.69 & 694.2 \\
\hline 31.2 & 1398 & 0.74 & 725.4 \\
\hline 31.2 & 1399 & 0.79 & 745.3 \\
\hline 31.1 & 1399 & 0.84 & 786.8 \\
\hline 31.3 & 1400 & 0.90 & 835.1 \\
\hline 31.3 & 1398 & 0.93 & 652.6 \\
\hline 31.2 & 1500 & 0.09 & 157.7 \\
\hline 31.6 & 1499 & 0.15 & 245.4 \\
\hline
\end{tabular}

\begin{tabular}{|c|c|c|c|}
\hline$T_{\text {sat }}[C]$ & $G\left[\mathrm{~kg} / \mathrm{m}^{2} \mathrm{~s}\right]$ & $x[-]$ & $(d p / d z)_{f}$ \\
\hline 31.2 & 1500 & 0.21 & 325.1 \\
\hline 31.2 & 1500 & 0.24 & 370.3 \\
\hline 31.3 & 1500 & 0.29 & 437.8 \\
\hline 31.2 & 1501 & 0.34 & 498.7 \\
\hline 31.1 & 1501 & 0.38 & 556.2 \\
\hline 30.9 & 1499 & 0.44 & 616 \\
\hline 30.8 & 1502 & 0.49 & 656.8 \\
\hline 31.0 & 1502 & 0.54 & 685.2 \\
\hline 31.1 & 1501 & 0.58 & 708.2 \\
\hline 31.3 & 1500 & 0.65 & 732.3 \\
\hline 31.4 & 1500 & 0.69 & 755.2 \\
\hline 31.3 & 1500 & 0.74 & 794.9 \\
\hline 31.1 & 1500 & 0.79 & 836.2 \\
\hline 31.1 & 1499 & 0.84 & 879.5 \\
\hline 30.9 & 1502 & 0.89 & 920.5 \\
\hline 30.8 & 1498 & 0.94 & 758.6 \\
\hline 41.0 & 405.6 & 0.10 & 12.32 \\
\hline 41.1 & 398.3 & 0.15 & 13.24 \\
\hline 41.1 & 392.8 & 0.21 & 17.35 \\
\hline 41.0 & 398.3 & 0.26 & 25.69 \\
\hline 40.9 & 407.5 & 0.29 & 31.24 \\
\hline 40.9 & 396.5 & 0.36 & 35.69 \\
\hline 40.9 & 398.3 & 0.40 & 41.27 \\
\hline 40.9 & 400.1 & 0.45 & 47.99 \\
\hline 40.8 & 402 & 0.50 & 49.68 \\
\hline 40.8 & 402 & 0.55 & 55.69 \\
\hline 40.8 & 392.8 & 0.62 & 57.89 \\
\hline 40.9 & 398.3 & 0.65 & 61.35 \\
\hline 41.0 & 403.8 & 0.70 & 65.47 \\
\hline 41.1 & 400.1 & 0.75 & 65.32 \\
\hline 41.2 & 402 & 0.81 & 68.54 \\
\hline 41.4 & 405.6 & 0.85 & 69.45 \\
\hline 41.4 & 394.7 & 0.92 & 70.35 \\
\hline 41.3 & 400.1 & 0.94 & 69.25 \\
\hline 41.0 & 507.9 & 0.11 & 17.32 \\
\hline 41.1 & 504.3 & 0.15 & 22.37 \\
\hline 41.0 & 498.8 & 0.21 & 32.54 \\
\hline 41.0 & 504.3 & 0.26 & 43.69 \\
\hline 41.0 & 504.3 & 0.31 & 50.32 \\
\hline 40.9 & 507.9 & 0.35 & 58.97 \\
\hline 40.9 & 498.8 & 0.41 & 64.35 \\
\hline 40.9 & 502.5 & 0.47 & 72.36 \\
\hline 40.8 & 478.7 & 0.55 & 77.37 \\
\hline 40.8 & 498.8 & 0.57 & 84.37 \\
\hline 40.9 & 493.3 & 0.62 & 90.46 \\
\hline 40.9 & 507.9 & 0.64 & 92.66 \\
\hline 41.0 & 497 & 0.72 & 97.65 \\
\hline 41.0 & 500.6 & 0.75 & 100.7 \\
\hline 41.1 & 497 & 0.80 & 102.7 \\
\hline 41.1 & 506.1 & 0.84 & 103.7 \\
\hline 41.2 & 506.1 & 0.88 & 103.5 \\
\hline 41.2 & 500.6 & 0.95 & 103.3 \\
\hline 40.9 & 593.8 & 0.10 & 23.68 \\
\hline 41.0 & 595.7 & 0.15 & 32.7 \\
\hline 41.0 & 597.5 & 0.20 & 45.68 \\
\hline 41.1 & 597.5 & 0.25 & 59.87 \\
\hline 41.2 & 595.7 & 0.30 & 72.63 \\
\hline
\end{tabular}




\begin{tabular}{|c|c|c|c|}
\hline$T_{\text {sat }}[C]$ & $G\left[\mathrm{~kg} / \mathrm{m}^{2} \mathrm{~s}\right]$ & $x[-]$ & $(d p / d z)_{f}$ \\
\hline 41.2 & 595.7 & 0.34 & 82.65 \\
\hline 41.1 & 597.5 & 0.40 & 91.65 \\
\hline 41.1 & 606.6 & 0.44 & 98.32 \\
\hline 41.1 & 599.3 & 0.49 & 107.7 \\
\hline 41.0 & 601.1 & 0.54 & 115.7 \\
\hline 41.0 & 601.1 & 0.60 & 133.5 \\
\hline 41.0 & 597.5 & 0.66 & 142.2 \\
\hline 40.9 & 593.8 & 0.72 & 145.7 \\
\hline 40.7 & 595.7 & 0.76 & 152.7 \\
\hline 40.7 & 613.9 & 0.78 & 154.4 \\
\hline 40.8 & 612.1 & 0.85 & 152.3 \\
\hline 40.9 & 619.4 & 0.89 & 147.7 \\
\hline 41.1 & 597.5 & 0.97 & 137.6 \\
\hline 40.6 & 701.6 & 0.11 & 32.25 \\
\hline 40.6 & 708.9 & 0.15 & 48.65 \\
\hline 40.9 & 699.8 & 0.21 & 72.37 \\
\hline 41.1 & 694.3 & 0.27 & 82.65 \\
\hline 41.3 & 698 & 0.31 & 95.65 \\
\hline 41.3 & 694.3 & 0.36 & 105.6 \\
\hline 41.3 & 698 & 0.41 & 120.7 \\
\hline 41.2 & 699.8 & 0.45 & 131.3 \\
\hline 41.1 & 698 & 0.51 & 142.4 \\
\hline 40.7 & 694.3 & 0.56 & 158.7 \\
\hline 40.6 & 703.5 & 0.59 & 170.7 \\
\hline 40.5 & 703.5 & 0.64 & 175.7 \\
\hline 40.6 & 698 & 0.70 & 185.7 \\
\hline 40.9 & 694.3 & 0.76 & 191.3 \\
\hline 41.0 & 699.8 & 0.80 & 193.2 \\
\hline 41.1 & 707.1 & 0.83 & 208.1 \\
\hline 41.1 & 696.1 & 0.90 & 210.8 \\
\hline 41.2 & 701.6 & 0.95 & 211.1 \\
\hline 40.9 & 798.5 & 0.10 & 40.65 \\
\hline 41.2 & 803.9 & 0.14 & 62.65 \\
\hline 41.3 & 794.8 & 0.20 & 88.32 \\
\hline 41.2 & 800.3 & 0.25 & 103.1 \\
\hline 41.2 & 798.5 & 0.30 & 123 \\
\hline 41.1 & 796.6 & 0.35 & 139.1 \\
\hline 41.0 & 798.5 & 0.39 & 147.5 \\
\hline 40.9 & 798.5 & 0.45 & 169.6 \\
\hline 40.6 & 803.9 & 0.49 & 185.9 \\
\hline 40.6 & 802.1 & 0.55 & 200.8 \\
\hline 40.7 & 803.9 & 0.59 & 211.9 \\
\hline 40.7 & 796.6 & 0.65 & 218.3 \\
\hline 40.8 & 796.6 & 0.70 & 231 \\
\hline 40.9 & 803.9 & 0.75 & 241.6 \\
\hline 41.0 & 800.3 & 0.79 & 250.6 \\
\hline 41.2 & 800.3 & 0.85 & 247.9 \\
\hline 41.3 & 798.5 & 0.90 & 253.1 \\
\hline 41.3 & 800.3 & 0.93 & 250.5 \\
\hline 40.7 & 906.3 & 0.11 & 54.66 \\
\hline 40.6 & 897.1 & 0.16 & 82.35 \\
\hline
\end{tabular}

\begin{tabular}{|c|c|c|c|}
\hline$T_{\text {sat }}[C]$ & $G\left[\mathrm{~kg} / \mathrm{m}^{2} \mathrm{~s}\right]$ & $x[-]$ & $(d p / d z)_{f}$ \\
\hline 40.6 & 899 & 0.21 & 108.5 \\
\hline 40.5 & 899 & 0.27 & 130.6 \\
\hline 40.6 & 908.1 & 0.30 & 150.3 \\
\hline 40.8 & 899 & 0.36 & 170.3 \\
\hline 41.2 & 897.1 & 0.41 & 185.6 \\
\hline 41.4 & 899 & 0.45 & 199 \\
\hline 41.5 & 902.6 & 0.50 & 218.3 \\
\hline 41.5 & 900.8 & 0.55 & 230.4 \\
\hline 41.3 & 902.5 & 0.59 & 240.5 \\
\hline 40.6 & 883.6 & 0.67 & 269.4 \\
\hline 40.7 & 924.5 & 0.68 & 272.4 \\
\hline 40.8 & 900.8 & 0.75 & 280.4 \\
\hline 40.8 & 913.6 & 0.79 & 285.7 \\
\hline 40.9 & 906.3 & 0.85 & 295.6 \\
\hline 41.0 & 899 & 0.90 & 301.3 \\
\hline 41.0 & 904.4 & 0.96 & 265.9 \\
\hline 40.9 & 1003 & 0.10 & 58.56 \\
\hline 41.2 & 999.5 & 0.14 & 88.56 \\
\hline 41.3 & 1009 & 0.19 & 113.7 \\
\hline 41.3 & 1007 & 0.24 & 132.5 \\
\hline 41.2 & 994 & 0.30 & 158.5 \\
\hline 41.2 & 999.5 & 0.35 & 175.9 \\
\hline 41.1 & 999.5 & 0.39 & 195.6 \\
\hline 41.0 & 1001 & 0.45 & 226.2 \\
\hline 40.7 & 1001 & 0.51 & 260.9 \\
\hline 40.6 & 999.5 & 0.57 & 272.8 \\
\hline 40.6 & 997.6 & 0.61 & 290 \\
\hline 40.6 & 997.6 & 0.65 & 308.4 \\
\hline 40.6 & 997.6 & 0.69 & 315.7 \\
\hline 40.7 & 999.5 & 0.74 & 325.9 \\
\hline 41.0 & 999.5 & 0.80 & 332.7 \\
\hline 41.2 & 999.5 & 0.85 & 346 \\
\hline 41.4 & 999.5 & 0.90 & 352.1 \\
\hline 41.6 & 997.6 & 0.95 & 328.7 \\
\hline 40.9 & 1100 & 0.10 & 66.64 \\
\hline 41.3 & 1102 & 0.15 & 105.5 \\
\hline 41.2 & 1104 & 0.20 & 135.2 \\
\hline 41.1 & 1100 & 0.25 & 162.3 \\
\hline 41.1 & 1104 & 0.30 & 188.4 \\
\hline 41.1 & 1104 & 0.35 & 215.7 \\
\hline 40.9 & 1098 & 0.40 & 243.8 \\
\hline 40.8 & 1100 & 0.45 & 272.9 \\
\hline 41.0 & 1100 & 0.49 & 288.6 \\
\hline 41.2 & 1104 & 0.55 & 312.6 \\
\hline 41.2 & 1102 & 0.60 & 331.9 \\
\hline 41.0 & 1102 & 0.65 & 344.7 \\
\hline 40.9 & 1100 & 0.71 & 365 \\
\hline 40.9 & 1107 & 0.75 & 384.6 \\
\hline 41.5 & 1102 & 0.80 & 388 \\
\hline 41.6 & 1109 & 0.84 & 402.9 \\
\hline 41.8 & 1104 & 0.91 & 397.2 \\
\hline 41.8 & 1107 & 0.95 & 329.7 \\
\hline
\end{tabular}




\section{B.2 Coeficiente de tranferencia de calor local}

As Tabelas B.7 a B12 apresentam os resultados experimentais para o coeficiente de transferencia de calor local $\left(\mathrm{em} \mathrm{kW} / \mathrm{m}^{2} \mathrm{C}\right]$.

Tabela B.7. R134a, geometría circular.

\begin{tabular}{|c|c|c|c|c|}
\hline$T_{\text {sat }}$ & $G$ & $\phi$ & $x$ & $\boldsymbol{h}$ \\
\hline 30.9 & 199.9 & 15121 & 0.07 & 4.73 \\
\hline 30.9 & 198.9 & 15098 & 0.14 & 4.74 \\
\hline 30.8 & 193.6 & 15098 & 0.18 & 4.87 \\
\hline 30.7 & 199.9 & 15167 & 0.22 & 5.13 \\
\hline 30.7 & 201.0 & 15179 & 0.28 & 5.15 \\
\hline 30.7 & 201.0 & 15038 & 0.34 & 5.06 \\
\hline 30.8 & 199.9 & 15026 & 0.38 & 5.09 \\
\hline 31.0 & 199.9 & 15005 & 0.44 & 5.21 \\
\hline 30.9 & 201.0 & 15030 & 0.50 & 5.26 \\
\hline 31.0 & 198.9 & 15053 & 0.53 & 5.32 \\
\hline 31.0 & 199.9 & 15042 & 0.58 & 5.40 \\
\hline 31.0 & 199.9 & 15018 & 0.62 & 5.58 \\
\hline 31.0 & 198.9 & 15030 & 0.67 & 5.86 \\
\hline 30.9 & 193.6 & 15042 & 0.73 & 6.21 \\
\hline 30.8 & 199.9 & 15030 & 0.77 & 6.49 \\
\hline 31.0 & 201.0 & 15018 & 0.81 & 7.10 \\
\hline 31.1 & 201.0 & 15042 & 0.88 & 7.82 \\
\hline 31.1 & 199.9 & 25060 & 0.19 & 6.88 \\
\hline 31.0 & 199.9 & 24867 & 0.23 & 6.74 \\
\hline 31.0 & 201.0 & 24905 & 0.28 & 6.67 \\
\hline 30.9 & 198.9 & 25060 & 0.34 & 6.70 \\
\hline 30.9 & 199.9 & 25118 & 0.39 & 6.72 \\
\hline 30.9 & 199.9 & 24983 & 0.45 & 6.50 \\
\hline 30.9 & 198.9 & 25214 & 0.49 & 6.78 \\
\hline 30.9 & 193.6 & 25040 & 0.53 & 6.74 \\
\hline 31.0 & 199.9 & 25137 & 0.62 & 6.93 \\
\hline 31.0 & 201.0 & 25040 & 0.64 & 6.89 \\
\hline 31.1 & 201.0 & 24963 & 0.71 & 7.11 \\
\hline 31.1 & 199.9 & 24886 & 0.72 & 7.20 \\
\hline 31.0 & 199.9 & 24847 & 0.77 & 7.42 \\
\hline 31.0 & 201.0 & 24867 & 0.84 & 7.87 \\
\hline 31.1 & 198.9 & 35111 & 0.31 & 8.19 \\
\hline 31.1 & 199.9 & 35072 & 0.35 & 8.20 \\
\hline 31.2 & 199.9 & 35246 & 0.42 & 8.29 \\
\hline 31.2 & 198.9 & 35091 & 0.45 & 8.29 \\
\hline 31.2 & 193.6 & 35033 & 0.49 & 8.25 \\
\hline 31.0 & 199.9 & 35303 & 0.55 & 8.27 \\
\hline 31.0 & 201.0 & 35111 & 0.60 & 8.29 \\
\hline 31.0 & 201.0 & 35207 & 0.64 & 8.43 \\
\hline 30.9 & 199.9 & 35246 & 0.69 & 8.44 \\
\hline 31.0 & 199.9 & 35284 & 0.78 & 8.48 \\
\hline 31.0 & 201.0 & 34898 & 0.79 & 8.54 \\
\hline 31.1 & 198.9 & 45065 & 0.41 & 9.65 \\
\hline 31.2 & 201.0 & 44969 & 0.51 & 9.65 \\
\hline 31.1 & 201.0 & 45161 & 0.55 & 9.70 \\
\hline 31.1 & 201.0 & 44872 & 0.60 & 9.66 \\
\hline
\end{tabular}

\begin{tabular}{|c|c|c|c|c|}
\hline $\boldsymbol{T}_{\text {sat }}$ & $\boldsymbol{G}$ & $\boldsymbol{\phi}$ & $\boldsymbol{x}$ & $\boldsymbol{h}$ \\
\hline 31.0 & 201.0 & 44872 & 0.66 & 9.51 \\
\hline 30.9 & 199.9 & 44776 & 0.71 & 9.53 \\
\hline 31.0 & 199.9 & 44718 & 0.73 & 9.81 \\
\hline 31.2 & 302.0 & 15169 & 0.05 & 5.04 \\
\hline 31.1 & 302.0 & 15084 & 0.10 & 4.94 \\
\hline 31.1 & 298.8 & 15084 & 0.15 & 5.10 \\
\hline 31.0 & 297.8 & 15096 & 0.20 & 5.22 \\
\hline 31.1 & 299.9 & 15084 & 0.25 & 5.29 \\
\hline 31.1 & 299.9 & 15096 & 0.29 & 5.30 \\
\hline 31.0 & 297.8 & 15169 & 0.36 & 5.32 \\
\hline 31.0 & 296.7 & 15084 & 0.40 & 5.32 \\
\hline 30.9 & 294.6 & 15084 & 0.47 & 5.64 \\
\hline 30.9 & 299.9 & 15084 & 0.50 & 5.85 \\
\hline 31.0 & 304.1 & 15084 & 0.55 & 6.14 \\
\hline 31.0 & 300.9 & 15084 & 0.59 & 6.50 \\
\hline 31.0 & 296.7 & 15084 & 0.66 & 6.91 \\
\hline 31.0 & 297.8 & 15084 & 0.72 & 7.45 \\
\hline 31.0 & 302.0 & 15084 & 0.75 & 7.87 \\
\hline 31.0 & 300.9 & 15084 & 0.81 & 8.63 \\
\hline 31.0 & 307.3 & 15084 & 0.83 & 9.06 \\
\hline 31.0 & 297.8 & 15084 & 0.91 & 9.74 \\
\hline 31.1 & 302.0 & 25195 & 0.09 & 7.00 \\
\hline 31.0 & 300.9 & 25079 & 0.12 & 6.97 \\
\hline 31.0 & 302.0 & 25040 & 0.17 & 7.22 \\
\hline 31.0 & 300.9 & 25079 & 0.22 & 7.10 \\
\hline 31.0 & 300.9 & 25079 & 0.26 & 7.10 \\
\hline 31.1 & 299.9 & 25137 & 0.33 & 6.80 \\
\hline 31.0 & 299.9 & 24847 & 0.39 & 6.81 \\
\hline 30.9 & 297.8 & 24732 & 0.42 & 7.01 \\
\hline 30.9 & 297.8 & 24693 & 0.47 & 7.08 \\
\hline 31.0 & 300.9 & 24732 & 0.52 & 7.20 \\
\hline 31.0 & 298.8 & 24655 & 0.57 & 7.35 \\
\hline 31.0 & 295.7 & 24655 & 0.64 & 7.51 \\
\hline 31.1 & 300.9 & 24655 & 0.67 & 7.90 \\
\hline 31.0 & 304.1 & 25040 & 0.73 & 8.33 \\
\hline 30.9 & 301.4 & 25002 & 0.77 & 8.77 \\
\hline 31.0 & 299.7 & 24983 & 0.83 & 9.36 \\
\hline 31.0 & 299.4 & 25021 & 0.87 & 9.84 \\
\hline 31.1 & 302.0 & 34937 & 0.17 & 8.83 \\
\hline 31.2 & 297.8 & 34956 & 0.24 & 8.67 \\
\hline 31.2 & 296.7 & 34995 & 0.29 & 8.70 \\
\hline 31.3 & 300.9 & 34995 & 0.34 & 8.75 \\
\hline 31.0 & 297.8 & 35053 & 0.40 & 8.37 \\
\hline 30.9 & 302.0 & 34956 & 0.44 & 8.42 \\
\hline 31.0 & 298.8 & 34783 & 0.51 & 8.44 \\
\hline 30.9 & 297.8 & 34802 & 0.55 & 8.51 \\
\hline 30.9 & 303.1 & 34937 & 0.59 & 8.61 \\
\hline 31.0 & 304.1 & 35246 & 0.64 & 8.70 \\
\hline 31.1 & 299.9 & 35149 & 0.70 & 8.80 \\
\hline & & & & \\
\hline
\end{tabular}




\begin{tabular}{|c|c|c|c|c|}
\hline$T_{\text {sat }}$ & $G$ & $\phi$ & $x$ & $h$ \\
\hline 30.9 & 305.2 & 34918 & 0.74 & 8.85 \\
\hline 30.9 & 299.9 & 34937 & 0.80 & 9.18 \\
\hline 31.1 & 295.7 & 44988 & 0.26 & 10.06 \\
\hline 31.2 & 300.9 & 45084 & 0.30 & 10.05 \\
\hline 31.2 & 300.9 & 44988 & 0.37 & 10.10 \\
\hline 31.3 & 303.1 & 44969 & 0.41 & 10.10 \\
\hline 31.2 & 302.0 & 44969 & 0.47 & 9.79 \\
\hline 31.0 & 299.9 & 45046 & 0.52 & 9.93 \\
\hline 31.0 & 299.9 & 44988 & 0.57 & 9.98 \\
\hline 31.0 & 303.1 & 44930 & 0.61 & 9.95 \\
\hline 31.0 & 299.9 & 44891 & 0.66 & 9.97 \\
\hline 30.9 & 304.1 & 44891 & 0.70 & 9.95 \\
\hline 30.9 & 307.3 & 44872 & 0.75 & 10.08 \\
\hline 31.1 & 297.8 & 55058 & 0.33 & 11.44 \\
\hline 31.2 & 300.9 & 55039 & 0.39 & 11.37 \\
\hline 31.3 & 297.8 & 55019 & 0.44 & 11.50 \\
\hline 31.4 & 297.8 & 55000 & 0.49 & 11.39 \\
\hline 31.0 & 299.9 & 56505 & 0.56 & 11.20 \\
\hline 30.9 & 304.1 & 56370 & 0.58 & 11.35 \\
\hline 30.9 & 299.9 & 56177 & 0.63 & 11.36 \\
\hline 31.1 & 300.9 & 55830 & 0.70 & 11.25 \\
\hline 31.0 & 297.8 & 55810 & 0.75 & 11.26 \\
\hline 31.2 & 295.7 & 64955 & 0.41 & 12.78 \\
\hline 31.0 & 299.9 & 64877 & 0.46 & 12.74 \\
\hline 31.0 & 297.8 & 64993 & 0.52 & 12.69 \\
\hline 31.2 & 295.7 & 65090 & 0.59 & 12.75 \\
\hline 31.1 & 298.8 & 64819 & 0.63 & 12.27 \\
\hline 31.1 & 298.8 & 64819 & 0.63 & 12.27 \\
\hline 31.1 & 302.0 & 64762 & 0.66 & 12.35 \\
\hline 31.0 & 296.7 & 64819 & 0.71 & 12.58 \\
\hline 31.1 & 403.0 & 15078 & 0.08 & 5.59 \\
\hline 31.1 & 399.9 & 15123 & 0.11 & 5.41 \\
\hline 31.0 & 400.9 & 15123 & 0.15 & 5.67 \\
\hline 30.9 & 398.8 & 15179 & 0.21 & 5.82 \\
\hline 30.8 & 397.8 & 15219 & 0.28 & 6.09 \\
\hline 31.0 & 399.9 & 15287 & 0.32 & 5.44 \\
\hline 31.0 & 400.9 & 15128 & 0.36 & 5.61 \\
\hline 31.0 & 397.8 & 15128 & 0.42 & 5.97 \\
\hline 30.9 & 399.9 & 15128 & 0.46 & 6.52 \\
\hline 30.9 & 395.7 & 15140 & 0.51 & 7.05 \\
\hline 31.0 & 399.9 & 15119 & 0.56 & 7.71 \\
\hline 31.0 & 400.9 & 15107 & 0.61 & 8.34 \\
\hline 31.0 & 396.7 & 15198 & 0.66 & 9.12 \\
\hline 31.0 & 391.4 & 15209 & 0.73 & 9.88 \\
\hline 31.0 & 399.9 & 15221 & 0.77 & 10.70 \\
\hline 31.0 & 399.9 & 15221 & 0.83 & 11.24 \\
\hline 31.0 & 396.7 & 15221 & 0.87 & 11.98 \\
\hline 31.0 & 399.9 & 15209 & 0.91 & 12.24 \\
\hline 31.0 & 399.9 & 25272 & 0.05 & 7.54 \\
\hline 31.1 & 399.9 & 25658 & 0.09 & 7.41 \\
\hline 31.0 & 400.9 & 25368 & 0.14 & 7.27 \\
\hline 31.0 & 397.8 & 25330 & 0.19 & 7.43 \\
\hline 31.0 & 398.8 & 25118 & 0.24 & 7.33 \\
\hline 31.0 & 400.9 & 25098 & 0.30 & 7.41 \\
\hline 31.1 & 405.1 & 25021 & 0.34 & 7.57 \\
\hline 31.1 & 400.9 & 25118 & 0.39 & 7.72 \\
\hline 30.9 & 402.0 & 24963 & 0.43 & 7.81 \\
\hline
\end{tabular}

\begin{tabular}{|c|c|c|c|c|}
\hline$T_{\text {sat }}$ & $G$ & $\phi$ & $x$ & $h$ \\
\hline 30.9 & 397.8 & 24963 & 0.50 & 8.00 \\
\hline 30.9 & 400.9 & 25060 & 0.55 & 8.25 \\
\hline 31.0 & 399.9 & 25021 & 0.61 & 8.78 \\
\hline 31.0 & 399.9 & 24963 & 0.64 & 8.79 \\
\hline 31.0 & 400.9 & 24809 & 0.70 & 9.52 \\
\hline 31.0 & 396.7 & 24905 & 0.77 & 10.32 \\
\hline 31.0 & 399.9 & 24925 & 0.81 & 10.69 \\
\hline 31.0 & 399.9 & 24905 & 0.85 & 11.39 \\
\hline 31.0 & 399.9 & 35014 & 0.13 & 8.94 \\
\hline 31.1 & 399.9 & 35033 & 0.17 & 9.20 \\
\hline 31.2 & 403.0 & 35053 & 0.22 & 9.10 \\
\hline 31.2 & 402.0 & 35053 & 0.27 & 9.09 \\
\hline 31.0 & 399.9 & 35053 & 0.34 & 8.88 \\
\hline 31.0 & 395.7 & 35072 & 0.37 & 8.93 \\
\hline 31.0 & 399.9 & 35072 & 0.43 & 9.00 \\
\hline 31.0 & 400.5 & 35091 & 0.48 & 9.06 \\
\hline 31.0 & 339.6 & 35072 & 0.53 & 9.45 \\
\hline 31.0 & 399.2 & 35072 & 0.58 & 9.57 \\
\hline 31.0 & 400.6 & 35072 & 0.63 & 9.68 \\
\hline 31.9 & 400.9 & 35072 & 0.68 & 9.87 \\
\hline 31.0 & 400.6 & 35053 & 0.73 & 10.08 \\
\hline 30.9 & 399.5 & 35053 & 0.78 & 10.39 \\
\hline 31.0 & 399.9 & 35014 & 0.84 & 10.90 \\
\hline 31.2 & 399.9 & 45065 & 0.18 & 10.85 \\
\hline 31.1 & 399.9 & 45026 & 0.22 & 10.86 \\
\hline 31.2 & 398.8 & 45084 & 0.26 & 10.70 \\
\hline 31.2 & 405.1 & 45065 & 0.30 & 10.74 \\
\hline 31.2 & 396.7 & 45084 & 0.36 & 10.78 \\
\hline 31.0 & 397.8 & 45065 & 0.42 & 10.60 \\
\hline 30.9 & 399.9 & 45123 & 0.45 & 10.51 \\
\hline 31.0 & 399.9 & 45104 & 0.51 & 10.64 \\
\hline 31.0 & 399.9 & 45123 & 0.57 & 10.55 \\
\hline 31.0 & 399.9 & 45026 & 0.62 & 10.61 \\
\hline 31.0 & 399.9 & 45123 & 0.67 & 10.80 \\
\hline 31.0 & 402.0 & 45123 & 0.70 & 10.82 \\
\hline 30.9 & 399.9 & 45123 & 0.77 & 11.00 \\
\hline 30.9 & 403.0 & 45084 & 0.79 & 11.19 \\
\hline 31.1 & 398.8 & 55039 & 0.25 & 12.29 \\
\hline 31.2 & 399.9 & 55039 & 0.29 & 12.18 \\
\hline 31.2 & 402.0 & 55193 & 0.35 & 12.24 \\
\hline 31.1 & 400.9 & 55077 & 0.39 & 12.21 \\
\hline 31.1 & 400.9 & 54904 & 0.43 & 12.11 \\
\hline 31.0 & 398.8 & 54904 & 0.50 & 11.91 \\
\hline 31.0 & 399.9 & 55135 & 0.55 & 11.94 \\
\hline 31.1 & 400.9 & 55251 & 0.60 & 12.06 \\
\hline 31.0 & 400.9 & 55752 & 0.64 & 12.22 \\
\hline 30.9 & 399.9 & 55000 & 0.70 & 11.89 \\
\hline 30.9 & 405.1 & 54537 & 0.74 & 11.78 \\
\hline 30.9 & 399.9 & 55058 & 0.81 & 11.98 \\
\hline 31.2 & 397.8 & 65128 & 0.33 & 13.56 \\
\hline 31.2 & 303.5 & 65128 & 0.38 & 13.51 \\
\hline 31.2 & 399.9 & 64955 & 0.42 & 13.39 \\
\hline 31.2 & 405.1 & 65205 & 0.46 & 13.62 \\
\hline 31.2 & 399.9 & 65302 & 0.52 & 13.58 \\
\hline 31.0 & 396.7 & 65070 & 0.57 & 13.08 \\
\hline 31.0 & 400.9 & 65610 & 0.62 & 13.16 \\
\hline 31.0 & 399.9 & 65996 & 0.67 & 13.22 \\
\hline
\end{tabular}




\begin{tabular}{|c|c|c|c|c|}
\hline $\boldsymbol{T}_{\text {sat }}$ & $G$ & $\phi$ & $x$ & $h$ \\
\hline 31.0 & 397.8 & 65147 & 0.73 & 13.01 \\
\hline 31.0 & 399.9 & 65302 & 0.78 & 13.08 \\
\hline 31.2 & 399.9 & 74369 & 0.38 & 14.64 \\
\hline 31.2 & 398.8 & 74755 & 0.41 & 14.60 \\
\hline 31.2 & 400.9 & 74195 & 0.45 & 14.58 \\
\hline 31.2 & 397.8 & 75140 & 0.51 & 14.72 \\
\hline 31.3 & 396.7 & 76066 & 0.56 & 14.92 \\
\hline 31.0 & 397.8 & 75411 & 0.62 & 14.59 \\
\hline 31.0 & 400.9 & 75353 & 0.65 & 14.51 \\
\hline 30.9 & 398.8 & 76124 & 0.71 & 14.72 \\
\hline 30.9 & 402.0 & 76587 & 0.75 & 14.54 \\
\hline 31.1 & 501.5 & 15038 & 0.06 & 5.86 \\
\hline 31.0 & 499.8 & 15130 & 0.11 & 5.72 \\
\hline 31.0 & 497.7 & 15310 & 0.16 & 6.16 \\
\hline 31.0 & 505.1 & 15074 & 0.21 & 6.11 \\
\hline 30.9 & 500.5 & 15011 & 0.27 & 6.58 \\
\hline 31.0 & 501.4 & 14972 & 0.31 & 6.91 \\
\hline 31.0 & 500.2 & 14943 & 0.37 & 7.41 \\
\hline 31.0 & 499.2 & 15202 & 0.42 & 8.13 \\
\hline 31.0 & 501.9 & 14941 & 0.47 & 8.74 \\
\hline 31.1 & 500.9 & 14976 & 0.52 & 9.51 \\
\hline 31.1 & 498.8 & 15238 & 0.57 & 10.59 \\
\hline 31.0 & 499.8 & 15206 & 0.62 & 11.11 \\
\hline 31.0 & 500.9 & 15283 & 0.66 & 12.34 \\
\hline 31.0 & 497.7 & 15429 & 0.72 & 13.30 \\
\hline 31.0 & 500.9 & 15522 & 0.77 & 14.69 \\
\hline 31.0 & 498.8 & 15177 & 0.83 & 15.55 \\
\hline 31.0 & 498.8 & 15184 & 0.88 & 16.42 \\
\hline 31.2 & 500.9 & 25349 & 0.06 & 7.08 \\
\hline 31.1 & 498.8 & 25060 & 0.10 & 7.39 \\
\hline 30.9 & 496.7 & 25407 & 0.16 & 7.57 \\
\hline 31.1 & 504.0 & 25040 & 0.20 & 7.31 \\
\hline 31.0 & 500.9 & 25040 & 0.26 & 7.57 \\
\hline 31.0 & 498.8 & 25098 & 0.30 & 7.69 \\
\hline 31.0 & 498.8 & 25021 & 0.35 & 7.96 \\
\hline 31.0 & 496.2 & 25098 & 0.40 & 8.19 \\
\hline 31.0 & 499.8 & 25021 & 0.45 & 8.49 \\
\hline 31.0 & 500.9 & 24963 & 0.51 & 9.06 \\
\hline 31.0 & 500.6 & 24925 & 0.55 & 9.49 \\
\hline 30.9 & 499.8 & 24905 & 0.61 & 10.15 \\
\hline 30.9 & 497.7 & 24944 & 0.66 & 10.75 \\
\hline 31.1 & 501.9 & 25098 & 0.70 & 11.65 \\
\hline 31.0 & 497.7 & 24963 & 0.76 & 12.36 \\
\hline 31.0 & 498.8 & 24944 & 0.81 & 13.35 \\
\hline 31.0 & 499.8 & 24963 & 0.86 & 14.02 \\
\hline 31.1 & 497.7 & 34937 & 0.06 & 9.03 \\
\hline 31.1 & 500.9 & 34898 & 0.08 & 8.99 \\
\hline 31.1 & 493.5 & 34898 & 0.13 & 8.93 \\
\hline 31.1 & 498.8 & 34918 & 0.18 & 9.19 \\
\hline 31.2 & 498.8 & 35033 & 0.23 & 9.11 \\
\hline 31.0 & 500.9 & 35091 & 0.29 & 9.12 \\
\hline 31.0 & 500.1 & 35130 & 0.33 & 9.18 \\
\hline 31.0 & 501.3 & 35168 & 0.38 & 9.36 \\
\hline 31.0 & 503.0 & 35111 & 0.42 & 9.54 \\
\hline 31.1 & 500.0 & 35149 & 0.49 & 9.75 \\
\hline 31.0 & 499.7 & 35207 & 0.54 & 10.09 \\
\hline 31.0 & 501.6 & 35323 & 0.58 & 10.49 \\
\hline
\end{tabular}

\begin{tabular}{|c|c|c|c|c|}
\hline$T_{\text {sat }}$ & $G$ & $\phi$ & $x$ & $h$ \\
\hline 30.9 & 499.2 & 35265 & 0.64 & 10.96 \\
\hline 30.9 & 499.5 & 35188 & 0.68 & 11.45 \\
\hline 31.0 & 501.0 & 35111 & 0.74 & 12.16 \\
\hline 31.0 & 501.5 & 35188 & 0.78 & 12.89 \\
\hline 31.0 & 498.9 & 35111 & 0.84 & 13.74 \\
\hline 31.1 & 499.8 & 45161 & 0.12 & 10.45 \\
\hline 30.8 & 497.7 & 45374 & 0.17 & 10.75 \\
\hline 30.8 & 503.0 & 45335 & 0.21 & 10.82 \\
\hline 31.1 & 501.4 & 44988 & 0.27 & 10.79 \\
\hline 30.9 & 499.6 & 45026 & 0.33 & 10.47 \\
\hline 31.0 & 499.3 & 45046 & 0.37 & 10.64 \\
\hline 31.0 & 499.0 & 45296 & 0.42 & 10.80 \\
\hline 31.0 & 501.9 & 45316 & 0.46 & 10.83 \\
\hline 31.0 & 501.6 & 45335 & 0.51 & 10.94 \\
\hline 31.0 & 501.4 & 45007 & 0.56 & 11.10 \\
\hline 31.0 & 500.6 & 44795 & 0.61 & 11.27 \\
\hline 31.0 & 500.0 & 44911 & 0.67 & 11.72 \\
\hline 30.9 & 500.8 & 45296 & 0.72 & 12.28 \\
\hline 30.9 & 499.2 & 45026 & 0.77 & 12.66 \\
\hline 30.9 & 501.6 & 45219 & 0.82 & 13.50 \\
\hline 31.1 & 499.8 & 55077 & 0.15 & 12.03 \\
\hline 31.0 & 499.4 & 55135 & 0.20 & 12.03 \\
\hline 31.0 & 496.7 & 54807 & 0.25 & 11.98 \\
\hline 31.1 & 501.1 & 55116 & 0.29 & 12.02 \\
\hline 31.0 & 499.5 & 55502 & 0.36 & 12.04 \\
\hline 31.0 & 501.1 & 55367 & 0.39 & 12.13 \\
\hline 31.0 & 501.4 & 55058 & 0.45 & 12.13 \\
\hline 31.0 & 500.5 & 55830 & 0.51 & 12.28 \\
\hline 31.0 & 499.6 & 56312 & 0.55 & 12.46 \\
\hline 31.0 & 501.0 & 55097 & 0.60 & 12.19 \\
\hline 31.0 & 500.2 & 54711 & 0.65 & 12.48 \\
\hline 31.0 & 499.0 & 55212 & 0.70 & 12.35 \\
\hline 30.9 & 500.8 & 55521 & 0.76 & 12.74 \\
\hline 31.0 & 499.0 & 56582 & 0.80 & 13.40 \\
\hline 31.2 & 496.7 & 65398 & 0.19 & 13.43 \\
\hline 31.0 & 497.7 & 65630 & 0.23 & 13.51 \\
\hline 31.1 & 499.1 & 64993 & 0.28 & 13.36 \\
\hline 31.3 & 500.1 & 64877 & 0.33 & 13.39 \\
\hline 31.0 & 499.1 & 65765 & 0.40 & 13.24 \\
\hline 31.0 & 499.9 & 65861 & 0.44 & 13.29 \\
\hline 31.0 & 498.4 & 65919 & 0.48 & 13.29 \\
\hline 31.1 & 500.2 & 65533 & 0.53 & 13.28 \\
\hline 31.1 & 500.8 & 65765 & 0.59 & 13.30 \\
\hline 31.0 & 500.0 & 65765 & 0.64 & 13.34 \\
\hline 30.9 & 500.2 & 65668 & 0.70 & 13.40 \\
\hline 31.0 & 499.2 & 65765 & 0.74 & 13.57 \\
\hline 31.1 & 500.0 & 65379 & 0.79 & 13.67 \\
\hline 31.3 & 499.6 & 74812 & 0.27 & 14.58 \\
\hline 31.2 & 498.8 & 74909 & 0.31 & 14.56 \\
\hline 31.1 & 499.9 & 74890 & 0.36 & 14.51 \\
\hline 31.1 & 500.9 & 75391 & 0.43 & 14.58 \\
\hline 31.0 & 499.6 & 74677 & 0.47 & 14.23 \\
\hline 31.0 & 500.4 & 75237 & 0.51 & 14.37 \\
\hline 31.0 & 500.1 & 75411 & 0.57 & 14.40 \\
\hline 31.0 & 500.9 & 75430 & 0.62 & 14.42 \\
\hline 31.0 & 500.8 & 75314 & 0.67 & 14.23 \\
\hline 30.9 & 499.8 & 75468 & 0.72 & 14.28 \\
\hline
\end{tabular}




\begin{tabular}{|c|c|c|c|c|}
\hline $\boldsymbol{T}_{\text {sat }}$ & $G$ & $\phi$ & $x$ & $h$ \\
\hline 31.0 & 500.2 & 75603 & 0.77 & 14.40 \\
\hline 31.1 & 500.6 & 85577 & 0.32 & 15.82 \\
\hline 31.1 & 497.7 & 85076 & 0.35 & 15.74 \\
\hline 31.1 & 500.9 & 85577 & 0.40 & 15.86 \\
\hline 31.2 & 499.4 & 85268 & 0.45 & 15.66 \\
\hline 31.0 & 499.9 & 85288 & 0.51 & 15.64 \\
\hline 31.0 & 499.2 & 85500 & 0.55 & 15.83 \\
\hline 30.9 & 500.0 & 85577 & 0.60 & 15.78 \\
\hline 31.1 & 500.1 & 85365 & 0.66 & 15.23 \\
\hline 30.9 & 499.8 & 85539 & 0.70 & 15.17 \\
\hline 30.9 & 500.6 & 85712 & 0.77 & 15.14 \\
\hline 31.0 & 599.6 & 15254 & 0.09 & 6.54 \\
\hline 31.0 & 599.8 & 15215 & 0.12 & 6.81 \\
\hline 31.0 & 599.7 & 15221 & 0.16 & 6.69 \\
\hline 31.1 & 599.6 & 15186 & 0.22 & 6.73 \\
\hline 31.0 & 600.1 & 15177 & 0.27 & 7.65 \\
\hline 31.0 & 600.1 & 15126 & 0.32 & 8.22 \\
\hline 31.0 & 601.5 & 15125 & 0.37 & 9.08 \\
\hline 30.9 & 600.0 & 15146 & 0.43 & 10.32 \\
\hline 31.0 & 599.7 & 15115 & 0.47 & 10.95 \\
\hline 31.0 & 600.8 & 15020 & 0.52 & 11.80 \\
\hline 31.0 & 600.4 & 15022 & 0.57 & 12.56 \\
\hline 31.0 & 599.9 & 15020 & 0.63 & 13.60 \\
\hline 31.0 & 598.9 & 15032 & 0.68 & 14.70 \\
\hline 31.0 & 600.1 & 15053 & 0.73 & 15.75 \\
\hline 31.0 & 598.5 & 15032 & 0.79 & 17.04 \\
\hline 31.0 & 598.7 & 15018 & 0.84 & 18.04 \\
\hline 30.9 & 599.9 & 15028 & 0.88 & 20.23 \\
\hline 31.1 & 600.0 & 24905 & 0.07 & 7.37 \\
\hline 31.1 & 600.0 & 24983 & 0.10 & 7.30 \\
\hline 31.1 & 600.9 & 25021 & 0.15 & 7.49 \\
\hline 31.1 & 598.8 & 25021 & 0.21 & 8.34 \\
\hline 31.0 & 600.8 & 25021 & 0.25 & 8.38 \\
\hline 31.0 & 600.1 & 25002 & 0.31 & 8.80 \\
\hline 31.0 & 602.0 & 24983 & 0.35 & 9.12 \\
\hline 31.0 & 599.9 & 25040 & 0.41 & 9.77 \\
\hline 31.0 & 600.1 & 25002 & 0.46 & 10.31 \\
\hline 31.0 & 599.7 & 25619 & 0.52 & 11.42 \\
\hline 31.0 & 598.8 & 24944 & 0.55 & 11.73 \\
\hline 31.0 & 599.3 & 24944 & 0.61 & 12.55 \\
\hline 31.0 & 600.2 & 24944 & 0.66 & 13.42 \\
\hline 31.0 & 600.7 & 24867 & 0.71 & 14.20 \\
\hline 31.0 & 600.8 & 24963 & 0.76 & 15.18 \\
\hline 30.9 & 599.5 & 24963 & 0.81 & 16.23 \\
\hline 30.9 & 601.1 & 25118 & 0.85 & 17.17 \\
\hline 31.2 & 600.0 & 34937 & 0.05 & 9.02 \\
\hline 31.1 & 601.3 & 34937 & 0.09 & 9.05 \\
\hline 31.1 & 600.5 & 35091 & 0.14 & 8.96 \\
\hline 31.1 & 600.3 & 34937 & 0.19 & 8.98 \\
\hline 31.1 & 599.4 & 35612 & 0.24 & 9.67 \\
\hline 31.0 & 600.1 & 35631 & 0.30 & 9.67 \\
\hline 31.0 & 600.3 & 35111 & 0.35 & 9.70 \\
\hline 31.0 & 599.5 & 35111 & 0.40 & 9.90 \\
\hline 31.0 & 599.3 & 35149 & 0.45 & 10.20 \\
\hline 31.0 & 600.0 & 35207 & 0.49 & 10.57 \\
\hline 31.0 & 599.1 & 35053 & 0.55 & 11.07 \\
\hline 31.0 & 601.7 & 35014 & 0.59 & 11.58 \\
\hline
\end{tabular}

\begin{tabular}{|c|c|c|c|c|}
\hline$T_{\text {sat }}$ & $G$ & $\phi$ & $x$ & $h$ \\
\hline 31.0 & 599.4 & 34918 & 0.65 & 12.24 \\
\hline 31.0 & 599.8 & 34995 & 0.70 & 12.94 \\
\hline 31.0 & 599.4 & 34918 & 0.76 & 13.83 \\
\hline 31.0 & 599.6 & 34995 & 0.80 & 14.52 \\
\hline 31.0 & 601.4 & 35053 & 0.86 & 15.59 \\
\hline 31.0 & 600.6 & 35226 & 0.90 & 16.52 \\
\hline 31.0 & 600.1 & 45046 & 0.09 & 10.26 \\
\hline 31.1 & 600.1 & 45258 & 0.12 & 10.41 \\
\hline 31.0 & 601.1 & 44525 & 0.18 & 10.53 \\
\hline 31.1 & 601.6 & 43830 & 0.23 & 10.42 \\
\hline 31.1 & 600.0 & 46280 & 0.29 & 11.04 \\
\hline 31.0 & 599.2 & 46030 & 0.34 & 10.91 \\
\hline 31.0 & 600.0 & 45605 & 0.38 & 10.91 \\
\hline 31.0 & 599.9 & 45123 & 0.44 & 10.80 \\
\hline 31.0 & 600.3 & 45200 & 0.48 & 10.92 \\
\hline 31.0 & 599.3 & 45258 & 0.54 & 11.08 \\
\hline 31.0 & 599.7 & 45335 & 0.58 & 11.38 \\
\hline 31.0 & 600.8 & 44988 & 0.63 & 11.77 \\
\hline 31.0 & 600.7 & 45451 & 0.68 & 12.53 \\
\hline 31.0 & 599.6 & 45663 & 0.74 & 13.29 \\
\hline 31.0 & 599.9 & 45239 & 0.78 & 13.95 \\
\hline 31.0 & 599.8 & 45084 & 0.83 & 14.26 \\
\hline 31.0 & 600.1 & 44795 & 0.87 & 14.81 \\
\hline 31.1 & 599.8 & 55347 & 0.12 & 11.72 \\
\hline 31.1 & 599.3 & 55367 & 0.16 & 11.84 \\
\hline 31.1 & 600.5 & 55289 & 0.21 & 12.05 \\
\hline 31.1 & 604.8 & 55289 & 0.26 & 12.09 \\
\hline 31.0 & 600.0 & 55444 & 0.32 & 11.71 \\
\hline 31.0 & 600.0 & 55617 & 0.37 & 11.90 \\
\hline 31.0 & 600.3 & 55135 & 0.41 & 11.89 \\
\hline 31.0 & 600.3 & 54942 & 0.47 & 11.91 \\
\hline 31.0 & 600.0 & 55289 & 0.51 & 12.06 \\
\hline 31.0 & 599.6 & 55617 & 0.56 & 12.33 \\
\hline 31.0 & 602.1 & 55116 & 0.61 & 12.46 \\
\hline 31.0 & 601.1 & 55328 & 0.67 & 12.92 \\
\hline 31.0 & 599.4 & 55560 & 0.72 & 13.36 \\
\hline 31.0 & 600.1 & 55675 & 0.77 & 13.89 \\
\hline 31.0 & 599.6 & 55540 & 0.82 & 14.54 \\
\hline 31.0 & 599.4 & 55540 & 0.88 & 15.90 \\
\hline 31.1 & 598.8 & 64858 & 0.16 & 13.07 \\
\hline 31.1 & 599.6 & 64916 & 0.20 & 13.19 \\
\hline 31.1 & 600.1 & 64955 & 0.25 & 13.26 \\
\hline 31.1 & 599.4 & 64877 & 0.31 & 13.35 \\
\hline 31.0 & 599.9 & 65765 & 0.36 & 13.27 \\
\hline 31.0 & 600.1 & 65475 & 0.40 & 13.51 \\
\hline 31.0 & 600.1 & 65572 & 0.45 & 13.60 \\
\hline 31.0 & 599.6 & 65147 & 0.51 & 13.35 \\
\hline 31.0 & 599.7 & 64955 & 0.55 & 13.35 \\
\hline 31.0 & 598.2 & 65263 & 0.59 & 13.50 \\
\hline 31.0 & 600.4 & 65533 & 0.65 & 13.65 \\
\hline 31.0 & 599.1 & 65321 & 0.70 & 13.90 \\
\hline 31.0 & 600.8 & 65533 & 0.76 & 14.32 \\
\hline 31.0 & 599.7 & 65765 & 0.80 & 14.82 \\
\hline 31.0 & 600.3 & 65398 & 0.85 & 15.49 \\
\hline 31.2 & 599.2 & 74890 & 0.20 & 14.49 \\
\hline 31.2 & 599.9 & 75546 & 0.24 & 14.65 \\
\hline 31.2 & 599.6 & 75681 & 0.28 & 14.71 \\
\hline
\end{tabular}




\begin{tabular}{|c|c|c|c|c|}
\hline$T_{\text {sat }}$ & $G$ & $\phi$ & $x$ & $h$ \\
\hline 31.2 & 598.8 & 75507 & 0.34 & 14.70 \\
\hline 30.9 & 600.6 & 75719 & 0.39 & 14.25 \\
\hline 31.0 & 599.4 & 75796 & 0.45 & 14.67 \\
\hline 31.0 & 599.8 & 75256 & 0.49 & 14.65 \\
\hline 31.0 & 598.8 & 75372 & 0.54 & 14.67 \\
\hline 31.0 & 600.9 & 75333 & 0.59 & 14.69 \\
\hline 31.0 & 593.2 & 75005 & 0.64 & 14.64 \\
\hline 31.0 & 599.7 & 75160 & 0.69 & 14.75 \\
\hline 31.0 & 598.5 & 75140 & 0.75 & 14.94 \\
\hline 31.0 & 600.1 & 75083 & 0.79 & 15.12 \\
\hline 31.0 & 600.0 & 74928 & 0.84 & 15.45 \\
\hline 31.2 & 600.2 & 85442 & 0.27 & 15.82 \\
\hline 31.2 & 599.1 & 85770 & 0.32 & 15.93 \\
\hline 31.2 & 600.8 & 85635 & 0.37 & 15.92 \\
\hline 31.3 & 599.5 & 85654 & 0.42 & 15.99 \\
\hline 31.0 & 598.7 & 85500 & 0.47 & 15.82 \\
\hline 31.0 & 599.9 & 85133 & 0.52 & 15.74 \\
\hline 31.0 & 599.7 & 85384 & 0.57 & 15.83 \\
\hline 31.0 & 599.7 & 85654 & 0.63 & 15.86 \\
\hline 31.0 & 602.1 & 85712 & 0.68 & 15.87 \\
\hline 31.0 & 599.9 & 85423 & 0.72 & 15.87 \\
\hline 31.0 & 600.1 & 85519 & 0.78 & 16.13 \\
\hline 31.0 & 700.1 & 15262 & 0.08 & 6.11 \\
\hline 30.9 & 699.1 & 15306 & 0.13 & 5.88 \\
\hline 31.1 & 700.0 & 15317 & 0.17 & 6.11 \\
\hline 31.0 & 701.2 & 15341 & 0.23 & 7.15 \\
\hline 31.0 & 702.3 & 15341 & 0.27 & 8.05 \\
\hline 31.0 & 700.3 & 15331 & 0.32 & 9.09 \\
\hline 31.0 & 700.7 & 15329 & 0.37 & 10.14 \\
\hline 31.0 & 701.5 & 15329 & 0.42 & 11.25 \\
\hline 31.0 & 700.6 & 15329 & 0.48 & 12.13 \\
\hline 31.0 & 701.3 & 15281 & 0.52 & 13.14 \\
\hline 31.0 & 700.3 & 15289 & 0.58 & 14.13 \\
\hline 31.0 & 700.4 & 15281 & 0.63 & 15.16 \\
\hline 30.9 & 700.6 & 15292 & 0.67 & 16.27 \\
\hline 31.0 & 700.1 & 15292 & 0.73 & 17.31 \\
\hline 31.0 & 699.7 & 15304 & 0.78 & 18.36 \\
\hline 31.0 & 701.0 & 15281 & 0.83 & 19.70 \\
\hline 31.1 & 700.9 & 25002 & 0.08 & 7.29 \\
\hline 30.9 & 700.1 & 25137 & 0.12 & 7.39 \\
\hline 31.0 & 699.1 & 25195 & 0.16 & 7.47 \\
\hline 31.0 & 701.3 & 25195 & 0.22 & 8.59 \\
\hline 31.0 & 702.2 & 25214 & 0.26 & 8.78 \\
\hline 31.0 & 697.5 & 25195 & 0.32 & 9.18 \\
\hline 31.0 & 702.7 & 25214 & 0.35 & 9.67 \\
\hline 31.0 & 700.8 & 25253 & 0.41 & 10.65 \\
\hline 31.0 & 699.8 & 25272 & 0.47 & 11.71 \\
\hline 31.0 & 699.9 & 25253 & 0.52 & 12.60 \\
\hline 31.0 & 700.1 & 25272 & 0.57 & 13.55 \\
\hline 31.0 & 699.9 & 25272 & 0.62 & 14.47 \\
\hline 31.0 & 699.1 & 25253 & 0.67 & 15.45 \\
\hline 31.0 & 699.2 & 25253 & 0.72 & 16.35 \\
\hline 31.0 & 699.7 & 25291 & 0.77 & 17.40 \\
\hline 31.0 & 698.9 & 25310 & 0.82 & 18.56 \\
\hline 31.0 & 700.1 & 25310 & 0.87 & 19.56 \\
\hline 31.0 & 700.2 & 35246 & 0.08 & 9.14 \\
\hline 31.0 & 699.9 & 35284 & 0.11 & 8.97 \\
\hline
\end{tabular}

\begin{tabular}{|c|c|c|c|c|}
\hline$T_{\text {sat }}$ & $G$ & $\phi$ & $x$ & $h$ \\
\hline 31.0 & 698.9 & 35265 & 0.16 & 9.02 \\
\hline 31.1 & 700.5 & 34918 & 0.20 & 8.96 \\
\hline 31.0 & 699.5 & 35265 & 0.26 & 9.93 \\
\hline 31.0 & 699.7 & 35381 & 0.31 & 10.18 \\
\hline 31.0 & 699.9 & 35400 & 0.35 & 10.46 \\
\hline 31.0 & 699.8 & 35400 & 0.40 & 10.81 \\
\hline 31.0 & 700.0 & 35381 & 0.45 & 11.29 \\
\hline 31.0 & 701.1 & 35381 & 0.50 & 11.93 \\
\hline 31.0 & 699.3 & 35323 & 0.55 & 12.57 \\
\hline 31.0 & 699.3 & 35323 & 0.60 & 13.33 \\
\hline 31.0 & 699.2 & 35323 & 0.65 & 14.09 \\
\hline 31.0 & 701.6 & 35361 & 0.70 & 14.99 \\
\hline 31.0 & 699.2 & 35323 & 0.75 & 15.81 \\
\hline 31.0 & 699.4 & 35284 & 0.80 & 16.81 \\
\hline 31.0 & 699.0 & 35323 & 0.86 & 17.92 \\
\hline 31.1 & 699.7 & 45779 & 0.07 & 10.74 \\
\hline 31.0 & 699.2 & 46068 & 0.09 & 10.73 \\
\hline 31.1 & 699.5 & 45258 & 0.13 & 10.62 \\
\hline 31.0 & 700.3 & 45026 & 0.19 & 10.79 \\
\hline 31.0 & 698.5 & 45702 & 0.25 & 11.50 \\
\hline 31.0 & 698.8 & 45046 & 0.29 & 11.16 \\
\hline 31.0 & 701.8 & 45065 & 0.34 & 11.28 \\
\hline 31.0 & 701.1 & 45219 & 0.39 & 11.74 \\
\hline 31.0 & 700.2 & 45432 & 0.44 & 12.12 \\
\hline 30.9 & 700.8 & 45470 & 0.49 & 12.54 \\
\hline 31.0 & 701.4 & 45489 & 0.53 & 12.97 \\
\hline 31.0 & 700.5 & 45393 & 0.59 & 13.62 \\
\hline 31.0 & 700.3 & 45200 & 0.64 & 14.23 \\
\hline 31.0 & 700.8 & 45432 & 0.69 & 15.19 \\
\hline 31.0 & 699.9 & 45354 & 0.74 & 15.97 \\
\hline 31.0 & 700.4 & 45470 & 0.79 & 17.01 \\
\hline 31.0 & 700.1 & 45161 & 0.84 & 18.04 \\
\hline 31.1 & 701.3 & 55251 & 0.10 & 11.74 \\
\hline 31.1 & 700.3 & 55174 & 0.12 & 11.74 \\
\hline 31.1 & 698.6 & 55058 & 0.17 & 11.91 \\
\hline 31.1 & 699.7 & 55367 & 0.23 & 12.06 \\
\hline 31.1 & 699.7 & 55251 & 0.28 & 12.30 \\
\hline 31.0 & 700.5 & 55347 & 0.33 & 12.72 \\
\hline 31.0 & 700.9 & 55174 & 0.37 & 12.79 \\
\hline 31.0 & 701.0 & 55232 & 0.42 & 12.97 \\
\hline 31.0 & 700.9 & 55154 & 0.48 & 13.11 \\
\hline 31.0 & 700.7 & 55328 & 0.53 & 13.47 \\
\hline 31.0 & 699.5 & 55097 & 0.58 & 13.74 \\
\hline 31.0 & 699.4 & 55077 & 0.63 & 14.26 \\
\hline 31.0 & 699.7 & 54962 & 0.69 & 14.84 \\
\hline 30.9 & 700.7 & 55540 & 0.73 & 15.73 \\
\hline 30.9 & 699.4 & 55598 & 0.78 & 16.53 \\
\hline 31.0 & 699.7 & 54981 & 0.83 & 17.28 \\
\hline 31.0 & 700.5 & 55000 & 0.88 & 18.40 \\
\hline 31.1 & 700.4 & 65745 & 0.14 & 13.37 \\
\hline 31.1 & 699.8 & 65437 & 0.16 & 13.47 \\
\hline 31.1 & 699.4 & 65321 & 0.22 & 13.59 \\
\hline 31.1 & 699.1 & 65340 & 0.27 & 13.69 \\
\hline 31.1 & 700.4 & 65070 & 0.31 & 13.74 \\
\hline 31.0 & 700.5 & 65321 & 0.37 & 13.77 \\
\hline 31.0 & 699.9 & 65514 & 0.42 & 13.99 \\
\hline 31.0 & 700.0 & 64955 & 0.46 & 13.98 \\
\hline
\end{tabular}




\begin{tabular}{|c|c|c|c|c|}
\hline $\boldsymbol{T}_{\text {sat }}$ & $G$ & $\phi$ & $x$ & $h$ \\
\hline 31.0 & 700.3 & 65070 & 0.52 & 13.95 \\
\hline 31.0 & 699.3 & 65495 & 0.57 & 14.36 \\
\hline 31.0 & 700.2 & 65591 & 0.62 & 14.65 \\
\hline 31.0 & 700.4 & 65533 & 0.67 & 14.98 \\
\hline 31.0 & 699.7 & 65649 & 0.71 & 15.36 \\
\hline 31.2 & 700.3 & 65147 & 0.76 & 15.77 \\
\hline 31.0 & 700.8 & 65977 & 0.82 & 17.22 \\
\hline 31.2 & 699.7 & 75565 & 0.16 & 14.23 \\
\hline 31.1 & 699.3 & 76124 & 0.20 & 14.62 \\
\hline 31.0 & 698.2 & 75449 & 0.25 & 14.72 \\
\hline 31.1 & 700.3 & 75546 & 0.31 & 14.91 \\
\hline 30.8 & 699.2 & 75546 & 0.36 & 14.63 \\
\hline 31.0 & 701.2 & 75411 & 0.39 & 14.97 \\
\hline 31.0 & 699.7 & 75430 & 0.45 & 15.08 \\
\hline 31.0 & 700.8 & 75140 & 0.50 & 15.00 \\
\hline 30.9 & 699.5 & 75623 & 0.55 & 15.12 \\
\hline 30.9 & 700.3 & 75642 & 0.60 & 15.28 \\
\hline 31.0 & 700.1 & 75623 & 0.65 & 15.47 \\
\hline 31.0 & 702.2 & 75816 & 0.71 & 15.83 \\
\hline 31.1 & 699.1 & 75835 & 0.75 & 16.15 \\
\hline 31.2 & 698.4 & 75951 & 0.80 & 16.72 \\
\hline 31.1 & 799.5 & 15030 & 0.09 & 6.63 \\
\hline 31.0 & 799.9 & 15038 & 0.12 & 6.93 \\
\hline 31.0 & 798.4 & 15038 & 0.18 & 6.00 \\
\hline 31.0 & 800.1 & 15038 & 0.23 & 7.18 \\
\hline 31.0 & 798.9 & 15038 & 0.27 & 8.15 \\
\hline 31.0 & 799.7 & 15038 & 0.33 & 9.38 \\
\hline 31.0 & 798.9 & 15038 & 0.38 & 10.48 \\
\hline 31.0 & 799.0 & 15036 & 0.43 & 11.40 \\
\hline 31.0 & 799.8 & 15024 & 0.49 & 12.76 \\
\hline 31.0 & 800.6 & 15026 & 0.53 & 13.49 \\
\hline 31.0 & 802.1 & 15026 & 0.58 & 14.53 \\
\hline 31.0 & 799.2 & 15038 & 0.63 & 15.52 \\
\hline 30.9 & 795.9 & 15038 & 0.69 & 16.64 \\
\hline 31.0 & 801.7 & 15038 & 0.73 & 17.62 \\
\hline 31.0 & 799.6 & 15038 & 0.78 & 18.51 \\
\hline 31.0 & 800.4 & 25272 & 0.08 & 7.63 \\
\hline 30.9 & 800.0 & 25310 & 0.12 & 7.74 \\
\hline 31.1 & 800.8 & 25465 & 0.17 & 8.91 \\
\hline 31.0 & 799.6 & 25233 & 0.22 & 8.86 \\
\hline 30.9 & 801.4 & 25253 & 0.27 & 9.51 \\
\hline 31.0 & 799.3 & 25253 & 0.31 & 9.99 \\
\hline 31.0 & 799.1 & 25272 & 0.37 & 10.87 \\
\hline 30.9 & 799.7 & 25272 & 0.42 & 11.75 \\
\hline 31.0 & 799.6 & 25291 & 0.46 & 12.64 \\
\hline 31.0 & 798.4 & 25310 & 0.53 & 13.88 \\
\hline 31.0 & 799.4 & 25330 & 0.56 & 14.80 \\
\hline 31.0 & 800.4 & 25330 & 0.61 & 15.83 \\
\hline 31.0 & 800.1 & 25349 & 0.66 & 16.85 \\
\hline 31.0 & 799.2 & 25349 & 0.70 & 18.22 \\
\hline 31.2 & 800.6 & 35091 & 0.07 & 9.39 \\
\hline 31.1 & 799.0 & 35246 & 0.10 & 9.55 \\
\hline 31.1 & 799.0 & 35226 & 0.15 & 9.86 \\
\hline 31.2 & 799.7 & 35168 & 0.21 & 11.12 \\
\hline 31.0 & 799.9 & 35111 & 0.26 & 10.94 \\
\hline 31.0 & 800.0 & 35188 & 0.31 & 11.46 \\
\hline 30.9 & 799.7 & 35226 & 0.35 & 12.00 \\
\hline
\end{tabular}

\begin{tabular}{|c|c|c|c|c|}
\hline$T_{\text {sat }}$ & $G$ & $\phi$ & $x$ & $h$ \\
\hline 31.0 & 799.8 & 35226 & 0.41 & 12.68 \\
\hline 31.0 & 799.4 & 35246 & 0.46 & 13.40 \\
\hline 31.0 & 799.2 & 35265 & 0.50 & 14.19 \\
\hline 31.0 & 798.9 & 35265 & 0.56 & 15.29 \\
\hline 31.0 & 799.9 & 35265 & 0.61 & 16.22 \\
\hline 31.0 & 798.7 & 35265 & 0.66 & 17.43 \\
\hline 31.0 & 799.6 & 35284 & 0.71 & 18.66 \\
\hline 30.9 & 800.6 & 35303 & 0.76 & 19.83 \\
\hline 30.8 & 809.7 & 35323 & 0.80 & 21.36 \\
\hline 41.2 & 200.5 & 15034 & 0.08 & 5.39 \\
\hline 41.2 & 197.9 & 15240 & 0.14 & 5.44 \\
\hline 41.2 & 200.4 & 15391 & 0.19 & 5.72 \\
\hline 41.2 & 201.0 & 15433 & 0.23 & 5.83 \\
\hline 40.9 & 200.1 & 15788 & 0.29 & 5.88 \\
\hline 40.9 & 200.2 & 15809 & 0.34 & 5.96 \\
\hline 40.9 & 199.5 & 16087 & 0.38 & 6.03 \\
\hline 41.0 & 199.7 & 15319 & 0.44 & 6.32 \\
\hline 41.0 & 199.8 & 15325 & 0.49 & 6.85 \\
\hline 40.9 & 199.6 & 15333 & 0.54 & 6.93 \\
\hline 40.9 & 200.4 & 15323 & 0.58 & 7.06 \\
\hline 41.0 & 199.7 & 15343 & 0.64 & 7.24 \\
\hline 41.0 & 201.4 & 15308 & 0.68 & 7.40 \\
\hline 40.8 & 201.2 & 15263 & 0.73 & 7.63 \\
\hline 40.8 & 200.5 & 15263 & 0.78 & 7.96 \\
\hline 41.1 & 200.7 & 15227 & 0.85 & 8.45 \\
\hline 41.1 & 198.7 & 24963 & 0.09 & 7.54 \\
\hline 41.1 & 200.7 & 25021 & 0.14 & 7.50 \\
\hline 41.0 & 201.0 & 25272 & 0.20 & 7.70 \\
\hline 41.0 & 198.1 & 25407 & 0.25 & 7.84 \\
\hline 40.9 & 199.7 & 25214 & 0.28 & 7.81 \\
\hline 40.9 & 199.5 & 25233 & 0.34 & 7.71 \\
\hline 41.1 & 200.6 & 25060 & 0.40 & 7.80 \\
\hline 41.0 & 197.6 & 25021 & 0.45 & 7.70 \\
\hline 40.9 & 199.9 & 25310 & 0.50 & 7.86 \\
\hline 40.8 & 199.6 & 25696 & 0.55 & 8.03 \\
\hline 41.0 & 201.7 & 25503 & 0.58 & 8.04 \\
\hline 41.0 & 199.5 & 25658 & 0.66 & 8.08 \\
\hline 40.9 & 200.2 & 25773 & 0.71 & 8.17 \\
\hline 40.9 & 200.9 & 25523 & 0.75 & 8.12 \\
\hline 40.9 & 200.9 & 25253 & 0.80 & 8.19 \\
\hline 41.1 & 199.0 & 35091 & 0.22 & 9.75 \\
\hline 41.0 & 199.4 & 35091 & 0.26 & 9.80 \\
\hline 41.0 & 200.4 & 35014 & 0.29 & 9.72 \\
\hline 41.1 & 200.4 & 34879 & 0.34 & 9.67 \\
\hline 41.2 & 199.3 & 35265 & 0.40 & 9.77 \\
\hline 41.2 & 199.5 & 35053 & 0.43 & 9.69 \\
\hline 41.1 & 201.3 & 35053 & 0.48 & 9.73 \\
\hline 41.0 & 200.0 & 34860 & 0.56 & 9.50 \\
\hline 40.9 & 200.4 & 34840 & 0.60 & 9.55 \\
\hline 40.9 & 199.4 & 35111 & 0.66 & 9.80 \\
\hline 41.1 & 199.4 & 35188 & 0.71 & 10.02 \\
\hline 41.0 & 199.8 & 34821 & 0.73 & 9.85 \\
\hline 41.2 & 199.7 & 45123 & 0.34 & 11.45 \\
\hline 41.1 & 199.9 & 44988 & 0.40 & 11.34 \\
\hline 41.1 & 196.4 & 44969 & 0.46 & 11.38 \\
\hline 41.2 & 198.4 & 45161 & 0.52 & 11.38 \\
\hline 40.9 & 199.8 & 45277 & 0.56 & 11.37 \\
\hline
\end{tabular}




\begin{tabular}{|c|c|c|c|c|}
\hline $\boldsymbol{T}_{\text {sat }}$ & $\boldsymbol{G}$ & $\boldsymbol{\phi}$ & $\boldsymbol{x}$ & $\boldsymbol{h}$ \\
\hline 41.0 & 200.1 & 45239 & 0.61 & 11.44 \\
\hline 41.0 & 199.8 & 45142 & 0.66 & 11.15 \\
\hline 41.1 & 199.2 & 45123 & 0.70 & 11.29 \\
\hline 41.1 & 399.3 & 14920 & 0.07 & 6.01 \\
\hline 41.1 & 401.5 & 14939 & 0.11 & 6.04 \\
\hline 41.0 & 398.2 & 14997 & 0.16 & 6.37 \\
\hline 40.9 & 400.1 & 15063 & 0.23 & 6.58 \\
\hline 40.9 & 399.2 & 15005 & 0.27 & 6.65 \\
\hline 41.0 & 402.4 & 15132 & 0.31 & 6.91 \\
\hline 40.8 & 401.0 & 15263 & 0.36 & 7.07 \\
\hline 40.9 & 400.9 & 15113 & 0.42 & 7.13 \\
\hline 41.0 & 400.6 & 14903 & 0.47 & 7.14 \\
\hline 41.0 & 400.0 & 14922 & 0.53 & 7.37 \\
\hline 40.9 & 399.1 & 15067 & 0.58 & 7.74 \\
\hline 40.9 & 398.7 & 15036 & 0.62 & 8.05 \\
\hline 40.9 & 400.5 & 15121 & 0.65 & 8.53 \\
\hline 41.0 & 398.9 & 14993 & 0.71 & 8.95 \\
\hline 40.9 & 400.1 & 15067 & 0.76 & 9.62 \\
\hline 40.9 & 399.6 & 14918 & 0.83 & 10.17 \\
\hline 40.9 & 400.5 & 14885 & 0.88 & 10.81 \\
\hline 41.1 & 399.6 & 25291 & 0.06 & 8.75 \\
\hline 41.1 & 398.9 & 25600 & 0.11 & 8.37 \\
\hline 41.1 & 398.8 & 25368 & 0.14 & 8.39 \\
\hline 41.1 & 399.1 & 25445 & 0.19 & 8.56 \\
\hline 41.0 & 399.3 & 25310 & 0.25 & 8.54 \\
\hline 40.9 & 399.4 & 25214 & 0.30 & 8.41 \\
\hline 41.0 & 400.8 & 25368 & 0.34 & 8.61 \\
\hline 41.0 & 399.8 & 25445 & 0.40 & 8.91 \\
\hline 41.0 & 398.4 & 25484 & 0.46 & 8.99 \\
\hline 40.9 & 399.4 & 25310 & 0.50 & 9.04 \\
\hline 40.9 & 401.2 & 24770 & 0.54 & 8.89 \\
\hline 40.9 & 400.7 & 25118 & 0.59 & 9.18 \\
\hline 41.0 & 399.3 & 25484 & 0.66 & 9.83 \\
\hline 41.0 & 399.8 & 25619 & 0.70 & 10.11 \\
\hline 41.0 & 400.6 & 25407 & 0.74 & 10.36 \\
\hline 40.9 & 399.6 & 25349 & 0.79 & 10.83 \\
\hline 40.9 & 400.0 & 25368 & 0.84 & 11.38 \\
\hline 41.1 & 400.7 & 35149 & 0.04 & 10.28 \\
\hline 41.2 & 399.3 & 35439 & 0.07 & 10.27 \\
\hline 41.2 & 398.3 & 34956 & 0.12 & 9.97 \\
\hline 41.1 & 402.3 & 35323 & 0.17 & 10.22 \\
\hline 41.0 & 399.9 & 35226 & 0.22 & 10.31 \\
\hline 41.0 & 398.8 & 35323 & 0.27 & 10.29 \\
\hline 41.1 & 403.0 & 36114 & 0.31 & 10.64 \\
\hline 41.0 & 399.9 & 34570 & 0.37 & 10.33 \\
\hline 41.0 & 400.9 & 34898 & 0.42 & 10.50 \\
\hline 40.9 & 400.2 & 35091 & 0.47 & 10.38 \\
\hline 41.0 & 401.1 & 35381 & 0.53 & 10.52 \\
\hline 40.9 & 399.0 & 35381 & 0.58 & 10.53 \\
\hline 40.9 & 398.9 & 35091 & 0.62 & 10.46 \\
\hline 40.9 & 400.6 & 35303 & 0.68 & 10.64 \\
\hline 41.0 & 400.9 & 35477 & 0.72 & 10.80 \\
\hline 41.0 & 398.3 & 35574 & 0.77 & 10.94 \\
\hline 40.8 & 400.4 & 34840 & 0.81 & 10.92 \\
\hline & & & & \\
\hline
\end{tabular}

\begin{tabular}{|c|c|c|c|c|}
\hline $\boldsymbol{T}_{\text {sat }}$ & $\boldsymbol{G}$ & $\boldsymbol{\phi}$ & $\boldsymbol{x}$ & $\boldsymbol{h}$ \\
\hline 41.1 & 400.8 & 45181 & 0.07 & 11.69 \\
\hline 41.0 & 400.4 & 45219 & 0.10 & 11.61 \\
\hline 40.9 & 399.0 & 45316 & 0.15 & 11.62 \\
\hline 40.9 & 399.2 & 45316 & 0.20 & 11.81 \\
\hline 40.9 & 399.5 & 45084 & 0.25 & 11.78 \\
\hline 41.1 & 399.5 & 44737 & 0.30 & 11.75 \\
\hline 41.1 & 399.4 & 45181 & 0.37 & 11.74 \\
\hline 41.0 & 400.5 & 45817 & 0.40 & 12.08 \\
\hline 41.0 & 400.6 & 45991 & 0.45 & 12.24 \\
\hline 41.0 & 399.2 & 46145 & 0.50 & 12.24 \\
\hline 40.9 & 400.8 & 45779 & 0.55 & 12.14 \\
\hline 40.9 & 400.7 & 45952 & 0.60 & 12.18 \\
\hline 40.9 & 399.4 & 45393 & 0.66 & 12.07 \\
\hline 40.9 & 399.2 & 45239 & 0.70 & 12.03 \\
\hline 40.9 & 400.1 & 45817 & 0.76 & 12.29 \\
\hline 40.9 & 402.3 & 45489 & 0.79 & 12.24 \\
\hline 41.1 & 398.7 & 54981 & 0.11 & 13.33 \\
\hline 41.1 & 398.0 & 55039 & 0.18 & 13.42 \\
\hline 41.2 & 399.9 & 54962 & 0.23 & 13.59 \\
\hline 41.1 & 400.1 & 54749 & 0.28 & 13.48 \\
\hline 41.0 & 399.9 & 54769 & 0.32 & 13.48 \\
\hline 40.9 & 400.5 & 55077 & 0.38 & 13.50 \\
\hline 41.0 & 401.2 & 55116 & 0.44 & 13.61 \\
\hline 40.9 & 397.7 & 55135 & 0.48 & 13.32 \\
\hline 41.1 & 400.7 & 55154 & 0.52 & 13.48 \\
\hline 41.0 & 398.5 & 55077 & 0.58 & 13.40 \\
\hline 40.9 & 398.2 & 55000 & 0.63 & 13.34 \\
\hline 40.9 & 399.9 & 55232 & 0.68 & 13.38 \\
\hline 40.9 & 402.4 & 55212 & 0.71 & 13.33 \\
\hline 40.9 & 399.6 & 55135 & 0.79 & 13.23 \\
\hline 41.0 & 400.7 & 65147 & 0.21 & 15.15 \\
\hline 41.1 & 399.5 & 65147 & 0.25 & 15.22 \\
\hline 41.2 & 400.5 & 65745 & 0.31 & 15.39 \\
\hline 41.3 & 396.6 & 65938 & 0.35 & 15.44 \\
\hline 41.1 & 398.5 & 65225 & 0.41 & 15.27 \\
\hline 41.0 & 402.1 & 65070 & 0.44 & 15.18 \\
\hline 40.8 & 399.8 & 65147 & 0.52 & 14.80 \\
\hline 40.9 & 400.0 & 65263 & 0.55 & 15.10 \\
\hline 40.9 & 400.7 & 65109 & 0.60 & 15.08 \\
\hline 41.0 & 399.6 & 65437 & 0.66 & 15.15 \\
\hline 41.0 & 399.8 & 65495 & 0.70 & 15.16 \\
\hline 41.1 & 400.4 & 65475 & 0.75 & 15.13 \\
\hline 41.0 & 400.2 & 74928 & 0.25 & 16.71 \\
\hline 41.1 & 400.4 & 74909 & 0.28 & 16.73 \\
\hline 41.3 & 399.9 & 74832 & 0.33 & 16.74 \\
\hline 41.1 & 401.2 & 74851 & 0.40 & 17.02 \\
\hline 41.1 & 396.8 & 75218 & 0.43 & 17.11 \\
\hline 40.9 & 398.8 & 76375 & 0.50 & 17.24 \\
\hline 40.8 & 399.9 & 75179 & 0.59 & 16.13 \\
\hline 41.0 & 401.2 & 74697 & 0.62 & 16.26 \\
\hline 41.2 & 400.9 & 76857 & 0.68 & 17.41 \\
\hline & 400.0 & 76954 & 0.74 & 17.14 \\
\hline 41.1 & & & & \\
\hline 40.55 \\
\hline 40
\end{tabular}


Tabela B.8. R1234ze(E), geometría circular.

\begin{tabular}{|c|c|c|c|c|}
\hline$T_{\text {sat }}$ & $G$ & $\phi$ & $x$ & $h$ \\
\hline 30.8 & 100.2 & 15958 & 0.11 & 3.73 \\
\hline 30.8 & 103.1 & 15692 & 0.16 & 3.64 \\
\hline 30.8 & 100.2 & 15630 & 0.25 & 4.51 \\
\hline 30.8 & 103.1 & 15402 & 0.29 & 4.17 \\
\hline 30.8 & 99.2 & 15344 & 0.38 & 5.21 \\
\hline 30.9 & 103.1 & 15413 & 0.42 & 4.90 \\
\hline 30.9 & 102.2 & 15209 & 0.46 & 6.21 \\
\hline 31.1 & 100.2 & 15708 & 0.54 & 6.14 \\
\hline 31.3 & 101.1 & 15942 & 0.55 & 6.05 \\
\hline 31.4 & 103.1 & 16081 & 0.59 & 8.13 \\
\hline 31.3 & 100.2 & 15702 & 0.66 & 8.50 \\
\hline 31.3 & 100.2 & 16083 & 0.72 & 7.28 \\
\hline 31.2 & 103.1 & 15706 & 0.73 & 7.48 \\
\hline 31.3 & 199.9 & 14252 & 0.08 & 3.88 \\
\hline 31.2 & 198.9 & 14203 & 0.12 & 3.92 \\
\hline 31.0 & 199.9 & 14252 & 0.17 & 4.27 \\
\hline 31.2 & 197.8 & 14295 & 0.23 & 4.44 \\
\hline 31.2 & 201.0 & 14915 & 0.27 & 4.76 \\
\hline 31.2 & 195.7 & 15568 & 0.34 & 5.51 \\
\hline 31.2 & 197.8 & 15528 & 0.38 & 5.43 \\
\hline 31.1 & 197.8 & 15540 & 0.42 & 5.51 \\
\hline 31.2 & 198.9 & 15544 & 0.46 & 5.98 \\
\hline 31.2 & 202.0 & 15568 & 0.51 & 6.26 \\
\hline 31.2 & 196.8 & 15609 & 0.57 & 6.87 \\
\hline 31.2 & 201.0 & 15632 & 0.61 & 7.53 \\
\hline 31.3 & 201.0 & 15605 & 0.66 & 8.12 \\
\hline 31.2 & 198.9 & 15687 & 0.72 & 9.06 \\
\hline 31.2 & 198.9 & 15409 & 0.78 & 9.27 \\
\hline 31.2 & 199.9 & 15402 & 0.82 & 10.05 \\
\hline 31.1 & 200.6 & 15413 & 0.86 & 10.57 \\
\hline 31.7 & 199.5 & 25485 & 0.06 & 5.84 \\
\hline 31.7 & 201.0 & 25483 & 0.10 & 6.00 \\
\hline 31.6 & 198.9 & 25839 & 0.14 & 6.36 \\
\hline 31.7 & 199.5 & 25485 & 0.17 & 6.08 \\
\hline 31.7 & 201.0 & 25483 & 0.21 & 6.03 \\
\hline 31.6 & 198.9 & 25839 & 0.26 & 5.92 \\
\hline 31.5 & 195.7 & 25930 & 0.31 & 5.95 \\
\hline 31.7 & 203.1 & 25840 & 0.34 & 6.22 \\
\hline 31.7 & 198.9 & 25461 & 0.40 & 6.27 \\
\hline 31.6 & 202.0 & 25474 & 0.45 & 5.96 \\
\hline 31.4 & 196.8 & 25157 & 0.53 & 6.40 \\
\hline 31.4 & 199.9 & 25028 & 0.56 & 6.78 \\
\hline 31.4 & 203.1 & 24917 & 0.60 & 7.30 \\
\hline 31.4 & 196.8 & 25052 & 0.67 & 7.75 \\
\hline 31.4 & 201.0 & 25060 & 0.71 & 8.36 \\
\hline 31.3 & 205.2 & 24909 & 0.74 & 8.96 \\
\hline 31.3 & 197.8 & 24936 & 0.81 & 9.42 \\
\hline 31.3 & 195.7 & 35711 & 0.13 & 7.78 \\
\hline 31.3 & 194.7 & 35949 & 0.19 & 7.98 \\
\hline 31.3 & 194.7 & 36011 & 0.26 & 7.45 \\
\hline 31.5 & 195.7 & 36167 & 0.30 & 7.74 \\
\hline 31.3 & 196.8 & 35525 & 0.34 & 7.59 \\
\hline 31.2 & 195.7 & 35711 & 0.38 & 7.80 \\
\hline 31.2 & 194.7 & 35949 & 0.44 & 7.91 \\
\hline
\end{tabular}

\begin{tabular}{|c|c|c|c|c|}
\hline $\boldsymbol{T}$ sat & $\boldsymbol{G}$ & $\boldsymbol{\phi}$ & $\boldsymbol{x}$ & $\boldsymbol{h}$ \\
\hline 31.2 & 194.7 & 36011 & 0.51 & 8.03 \\
\hline 31.4 & 195.7 & 36167 & 0.55 & 8.57 \\
\hline 31.3 & 196.8 & 35525 & 0.59 & 8.53 \\
\hline 31.3 & 192.6 & 35847 & 0.65 & 8.98 \\
\hline 31.3 & 196.8 & 35769 & 0.68 & 9.22 \\
\hline 31.2 & 202.0 & 35645 & 0.73 & 9.42 \\
\hline 31.3 & 201.0 & 35392 & 0.77 & 9.70 \\
\hline 31.2 & 197.8 & 35079 & 0.84 & 10.14 \\
\hline 30.9 & 196.8 & 46750 & 0.20 & 8.87 \\
\hline 30.9 & 202.0 & 46454 & 0.24 & 8.55 \\
\hline 30.9 & 198.9 & 46176 & 0.29 & 8.23 \\
\hline 31.1 & 205.2 & 46083 & 0.32 & 8.58 \\
\hline 31.3 & 199.9 & 45809 & 0.42 & 8.52 \\
\hline 31.3 & 199.9 & 44959 & 0.45 & 8.33 \\
\hline 31.3 & 199.9 & 44728 & 0.48 & 8.31 \\
\hline 30.8 & 196.8 & 46750 & 0.52 & 8.71 \\
\hline 30.8 & 202.0 & 46454 & 0.55 & 8.65 \\
\hline 30.8 & 198.9 & 46176 & 0.60 & 8.54 \\
\hline 31.1 & 205.2 & 46083 & 0.62 & 8.90 \\
\hline 31.2 & 199.9 & 45809 & 0.73 & 9.06 \\
\hline 31.2 & 199.9 & 44959 & 0.76 & 9.76 \\
\hline 31.2 & 199.9 & 44728 & 0.79 & 9.23 \\
\hline 31.0 & 307.3 & 15691 & 0.04 & 3.57 \\
\hline 30.9 & 303.1 & 15553 & 0.10 & 3.49 \\
\hline 31.0 & 308.3 & 15534 & 0.14 & 3.66 \\
\hline 31.2 & 310.4 & 15489 & 0.19 & 3.89 \\
\hline 31.2 & 293.6 & 15363 & 0.27 & 4.14 \\
\hline 31.1 & 307.3 & 15335 & 0.30 & 4.55 \\
\hline 32.0 & 312.5 & 15238 & 0.34 & 4.81 \\
\hline 31.9 & 303.1 & 15212 & 0.40 & 5.34 \\
\hline 31.9 & 295.7 & 15216 & 0.45 & 6.17 \\
\hline 31.7 & 304.1 & 15140 & 0.49 & 6.64 \\
\hline 31.8 & 302.0 & 15176 & 0.53 & 7.15 \\
\hline 31.8 & 303.1 & 15171 & 0.59 & 7.73 \\
\hline 31.6 & 304.1 & 15179 & 0.63 & 8.34 \\
\hline 31.5 & 300.9 & 15172 & 0.68 & 8.88 \\
\hline 31.4 & 302.0 & 15163 & 0.74 & 9.31 \\
\hline 31.4 & 300.9 & 15143 & 0.79 & 9.94 \\
\hline 31.3 & 303.1 & 15087 & 0.83 & 10.70 \\
\hline 31.2 & 300.9 & 15079 & 0.89 & 11.30 \\
\hline 31.0 & 295.7 & 25520 & 0.02 & 5.53 \\
\hline 31.0 & 306.2 & 25441 & 0.07 & 5.41 \\
\hline 31.0 & 295.7 & 25520 & 0.10 & 5.53 \\
\hline 31.0 & 306.2 & 25441 & 0.14 & 5.29 \\
\hline 31.1 & 302.0 & 25406 & 0.21 & 5.27 \\
\hline 31.2 & 300.9 & 25406 & 0.27 & 5.35 \\
\hline 31.2 & 303.1 & 25362 & 0.33 & 5.54 \\
\hline 31.1 & 290.4 & 25306 & 0.41 & 5.78 \\
\hline 31.1 & 309.4 & 25279 & 0.42 & 6.02 \\
\hline 31.1 & 312.5 & 25222 & 0.46 & 6.39 \\
\hline 31.1 & 315.7 & 25195 & 0.49 & 6.69 \\
\hline 31.2 & 306.2 & 25182 & 0.53 & 6.97 \\
\hline 31.2 & 304.1 & 25157 & 0.61 & 7.57 \\
\hline 31.2 & 297.8 & 25098 & 0.66 & 7.91 \\
\hline 31.3 & 299.9 & 25087 & 0.71 & 8.53 \\
\hline 31.2 & 299.9 & 25075 & 0.75 & 9.16 \\
\hline 31.2 & 303.1 & 25064 & 0.79 & 9.53 \\
\hline & & & & \\
\hline
\end{tabular}




\begin{tabular}{|c|c|c|c|c|}
\hline$T_{\text {sat }}$ & $G$ & $\phi$ & $x$ & $h$ \\
\hline 31.2 & 300.9 & 25021 & 0.86 & 10.12 \\
\hline 31.2 & 303.1 & 35908 & 0.05 & 7.16 \\
\hline 31.3 & 294.6 & 35770 & 0.11 & 7.34 \\
\hline 31.2 & 303.1 & 35908 & 0.16 & 7.29 \\
\hline 31.3 & 294.6 & 35770 & 0.22 & 6.90 \\
\hline 31.4 & 297.8 & 35616 & 0.27 & 6.91 \\
\hline 31.6 & 299.9 & 35546 & 0.31 & 7.04 \\
\hline 31.7 & 302.0 & 35397 & 0.39 & 7.27 \\
\hline 31.8 & 300.9 & 35398 & 0.42 & 7.41 \\
\hline 31.8 & 302.0 & 35784 & 0.46 & 7.75 \\
\hline 31.8 & 298.8 & 35956 & 0.52 & 8.26 \\
\hline 31.8 & 302.0 & 36227 & 0.56 & 8.71 \\
\hline 31.7 & 295.7 & 36005 & 0.63 & 9.23 \\
\hline 31.5 & 302.0 & 35814 & 0.65 & 9.73 \\
\hline 31.5 & 300.9 & 35753 & 0.71 & 10.33 \\
\hline 31.4 & 302.0 & 35723 & 0.75 & 10.95 \\
\hline 31.3 & 296.7 & 35748 & 0.83 & 11.70 \\
\hline 30.8 & 303.1 & 44858 & 0.09 & 8.69 \\
\hline 30.8 & 299.9 & 44670 & 0.14 & 8.49 \\
\hline 30.5 & 302.0 & 44490 & 0.19 & 7.66 \\
\hline 31.2 & 303.1 & 45002 & 0.24 & 8.62 \\
\hline 31.3 & 303.1 & 45219 & 0.28 & 8.70 \\
\hline 31.3 & 299.9 & 45318 & 0.34 & 8.85 \\
\hline 31.4 & 298.8 & 45616 & 0.39 & 9.05 \\
\hline 31.4 & 302.0 & 46032 & 0.43 & 9.28 \\
\hline 31.5 & 303.1 & 45956 & 0.47 & 9.38 \\
\hline 31.5 & 302.0 & 45722 & 0.53 & 9.52 \\
\hline 31.4 & 297.8 & 45785 & 0.58 & 9.59 \\
\hline 31.5 & 297.8 & 45788 & 0.64 & 9.80 \\
\hline 31.3 & 303.1 & 45956 & 0.68 & 10.58 \\
\hline 31.3 & 302.0 & 45722 & 0.73 & 11.06 \\
\hline 31.2 & 297.8 & 45785 & 0.79 & 11.49 \\
\hline 31.3 & 297.8 & 45788 & 0.84 & 12.08 \\
\hline 31.5 & 303.1 & 55939 & 0.13 & 10.23 \\
\hline 31.5 & 296.7 & 55474 & 0.16 & 9.90 \\
\hline 31.5 & 299.9 & 56249 & 0.21 & 9.91 \\
\hline 31.6 & 300.9 & 55960 & 0.26 & 9.93 \\
\hline 31.8 & 298.8 & 55937 & 0.31 & 10.05 \\
\hline 31.8 & 298.8 & 55805 & 0.35 & 10.18 \\
\hline 31.8 & 307.3 & 55830 & 0.41 & 10.15 \\
\hline 31.7 & 300.9 & 55637 & 0.46 & 10.13 \\
\hline 31.7 & 300.9 & 55568 & 0.51 & 10.04 \\
\hline 31.6 & 299.9 & 55351 & 0.58 & 10.05 \\
\hline 31.7 & 298.8 & 55805 & 0.60 & 10.12 \\
\hline 31.6 & 307.3 & 55830 & 0.65 & 10.44 \\
\hline 31.6 & 300.9 & 55637 & 0.71 & 10.55 \\
\hline 31.5 & 300.9 & 55568 & 0.76 & 10.82 \\
\hline 31.4 & 299.9 & 55351 & 0.83 & 11.40 \\
\hline 30.7 & 400.9 & 16195 & 0.02 & 4.24 \\
\hline 30.5 & 399.4 & 15472 & 0.07 & 3.74 \\
\hline 30.9 & 399.9 & 15496 & 0.13 & 4.20 \\
\hline 31.0 & 399.9 & 15456 & 0.17 & 4.53 \\
\hline 31.2 & 400.9 & 15430 & 0.23 & 5.23 \\
\hline 31.2 & 399.9 & 15401 & 0.27 & 5.87 \\
\hline 31.4 & 399.9 & 15371 & 0.33 & 6.66 \\
\hline 31.4 & 403.0 & 15351 & 0.37 & 7.34 \\
\hline 31.6 & 399.9 & 15330 & 0.43 & 8.29 \\
\hline
\end{tabular}

\begin{tabular}{|c|c|c|c|c|}
\hline$T_{\text {sat }}$ & $G$ & $\phi$ & $x$ & $h$ \\
\hline 31.7 & 399.9 & 15320 & 0.47 & 8.93 \\
\hline 31.7 & 398.8 & 15287 & 0.51 & 9.49 \\
\hline 31.8 & 399.9 & 15265 & 0.57 & 10.33 \\
\hline 31.9 & 400.9 & 15243 & 0.62 & 11.03 \\
\hline 31.9 & 399.9 & 15233 & 0.69 & 12.02 \\
\hline 31.9 & 399.9 & 15223 & 0.73 & 12.38 \\
\hline 32.0 & 399.9 & 15212 & 0.77 & 13.09 \\
\hline 31.9 & 395.7 & 15214 & 0.84 & 13.98 \\
\hline 32.0 & 399.9 & 15203 & 0.89 & 14.64 \\
\hline 30.9 & 398.8 & 25708 & 0.03 & 5.65 \\
\hline 30.8 & 400.9 & 24774 & 0.07 & 5.35 \\
\hline 30.9 & 398.8 & 25704 & 0.12 & 5.47 \\
\hline 31.0 & 398.8 & 25519 & 0.17 & 5.41 \\
\hline 31.1 & 402.0 & 25752 & 0.22 & 5.63 \\
\hline 31.1 & 402.0 & 25692 & 0.27 & 6.31 \\
\hline 31.2 & 397.8 & 25558 & 0.31 & 6.90 \\
\hline 31.3 & 399.9 & 25578 & 0.37 & 7.85 \\
\hline 31.4 & 399.9 & 25626 & 0.43 & 8.90 \\
\hline 31.5 & 400.9 & 25600 & 0.47 & 9.74 \\
\hline 31.5 & 399.9 & 25890 & 0.52 & 10.17 \\
\hline 31.6 & 396.7 & 25864 & 0.58 & 11.22 \\
\hline 31.7 & 399.9 & 25767 & 0.62 & 11.79 \\
\hline 31.7 & 396.7 & 25697 & 0.67 & 12.70 \\
\hline 31.8 & 398.8 & 25628 & 0.72 & 13.58 \\
\hline 31.8 & 400.9 & 25516 & 0.77 & 14.40 \\
\hline 31.8 & 396.7 & 25046 & 0.82 & 14.69 \\
\hline 31.6 & 400.9 & 25516 & 0.83 & 14.82 \\
\hline 31.6 & 396.7 & 25046 & 0.88 & 14.87 \\
\hline 30.9 & 398.8 & 35151 & 0.05 & 7.54 \\
\hline 30.9 & 399.9 & 35117 & 0.06 & 7.58 \\
\hline 30.8 & 398.8 & 35151 & 0.09 & 7.27 \\
\hline 30.8 & 399.9 & 35117 & 0.10 & 7.36 \\
\hline 30.9 & 398.8 & 35028 & 0.16 & 6.97 \\
\hline 30.9 & 395.7 & 34941 & 0.21 & 6.86 \\
\hline 31.2 & 399.9 & 34974 & 0.25 & 7.23 \\
\hline 31.3 & 402.0 & 34960 & 0.30 & 7.58 \\
\hline 31.3 & 402.0 & 34860 & 0.34 & 7.88 \\
\hline 31.3 & 402.0 & 35545 & 0.40 & 8.67 \\
\hline 31.3 & 399.9 & 35500 & 0.45 & 9.15 \\
\hline 31.4 & 399.9 & 35367 & 0.50 & 9.58 \\
\hline 31.4 & 398.8 & 35320 & 0.55 & 10.19 \\
\hline 31.5 & 399.9 & 35290 & 0.60 & 10.84 \\
\hline 31.5 & 397.8 & 35294 & 0.66 & 11.77 \\
\hline 31.5 & 402.0 & 35127 & 0.69 & 12.34 \\
\hline 31.6 & 399.9 & 35147 & 0.75 & 13.06 \\
\hline 31.5 & 399.9 & 35134 & 0.80 & 13.79 \\
\hline 31.5 & 399.9 & 35086 & 0.85 & 14.40 \\
\hline 30.7 & 399.9 & 45408 & 0.04 & 8.21 \\
\hline 30.7 & 402.0 & 45505 & 0.07 & 8.26 \\
\hline 30.8 & 402.0 & 45384 & 0.12 & 8.27 \\
\hline 31.0 & 399.9 & 45402 & 0.17 & 8.21 \\
\hline 31.3 & 397.8 & 45260 & 0.22 & 8.31 \\
\hline 31.4 & 396.7 & 45221 & 0.27 & 8.35 \\
\hline 31.4 & 403.0 & 45202 & 0.31 & 8.04 \\
\hline 31.5 & 399.9 & 45146 & 0.36 & 8.15 \\
\hline 31.6 & 395.7 & 45112 & 0.42 & 8.65 \\
\hline 31.7 & 399.9 & 45136 & 0.47 & 9.22 \\
\hline
\end{tabular}




\begin{tabular}{|c|c|c|c|c|}
\hline$T_{\text {sat }}$ & $G$ & $\phi$ & $x$ & $h$ \\
\hline 31.8 & 399.9 & 45080 & 0.52 & 9.76 \\
\hline 31.8 & 402.0 & 45007 & 0.56 & 10.41 \\
\hline 31.9 & 399.9 & 44953 & 0.62 & 11.13 \\
\hline 31.9 & 399.9 & 45134 & 0.67 & 11.90 \\
\hline 31.9 & 399.9 & 45158 & 0.72 & 12.79 \\
\hline 31.6 & 399.9 & 44953 & 0.77 & 14.26 \\
\hline 31.6 & 399.9 & 45134 & 0.82 & 15.22 \\
\hline 31.6 & 399.9 & 45158 & 0.87 & 16.39 \\
\hline 30.6 & 396.7 & 56027 & 0.08 & 10.16 \\
\hline 30.7 & 399.9 & 55572 & 0.11 & 10.04 \\
\hline 30.8 & 397.8 & 55411 & 0.17 & 9.69 \\
\hline 30.6 & 396.7 & 56027 & 0.21 & 9.53 \\
\hline 30.6 & 399.9 & 55572 & 0.24 & 9.39 \\
\hline 30.7 & 397.8 & 55411 & 0.30 & 9.44 \\
\hline 31.0 & 399.9 & 55273 & 0.33 & 9.64 \\
\hline 31.1 & 398.8 & 55135 & 0.38 & 9.83 \\
\hline 31.2 & 399.9 & 55495 & 0.43 & 10.30 \\
\hline 31.2 & 402.0 & 56160 & 0.48 & 10.56 \\
\hline 31.3 & 399.9 & 56894 & 0.54 & 10.89 \\
\hline 31.3 & 396.7 & 56032 & 0.58 & 11.07 \\
\hline 31.3 & 403.0 & 56236 & 0.63 & 11.43 \\
\hline 31.2 & 399.9 & 55529 & 0.69 & 12.57 \\
\hline 31.2 & 399.9 & 55370 & 0.75 & 13.18 \\
\hline 31.2 & 399.9 & 55370 & 0.79 & 13.78 \\
\hline 31.2 & 399.9 & 55531 & 0.84 & 14.73 \\
\hline 31.3 & 398.8 & 65135 & 0.10 & 11.20 \\
\hline 31.3 & 396.7 & 65008 & 0.16 & 11.00 \\
\hline 31.0 & 399.9 & 62895 & 0.21 & 10.32 \\
\hline 31.2 & 398.8 & 65135 & 0.25 & 10.69 \\
\hline 31.2 & 396.7 & 65008 & 0.31 & 10.53 \\
\hline 30.9 & 399.9 & 62895 & 0.35 & 10.53 \\
\hline 31.6 & 402.0 & 66286 & 0.39 & 11.13 \\
\hline 31.7 & 399.9 & 66479 & 0.46 & 11.23 \\
\hline 31.8 & 400.9 & 66037 & 0.51 & 11.16 \\
\hline 31.8 & 403.0 & 65522 & 0.55 & 11.11 \\
\hline 31.8 & 399.9 & 65721 & 0.61 & 11.42 \\
\hline 31.8 & 402.0 & 65435 & 0.65 & 11.62 \\
\hline 31.7 & 397.8 & 65017 & 0.71 & 12.18 \\
\hline 31.6 & 399.9 & 63987 & 0.75 & 12.35 \\
\hline 31.6 & 397.8 & 65017 & 0.78 & 13.02 \\
\hline 31.5 & 399.9 & 63987 & 0.82 & 13.49 \\
\hline 30.9 & 399.9 & 74881 & 0.13 & 12.07 \\
\hline 30.9 & 400.9 & 75046 & 0.16 & 12.01 \\
\hline 31.0 & 396.7 & 75257 & 0.21 & 12.03 \\
\hline 31.4 & 398.8 & 75222 & 0.27 & 12.06 \\
\hline 31.6 & 404.1 & 75012 & 0.31 & 12.12 \\
\hline 31.6 & 399.9 & 75172 & 0.35 & 12.17 \\
\hline 30.8 & 399.9 & 74881 & 0.38 & 11.75 \\
\hline 30.8 & 400.9 & 75046 & 0.42 & 11.75 \\
\hline 30.8 & 396.7 & 75257 & 0.47 & 11.68 \\
\hline 31.2 & 398.8 & 75222 & 0.52 & 12.10 \\
\hline 31.4 & 404.1 & 75012 & 0.56 & 12.24 \\
\hline 31.4 & 399.9 & 75172 & 0.61 & 12.40 \\
\hline 31.4 & 399.9 & 75487 & 0.66 & 12.60 \\
\hline 31.5 & 399.9 & 75387 & 0.72 & 13.07 \\
\hline 31.3 & 400.9 & 74853 & 0.76 & 13.10 \\
\hline 31.4 & 397.8 & 74615 & 0.81 & 13.49 \\
\hline
\end{tabular}

\begin{tabular}{|c|c|c|c|c|}
\hline$T_{\text {sat }}$ & $G$ & $\phi$ & $x$ & $h$ \\
\hline 30.2 & 503.0 & 15484 & 0.06 & 3.26 \\
\hline 30.5 & 503.0 & 15311 & 0.12 & 3.59 \\
\hline 30.7 & 501.9 & 15192 & 0.17 & 4.84 \\
\hline 30.8 & 504.0 & 15168 & 0.22 & 5.86 \\
\hline 30.9 & 496.7 & 15514 & 0.27 & 6.90 \\
\hline 31.0 & 496.7 & 15336 & 0.31 & 7.70 \\
\hline 31.0 & 497.7 & 15157 & 0.37 & 8.56 \\
\hline 31.2 & 500.9 & 15432 & 0.43 & 9.99 \\
\hline 31.2 & 497.7 & 14659 & 0.46 & 9.80 \\
\hline 31.3 & 505.1 & 15444 & 0.52 & 11.62 \\
\hline 31.4 & 505.1 & 14921 & 0.56 & 12.01 \\
\hline 31.4 & 493.5 & 14797 & 0.62 & 12.16 \\
\hline 31.5 & 505.1 & 15376 & 0.66 & 13.81 \\
\hline 31.5 & 494.6 & 14958 & 0.72 & 13.92 \\
\hline 31.5 & 499.8 & 14895 & 0.77 & 14.64 \\
\hline 31.5 & 496.7 & 14874 & 0.84 & 15.56 \\
\hline 31.5 & 498.8 & 15064 & 0.87 & 15.82 \\
\hline 31.5 & 504.0 & 15349 & 0.91 & 16.47 \\
\hline 30.7 & 498.8 & 25135 & 0.05 & 5.08 \\
\hline 30.8 & 503.0 & 25265 & 0.09 & 5.07 \\
\hline 30.5 & 501.9 & 25140 & 0.14 & 5.04 \\
\hline 30.3 & 499.8 & 25201 & 0.18 & 5.26 \\
\hline 30.5 & 497.7 & 25448 & 0.24 & 6.20 \\
\hline 30.7 & 501.9 & 25412 & 0.30 & 7.24 \\
\hline 30.8 & 501.9 & 25208 & 0.34 & 8.09 \\
\hline 30.9 & 498.8 & 25227 & 0.40 & 8.91 \\
\hline 31.0 & 499.8 & 25663 & 0.45 & 9.78 \\
\hline 31.1 & 496.7 & 25351 & 0.50 & 10.49 \\
\hline 31.2 & 505.1 & 25576 & 0.54 & 11.31 \\
\hline 31.3 & 500.9 & 25472 & 0.59 & 11.93 \\
\hline 31.4 & 503.0 & 25189 & 0.64 & 12.82 \\
\hline 31.5 & 501.9 & 25191 & 0.69 & 13.64 \\
\hline 31.4 & 498.8 & 25253 & 0.75 & 14.33 \\
\hline 31.4 & 499.8 & 25121 & 0.80 & 15.06 \\
\hline 31.4 & 499.8 & 25678 & 0.85 & 16.19 \\
\hline 31.4 & 500.9 & 25379 & 0.89 & 16.71 \\
\hline 30.8 & 498.8 & 35659 & 0.07 & 7.08 \\
\hline 30.8 & 499.8 & 35744 & 0.12 & 6.89 \\
\hline 30.8 & 500.9 & 35580 & 0.17 & 6.46 \\
\hline 31.4 & 500.9 & 35668 & 0.22 & 7.34 \\
\hline 31.4 & 498.8 & 35670 & 0.27 & 7.83 \\
\hline 31.5 & 499.8 & 35674 & 0.31 & 8.30 \\
\hline 31.5 & 503.0 & 35400 & 0.38 & 9.14 \\
\hline 31.6 & 500.9 & 35332 & 0.41 & 9.56 \\
\hline 31.7 & 496.7 & 35391 & 0.47 & 10.55 \\
\hline 31.7 & 499.8 & 35271 & 0.51 & 10.98 \\
\hline 31.7 & 499.8 & 35452 & 0.56 & 11.92 \\
\hline 31.8 & 498.8 & 35508 & 0.62 & 12.73 \\
\hline 31.8 & 498.8 & 35565 & 0.67 & 13.43 \\
\hline 31.8 & 498.8 & 35373 & 0.73 & 14.30 \\
\hline 31.8 & 500.9 & 35323 & 0.77 & 14.76 \\
\hline 31.7 & 501.9 & 35166 & 0.81 & 15.07 \\
\hline 31.6 & 501.9 & 35152 & 0.87 & 15.68 \\
\hline 30.1 & 500.9 & 44896 & 0.02 & 7.88 \\
\hline 30.3 & 497.7 & 44892 & 0.06 & 8.11 \\
\hline 30.1 & 500.9 & 44896 & 0.10 & 8.04 \\
\hline 30.2 & 497.7 & 44892 & 0.15 & 7.78 \\
\hline
\end{tabular}




\begin{tabular}{|c|c|c|c|c|}
\hline$T_{\text {sat }}$ & $G$ & $\phi$ & $x$ & $h$ \\
\hline 29.9 & 500.9 & 45150 & 0.20 & 7.20 \\
\hline 30.9 & 501.9 & 45087 & 0.25 & 8.31 \\
\hline 31.0 & 499.8 & 45107 & 0.30 & 8.49 \\
\hline 31.1 & 500.9 & 44849 & 0.35 & 8.96 \\
\hline 31.1 & 501.9 & 44954 & 0.39 & 9.59 \\
\hline 31.3 & 503.0 & 44817 & 0.45 & 10.30 \\
\hline 31.4 & 505.1 & 44780 & 0.50 & 10.98 \\
\hline 31.4 & 498.8 & 44723 & 0.55 & 11.56 \\
\hline 31.5 & 496.7 & 44746 & 0.59 & 12.06 \\
\hline 31.6 & 501.9 & 45012 & 0.65 & 13.14 \\
\hline 31.6 & 501.9 & 44894 & 0.69 & 13.63 \\
\hline 31.5 & 503.0 & 44778 & 0.74 & 14.42 \\
\hline 31.5 & 499.8 & 44661 & 0.80 & 15.08 \\
\hline 31.4 & 498.8 & 44789 & 0.86 & 16.11 \\
\hline 30.5 & 498.8 & 54868 & 0.04 & 9.09 \\
\hline 30.6 & 499.8 & 54748 & 0.07 & 9.26 \\
\hline 30.7 & 499.8 & 54859 & 0.13 & 9.16 \\
\hline 30.4 & 498.8 & 54868 & 0.14 & 9.17 \\
\hline 30.5 & 499.8 & 54748 & 0.17 & 9.09 \\
\hline 30.6 & 499.8 & 54859 & 0.22 & 8.76 \\
\hline 31.0 & 499.8 & 54878 & 0.27 & 9.18 \\
\hline 31.2 & 498.8 & 54965 & 0.32 & 9.17 \\
\hline 31.3 & 496.7 & 54807 & 0.37 & 9.32 \\
\hline 31.4 & 498.8 & 55012 & 0.42 & 9.69 \\
\hline 31.5 & 501.9 & 54971 & 0.46 & 10.31 \\
\hline 31.6 & 497.7 & 54885 & 0.53 & 10.92 \\
\hline 31.6 & 497.7 & 54979 & 0.58 & 11.49 \\
\hline 31.7 & 499.8 & 54846 & 0.62 & 12.09 \\
\hline 31.7 & 501.9 & 55009 & 0.67 & 12.93 \\
\hline 31.7 & 500.9 & 54853 & 0.71 & 13.75 \\
\hline 31.6 & 500.9 & 54882 & 0.76 & 14.46 \\
\hline 31.5 & 505.1 & 54867 & 0.82 & 15.71 \\
\hline 30.7 & 504.0 & 65136 & 0.09 & 10.98 \\
\hline 30.8 & 501.9 & 64959 & 0.14 & 10.70 \\
\hline 31.0 & 498.8 & 64957 & 0.18 & 10.96 \\
\hline 31.4 & 498.8 & 65151 & 0.24 & 11.26 \\
\hline 31.6 & 496.7 & 64978 & 0.30 & 11.24 \\
\hline 31.6 & 497.7 & 65301 & 0.34 & 11.36 \\
\hline 31.7 & 497.7 & 64907 & 0.40 & 11.49 \\
\hline 31.7 & 495.6 & 65083 & 0.43 & 11.57 \\
\hline 31.8 & 500.9 & 64938 & 0.48 & 11.94 \\
\hline 31.8 & 492.5 & 64992 & 0.53 & 12.07 \\
\hline 31.9 & 494.6 & 64970 & 0.57 & 12.46 \\
\hline 31.8 & 498.8 & 65224 & 0.63 & 12.95 \\
\hline 31.8 & 499.8 & 65057 & 0.68 & 13.74 \\
\hline 31.4 & 492.5 & 64992 & 0.71 & 14.08 \\
\hline 31.5 & 494.6 & 64970 & 0.75 & 14.78 \\
\hline 31.4 & 498.8 & 65224 & 0.81 & 16.08 \\
\hline 31.3 & 499.8 & 65057 & 0.85 & 17.06 \\
\hline 30.4 & 497.7 & 75154 & 0.09 & 11.64 \\
\hline 30.5 & 499.8 & 74854 & 0.14 & 11.45 \\
\hline 31.0 & 503.0 & 75198 & 0.22 & 12.02 \\
\hline 31.2 & 503.0 & 75282 & 0.24 & 12.25 \\
\hline 30.6 & 497.7 & 75154 & 0.29 & 11.91 \\
\hline 30.7 & 499.8 & 74854 & 0.34 & 11.92 \\
\hline 31.2 & 503.0 & 75198 & 0.42 & 11.75 \\
\hline 31.4 & 503.0 & 75282 & 0.44 & 11.97 \\
\hline
\end{tabular}

\begin{tabular}{|c|c|c|c|c|}
\hline$T_{\text {sat }}$ & $G$ & $\phi$ & $x$ & $h$ \\
\hline 31.6 & 498.8 & 75225 & 0.50 & 12.11 \\
\hline 31.7 & 500.9 & 75352 & 0.55 & 12.33 \\
\hline 31.8 & 500.9 & 75247 & 0.59 & 12.62 \\
\hline 31.8 & 498.8 & 75250 & 0.65 & 13.25 \\
\hline 31.9 & 491.4 & 75278 & 0.70 & 13.72 \\
\hline 31.9 & 493.5 & 75145 & 0.76 & 14.61 \\
\hline 31.8 & 497.7 & 74533 & 0.79 & 15.23 \\
\hline 31.7 & 489.3 & 74783 & 0.85 & 16.18 \\
\hline 31.7 & 495.6 & 84660 & 0.11 & 13.30 \\
\hline 31.8 & 501.9 & 84744 & 0.15 & 13.19 \\
\hline 31.8 & 505.1 & 84457 & 0.19 & 13.01 \\
\hline 32.2 & 495.6 & 84341 & 0.27 & 13.84 \\
\hline 32.2 & 493.5 & 84513 & 0.31 & 13.67 \\
\hline 32.2 & 497.7 & 84398 & 0.34 & 13.65 \\
\hline 32.3 & 504.0 & 84341 & 0.40 & 13.84 \\
\hline 32.3 & 499.8 & 84228 & 0.44 & 13.76 \\
\hline 32.3 & 493.5 & 84490 & 0.50 & 13.93 \\
\hline 32.2 & 496.7 & 84581 & 0.55 & 13.72 \\
\hline 32.1 & 487.2 & 84613 & 0.60 & 13.91 \\
\hline 32.0 & 504.0 & 84341 & 0.63 & 13.50 \\
\hline 31.9 & 499.8 & 84228 & 0.67 & 13.76 \\
\hline 31.9 & 493.5 & 84490 & 0.73 & 14.42 \\
\hline 31.8 & 496.7 & 84581 & 0.78 & 15.11 \\
\hline 31.7 & 487.2 & 84613 & 0.83 & 15.53 \\
\hline 41.4 & 101.1 & 15083 & 0.01 & 4.72 \\
\hline 41.4 & 100.2 & 15023 & 0.08 & 4.47 \\
\hline 41.4 & 101.1 & 15000 & 0.11 & 4.25 \\
\hline 41.4 & 101.1 & 15083 & 0.16 & 4.29 \\
\hline 41.4 & 100.2 & 15023 & 0.22 & 4.36 \\
\hline 41.4 & 101.1 & 15000 & 0.25 & 4.36 \\
\hline 41.4 & 100.2 & 14964 & 0.30 & 4.29 \\
\hline 41.4 & 101.1 & 14952 & 0.36 & 4.17 \\
\hline 40.9 & 100.2 & 14955 & 0.41 & 3.86 \\
\hline 41.0 & 97.3 & 14954 & 0.48 & 3.96 \\
\hline 41.1 & 100.2 & 14954 & 0.52 & 4.04 \\
\hline 41.1 & 101.1 & 14967 & 0.56 & 4.24 \\
\hline 41.2 & 102.2 & 14968 & 0.60 & 4.21 \\
\hline 41.2 & 103.1 & 14969 & 0.64 & 4.53 \\
\hline 41.2 & 100.2 & 14966 & 0.72 & 4.28 \\
\hline 41.2 & 100.2 & 14956 & 0.76 & 4.25 \\
\hline 42.0 & 202.0 & 15873 & 0.04 & 7.22 \\
\hline 42.0 & 202.0 & 16134 & 0.11 & 5.70 \\
\hline 41.9 & 198.9 & 15703 & 0.16 & 5.38 \\
\hline 41.9 & 199.9 & 15419 & 0.20 & 5.65 \\
\hline 41.4 & 201.0 & 15286 & 0.26 & 4.70 \\
\hline 41.5 & 198.9 & 15124 & 0.31 & 4.74 \\
\hline 41.5 & 198.9 & 15917 & 0.35 & 5.11 \\
\hline 41.5 & 199.9 & 16116 & 0.40 & 5.22 \\
\hline 41.5 & 201.0 & 16249 & 0.46 & 5.34 \\
\hline 41.5 & 201.0 & 15862 & 0.50 & 5.31 \\
\hline 41.5 & 202.0 & 15897 & 0.53 & 5.44 \\
\hline 41.5 & 203.1 & 16034 & 0.57 & 5.68 \\
\hline 41.5 & 203.1 & 15915 & 0.61 & 5.85 \\
\hline 41.5 & 210.5 & 15929 & 0.62 & 6.03 \\
\hline 41.5 & 201.0 & 16005 & 0.72 & 6.35 \\
\hline 41.4 & 201.0 & 15690 & 0.77 & 6.42 \\
\hline 41.5 & 193.6 & 15870 & 0.89 & 7.16 \\
\hline
\end{tabular}




\begin{tabular}{|c|c|c|c|c|}
\hline$T_{\text {sat }}$ & $G$ & $\phi$ & $x$ & $h$ \\
\hline 41.4 & 199.9 & 25585 & 0.01 & 7.35 \\
\hline 41.4 & 199.9 & 25671 & 0.06 & 7.16 \\
\hline 41.4 & 203.1 & 26903 & 0.11 & 7.32 \\
\hline 41.4 & 199.9 & 25585 & 0.14 & 6.78 \\
\hline 41.4 & 199.9 & 25671 & 0.19 & 6.96 \\
\hline 41.3 & 202.0 & 25411 & 0.23 & 6.97 \\
\hline 41.3 & 199.9 & 25455 & 0.28 & 6.96 \\
\hline 41.3 & 198.9 & 26264 & 0.34 & 6.80 \\
\hline 40.9 & 201.0 & 25800 & 0.38 & 6.09 \\
\hline 41.0 & 201.0 & 25713 & 0.43 & 6.15 \\
\hline 41.0 & 197.8 & 26060 & 0.51 & 6.22 \\
\hline 40.9 & 198.9 & 25734 & 0.54 & 6.34 \\
\hline 40.9 & 196.8 & 25906 & 0.60 & 6.55 \\
\hline 40.9 & 199.9 & 25866 & 0.66 & 6.67 \\
\hline 40.9 & 203.1 & 25768 & 0.70 & 6.91 \\
\hline 40.9 & 202.0 & 25585 & 0.76 & 7.06 \\
\hline 40.9 & 195.7 & 25173 & 0.81 & 7.10 \\
\hline 42.0 & 202.0 & 35467 & 0.03 & 9.10 \\
\hline 42.0 & 202.0 & 35655 & 0.11 & 8.83 \\
\hline 41.9 & 197.8 & 34484 & 0.15 & 8.54 \\
\hline 41.9 & 202.0 & 35361 & 0.18 & 8.80 \\
\hline 42.0 & 202.0 & 35467 & 0.20 & 8.82 \\
\hline 41.9 & 202.0 & 35655 & 0.27 & 8.83 \\
\hline 41.9 & 197.8 & 34484 & 0.31 & 8.25 \\
\hline 41.9 & 202.0 & 35361 & 0.35 & 8.32 \\
\hline 41.9 & 201.0 & 35994 & 0.41 & 8.31 \\
\hline 41.4 & 202.0 & 36114 & 0.46 & 7.45 \\
\hline 41.5 & 202.0 & 36027 & 0.52 & 7.67 \\
\hline 41.5 & 201.0 & 35145 & 0.59 & 7.30 \\
\hline 41.5 & 205.2 & 36285 & 0.62 & 7.51 \\
\hline 41.4 & 199.9 & 35751 & 0.67 & 7.35 \\
\hline 41.2 & 199.9 & 35579 & 0.72 & 7.18 \\
\hline 40.8 & 201.0 & 44813 & 0.11 & 10.13 \\
\hline 40.8 & 198.9 & 45223 & 0.22 & 10.36 \\
\hline 40.7 & 199.9 & 44180 & 0.28 & 9.92 \\
\hline 40.7 & 196.8 & 43413 & 0.30 & 9.60 \\
\hline 40.8 & 201.0 & 44813 & 0.32 & 9.80 \\
\hline 40.7 & 198.9 & 45223 & 0.44 & 9.65 \\
\hline 40.7 & 199.9 & 44180 & 0.49 & 9.32 \\
\hline 40.7 & 196.8 & 43413 & 0.51 & 9.14 \\
\hline 40.4 & 198.9 & 46414 & 0.58 & 9.02 \\
\hline 40.6 & 198.9 & 46001 & 0.60 & 9.16 \\
\hline 41.0 & 201.0 & 44985 & 0.67 & 8.51 \\
\hline 41.8 & 304.1 & 14904 & 0.03 & 5.71 \\
\hline 41.8 & 296.7 & 14855 & 0.09 & 4.72 \\
\hline 41.8 & 297.8 & 15265 & 0.15 & 5.11 \\
\hline 41.3 & 298.8 & 14535 & 0.21 & 4.06 \\
\hline 41.3 & 302.0 & 14616 & 0.25 & 4.21 \\
\hline 41.3 & 300.9 & 14616 & 0.28 & 4.24 \\
\hline 41.3 & 300.9 & 15517 & 0.33 & 4.59 \\
\hline 41.1 & 298.8 & 15100 & 0.38 & 4.46 \\
\hline 41.2 & 304.1 & 14335 & 0.43 & 4.83 \\
\hline 41.2 & 299.9 & 15499 & 0.49 & 5.58 \\
\hline 41.1 & 302.0 & 15252 & 0.53 & 5.98 \\
\hline 41.1 & 296.7 & 15716 & 0.60 & 6.78 \\
\hline 41.2 & 297.8 & 15468 & 0.67 & 7.12 \\
\hline 41.1 & 306.2 & 15085 & 0.67 & 7.29 \\
\hline
\end{tabular}

\begin{tabular}{|c|c|c|c|c|}
\hline $\boldsymbol{T}_{\text {sat }}$ & $\boldsymbol{G}$ & $\boldsymbol{\phi}$ & $\boldsymbol{x}$ & $\boldsymbol{h}$ \\
\hline 41.1 & 300.9 & 15135 & 0.72 & 7.57 \\
\hline 41.1 & 304.1 & 15580 & 0.77 & 8.22 \\
\hline 41.1 & 297.8 & 15275 & 0.83 & 8.59 \\
\hline 41.1 & 295.7 & 15308 & 0.91 & 9.22 \\
\hline 40.9 & 300.9 & 25709 & 0.05 & 7.20 \\
\hline 40.9 & 302.0 & 25632 & 0.08 & 7.02 \\
\hline 40.9 & 307.3 & 25824 & 0.10 & 6.85 \\
\hline 40.9 & 302.0 & 26034 & 0.19 & 7.20 \\
\hline 40.3 & 297.8 & 25571 & 0.25 & 5.90 \\
\hline 40.3 & 297.8 & 25556 & 0.30 & 5.95 \\
\hline 40.3 & 297.8 & 25496 & 0.35 & 5.97 \\
\hline 40.4 & 294.6 & 25543 & 0.43 & 6.22 \\
\hline 40.4 & 299.9 & 25500 & 0.46 & 6.28 \\
\hline 40.3 & 304.1 & 24994 & 0.48 & 6.29 \\
\hline 40.3 & 307.3 & 25863 & 0.53 & 6.81 \\
\hline 40.3 & 302.0 & 25596 & 0.59 & 6.81 \\
\hline 40.6 & 315.7 & 25730 & 0.63 & 7.23 \\
\hline 40.7 & 307.3 & 25340 & 0.68 & 7.39 \\
\hline 41.0 & 302.0 & 25352 & 0.75 & 7.65 \\
\hline 41.0 & 299.9 & 25010 & 0.79 & 7.82 \\
\hline 41.2 & 298.8 & 25517 & 0.83 & 8.27 \\
\hline 41.9 & 296.7 & 35433 & 0.07 & 8.85 \\
\hline 41.9 & 297.8 & 35415 & 0.10 & 8.72 \\
\hline 41.9 & 300.9 & 35765 & 0.15 & 8.91 \\
\hline 41.9 & 300.9 & 35396 & 0.19 & 8.99 \\
\hline 41.9 & 300.9 & 35763 & 0.25 & 8.66 \\
\hline 41.9 & 297.8 & 35550 & 0.31 & 8.47 \\
\hline 41.6 & 302.0 & 35461 & 0.37 & 7.78 \\
\hline 41.6 & 288.3 & 35619 & 0.45 & 7.78 \\
\hline 41.6 & 292.5 & 35039 & 0.48 & 7.61 \\
\hline 41.6 & 300.9 & 35040 & 0.51 & 7.74 \\
\hline 41.6 & 295.7 & 35199 & 0.56 & 7.78 \\
\hline 41.5 & 302.0 & 34920 & 0.59 & 7.73 \\
\hline 41.5 & 296.7 & 34660 & 0.67 & 7.83 \\
\hline 41.5 & 299.9 & 35241 & 0.70 & 8.08 \\
\hline 41.4 & 297.8 & 34102 & 0.75 & 8.05 \\
\hline 41.4 & 298.8 & 35668 & 0.82 & 8.74 \\
\hline 40.9 & 302.0 & 45398 & 0.07 & 10.38 \\
\hline 41.0 & 299.9 & 45397 & 0.11 & 10.42 \\
\hline 40.9 & 302.0 & 45398 & 0.14 & 10.33 \\
\hline 40.9 & 299.9 & 45397 & 0.22 & 10.28 \\
\hline 41.0 & 304.1 & 45135 & 0.25 & 10.00 \\
\hline 40.9 & 297.8 & 45095 & 0.31 & 9.85 \\
\hline 40.8 & 303.1 & 45035 & 0.33 & 9.70 \\
\hline 40.5 & 292.5 & 45977 & 0.42 & 9.35 \\
\hline 40.6 & 298.8 & 45115 & 0.48 & 9.31 \\
\hline 40.5 & 291.5 & 45518 & 0.53 & 9.35 \\
\hline 40.5 & 303.1 & 45238 & 0.55 & 9.39 \\
\hline 40.5 & 286.2 & 45099 & 0.64 & 9.38 \\
\hline 40.3 & 299.9 & 45523 & 0.67 & 9.53 \\
\hline 40.9 & 309.4 & 45589 & 0.71 & 9.33 \\
\hline 41.0 & 296.7 & 44803 & 0.78 & 9.30 \\
\hline 41.5 & 398.8 & 15669 & 0.06 & 4.52 \\
\hline 41.4 & 399.9 & 15071 & 0.10 & 4.19 \\
\hline 41.0 & 400.9 & 14667 & 0.15 & 3.57 \\
\hline 41.1 & 402.0 & 15311 & 0.21 & 3.87 \\
\hline 41.2 & 399.9 & 15209 & 0.26 & 4.05 \\
\hline & & & & \\
\hline
\end{tabular}




\begin{tabular}{|c|c|c|c|c|}
\hline$T_{\text {sat }}$ & $G$ & $\phi$ & $x$ & $h$ \\
\hline 41.2 & 399.9 & 15265 & 0.31 & 4.66 \\
\hline 41.2 & 398.8 & 15075 & 0.35 & 5.07 \\
\hline 41.2 & 400.9 & 15001 & 0.40 & 5.70 \\
\hline 41.3 & 399.9 & 15429 & 0.46 & 6.27 \\
\hline 41.2 & 399.9 & 15055 & 0.51 & 6.51 \\
\hline 41.2 & 392.5 & 14909 & 0.57 & 6.90 \\
\hline 41.2 & 398.8 & 15073 & 0.61 & 7.45 \\
\hline 41.2 & 402.0 & 15362 & 0.65 & 8.18 \\
\hline 41.2 & 405.1 & 15353 & 0.70 & 8.83 \\
\hline 41.2 & 395.7 & 14908 & 0.76 & 8.74 \\
\hline 41.1 & 399.9 & 14717 & 0.80 & 9.32 \\
\hline 41.1 & 399.9 & 15063 & 0.86 & 9.65 \\
\hline 41.1 & 399.9 & 15213 & 0.91 & 10.21 \\
\hline 41.2 & 405.1 & 24737 & 0.03 & 6.50 \\
\hline 41.3 & 398.8 & 24778 & 0.07 & 6.34 \\
\hline 41.2 & 403.0 & 25244 & 0.12 & 6.46 \\
\hline 40.7 & 399.9 & 25151 & 0.18 & 5.48 \\
\hline 40.9 & 399.9 & 25208 & 0.22 & 5.62 \\
\hline 41.0 & 403.0 & 25416 & 0.27 & 5.56 \\
\hline 41.1 & 399.9 & 25143 & 0.32 & 5.42 \\
\hline 41.1 & 403.0 & 24844 & 0.37 & 5.50 \\
\hline 41.2 & 402.0 & 25375 & 0.43 & 6.02 \\
\hline 41.2 & 400.9 & 25258 & 0.46 & 6.33 \\
\hline 41.2 & 403.0 & 25159 & 0.51 & 6.82 \\
\hline 41.2 & 399.9 & 25165 & 0.58 & 7.50 \\
\hline 41.2 & 396.7 & 24975 & 0.64 & 7.98 \\
\hline 41.2 & 399.9 & 24813 & 0.68 & 8.36 \\
\hline 41.2 & 398.8 & 25358 & 0.73 & 9.13 \\
\hline 41.2 & 396.7 & 24791 & 0.79 & 9.43 \\
\hline 41.1 & 399.9 & 24550 & 0.82 & 9.74 \\
\hline 41.2 & 399.9 & 24762 & 0.87 & 10.41 \\
\hline 40.6 & 399.9 & 35275 & 0.05 & 8.28 \\
\hline 40.5 & 399.9 & 34680 & 0.09 & 7.89 \\
\hline 40.5 & 399.9 & 35237 & 0.15 & 8.23 \\
\hline 40.6 & 393.5 & 34933 & 0.19 & 7.98 \\
\hline 40.2 & 399.9 & 35179 & 0.24 & 7.18 \\
\hline 40.4 & 402.0 & 34133 & 0.29 & 7.19 \\
\hline 40.5 & 399.9 & 35104 & 0.35 & 7.54 \\
\hline 40.5 & 406.2 & 34727 & 0.39 & 7.65 \\
\hline 40.5 & 396.7 & 35163 & 0.45 & 7.82 \\
\hline 40.6 & 392.5 & 35089 & 0.51 & 7.91 \\
\hline 40.6 & 402.0 & 34893 & 0.54 & 8.19 \\
\hline 40.6 & 411.4 & 35182 & 0.57 & 8.41 \\
\hline 40.7 & 395.7 & 34860 & 0.65 & 8.56 \\
\hline 40.8 & 402.0 & 34590 & 0.68 & 8.84 \\
\hline 40.9 & 398.8 & 34879 & 0.73 & 9.11 \\
\hline 41.0 & 400.9 & 35096 & 0.78 & 9.52 \\
\hline 41.1 & 403.0 & 34899 & 0.83 & 10.12 \\
\hline 41.3 & 395.7 & 44972 & 0.06 & 9.82 \\
\hline 41.2 & 392.5 & 45424 & 0.11 & 9.80 \\
\hline 41.3 & 402.0 & 45424 & 0.16 & 10.30 \\
\hline 41.2 & 396.7 & 45586 & 0.21 & 9.70 \\
\hline 41.3 & 391.4 & 45193 & 0.26 & 9.56 \\
\hline 41.0 & 400.9 & 45066 & 0.32 & 8.79 \\
\hline 41.1 & 396.7 & 45249 & 0.36 & 8.73 \\
\hline 41.2 & 396.7 & 45557 & 0.42 & 8.80 \\
\hline 41.2 & 399.9 & 45556 & 0.45 & 8.62 \\
\hline
\end{tabular}

\begin{tabular}{|c|c|c|c|c|}
\hline$T_{\text {sat }}$ & $G$ & $\phi$ & $x$ & $h$ \\
\hline 41.2 & 400.9 & 45182 & 0.50 & 8.34 \\
\hline 41.2 & 402.0 & 45077 & 0.55 & 8.24 \\
\hline 41.2 & 398.8 & 45386 & 0.60 & 8.26 \\
\hline 41.2 & 399.9 & 45224 & 0.66 & 8.52 \\
\hline 41.2 & 402.0 & 44960 & 0.70 & 8.89 \\
\hline 41.1 & 398.8 & 44902 & 0.75 & 9.18 \\
\hline 41.1 & 397.8 & 44785 & 0.82 & 9.74 \\
\hline 40.4 & 406.2 & 55241 & 0.04 & 11.74 \\
\hline 40.5 & 397.8 & 55011 & 0.09 & 11.58 \\
\hline 40.5 & 397.8 & 55442 & 0.14 & 11.69 \\
\hline 40.4 & 406.2 & 55241 & 0.18 & 11.98 \\
\hline 40.4 & 397.8 & 55011 & 0.24 & 11.83 \\
\hline 40.5 & 397.8 & 55442 & 0.29 & 11.70 \\
\hline 40.6 & 397.8 & 55142 & 0.34 & 11.36 \\
\hline 40.6 & 398.8 & 55026 & 0.39 & 11.16 \\
\hline 40.5 & 399.9 & 54909 & 0.46 & 10.66 \\
\hline 40.6 & 397.8 & 54587 & 0.49 & 10.38 \\
\hline 40.7 & 398.8 & 54926 & 0.55 & 10.37 \\
\hline 40.8 & 400.9 & 54900 & 0.58 & 10.20 \\
\hline 40.8 & 397.8 & 55079 & 0.65 & 10.02 \\
\hline 40.9 & 399.9 & 55031 & 0.70 & 10.04 \\
\hline 41.0 & 402.0 & 55006 & 0.75 & 10.28 \\
\hline 41.2 & 407.2 & 54822 & 0.77 & 10.62 \\
\hline 41.2 & 398.8 & 54711 & 0.85 & 11.24 \\
\hline 41.3 & 399.9 & 65241 & 0.02 & 13.11 \\
\hline 41.3 & 396.7 & 65165 & 0.08 & 13.16 \\
\hline 41.4 & 397.8 & 65587 & 0.14 & 13.47 \\
\hline 41.4 & 403.0 & 65411 & 0.20 & 13.28 \\
\hline 41.3 & 399.9 & 65241 & 0.25 & 13.53 \\
\hline 41.3 & 396.7 & 65165 & 0.32 & 13.23 \\
\hline 41.3 & 397.8 & 65587 & 0.37 & 13.24 \\
\hline 41.3 & 403.0 & 65411 & 0.43 & 13.01 \\
\hline 40.9 & 397.8 & 65165 & 0.49 & 11.81 \\
\hline 41.1 & 405.1 & 65208 & 0.52 & 12.16 \\
\hline 41.2 & 403.0 & 65087 & 0.57 & 12.08 \\
\hline 41.2 & 400.9 & 65330 & 0.61 & 11.96 \\
\hline 41.1 & 403.0 & 65280 & 0.66 & 11.70 \\
\hline 41.1 & 403.0 & 65403 & 0.71 & 11.36 \\
\hline 41.0 & 398.8 & 65353 & 0.78 & 11.20 \\
\hline 40.9 & 400.9 & 65255 & 0.82 & 11.32 \\
\hline 41.1 & 402.0 & 74792 & 0.05 & 14.26 \\
\hline 41.1 & 403.0 & 74764 & 0.08 & 14.33 \\
\hline 41.1 & 406.2 & 74764 & 0.13 & 14.60 \\
\hline 41.2 & 393.5 & 74875 & 0.19 & 14.56 \\
\hline 41.2 & 405.1 & 74869 & 0.24 & 14.38 \\
\hline 41.0 & 402.0 & 74792 & 0.32 & 14.47 \\
\hline 41.1 & 403.0 & 74764 & 0.35 & 14.43 \\
\hline 41.0 & 406.2 & 74764 & 0.39 & 14.32 \\
\hline 41.1 & 393.5 & 74875 & 0.47 & 14.25 \\
\hline 41.1 & 405.1 & 74869 & 0.50 & 14.12 \\
\hline 40.9 & 399.9 & 74842 & 0.56 & 13.57 \\
\hline 41.0 & 398.8 & 74820 & 0.60 & 13.73 \\
\hline 40.9 & 399.9 & 74815 & 0.65 & 13.70 \\
\hline 40.9 & 399.9 & 74896 & 0.71 & 13.66 \\
\hline 41.0 & 398.8 & 74872 & 0.76 & 13.43 \\
\hline 41.2 & 399.9 & 74839 & 0.81 & 13.37 \\
\hline 41.7 & 400.9 & 84698 & 0.08 & 15.71 \\
\hline
\end{tabular}




\begin{tabular}{|c|c|c|c|c|}
\hline$T_{\text {sat }}$ & $G$ & $\phi$ & $x$ & $h$ \\
\hline 41.7 & 397.8 & 84755 & 0.13 & 15.96 \\
\hline 41.7 & 396.7 & 84868 & 0.18 & 16.03 \\
\hline 41.8 & 396.7 & 84695 & 0.22 & 15.89 \\
\hline 41.7 & 404.1 & 84751 & 0.28 & 15.91 \\
\hline 41.6 & 399.9 & 84693 & 0.33 & 15.82 \\
\hline 41.6 & 400.9 & 84698 & 0.38 & 16.24 \\
\hline 41.6 & 397.8 & 84755 & 0.43 & 16.03 \\
\hline 41.6 & 396.7 & 84868 & 0.49 & 16.04 \\
\hline 41.7 & 396.7 & 84695 & 0.53 & 15.90 \\
\hline 41.6 & 404.1 & 84751 & 0.58 & 15.62 \\
\hline 41.4 & 399.9 & 84693 & 0.63 & 14.94 \\
\hline 41.5 & 403.0 & 84635 & 0.68 & 14.91 \\
\hline 41.4 & 400.9 & 84748 & 0.73 & 14.65 \\
\hline 41.3 & 398.8 & 84661 & 0.78 & 14.18 \\
\hline 41.0 & 505.1 & 14679 & 0.06 & 4.01 \\
\hline 41.1 & 496.7 & 14733 & 0.12 & 4.07 \\
\hline 40.7 & 499.8 & 14366 & 0.16 & 3.72 \\
\hline 40.9 & 489.3 & 15184 & 0.23 & 4.70 \\
\hline 41.0 & 496.7 & 14941 & 0.27 & 5.21 \\
\hline 41.1 & 503.0 & 14845 & 0.32 & 5.82 \\
\hline 41.1 & 496.7 & 15029 & 0.38 & 6.46 \\
\hline 41.2 & 505.1 & 14750 & 0.41 & 6.97 \\
\hline 41.2 & 501.9 & 14523 & 0.47 & 7.31 \\
\hline 41.2 & 508.2 & 14777 & 0.50 & 7.96 \\
\hline 41.2 & 503.0 & 14860 & 0.57 & 8.48 \\
\hline 41.2 & 498.8 & 14671 & 0.63 & 9.02 \\
\hline 41.2 & 497.7 & 14600 & 0.67 & 9.38 \\
\hline 41.1 & 504.0 & 15398 & 0.70 & 10.73 \\
\hline 41.1 & 498.8 & 15933 & 0.77 & 11.72 \\
\hline 41.1 & 504.0 & 15609 & 0.82 & 11.97 \\
\hline 41.1 & 505.1 & 15487 & 0.85 & 12.07 \\
\hline 41.0 & 500.9 & 15021 & 0.91 & 12.35 \\
\hline 41.0 & 496.7 & 25026 & 0.05 & 6.72 \\
\hline 41.0 & 503.0 & 24993 & 0.09 & 6.79 \\
\hline 41.1 & 508.2 & 24993 & 0.13 & 6.86 \\
\hline 40.7 & 498.8 & 24805 & 0.20 & 6.00 \\
\hline 40.8 & 503.0 & 24744 & 0.24 & 6.17 \\
\hline 41.0 & 497.7 & 24747 & 0.29 & 6.64 \\
\hline 41.0 & 498.8 & 24733 & 0.34 & 6.81 \\
\hline 41.1 & 499.8 & 24720 & 0.39 & 7.25 \\
\hline 41.2 & 499.8 & 24722 & 0.44 & 7.54 \\
\hline 41.3 & 496.7 & 24725 & 0.50 & 7.97 \\
\hline 41.3 & 500.9 & 24727 & 0.54 & 8.38 \\
\hline 41.4 & 501.9 & 24728 & 0.58 & 8.80 \\
\hline 41.4 & 500.9 & 24730 & 0.65 & 9.23 \\
\hline 41.5 & 503.0 & 24731 & 0.68 & 9.69 \\
\hline 41.5 & 498.8 & 24486 & 0.74 & 10.14 \\
\hline 41.5 & 503.0 & 24520 & 0.78 & 10.59 \\
\hline 41.4 & 503.0 & 24569 & 0.83 & 11.08 \\
\hline 41.4 & 496.7 & 24724 & 0.88 & 11.52 \\
\hline 41.1 & 501.9 & 35690 & 0.06 & 8.62 \\
\hline 41.2 & 497.7 & 35652 & 0.12 & 8.92 \\
\hline 41.2 & 503.0 & 35561 & 0.17 & 8.53 \\
\hline 40.8 & 500.9 & 35540 & 0.22 & 7.64 \\
\hline 41.0 & 505.1 & 35485 & 0.26 & 8.00 \\
\hline 41.1 & 505.1 & 35342 & 0.30 & 8.32 \\
\hline 41.1 & 491.4 & 35416 & 0.37 & 8.63 \\
\hline
\end{tabular}

\begin{tabular}{|c|c|c|c|c|}
\hline$T_{\text {sat }}$ & $G$ & $\phi$ & $x$ & $h$ \\
\hline 41.2 & 497.7 & 35382 & 0.41 & 8.85 \\
\hline 41.3 & 498.8 & 35347 & 0.47 & 9.12 \\
\hline 41.3 & 504.0 & 35295 & 0.51 & 9.45 \\
\hline 41.3 & 505.1 & 35260 & 0.56 & 9.71 \\
\hline 41.4 & 503.0 & 35208 & 0.60 & 10.00 \\
\hline 41.4 & 493.5 & 35193 & 0.68 & 10.45 \\
\hline 41.4 & 499.8 & 35178 & 0.72 & 10.75 \\
\hline 41.4 & 501.9 & 35162 & 0.75 & 11.21 \\
\hline 41.4 & 503.0 & 35147 & 0.80 & 11.74 \\
\hline 41.3 & 499.8 & 35116 & 0.86 & 12.19 \\
\hline 41.4 & 503.0 & 45395 & 0.04 & 11.16 \\
\hline 41.4 & 496.7 & 46372 & 0.09 & 11.20 \\
\hline 41.5 & 493.5 & 45271 & 0.14 & 11.26 \\
\hline 41.5 & 504.0 & 45938 & 0.19 & 11.18 \\
\hline 41.5 & 499.8 & 45309 & 0.23 & 10.94 \\
\hline 41.2 & 499.8 & 45859 & 0.28 & 10.42 \\
\hline 41.3 & 499.8 & 45584 & 0.32 & 10.56 \\
\hline 41.4 & 505.1 & 45742 & 0.38 & 11.24 \\
\hline 41.4 & 497.7 & 45429 & 0.44 & 11.27 \\
\hline 41.4 & 503.0 & 45960 & 0.48 & 11.44 \\
\hline 41.4 & 498.8 & 45816 & 0.54 & 11.77 \\
\hline 41.4 & 497.7 & 45385 & 0.59 & 11.65 \\
\hline 41.4 & 505.1 & 45151 & 0.62 & 11.81 \\
\hline 41.4 & 498.8 & 45429 & 0.68 & 12.11 \\
\hline 41.3 & 493.5 & 45374 & 0.75 & 12.43 \\
\hline 41.3 & 503.0 & 45005 & 0.78 & 12.83 \\
\hline 41.2 & 497.7 & 45264 & 0.85 & 13.36 \\
\hline 40.1 & 496.7 & 55900 & 0.06 & 12.07 \\
\hline 40.2 & 499.8 & 55654 & 0.12 & 12.35 \\
\hline 40.3 & 503.0 & 55277 & 0.16 & 12.33 \\
\hline 40.4 & 494.6 & 55301 & 0.21 & 12.01 \\
\hline 40.1 & 505.1 & 55229 & 0.24 & 11.08 \\
\hline 40.4 & 496.7 & 55514 & 0.31 & 11.64 \\
\hline 40.6 & 499.8 & 55187 & 0.37 & 12.05 \\
\hline 40.6 & 505.1 & 55115 & 0.39 & 12.07 \\
\hline 40.7 & 499.8 & 54783 & 0.47 & 12.24 \\
\hline 40.8 & 501.9 & 55070 & 0.50 & 12.49 \\
\hline 40.8 & 501.9 & 55292 & 0.56 & 12.82 \\
\hline 40.9 & 501.9 & 55532 & 0.61 & 13.12 \\
\hline 40.9 & 496.7 & 55097 & 0.67 & 13.25 \\
\hline 41.1 & 497.7 & 55358 & 0.71 & 13.44 \\
\hline 41.2 & 500.9 & 55096 & 0.76 & 13.60 \\
\hline 41.8 & 500.9 & 65187 & 0.06 & 14.14 \\
\hline 41.7 & 498.8 & 66509 & 0.11 & 13.47 \\
\hline 41.7 & 500.9 & 65187 & 0.15 & 13.75 \\
\hline 41.7 & 498.8 & 66509 & 0.19 & 14.47 \\
\hline 41.6 & 495.6 & 65516 & 0.25 & 13.90 \\
\hline 41.7 & 500.9 & 65684 & 0.30 & 13.84 \\
\hline 41.7 & 499.8 & 64690 & 0.35 & 13.45 \\
\hline 41.2 & 495.6 & 65609 & 0.41 & 12.44 \\
\hline 41.5 & 503.0 & 65777 & 0.44 & 12.97 \\
\hline 41.6 & 501.9 & 65437 & 0.51 & 13.32 \\
\hline 41.6 & 505.1 & 65268 & 0.53 & 13.19 \\
\hline 41.5 & 505.1 & 66577 & 0.58 & 13.59 \\
\hline 41.4 & 507.2 & 66143 & 0.63 & 13.55 \\
\hline 41.3 & 495.6 & 66095 & 0.70 & 13.67 \\
\hline 41.3 & 496.7 & 65589 & 0.75 & 13.80 \\
\hline
\end{tabular}




\begin{tabular}{|c|c|c|c|c|}
\hline $\boldsymbol{T}_{\text {sat }}$ & $\boldsymbol{G}$ & $\boldsymbol{\phi}$ & $\boldsymbol{x}$ & $\boldsymbol{h}$ \\
\hline 41.2 & 503.0 & 64986 & 0.80 & 14.01 \\
\hline 41.2 & 506.1 & 65400 & 0.83 & 14.29 \\
\hline 40.2 & 500.9 & 75293 & 0.07 & 14.13 \\
\hline 40.3 & 498.8 & 75846 & 0.12 & 14.55 \\
\hline 40.4 & 500.9 & 75554 & 0.16 & 14.40 \\
\hline 40.4 & 497.7 & 74310 & 0.21 & 14.08 \\
\hline 40.1 & 493.5 & 75400 & 0.23 & 14.59 \\
\hline 40.1 & 500.9 & 75293 & 0.28 & 14.32 \\
\hline 40.2 & 498.8 & 75846 & 0.34 & 14.46 \\
\hline 40.3 & 500.9 & 75554 & 0.38 & 14.47 \\
\hline 40.3 & 497.7 & 74310 & 0.42 & 14.12 \\
\hline 40.2 & 500.9 & 75736 & 0.48 & 13.96 \\
\hline 40.3 & 497.7 & 76024 & 0.52 & 14.13 \\
\hline 40.5 & 498.8 & 76180 & 0.57 & 14.17 \\
\hline 40.6 & 503.0 & 75411 & 0.62 & 14.12 \\
\hline 40.7 & 501.9 & 75698 & 0.68 & 14.21 \\
\hline 40.8 & 497.7 & 75141 & 0.73 & 14.17 \\
\hline 40.8 & 498.8 & 75062 & 0.78 & 14.21 \\
\hline 40.9 & 496.7 & 75291 & 0.84 & 14.70 \\
\hline 40.8 & 498.8 & 86072 & 0.03 & 15.87 \\
\hline 40.9 & 498.8 & 86241 & 0.08 & 15.94 \\
\hline 40.8 & 500.9 & 83107 & 0.12 & 15.64 \\
\hline 40.9 & 499.8 & 88107 & 0.18 & 16.32 \\
\hline 40.9 & 500.9 & 86994 & 0.21 & 16.09 \\
\hline 40.7 & 498.8 & 86072 & 0.28 & 15.81 \\
\hline 40.8 & 498.8 & 86241 & 0.32 & 15.97 \\
\hline & & & & \\
\hline
\end{tabular}

\begin{tabular}{|c|c|c|c|c|}
\hline $\boldsymbol{T}_{\text {sat }}$ & $\boldsymbol{G}$ & $\boldsymbol{\phi}$ & $\boldsymbol{x}$ & $\boldsymbol{h}$ \\
\hline 40.7 & 500.9 & 83107 & 0.36 & 15.14 \\
\hline 40.7 & 499.8 & 88107 & 0.43 & 15.80 \\
\hline 40.8 & 500.9 & 86994 & 0.46 & 15.63 \\
\hline 40.5 & 505.1 & 88340 & 0.53 & 15.13 \\
\hline 40.6 & 498.8 & 83148 & 0.56 & 14.50 \\
\hline 40.7 & 495.6 & 86429 & 0.62 & 14.95 \\
\hline 40.8 & 503.0 & 87133 & 0.66 & 14.91 \\
\hline 40.9 & 503.0 & 85772 & 0.71 & 14.65 \\
\hline 41.0 & 504.0 & 86759 & 0.77 & 14.80 \\
\hline 41.1 & 500.9 & 85966 & 0.82 & 14.72 \\
\hline 41.6 & 500.9 & 95259 & 0.08 & 16.98 \\
\hline 41.7 & 505.1 & 95048 & 0.12 & 17.13 \\
\hline 41.7 & 500.9 & 95197 & 0.17 & 17.11 \\
\hline 41.8 & 498.8 & 95196 & 0.23 & 17.06 \\
\hline 41.8 & 499.8 & 94926 & 0.28 & 17.04 \\
\hline 41.7 & 500.9 & 94686 & 0.33 & 16.43 \\
\hline 41.5 & 500.9 & 95259 & 0.35 & 17.31 \\
\hline 41.5 & 505.1 & 95048 & 0.39 & 17.03 \\
\hline 41.6 & 500.9 & 95197 & 0.44 & 17.10 \\
\hline 41.6 & 498.8 & 95196 & 0.50 & 17.05 \\
\hline 41.7 & 499.8 & 94926 & 0.55 & 17.05 \\
\hline 41.5 & 500.9 & 94686 & 0.60 & 16.40 \\
\hline 41.6 & 495.6 & 95522 & 0.65 & 16.73 \\
\hline 41.6 & 499.8 & 95283 & 0.71 & 16.74 \\
\hline 41.5 & 503.0 & 94747 & 0.74 & 16.59 \\
\hline 41.4 & 496.7 & 94658 & 0.80 & 16.41 \\
\hline & & & & \\
\hline
\end{tabular}

Tabela B.9. R1234yf, geometría circular.

\begin{tabular}{|c|c|c|c|c|}
\hline $\boldsymbol{T}_{\text {sat }}$ & $\boldsymbol{G}$ & $\boldsymbol{\phi}$ & $\boldsymbol{x}$ & $\boldsymbol{h}$ \\
\hline 31.6 & 98.9 & 16300 & 0.16 & 5.13 \\
\hline 31.7 & 99.0 & 15554 & 0.25 & 5.22 \\
\hline 31.6 & 100.7 & 15567 & 0.28 & 5.30 \\
\hline 31.5 & 100.8 & 15653 & 0.33 & 5.18 \\
\hline 31.6 & 98.9 & 16300 & 0.42 & 5.69 \\
\hline 31.7 & 99.0 & 15554 & 0.50 & 5.92 \\
\hline 31.6 & 100.7 & 15567 & 0.52 & 6.23 \\
\hline 31.5 & 100.8 & 15653 & 0.57 & 6.26 \\
\hline 31.4 & 97.9 & 15593 & 0.63 & 6.16 \\
\hline 31.4 & 100.1 & 15745 & 0.67 & 6.27 \\
\hline 31.3 & 99.8 & 15787 & 0.73 & 6.42 \\
\hline 31.2 & 99.9 & 15670 & 0.79 & 6.32 \\
\hline 31.1 & 101.3 & 15757 & 0.83 & 6.61 \\
\hline 31.2 & 199.8 & 15430 & 0.04 & 4.89 \\
\hline 31.2 & 199.1 & 15442 & 0.09 & 4.89 \\
\hline 31.2 & 199.8 & 15430 & 0.12 & 4.78 \\
\hline 31.2 & 199.1 & 15442 & 0.17 & 4.89 \\
\hline 31.3 & 201.0 & 15684 & 0.21 & 5.48 \\
\hline 31.4 & 199.6 & 15630 & 0.26 & 5.51 \\
\hline 31.3 & 200.9 & 15480 & 0.30 & 5.42 \\
\hline 31.3 & 199.5 & 15380 & 0.37 & 5.35 \\
\hline 31.3 & 201.4 & 15174 & 0.40 & 5.32 \\
\hline 31.3 & 202.2 & 15038 & 0.45 & 5.45 \\
\hline 31.2 & 201.1 & 15077 & 0.50 & 5.76 \\
\hline & & & & \\
\hline
\end{tabular}

\begin{tabular}{|c|c|c|c|c|}
\hline $\boldsymbol{T}_{\text {sat }}$ & $\boldsymbol{G}$ & $\boldsymbol{\phi}$ & $\boldsymbol{x}$ & $\boldsymbol{h}$ \\
\hline 31.2 & 199.8 & 15057 & 0.56 & 5.85 \\
\hline 31.2 & 199.9 & 15030 & 0.59 & 5.98 \\
\hline 31.1 & 200.4 & 15426 & 0.66 & 6.60 \\
\hline 31.1 & 201.3 & 15490 & 0.70 & 6.91 \\
\hline 31.1 & 200.6 & 15294 & 0.76 & 7.16 \\
\hline 31.1 & 201.3 & 15234 & 0.80 & 7.42 \\
\hline 31.1 & 201.5 & 15201 & 0.85 & 7.82 \\
\hline 30.8 & 200.9 & 25410 & 0.11 & 6.94 \\
\hline 30.8 & 201.7 & 25304 & 0.16 & 7.09 \\
\hline 30.8 & 199.5 & 25374 & 0.20 & 7.61 \\
\hline 30.8 & 200.9 & 25410 & 0.24 & 6.80 \\
\hline 30.8 & 201.7 & 25304 & 0.28 & 6.72 \\
\hline 31.2 & 199.5 & 25374 & 0.33 & 7.44 \\
\hline 31.1 & 201.7 & 25627 & 0.38 & 7.49 \\
\hline 31.1 & 200.6 & 25557 & 0.43 & 7.42 \\
\hline 31.1 & 201.2 & 25518 & 0.49 & 7.42 \\
\hline 31.0 & 200.1 & 25336 & 0.54 & 7.40 \\
\hline 31.0 & 198.8 & 25700 & 0.58 & 7.47 \\
\hline 31.0 & 200.6 & 26034 & 0.64 & 7.54 \\
\hline 31.0 & 200.8 & 25808 & 0.68 & 7.62 \\
\hline 31.0 & 200.3 & 26033 & 0.74 & 7.71 \\
\hline 31.0 & 200.4 & 25795 & 0.79 & 7.78 \\
\hline 31.5 & 199.6 & 36075 & 0.18 & 9.12 \\
\hline 31.4 & 201.8 & 35372 & 0.24 & 8.97 \\
\hline 31.4 & 201.3 & 35219 & 0.27 & 9.70 \\
\hline 31.3 & 199.8 & 35889 & 0.34 & 9.87 \\
\hline & & & & \\
\hline
\end{tabular}




\begin{tabular}{|c|c|c|c|c|}
\hline $\boldsymbol{T}_{\text {sat }}$ & $\boldsymbol{G}$ & $\boldsymbol{\phi}$ & $\boldsymbol{x}$ & $\boldsymbol{h}$ \\
\hline 31.5 & 199.6 & 36075 & 0.37 & 8.67 \\
\hline 31.4 & 201.8 & 35372 & 0.42 & 8.46 \\
\hline 31.4 & 201.3 & 35219 & 0.45 & 9.23 \\
\hline 31.3 & 199.8 & 35889 & 0.52 & 9.31 \\
\hline 31.2 & 201.4 & 35817 & 0.56 & 9.30 \\
\hline 31.2 & 200.5 & 35581 & 0.63 & 9.14 \\
\hline 31.0 & 200.4 & 34936 & 0.67 & 9.11 \\
\hline 30.9 & 199.8 & 34303 & 0.71 & 9.12 \\
\hline 30.6 & 299.7 & 15227 & 0.05 & 4.24 \\
\hline 30.6 & 300.4 & 15293 & 0.13 & 4.41 \\
\hline 30.9 & 299.7 & 15307 & 0.19 & 4.77 \\
\hline 30.9 & 298.8 & 15306 & 0.24 & 4.75 \\
\hline 30.9 & 300.0 & 15278 & 0.29 & 4.64 \\
\hline 30.9 & 300.8 & 15297 & 0.34 & 4.82 \\
\hline 30.9 & 298.8 & 15281 & 0.39 & 5.05 \\
\hline 30.9 & 298.9 & 15297 & 0.43 & 5.30 \\
\hline 30.9 & 300.9 & 15288 & 0.49 & 5.66 \\
\hline 30.9 & 300.0 & 15301 & 0.54 & 6.02 \\
\hline 30.9 & 298.6 & 15277 & 0.58 & 6.33 \\
\hline 30.9 & 299.1 & 15275 & 0.64 & 6.76 \\
\hline 30.9 & 299.5 & 15266 & 0.69 & 7.14 \\
\hline 30.9 & 299.5 & 15286 & 0.74 & 7.55 \\
\hline 30.9 & 301.5 & 15264 & 0.79 & 8.12 \\
\hline 30.9 & 298.6 & 15248 & 0.84 & 8.51 \\
\hline 30.8 & 298.8 & 15207 & 0.91 & 9.06 \\
\hline 30.2 & 300.4 & 25220 & 0.05 & 6.40 \\
\hline 30.2 & 300.2 & 25140 & 0.07 & 6.37 \\
\hline 30.2 & 299.7 & 25157 & 0.11 & 6.51 \\
\hline 30.2 & 300.4 & 25220 & 0.13 & 6.38 \\
\hline 30.2 & 300.2 & 25140 & 0.15 & 6.38 \\
\hline 30.2 & 299.7 & 25157 & 0.20 & 6.33 \\
\hline 30.6 & 302.0 & 25198 & 0.25 & 7.01 \\
\hline 30.6 & 299.7 & 25198 & 0.29 & 7.52 \\
\hline 30.5 & 299.5 & 25125 & 0.33 & 7.38 \\
\hline 30.8 & 300.5 & 25706 & 0.39 & 7.49 \\
\hline 31.1 & 298.1 & 25247 & 0.43 & 7.46 \\
\hline 31.3 & 299.9 & 25068 & 0.49 & 7.48 \\
\hline 31.4 & 298.5 & 25133 & 0.53 & 7.73 \\
\hline 31.5 & 300.1 & 24739 & 0.60 & 7.76 \\
\hline 31.5 & 300.3 & 25206 & 0.64 & 8.13 \\
\hline 31.5 & 299.3 & 24844 & 0.69 & 8.31 \\
\hline 31.5 & 301.2 & 25467 & 0.74 & 8.81 \\
\hline 31.4 & 298.6 & 25144 & 0.78 & 8.95 \\
\hline 31.4 & 298.6 & 25639 & 0.82 & 9.45 \\
\hline 31.4 & 299.1 & 25282 & 0.90 & 10.08 \\
\hline 31.4 & 302.6 & 35424 & 0.08 & 8.65 \\
\hline 31.3 & 300.3 & 34904 & 0.12 & 8.54 \\
\hline 31.3 & 301.0 & 35792 & 0.16 & 8.87 \\
\hline 31.7 & 300.3 & 36280 & 0.23 & 9.04 \\
\hline 31.3 & 302.6 & 35424 & 0.26 & 9.22 \\
\hline 31.3 & 300.3 & 34904 & 0.30 & 9.01 \\
\hline 31.2 & 301.0 & 35792 & 0.35 & 9.26 \\
\hline 31.7 & 300.3 & 36280 & 0.42 & 9.60 \\
\hline 31.6 & 300.9 & 35809 & 0.47 & 10.31 \\
\hline 31.6 & 300.1 & 35740 & 0.51 & 10.29 \\
\hline 31.5 & 297.2 & 35933 & 0.56 & 10.28 \\
\hline 31.5 & 301.0 & 36014 & 0.61 & 10.36 \\
\hline
\end{tabular}

\begin{tabular}{|c|c|c|c|c|}
\hline$T_{\text {sat }}$ & $G$ & $\phi$ & $x$ & $h$ \\
\hline 31.4 & 299.7 & 35590 & 0.66 & 10.25 \\
\hline 31.4 & 298.7 & 35339 & 0.71 & 10.28 \\
\hline 31.4 & 299.5 & 35086 & 0.76 & 10.25 \\
\hline 31.2 & 298.4 & 35026 & 0.81 & 10.55 \\
\hline 31.1 & 299.8 & 35646 & 0.85 & 10.90 \\
\hline 31.2 & 299.6 & 45037 & 0.13 & 10.15 \\
\hline 31.1 & 300.4 & 45120 & 0.20 & 10.26 \\
\hline 31.6 & 299.5 & 45041 & 0.25 & 10.56 \\
\hline 31.5 & 298.4 & 45138 & 0.30 & 11.04 \\
\hline 31.5 & 300.1 & 45226 & 0.35 & 11.15 \\
\hline 31.4 & 300.7 & 44586 & 0.39 & 10.97 \\
\hline 31.4 & 300.1 & 45041 & 0.43 & 11.10 \\
\hline 31.5 & 299.5 & 45138 & 0.48 & 11.42 \\
\hline 31.4 & 298.4 & 45226 & 0.53 & 11.22 \\
\hline 31.4 & 300.1 & 44586 & 0.58 & 11.04 \\
\hline 31.4 & 300.7 & 45643 & 0.62 & 10.86 \\
\hline 31.3 & 300.1 & 45068 & 0.68 & 10.94 \\
\hline 31.2 & 299.0 & 44864 & 0.74 & 10.65 \\
\hline 31.2 & 301.7 & 44678 & 0.78 & 10.59 \\
\hline 31.1 & 301.6 & 44723 & 0.84 & 10.77 \\
\hline 31.0 & 300.9 & 55083 & 0.18 & 11.68 \\
\hline 31.0 & 300.6 & 55241 & 0.22 & 11.67 \\
\hline 30.9 & 298.7 & 55288 & 0.27 & 11.68 \\
\hline 31.4 & 299.0 & 55012 & 0.31 & 12.01 \\
\hline 31.0 & 300.9 & 55083 & 0.37 & 11.82 \\
\hline 31.0 & 300.6 & 55241 & 0.40 & 12.00 \\
\hline 30.9 & 298.7 & 55288 & 0.46 & 11.77 \\
\hline 31.4 & 299.0 & 55012 & 0.50 & 12.40 \\
\hline 31.3 & 300.3 & 55388 & 0.55 & 12.30 \\
\hline 31.3 & 298.4 & 55426 & 0.61 & 12.46 \\
\hline 31.2 & 300.5 & 54846 & 0.66 & 11.89 \\
\hline 31.1 & 299.8 & 55057 & 0.70 & 11.99 \\
\hline 31.1 & 300.5 & 54846 & 0.75 & 12.71 \\
\hline 31.1 & 299.8 & 55057 & 0.79 & 12.89 \\
\hline 31.0 & 399.2 & 15254 & 0.05 & 4.64 \\
\hline 30.9 & 398.9 & 15385 & 0.09 & 4.64 \\
\hline 30.9 & 400.3 & 15312 & 0.13 & 4.52 \\
\hline 30.9 & 400.2 & 15103 & 0.17 & 4.98 \\
\hline 31.1 & 399.9 & 15286 & 0.20 & 4.54 \\
\hline 30.9 & 399.2 & 15345 & 0.23 & 4.90 \\
\hline 31.1 & 398.9 & 15356 & 0.26 & 4.91 \\
\hline 30.9 & 399.8 & 15237 & 0.31 & 4.87 \\
\hline 30.9 & 400.0 & 15478 & 0.33 & 5.13 \\
\hline 31.1 & 399.5 & 15203 & 0.39 & 5.26 \\
\hline 31.1 & 399.1 & 15153 & 0.44 & 5.26 \\
\hline 31.0 & 398.7 & 15479 & 0.46 & 5.92 \\
\hline 31.0 & 400.5 & 15061 & 0.51 & 6.08 \\
\hline 31.0 & 399.7 & 15377 & 0.54 & 6.71 \\
\hline 31.0 & 398.6 & 15434 & 0.58 & 7.13 \\
\hline 30.9 & 399.1 & 15343 & 0.62 & 7.82 \\
\hline 30.9 & 3 & 15029 & 0.66 & 8.27 \\
\hline 31.1 & 400.3 & 15075 & 0.70 & 8.54 \\
\hline 31.0 & 400.3 & 15417 & 0.72 & 9.10 \\
\hline 30.9 & 400.0 & 15463 & 0.76 & 9.47 \\
\hline 31.1 & 398.6 & 15124 & 0.80 & 9.93 \\
\hline 31.0 & 398.6 & 15342 & 0.85 & 10.35 \\
\hline 31.1 & 399.9 & 15065 & 0.91 & 11.04 \\
\hline
\end{tabular}




\begin{tabular}{|c|c|c|c|c|}
\hline$T_{\text {sat }}$ & $G$ & $\phi$ & $x$ & $h$ \\
\hline 31.1 & 399.6 & 25274 & 0.06 & 6.27 \\
\hline 31.1 & 399.5 & 25197 & 0.09 & 6.80 \\
\hline 30.9 & 399.9 & 25080 & 0.14 & 6.73 \\
\hline 30.9 & 399.8 & 25250 & 0.19 & 6.89 \\
\hline 30.9 & 400.2 & 25138 & 0.20 & 6.80 \\
\hline 31.0 & 399.3 & 25284 & 0.23 & 7.12 \\
\hline 31.0 & 398.5 & 25195 & 0.27 & 7.34 \\
\hline 30.9 & 399.4 & 25426 & 0.31 & 7.45 \\
\hline 31.0 & 398.7 & 25183 & 0.35 & 7.12 \\
\hline 31.1 & 399.9 & 25423 & 0.39 & 7.35 \\
\hline 30.9 & 399.5 & 25286 & 0.44 & 7.43 \\
\hline 31.0 & 399.7 & 25230 & 0.49 & 7.59 \\
\hline 30.9 & 400.0 & 25320 & 0.52 & 7.85 \\
\hline 31.1 & 400.2 & 25036 & 0.57 & 8.15 \\
\hline 30.9 & 399.7 & 25209 & 0.61 & 8.51 \\
\hline 31.0 & 400.5 & 25428 & 0.64 & 8.66 \\
\hline 31.0 & 399.4 & 25368 & 0.68 & 8.93 \\
\hline 30.9 & 399.6 & 25132 & 0.72 & 9.44 \\
\hline 30.9 & 400.0 & 25327 & 0.76 & 9.94 \\
\hline 31.0 & 400.4 & 25167 & 0.81 & 10.65 \\
\hline 30.9 & 400.3 & 25322 & 0.86 & 11.32 \\
\hline 31.0 & 400.2 & 35217 & 0.07 & 8.90 \\
\hline 31.0 & 398.6 & 35472 & 0.12 & 8.80 \\
\hline 31.0 & 399.3 & 35467 & 0.16 & 8.65 \\
\hline 31.2 & 400.1 & 35206 & 0.21 & 8.62 \\
\hline 30.9 & 399.2 & 35178 & 0.27 & 8.99 \\
\hline 31.0 & 399.5 & 35144 & 0.32 & 9.13 \\
\hline 30.9 & 400.5 & 35250 & 0.37 & 9.52 \\
\hline 31.0 & 398.6 & 35107 & 0.43 & 9.69 \\
\hline 30.9 & 399.1 & 35425 & 0.49 & 9.76 \\
\hline 31.0 & 399.1 & 35308 & 0.53 & 10.06 \\
\hline 30.9 & 398.5 & 35073 & 0.58 & 10.17 \\
\hline 31.1 & 400.1 & 35174 & 0.62 & 10.17 \\
\hline 31.1 & 400.3 & 35307 & 0.67 & 10.50 \\
\hline 31.2 & 398.8 & 35200 & 0.72 & 10.87 \\
\hline 31.1 & 399.2 & 35367 & 0.78 & 11.12 \\
\hline 30.9 & 400.2 & 35146 & 0.83 & 11.49 \\
\hline 31.1 & 399.4 & 35189 & 0.86 & 11.78 \\
\hline 31.0 & 399.4 & 45377 & 0.10 & 10.81 \\
\hline 31.0 & 399.8 & 45482 & 0.14 & 10.72 \\
\hline 30.9 & 399.8 & 45462 & 0.18 & 10.52 \\
\hline 31.0 & 399.1 & 45399 & 0.23 & 10.30 \\
\hline 30.9 & 398.6 & 45349 & 0.26 & 10.41 \\
\hline 30.9 & 399.4 & 45490 & 0.31 & 10.54 \\
\hline 31.1 & 400.5 & 45426 & 0.36 & 10.39 \\
\hline 30.9 & 399.0 & 45050 & 0.42 & 10.70 \\
\hline 31.1 & 400.1 & 45300 & 0.45 & 10.34 \\
\hline 31.1 & 398.8 & 45345 & 0.50 & 10.93 \\
\hline 31.0 & 399.0 & 45168 & 0.54 & 10.94 \\
\hline 31.0 & 400.4 & 45147 & 0.59 & 10.86 \\
\hline 31.1 & 399.6 & 45195 & 0.63 & 11.12 \\
\hline 31.0 & 399.8 & 45007 & 0.67 & 11.13 \\
\hline 31.0 & 399.9 & 45429 & 0.72 & 11.33 \\
\hline 31.0 & 399.2 & 45034 & 0.76 & 11.45 \\
\hline 31.1 & 399.1 & 45478 & 0.81 & 11.63 \\
\hline 31.1 & 399.3 & 55116 & 0.13 & 12.02 \\
\hline 31.1 & 400.1 & 55145 & 0.18 & 12.08 \\
\hline
\end{tabular}

\begin{tabular}{|c|c|c|c|c|}
\hline$T_{\text {sat }}$ & $G$ & $\phi$ & $x$ & $h$ \\
\hline 31.0 & 399.8 & 55110 & 0.21 & 12.11 \\
\hline 31.1 & 399.7 & 55029 & 0.25 & 11.84 \\
\hline 31.0 & 398.7 & 55181 & 0.29 & 12.22 \\
\hline 31.1 & 400.3 & 55415 & 0.34 & 12.19 \\
\hline 31.1 & 398.8 & 55065 & 0.38 & 12.15 \\
\hline 31.0 & 398.6 & 55325 & 0.43 & 12.26 \\
\hline 31.0 & 399.4 & 55148 & 0.49 & 11.99 \\
\hline 31.1 & 400.1 & 55405 & 0.53 & 12.27 \\
\hline 31.2 & 398.8 & 55191 & 0.58 & 12.30 \\
\hline 30.9 & 400.0 & 55148 & 0.63 & 12.73 \\
\hline 30.9 & 399.0 & 55203 & 0.68 & 12.82 \\
\hline 30.9 & 398.6 & 55113 & 0.73 & 12.73 \\
\hline 31.1 & 399.9 & 55386 & 0.77 & 12.95 \\
\hline 30.9 & 400.3 & 55045 & 0.81 & 13.30 \\
\hline 41.7 & 98.4 & 15533 & 0.09 & 5.43 \\
\hline 41.6 & 100.4 & 15418 & 0.18 & 5.46 \\
\hline 41.6 & 100.3 & 15363 & 0.22 & 5.43 \\
\hline 41.3 & 103.8 & 15284 & 0.27 & 4.88 \\
\hline 41.4 & 100.5 & 15206 & 0.33 & 4.99 \\
\hline 41.3 & 101.8 & 15335 & 0.36 & 5.07 \\
\hline 41.3 & 98.6 & 15294 & 0.42 & 5.08 \\
\hline 41.3 & 99.8 & 15286 & 0.48 & 5.21 \\
\hline 41.2 & 100.9 & 15273 & 0.52 & 5.35 \\
\hline 41.4 & 100.5 & 15206 & 0.59 & 5.70 \\
\hline 41.3 & 101.8 & 15335 & 0.61 & 5.88 \\
\hline 41.3 & 98.6 & 15294 & 0.68 & 6.02 \\
\hline 41.3 & 99.8 & 15286 & 0.73 & 6.09 \\
\hline 41.2 & 100.9 & 15273 & 0.78 & 6.12 \\
\hline 41.1 & 99.7 & 15045 & 0.82 & 6.21 \\
\hline 41.6 & 200.1 & 15543 & 0.03 & 5.41 \\
\hline 41.5 & 200.8 & 15511 & 0.05 & 5.41 \\
\hline 41.5 & 201.5 & 15480 & 0.10 & 5.45 \\
\hline 41.2 & 200.5 & 15495 & 0.15 & 5.35 \\
\hline 41.0 & 199.7 & 15571 & 0.20 & 5.38 \\
\hline 40.9 & 200.6 & 15537 & 0.25 & 5.43 \\
\hline 40.5 & 200.0 & 15553 & 0.29 & 5.09 \\
\hline 40.4 & 201.3 & 15550 & 0.35 & 5.16 \\
\hline 40.4 & 200.7 & 15412 & 0.39 & 5.10 \\
\hline 40.5 & 200.0 & 15410 & 0.45 & 5.08 \\
\hline 40.6 & 199.6 & 15370 & 0.50 & 5.09 \\
\hline 40.8 & 200.8 & 15313 & 0.54 & 5.10 \\
\hline 41.3 & 200.8 & 15265 & 0.60 & 5.16 \\
\hline 41.7 & 201.4 & 15055 & 0.63 & 5.17 \\
\hline 41.5 & 199.2 & 14940 & 0.70 & 5.25 \\
\hline 41.4 & 200.9 & 14885 & 0.74 & 5.33 \\
\hline 41.3 & 201.0 & 14833 & 0.79 & 5.44 \\
\hline 41.2 & 199.7 & 14790 & 0.85 & 5.55 \\
\hline 41.5 & 201.2 & 25272 & 0.07 & 7.83 \\
\hline 41.4 & 201.0 & 25310 & 0.11 & 7.83 \\
\hline 41.6 & 201.2 & 25272 & 0.14 & 7.70 \\
\hline 41.5 & 201.0 & 25310 & 0.17 & 7.69 \\
\hline 41.4 & 198.3 & 25170 & 0.28 & 7.75 \\
\hline 41.3 & 198.8 & 25424 & 0.32 & 7.82 \\
\hline 41.3 & 200.7 & 25155 & 0.37 & 7.63 \\
\hline 41.1 & 200.5 & 25302 & 0.42 & 7.35 \\
\hline 41.1 & 202.1 & 25200 & 0.46 & 7.34 \\
\hline 41.1 & 200.8 & 25346 & 0.51 & 7.39 \\
\hline
\end{tabular}




\begin{tabular}{|c|c|c|c|c|}
\hline$T_{\text {sat }}$ & $G$ & $\phi$ & $x$ & $h$ \\
\hline 41.0 & 200.4 & 25092 & 0.57 & 7.34 \\
\hline 40.9 & 200.3 & 25299 & 0.62 & 7.42 \\
\hline 40.9 & 200.7 & 25299 & 0.68 & 7.41 \\
\hline 40.8 & 200.2 & 25196 & 0.72 & 7.35 \\
\hline 41.0 & 199.8 & 25104 & 0.78 & 7.33 \\
\hline 41.6 & 199.1 & 34973 & 0.09 & 9.91 \\
\hline 41.4 & 198.4 & 35077 & 0.16 & 9.99 \\
\hline 41.4 & 200.7 & 34973 & 0.21 & 10.02 \\
\hline 41.3 & 200.8 & 35077 & 0.26 & 10.04 \\
\hline 41.5 & 199.1 & 35008 & 0.28 & 9.77 \\
\hline 41.4 & 198.4 & 34888 & 0.35 & 9.72 \\
\hline 41.4 & 200.7 & 34835 & 0.40 & 9.59 \\
\hline 41.2 & 200.8 & 34870 & 0.46 & 9.52 \\
\hline 41.0 & 200.0 & 34949 & 0.50 & 8.98 \\
\hline 41.1 & 200.4 & 34960 & 0.55 & 9.33 \\
\hline 41.1 & 200.8 & 34948 & 0.61 & 9.35 \\
\hline 41.0 & 202.2 & 35203 & 0.65 & 9.29 \\
\hline 40.8 & 199.6 & 35185 & 0.71 & 9.81 \\
\hline 41.3 & 297.5 & 15704 & 0.03 & 5.87 \\
\hline 41.3 & 296.8 & 15797 & 0.08 & 5.71 \\
\hline 41.3 & 300.8 & 15808 & 0.12 & 5.81 \\
\hline 41.3 & 300.3 & 15777 & 0.19 & 6.07 \\
\hline 41.3 & 302.4 & 15753 & 0.22 & 6.10 \\
\hline 41.3 & 300.0 & 15571 & 0.28 & 6.10 \\
\hline 41.3 & 303.2 & 15466 & 0.32 & 6.17 \\
\hline 41.3 & 299.8 & 15782 & 0.39 & 6.56 \\
\hline 41.3 & 300.6 & 15564 & 0.43 & 6.58 \\
\hline 41.1 & 297.6 & 15521 & 0.49 & 6.24 \\
\hline 41.1 & 302.4 & 15370 & 0.53 & 6.29 \\
\hline 41.1 & 296.2 & 15225 & 0.60 & 6.38 \\
\hline 41.1 & 301.5 & 15237 & 0.64 & 6.51 \\
\hline 41.0 & 300.8 & 15318 & 0.70 & 6.67 \\
\hline 41.0 & 301.6 & 15113 & 0.73 & 6.70 \\
\hline 40.9 & 300.0 & 14938 & 0.78 & 6.79 \\
\hline 40.8 & 298.1 & 14877 & 0.84 & 7.13 \\
\hline 40.6 & 301.8 & 15072 & 0.87 & 7.43 \\
\hline 41.6 & 303.9 & 25938 & 0.05 & 7.93 \\
\hline 41.5 & 296.7 & 26154 & 0.09 & 8.04 \\
\hline 41.5 & 302.5 & 26040 & 0.13 & 8.04 \\
\hline 41.5 & 299.7 & 26011 & 0.18 & 8.18 \\
\hline 41.5 & 300.4 & 25620 & 0.24 & 8.13 \\
\hline 41.3 & 302.6 & 25478 & 0.28 & 7.75 \\
\hline 41.4 & 300.4 & 25491 & 0.33 & 7.83 \\
\hline 41.3 & 299.4 & 25566 & 0.39 & 7.89 \\
\hline 41.3 & 305.9 & 25522 & 0.42 & 7.95 \\
\hline 41.3 & 298.6 & 25457 & 0.48 & 8.01 \\
\hline 41.2 & 299.4 & 25317 & 0.52 & 7.98 \\
\hline 41.2 & 296.8 & 25089 & 0.59 & 7.92 \\
\hline 41.1 & 296.7 & 24970 & 0.64 & 7.97 \\
\hline 41.1 & 300.8 & 25039 & 0.67 & 8.00 \\
\hline 41.0 & 299.6 & 25040 & 0.73 & 8.03 \\
\hline 41.0 & 302.6 & 25062 & 0.78 & 8.10 \\
\hline 40.8 & 302.0 & 25041 & 0.84 & 8.10 \\
\hline 40.8 & 302.0 & 25041 & 0.88 & 8.53 \\
\hline 40.6 & 301.0 & 34887 & 0.06 & 9.59 \\
\hline 40.8 & 299.9 & 34988 & 0.10 & 9.74 \\
\hline 41.0 & 298.7 & 34780 & 0.17 & 9.80 \\
\hline
\end{tabular}

\begin{tabular}{|c|c|c|c|c|}
\hline$T_{\text {sat }}$ & $G$ & $\phi$ & $x$ & $h$ \\
\hline 41.2 & 301.0 & 34591 & 0.21 & 9.80 \\
\hline 41.3 & 299.9 & 35000 & 0.24 & 9.94 \\
\hline 41.3 & 297.5 & 35779 & 0.31 & 10.05 \\
\hline 41.3 & 302.0 & 35823 & 0.35 & 10.03 \\
\hline 41.2 & 300.5 & 35708 & 0.40 & 10.02 \\
\hline 41.2 & 299.0 & 35569 & 0.45 & 10.06 \\
\hline 41.2 & 299.6 & 35396 & 0.50 & 10.02 \\
\hline 41.2 & 299.9 & 35065 & 0.56 & 9.92 \\
\hline 41.1 & 297.8 & 35693 & 0.61 & 10.13 \\
\hline 40.8 & 298.2 & 35211 & 0.67 & 9.93 \\
\hline 41.2 & 296.5 & 35396 & 0.70 & 10.37 \\
\hline 41.1 & 299.8 & 35065 & 0.76 & 10.27 \\
\hline 41.0 & 299.8 & 35693 & 0.80 & 10.48 \\
\hline 40.7 & 300.4 & 35211 & 0.86 & 10.33 \\
\hline 41.3 & 299.4 & 45485 & 0.06 & 10.98 \\
\hline 41.1 & 296.6 & 45955 & 0.12 & 11.11 \\
\hline 41.1 & 298.3 & 45747 & 0.16 & 11.08 \\
\hline 41.0 & 300.3 & 45746 & 0.21 & 11.18 \\
\hline 41.4 & 299.4 & 46339 & 0.27 & 11.28 \\
\hline 41.2 & 296.6 & 45576 & 0.33 & 11.38 \\
\hline 41.2 & 298.3 & 45122 & 0.37 & 11.22 \\
\hline 41.2 & 300.3 & 44952 & 0.42 & 11.13 \\
\hline 41.2 & 299.3 & 44906 & 0.47 & 11.01 \\
\hline 41.2 & 300.5 & 44548 & 0.52 & 10.99 \\
\hline 41.1 & 305.8 & 45571 & 0.56 & 11.24 \\
\hline 41.2 & 298.5 & 45122 & 0.62 & 11.59 \\
\hline 41.2 & 298.5 & 44952 & 0.67 & 11.60 \\
\hline 41.1 & 301.0 & 44906 & 0.72 & 11.13 \\
\hline 41.2 & 297.6 & 44548 & 0.77 & 11.11 \\
\hline 41.0 & 302.8 & 45571 & 0.81 & 11.31 \\
\hline 41.2 & 299.6 & 55180 & 0.09 & 12.93 \\
\hline 41.1 & 299.1 & 55978 & 0.14 & 13.06 \\
\hline 41.0 & 298.1 & 55476 & 0.17 & 13.01 \\
\hline 40.9 & 297.8 & 55545 & 0.22 & 13.08 \\
\hline 40.9 & 299.7 & 55523 & 0.28 & 13.03 \\
\hline 40.9 & 299.6 & 55455 & 0.32 & 12.99 \\
\hline 41.0 & 299.1 & 55410 & 0.40 & 13.40 \\
\hline 41.0 & 298.1 & 55275 & 0.45 & 13.26 \\
\hline 40.8 & 297.8 & 55297 & 0.49 & 13.25 \\
\hline 40.9 & 299.7 & 55545 & 0.53 & 13.77 \\
\hline 40.9 & 298.1 & 55523 & 0.58 & 13.71 \\
\hline 40.8 & 298.1 & 55455 & 0.63 & 13.66 \\
\hline 41.0 & 297.8 & 55410 & 0.71 & 14.20 \\
\hline 40.9 & 300.9 & 55275 & 0.75 & 14.18 \\
\hline 40.8 & 298.9 & 55297 & 0.80 & 14.42 \\
\hline 40.9 & 399.3 & 15325 & 0.06 & 6.33 \\
\hline 40.9 & 400.3 & 15370 & 0.11 & 6.30 \\
\hline 41.2 & 400.5 & 15017 & 0.16 & 6.19 \\
\hline 41.1 & 399.9 & 15229 & 0.22 & 6.32 \\
\hline 40.8 & 400.9 & 15482 & 0.26 & 6.32 \\
\hline 41.1 & 400.0 & 15487 & 0.31 & 6.35 \\
\hline 40.9 & 399.6 & 15026 & 0.35 & 6.55 \\
\hline 40.9 & 400.1 & 15036 & 0.40 & 6.41 \\
\hline 40.8 & 400.1 & 15386 & 0.46 & 6.47 \\
\hline 41.0 & 399.0 & 15224 & 0.51 & 6.62 \\
\hline 41.0 & 400.0 & 15098 & 0.58 & 6.84 \\
\hline 41.1 & 400.8 & 15454 & 0.61 & 6.68 \\
\hline
\end{tabular}




\begin{tabular}{|c|c|c|c|c|}
\hline$T_{\text {sat }}$ & $G$ & $\phi$ & $x$ & $h$ \\
\hline 40.8 & 400.9 & 15295 & 0.67 & 7.37 \\
\hline 41.1 & 400.0 & 15172 & 0.71 & 7.58 \\
\hline 41.0 & 399.6 & 15266 & 0.75 & 7.68 \\
\hline 41.2 & 399.1 & 15440 & 0.79 & 8.08 \\
\hline 40.9 & 400.9 & 15274 & 0.83 & 8.29 \\
\hline 40.9 & 400.6 & 15033 & 0.88 & 8.41 \\
\hline 41.0 & 400.1 & 25146 & 0.06 & 8.37 \\
\hline 41.0 & 399.3 & 25128 & 0.10 & 8.17 \\
\hline 41.2 & 399.8 & 25480 & 0.14 & 8.09 \\
\hline 41.1 & 399.8 & 25345 & 0.20 & 8.09 \\
\hline 41.0 & 399.6 & 25214 & 0.23 & 8.24 \\
\hline 41.2 & 400.5 & 25252 & 0.28 & 8.23 \\
\hline 40.9 & 400.2 & 25006 & 0.31 & 8.17 \\
\hline 40.9 & 400.2 & 25128 & 0.35 & 8.35 \\
\hline 40.9 & 399.8 & 25223 & 0.41 & 8.57 \\
\hline 41.1 & 400.2 & 25457 & 0.46 & 8.57 \\
\hline 40.8 & 400.6 & 25282 & 0.50 & 8.66 \\
\hline 40.9 & 399.9 & 25215 & 0.53 & 8.63 \\
\hline 40.8 & 400.3 & 25207 & 0.58 & 8.82 \\
\hline 41.0 & 400.6 & 25141 & 0.63 & 9.05 \\
\hline 40.8 & 399.7 & 25428 & 0.67 & 9.32 \\
\hline 41.2 & 399.8 & 25192 & 0.71 & 9.47 \\
\hline 41.2 & 400.4 & 25395 & 0.74 & 9.66 \\
\hline 41.2 & 399.5 & 25416 & 0.78 & 9.84 \\
\hline 41.0 & 400.0 & 25196 & 0.81 & 9.82 \\
\hline 41.0 & 399.4 & 25247 & 0.85 & 10.03 \\
\hline 40.8 & 400.9 & 35485 & 0.05 & 9.85 \\
\hline 41.0 & 400.3 & 35474 & 0.09 & 9.83 \\
\hline 41.1 & 400.0 & 35323 & 0.13 & 9.73 \\
\hline 40.8 & 399.0 & 35303 & 0.17 & 9.85 \\
\hline 40.9 & 399.7 & 35378 & 0.21 & 9.85 \\
\hline 40.9 & 400.5 & 35423 & 0.26 & 9.86 \\
\hline 41.0 & 400.8 & 35131 & 0.29 & 9.92 \\
\hline 41.1 & 400.3 & 35322 & 0.33 & 10.10 \\
\hline 41.0 & 399.3 & 35039 & 0.37 & 10.10 \\
\hline 41.1 & 400.6 & 35454 & 0.40 & 10.16 \\
\hline 41.2 & 399.6 & 35458 & 0.43 & 10.14 \\
\hline 41.0 & 400.7 & 35447 & 0.46 & 10.10 \\
\hline 40.8 & 399.4 & 35348 & 0.51 & 10.16 \\
\hline 40.8 & 400.0 & 35451 & 0.54 & 10.20 \\
\hline 41.0 & 399.8 & 35393 & 0.57 & 10.14 \\
\hline
\end{tabular}

\begin{tabular}{|c|c|c|c|c|}
$\boldsymbol{T}_{\text {sat }}$ & $\boldsymbol{G}$ & $\boldsymbol{\phi}$ & $\boldsymbol{x}$ & $\boldsymbol{h}$ \\
\hline 40.9 & 401.0 & 35218 & 0.64 & 10.37 \\
\hline 40.9 & 400.7 & 35042 & 0.70 & 10.54 \\
\hline 40.9 & 399.8 & 35136 & 0.74 & 10.51 \\
\hline 40.9 & 400.0 & 35258 & 0.78 & 10.78 \\
\hline 40.9 & 400.3 & 35099 & 0.80 & 10.90 \\
\hline 41.1 & 400.7 & 45301 & 0.06 & 11.60 \\
\hline 40.8 & 400.4 & 45139 & 0.11 & 11.63 \\
\hline 40.9 & 400.0 & 45318 & 0.17 & 11.59 \\
\hline 41.2 & 399.9 & 45213 & 0.19 & 11.83 \\
\hline 41.1 & 400.3 & 45425 & 0.22 & 11.65 \\
\hline 41.1 & 399.1 & 45327 & 0.26 & 11.81 \\
\hline 41.1 & 400.1 & 45453 & 0.30 & 11.76 \\
\hline 40.9 & 399.8 & 45421 & 0.33 & 11.78 \\
\hline 40.9 & 399.1 & 45264 & 0.35 & 11.82 \\
\hline 41.1 & 400.1 & 45130 & 0.40 & 11.99 \\
\hline 40.9 & 399.6 & 45399 & 0.43 & 12.14 \\
\hline 40.8 & 400.3 & 45051 & 0.49 & 12.23 \\
\hline 41.0 & 399.8 & 45206 & 0.54 & 12.05 \\
\hline 41.0 & 400.2 & 45462 & 0.58 & 12.30 \\
\hline 40.9 & 400.1 & 45368 & 0.63 & 11.98 \\
\hline 41.1 & 400.0 & 45453 & 0.66 & 12.22 \\
\hline 41.2 & 400.6 & 45201 & 0.71 & 12.16 \\
\hline 41.0 & 400.4 & 45371 & 0.76 & 12.42 \\
\hline 41.2 & 400.8 & 45364 & 0.80 & 12.40 \\
\hline 41.0 & 399.9 & 55489 & 0.09 & 14.06 \\
\hline 40.9 & 400.6 & 55417 & 0.15 & 14.06 \\
\hline 41.0 & 400.6 & 55346 & 0.18 & 13.98 \\
\hline 41.0 & 399.2 & 55207 & 0.22 & 14.16 \\
\hline 41.1 & 401.0 & 55325 & 0.26 & 14.07 \\
\hline 40.9 & 399.3 & 55014 & 0.30 & 14.01 \\
\hline 40.9 & 400.9 & 55107 & 0.34 & 13.94 \\
\hline 41.0 & 399.8 & 55042 & 0.38 & 13.94 \\
\hline 41.0 & 399.6 & 55423 & 0.42 & 13.91 \\
\hline 40.9 & 399.9 & 55271 & 0.46 & 13.80 \\
\hline 41.0 & 399.7 & 55325 & 0.51 & 13.82 \\
\hline 41.2 & 400.1 & 55233 & 0.56 & 13.79 \\
\hline 41.1 & 400.6 & 55326 & 0.60 & 13.87 \\
\hline 41.0 & 400.1 & 55453 & 0.65 & 14.06 \\
\hline 40.9 & 400.1 & 55474 & 0.70 & 14.12 \\
\hline 41.1 & 399.1 & 55026 & 0.73 & 14.09 \\
\hline 41.0 & 399.1 & 55030 & 0.77 & 14.00 \\
\hline & & & & \\
\hline
\end{tabular}

Tabela B.10. R600a, geometría circular.

\begin{tabular}{|c|c|c|c|c|}
\hline $\boldsymbol{T}_{\text {sat }}$ & $\boldsymbol{G}$ & $\boldsymbol{\phi}$ & $\boldsymbol{x}$ & $\boldsymbol{h}$ \\
\hline 31.4 & 201.2 & 15417 & 0.03 & 2.83 \\
\hline 31.4 & 200.0 & 15726 & 0.08 & 4.08 \\
\hline 31.5 & 199.8 & 15860 & 0.14 & 4.41 \\
\hline 31.5 & 200.3 & 15750 & 0.19 & 4.77 \\
\hline 31.5 & 200.1 & 15595 & 0.23 & 5.51 \\
\hline 31.4 & 201.3 & 15530 & 0.29 & 6.70 \\
\hline 31.4 & 201.8 & 15397 & 0.33 & 7.51 \\
\hline 31.5 & 199.1 & 15388 & 0.39 & 8.54 \\
\hline 31.5 & 199.6 & 15571 & 0.43 & 9.46 \\
\hline
\end{tabular}

\begin{tabular}{|c|c|c|c|c|}
\hline $\boldsymbol{T}_{\text {sat }}$ & $\boldsymbol{G}$ & $\boldsymbol{\phi}$ & $\boldsymbol{x}$ & $\boldsymbol{h}$ \\
\hline 31.5 & 201.2 & 15067 & 0.49 & 10.37 \\
\hline 31.6 & 199.7 & 15083 & 0.53 & 11.03 \\
\hline 31.6 & 200.5 & 15495 & 0.59 & 12.28 \\
\hline 31.6 & 199.7 & 15355 & 0.64 & 13.13 \\
\hline 32.1 & 199.6 & 14754 & 0.68 & 13.34 \\
\hline 32.0 & 199.0 & 14838 & 0.73 & 14.08 \\
\hline 31.9 & 201.3 & 15429 & 0.78 & 15.79 \\
\hline 31.9 & 202.1 & 15206 & 0.82 & 16.32 \\
\hline 31.8 & 199.3 & 15673 & 0.88 & 17.86 \\
\hline 31.5 & 199.3 & 15673 & 0.91 & 19.81 \\
\hline 31.5 & 202.0 & 26573 & 0.03 & 3.92 \\
\hline
\end{tabular}




\begin{tabular}{|c|c|c|c|c|}
\hline $\boldsymbol{T}_{\text {sat }}$ & $\boldsymbol{G}$ & $\boldsymbol{\phi}$ & $\boldsymbol{x}$ & $\boldsymbol{h}$ \\
\hline 31.6 & 198.9 & 26724 & 0.08 & 4.06 \\
\hline 31.7 & 197.8 & 26744 & 0.13 & 4.19 \\
\hline 31.7 & 198.9 & 26682 & 0.17 & 4.29 \\
\hline 31.7 & 203.1 & 26117 & 0.22 & 4.85 \\
\hline 31.8 & 202.0 & 26157 & 0.26 & 5.59 \\
\hline 31.8 & 204.1 & 25981 & 0.33 & 6.78 \\
\hline 31.8 & 202.1 & 24532 & 0.37 & 7.18 \\
\hline 31.8 & 198.9 & 25265 & 0.43 & 8.60 \\
\hline 31.8 & 201.0 & 25955 & 0.47 & 9.71 \\
\hline 31.8 & 201.0 & 26075 & 0.53 & 11.09 \\
\hline 31.8 & 202.0 & 25692 & 0.58 & 11.76 \\
\hline 31.7 & 200.3 & 25662 & 0.63 & 12.52 \\
\hline 31.7 & 203.1 & 25569 & 0.67 & 13.20 \\
\hline 32.0 & 201.0 & 25206 & 0.72 & 14.00 \\
\hline 31.8 & 202.0 & 25298 & 0.76 & 15.08 \\
\hline 31.7 & 201.0 & 25147 & 0.81 & 15.89 \\
\hline 31.6 & 201.0 & 25147 & 0.84 & 16.29 \\
\hline 31.4 & 201.0 & 25147 & 0.86 & 16.84 \\
\hline 31.8 & 201.0 & 35840 & 0.02 & 5.40 \\
\hline 31.7 & 199.9 & 35252 & 0.07 & 5.22 \\
\hline 31.6 & 197.8 & 34193 & 0.13 & 4.92 \\
\hline 31.7 & 201.0 & 34992 & 0.18 & 5.41 \\
\hline 31.7 & 202.0 & 34953 & 0.22 & 5.47 \\
\hline 31.7 & 202.0 & 35322 & 0.27 & 5.98 \\
\hline 31.7 & 202.0 & 35221 & 0.32 & 6.83 \\
\hline 31.7 & 199.9 & 35217 & 0.39 & 8.01 \\
\hline 31.7 & 197.8 & 34865 & 0.43 & 8.61 \\
\hline 31.7 & 204.1 & 35845 & 0.48 & 9.96 \\
\hline 31.8 & 201.0 & 35731 & 0.53 & 10.81 \\
\hline 31.8 & 199.9 & 35788 & 0.59 & 11.89 \\
\hline 31.7 & 198.9 & 35844 & 0.63 & 12.75 \\
\hline 31.5 & 199.9 & 35494 & 0.68 & 13.86 \\
\hline 31.8 & 198.9 & 35218 & 0.72 & 14.36 \\
\hline 31.9 & 202.0 & 34996 & 0.76 & 15.24 \\
\hline 31.8 & 202.0 & 34996 & 0.80 & 15.69 \\
\hline 31.7 & 202.0 & 34996 & 0.84 & 15.90 \\
\hline 31.3 & 202.0 & 45261 & 0.06 & 6.34 \\
\hline 31.4 & 201.0 & 45415 & 0.14 & 6.33 \\
\hline 31.7 & 201.0 & 45358 & 0.17 & 6.60 \\
\hline 31.7 & 197.8 & 44891 & 0.22 & 6.50 \\
\hline 31.7 & 202.0 & 46597 & 0.27 & 6.90 \\
\hline 31.6 & 201.0 & 46396 & 0.33 & 7.48 \\
\hline 31.5 & 198.7 & 45931 & 0.37 & 7.97 \\
\hline 31.5 & 201.0 & 45824 & 0.42 & 8.72 \\
\hline 31.5 & 199.9 & 44686 & 0.47 & 9.22 \\
\hline 31.5 & 199.9 & 46171 & 0.52 & 10.21 \\
\hline 32.2 & 202.0 & 45432 & 0.57 & 11.08 \\
\hline 32.1 & 201.0 & 45773 & 0.61 & 11.65 \\
\hline 31.8 & 199.9 & 45390 & 0.66 & 12.59 \\
\hline 31.7 & 199.9 & 46605 & 0.73 & 13.94 \\
\hline 31.8 & 201.0 & 45773 & 0.77 & 15.20 \\
\hline 31.5 & 199.9 & 45390 & 0.82 & 16.48 \\
\hline 31.3 & 199.9 & 46605 & 0.88 & 18.58 \\
\hline 31.4 & 202.0 & 55376 & 0.09 & 7.60 \\
\hline 31.5 & 202.0 & 55331 & 0.12 & 7.51 \\
\hline 31.5 & 202.0 & 55331 & 0.16 & 7.39 \\
\hline 31.9 & 205.2 & 55311 & 0.21 & 7.59 \\
\hline & & & & \\
\hline
\end{tabular}

\begin{tabular}{|c|c|c|c|c|}
\hline$T_{\text {sat }}$ & $G$ & $\phi$ & $x$ & $h$ \\
\hline 31.9 & 202.0 & 55407 & 0.27 & 7.69 \\
\hline 31.9 & 197.8 & 55350 & 0.33 & 7.88 \\
\hline 31.8 & 198.9 & 55141 & 0.38 & 8.14 \\
\hline 31.8 & 202.0 & 55222 & 0.42 & 8.66 \\
\hline 31.8 & 199.9 & 55267 & 0.46 & 9.10 \\
\hline 31.8 & 199.9 & 55430 & 0.51 & 9.75 \\
\hline 31.7 & 199.9 & 55268 & 0.58 & 10.85 \\
\hline 31.9 & 201.0 & 55071 & 0.61 & 11.46 \\
\hline 32.1 & 197.8 & 54982 & 0.66 & 12.09 \\
\hline 31.5 & 199.9 & 55430 & 0.70 & 13.01 \\
\hline 31.3 & 199.9 & 55268 & 0.76 & 14.50 \\
\hline 31.5 & 201.0 & 55071 & 0.80 & 15.40 \\
\hline 31.7 & 197.8 & 54982 & 0.85 & 16.11 \\
\hline 31.4 & 196.8 & 66053 & 0.13 & 8.65 \\
\hline 31.5 & 202.0 & 65931 & 0.17 & 8.49 \\
\hline 31.5 & 199.9 & 65810 & 0.22 & 8.44 \\
\hline 31.9 & 201.0 & 65717 & 0.26 & 8.89 \\
\hline 31.9 & 199.9 & 65606 & 0.32 & 8.90 \\
\hline 31.8 & 205.2 & 65784 & 0.36 & 9.14 \\
\hline 31.8 & 202.0 & 65767 & 0.41 & 9.35 \\
\hline 31.8 & 201.0 & 65747 & 0.45 & 9.57 \\
\hline 31.8 & 202.0 & 65539 & 0.51 & 10.01 \\
\hline 31.7 & 199.9 & 65982 & 0.55 & 10.50 \\
\hline 31.6 & 202.0 & 65562 & 0.61 & 11.30 \\
\hline 31.6 & 202.0 & 65767 & 0.63 & 11.78 \\
\hline 31.5 & 201.0 & 65747 & 0.67 & 12.29 \\
\hline 31.5 & 202.0 & 65539 & 0.73 & 13.39 \\
\hline 31.4 & 199.9 & 65982 & 0.78 & 14.01 \\
\hline 31.3 & 202.0 & 65562 & 0.83 & 15.49 \\
\hline 31.5 & 198.9 & 76265 & 0.16 & 9.52 \\
\hline 31.6 & 201.0 & 76057 & 0.22 & 9.43 \\
\hline 32.2 & 202.0 & 76006 & 0.28 & 10.05 \\
\hline 32.2 & 203.1 & 75880 & 0.32 & 10.06 \\
\hline 32.1 & 198.9 & 75861 & 0.37 & 10.11 \\
\hline 32.2 & 202.0 & 75702 & 0.40 & 10.13 \\
\hline 32.1 & 201.0 & 75476 & 0.46 & 10.33 \\
\hline 31.9 & 202.0 & 75042 & 0.51 & 10.47 \\
\hline 31.9 & 202.0 & 74942 & 0.55 & 10.61 \\
\hline 32.0 & 201.0 & 75702 & 0.57 & 11.20 \\
\hline 31.9 & 202.0 & 75476 & 0.63 & 11.76 \\
\hline 31.7 & 199.9 & 75042 & 0.68 & 12.36 \\
\hline 31.8 & 201.0 & 75476 & 0.72 & 13.23 \\
\hline 31.6 & 202.0 & 75042 & 0.76 & 14.21 \\
\hline 31.6 & 199.9 & 74942 & 0.80 & 14.70 \\
\hline 31.0 & 300.9 & 15648 & 0.03 & 2.55 \\
\hline 31.2 & 302.0 & 15651 & 0.08 & 3.56 \\
\hline 31.3 & 299.9 & 15642 & 0.13 & 4.39 \\
\hline 31.4 & 302.0 & 15655 & 0.17 & 5.49 \\
\hline 31.4 & 298.8 & 15636 & 0.24 & 7.48 \\
\hline 31.4 & 302.0 & 15639 & 0.27 & 8.24 \\
\hline 31.6 & 297.8 & 15630 & 0.34 & 9.48 \\
\hline 31.7 & 299.9 & 15632 & 0.38 & 10.72 \\
\hline 31.7 & 300.9 & 15612 & 0.44 & 11.89 \\
\hline 31.7 & 299.9 & 15602 & 0.48 & 13.01 \\
\hline 31.5 & 300.9 & 15565 & 0.54 & 15.35 \\
\hline 31.6 & 300.9 & 15564 & 0.58 & 16.44 \\
\hline 31.6 & 303.1 & 15711 & 0.64 & 16.82 \\
\hline
\end{tabular}




\begin{tabular}{|c|c|c|c|c|}
\hline$T_{\text {sat }}$ & $G$ & $\phi$ & $x$ & $h$ \\
\hline 31.6 & 299.9 & 15679 & 0.69 & 18.56 \\
\hline 31.5 & 298.8 & 15657 & 0.73 & 18.87 \\
\hline 31.9 & 297.8 & 15638 & 0.79 & 19.67 \\
\hline 31.9 & 299.9 & 15465 & 0.82 & 21.02 \\
\hline 31.7 & 300.9 & 15424 & 0.87 & 21.24 \\
\hline 30.6 & 297.8 & 26471 & 0.03 & 3.89 \\
\hline 30.7 & 308.3 & 25966 & 0.06 & 3.64 \\
\hline 30.7 & 299.9 & 25826 & 0.11 & 3.78 \\
\hline 31.3 & 300.9 & 26338 & 0.16 & 5.17 \\
\hline 31.4 & 297.8 & 25313 & 0.23 & 6.92 \\
\hline 31.5 & 302.0 & 25799 & 0.26 & 8.09 \\
\hline 31.6 & 298.8 & 26042 & 0.31 & 9.09 \\
\hline 31.6 & 297.8 & 26344 & 0.36 & 10.45 \\
\hline 31.7 & 296.7 & 26684 & 0.42 & 11.97 \\
\hline 31.8 & 299.9 & 26279 & 0.47 & 12.88 \\
\hline 31.9 & 298.8 & 25649 & 0.52 & 13.91 \\
\hline 31.9 & 300.9 & 25637 & 0.55 & 14.67 \\
\hline 31.9 & 300.9 & 26269 & 0.61 & 15.86 \\
\hline 31.9 & 300.9 & 26143 & 0.66 & 16.85 \\
\hline 31.9 & 298.8 & 26894 & 0.72 & 19.00 \\
\hline 31.9 & 303.1 & 26527 & 0.75 & 18.72 \\
\hline 31.9 & 299.9 & 26416 & 0.81 & 19.64 \\
\hline 31.8 & 300.9 & 26165 & 0.85 & 20.68 \\
\hline 31.7 & 298.8 & 26014 & 0.91 & 22.40 \\
\hline 30.2 & 298.8 & 36081 & 0.05 & 5.01 \\
\hline 30.3 & 300.9 & 35925 & 0.09 & 4.74 \\
\hline 30.2 & 303.1 & 36435 & 0.14 & 4.79 \\
\hline 31.1 & 304.1 & 36587 & 0.19 & 6.47 \\
\hline 31.2 & 300.9 & 36605 & 0.24 & 7.79 \\
\hline 31.2 & 304.1 & 35037 & 0.29 & 9.05 \\
\hline 31.4 & 297.8 & 34894 & 0.35 & 10.47 \\
\hline 31.5 & 299.9 & 37171 & 0.40 & 12.56 \\
\hline 31.6 & 296.7 & 36865 & 0.44 & 13.46 \\
\hline 31.6 & 299.9 & 36325 & 0.50 & 14.50 \\
\hline 31.7 & 297.8 & 36359 & 0.54 & 15.36 \\
\hline 31.8 & 302.0 & 36949 & 0.58 & 16.84 \\
\hline 31.8 & 299.9 & 36587 & 0.62 & 17.57 \\
\hline 31.8 & 298.8 & 36771 & 0.69 & 19.42 \\
\hline 31.7 & 296.7 & 36448 & 0.74 & 20.40 \\
\hline 31.6 & 304.1 & 36146 & 0.78 & 21.58 \\
\hline 31.6 & 298.8 & 36132 & 0.85 & 22.70 \\
\hline 31.5 & 302.0 & 35694 & 0.88 & 22.80 \\
\hline 30.3 & 303.1 & 44316 & 0.01 & 5.91 \\
\hline 30.5 & 302.0 & 46647 & 0.05 & 6.13 \\
\hline 30.7 & 303.1 & 46740 & 0.10 & 6.15 \\
\hline 31.3 & 302.0 & 46599 & 0.15 & 6.64 \\
\hline 31.4 & 300.9 & 46425 & 0.20 & 6.92 \\
\hline 31.5 & 300.9 & 46095 & 0.25 & 8.21 \\
\hline 31.6 & 302.0 & 45631 & 0.31 & 9.66 \\
\hline 31.7 & 298.8 & 45866 & 0.36 & 10.57 \\
\hline 31.8 & 298.8 & 45299 & 0.41 & 11.64 \\
\hline 32.0 & 298.8 & 42386 & 0.45 & 12.28 \\
\hline 32.4 & 299.9 & 45784 & 0.51 & 14.48 \\
\hline 32.4 & 299.9 & 45154 & 0.55 & 15.48 \\
\hline 32.5 & 299.9 & 45289 & 0.60 & 16.65 \\
\hline 32.5 & 302.0 & 45312 & 0.64 & 18.11 \\
\hline 32.5 & 299.9 & 45748 & 0.71 & 19.53 \\
\hline
\end{tabular}

\begin{tabular}{|c|c|c|c|c|}
\hline$T_{\text {sat }}$ & $G$ & $\phi$ & $x$ & $h$ \\
\hline 32.4 & 303.1 & 45583 & 0.74 & 20.15 \\
\hline 32.4 & 297.8 & 45304 & 0.80 & 21.71 \\
\hline 32.2 & 297.8 & 45304 & 0.84 & 23.75 \\
\hline 30.7 & 299.9 & 55836 & 0.03 & 7.25 \\
\hline 30.8 & 303.1 & 56133 & 0.07 & 7.32 \\
\hline 30.2 & 300.9 & 56152 & 0.12 & 6.64 \\
\hline 31.5 & 299.9 & 55691 & 0.18 & 7.34 \\
\hline 31.5 & 302.0 & 55495 & 0.22 & 7.35 \\
\hline 31.6 & 299.9 & 54801 & 0.27 & 8.53 \\
\hline 31.8 & 299.9 & 56294 & 0.33 & 9.99 \\
\hline 31.9 & 299.9 & 55973 & 0.36 & 10.78 \\
\hline 32.0 & 299.9 & 55658 & 0.40 & 11.72 \\
\hline 32.1 & 298.8 & 55795 & 0.47 & 13.45 \\
\hline 32.2 & 302.0 & 55841 & 0.51 & 14.47 \\
\hline 32.2 & 300.9 & 55913 & 0.57 & 15.97 \\
\hline 32.2 & 300.9 & 55832 & 0.61 & 16.84 \\
\hline 32.4 & 302.0 & 55511 & 0.66 & 17.95 \\
\hline 32.5 & 295.7 & 55225 & 0.72 & 19.19 \\
\hline 32.2 & 299.9 & 55086 & 0.76 & 20.68 \\
\hline 32.0 & 299.9 & 55086 & 0.80 & 21.58 \\
\hline 31.8 & 299.9 & 55086 & 0.84 & 21.98 \\
\hline 30.5 & 299.9 & 65739 & 0.05 & 8.58 \\
\hline 30.5 & 303.1 & 65384 & 0.08 & 8.47 \\
\hline 30.7 & 300.9 & 65479 & 0.13 & 8.50 \\
\hline 31.6 & 298.8 & 66034 & 0.18 & 8.66 \\
\hline 31.8 & 298.8 & 66449 & 0.24 & 8.81 \\
\hline 31.9 & 299.9 & 66125 & 0.28 & 9.32 \\
\hline 32.0 & 299.9 & 64401 & 0.34 & 10.03 \\
\hline 32.1 & 297.8 & 65961 & 0.39 & 11.45 \\
\hline 32.3 & 298.8 & 66084 & 0.44 & 12.34 \\
\hline 32.3 & 302.0 & 66184 & 0.47 & 13.22 \\
\hline 32.4 & 298.8 & 65837 & 0.53 & 14.39 \\
\hline 32.4 & 302.0 & 65514 & 0.57 & 15.34 \\
\hline 32.3 & 302.0 & 64322 & 0.63 & 16.54 \\
\hline 32.3 & 299.9 & 65033 & 0.68 & 17.90 \\
\hline 32.2 & 302.0 & 65274 & 0.72 & 19.25 \\
\hline 31.7 & 302.0 & 64322 & 0.77 & 21.51 \\
\hline 31.6 & 299.9 & 65033 & 0.83 & 23.38 \\
\hline 31.5 & 302.0 & 65274 & 0.87 & 25.08 \\
\hline 31.2 & 302.0 & 75163 & 0.07 & 9.53 \\
\hline 31.4 & 303.1 & 75030 & 0.11 & 9.42 \\
\hline 31.5 & 298.8 & 75211 & 0.15 & 9.35 \\
\hline 32.0 & 300.9 & 75058 & 0.20 & 10.04 \\
\hline 32.0 & 302.0 & 75408 & 0.26 & 9.79 \\
\hline 32.0 & 299.9 & 75466 & 0.30 & 10.00 \\
\hline 31.6 & 302.0 & 75408 & 0.43 & 12.17 \\
\hline 31.6 & 299.9 & 75466 & 0.47 & 12.72 \\
\hline 31.7 & 298.8 & 75630 & 0.52 & 13.86 \\
\hline 31.8 & 297.8 & 75637 & 0.58 & 15.04 \\
\hline 31.6 & 297.8 & 75388 & 0.63 & 16.17 \\
\hline 31.8 & 300.9 & 75652 & 0.67 & 17.38 \\
\hline 32.1 & 300.9 & 75288 & 0.72 & 18.47 \\
\hline 32.0 & 302.0 & 75868 & 0.77 & 20.04 \\
\hline 31.9 & 300.9 & 75537 & 0.81 & 21.10 \\
\hline 31.8 & 302.0 & 75648 & 0.86 & 22.82 \\
\hline 31.1 & 297.8 & 87376 & 0.10 & 10.96 \\
\hline 31.4 & 303.1 & 86174 & 0.16 & 10.79 \\
\hline
\end{tabular}




\begin{tabular}{|c|c|c|c|c|}
\hline $\boldsymbol{T}_{\text {sat }}$ & $\boldsymbol{G}$ & $\boldsymbol{\phi}$ & $\boldsymbol{x}$ & $\boldsymbol{h}$ \\
\hline 32.0 & 304.1 & 85633 & 0.22 & 11.35 \\
\hline 32.1 & 296.7 & 85694 & 0.26 & 11.58 \\
\hline 32.3 & 302.0 & 85271 & 0.32 & 11.93 \\
\hline 32.5 & 297.8 & 85158 & 0.37 & 12.19 \\
\hline 32.7 & 298.8 & 84649 & 0.41 & 12.48 \\
\hline 31.8 & 296.7 & 85694 & 0.46 & 13.01 \\
\hline 32.0 & 302.0 & 85271 & 0.51 & 13.77 \\
\hline 32.1 & 297.8 & 85158 & 0.56 & 14.43 \\
\hline 32.2 & 298.8 & 84649 & 0.60 & 15.07 \\
\hline 32.2 & 296.7 & 85785 & 0.67 & 16.65 \\
\hline 32.2 & 302.0 & 85368 & 0.69 & 17.37 \\
\hline 32.0 & 298.8 & 84672 & 0.76 & 18.52 \\
\hline 31.9 & 300.9 & 84510 & 0.79 & 19.41 \\
\hline 31.7 & 298.8 & 85502 & 0.84 & 21.03 \\
\hline 31.8 & 304.1 & 94235 & 0.14 & 11.47 \\
\hline 31.9 & 300.9 & 94263 & 0.18 & 11.44 \\
\hline 32.5 & 299.9 & 94234 & 0.23 & 11.97 \\
\hline 32.7 & 299.9 & 94236 & 0.28 & 12.03 \\
\hline 32.7 & 299.9 & 94774 & 0.32 & 12.08 \\
\hline 32.6 & 297.8 & 94932 & 0.39 & 12.54 \\
\hline 32.6 & 300.9 & 94789 & 0.43 & 12.77 \\
\hline 32.6 & 300.9 & 95004 & 0.48 & 13.14 \\
\hline 32.3 & 299.9 & 94774 & 0.54 & 13.98 \\
\hline 32.2 & 297.8 & 94932 & 0.61 & 15.09 \\
\hline 32.1 & 300.9 & 94789 & 0.64 & 15.75 \\
\hline 32.0 & 300.9 & 95004 & 0.69 & 16.56 \\
\hline 31.9 & 296.7 & 94834 & 0.75 & 17.62 \\
\hline 31.8 & 299.9 & 94753 & 0.79 & 18.74 \\
\hline 31.9 & 300.9 & 94847 & 0.83 & 19.74 \\
\hline 31.6 & 299.9 & 104857 & 0.15 & 12.39 \\
\hline 31.7 & 303.1 & 104825 & 0.20 & 12.53 \\
\hline 32.3 & 302.0 & 104918 & 0.25 & 13.05 \\
\hline 32.5 & 300.9 & 104888 & 0.30 & 13.21 \\
\hline 32.6 & 302.0 & 105519 & 0.34 & 13.43 \\
\hline 32.7 & 299.9 & 105427 & 0.40 & 13.63 \\
\hline 32.6 & 298.8 & 105275 & 0.44 & 13.85 \\
\hline 32.0 & 302.0 & 104918 & 0.49 & 14.18 \\
\hline 32.1 & 300.9 & 104888 & 0.54 & 14.89 \\
\hline 32.1 & 302.0 & 105519 & 0.58 & 15.43 \\
\hline 32.2 & 299.9 & 105427 & 0.64 & 16.00 \\
\hline 32.1 & 298.8 & 105275 & 0.68 & 16.67 \\
\hline 32.0 & 298.8 & 105344 & 0.74 & 17.54 \\
\hline 32.0 & 300.9 & 105034 & 0.77 & 18.09 \\
\hline 31.8 & 302.0 & 105138 & 0.81 & 19.19 \\
\hline 30.5 & 404.1 & 25582 & 0.10 & 5.39 \\
\hline 30.7 & 402.0 & 25599 & 0.14 & 6.90 \\
\hline 31.1 & 398.8 & 25620 & 0.20 & 8.92 \\
\hline 31.6 & 397.8 & 25607 & 0.26 & 10.76 \\
\hline 31.9 & 399.9 & 25606 & 0.31 & 12.51 \\
\hline 32.1 & 400.9 & 25579 & 0.35 & 13.68 \\
\hline 32.2 & 398.8 & 25624 & 0.40 & 15.19 \\
\hline 32.3 & 406.2 & 25624 & 0.43 & 16.48 \\
\hline 32.5 & 400.9 & 25594 & 0.48 & 17.58 \\
\hline 32.7 & 405.1 & 25607 & 0.53 & 19.10 \\
\hline 32.8 & 399.9 & 25637 & 0.61 & 20.93 \\
\hline 32.9 & 402.0 & 25536 & 0.64 & 22.03 \\
\hline 32.9 & 399.9 & 25523 & 0.68 & 22.60 \\
\hline & & & & \\
\hline
\end{tabular}

\begin{tabular}{|c|c|c|c|c|}
\hline$T_{\text {sat }}$ & $G$ & $\phi$ & $x$ & $h$ \\
\hline 32.9 & 399.9 & 25423 & 0.73 & 22.99 \\
\hline 32.9 & 399.9 & 25553 & 0.77 & 24.39 \\
\hline 32.9 & 399.9 & 25570 & 0.83 & 25.18 \\
\hline 32.7 & 399.9 & 25518 & 0.90 & 25.50 \\
\hline 30.1 & 399.9 & 35990 & 0.07 & 4.31 \\
\hline 31.2 & 398.8 & 35802 & 0.12 & 5.55 \\
\hline 31.3 & 399.9 & 35793 & 0.17 & 7.43 \\
\hline 31.6 & 402.0 & 36100 & 0.22 & 9.40 \\
\hline 32.0 & 399.9 & 35965 & 0.28 & 11.16 \\
\hline 32.4 & 400.9 & 36105 & 0.33 & 12.69 \\
\hline 32.5 & 400.9 & 35968 & 0.37 & 13.91 \\
\hline 32.7 & 398.8 & 35968 & 0.41 & 15.10 \\
\hline 32.8 & 400.9 & 35727 & 0.47 & 16.51 \\
\hline 32.9 & 399.9 & 35992 & 0.52 & 18.01 \\
\hline 33.0 & 398.8 & 36027 & 0.56 & 19.60 \\
\hline 33.1 & 399.9 & 36046 & 0.60 & 20.95 \\
\hline 33.0 & 399.9 & 36209 & 0.66 & 22.88 \\
\hline 32.9 & 398.8 & 35794 & 0.71 & 23.56 \\
\hline 32.8 & 399.9 & 35605 & 0.76 & 24.11 \\
\hline 32.7 & 399.9 & 35732 & 0.81 & 26.12 \\
\hline 32.5 & 398.8 & 35736 & 0.87 & 27.06 \\
\hline 30.5 & 402.0 & 46789 & 0.04 & 5.73 \\
\hline 30.5 & 400.9 & 46668 & 0.09 & 5.55 \\
\hline 31.7 & 399.9 & 46687 & 0.14 & 6.42 \\
\hline 31.8 & 396.7 & 46847 & 0.19 & 7.67 \\
\hline 32.0 & 402.0 & 46436 & 0.25 & 9.60 \\
\hline 32.2 & 398.8 & 46401 & 0.29 & 10.85 \\
\hline 32.3 & 402.0 & 46471 & 0.34 & 12.33 \\
\hline 32.5 & 400.9 & 46454 & 0.39 & 13.81 \\
\hline 32.5 & 400.9 & 46500 & 0.44 & 15.02 \\
\hline 32.7 & 406.2 & 46505 & 0.49 & 16.90 \\
\hline 32.8 & 403.0 & 46486 & 0.54 & 18.29 \\
\hline 32.9 & 399.9 & 46405 & 0.59 & 19.34 \\
\hline 33.0 & 399.9 & 46367 & 0.64 & 20.55 \\
\hline 32.8 & 399.9 & 46229 & 0.69 & 21.88 \\
\hline 32.6 & 402.0 & 46073 & 0.74 & 22.91 \\
\hline 32.4 & 403.0 & 45834 & 0.78 & 24.11 \\
\hline 32.6 & 403.0 & 46073 & 0.83 & 25.11 \\
\hline 32.4 & 396.7 & 45834 & 0.89 & 25.75 \\
\hline 30.3 & 398.8 & 55314 & 0.05 & 6.89 \\
\hline 30.3 & 398.8 & 55314 & 0.08 & 6.77 \\
\hline 30.4 & 399.9 & 55284 & 0.13 & 6.46 \\
\hline 31.1 & 402.0 & 55308 & 0.18 & 7.08 \\
\hline 31.5 & 403.0 & 55458 & 0.23 & 8.55 \\
\hline 31.6 & 402.0 & 55365 & 0.28 & 10.12 \\
\hline 31.8 & 400.9 & 55397 & 0.33 & 11.41 \\
\hline 31.9 & 399.9 & 55362 & 0.38 & 12.99 \\
\hline 31.7 & 399.9 & 55282 & 0.43 & 14.16 \\
\hline 31.8 & 399.9 & 55222 & 0.48 & 15.89 \\
\hline 32.0 & 404.1 & 55224 & 0.53 & 17.57 \\
\hline 32.1 & 399.9 & 55295 & 0.59 & 18.80 \\
\hline 32.2 & 397.8 & 55320 & 0.64 & 20.20 \\
\hline 32.1 & 399.9 & 55280 & 0.68 & 21.73 \\
\hline 32.1 & 399.9 & 55351 & 0.73 & 23.05 \\
\hline 32.1 & 405.1 & 55401 & 0.77 & 24.17 \\
\hline 32.0 & 399.9 & 55382 & 0.83 & 25.70 \\
\hline 32.1 & 399.9 & 55313 & 0.88 & 26.54 \\
\hline
\end{tabular}




\begin{tabular}{|c|c|c|c|c|}
\hline$T_{\text {sat }}$ & $G$ & $\phi$ & $x$ & $h$ \\
\hline 30.4 & 400.9 & 65449 & 0.05 & 7.96 \\
\hline 30.7 & 400.9 & 65420 & 0.09 & 7.93 \\
\hline 30.3 & 400.9 & 65449 & 0.12 & 7.46 \\
\hline 30.6 & 400.9 & 65420 & 0.17 & 7.54 \\
\hline 31.0 & 400.9 & 65426 & 0.21 & 8.23 \\
\hline 31.3 & 400.9 & 65391 & 0.27 & 9.84 \\
\hline 31.4 & 398.8 & 65401 & 0.31 & 10.77 \\
\hline 31.7 & 403.0 & 65363 & 0.37 & 12.52 \\
\hline 32.0 & 404.1 & 65344 & 0.42 & 13.94 \\
\hline 32.1 & 398.8 & 65372 & 0.47 & 15.09 \\
\hline 32.2 & 399.9 & 65252 & 0.52 & 16.05 \\
\hline 32.2 & 399.9 & 65259 & 0.56 & 17.53 \\
\hline 32.3 & 397.8 & 65262 & 0.62 & 18.77 \\
\hline 32.4 & 400.9 & 65217 & 0.67 & 20.22 \\
\hline 32.2 & 399.9 & 65100 & 0.72 & 21.61 \\
\hline 32.1 & 398.8 & 65032 & 0.76 & 22.83 \\
\hline 32.0 & 399.9 & 65061 & 0.81 & 23.93 \\
\hline 32.1 & 402.0 & 64989 & 0.85 & 25.09 \\
\hline 30.6 & 402.0 & 75832 & 0.07 & 9.20 \\
\hline 30.8 & 404.1 & 75934 & 0.10 & 9.02 \\
\hline 30.6 & 402.0 & 75832 & 0.11 & 8.70 \\
\hline 30.7 & 404.1 & 75934 & 0.14 & 8.62 \\
\hline 31.2 & 400.9 & 75931 & 0.20 & 9.02 \\
\hline 31.7 & 400.9 & 75615 & 0.25 & 9.88 \\
\hline 31.9 & 399.9 & 75648 & 0.30 & 10.82 \\
\hline 32.0 & 399.9 & 75683 & 0.34 & 11.67 \\
\hline 31.9 & 402.0 & 75569 & 0.40 & 13.23 \\
\hline 32.1 & 399.9 & 75521 & 0.45 & 14.37 \\
\hline 32.1 & 399.9 & 75476 & 0.51 & 15.71 \\
\hline 32.2 & 396.7 & 75508 & 0.56 & 16.90 \\
\hline 32.3 & 399.9 & 75514 & 0.60 & 18.19 \\
\hline 32.3 & 400.9 & 75545 & 0.65 & 19.34 \\
\hline 32.3 & 398.8 & 75471 & 0.71 & 20.92 \\
\hline 32.3 & 399.9 & 75476 & 0.75 & 22.16 \\
\hline 32.2 & 402.0 & 75481 & 0.79 & 23.44 \\
\hline 32.2 & 399.9 & 75431 & 0.84 & 24.66 \\
\hline 31.2 & 400.9 & 85741 & 0.04 & 9.97 \\
\hline 31.5 & 403.0 & 85738 & 0.09 & 10.27 \\
\hline 31.1 & 400.9 & 85741 & 0.14 & 9.92 \\
\hline 31.3 & 403.0 & 85738 & 0.18 & 9.94 \\
\hline 30.1 & 400.9 & 85707 & 0.24 & 8.57 \\
\hline 32.1 & 396.7 & 85796 & 0.28 & 10.88 \\
\hline 32.0 & 399.9 & 85722 & 0.34 & 11.81 \\
\hline 31.9 & 400.9 & 85679 & 0.39 & 12.95 \\
\hline 31.8 & 402.0 & 85837 & 0.44 & 14.18 \\
\hline 31.8 & 400.9 & 85672 & 0.48 & 14.99 \\
\hline 31.9 & 400.9 & 85393 & 0.53 & 16.15 \\
\hline 32.0 & 397.8 & 85258 & 0.59 & 17.53 \\
\hline 32.0 & 399.9 & 85210 & 0.64 & 19.02 \\
\hline 31.9 & 403.0 & 85274 & 0.68 & 20.23 \\
\hline 32.0 & 399.9 & 85308 & 0.74 & 21.96 \\
\hline 31.9 & 400.9 & 85286 & 0.78 & 23.39 \\
\hline 32.3 & 399.9 & 85224 & 0.84 & 24.26 \\
\hline 32.8 & 398.8 & 95467 & 0.06 & 11.32 \\
\hline 32.5 & 402.0 & 95470 & 0.11 & 11.37 \\
\hline 32.5 & 402.0 & 95743 & 0.15 & 11.35 \\
\hline 32.7 & 398.8 & 95467 & 0.17 & 11.23 \\
\hline
\end{tabular}

\begin{tabular}{|c|c|c|c|c|}
\hline$T_{\text {sat }}$ & $G$ & $\phi$ & $x$ & $h$ \\
\hline 32.4 & 402.0 & 95470 & 0.22 & 11.04 \\
\hline 32.3 & 402.0 & 95743 & 0.25 & 11.02 \\
\hline 31.9 & 399.9 & 96464 & 0.32 & 11.52 \\
\hline 31.9 & 400.9 & 96290 & 0.37 & 12.27 \\
\hline 32.1 & 399.9 & 96422 & 0.43 & 13.69 \\
\hline 32.1 & 399.9 & 96219 & 0.47 & 14.72 \\
\hline 32.2 & 399.9 & 96591 & 0.52 & 15.87 \\
\hline 32.1 & 399.9 & 96511 & 0.57 & 17.03 \\
\hline 32.0 & 399.9 & 95980 & 0.63 & 18.83 \\
\hline 32.1 & 400.9 & 95865 & 0.67 & 19.89 \\
\hline 32.0 & 399.9 & 96264 & 0.71 & 21.01 \\
\hline 32.3 & 397.8 & 96506 & 0.76 & 22.27 \\
\hline 32.4 & 400.9 & 95874 & 0.81 & 23.43 \\
\hline 31.4 & 399.9 & 105754 & 0.13 & 12.24 \\
\hline 30.8 & 396.7 & 105947 & 0.19 & 11.46 \\
\hline 32.1 & 404.1 & 105277 & 0.23 & 12.85 \\
\hline 32.2 & 397.8 & 103505 & 0.29 & 12.78 \\
\hline 32.3 & 399.9 & 107629 & 0.33 & 13.59 \\
\hline 32.4 & 399.9 & 106613 & 0.38 & 14.02 \\
\hline 32.5 & 397.8 & 106746 & 0.44 & 14.60 \\
\hline 32.7 & 406.2 & 106049 & 0.48 & 15.28 \\
\hline 32.8 & 400.9 & 105764 & 0.52 & 15.76 \\
\hline 32.9 & 399.9 & 106123 & 0.58 & 16.82 \\
\hline 32.8 & 403.0 & 106132 & 0.61 & 17.73 \\
\hline 32.9 & 398.8 & 105850 & 0.67 & 18.83 \\
\hline 32.3 & 399.9 & 106123 & 0.70 & 19.26 \\
\hline 32.1 & 403.0 & 106132 & 0.73 & 20.34 \\
\hline 32.2 & 398.8 & 105850 & 0.79 & 21.54 \\
\hline 31.1 & 399.9 & 117175 & 0.10 & 13.52 \\
\hline 31.5 & 403.0 & 117271 & 0.16 & 13.64 \\
\hline 31.1 & 398.8 & 117397 & 0.20 & 12.77 \\
\hline 32.6 & 399.9 & 116800 & 0.27 & 14.64 \\
\hline 32.7 & 402.0 & 117341 & 0.31 & 15.11 \\
\hline 32.8 & 403.0 & 117410 & 0.35 & 15.33 \\
\hline 33.0 & 402.0 & 117279 & 0.39 & 15.56 \\
\hline 33.0 & 404.1 & 117219 & 0.45 & 16.09 \\
\hline 33.0 & 400.9 & 117156 & 0.49 & 16.36 \\
\hline 33.0 & 399.9 & 117031 & 0.55 & 16.97 \\
\hline 33.0 & 402.0 & 117208 & 0.60 & 17.58 \\
\hline 32.6 & 399.9 & 116620 & 0.67 & 18.79 \\
\hline 32.2 & 400.9 & 117156 & 0.69 & 19.85 \\
\hline 32.1 & 399.9 & 117031 & 0.75 & 21.52 \\
\hline 31.9 & 402.0 & 117208 & 0.80 & 22.77 \\
\hline 31.5 & 399.9 & 116620 & 0.87 & 25.31 \\
\hline 31.1 & 398.8 & 126161 & 0.10 & 14.40 \\
\hline 31.5 & 400.9 & 126549 & 0.16 & 14.54 \\
\hline 31.1 & 399.9 & 126196 & 0.20 & 14.48 \\
\hline 32.6 & 399.9 & 125951 & 0.27 & 14.46 \\
\hline 32.7 & 399.9 & 125035 & 0.31 & 15.28 \\
\hline 32.8 & 400.9 & 126184 & 0.35 & 15.52 \\
\hline 33.0 & 399.9 & 124699 & 0.39 & 15.57 \\
\hline 32.1 & 399.9 & 125035 & 0.51 & 17.08 \\
\hline 32.2 & 400.9 & 126184 & 0.55 & 17.89 \\
\hline 32.2 & 398.8 & 124699 & 0.59 & 18.11 \\
\hline 32.2 & 398.8 & 125344 & 0.65 & 19.37 \\
\hline 32.2 & 404.1 & 127118 & 0.69 & 20.19 \\
\hline 32.1 & 399.9 & 126160 & 0.75 & 21.39 \\
\hline
\end{tabular}




\begin{tabular}{|c|c|c|c|c|}
\hline $\boldsymbol{T}$ sat & $\boldsymbol{G}$ & $\boldsymbol{\phi}$ & $\boldsymbol{x}$ & $\boldsymbol{h}$ \\
\hline 31.9 & 399.9 & 125457 & 0.80 & 22.35 \\
\hline 31.5 & 404.1 & 125152 & 0.87 & 23.35 \\
\hline 32.1 & 400.9 & 136224 & 0.16 & 14.58 \\
\hline 32.2 & 403.0 & 135379 & 0.21 & 14.45 \\
\hline 33.0 & 399.9 & 135187 & 0.26 & 15.40 \\
\hline 32.9 & 397.8 & 136814 & 0.31 & 15.54 \\
\hline 33.0 & 397.8 & 137746 & 0.35 & 15.48 \\
\hline 33.0 & 405.1 & 136905 & 0.40 & 15.42 \\
\hline 33.1 & 396.7 & 136099 & 0.46 & 15.55 \\
\hline 33.6 & 399.9 & 138098 & 0.50 & 16.21 \\
\hline 33.5 & 399.9 & 136542 & 0.55 & 16.50 \\
\hline 33.3 & 399.9 & 135568 & 0.58 & 16.84 \\
\hline 32.6 & 396.7 & 136099 & 0.61 & 16.91 \\
\hline 33.0 & 399.9 & 138098 & 0.65 & 18.32 \\
\hline 32.9 & 399.9 & 136542 & 0.70 & 19.35 \\
\hline 32.6 & 399.9 & 135568 & 0.73 & 20.08 \\
\hline 31.6 & 503.0 & 35701 & 0.08 & 4.31 \\
\hline 31.4 & 498.8 & 35735 & 0.12 & 6.25 \\
\hline 32.0 & 505.1 & 36180 & 0.15 & 8.14 \\
\hline 32.6 & 497.7 & 36859 & 0.20 & 10.00 \\
\hline 31.8 & 501.9 & 36918 & 0.26 & 13.08 \\
\hline 32.4 & 500.9 & 36629 & 0.30 & 14.71 \\
\hline 32.3 & 500.9 & 36416 & 0.35 & 16.88 \\
\hline 32.3 & 499.8 & 35368 & 0.40 & 18.10 \\
\hline 32.5 & 495.6 & 35351 & 0.46 & 20.47 \\
\hline 32.6 & 498.8 & 35983 & 0.50 & 22.01 \\
\hline 32.4 & 504.0 & 35922 & 0.55 & 24.86 \\
\hline 32.4 & 501.9 & 36470 & 0.61 & 25.80 \\
\hline 32.4 & 498.8 & 36556 & 0.66 & 27.11 \\
\hline 30.9 & 497.7 & 45158 & 0.06 & 5.24 \\
\hline 32.3 & 503.0 & 45276 & 0.09 & 5.86 \\
\hline 32.4 & 498.8 & 45398 & 0.16 & 8.36 \\
\hline 32.6 & 499.8 & 44826 & 0.20 & 9.92 \\
\hline 32.5 & 495.6 & 45254 & 0.26 & 12.52 \\
\hline 32.7 & 495.6 & 45301 & 0.31 & 14.49 \\
\hline 32.9 & 496.7 & 45558 & 0.36 & 16.46 \\
\hline 32.8 & 498.8 & 45448 & 0.41 & 18.21 \\
\hline 33.2 & 503.0 & 45543 & 0.45 & 20.03 \\
\hline 33.2 & 500.9 & 45430 & 0.50 & 21.55 \\
\hline 33.3 & 495.6 & 45627 & 0.56 & 23.35 \\
\hline 33.2 & 496.7 & 45767 & 0.62 & 24.78 \\
\hline 33.4 & 497.7 & 45884 & 0.66 & 26.60 \\
\hline 33.4 & 492.5 & 45729 & 0.71 & 26.98 \\
\hline 31.9 & 500.9 & 55339 & 0.09 & 8.73 \\
\hline 32.3 & 498.8 & 55308 & 0.14 & 9.36 \\
\hline 32.7 & 504.0 & 54878 & 0.18 & 10.29 \\
\hline 32.7 & 496.7 & 55845 & 0.24 & 12.15 \\
\hline 32.8 & 500.9 & 55444 & 0.28 & 13.56 \\
\hline 32.7 & 496.7 & 55282 & 0.33 & 15.15 \\
\hline 32.9 & 501.9 & 55567 & 0.38 & 17.05 \\
\hline 33.2 & 501.9 & 54899 & 0.44 & 18.81 \\
\hline 33.3 & 500.9 & 55161 & 0.48 & 20.35 \\
\hline 33.3 & 499.8 & 54430 & 0.54 & 21.36 \\
\hline 33.3 & 499.8 & 55017 & 0.58 & 22.89 \\
\hline 33.3 & 493.5 & 54848 & 0.64 & 24.65 \\
\hline 33.3 & 486.1 & 54374 & 0.68 & 25.09 \\
\hline 32.3 & 500.9 & 65148 & 0.13 & 8.53 \\
\hline & & & & \\
\hline
\end{tabular}

\begin{tabular}{|c|c|c|c|c|}
\hline$T_{\text {sat }}$ & $G$ & $\phi$ & $x$ & $h$ \\
\hline 32.7 & 498.8 & 65628 & 0.16 & 8.94 \\
\hline 32.5 & 499.8 & 65468 & 0.21 & 10.85 \\
\hline 33.0 & 498.8 & 65781 & 0.25 & 12.28 \\
\hline 33.2 & 500.9 & 66151 & 0.31 & 14.39 \\
\hline 33.2 & 497.7 & 66279 & 0.36 & 16.25 \\
\hline 33.4 & 496.7 & 65568 & 0.42 & 17.95 \\
\hline 33.4 & 501.9 & 65788 & 0.46 & 19.26 \\
\hline 33.5 & 501.9 & 65863 & 0.51 & 20.84 \\
\hline 33.6 & 500.9 & 66607 & 0.55 & 22.60 \\
\hline 33.6 & 494.6 & 65895 & 0.61 & 23.85 \\
\hline 33.3 & 487.2 & 65927 & 0.66 & 24.86 \\
\hline 32.6 & 499.8 & 76062 & 0.16 & 9.97 \\
\hline 32.6 & 498.8 & 75914 & 0.18 & 10.17 \\
\hline 32.3 & 499.8 & 76062 & 0.23 & 10.85 \\
\hline 32.3 & 498.8 & 75914 & 0.25 & 11.57 \\
\hline 32.6 & 500.9 & 76055 & 0.30 & 13.36 \\
\hline 32.6 & 499.8 & 75888 & 0.35 & 15.46 \\
\hline 32.8 & 498.8 & 75949 & 0.41 & 17.39 \\
\hline 32.9 & 500.9 & 76320 & 0.46 & 19.32 \\
\hline 32.9 & 496.7 & 76376 & 0.51 & 20.86 \\
\hline 33.1 & 500.9 & 76354 & 0.55 & 22.58 \\
\hline 32.9 & 503.0 & 76569 & 0.60 & 24.27 \\
\hline 32.8 & 498.8 & 76239 & 0.66 & 26.14 \\
\hline 32.5 & 492.5 & 76119 & 0.72 & 27.89 \\
\hline 32.6 & 501.9 & 85316 & 0.17 & 11.44 \\
\hline 32.4 & 497.7 & 84999 & 0.21 & 11.73 \\
\hline 32.3 & 501.9 & 85316 & 0.24 & 11.75 \\
\hline 32.1 & 497.7 & 84999 & 0.29 & 13.07 \\
\hline 32.6 & 499.8 & 85421 & 0.34 & 15.08 \\
\hline 32.6 & 498.8 & 85546 & 0.39 & 17.13 \\
\hline 32.8 & 499.8 & 85609 & 0.44 & 18.97 \\
\hline 32.9 & 499.8 & 85866 & 0.49 & 21.08 \\
\hline 33.0 & 500.9 & 86315 & 0.53 & 23.06 \\
\hline 32.9 & 499.8 & 85935 & 0.59 & 24.73 \\
\hline 33.0 & 497.7 & 85771 & 0.64 & 26.54 \\
\hline 33.1 & 500.9 & 85858 & 0.68 & 28.54 \\
\hline 32.9 & 487.2 & 85754 & 0.76 & 30.06 \\
\hline 32.6 & 500.9 & 94752 & 0.16 & 11.68 \\
\hline 32.4 & 499.8 & 95348 & 0.20 & 12.25 \\
\hline 32.2 & 500.9 & 94752 & 0.24 & 11.72 \\
\hline 32.6 & 499.8 & 95348 & 0.29 & 13.04 \\
\hline 32.5 & 497.7 & 95682 & 0.33 & 14.26 \\
\hline 32.2 & 500.9 & 95528 & 0.38 & 16.14 \\
\hline 32.7 & 501.9 & 95502 & 0.43 & 18.05 \\
\hline 32.7 & 496.7 & 95397 & 0.49 & 20.43 \\
\hline 32.8 & 499.8 & 95286 & 0.53 & 21.93 \\
\hline 32.7 & 500.9 & 95059 & 0.57 & 23.48 \\
\hline 32.6 & 499.8 & 95245 & 0.63 & 25.99 \\
\hline 32.6 & 499.8 & 95220 & 0.68 & 27.82 \\
\hline 32.4 & 486.1 & 94758 & 0.74 & 29.09 \\
\hline 32.7 & 501.9 & 105519 & 0.19 & 13.10 \\
\hline 33.1 & 497.7 & 106113 & 0.22 & 13.55 \\
\hline 32.4 & 501.9 & 105519 & 0.28 & 13.30 \\
\hline 32.7 & 497.7 & 106113 & 0.32 & 14.10 \\
\hline 32.8 & 501.9 & 107242 & 0.36 & 15.55 \\
\hline 33.0 & 497.7 & 106536 & 0.42 & 17.23 \\
\hline 32.9 & 501.9 & 105335 & 0.46 & 18.85 \\
\hline
\end{tabular}




\begin{tabular}{|c|c|c|c|c|}
\hline $\boldsymbol{T}_{\text {sat }}$ & $\boldsymbol{G}$ & $\boldsymbol{\phi}$ & $\boldsymbol{x}$ & $\boldsymbol{h}$ \\
\hline 33.0 & 503.0 & 105313 & 0.51 & 20.48 \\
\hline 33.0 & 497.7 & 104981 & 0.57 & 22.46 \\
\hline 32.9 & 495.6 & 105053 & 0.63 & 24.77 \\
\hline 33.0 & 499.8 & 105214 & 0.67 & 26.44 \\
\hline 32.8 & 499.8 & 105565 & 0.71 & 28.64 \\
\hline 32.7 & 495.6 & 105386 & 0.77 & 30.42 \\
\hline 31.8 & 490.4 & 104851 & 0.84 & 32.41 \\
\hline 31.6 & 498.8 & 114992 & 0.16 & 13.97 \\
\hline 33.0 & 499.8 & 114579 & 0.20 & 14.32 \\
\hline 31.3 & 498.8 & 114992 & 0.27 & 13.48 \\
\hline 32.6 & 499.8 & 114579 & 0.31 & 14.18 \\
\hline 32.8 & 498.8 & 115107 & 0.35 & 15.17 \\
\hline 32.9 & 503.0 & 115081 & 0.40 & 16.47 \\
\hline 33.1 & 498.8 & 115547 & 0.45 & 18.13 \\
\hline 33.2 & 500.9 & 115587 & 0.50 & 19.80 \\
\hline 33.3 & 500.9 & 115038 & 0.55 & 21.22 \\
\hline 33.3 & 499.8 & 115572 & 0.61 & 23.41 \\
\hline 33.4 & 498.8 & 115683 & 0.66 & 25.03 \\
\hline 33.5 & 496.7 & 115034 & 0.71 & 26.60 \\
\hline 33.4 & 498.8 & 114739 & 0.75 & 28.31 \\
\hline 33.2 & 496.7 & 115404 & 0.82 & 30.73 \\
\hline 33.0 & 500.9 & 124865 & 0.19 & 14.83 \\
\hline 33.2 & 499.8 & 125627 & 0.22 & 15.38 \\
\hline 33.4 & 497.7 & 124776 & 0.28 & 15.29 \\
\hline 33.3 & 495.6 & 125135 & 0.34 & 15.45 \\
\hline 32.5 & 500.9 & 124865 & 0.36 & 15.39 \\
\hline 32.6 & 499.8 & 125627 & 0.39 & 16.53 \\
\hline 32.7 & 497.7 & 124776 & 0.45 & 17.80 \\
\hline 32.5 & 495.6 & 125135 & 0.51 & 19.59 \\
\hline 32.5 & 493.5 & 124970 & 0.56 & 21.15 \\
\hline 32.7 & 501.9 & 124488 & 0.59 & 22.56 \\
\hline 32.5 & 500.9 & 124883 & 0.65 & 24.35 \\
\hline 32.3 & 493.5 & 125553 & 0.70 & 26.26 \\
\hline 30.7 & 497.7 & 135000 & 0.18 & 12.43 \\
\hline 33.0 & 497.7 & 135081 & 0.21 & 16.41 \\
\hline 32.9 & 499.8 & 135051 & 0.26 & 16.55 \\
\hline 33.1 & 499.8 & 135342 & 0.30 & 16.83 \\
\hline 33.5 & 499.8 & 135411 & 0.36 & 17.09 \\
\hline 33.7 & 498.8 & 135706 & 0.42 & 17.65 \\
\hline 33.7 & 499.8 & 135602 & 0.46 & 18.02 \\
\hline 33.7 & 495.6 & 135645 & 0.51 & 18.47 \\
\hline 33.7 & 500.9 & 135401 & 0.56 & 19.52 \\
\hline 33.4 & 488.3 & 135162 & 0.62 & 20.74 \\
\hline 32.9 & 500.9 & 135401 & 0.68 & 22.84 \\
\hline 32.5 & 488.3 & 135162 & 0.75 & 24.44 \\
\hline 31.8 & 503.0 & 145546 & 0.21 & 17.89 \\
\hline 33.6 & 497.7 & 145583 & 0.23 & 17.63 \\
\hline 33.3 & 498.8 & 145662 & 0.28 & 17.60 \\
\hline 31.4 & 503.0 & 145546 & 0.34 & 15.98 \\
\hline 33.3 & 497.7 & 145583 & 0.36 & 19.18 \\
\hline 32.8 & 498.8 & 145662 & 0.42 & 19.30 \\
\hline 33.3 & 499.8 & 145767 & 0.46 & 19.55 \\
\hline 33.2 & 498.8 & 145125 & 0.52 & 19.85 \\
\hline 32.9 & 503.0 & 145324 & 0.56 & 20.09 \\
\hline 32.9 & 497.7 & 145519 & 0.62 & 20.88 \\
\hline 32.8 & 501.9 & 144389 & 0.67 & 22.05 \\
\hline 32.5 & 489.3 & 144821 & 0.74 & 23.29 \\
\hline & & & & \\
\hline
\end{tabular}

\begin{tabular}{|c|c|c|c|c|}
\hline$T_{\text {sat }}$ & $G$ & $\phi$ & $x$ & $h$ \\
\hline 42.1 & 201.0 & 26452 & 0.05 & 5.86 \\
\hline 42.1 & 199.9 & 26468 & 0.09 & 5.29 \\
\hline 42.1 & 198.9 & 25890 & 0.15 & 5.33 \\
\hline 41.9 & 198.9 & 26584 & 0.20 & 5.38 \\
\hline 41.9 & 201.0 & 27039 & 0.26 & 6.13 \\
\hline 42.0 & 202.0 & 25837 & 0.28 & 6.53 \\
\hline 41.8 & 195.7 & 24394 & 0.36 & 7.21 \\
\hline 41.8 & 201.0 & 24614 & 0.39 & 8.27 \\
\hline 41.7 & 202.0 & 24462 & 0.43 & 8.69 \\
\hline 41.7 & 199.9 & 26392 & 0.50 & 10.79 \\
\hline 41.6 & 202.0 & 25612 & 0.54 & 11.29 \\
\hline 41.6 & 199.9 & 27020 & 0.60 & 12.82 \\
\hline 41.6 & 201.0 & 26313 & 0.66 & 13.40 \\
\hline 41.5 & 199.9 & 25918 & 0.70 & 13.93 \\
\hline 41.5 & 202.0 & 25835 & 0.76 & 14.43 \\
\hline 41.4 & 199.9 & 27266 & 0.80 & 15.59 \\
\hline 41.3 & 199.9 & 26439 & 0.83 & 16.09 \\
\hline 41.2 & 202.0 & 37368 & 0.04 & 7.32 \\
\hline 41.2 & 202.0 & 37392 & 0.08 & 7.05 \\
\hline 41.2 & 202.0 & 36785 & 0.14 & 6.97 \\
\hline 41.1 & 201.0 & 37409 & 0.20 & 7.21 \\
\hline 40.9 & 198.9 & 37178 & 0.25 & 6.83 \\
\hline 41.2 & 202.0 & 36040 & 0.30 & 7.40 \\
\hline 41.2 & 199.9 & 35905 & 0.35 & 8.16 \\
\hline 41.1 & 201.0 & 34037 & 0.39 & 8.77 \\
\hline 41.0 & 199.9 & 36608 & 0.45 & 10.42 \\
\hline 41.0 & 202.0 & 36526 & 0.48 & 11.26 \\
\hline 40.9 & 199.9 & 37437 & 0.55 & 11.99 \\
\hline 40.9 & 197.8 & 37308 & 0.60 & 12.83 \\
\hline 40.9 & 202.0 & 37178 & 0.63 & 13.55 \\
\hline 41.0 & 201.0 & 37636 & 0.69 & 14.52 \\
\hline 41.0 & 201.0 & 37532 & 0.73 & 15.11 \\
\hline 41.1 & 199.9 & 37051 & 0.78 & 15.40 \\
\hline 41.5 & 201.0 & 36715 & 0.82 & 16.22 \\
\hline 41.1 & 201.0 & 45248 & 0.04 & 8.66 \\
\hline 41.2 & 201.0 & 46861 & 0.09 & 9.05 \\
\hline 41.7 & 204.1 & 45621 & 0.16 & 8.55 \\
\hline 41.9 & 201.0 & 44510 & 0.21 & 8.28 \\
\hline 42.2 & 202.0 & 44593 & 0.27 & 8.21 \\
\hline 42.1 & 201.0 & 41501 & 0.31 & 7.90 \\
\hline 42.1 & 204.1 & 44478 & 0.34 & 8.90 \\
\hline 42.1 & 202.0 & 46013 & 0.39 & 9.65 \\
\hline 41.7 & 196.8 & 46243 & 0.48 & 11.12 \\
\hline 41.5 & 199.9 & 46574 & 0.52 & 11.93 \\
\hline 41.5 & 201.0 & 46443 & 0.57 & 12.82 \\
\hline 41.4 & 199.9 & 44191 & 0.61 & 13.06 \\
\hline 41.3 & 201.0 & 44797 & 0.65 & 13.88 \\
\hline 41.1 & 199.9 & 47128 & 0.72 & 15.60 \\
\hline 41.0 & 202.0 & 46471 & 0.74 & 15.95 \\
\hline 40.9 & 195.7 & 56743 & 0.03 & 10.13 \\
\hline 40.8 & 202.0 & 56395 & 0.10 & 9.87 \\
\hline 40.7 & 199.9 & 56373 & 0.15 & 9.60 \\
\hline 40.5 & 198.9 & 56088 & 0.22 & 9.36 \\
\hline 40.9 & 202.0 & 56270 & 0.25 & 9.74 \\
\hline 41.0 & 202.0 & 56290 & 0.28 & 9.72 \\
\hline 41.2 & 199.9 & 55367 & 0.35 & 9.78 \\
\hline 41.6 & 201.0 & 54891 & 0.38 & 9.86 \\
\hline
\end{tabular}




\begin{tabular}{|c|c|c|c|c|}
\hline $\boldsymbol{T}$ sat & $\boldsymbol{G}$ & $\boldsymbol{\phi}$ & $\boldsymbol{x}$ & $\boldsymbol{h}$ \\
\hline 42.1 & 199.9 & 56177 & 0.45 & 9.99 \\
\hline 42.0 & 202.0 & 56635 & 0.50 & 10.59 \\
\hline 42.0 & 202.0 & 56539 & 0.53 & 11.02 \\
\hline 41.8 & 197.8 & 57225 & 0.61 & 12.07 \\
\hline 41.7 & 199.9 & 57560 & 0.64 & 12.75 \\
\hline 41.8 & 202.0 & 56635 & 0.70 & 13.57 \\
\hline 41.8 & 202.0 & 56539 & 0.73 & 14.25 \\
\hline 41.6 & 197.8 & 57225 & 0.81 & 15.91 \\
\hline 41.5 & 199.9 & 57560 & 0.84 & 16.92 \\
\hline 40.9 & 202.0 & 64196 & 0.05 & 10.79 \\
\hline 40.9 & 203.1 & 64493 & 0.10 & 10.77 \\
\hline 40.9 & 201.0 & 65726 & 0.15 & 10.78 \\
\hline 40.9 & 202.0 & 65066 & 0.21 & 10.69 \\
\hline 41.0 & 204.1 & 65044 & 0.27 & 11.15 \\
\hline 41.0 & 203.1 & 64484 & 0.33 & 11.27 \\
\hline 41.0 & 199.9 & 64392 & 0.38 & 11.37 \\
\hline 41.0 & 199.9 & 63672 & 0.43 & 11.87 \\
\hline 40.9 & 199.9 & 66356 & 0.48 & 11.74 \\
\hline 41.0 & 198.9 & 65806 & 0.53 & 12.23 \\
\hline 41.2 & 199.9 & 65208 & 0.59 & 12.60 \\
\hline 41.3 & 197.8 & 64873 & 0.63 & 13.00 \\
\hline 41.1 & 199.9 & 66356 & 0.68 & 13.45 \\
\hline 41.2 & 198.9 & 65806 & 0.75 & 13.85 \\
\hline 41.0 & 199.9 & 65208 & 0.79 & 14.15 \\
\hline 41.1 & 197.8 & 64873 & 0.83 & 14.42 \\
\hline 41.9 & 202.0 & 76634 & 0.12 & 12.59 \\
\hline 41.8 & 197.8 & 76167 & 0.20 & 12.06 \\
\hline 41.8 & 199.9 & 75909 & 0.24 & 12.24 \\
\hline 42.1 & 199.9 & 76894 & 0.30 & 13.50 \\
\hline 42.1 & 202.0 & 76820 & 0.33 & 13.33 \\
\hline 41.8 & 202.0 & 78425 & 0.39 & 13.52 \\
\hline 41.7 & 201.0 & 76107 & 0.45 & 13.04 \\
\hline 41.6 & 202.0 & 75694 & 0.47 & 13.08 \\
\hline 41.4 & 198.9 & 75647 & 0.55 & 12.78 \\
\hline 41.6 & 201.0 & 76107 & 0.62 & 13.92 \\
\hline 41.5 & 202.0 & 75694 & 0.64 & 13.99 \\
\hline 41.2 & 198.9 & 75647 & 0.73 & 13.92 \\
\hline 41.3 & 302.0 & 14651 & 0.06 & 4.27 \\
\hline 41.2 & 303.1 & 14645 & 0.10 & 4.25 \\
\hline 41.3 & 299.9 & 14651 & 0.17 & 5.35 \\
\hline 41.4 & 303.1 & 14663 & 0.22 & 6.79 \\
\hline 41.5 & 298.8 & 14685 & 0.26 & 7.53 \\
\hline 41.6 & 297.8 & 14699 & 0.33 & 8.79 \\
\hline 41.7 & 302.0 & 14668 & 0.35 & 9.89 \\
\hline 41.8 & 304.1 & 14716 & 0.41 & 11.08 \\
\hline 41.9 & 302.0 & 14782 & 0.46 & 12.03 \\
\hline 42.0 & 303.1 & 14707 & 0.50 & 13.00 \\
\hline 42.0 & 302.0 & 14727 & 0.56 & 14.16 \\
\hline 42.1 & 304.1 & 14706 & 0.60 & 15.32 \\
\hline 42.1 & 297.8 & 14753 & 0.67 & 16.35 \\
\hline 42.1 & 299.9 & 14697 & 0.72 & 17.28 \\
\hline 42.0 & 300.9 & 14710 & 0.76 & 17.90 \\
\hline 42.0 & 300.9 & 14734 & 0.81 & 18.91 \\
\hline 41.9 & 296.7 & 14717 & 0.86 & 19.63 \\
\hline 41.7 & 297.8 & 14731 & 0.90 & 20.03 \\
\hline 40.6 & 299.9 & 24534 & 0.02 & 4.40 \\
\hline 40.6 & 299.9 & 26740 & 0.07 & 5.16 \\
\hline & & & & \\
\hline
\end{tabular}

\begin{tabular}{|c|c|c|c|c|}
\hline$T_{\text {sat }}$ & $G$ & $\phi$ & $x$ & $h$ \\
\hline 40.5 & 297.8 & 27573 & 0.11 & 5.15 \\
\hline 40.6 & 303.1 & 26986 & 0.16 & 5.99 \\
\hline 40.6 & 298.8 & 26229 & 0.22 & 7.38 \\
\hline 40.7 & 300.9 & 27572 & 0.26 & 8.72 \\
\hline 40.9 & 303.1 & 27348 & 0.32 & 10.14 \\
\hline 41.0 & 303.1 & 27185 & 0.36 & 10.95 \\
\hline 41.1 & 298.8 & 27678 & 0.42 & 11.79 \\
\hline 41.2 & 302.0 & 26995 & 0.47 & 12.57 \\
\hline 41.3 & 303.1 & 26736 & 0.51 & 13.09 \\
\hline 41.4 & 299.9 & 26648 & 0.58 & 14.25 \\
\hline 41.5 & 300.9 & 26506 & 0.62 & 14.71 \\
\hline 41.5 & 300.9 & 26446 & 0.66 & 15.24 \\
\hline 41.5 & 296.7 & 27028 & 0.72 & 16.10 \\
\hline 41.6 & 299.9 & 27055 & 0.77 & 16.50 \\
\hline 41.6 & 297.8 & 26519 & 0.82 & 16.70 \\
\hline 41.5 & 303.1 & 26030 & 0.85 & 17.02 \\
\hline 40.0 & 299.9 & 34617 & 0.03 & 5.91 \\
\hline 40.2 & 303.1 & 35324 & 0.08 & 6.14 \\
\hline 40.3 & 304.1 & 34834 & 0.13 & 6.03 \\
\hline 40.5 & 298.8 & 34468 & 0.20 & 6.07 \\
\hline 40.6 & 302.0 & 34784 & 0.24 & 6.34 \\
\hline 40.6 & 302.0 & 34866 & 0.29 & 7.40 \\
\hline 40.7 & 299.9 & 34910 & 0.34 & 8.30 \\
\hline 40.8 & 297.8 & 35006 & 0.39 & 9.44 \\
\hline 40.9 & 300.9 & 35135 & 0.45 & 10.69 \\
\hline 40.9 & 302.0 & 34810 & 0.50 & 11.68 \\
\hline 41.0 & 298.8 & 34743 & 0.55 & 12.57 \\
\hline 41.1 & 299.9 & 34937 & 0.59 & 13.53 \\
\hline 41.1 & 299.9 & 34871 & 0.64 & 14.75 \\
\hline 41.2 & 299.9 & 34734 & 0.69 & 15.47 \\
\hline 41.2 & 302.0 & 34945 & 0.72 & 16.69 \\
\hline 41.2 & 298.8 & 34947 & 0.79 & 18.01 \\
\hline 41.3 & 299.9 & 34914 & 0.84 & 18.71 \\
\hline 41.3 & 298.8 & 34897 & 0.88 & 19.61 \\
\hline 41.5 & 297.8 & 47909 & 0.02 & 8.65 \\
\hline 41.4 & 302.0 & 46682 & 0.06 & 8.06 \\
\hline 41.5 & 299.9 & 46660 & 0.11 & 8.04 \\
\hline 41.5 & 300.9 & 46582 & 0.16 & 8.12 \\
\hline 41.5 & 298.8 & 45979 & 0.22 & 7.85 \\
\hline 41.5 & 300.9 & 47316 & 0.27 & 7.95 \\
\hline 41.6 & 297.8 & 47282 & 0.32 & 8.37 \\
\hline 41.5 & 300.9 & 46673 & 0.36 & 9.12 \\
\hline 41.5 & 299.9 & 46699 & 0.42 & 10.14 \\
\hline 41.5 & 303.1 & 46955 & 0.45 & 10.58 \\
\hline 41.6 & 303.1 & 46446 & 0.52 & 11.78 \\
\hline 41.6 & 300.9 & 46352 & 0.57 & 12.56 \\
\hline 41.7 & 299.9 & 46139 & 0.63 & 13.62 \\
\hline 41.7 & 300.9 & 45845 & 0.66 & 14.41 \\
\hline 41.6 & 298.8 & 46312 & 0.71 & 15.43 \\
\hline 41.5 & 302.0 & 45778 & 0.76 & 16.48 \\
\hline 41.4 & 303.1 & 45494 & 0.80 & 17.29 \\
\hline 41.3 & 299.9 & 45638 & 0.86 & 18.40 \\
\hline 41.1 & 304.1 & 56410 & 0.08 & 9.83 \\
\hline 41.2 & 299.9 & 56932 & 0.13 & 10.22 \\
\hline 41.2 & 300.9 & 55992 & 0.18 & 9.88 \\
\hline 41.3 & 297.8 & 56100 & 0.24 & 9.85 \\
\hline 40.9 & 299.9 & 55050 & 0.28 & 9.07 \\
\hline
\end{tabular}




\begin{tabular}{|c|c|c|c|c|}
\hline$T_{\text {sat }}$ & $G$ & $\phi$ & $x$ & $h$ \\
\hline 41.3 & 297.8 & 55930 & 0.34 & 10.21 \\
\hline 41.3 & 304.1 & 55696 & 0.40 & 11.05 \\
\hline 41.4 & 300.9 & 55613 & 0.44 & 11.55 \\
\hline 41.4 & 299.9 & 55511 & 0.49 & 12.48 \\
\hline 41.5 & 300.9 & 55495 & 0.55 & 13.65 \\
\hline 41.5 & 299.9 & 55586 & 0.59 & 14.21 \\
\hline 41.5 & 299.9 & 55569 & 0.63 & 15.13 \\
\hline 41.5 & 299.9 & 55425 & 0.70 & 16.36 \\
\hline 41.5 & 297.8 & 55237 & 0.76 & 17.81 \\
\hline 41.4 & 304.1 & 55178 & 0.78 & 18.77 \\
\hline 41.3 & 296.7 & 54837 & 0.85 & 19.91 \\
\hline 41.2 & 302.0 & 54822 & 0.87 & 21.48 \\
\hline 40.9 & 300.9 & 66519 & 0.03 & 11.23 \\
\hline 40.6 & 303.1 & 66314 & 0.05 & 11.09 \\
\hline 40.7 & 300.9 & 66359 & 0.12 & 11.42 \\
\hline 40.8 & 300.9 & 66519 & 0.14 & 11.48 \\
\hline 40.6 & 303.1 & 66314 & 0.15 & 11.27 \\
\hline 40.7 & 300.9 & 66359 & 0.23 & 11.18 \\
\hline 40.7 & 299.9 & 67542 & 0.28 & 11.13 \\
\hline 41.0 & 298.8 & 66766 & 0.34 & 11.15 \\
\hline 41.4 & 297.8 & 67461 & 0.39 & 11.77 \\
\hline 41.7 & 297.8 & 66640 & 0.44 & 12.23 \\
\hline 41.8 & 292.5 & 67811 & 0.50 & 13.23 \\
\hline 41.7 & 298.8 & 67218 & 0.54 & 13.25 \\
\hline 41.6 & 299.9 & 66665 & 0.59 & 14.32 \\
\hline 41.6 & 303.1 & 66180 & 0.63 & 15.25 \\
\hline 41.6 & 299.9 & 64896 & 0.67 & 15.65 \\
\hline 41.5 & 299.9 & 66898 & 0.73 & 17.65 \\
\hline 41.4 & 296.7 & 66976 & 0.79 & 19.14 \\
\hline 41.3 & 299.9 & 66705 & 0.84 & 20.92 \\
\hline 41.2 & 302.0 & 66569 & 0.86 & 21.98 \\
\hline 41.8 & 299.9 & 73911 & 0.03 & 12.57 \\
\hline 41.8 & 298.8 & 73736 & 0.08 & 12.74 \\
\hline 41.9 & 300.9 & 73784 & 0.13 & 12.71 \\
\hline 41.8 & 299.9 & 74916 & 0.17 & 12.60 \\
\hline 41.7 & 299.9 & 73911 & 0.21 & 12.21 \\
\hline 41.7 & 298.8 & 73736 & 0.26 & 11.99 \\
\hline 41.8 & 300.9 & 73784 & 0.30 & 12.01 \\
\hline 41.4 & 302.0 & 74823 & 0.36 & 12.39 \\
\hline 41.7 & 300.9 & 75021 & 0.41 & 12.35 \\
\hline 41.6 & 297.8 & 74406 & 0.47 & 12.62 \\
\hline 41.6 & 300.9 & 77357 & 0.52 & 13.52 \\
\hline 41.5 & 302.0 & 77184 & 0.55 & 13.99 \\
\hline 41.4 & 296.7 & 76617 & 0.63 & 15.29 \\
\hline 41.4 & 298.8 & 76069 & 0.67 & 16.10 \\
\hline 41.3 & 300.9 & 75825 & 0.71 & 16.89 \\
\hline 41.2 & 300.9 & 75831 & 0.76 & 18.00 \\
\hline 41.2 & 303.1 & 76918 & 0.80 & 19.80 \\
\hline 41.2 & 296.7 & 76043 & 0.87 & 20.57 \\
\hline 41.5 & 300.9 & 86574 & 0.09 & 12.97 \\
\hline 41.5 & 300.9 & 86942 & 0.14 & 13.85 \\
\hline 41.4 & 303.1 & 83086 & 0.17 & 13.74 \\
\hline 41.4 & 300.9 & 86574 & 0.22 & 14.41 \\
\hline 41.5 & 300.9 & 86942 & 0.28 & 14.56 \\
\hline 41.6 & 299.9 & 86733 & 0.33 & 14.68 \\
\hline 41.8 & 298.8 & 85709 & 0.39 & 15.27 \\
\hline 41.7 & 298.8 & 85709 & 0.46 & 15.55 \\
\hline
\end{tabular}

\begin{tabular}{|c|c|c|c|c|}
\hline$T_{\text {sat }}$ & $G$ & $\phi$ & $x$ & $h$ \\
\hline 41.6 & 299.9 & 86040 & 0.51 & 15.90 \\
\hline 41.6 & 300.9 & 86014 & 0.55 & 16.26 \\
\hline 41.6 & 304.1 & 85607 & 0.58 & 16.47 \\
\hline 41.5 & 300.9 & 83899 & 0.64 & 16.53 \\
\hline 41.5 & 298.8 & 85377 & 0.71 & 17.63 \\
\hline 41.4 & 299.9 & 85328 & 0.76 & 18.19 \\
\hline 41.3 & 299.9 & 85541 & 0.80 & 18.79 \\
\hline 41.2 & 299.9 & 84722 & 0.83 & 19.29 \\
\hline 41.3 & 297.8 & 94633 & 0.09 & 13.60 \\
\hline 41.7 & 299.9 & 95239 & 0.15 & 13.85 \\
\hline 41.3 & 302.0 & 95385 & 0.20 & 13.95 \\
\hline 41.5 & 303.1 & 95418 & 0.26 & 14.10 \\
\hline 41.4 & 299.9 & 95239 & 0.31 & 14.35 \\
\hline 41.2 & 299.9 & 95385 & 0.36 & 14.65 \\
\hline 41.2 & 299.9 & 95418 & 0.41 & 14.45 \\
\hline 41.9 & 297.8 & 94633 & 0.46 & 14.86 \\
\hline 41.8 & 299.9 & 95239 & 0.51 & 14.98 \\
\hline 41.8 & 302.0 & 95385 & 0.54 & 15.21 \\
\hline 41.8 & 303.1 & 95418 & 0.59 & 15.40 \\
\hline 41.7 & 297.8 & 94633 & 0.61 & 16.37 \\
\hline 41.6 & 299.9 & 95239 & 0.66 & 16.58 \\
\hline 41.6 & 302.0 & 95385 & 0.69 & 16.81 \\
\hline 41.5 & 303.1 & 95418 & 0.73 & 17.06 \\
\hline 41.4 & 302.0 & 106432 & 0.06 & 15.55 \\
\hline 41.3 & 300.9 & 105717 & 0.13 & 15.47 \\
\hline 41.1 & 299.9 & 104973 & 0.18 & 15.37 \\
\hline 41.1 & 299.9 & 103931 & 0.21 & 15.24 \\
\hline 41.4 & 298.8 & 107085 & 0.28 & 16.27 \\
\hline 41.2 & 299.9 & 106355 & 0.33 & 16.16 \\
\hline 41.3 & 297.8 & 105680 & 0.39 & 16.16 \\
\hline 41.4 & 302.0 & 105926 & 0.43 & 16.17 \\
\hline 41.4 & 300.9 & 105988 & 0.48 & 16.32 \\
\hline 41.5 & 300.9 & 105806 & 0.52 & 16.47 \\
\hline 41.5 & 300.9 & 106115 & 0.58 & 16.52 \\
\hline 41.4 & 300.9 & 105806 & 0.60 & 16.24 \\
\hline 41.4 & 300.9 & 106115 & 0.66 & 16.48 \\
\hline 41.0 & 300.9 & 105988 & 0.73 & 16.58 \\
\hline 41.1 & 300.9 & 105806 & 0.77 & 17.09 \\
\hline 41.1 & 300.9 & 106115 & 0.83 & 18.06 \\
\hline 41.1 & 398.8 & 23789 & 0.03 & 3.60 \\
\hline 41.3 & 399.9 & 23880 & 0.08 & 4.39 \\
\hline 41.4 & 405.1 & 23967 & 0.14 & 5.27 \\
\hline 41.6 & 402.0 & 24089 & 0.18 & 6.93 \\
\hline 41.8 & 400.9 & 24181 & 0.22 & 8.34 \\
\hline 41.8 & 403.0 & 24067 & 0.26 & 9.32 \\
\hline 41.8 & 398.8 & 24505 & 0.33 & 11.25 \\
\hline 41.9 & 398.8 & 24442 & 0.39 & 12.42 \\
\hline 41.9 & 399.9 & 24443 & 0.43 & 13.61 \\
\hline 41.9 & 399.9 & 24679 & 0.47 & 14.79 \\
\hline 41.8 & 398.8 & 24684 & 0.52 & 15.85 \\
\hline 41.6 & 395.7 & 23364 & 0.60 & 17.36 \\
\hline 41.6 & 398.8 & 23378 & 0.63 & 17.70 \\
\hline 41.5 & 402.0 & 24221 & 0.66 & 19.04 \\
\hline 41.2 & 398.8 & 25056 & 0.73 & 20.69 \\
\hline 42.1 & 405.1 & 24681 & 0.75 & 20.44 \\
\hline 42.0 & 403.0 & 24697 & 0.81 & 21.34 \\
\hline 41.8 & 399.9 & 24769 & 0.87 & 22.57 \\
\hline
\end{tabular}




\begin{tabular}{|c|c|c|c|c|}
\hline \multicolumn{1}{|c|}{$\boldsymbol{T}$ sat } & $\boldsymbol{G}$ & $\boldsymbol{\phi}$ & $\boldsymbol{x}$ & $\boldsymbol{h}$ \\
\hline 41.6 & 400.9 & 24616 & 0.92 & 22.69 \\
\hline 42.3 & 397.8 & 35453 & 0.05 & 6.32 \\
\hline 42.4 & 399.9 & 35652 & 0.11 & 6.31 \\
\hline 42.2 & 398.8 & 35587 & 0.15 & 6.19 \\
\hline 42.3 & 399.9 & 35753 & 0.20 & 7.28 \\
\hline 42.2 & 398.8 & 35474 & 0.26 & 9.06 \\
\hline 42.1 & 402.0 & 35507 & 0.32 & 10.76 \\
\hline 42.1 & 398.8 & 35276 & 0.36 & 11.76 \\
\hline 41.8 & 399.9 & 35492 & 0.41 & 13.21 \\
\hline 41.8 & 399.9 & 35413 & 0.46 & 14.56 \\
\hline 41.9 & 399.9 & 35344 & 0.51 & 15.73 \\
\hline 41.6 & 402.0 & 35037 & 0.56 & 17.17 \\
\hline 41.7 & 399.9 & 35122 & 0.61 & 17.99 \\
\hline 41.8 & 400.9 & 35072 & 0.66 & 19.31 \\
\hline 41.8 & 394.6 & 35174 & 0.72 & 19.76 \\
\hline 41.8 & 402.0 & 35209 & 0.75 & 20.59 \\
\hline 41.8 & 398.8 & 35143 & 0.80 & 22.04 \\
\hline 41.9 & 400.9 & 35143 & 0.85 & 22.18 \\
\hline 41.8 & 399.9 & 35045 & 0.90 & 23.39 \\
\hline 40.6 & 404.1 & 45583 & 0.04 & 7.22 \\
\hline 40.8 & 406.2 & 45538 & 0.09 & 7.37 \\
\hline 41.0 & 399.9 & 45572 & 0.15 & 7.29 \\
\hline 41.0 & 399.9 & 45386 & 0.20 & 7.49 \\
\hline 41.2 & 399.9 & 45339 & 0.25 & 8.69 \\
\hline 41.2 & 399.9 & 45160 & 0.30 & 9.92 \\
\hline 41.3 & 402.0 & 45207 & 0.35 & 11.33 \\
\hline 41.4 & 402.0 & 45097 & 0.40 & 12.44 \\
\hline 41.4 & 400.9 & 44715 & 0.43 & 13.04 \\
\hline 41.4 & 398.8 & 45398 & 0.49 & 14.69 \\
\hline 41.6 & 396.7 & 44725 & 0.54 & 15.56 \\
\hline 41.6 & 405.1 & 44652 & 0.59 & 17.10 \\
\hline 41.6 & 399.9 & 45310 & 0.64 & 18.23 \\
\hline 42.1 & 399.9 & 45109 & 0.69 & 19.26 \\
\hline 42.2 & 404.1 & 45129 & 0.73 & 19.71 \\
\hline 42.1 & 400.9 & 45134 & 0.80 & 21.34 \\
\hline 42.0 & 399.9 & 45214 & 0.84 & 21.80 \\
\hline 41.8 & 402.0 & 45085 & 0.88 & 22.72 \\
\hline 40.1 & 404.1 & 54663 & 0.03 & 8.34 \\
\hline 40.3 & 398.8 & 54635 & 0.07 & 8.33 \\
\hline 40.5 & 405.1 & 54562 & 0.13 & 8.42 \\
\hline 40.6 & 400.9 & 54579 & 0.19 & 7.97 \\
\hline 41.2 & 408.3 & 54536 & 0.24 & 8.96 \\
\hline 41.3 & 399.9 & 54563 & 0.29 & 9.76 \\
\hline 41.4 & 402.0 & 54570 & 0.32 & 10.51 \\
\hline 41.6 & 403.0 & 54577 & 0.38 & 11.74 \\
\hline 41.8 & 402.0 & 54587 & 0.43 & 12.81 \\
\hline 41.9 & 399.9 & 54565 & 0.49 & 14.13 \\
\hline 42.0 & 399.9 & 54569 & 0.54 & 15.25 \\
\hline 42.1 & 399.9 & 54529 & 0.58 & 16.31 \\
\hline 42.1 & 399.9 & 54533 & 0.63 & 17.47 \\
\hline 42.1 & 400.9 & 54580 & 0.67 & 18.39 \\
\hline 42.1 & 397.8 & 55583 & 0.73 & 20.04 \\
\hline 42.0 & 399.9 & 55234 & 0.78 & 21.13 \\
\hline 41.7 & 403.0 & 55221 & 0.82 & 22.54 \\
\hline 41.7 & 398.8 & 55159 & 0.89 & 23.99 \\
\hline 41.5 & 399.9 & 64996 & 0.06 & 10.18 \\
\hline 41.4 & 399.9 & 65167 & 0.11 & 10.44 \\
\hline & & & & \\
\hline
\end{tabular}

\begin{tabular}{|c|c|c|c|c|}
\hline$T_{\text {sat }}$ & $G$ & $\phi$ & $x$ & $h$ \\
\hline 41.4 & 399.9 & 65118 & 0.16 & 10.22 \\
\hline 40.7 & 400.9 & 65242 & 0.21 & 9.38 \\
\hline 41.5 & 402.0 & 65486 & 0.25 & 10.49 \\
\hline 41.6 & 399.9 & 65516 & 0.32 & 11.27 \\
\hline 41.7 & 399.9 & 65520 & 0.36 & 11.79 \\
\hline 41.7 & 399.9 & 65770 & 0.40 & 12.66 \\
\hline 41.7 & 402.0 & 65707 & 0.46 & 14.06 \\
\hline 41.7 & 399.9 & 65859 & 0.50 & 14.79 \\
\hline 41.7 & 399.9 & 66475 & 0.57 & 16.43 \\
\hline 41.6 & 399.9 & 66359 & 0.60 & 17.26 \\
\hline 42.5 & 399.9 & 65567 & 0.66 & 18.20 \\
\hline 42.6 & 397.8 & 65788 & 0.71 & 19.45 \\
\hline 42.5 & 398.8 & 65868 & 0.76 & 20.67 \\
\hline 42.3 & 402.0 & 65731 & 0.81 & 22.02 \\
\hline 42.0 & 400.9 & 65182 & 0.84 & 22.91 \\
\hline 41.4 & 399.9 & 74743 & 0.04 & 11.27 \\
\hline 41.3 & 400.9 & 75007 & 0.10 & 11.68 \\
\hline 41.3 & 402.0 & 75111 & 0.15 & 11.65 \\
\hline 41.4 & 399.9 & 75213 & 0.20 & 11.57 \\
\hline 41.4 & 399.9 & 75084 & 0.25 & 11.57 \\
\hline 41.6 & 397.8 & 75006 & 0.30 & 12.13 \\
\hline 41.9 & 399.9 & 75740 & 0.35 & 12.83 \\
\hline 41.7 & 399.9 & 74385 & 0.40 & 12.99 \\
\hline 41.5 & 399.9 & 74630 & 0.45 & 13.71 \\
\hline 41.9 & 402.0 & 74496 & 0.49 & 14.22 \\
\hline 42.2 & 402.0 & 74182 & 0.55 & 15.28 \\
\hline 42.3 & 399.9 & 74164 & 0.60 & 16.10 \\
\hline 42.4 & 396.7 & 74190 & 0.66 & 17.25 \\
\hline 42.3 & 335.7 & 74222 & 0.71 & 18.17 \\
\hline 42.2 & 397.8 & 74309 & 0.76 & 19.56 \\
\hline 42.2 & 393.5 & 74339 & 0.80 & 20.49 \\
\hline 42.1 & 407.2 & 74371 & 0.80 & 21.14 \\
\hline 41.0 & 399.9 & 85143 & 0.04 & 12.52 \\
\hline 41.3 & 402.0 & 85168 & 0.08 & 12.82 \\
\hline 41.5 & 399.9 & 85192 & 0.14 & 13.02 \\
\hline 41.8 & 402.0 & 85109 & 0.19 & 13.25 \\
\hline 42.0 & 402.0 & 85188 & 0.23 & 13.50 \\
\hline 42.2 & 400.9 & 85188 & 0.27 & 13.69 \\
\hline 42.4 & 397.8 & 85507 & 0.35 & 14.02 \\
\hline 42.5 & 398.8 & 85423 & 0.39 & 14.30 \\
\hline 42.6 & 399.9 & 85540 & 0.43 & 14.65 \\
\hline 42.7 & 402.0 & 85428 & 0.48 & 14.92 \\
\hline 42.7 & 402.0 & 85374 & 0.52 & 15.32 \\
\hline 42.8 & 397.8 & 85291 & 0.57 & 15.79 \\
\hline 42.7 & 405.1 & 85385 & 0.61 & 16.38 \\
\hline 42.7 & 403.0 & 85159 & 0.65 & 16.62 \\
\hline 42.6 & 400.9 & 85281 & 0.71 & 17.97 \\
\hline 42.2 & 397.8 & 85291 & 0.72 & 19.06 \\
\hline 42.0 & 405.1 & 85385 & 0.76 & 20.41 \\
\hline 42.0 & 403.0 & 85159 & 0.80 & 21.23 \\
\hline 41.9 & 400.9 & 85281 & 0.86 & 22.69 \\
\hline 40.4 & 403.0 & 94440 & 0.05 & 13.23 \\
\hline 40.6 & 402.0 & 94466 & 0.11 & 13.36 \\
\hline 40.0 & 403.0 & 94440 & 0.16 & 13.95 \\
\hline 40.2 & 402.0 & 94466 & 0.22 & 14.07 \\
\hline 40.4 & 399.9 & 94493 & 0.28 & 14.16 \\
\hline 40.6 & 397.8 & 94460 & 0.33 & 14.50 \\
\hline
\end{tabular}




\begin{tabular}{|c|c|c|c|c|}
\hline $\boldsymbol{T}_{\text {sat }}$ & $\boldsymbol{G}$ & $\boldsymbol{\phi}$ & $\boldsymbol{x}$ & $\boldsymbol{h}$ \\
\hline 40.9 & 403.0 & 94428 & 0.37 & 15.06 \\
\hline 41.2 & 399.9 & 94516 & 0.42 & 15.59 \\
\hline 41.3 & 399.9 & 94485 & 0.48 & 16.14 \\
\hline 41.4 & 398.8 & 94514 & 0.52 & 16.59 \\
\hline 41.6 & 399.9 & 94545 & 0.58 & 17.15 \\
\hline 41.6 & 403.0 & 94455 & 0.62 & 17.77 \\
\hline 41.7 & 402.0 & 94456 & 0.67 & 18.41 \\
\hline 41.7 & 396.7 & 94459 & 0.72 & 19.33 \\
\hline 41.7 & 402.0 & 94463 & 0.77 & 20.45 \\
\hline 41.7 & 396.7 & 94559 & 0.83 & 21.89 \\
\hline 41.7 & 397.8 & 93749 & 0.86 & 23.07 \\
\hline 41.9 & 399.9 & 106568 & 0.08 & 15.09 \\
\hline 42.0 & 399.9 & 106310 & 0.12 & 15.14 \\
\hline 42.2 & 399.9 & 106469 & 0.18 & 15.39 \\
\hline 41.5 & 400.9 & 106603 & 0.21 & 15.84 \\
\hline 41.7 & 399.9 & 106568 & 0.27 & 15.96 \\
\hline 41.8 & 399.9 & 106310 & 0.30 & 16.10 \\
\hline 42.0 & 399.9 & 106469 & 0.37 & 16.45 \\
\hline 42.0 & 404.1 & 106083 & 0.40 & 16.28 \\
\hline 42.3 & 399.9 & 106147 & 0.46 & 17.39 \\
\hline 42.3 & 399.9 & 106436 & 0.51 & 17.76 \\
\hline 42.3 & 402.0 & 108110 & 0.56 & 18.31 \\
\hline 42.3 & 399.9 & 106726 & 0.61 & 18.41 \\
\hline 42.3 & 399.9 & 106502 & 0.66 & 18.84 \\
\hline 42.3 & 399.9 & 107084 & 0.71 & 19.42 \\
\hline 42.2 & 399.9 & 107120 & 0.77 & 20.69 \\
\hline 42.1 & 402.0 & 106350 & 0.80 & 21.16 \\
\hline 42.1 & 399.9 & 105968 & 0.84 & 22.13 \\
\hline 41.0 & 402.0 & 113712 & 0.05 & 15.53 \\
\hline 41.2 & 399.9 & 114153 & 0.11 & 15.91 \\
\hline 41.4 & 396.7 & 114151 & 0.15 & 16.06 \\
\hline 40.7 & 399.9 & 114945 & 0.22 & 17.13 \\
\hline 40.8 & 402.0 & 113712 & 0.25 & 17.10 \\
\hline 41.0 & 399.9 & 114153 & 0.31 & 17.28 \\
\hline 41.2 & 396.7 & 114151 & 0.36 & 17.59 \\
\hline 40.3 & 396.7 & 112016 & 0.40 & 17.16 \\
\hline 41.7 & 399.9 & 115069 & 0.45 & 18.43 \\
\hline 41.8 & 404.1 & 114720 & 0.50 & 18.78 \\
\hline 41.8 & 402.0 & 114846 & 0.55 & 18.97 \\
\hline 41.8 & 400.9 & 115482 & 0.60 & 19.70 \\
\hline 41.8 & 402.0 & 115326 & 0.65 & 20.01 \\
\hline 41.7 & 399.9 & 115042 & 0.69 & 20.20 \\
\hline 41.7 & 402.0 & 114315 & 0.74 & 21.32 \\
\hline 41.6 & 399.9 & 114352 & 0.80 & 21.75 \\
\hline 41.1 & 391.4 & 114555 & 0.87 & 23.14 \\
\hline 40.8 & 402.0 & 124586 & 0.07 & 16.03 \\
\hline 41.1 & 400.9 & 124300 & 0.13 & 16.39 \\
\hline 41.2 & 399.9 & 125000 & 0.17 & 16.82 \\
\hline 40.7 & 404.1 & 124277 & 0.23 & 17.50 \\
\hline 40.6 & 402.0 & 124586 & 0.28 & 17.10 \\
\hline 40.8 & 400.9 & 124300 & 0.35 & 17.11 \\
\hline 40.9 & 399.9 & 125000 & 0.39 & 17.54 \\
\hline 40.3 & 404.1 & 124277 & 0.44 & 18.15 \\
\hline 41.4 & 402.0 & 127380 & 0.50 & 18.66 \\
\hline 41.5 & 400.9 & 126945 & 0.54 & 19.06 \\
\hline 41.6 & 399.9 & 127715 & 0.58 & 19.23 \\
\hline 41.7 & 400.9 & 127587 & 0.64 & 19.45 \\
\hline & & & & \\
\hline
\end{tabular}

\begin{tabular}{|c|c|c|c|c|}
\hline$T_{\text {sat }}$ & $G$ & $\phi$ & $x$ & $h$ \\
\hline 41.8 & 400.9 & 126771 & 0.68 & 20.12 \\
\hline 41.8 & 402.0 & 127188 & 0.73 & 20.32 \\
\hline 41.8 & 399.9 & 125930 & 0.78 & 20.75 \\
\hline 41.6 & 399.9 & 126269 & 0.82 & 22.12 \\
\hline 40.4 & 400.9 & 136951 & 0.06 & 17.77 \\
\hline 40.6 & 399.9 & 136877 & 0.09 & 18.10 \\
\hline 40.7 & 402.0 & 136559 & 0.14 & 18.28 \\
\hline 41.0 & 399.9 & 133175 & 0.20 & 18.02 \\
\hline 39.6 & 403.0 & 136362 & 0.23 & 18.40 \\
\hline 40.2 & 400.9 & 136951 & 0.30 & 19.04 \\
\hline 40.3 & 399.9 & 136877 & 0.33 & 19.06 \\
\hline 40.4 & 402.0 & 136559 & 0.38 & 19.31 \\
\hline 40.6 & 399.9 & 133175 & 0.43 & 19.06 \\
\hline 39.2 & 403.0 & 136362 & 0.47 & 19.35 \\
\hline 41.3 & 397.8 & 136641 & 0.53 & 21.14 \\
\hline 41.3 & 399.9 & 136358 & 0.58 & 21.16 \\
\hline 41.4 & 399.9 & 134390 & 0.63 & 21.08 \\
\hline 41.5 & 399.9 & 136505 & 0.69 & 21.74 \\
\hline 41.5 & 403.0 & 134959 & 0.73 & 21.73 \\
\hline 41.5 & 397.8 & 136602 & 0.80 & 22.61 \\
\hline 41.3 & 397.8 & 136025 & 0.85 & 22.78 \\
\hline 40.7 & 499.8 & 34501 & 0.06 & 4.88 \\
\hline 40.5 & 504.0 & 34465 & 0.10 & 5.00 \\
\hline 41.2 & 499.8 & 34538 & 0.18 & 8.56 \\
\hline 41.6 & 499.8 & 34530 & 0.23 & 10.31 \\
\hline 41.8 & 498.8 & 34569 & 0.27 & 12.08 \\
\hline 42.0 & 505.1 & 34619 & 0.33 & 14.21 \\
\hline 42.2 & 498.8 & 34602 & 0.37 & 15.07 \\
\hline 42.2 & 499.8 & 34694 & 0.42 & 16.74 \\
\hline 42.2 & 501.9 & 34729 & 0.46 & 18.13 \\
\hline 42.2 & 501.9 & 34798 & 0.52 & 19.03 \\
\hline 42.1 & 499.8 & 34919 & 0.56 & 20.56 \\
\hline 42.0 & 495.6 & 35268 & 0.63 & 22.72 \\
\hline 42.0 & 500.9 & 35121 & 0.67 & 23.17 \\
\hline 42.0 & 500.9 & 35100 & 0.72 & 23.08 \\
\hline 42.1 & 504.0 & 35199 & 0.77 & 25.37 \\
\hline 42.1 & 505.1 & 35101 & 0.81 & 24.95 \\
\hline 42.1 & 501.9 & 34910 & 0.86 & 24.13 \\
\hline 41.9 & 495.6 & 34947 & 0.92 & 24.71 \\
\hline 40.8 & 499.8 & 44705 & 0.06 & 6.86 \\
\hline 41.0 & 499.8 & 44645 & 0.11 & 6.83 \\
\hline 41.2 & 499.8 & 44652 & 0.15 & 7.65 \\
\hline 41.5 & 499.8 & 44657 & 0.21 & 9.87 \\
\hline 41.6 & 500.9 & 44623 & 0.25 & 11.09 \\
\hline 41.7 & 497.7 & 44655 & 0.31 & 13.34 \\
\hline 42.0 & 498.8 & 44657 & 0.36 & 14.86 \\
\hline 42.0 & 501.9 & 44644 & 0.40 & 16.40 \\
\hline 41.8 & 501.9 & 44576 & 0.44 & 17.84 \\
\hline 41.7 & 503.0 & 44680 & 0.51 & 20.11 \\
\hline 41.7 & 500.9 & 44686 & 0.56 & 21.23 \\
\hline 41.8 & 499.8 & 44687 & 0.61 & 22.65 \\
\hline 41.7 & 497.7 & 44609 & 0.65 & 22.93 \\
\hline 41.8 & 503.0 & 44614 & 0.69 & 24.01 \\
\hline 41.8 & 499.8 & 44424 & 0.76 & 25.07 \\
\hline 41.9 & 500.9 & 44499 & 0.81 & 26.45 \\
\hline 41.9 & 498.8 & 44558 & 0.85 & 26.14 \\
\hline 41.8 & 495.6 & 44544 & 0.91 & 27.96 \\
\hline
\end{tabular}




\begin{tabular}{|c|c|c|c|c|}
\hline $\boldsymbol{T}_{\text {sat }}$ & $\boldsymbol{G}$ & $\phi$ & $x$ & $h$ \\
\hline 40.7 & 498.8 & 56232 & 0.05 & 8.24 \\
\hline 40.9 & 501.9 & 56185 & 0.09 & 8.36 \\
\hline 41.1 & 501.9 & 56051 & 0.14 & 8.46 \\
\hline 40.9 & 500.9 & 55409 & 0.20 & 9.15 \\
\hline 41.1 & 500.9 & 55265 & 0.24 & 10.34 \\
\hline 41.5 & 503.0 & 54988 & 0.29 & 11.73 \\
\hline 41.6 & 499.8 & 55805 & 0.35 & 13.56 \\
\hline 41.8 & 497.7 & 54879 & 0.41 & 15.41 \\
\hline 42.0 & 498.8 & 55250 & 0.45 & 16.71 \\
\hline 42.1 & 496.7 & 54777 & 0.51 & 18.16 \\
\hline 42.0 & 501.9 & 54259 & 0.54 & 19.40 \\
\hline 42.0 & 503.0 & 55322 & 0.59 & 21.67 \\
\hline 42.0 & 500.9 & 55454 & 0.64 & 22.91 \\
\hline 42.0 & 499.8 & 55371 & 0.70 & 23.93 \\
\hline 41.9 & 497.7 & 55442 & 0.75 & 25.93 \\
\hline 41.8 & 501.9 & 55596 & 0.79 & 27.07 \\
\hline 41.8 & 499.8 & 55511 & 0.84 & 27.65 \\
\hline 41.7 & 500.9 & 55646 & 0.89 & 29.13 \\
\hline 40.6 & 498.8 & 64707 & 0.07 & 9.27 \\
\hline 40.7 & 498.8 & 64489 & 0.14 & 9.03 \\
\hline 41.0 & 500.9 & 64605 & 0.18 & 9.19 \\
\hline 41.5 & 499.8 & 64654 & 0.23 & 9.99 \\
\hline 41.6 & 500.9 & 64831 & 0.27 & 11.28 \\
\hline 41.7 & 498.8 & 64866 & 0.32 & 12.67 \\
\hline 41.8 & 501.9 & 65377 & 0.37 & 14.24 \\
\hline 41.9 & 499.8 & 65505 & 0.42 & 15.74 \\
\hline 41.8 & 497.7 & 65565 & 0.49 & 17.69 \\
\hline 41.7 & 498.8 & 65191 & 0.54 & 19.23 \\
\hline 41.7 & 501.9 & 65170 & 0.57 & 20.48 \\
\hline 41.8 & 504.0 & 65124 & 0.61 & 21.64 \\
\hline 41.9 & 500.9 & 65317 & 0.66 & 22.85 \\
\hline 41.9 & 501.9 & 65989 & 0.71 & 24.32 \\
\hline 42.0 & 497.7 & 65871 & 0.77 & 25.25 \\
\hline 42.0 & 500.9 & 66016 & 0.82 & 26.38 \\
\hline 41.8 & 499.8 & 65904 & 0.88 & 27.80 \\
\hline 41.0 & 503.0 & 74901 & 0.03 & 10.57 \\
\hline 41.3 & 505.1 & 74972 & 0.07 & 10.58 \\
\hline 41.6 & 501.9 & 75199 & 0.12 & 10.77 \\
\hline 42.0 & 504.0 & 75194 & 0.17 & 11.02 \\
\hline 41.6 & 498.8 & 74657 & 0.22 & 10.65 \\
\hline 42.0 & 498.8 & 74790 & 0.27 & 11.49 \\
\hline 41.8 & 496.7 & 74880 & 0.32 & 12.63 \\
\hline 42.2 & 505.1 & 74886 & 0.37 & 14.32 \\
\hline 42.3 & 498.8 & 74967 & 0.42 & 15.35 \\
\hline 42.5 & 500.9 & 74842 & 0.47 & 16.64 \\
\hline 42.3 & 500.9 & 74826 & 0.52 & 18.17 \\
\hline 42.3 & 499.8 & 74885 & 0.56 & 19.27 \\
\hline 42.2 & 500.9 & 74760 & 0.60 & 20.27 \\
\hline 42.2 & 498.8 & 74764 & 0.65 & 21.51 \\
\hline 42.1 & 503.0 & 74485 & 0.70 & 22.78 \\
\hline 42.2 & 501.9 & 74644 & 0.75 & 24.39 \\
\hline 42.1 & 500.9 & 74651 & 0.81 & 26.17 \\
\hline 42.1 & 501.9 & 74600 & 0.86 & 27.12 \\
\hline 40.9 & 500.9 & 87110 & 0.05 & 12.33 \\
\hline 41.2 & 500.9 & 87160 & 0.10 & 12.79 \\
\hline 41.5 & 499.8 & 86905 & 0.16 & 13.01 \\
\hline 41.7 & 498.8 & 86597 & 0.21 & 12.89 \\
\hline
\end{tabular}

\begin{tabular}{|c|c|c|c|c|}
\hline$T_{\text {sat }}$ & $G$ & $\phi$ & $x$ & $h$ \\
\hline 41.7 & 500.9 & 87435 & 0.25 & 13.42 \\
\hline 41.9 & 500.9 & 86523 & 0.31 & 14.18 \\
\hline 41.9 & 503.0 & 85417 & 0.35 & 14.93 \\
\hline 42.2 & 499.8 & 86117 & 0.41 & 16.37 \\
\hline 42.4 & 503.0 & 86508 & 0.46 & 17.60 \\
\hline 42.4 & 501.9 & 86625 & 0.50 & 18.68 \\
\hline 42.4 & 498.8 & 86128 & 0.55 & 19.53 \\
\hline 42.4 & 500.9 & 86053 & 0.60 & 21.34 \\
\hline 42.5 & 500.9 & 86280 & 0.65 & 22.76 \\
\hline 42.3 & 503.0 & 85397 & 0.70 & 23.77 \\
\hline 42.3 & 499.8 & 85793 & 0.77 & 25.72 \\
\hline 42.0 & 499.8 & 85526 & 0.81 & 27.13 \\
\hline 41.7 & 496.7 & 84335 & 0.87 & 29.11 \\
\hline 40.5 & 503.0 & 96959 & 0.05 & 14.28 \\
\hline 40.8 & 497.7 & 95492 & 0.10 & 14.19 \\
\hline 41.0 & 500.9 & 94086 & 0.15 & 14.21 \\
\hline 41.2 & 500.9 & 93857 & 0.19 & 14.27 \\
\hline 41.4 & 499.8 & 93913 & 0.25 & 14.64 \\
\hline 41.9 & 499.8 & 94813 & 0.30 & 16.15 \\
\hline 42.1 & 500.9 & 94787 & 0.35 & 17.09 \\
\hline 42.3 & 498.8 & 94565 & 0.39 & 17.92 \\
\hline 42.4 & 499.8 & 94374 & 0.45 & 19.12 \\
\hline 42.5 & 499.8 & 94124 & 0.49 & 19.77 \\
\hline 42.4 & 501.9 & 94508 & 0.54 & 21.76 \\
\hline 42.3 & 500.9 & 98680 & 0.59 & 22.48 \\
\hline 42.4 & 500.9 & 97519 & 0.63 & 23.51 \\
\hline 42.4 & 498.8 & 97967 & 0.69 & 24.47 \\
\hline 42.3 & 500.9 & 97068 & 0.73 & 25.39 \\
\hline 42.2 & 501.9 & 96580 & 0.79 & 27.25 \\
\hline 41.9 & 497.7 & 96306 & 0.85 & 29.08 \\
\hline 40.1 & 498.8 & 105019 & 0.07 & 14.79 \\
\hline 40.4 & 500.9 & 105101 & 0.13 & 15.27 \\
\hline 40.7 & 500.9 & 103493 & 0.18 & 15.23 \\
\hline 41.0 & 499.8 & 106046 & 0.24 & 15.94 \\
\hline 41.1 & 505.1 & 105631 & 0.27 & 16.49 \\
\hline 41.2 & 498.8 & 106024 & 0.33 & 17.65 \\
\hline 41.3 & 496.7 & 105522 & 0.38 & 18.35 \\
\hline 41.5 & 497.7 & 106594 & 0.44 & 19.63 \\
\hline 41.7 & 500.9 & 106567 & 0.48 & 20.39 \\
\hline 41.8 & 504.0 & 106302 & 0.53 & 21.08 \\
\hline 41.8 & 499.8 & 105980 & 0.59 & 22.37 \\
\hline 41.9 & 499.8 & 106014 & 0.64 & 23.85 \\
\hline 41.9 & 501.9 & 106018 & 0.68 & 25.03 \\
\hline 41.9 & 499.8 & 105814 & 0.74 & 26.38 \\
\hline 41.9 & 498.8 & 105702 & 0.79 & 27.92 \\
\hline 41.6 & 501.9 & 104703 & 0.83 & 29.90 \\
\hline 40.8 & 497.7 & 117150 & 0.06 & 16.59 \\
\hline 40.7 & 497.7 & 117150 & 0.10 & 16.25 \\
\hline 40.7 & 500.9 & 116096 & 0.13 & 16.32 \\
\hline 40.9 & 499.8 & 117084 & 0.17 & 16.63 \\
\hline 41.2 & 501.9 & 116379 & 0.23 & 16.68 \\
\hline 40.8 & 501.9 & 117154 & 0.27 & 16.99 \\
\hline 41.4 & 498.8 & 116833 & 0.33 & 18.30 \\
\hline 41.6 & 500.9 & 116417 & 0.37 & 18.78 \\
\hline 41.7 & 503.0 & 116004 & 0.41 & 19.20 \\
\hline 41.9 & 499.8 & 116770 & 0.46 & 19.75 \\
\hline 42.0 & 503.0 & 115494 & 0.51 & 20.31 \\
\hline
\end{tabular}




\begin{tabular}{|c|c|c|c|c|}
\hline $\boldsymbol{T}_{\text {sat }}$ & $\boldsymbol{G}$ & $\boldsymbol{\phi}$ & $\boldsymbol{x}$ & $\boldsymbol{h}$ \\
\hline 42.1 & 500.9 & 116326 & 0.57 & 21.39 \\
\hline 42.2 & 505.1 & 116010 & 0.61 & 21.98 \\
\hline 42.3 & 501.9 & 115565 & 0.65 & 22.94 \\
\hline 42.3 & 496.7 & 115026 & 0.71 & 23.99 \\
\hline 42.2 & 497.7 & 114680 & 0.76 & 25.00 \\
\hline 42.0 & 503.0 & 115106 & 0.80 & 26.81 \\
\hline 41.3 & 505.1 & 127294 & 0.03 & 17.33 \\
\hline 41.7 & 497.7 & 128202 & 0.09 & 17.61 \\
\hline 41.4 & 500.9 & 120671 & 0.12 & 17.01 \\
\hline 41.8 & 500.9 & 127317 & 0.12 & 17.69 \\
\hline 41.9 & 500.9 & 126373 & 0.19 & 18.06 \\
\hline 42.4 & 498.8 & 125899 & 0.22 & 19.33 \\
\hline 42.6 & 498.8 & 125901 & 0.29 & 19.62 \\
\hline 42.7 & 500.9 & 126408 & 0.32 & 19.96 \\
\hline 42.0 & 498.8 & 125899 & 0.40 & 20.39 \\
\hline 42.1 & 498.8 & 125901 & 0.47 & 21.25 \\
\hline 42.1 & 500.9 & 126408 & 0.50 & 22.09 \\
\hline 42.2 & 501.9 & 126544 & 0.56 & 23.13 \\
\hline 42.2 & 501.9 & 127493 & 0.62 & 24.21 \\
\hline 42.2 & 498.8 & 127428 & 0.67 & 24.92 \\
\hline 42.1 & 499.8 & 126142 & 0.71 & 25.11 \\
\hline
\end{tabular}

\begin{tabular}{|c|c|c|c|c|}
\hline $\boldsymbol{T}_{\text {sat }}$ & $\boldsymbol{G}$ & $\boldsymbol{\phi}$ & $\boldsymbol{x}$ & $\boldsymbol{h}$ \\
\hline 41.9 & 501.9 & 125771 & 0.75 & 25.78 \\
\hline 41.8 & 499.8 & 125199 & 0.80 & 27.03 \\
\hline 41.5 & 500.9 & 125210 & 0.85 & 29.18 \\
\hline 40.7 & 504.0 & 136595 & 0.07 & 18.34 \\
\hline 41.0 & 500.9 & 136481 & 0.11 & 18.61 \\
\hline 41.3 & 497.7 & 136624 & 0.17 & 18.90 \\
\hline 40.0 & 501.9 & 136490 & 0.21 & 18.86 \\
\hline 40.4 & 504.0 & 136595 & 0.26 & 19.43 \\
\hline 40.7 & 500.9 & 136481 & 0.31 & 19.68 \\
\hline 41.0 & 497.7 & 136624 & 0.36 & 20.07 \\
\hline 40.8 & 500.9 & 137886 & 0.40 & 19.36 \\
\hline 41.3 & 500.9 & 137517 & 0.46 & 20.73 \\
\hline 41.4 & 504.0 & 137147 & 0.50 & 21.18 \\
\hline 41.5 & 498.8 & 136373 & 0.57 & 21.51 \\
\hline 41.6 & 498.8 & 136261 & 0.61 & 21.74 \\
\hline 41.6 & 500.9 & 136187 & 0.66 & 21.82 \\
\hline 41.6 & 498.8 & 135523 & 0.71 & 22.04 \\
\hline 41.7 & 501.9 & 135155 & 0.75 & 22.53 \\
\hline 41.7 & 497.7 & 135120 & 0.81 & 23.15 \\
\hline 41.4 & 497.7 & 134795 & 0.86 & 24.13 \\
\hline
\end{tabular}

Tabela B.11. R134a, geometría quadrada.

\begin{tabular}{|l|l|l|l|l|}
\hline $\boldsymbol{T}_{\text {sat }}$ & $\boldsymbol{G}$ & $\boldsymbol{\phi}$ & $\boldsymbol{x}$ & $\boldsymbol{h}$ \\
\hline 31.0 & 201.6 & 15025 & 0.01 & 4.21 \\
\hline 31.0 & 199.3 & 15026 & 0.05 & 4.06 \\
\hline 31.0 & 201.6 & 15025 & 0.09 & 4.53 \\
\hline 31.0 & 199.3 & 15026 & 0.14 & 4.63 \\
\hline 31.0 & 200.8 & 15031 & 0.21 & 5.11 \\
\hline 31.0 & 195.4 & 15032 & 0.25 & 5.27 \\
\hline 31.1 & 200.8 & 15034 & 0.29 & 5.46 \\
\hline 31.1 & 197.7 & 15036 & 0.36 & 5.66 \\
\hline 31.1 & 200.0 & 15036 & 0.39 & 5.75 \\
\hline 31.1 & 198.2 & 15034 & 0.45 & 5.65 \\
\hline 31.1 & 197.8 & 15034 & 0.50 & 5.49 \\
\hline 31.1 & 198.1 & 15033 & 0.56 & 5.53 \\
\hline 31.2 & 198.7 & 15032 & 0.61 & 5.55 \\
\hline 31.1 & 200.8 & 15037 & 0.64 & 5.60 \\
\hline 31.1 & 199.2 & 15035 & 0.69 & 5.76 \\
\hline 31.2 & 200.9 & 15036 & 0.74 & 5.99 \\
\hline 31.2 & 199.9 & 15039 & 0.81 & 6.37 \\
\hline 31.3 & 199.8 & 15039 & 0.85 & 6.73 \\
\hline 31.0 & 198.0 & 24981 & 0.09 & 5.71 \\
\hline 31.0 & 199.0 & 24979 & 0.14 & 5.77 \\
\hline 31.1 & 200.1 & 24981 & 0.20 & 5.93 \\
\hline 31.0 & 198.0 & 24981 & 0.23 & 6.32 \\
\hline 31.0 & 199.0 & 24979 & 0.28 & 6.31 \\
\hline 31.0 & 200.1 & 24981 & 0.33 & 6.39 \\
\hline 31.1 & 198.6 & 24979 & 0.37 & 6.50 \\
\hline 31.1 & 199.3 & 24983 & 0.42 & 6.65 \\
\hline 31.1 & 199.7 & 24985 & 0.46 & 6.89 \\
\hline 31.2 & 202.0 & 24986 & 0.51 & 7.02 \\
\hline 31.2 & 199.7 & 24985 & 0.57 & 7.04 \\
\hline 31.2 & 198.5 & 24984 & 0.63 & 7.05 \\
\hline & & & & \\
\hline 31 \\
\hline 31 \\
\hline 31
\end{tabular}

\begin{tabular}{|c|c|c|c|c|}
\hline$T_{\text {sat }}$ & $G$ & $\phi$ & $x$ & $h$ \\
\hline 31.3 & 199.3 & 24984 & 0.67 & 6.99 \\
\hline 31.2 & 199.2 & 24987 & 0.73 & 7.10 \\
\hline 31.0 & 199.8 & 24989 & 0.78 & 7.14 \\
\hline 30.9 & 200.5 & 35073 & 0.17 & 7.24 \\
\hline 30.9 & 199.4 & 35073 & 0.21 & 7.27 \\
\hline 30.7 & 200.4 & 35077 & 0.25 & 7.20 \\
\hline 31.2 & 198.2 & 35050 & 0.31 & 7.27 \\
\hline 30.9 & 200.5 & 35073 & 0.35 & 7.63 \\
\hline 30.9 & 199.4 & 35073 & 0.40 & 7.53 \\
\hline 30.7 & 200.4 & 35077 & 0.43 & 7.50 \\
\hline 31.1 & 198.2 & 35050 & 0.50 & 7.83 \\
\hline 31.0 & 200.0 & 35044 & 0.55 & 8.07 \\
\hline 31.2 & 199.8 & 35059 & 0.60 & 8.64 \\
\hline 30.8 & 199.9 & 35047 & 0.64 & 8.63 \\
\hline 31.2 & 200.1 & 35059 & 0.69 & 8.68 \\
\hline 31.0 & 299.9 & 15045 & 0.04 & 4.46 \\
\hline 30.9 & 295.9 & 15047 & 0.09 & 4.56 \\
\hline 31.0 & 301.3 & 15054 & 0.15 & 5.38 \\
\hline 31.1 & 299.9 & 15054 & 0.18 & 5.40 \\
\hline 31.1 & 295.9 & 15055 & 0.23 & 5.50 \\
\hline 31.1 & 298.6 & 15055 & 0.28 & 5.69 \\
\hline 31.1 & 299.9 & 15055 & 0.32 & 5.68 \\
\hline 31.2 & 299.9 & 15054 & 0.38 & 5.71 \\
\hline 31.3 & 297.3 & 15054 & 0.43 & 5.82 \\
\hline 31.1 & 297.3 & 15056 & 0.48 & 5.94 \\
\hline 31.2 & 301.3 & 15056 & 0.53 & 6.09 \\
\hline 31.2 & 290.6 & 15057 & 0.59 & 6.31 \\
\hline 31.2 & 298.6 & 15058 & 0.62 & 6.50 \\
\hline 31.2 & 294.6 & 15061 & 0.69 & 6.74 \\
\hline 31.1 & 299.9 & 15066 & 0.73 & 7.13 \\
\hline 31.2 & 303.9 & 15067 & 0.78 & 7.77 \\
\hline 31.3 & 299.9 & 15056 & 0.84 & 8.20 \\
\hline
\end{tabular}




\begin{tabular}{|c|c|c|c|c|}
\hline \multicolumn{7}{|c|}{$\boldsymbol{T}_{\text {sat }}$} & $\boldsymbol{G}$ & $\boldsymbol{\phi}$ & $\boldsymbol{x}$ & $\boldsymbol{h}$ \\
\hline 31.2 & 297.3 & 15060 & 0.89 & 8.73 \\
\hline 31.1 & 299.9 & 25042 & 0.03 & 6.09 \\
\hline 31.1 & 301.3 & 25042 & 0.09 & 6.26 \\
\hline 31.1 & 299.9 & 25042 & 0.12 & 6.79 \\
\hline 31.1 & 301.3 & 25042 & 0.17 & 6.62 \\
\hline 31.1 & 301.3 & 25046 & 0.24 & 6.83 \\
\hline 31.2 & 301.3 & 25044 & 0.27 & 6.90 \\
\hline 31.1 & 297.3 & 25030 & 0.33 & 7.00 \\
\hline 31.1 & 297.3 & 25047 & 0.37 & 7.00 \\
\hline 31.2 & 298.6 & 25045 & 0.43 & 7.04 \\
\hline 31.3 & 301.3 & 25045 & 0.48 & 7.09 \\
\hline 31.1 & 298.6 & 25032 & 0.54 & 7.16 \\
\hline 31.1 & 297.3 & 25032 & 0.60 & 7.26 \\
\hline 31.1 & 301.3 & 25030 & 0.64 & 7.30 \\
\hline 31.1 & 299.9 & 25034 & 0.69 & 7.43 \\
\hline 31.2 & 302.6 & 25036 & 0.73 & 7.73 \\
\hline 31.2 & 297.3 & 25035 & 0.80 & 8.04 \\
\hline 31.2 & 298.6 & 25041 & 0.84 & 8.52 \\
\hline 31.0 & 298.6 & 35004 & 0.08 & 7.52 \\
\hline 31.1 & 305.3 & 35003 & 0.11 & 7.60 \\
\hline 30.9 & 297.3 & 35002 & 0.17 & 7.34 \\
\hline 31.0 & 298.6 & 35004 & 0.21 & 8.08 \\
\hline 31.1 & 305.3 & 35003 & 0.23 & 8.06 \\
\hline 30.8 & 297.3 & 35002 & 0.30 & 7.65 \\
\hline 31.1 & 298.6 & 35004 & 0.33 & 8.29 \\
\hline 31.2 & 303.9 & 35003 & 0.36 & 8.31 \\
\hline 31.2 & 301.3 & 35003 & 0.42 & 8.35 \\
\hline 31.2 & 298.6 & 35005 & 0.48 & 8.40 \\
\hline 31.3 & 299.9 & 35002 & 0.53 & 8.43 \\
\hline 31.3 & 303.9 & 35001 & 0.57 & 8.47 \\
\hline 31.3 & 298.6 & 35002 & 0.63 & 8.46 \\
\hline 31.1 & 298.6 & 35007 & 0.69 & 8.47 \\
\hline 31.2 & 305.3 & 35007 & 0.72 & 8.63 \\
\hline 31.2 & 294.6 & 35009 & 0.80 & 8.83 \\
\hline 31.0 & 299.9 & 44903 & 0.13 & 8.89 \\
\hline 31.1 & 299.9 & 44902 & 0.18 & 8.99 \\
\hline 31.1 & 299.9 & 44900 & 0.23 & 8.90 \\
\hline 31.0 & 299.9 & 44903 & 0.29 & 9.33 \\
\hline 31.0 & 299.9 & 44902 & 0.34 & 9.33 \\
\hline 31.1 & 299.9 & 44900 & 0.39 & 9.26 \\
\hline 31.3 & 297.3 & 44898 & 0.44 & 9.58 \\
\hline 31.3 & 299.9 & 44900 & 0.48 & 9.79 \\
\hline 31.2 & 298.6 & 44904 & 0.53 & 10.06 \\
\hline 31.1 & 295.9 & 44906 & 0.59 & 10.03 \\
\hline 31.0 & 285.3 & 44885 & 0.68 & 9.80 \\
\hline 31.1 & 299.9 & 44906 & 0.69 & 9.83 \\
\hline 31.1 & 298.6 & 44906 & 0.73 & 10.06 \\
\hline 31.1 & 299.9 & 44906 & 0.77 & 10.72 \\
\hline 31.1 & 298.6 & 44906 & 0.81 & 10.89 \\
\hline 31.1 & 301.9 & 54936 & 0.18 & 10.16 \\
\hline 31.2 & 298.6 & 54934 & 0.24 & 10.12 \\
\hline 31.3 & 303.9 & 54934 & 0.29 & 10.26 \\
\hline 31.3 & 303.9 & 54933 & 0.33 & 10.23 \\
\hline 31.0 & 311.9 & 54936 & 0.36 & 10.57 \\
\hline 31.1 & 298.6 & 54934 & 0.43 & 10.60 \\
\hline 31.2 & 303.9 & 54934 & 0.49 & 10.93 \\
\hline 31.3 & 303.9 & 54933 & 0.52 & 10.92 \\
\hline & & & & \\
\hline
\end{tabular}

\begin{tabular}{|l|l|l|l|l|}
\hline \multicolumn{1}{|c|}{$\boldsymbol{T}_{\text {sat }}$} & \multicolumn{1}{|c|}{$\boldsymbol{\phi}$} & \multicolumn{1}{|c|}{$\boldsymbol{x}$} & \multicolumn{1}{|c|}{$\boldsymbol{h}$} \\
\hline 31.3 & 299.9 & 54937 & 0.58 & 11.26 \\
\hline 31.1 & 298.6 & 54943 & 0.63 & 11.65 \\
\hline 31.2 & 297.3 & 54967 & 0.69 & 11.69 \\
\hline 31.0 & 298.6 & 54943 & 0.73 & 12.43 \\
\hline 31.1 & 297.3 & 54967 & 0.79 & 12.06 \\
\hline 30.6 & 400.2 & 15013 & 0.05 & 4.73 \\
\hline 31.0 & 402.1 & 15020 & 0.10 & 4.99 \\
\hline 31.0 & 399.9 & 15008 & 0.15 & 5.07 \\
\hline 31.1 & 401.0 & 15008 & 0.21 & 5.20 \\
\hline 31.2 & 399.4 & 15019 & 0.24 & 5.18 \\
\hline 31.0 & 400.4 & 15010 & 0.30 & 5.15 \\
\hline 31.1 & 398.0 & 15010 & 0.34 & 5.31 \\
\hline 31.1 & 398.8 & 15011 & 0.39 & 5.47 \\
\hline 31.3 & 400.5 & 15010 & 0.44 & 5.72 \\
\hline 31.3 & 401.2 & 15012 & 0.50 & 6.10 \\
\hline 31.4 & 398.8 & 15014 & 0.55 & 6.47 \\
\hline 31.2 & 400.2 & 15020 & 0.60 & 6.85 \\
\hline 31.0 & 399.4 & 15028 & 0.65 & 7.32 \\
\hline 31.3 & 400.4 & 15025 & 0.69 & 7.73 \\
\hline 31.3 & 400.9 & 15027 & 0.75 & 8.21 \\
\hline 31.3 & 403.1 & 15027 & 0.79 & 8.64 \\
\hline 31.4 & 399.3 & 15025 & 0.85 & 9.35 \\
\hline 31.4 & 400.8 & 15018 & 0.90 & 10.15 \\
\hline 31.0 & 398.8 & 25012 & 0.07 & 6.05 \\
\hline 30.9 & 399.8 & 25017 & 0.11 & 6.24 \\
\hline 30.9 & 401.3 & 25017 & 0.16 & 6.23 \\
\hline 30.9 & 400.4 & 25022 & 0.21 & 6.83 \\
\hline 30.9 & 401.1 & 25021 & 0.26 & 6.95 \\
\hline 31.0 & 402.5 & 25019 & 0.31 & 7.00 \\
\hline 31.0 & 400.1 & 25018 & 0.36 & 7.09 \\
\hline 31.0 & 399.6 & 25022 & 0.41 & 7.21 \\
\hline 31.0 & 400.0 & 25021 & 0.47 & 7.35 \\
\hline 31.0 & 398.9 & 25020 & 0.52 & 7.49 \\
\hline 31.1 & 399.2 & 25009 & 0.57 & 7.69 \\
\hline 31.1 & 401.1 & 25013 & 0.63 & 7.92 \\
\hline 31.1 & 400.7 & 25014 & 0.66 & 8.08 \\
\hline 31.1 & 398.5 & 25016 & 0.72 & 8.43 \\
\hline 31.1 & 402.1 & 25020 & 0.76 & 8.86 \\
\hline 31.1 & 401.1 & 25023 & 0.82 & 9.43 \\
\hline 31.1 & 399.7 & 25014 & 0.86 & 10.00 \\
\hline 31.0 & 400.4 & 34945 & 0.04 & 7.47 \\
\hline 31.0 & 399.9 & 34947 & 0.08 & 7.40 \\
\hline 31.0 & 400.4 & 34945 & 0.13 & 7.79 \\
\hline 31.0 & 399.9 & 34947 & 0.17 & 7.75 \\
\hline 31.0 & 400.0 & 34947 & 0.22 & 7.83 \\
\hline 31.2 & 399.7 & 34946 & 0.27 & 8.11 \\
\hline 31.3 & 398.7 & 34944 & 0.32 & 8.19 \\
\hline 31.2 & 398.8 & 34948 & 0.37 & 8.24 \\
\hline 31.1 & 400.0 & 34949 & 0.42 & 8.27 \\
\hline 31.1 & 398.7 & 34948 & 0.47 & 8.34 \\
\hline 31.2 & 400.6 & 34950 & 0.52 & 8.42 \\
\hline 31.2 & 398.5 & 34951 & 0.57 & 8.48 \\
\hline 31.2 & 399.5 & 34948 & 0.62 & 8.63 \\
\hline 31.2 & 400.5 & 34947 & 0.67 & 8.76 \\
\hline 31.3 & 398.2 & 34947 & 0.72 & 8.96 \\
\hline 31.3 & 400.7 & 34946 & 0.77 & 9.24 \\
\hline 31.3 & 400.2 & 34941 & 0.83 & 10.18 \\
\hline & & & & \\
\hline
\end{tabular}




\begin{tabular}{|c|c|c|c|c|}
\hline$T_{\text {sat }}$ & $G$ & $\phi$ & $x$ & $h$ \\
\hline 31.0 & 400.8 & 44971 & 0.07 & 8.78 \\
\hline 31.1 & 398.7 & 44970 & 0.11 & 8.80 \\
\hline 31.2 & 399.6 & 44969 & 0.16 & 9.00 \\
\hline 31.0 & 400.8 & 44971 & 0.19 & 9.43 \\
\hline 31.1 & 398.7 & 44970 & 0.23 & 9.44 \\
\hline 31.1 & 399.6 & 44969 & 0.28 & 9.47 \\
\hline 31.2 & 399.9 & 44969 & 0.34 & 9.53 \\
\hline 31.3 & 400.4 & 44969 & 0.38 & 9.56 \\
\hline 31.1 & 399.7 & 44971 & 0.44 & 9.64 \\
\hline 31.1 & 398.6 & 44972 & 0.49 & 9.63 \\
\hline 31.3 & 398.9 & 44979 & 0.54 & 9.67 \\
\hline 31.4 & 400.4 & 44970 & 0.58 & 9.69 \\
\hline 31.4 & 398.6 & 44987 & 0.63 & 9.74 \\
\hline 31.4 & 399.9 & 44970 & 0.69 & 9.83 \\
\hline 31.5 & 401.9 & 44971 & 0.73 & 9.91 \\
\hline 31.5 & 401.1 & 44971 & 0.79 & 10.60 \\
\hline 31.1 & 401.9 & 55008 & 0.10 & 9.98 \\
\hline 31.2 & 400.3 & 55006 & 0.15 & 10.49 \\
\hline 31.3 & 399.6 & 55005 & 0.20 & 10.33 \\
\hline 31.1 & 401.9 & 55008 & 0.25 & 10.77 \\
\hline 31.2 & 400.3 & 55006 & 0.29 & 10.81 \\
\hline 31.2 & 399.6 & 55005 & 0.34 & 10.81 \\
\hline 31.4 & 400.4 & 55028 & 0.42 & 11.01 \\
\hline 31.4 & 402.1 & 55024 & 0.45 & 10.97 \\
\hline 31.5 & 400.9 & 55020 & 0.49 & 11.12 \\
\hline 31.3 & 399.5 & 55024 & 0.55 & 11.05 \\
\hline 31.2 & 399.4 & 55008 & 0.60 & 11.00 \\
\hline 31.2 & 398.9 & 55007 & 0.65 & 10.98 \\
\hline 31.3 & 400.9 & 55023 & 0.68 & 11.03 \\
\hline 31.3 & 402.1 & 55033 & 0.74 & 11.79 \\
\hline 31.2 & 400.9 & 55023 & 0.76 & 12.13 \\
\hline 31.3 & 402.1 & 55033 & 0.82 & 12.28 \\
\hline 31.3 & 401.3 & 64926 & 0.14 & 11.72 \\
\hline 31.4 & 401.8 & 64927 & 0.18 & 11.60 \\
\hline 31.5 & 400.3 & 65003 & 0.24 & 11.64 \\
\hline 31.6 & 399.9 & 65007 & 0.29 & 11.73 \\
\hline 31.2 & 401.3 & 64926 & 0.31 & 12.07 \\
\hline 31.3 & 401.8 & 64927 & 0.36 & 12.12 \\
\hline 31.5 & 400.3 & 65003 & 0.42 & 12.21 \\
\hline 31.5 & 399.9 & 65007 & 0.46 & 12.33 \\
\hline 31.2 & 401.2 & 65011 & 0.52 & 12.67 \\
\hline 31.3 & 402.0 & 65012 & 0.56 & 12.87 \\
\hline 31.4 & 400.5 & 65013 & 0.60 & 12.60 \\
\hline 31.6 & 400.9 & 65033 & 0.66 & 12.37 \\
\hline 31.6 & 399.9 & 65033 & 0.71 & 12.48 \\
\hline 31.5 & 400.9 & 65033 & 0.74 & 13.51 \\
\hline 31.5 & 399.9 & 65033 & 0.79 & 13.45 \\
\hline 31.2 & 400.9 & 75015 & 0.17 & 12.58 \\
\hline 31.1 & 399.4 & 75015 & 0.22 & 12.60 \\
\hline 31.2 & 398.9 & 75013 & 0.27 & 12.82 \\
\hline 31.3 & 400.2 & 74987 & 0.35 & 12.87 \\
\hline 31.2 & 400.9 & 75015 & 0.37 & 13.25 \\
\hline 31.0 & 399.4 & 75015 & 0.42 & 13.22 \\
\hline 31.2 & 398.9 & 75013 & 0.47 & 13.26 \\
\hline 31.2 & 400.2 & 74987 & 0.56 & 13.86 \\
\hline 31.4 & 401.0 & 75006 & 0.58 & 14.25 \\
\hline 31.4 & 400.4 & 75015 & 0.62 & 14.30 \\
\hline
\end{tabular}

\begin{tabular}{|c|c|c|c|c|}
\hline$T_{\text {sat }}$ & $G$ & $\phi$ & $x$ & $h$ \\
\hline 31.5 & 400.6 & 75038 & 0.68 & 14.14 \\
\hline 31.3 & 400.4 & 75015 & 0.72 & 14.36 \\
\hline 31.4 & 400.6 & 75038 & 0.78 & 14.54 \\
\hline 30.9 & 502.4 & 15014 & 0.03 & 4.92 \\
\hline 30.9 & 502.1 & 15016 & 0.06 & 5.12 \\
\hline 31.0 & 501.5 & 15019 & 0.12 & 5.63 \\
\hline 31.0 & 498.6 & 15020 & 0.17 & 5.71 \\
\hline 31.1 & 499.4 & 15017 & 0.20 & 5.80 \\
\hline 31.3 & 500.1 & 15017 & 0.25 & 6.07 \\
\hline 31.4 & 497.4 & 15017 & 0.31 & 6.35 \\
\hline 31.3 & 499.9 & 15019 & 0.36 & 6.62 \\
\hline 31.4 & 499.7 & 15022 & 0.41 & 6.92 \\
\hline 31.4 & 500.3 & 15023 & 0.46 & 7.30 \\
\hline 31.4 & 500.4 & 15026 & 0.51 & 7.72 \\
\hline 31.4 & 498.8 & 15029 & 0.56 & 8.13 \\
\hline 31.4 & 500.3 & 15024 & 0.60 & 8.52 \\
\hline 31.4 & 501.8 & 15020 & 0.65 & 8.91 \\
\hline 31.5 & 501.6 & 15026 & 0.71 & 9.41 \\
\hline 31.5 & 498.4 & 15020 & 0.76 & 9.92 \\
\hline 31.5 & 499.9 & 15022 & 0.81 & 10.40 \\
\hline 31.4 & 499.9 & 15025 & 0.85 & 10.91 \\
\hline 31.3 & 500.3 & 15029 & 0.91 & 11.83 \\
\hline 30.9 & 499.3 & 24977 & 0.05 & 6.38 \\
\hline 31.0 & 499.0 & 24976 & 0.08 & 6.51 \\
\hline 31.2 & 501.8 & 24977 & 0.14 & 7.21 \\
\hline 31.2 & 499.2 & 24981 & 0.18 & 7.26 \\
\hline 31.1 & 499.3 & 24982 & 0.23 & 7.28 \\
\hline 31.2 & 500.5 & 24980 & 0.28 & 7.40 \\
\hline 31.3 & 498.3 & 24979 & 0.33 & 7.52 \\
\hline 31.4 & 500.7 & 24979 & 0.38 & 7.68 \\
\hline 31.4 & 501.4 & 24981 & 0.42 & 7.82 \\
\hline 31.3 & 500.0 & 24985 & 0.48 & 8.09 \\
\hline 31.4 & 500.3 & 24985 & 0.53 & 8.39 \\
\hline 31.5 & 499.9 & 24984 & 0.58 & 8.69 \\
\hline 31.5 & 498.7 & 24979 & 0.63 & 9.01 \\
\hline 31.4 & 499.1 & 24976 & 0.67 & 9.40 \\
\hline 31.4 & 498.1 & 24977 & 0.73 & 9.92 \\
\hline 31.4 & 499.9 & 24979 & 0.78 & 10.38 \\
\hline 31.5 & 499.8 & 24984 & 0.83 & 11.00 \\
\hline 31.4 & 499.6 & 24975 & 0.88 & 11.71 \\
\hline 31.0 & 502.6 & 35050 & 0.02 & 7.56 \\
\hline 31.1 & 499.4 & 35048 & 0.08 & 7.65 \\
\hline 31.0 & 502.6 & 35050 & 0.10 & 8.26 \\
\hline 31.1 & 499.4 & 35048 & 0.15 & 8.27 \\
\hline 31.4 & 499.6 & 35047 & 0.22 & 8.57 \\
\hline 31.2 & 498.3 & 35050 & 0.25 & 8.58 \\
\hline 31.3 & 499.9 & 35048 & 0.30 & 8.63 \\
\hline 31.4 & 501.0 & 35048 & 0.34 & 8.73 \\
\hline 31.5 & 500.5 & 35047 & 0.39 & 8.80 \\
\hline 31.5 & 497.7 & 35048 & 0.45 & 8.90 \\
\hline 31.5 & 499.5 & 35049 & 0.50 & 9.04 \\
\hline 31.4 & 499.7 & 35051 & 0.54 & 9.20 \\
\hline 31.4 & 499.6 & 35053 & 0.59 & 9.37 \\
\hline 31.4 & 499.8 & 35054 & 0.65 & 9.65 \\
\hline 31.5 & 501.0 & 35056 & 0.70 & 10.01 \\
\hline 31.4 & 499.3 & 35048 & 0.75 & 10.41 \\
\hline 31.4 & 499.5 & 35043 & 0.80 & 10.90 \\
\hline
\end{tabular}




\begin{tabular}{|l|l|l|l|l|}
\hline \multicolumn{7}{|c|}{$\boldsymbol{T}_{\text {sat }}$} & $\boldsymbol{G}$ & $\boldsymbol{\phi}$ & \multicolumn{1}{|c|}{$\boldsymbol{\phi}$} & \multicolumn{1}{|c|}{$\boldsymbol{h}$} \\
\hline 31.3 & 500.1 & 35048 & 0.85 & 11.53 \\
\hline 31.2 & 498.7 & 44953 & 0.04 & 8.87 \\
\hline 31.2 & 500.9 & 44937 & 0.07 & 8.90 \\
\hline 31.2 & 498.7 & 44953 & 0.14 & 9.41 \\
\hline 31.1 & 500.9 & 44937 & 0.17 & 9.39 \\
\hline 31.3 & 501.5 & 44953 & 0.24 & 9.78 \\
\hline 31.3 & 499.8 & 44950 & 0.26 & 9.98 \\
\hline 31.3 & 501.1 & 44946 & 0.32 & 9.99 \\
\hline 31.4 & 499.2 & 44954 & 0.37 & 10.06 \\
\hline 31.5 & 500.7 & 44954 & 0.42 & 10.12 \\
\hline 31.5 & 500.4 & 44945 & 0.47 & 10.15 \\
\hline 31.4 & 499.2 & 44943 & 0.53 & 10.16 \\
\hline 31.5 & 500.8 & 44945 & 0.57 & 10.24 \\
\hline 31.5 & 499.2 & 44954 & 0.62 & 10.34 \\
\hline 31.5 & 499.4 & 44952 & 0.67 & 10.51 \\
\hline 31.5 & 500.1 & 44938 & 0.71 & 10.73 \\
\hline 31.5 & 498.8 & 44942 & 0.77 & 11.11 \\
\hline 31.4 & 499.6 & 44947 & 0.82 & 11.59 \\
\hline 31.3 & 499.6 & 44947 & 0.87 & 12.87 \\
\hline 31.3 & 500.1 & 55063 & 0.07 & 10.12 \\
\hline 31.3 & 499.1 & 55064 & 0.12 & 10.24 \\
\hline 31.2 & 500.1 & 55063 & 0.19 & 10.99 \\
\hline 31.2 & 499.1 & 55064 & 0.24 & 10.93 \\
\hline 31.4 & 500.7 & 55063 & 0.30 & 11.24 \\
\hline 31.5 & 499.6 & 55063 & 0.34 & 11.27 \\
\hline 31.5 & 500.0 & 55061 & 0.39 & 11.21 \\
\hline 31.4 & 500.9 & 55063 & 0.44 & 11.22 \\
\hline 31.5 & 500.7 & 55061 & 0.49 & 11.22 \\
\hline 31.5 & 499.7 & 55061 & 0.53 & 11.24 \\
\hline 31.6 & 499.9 & 55058 & 0.59 & 11.25 \\
\hline 31.6 & 499.8 & 55059 & 0.64 & 11.28 \\
\hline 31.4 & 500.8 & 55063 & 0.70 & 11.35 \\
\hline 31.4 & 499.7 & 55065 & 0.74 & 11.59 \\
\hline 31.4 & 500.8 & 55069 & 0.79 & 11.87 \\
\hline 31.3 & 500.8 & 55069 & 0.85 & 13.24 \\
\hline 31.3 & 499.7 & 64993 & 0.10 & 11.71 \\
\hline 31.4 & 499.6 & 64991 & 0.13 & 11.65 \\
\hline 31.6 & 498.6 & 64989 & 0.18 & 11.57 \\
\hline 31.6 & 500.1 & 64992 & 0.22 & 11.97 \\
\hline 31.2 & 499.7 & 64993 & 0.24 & 12.15 \\
\hline 31.3 & 499.6 & 64991 & 0.27 & 12.19 \\
\hline 31.5 & 498.6 & 64989 & 0.32 & 12.47 \\
\hline 31.5 & 500.1 & 64992 & 0.36 & 12.72 \\
\hline 31.5 & 499.5 & 64991 & 0.42 & 12.59 \\
\hline 31.5 & 500.1 & 64991 & 0.46 & 12.58 \\
\hline 31.6 & 499.9 & 64989 & 0.51 & 12.64 \\
\hline 31.6 & 501.4 & 64988 & 0.56 & 12.57 \\
\hline 31.6 & 499.6 & 64989 & 0.61 & 12.53 \\
\hline 31.5 & 499.7 & 64990 & 0.67 & 12.47 \\
\hline 31.5 & 500.9 & 64989 & 0.71 & 12.48 \\
\hline 31.5 & 501.0 & 64992 & 0.76 & 12.52 \\
\hline 31.4 & 500.9 & 64989 & 0.78 & 13.11 \\
\hline 31.4 & 501.0 & 64992 & 0.83 & 13.69 \\
\hline 31.4 & 499.6 & 73751 & 0.12 & 12.71 \\
\hline 31.3 & 498.9 & 73752 & 0.18 & 12.89 \\
\hline 31.6 & 498.6 & 73978 & 0.25 & 12.87 \\
\hline 31.3 & 499.6 & 73751 & 0.28 & 13.23 \\
\hline & & & & \\
\hline
\end{tabular}

\begin{tabular}{|l|l|l|l|l|}
\hline \multicolumn{1}{|c|}{$\boldsymbol{T}_{\text {sat }}$} & \multicolumn{1}{|c|}{$\boldsymbol{\phi}$} & \multicolumn{1}{|c|}{$\boldsymbol{\boldsymbol { h }}$} & \multicolumn{1}{c|}{} \\
\hline 31.2 & 498.9 & 73752 & 0.34 & 13.21 \\
\hline 31.5 & 498.6 & 73978 & 0.40 & 13.67 \\
\hline 31.6 & 502.8 & 73975 & 0.43 & 13.60 \\
\hline 31.6 & 500.9 & 73977 & 0.48 & 13.68 \\
\hline 31.7 & 500.9 & 74976 & 0.54 & 13.89 \\
\hline 31.6 & 500.9 & 74978 & 0.58 & 13.72 \\
\hline 31.6 & 500.4 & 74977 & 0.63 & 13.67 \\
\hline 31.6 & 499.7 & 74978 & 0.67 & 13.61 \\
\hline 31.6 & 499.4 & 74977 & 0.72 & 14.04 \\
\hline 31.5 & 499.7 & 74978 & 0.75 & 14.43 \\
\hline 31.5 & 499.4 & 74977 & 0.80 & 15.16 \\
\hline 30.9 & 599.0 & 15018 & 0.07 & 4.90 \\
\hline 31.3 & 598.6 & 15017 & 0.12 & 5.49 \\
\hline 31.3 & 599.1 & 15017 & 0.16 & 5.65 \\
\hline 31.2 & 599.2 & 15010 & 0.22 & 6.08 \\
\hline 31.4 & 599.6 & 15012 & 0.26 & 6.42 \\
\hline 31.4 & 599.5 & 15012 & 0.31 & 6.88 \\
\hline 31.4 & 601.6 & 15015 & 0.37 & 7.40 \\
\hline 31.4 & 598.7 & 15019 & 0.41 & 7.80 \\
\hline 31.5 & 599.6 & 15020 & 0.47 & 8.39 \\
\hline 31.6 & 598.9 & 15019 & 0.52 & 8.78 \\
\hline 31.6 & 600.7 & 15020 & 0.57 & 9.31 \\
\hline 31.7 & 599.3 & 15021 & 0.62 & 9.69 \\
\hline 31.6 & 599.8 & 15024 & 0.67 & 10.21 \\
\hline 31.5 & 599.3 & 15027 & 0.72 & 10.64 \\
\hline 31.5 & 599.0 & 15029 & 0.77 & 11.38 \\
\hline 31.5 & 600.2 & 15024 & 0.83 & 11.92 \\
\hline 31.5 & 599.2 & 15019 & 0.87 & 12.46 \\
\hline 31.5 & 599.8 & 15026 & 0.91 & 13.07 \\
\hline 31.0 & 598.6 & 25047 & 0.04 & 6.76 \\
\hline 31.1 & 599.2 & 25045 & 0.09 & 6.99 \\
\hline 31.2 & 600.3 & 25047 & 0.15 & 7.57 \\
\hline 31.3 & 600.2 & 25047 & 0.19 & 7.65 \\
\hline 31.4 & 599.6 & 25047 & 0.24 & 7.86 \\
\hline 31.4 & 599.7 & 25046 & 0.29 & 8.03 \\
\hline 31.4 & 599.4 & 25043 & 0.34 & 8.21 \\
\hline 31.4 & 600.9 & 25041 & 0.39 & 8.48 \\
\hline 31.4 & 600.6 & 25036 & 0.43 & 8.71 \\
\hline 31.4 & 601.3 & 25038 & 0.48 & 9.03 \\
\hline 31.6 & 600.3 & 25038 & 0.54 & 9.51 \\
\hline 31.6 & 600.1 & 25040 & 0.59 & 9.92 \\
\hline 31.6 & 599.9 & 25042 & 0.64 & 10.34 \\
\hline 31.5 & 599.1 & 25048 & 0.71 & 11.00 \\
\hline 31.5 & 601.3 & 25049 & 0.75 & 11.45 \\
\hline 31.5 & 599.4 & 25048 & 0.80 & 12.02 \\
\hline 31.6 & 600.6 & 25040 & 0.85 & 12.73 \\
\hline 31.5 & 600.9 & 25040 & 0.90 & 13.52 \\
\hline 31.0 & 600.0 & 35007 & 0.05 & 8.06 \\
\hline 31.2 & 599.8 & 35004 & 0.11 & 8.37 \\
\hline 31.3 & 601.8 & 35007 & 0.17 & 8.91 \\
\hline 31.4 & 598.8 & 35005 & 0.21 & 8.96 \\
\hline 31.3 & 598.5 & 35007 & 0.26 & 9.06 \\
\hline 31.4 & 600.3 & 35006 & 0.31 & 9.18 \\
\hline 31.5 & 599.9 & 35005 & 0.37 & 9.36 \\
\hline 31.5 & 599.1 & 35006 & 0.41 & 9.49 \\
\hline 31.4 & 600.6 & 35010 & 0.46 & 9.65 \\
\hline 31.5 & 601.0 & 35009 & 0.52 & 9.91 \\
\hline & & & & \\
\hline
\end{tabular}




\begin{tabular}{|c|c|c|c|c|}
\hline$T_{\text {sat }}$ & $G$ & $\phi$ & $x$ & $h$ \\
\hline 31.6 & 600.3 & 35010 & 0.56 & 10.17 \\
\hline 31.6 & 600.3 & 35011 & 0.61 & 10.48 \\
\hline 31.7 & 599.6 & 35013 & 0.67 & 10.97 \\
\hline 31.6 & 600.3 & 35015 & 0.72 & 11.43 \\
\hline 31.6 & 599.4 & 35006 & 0.76 & 11.91 \\
\hline 31.5 & 599.5 & 35006 & 0.82 & 12.62 \\
\hline 31.4 & 599.4 & 35010 & 0.87 & 13.36 \\
\hline 31.2 & 600.1 & 44902 & 0.01 & 9.03 \\
\hline 31.3 & 600.1 & 44914 & 0.06 & 9.00 \\
\hline 31.1 & 600.1 & 44902 & 0.09 & 9.37 \\
\hline 31.2 & 600.1 & 44914 & 0.14 & 9.47 \\
\hline 31.2 & 600.0 & 44908 & 0.21 & 10.32 \\
\hline 31.4 & 600.8 & 44905 & 0.24 & 10.42 \\
\hline 31.5 & 599.1 & 44906 & 0.29 & 10.42 \\
\hline 31.5 & 602.4 & 44904 & 0.34 & 10.54 \\
\hline 31.5 & 599.6 & 44904 & 0.39 & 10.63 \\
\hline 31.5 & 599.5 & 44904 & 0.44 & 10.69 \\
\hline 31.6 & 599.8 & 44904 & 0.49 & 10.86 \\
\hline 31.7 & 599.6 & 44908 & 0.54 & 10.99 \\
\hline 31.6 & 602.4 & 44906 & 0.59 & 11.15 \\
\hline 31.6 & 600.0 & 44906 & 0.64 & 11.37 \\
\hline 31.7 & 600.5 & 44908 & 0.70 & 11.72 \\
\hline 31.7 & 599.7 & 44910 & 0.75 & 12.18 \\
\hline 31.7 & 599.3 & 44914 & 0.81 & 12.78 \\
\hline 31.6 & 600.0 & 44896 & 0.84 & 13.30 \\
\hline 31.2 & 598.1 & 54961 & 0.04 & 10.73 \\
\hline 31.4 & 600.4 & 54959 & 0.09 & 10.81 \\
\hline 31.2 & 598.1 & 54961 & 0.14 & 11.03 \\
\hline 31.3 & 600.4 & 54959 & 0.17 & 11.08 \\
\hline 31.2 & 602.0 & 54965 & 0.24 & 11.35 \\
\hline 31.5 & 600.2 & 54961 & 0.28 & 11.86 \\
\hline 31.6 & 600.2 & 54960 & 0.32 & 11.87 \\
\hline 31.6 & 598.4 & 54961 & 0.36 & 11.88 \\
\hline 31.7 & 599.7 & 54958 & 0.41 & 11.97 \\
\hline 31.8 & 600.1 & 54959 & 0.47 & 12.02 \\
\hline 31.8 & 601.6 & 54957 & 0.51 & 12.06 \\
\hline 31.7 & 600.6 & 54959 & 0.57 & 12.09 \\
\hline 31.6 & 599.8 & 54961 & 0.61 & 12.16 \\
\hline 31.6 & 599.1 & 54962 & 0.66 & 12.27 \\
\hline 31.6 & 599.5 & 54963 & 0.73 & 12.49 \\
\hline 31.6 & 600.0 & 54966 & 0.78 & 12.79 \\
\hline 31.4 & 600.0 & 54953 & 0.84 & 13.36 \\
\hline 31.3 & 599.8 & 64981 & 0.07 & 11.39 \\
\hline 31.5 & 599.5 & 64978 & 0.12 & 11.52 \\
\hline 31.4 & 599.2 & 64978 & 0.17 & 11.50 \\
\hline 31.2 & 599.8 & 64981 & 0.18 & 12.16 \\
\hline 31.4 & 599.5 & 64978 & 0.24 & 12.26 \\
\hline 31.3 & 599.2 & 64978 & 0.28 & 12.19 \\
\hline 31.6 & 600.1 & 64980 & 0.34 & 12.85 \\
\hline 31.6 & 601.0 & 64979 & 0.39 & 12.81 \\
\hline 31.7 & 601.3 & 64977 & 0.43 & 12.89 \\
\hline 31.8 & 600.4 & 64976 & 0.49 & 12.92 \\
\hline 31.6 & 599.4 & 64978 & 0.54 & 12.89 \\
\hline 31.7 & 598.3 & 64977 & 0.59 & 12.93 \\
\hline 31.7 & 599.2 & 64976 & 0.64 & 12.96 \\
\hline 31.7 & 598.6 & 64977 & 0.69 & 13.03 \\
\hline 31.7 & 599.3 & 64979 & 0.74 & 13.14 \\
\hline
\end{tabular}

\begin{tabular}{|c|c|c|c|c|}
\hline$T_{\text {sat }}$ & $G$ & $\phi$ & $x$ & $h$ \\
\hline 31.6 & 601.1 & 64984 & 0.79 & 13.38 \\
\hline 31.4 & 600.5 & 74974 & 0.09 & 12.52 \\
\hline 31.5 & 600.2 & 74976 & 0.13 & 12.57 \\
\hline 31.7 & 596.1 & 74950 & 0.21 & 13.19 \\
\hline 31.3 & 600.5 & 74974 & 0.23 & 13.48 \\
\hline 31.4 & 600.2 & 74976 & 0.26 & 13.56 \\
\hline 31.6 & 596.1 & 74950 & 0.34 & 13.97 \\
\hline 31.6 & 600.5 & 74962 & 0.37 & 13.99 \\
\hline 31.6 & 599.8 & 74948 & 0.42 & 13.92 \\
\hline 31.8 & 598.2 & 74976 & 0.47 & 14.04 \\
\hline 31.8 & 600.2 & 74975 & 0.51 & 14.03 \\
\hline 31.8 & 599.8 & 74971 & 0.57 & 13.97 \\
\hline 31.8 & 599.0 & 74976 & 0.62 & 13.93 \\
\hline 31.7 & 600.1 & 74975 & 0.67 & 13.88 \\
\hline 31.7 & 598.6 & 74972 & 0.72 & 13.91 \\
\hline 31.6 & 599.4 & 74976 & 0.76 & 13.93 \\
\hline 30.9 & 699.3 & 15097 & 0.03 & 4.57 \\
\hline 31.0 & 700.2 & 15093 & 0.07 & 4.93 \\
\hline 31.3 & 699.8 & 15097 & 0.12 & 5.16 \\
\hline 31.3 & 700.0 & 15097 & 0.17 & 5.45 \\
\hline 31.3 & 700.7 & 15096 & 0.21 & 5.91 \\
\hline 31.4 & 699.8 & 15094 & 0.27 & 6.54 \\
\hline 31.5 & 700.0 & 15095 & 0.31 & 7.20 \\
\hline 31.6 & 700.1 & 15097 & 0.37 & 7.91 \\
\hline 31.6 & 700.3 & 15101 & 0.41 & 8.51 \\
\hline 31.6 & 700.0 & 15102 & 0.47 & 9.20 \\
\hline 31.7 & 700.2 & 15102 & 0.52 & 9.87 \\
\hline 31.7 & 699.5 & 15104 & 0.58 & 10.46 \\
\hline 31.7 & 699.8 & 15106 & 0.62 & 10.83 \\
\hline 31.6 & 699.5 & 15110 & 0.67 & 11.33 \\
\hline 31.8 & 699.9 & 15107 & 0.72 & 11.90 \\
\hline 31.7 & 700.3 & 15107 & 0.77 & 12.45 \\
\hline 31.6 & 699.4 & 15107 & 0.83 & 13.08 \\
\hline 31.5 & 699.2 & 15103 & 0.89 & 13.74 \\
\hline 31.6 & 699.3 & 15103 & 0.92 & 14.39 \\
\hline 31.0 & 698.9 & 24980 & 0.05 & 6.61 \\
\hline 31.3 & 699.6 & 24982 & 0.11 & 7.41 \\
\hline 31.2 & 699.8 & 24969 & 0.15 & 7.63 \\
\hline 31.4 & 698.9 & 24979 & 0.20 & 7.88 \\
\hline 31.5 & 699.2 & 24969 & 0.25 & 8.21 \\
\hline 31.5 & 700.0 & 24971 & 0.30 & 8.49 \\
\hline 31.6 & 700.3 & 24970 & 0.35 & 8.83 \\
\hline 31.7 & 700.2 & 24971 & 0.40 & 9.18 \\
\hline 31.6 & 698.7 & 24975 & 0.44 & 9.56 \\
\hline 31.6 & 699.0 & 24978 & 0.50 & 10.05 \\
\hline 31.7 & 699.6 & 24976 & 0.54 & 10.45 \\
\hline 31.8 & 700.1 & 24977 & 0.60 & 11.00 \\
\hline 31.7 & 699.7 & 24982 & 0.65 & 11.55 \\
\hline 31.6 & 700.0 & 24981 & 0.70 & 12.11 \\
\hline 31.5 & 700.3 & 24974 & 0.76 & 12.81 \\
\hline 31.6 & 700.3 & 24973 & 0.81 & 13.26 \\
\hline 31.6 & 699.5 & 24975 & 0.86 & 14.02 \\
\hline 31.6 & 699.5 & 24978 & 0.91 & 14.83 \\
\hline 31.0 & 699.4 & 34989 & 0.03 & 8.01 \\
\hline 31.0 & 699.4 & 34997 & 0.08 & 8.29 \\
\hline 31.3 & 705.2 & 34989 & 0.14 & 9.15 \\
\hline 31.5 & 698.5 & 34988 & 0.18 & 9.63 \\
\hline
\end{tabular}




\begin{tabular}{|l|l|l|l|l|}
\hline \multicolumn{7}{|c|}{$\boldsymbol{T}_{\text {sat }}$} & \multicolumn{1}{|c|}{$\boldsymbol{\phi}$} & $\boldsymbol{1}$ & \multicolumn{1}{|c|}{$\boldsymbol{h}$} \\
\hline 31.5 & 699.9 & 34988 & 0.23 & 9.50 \\
\hline 31.5 & 699.9 & 34989 & 0.27 & 9.70 \\
\hline 31.5 & 693.2 & 34989 & 0.33 & 9.93 \\
\hline 31.7 & 697.2 & 34987 & 0.38 & 10.06 \\
\hline 31.7 & 701.2 & 34988 & 0.43 & 10.33 \\
\hline 31.6 & 699.9 & 34992 & 0.47 & 10.55 \\
\hline 31.6 & 698.5 & 34994 & 0.53 & 10.89 \\
\hline 31.8 & 697.2 & 34993 & 0.58 & 11.25 \\
\hline 31.8 & 698.5 & 34994 & 0.63 & 11.75 \\
\hline 31.9 & 699.9 & 34995 & 0.68 & 12.14 \\
\hline 31.7 & 699.2 & 34998 & 0.73 & 12.65 \\
\hline 31.7 & 697.2 & 34985 & 0.78 & 13.51 \\
\hline 31.6 & 698.5 & 34989 & 0.83 & 13.97 \\
\hline 31.6 & 697.2 & 34992 & 0.88 & 14.85 \\
\hline 31.1 & 701.9 & 44967 & 0.07 & 9.79 \\
\hline 31.2 & 699.9 & 44965 & 0.10 & 10.00 \\
\hline 30.7 & 698.5 & 44963 & 0.17 & 8.77 \\
\hline 31.6 & 701.2 & 44962 & 0.21 & 10.24 \\
\hline 31.6 & 698.5 & 44984 & 0.25 & 10.46 \\
\hline 31.5 & 697.2 & 44967 & 0.31 & 10.46 \\
\hline 31.7 & 703.9 & 44984 & 0.35 & 10.74 \\
\hline 31.6 & 699.9 & 44964 & 0.40 & 10.66 \\
\hline 31.7 & 697.2 & 44967 & 0.45 & 10.97 \\
\hline 31.8 & 701.2 & 44968 & 0.50 & 11.10 \\
\hline 31.8 & 702.5 & 44964 & 0.56 & 11.46 \\
\hline 31.8 & 705.2 & 44968 & 0.61 & 11.78 \\
\hline 31.7 & 695.9 & 44975 & 0.67 & 12.19 \\
\hline 31.7 & 697.2 & 44974 & 0.72 & 12.83 \\
\hline 31.7 & 698.5 & 44955 & 0.77 & 13.32 \\
\hline 31.7 & 705.2 & 44963 & 0.80 & 13.95 \\
\hline 31.5 & 701.2 & 44964 & 0.85 & 14.50 \\
\hline 31.2 & 695.9 & 54939 & 0.07 & 10.61 \\
\hline 31.3 & 698.9 & 54937 & 0.09 & 10.74 \\
\hline 31.2 & 695.9 & 54939 & 0.11 & 11.25 \\
\hline 31.3 & 698.9 & 54937 & 0.13 & 11.36 \\
\hline 31.3 & 699.4 & 54937 & 0.18 & 11.47 \\
\hline 31.6 & 699.5 & 54937 & 0.25 & 12.13 \\
\hline 31.6 & 700.0 & 54936 & 0.28 & 12.13 \\
\hline 31.8 & 701.8 & 54934 & 0.33 & 12.32 \\
\hline 31.8 & 699.2 & 54933 & 0.38 & 12.40 \\
\hline 31.7 & 698.7 & 54936 & 0.44 & 12.49 \\
\hline 31.8 & 698.2 & 54935 & 0.50 & 12.61 \\
\hline 31.8 & 701.0 & 54936 & 0.54 & 12.73 \\
\hline 31.8 & 699.3 & 54936 & 0.58 & 12.81 \\
\hline 31.9 & 700.0 & 54936 & 0.63 & 12.98 \\
\hline 31.9 & 699.5 & 54937 & 0.68 & 13.16 \\
\hline 31.8 & 699.7 & 54940 & 0.73 & 13.48 \\
\hline 31.7 & 700.0 & 54923 & 0.79 & 14.08 \\
\hline 31.4 & 701.2 & 54933 & 0.84 & 15.01 \\
\hline 31.4 & 699.9 & 64952 & 0.04 & 11.56 \\
\hline 31.4 & 699.9 & 64947 & 0.07 & 11.81 \\
\hline 31.6 & 705.2 & 64949 & 0.11 & 11.93 \\
\hline 31.3 & 699.9 & 64952 & 0.14 & 12.34 \\
\hline 31.4 & 699.9 & 64947 & 0.17 & 12.26 \\
\hline 31.5 & 705.2 & 64949 & 0.21 & 12.48 \\
\hline 31.7 & 705.2 & 64953 & 0.27 & 13.27 \\
\hline 31.7 & 698.5 & 64952 & 0.32 & 13.32 \\
\hline & & & & \\
\hline
\end{tabular}

\begin{tabular}{|l|l|l|l|l|}
\hline $\boldsymbol{T}_{\text {sat }}$ & $\boldsymbol{G}$ & $\boldsymbol{\phi}$ & $\boldsymbol{x}$ & \multicolumn{1}{|c|}{} \\
\hline 31.9 & 701.2 & 64950 & 0.36 & 13.38 \\
\hline 31.9 & 703.9 & 64950 & 0.41 & 13.40 \\
\hline 31.9 & 698.5 & 64951 & 0.46 & 13.44 \\
\hline 31.9 & 701.2 & 64949 & 0.51 & 13.53 \\
\hline 32.0 & 701.2 & 64944 & 0.57 & 13.59 \\
\hline 32.0 & 699.9 & 64975 & 0.61 & 13.77 \\
\hline 32.0 & 697.2 & 64946 & 0.66 & 13.80 \\
\hline 31.8 & 698.5 & 64954 & 0.72 & 13.94 \\
\hline 31.8 & 698.5 & 64957 & 0.76 & 14.24 \\
\hline 31.7 & 699.9 & 64963 & 0.82 & 14.79 \\
\hline 40.8 & 399.9 & 14815 & 0.05 & 5.41 \\
\hline 40.9 & 403.9 & 14814 & 0.09 & 5.50 \\
\hline 40.7 & 402.6 & 14817 & 0.15 & 5.50 \\
\hline 40.8 & 403.9 & 14820 & 0.20 & 5.68 \\
\hline 40.8 & 399.9 & 14817 & 0.24 & 5.68 \\
\hline 40.9 & 402.6 & 14819 & 0.28 & 5.64 \\
\hline 40.9 & 403.9 & 14817 & 0.34 & 5.79 \\
\hline 40.9 & 403.9 & 14817 & 0.39 & 5.88 \\
\hline 40.9 & 397.3 & 14820 & 0.46 & 6.03 \\
\hline 40.9 & 397.3 & 14818 & 0.50 & 6.06 \\
\hline 40.9 & 399.9 & 14819 & 0.55 & 6.17 \\
\hline 40.9 & 399.9 & 14822 & 0.59 & 6.30 \\
\hline 40.9 & 401.3 & 14822 & 0.64 & 6.61 \\
\hline 40.9 & 403.9 & 14824 & 0.68 & 6.84 \\
\hline 40.9 & 401.3 & 14827 & 0.74 & 7.28 \\
\hline 40.9 & 403.9 & 14818 & 0.80 & 7.95 \\
\hline 40.9 & 398.6 & 14821 & 0.85 & 8.50 \\
\hline 40.9 & 397.3 & 14825 & 0.91 & 9.32 \\
\hline 41.0 & 403.9 & 24822 & 0.02 & 7.96 \\
\hline 41.0 & 402.6 & 24819 & 0.06 & 7.75 \\
\hline 41.1 & 397.3 & 24835 & 0.11 & 7.80 \\
\hline 41.1 & 401.3 & 24834 & 0.15 & 7.92 \\
\hline 40.9 & 401.3 & 24836 & 0.21 & 7.70 \\
\hline 41.0 & 395.9 & 24836 & 0.26 & 7.86 \\
\hline 41.0 & 393.3 & 24838 & 0.31 & 8.03 \\
\hline 41.0 & 401.3 & 24838 & 0.35 & 8.06 \\
\hline 41.0 & 401.3 & 24822 & 0.40 & 8.15 \\
\hline 40.8 & 403.9 & 24826 & 0.45 & 8.12 \\
\hline 41.0 & 395.9 & 24841 & 0.51 & 8.38 \\
\hline 41.0 & 399.9 & 24839 & 0.55 & 8.36 \\
\hline 41.1 & 401.3 & 24837 & 0.60 & 8.39 \\
\hline 41.1 & 402.6 & 24838 & 0.65 & 8.45 \\
\hline 41.0 & 395.9 & 24825 & 0.72 & 8.44 \\
\hline 40.8 & 401.3 & 24829 & 0.75 & 8.59 \\
\hline 40.8 & 398.6 & 24833 & 0.81 & 9.30 \\
\hline 40.8 & 401.3 & 24835 & 0.86 & 9.72 \\
\hline 40.9 & 397.3 & 34764 & 0.07 & 9.48 \\
\hline 41.0 & 397.3 & 34762 & 0.12 & 9.54 \\
\hline 41.0 & 402.6 & 34761 & 0.16 & 9.70 \\
\hline 41.0 & 403.9 & 34760 & 0.21 & 9.60 \\
\hline 40.9 & 403.9 & 34760 & 0.28 & 9.25 \\
\hline 41.1 & 403.9 & 34760 & 0.31 & 9.62 \\
\hline 41.1 & 403.9 & 34759 & 0.35 & 9.71 \\
\hline 41.1 & 401.3 & 34759 & 0.41 & 9.68 \\
\hline 41.2 & 401.3 & 34758 & 0.46 & 9.94 \\
\hline 41.2 & 395.9 & 34758 & 0.52 & 9.86 \\
\hline 41.2 & 397.3 & 34758 & 0.57 & 9.81 \\
\hline & & & & \\
\hline
\end{tabular}




\begin{tabular}{|c|c|c|c|c|}
\hline$T_{\text {sat }}$ & $G$ & $\phi$ & $x$ & $h$ \\
\hline 41.3 & 393.3 & 34757 & 0.63 & 9.89 \\
\hline 41.3 & 402.6 & 34757 & 0.67 & 9.97 \\
\hline 41.3 & 399.9 & 34758 & 0.72 & 10.08 \\
\hline 41.3 & 397.3 & 34761 & 0.78 & 10.64 \\
\hline 41.3 & 398.6 & 34763 & 0.82 & 10.68 \\
\hline 41.1 & 402.6 & 44769 & 0.06 & 10.80 \\
\hline 41.1 & 402.6 & 44769 & 0.12 & 11.39 \\
\hline 41.1 & 399.9 & 44768 & 0.18 & 11.51 \\
\hline 41.2 & 401.3 & 44768 & 0.22 & 11.52 \\
\hline 41.2 & 395.9 & 44789 & 0.29 & 11.50 \\
\hline 40.9 & 401.3 & 44789 & 0.33 & 11.15 \\
\hline 41.2 & 401.3 & 44766 & 0.37 & 11.30 \\
\hline 41.3 & 398.6 & 44765 & 0.42 & 11.47 \\
\hline 41.3 & 402.6 & 44765 & 0.47 & 11.58 \\
\hline 41.3 & 402.6 & 44787 & 0.52 & 11.61 \\
\hline 41.4 & 395.9 & 44787 & 0.59 & 11.61 \\
\hline 41.2 & 395.9 & 44768 & 0.64 & 11.47 \\
\hline 41.1 & 397.3 & 44771 & 0.69 & 11.62 \\
\hline 41.0 & 398.6 & 44774 & 0.73 & 11.88 \\
\hline 40.8 & 399.9 & 44779 & 0.78 & 12.29 \\
\hline 40.9 & 405.3 & 54744 & 0.03 & 12.13 \\
\hline 41.0 & 397.3 & 54742 & 0.09 & 11.98 \\
\hline 41.1 & 401.3 & 54741 & 0.13 & 11.84 \\
\hline 40.9 & 405.3 & 54744 & 0.18 & 12.92 \\
\hline 41.0 & 397.3 & 54742 & 0.24 & 12.91 \\
\hline 41.1 & 401.3 & 54741 & 0.29 & 12.94 \\
\hline 41.1 & 398.6 & 54764 & 0.34 & 13.02 \\
\hline 41.2 & 401.3 & 54764 & 0.39 & 13.41 \\
\hline 41.0 & 402.6 & 54762 & 0.43 & 12.44 \\
\hline 41.1 & 395.9 & 54746 & 0.49 & 13.40 \\
\hline 41.0 & 401.3 & 54743 & 0.54 & 13.16 \\
\hline 40.9 & 402.6 & 54745 & 0.58 & 13.03 \\
\hline 40.9 & 401.3 & 54744 & 0.64 & 13.04 \\
\hline 40.9 & 398.6 & 54746 & 0.69 & 13.27 \\
\hline 40.8 & 399.9 & 54773 & 0.74 & 13.57 \\
\hline 40.9 & 398.6 & 54746 & 0.77 & 13.94 \\
\hline 40.8 & 399.9 & 54773 & 0.81 & 14.06 \\
\hline 40.9 & 394.6 & 64791 & 0.07 & 13.87 \\
\hline 41.0 & 398.6 & 64785 & 0.12 & 13.70 \\
\hline 41.1 & 399.9 & 64788 & 0.16 & 13.70 \\
\hline 41.2 & 398.6 & 64787 & 0.22 & 13.92 \\
\hline 40.9 & 394.6 & 64791 & 0.26 & 14.48 \\
\hline 41.0 & 398.6 & 64785 & 0.31 & 14.56 \\
\hline 41.1 & 399.9 & 64788 & 0.35 & 14.53 \\
\hline 41.1 & 398.6 & 64787 & 0.40 & 14.60 \\
\hline 41.3 & 401.3 & 64811 & 0.46 & 14.72 \\
\hline 41.2 & 402.6 & 64810 & 0.50 & 13.97 \\
\hline 41.2 & 403.9 & 64811 & 0.54 & 14.66 \\
\hline 41.3 & 398.6 & 64812 & 0.60 & 14.91 \\
\hline 41.3 & 401.3 & 64810 & 0.63 & 14.70 \\
\hline 41.3 & 398.6 & 64812 & 0.69 & 15.22 \\
\hline 41.3 & 401.3 & 64810 & 0.72 & 15.26 \\
\hline 40.9 & 599.9 & 14814 & 0.01 & 5.54 \\
\hline 41.0 & 597.2 & 14810 & 0.07 & 5.34 \\
\hline 40.6 & 598.6 & 14822 & 0.12 & 5.39 \\
\hline 40.8 & 599.9 & 14818 & 0.17 & 5.60 \\
\hline 40.9 & 598.6 & 14818 & 0.21 & 5.80 \\
\hline
\end{tabular}

\begin{tabular}{|c|c|c|c|c|}
\hline$T_{\text {sat }}$ & $G$ & $\phi$ & $x$ & $h$ \\
\hline 41.0 & 598.6 & 14816 & 0.26 & 5.98 \\
\hline 41.1 & 598.6 & 14816 & 0.31 & 6.09 \\
\hline 41.1 & 599.9 & 14816 & 0.36 & 6.33 \\
\hline 41.1 & 603.9 & 14817 & 0.41 & 6.55 \\
\hline 41.2 & 597.2 & 14818 & 0.46 & 6.78 \\
\hline 41.2 & 594.6 & 14820 & 0.52 & 7.29 \\
\hline 41.2 & 597.2 & 14823 & 0.57 & 7.67 \\
\hline 41.2 & 611.9 & 14828 & 0.62 & 8.42 \\
\hline 41.2 & 602.6 & 14816 & 0.68 & 8.80 \\
\hline 41.2 & 603.9 & 14818 & 0.72 & 9.46 \\
\hline 41.1 & 601.2 & 14822 & 0.79 & 10.08 \\
\hline 41.1 & 598.6 & 14824 & 0.82 & 10.24 \\
\hline 41.0 & 597.2 & 14827 & 0.88 & 10.98 \\
\hline 41.0 & 598.6 & 14828 & 0.91 & 11.66 \\
\hline 40.9 & 598.6 & 24779 & 0.04 & 7.47 \\
\hline 40.9 & 597.2 & 24777 & 0.09 & 7.48 \\
\hline 41.1 & 602.6 & 24777 & 0.13 & 7.91 \\
\hline 41.0 & 599.9 & 24775 & 0.18 & 7.54 \\
\hline 41.2 & 602.6 & 24773 & 0.23 & 7.74 \\
\hline 41.3 & 603.9 & 24772 & 0.28 & 7.89 \\
\hline 40.9 & 605.2 & 24781 & 0.32 & 7.95 \\
\hline 41.1 & 601.2 & 24778 & 0.38 & 8.08 \\
\hline 41.2 & 601.2 & 24777 & 0.43 & 8.30 \\
\hline 41.3 & 595.9 & 24776 & 0.50 & 8.41 \\
\hline 41.5 & 595.9 & 24769 & 0.55 & 8.61 \\
\hline 41.3 & 601.2 & 24777 & 0.59 & 8.53 \\
\hline 41.2 & 619.9 & 24780 & 0.62 & 8.87 \\
\hline 41.2 & 598.6 & 24783 & 0.70 & 9.25 \\
\hline 41.2 & 603.9 & 24769 & 0.74 & 9.72 \\
\hline 41.1 & 601.2 & 24772 & 0.79 & 10.12 \\
\hline 41.1 & 603.9 & 24775 & 0.84 & 10.77 \\
\hline 41.1 & 599.9 & 24779 & 0.89 & 11.33 \\
\hline 41.1 & 597.2 & 34758 & 0.07 & 9.32 \\
\hline 41.2 & 606.6 & 34756 & 0.10 & 9.35 \\
\hline 41.0 & 601.2 & 34760 & 0.15 & 9.42 \\
\hline 41.1 & 602.6 & 34763 & 0.22 & 10.35 \\
\hline 41.1 & 597.2 & 34763 & 0.26 & 10.30 \\
\hline 41.2 & 601.2 & 34762 & 0.30 & 10.42 \\
\hline 41.2 & 599.9 & 34762 & 0.36 & 10.57 \\
\hline 41.3 & 598.6 & 34762 & 0.41 & 10.69 \\
\hline 41.3 & 601.2 & 34762 & 0.45 & 10.66 \\
\hline 41.3 & 602.6 & 34762 & 0.51 & 10.80 \\
\hline 41.3 & 598.6 & 34763 & 0.56 & 10.85 \\
\hline 41.2 & 614.6 & 34764 & 0.59 & 10.80 \\
\hline 41.2 & 603.9 & 34765 & 0.65 & 10.97 \\
\hline 41.1 & 594.6 & 34766 & 0.73 & 10.99 \\
\hline 41.1 & 601.2 & 34768 & 0.76 & 11.24 \\
\hline 41.0 & 597.2 & 34751 & 0.82 & 11.38 \\
\hline 41.0 & 603.9 & 34755 & 0.85 & 11.87 \\
\hline 40.9 & 599.9 & 44772 & 0.16 & 10.16 \\
\hline 41.1 & 599.9 & 44771 & 0.20 & 10.54 \\
\hline 40.8 & 599.9 & 44772 & 0.24 & 11.11 \\
\hline 41.0 & 599.9 & 44771 & 0.29 & 11.53 \\
\hline 41.2 & 597.2 & 44769 & 0.33 & 11.66 \\
\hline 41.3 & 598.6 & 44766 & 0.38 & 11.76 \\
\hline 41.4 & 599.9 & 44764 & 0.43 & 11.88 \\
\hline 41.5 & 605.2 & 44786 & 0.48 & 11.88 \\
\hline
\end{tabular}




\begin{tabular}{|c|c|c|c|c|}
\hline $\boldsymbol{T}_{\text {sat }}$ & $\boldsymbol{G}$ & $\boldsymbol{\phi}$ & $\boldsymbol{x}$ & $\boldsymbol{h}$ \\
\hline 41.5 & 602.6 & 44786 & 0.53 & 11.88 \\
\hline 41.1 & 598.6 & 44771 & 0.60 & 11.68 \\
\hline 41.2 & 595.9 & 44770 & 0.65 & 11.93 \\
\hline & & & & \\
\hline
\end{tabular}

\begin{tabular}{|c|c|c|c|c|}
\hline $\boldsymbol{T}_{\text {sat }}$ & $\boldsymbol{G}$ & $\boldsymbol{\phi}$ & $\boldsymbol{x}$ & $\boldsymbol{h}$ \\
\hline 41.3 & 601.2 & 44768 & 0.69 & 11.85 \\
\hline 41.4 & 601.2 & 44765 & 0.74 & 11.97 \\
\hline 41.3 & 601.2 & 44769 & 0.79 & 12.03 \\
\hline 40.4 & 601.2 & 44768 & 0.84 & 12.42 \\
\hline
\end{tabular}

Tabela B.12. R134a, geometría triangular.

\begin{tabular}{|c|c|c|c|c|}
\hline$T_{\text {sat }}$ & $G$ & $\phi$ & $x$ & $h$ \\
\hline 31.5 & 200.7 & 14983 & 0.05 & 6.64 \\
\hline 31.5 & 201.7 & 14984 & 0.09 & 6.83 \\
\hline 31.4 & 203.9 & 14987 & 0.15 & 6.72 \\
\hline 31.4 & 200.7 & 14983 & 0.21 & 6.70 \\
\hline 31.5 & 201.7 & 14984 & 0.26 & 6.72 \\
\hline 31.4 & 203.9 & 14987 & 0.31 & 6.73 \\
\hline 31.3 & 201.7 & 15075 & 0.36 & 6.48 \\
\hline 30.8 & 198.6 & 14991 & 0.43 & 7.00 \\
\hline 30.9 & 193.5 & 14991 & 0.48 & 7.15 \\
\hline 31.0 & 202.1 & 14989 & 0.51 & 7.26 \\
\hline 31.1 & 200.9 & 14987 & 0.56 & 7.21 \\
\hline 31.2 & 199.4 & 14985 & 0.61 & 7.24 \\
\hline 31.2 & 200.7 & 14984 & 0.66 & 7.37 \\
\hline 31.3 & 204.8 & 14983 & 0.71 & 7.47 \\
\hline 31.4 & 199.7 & 14984 & 0.77 & 7.70 \\
\hline 31.4 & 199.2 & 14987 & 0.82 & 7.84 \\
\hline 31.4 & 200.0 & 14984 & 0.85 & 8.26 \\
\hline 31.4 & 299.0 & 15066 & 0.02 & 6.92 \\
\hline 31.4 & 299.5 & 15068 & 0.07 & 7.10 \\
\hline 31.2 & 298.3 & 15077 & 0.14 & 7.19 \\
\hline 31.3 & 302.1 & 15075 & 0.17 & 7.30 \\
\hline 30.8 & 299.3 & 15075 & 0.23 & 6.90 \\
\hline 30.8 & 301.8 & 15072 & 0.27 & 6.36 \\
\hline 30.9 & 301.0 & 15070 & 0.33 & 6.48 \\
\hline 30.6 & 299.6 & 15079 & 0.39 & 6.57 \\
\hline 30.7 & 299.9 & 15076 & 0.43 & 6.50 \\
\hline 31.3 & 299.9 & 15076 & 0.49 & 6.38 \\
\hline 30.9 & 299.0 & 15073 & 0.52 & 6.67 \\
\hline 31.0 & 283.2 & 15072 & 0.61 & 6.82 \\
\hline 30.8 & 298.2 & 15077 & 0.63 & 6.98 \\
\hline 30.6 & 300.5 & 15081 & 0.68 & 7.08 \\
\hline 30.7 & 298.0 & 15084 & 0.73 & 7.24 \\
\hline 30.7 & 303.2 & 15080 & 0.76 & 7.33 \\
\hline 31.3 & 300.8 & 24981 & 0.05 & 7.87 \\
\hline 31.4 & 300.1 & 24983 & 0.10 & 8.04 \\
\hline 31.5 & 300.8 & 24995 & 0.16 & 8.11 \\
\hline 31.5 & 297.5 & 24989 & 0.23 & 8.06 \\
\hline 31.5 & 298.5 & 24989 & 0.27 & 8.39 \\
\hline 31.6 & 300.9 & 24990 & 0.30 & 8.39 \\
\hline 30.7 & 300.5 & 24991 & 0.36 & 7.72 \\
\hline 30.7 & 301.3 & 24991 & 0.40 & 7.74 \\
\hline 30.7 & 301.3 & 24992 & 0.45 & 7.63 \\
\hline 30.7 & 301.0 & 24991 & 0.51 & 7.58 \\
\hline 30.8 & 296.4 & 24992 & 0.58 & 7.77 \\
\hline 30.8 & 297.2 & 24992 & 0.61 & 7.74 \\
\hline 30.8 & 297.9 & 24995 & 0.67 & 7.88 \\
\hline
\end{tabular}

\begin{tabular}{|c|c|c|c|c|}
\hline$T_{\text {sat }}$ & $G$ & $\phi$ & $x$ & $\boldsymbol{h}$ \\
\hline 30.6 & 301.0 & 24991 & 0.69 & 7.65 \\
\hline 30.6 & 296.4 & 24992 & 0.76 & 7.78 \\
\hline 30.6 & 297.2 & 24992 & 0.80 & 7.81 \\
\hline 30.7 & 297.9 & 24995 & 0.85 & 8.06 \\
\hline 31.6 & 298.2 & 34969 & 0.12 & 11.05 \\
\hline 31.6 & 298.1 & 34968 & 0.15 & 11.12 \\
\hline 31.6 & 299.9 & 34972 & 0.19 & 11.19 \\
\hline 31.7 & 302.0 & 34972 & 0.25 & 11.25 \\
\hline 30.8 & 302.9 & 34975 & 0.30 & 9.81 \\
\hline 30.8 & 296.9 & 34963 & 0.35 & 9.70 \\
\hline 30.8 & 298.0 & 34966 & 0.39 & 9.67 \\
\hline 30.9 & 300.4 & 34968 & 0.44 & 10.10 \\
\hline 30.9 & 297.9 & 34971 & 0.49 & 10.12 \\
\hline 30.9 & 299.8 & 34976 & 0.53 & 9.75 \\
\hline 30.7 & 302.9 & 34975 & 0.55 & 9.23 \\
\hline 30.7 & 296.9 & 34963 & 0.61 & 9.63 \\
\hline 30.7 & 298.0 & 34966 & 0.65 & 9.36 \\
\hline 30.7 & 300.4 & 34968 & 0.70 & 9.39 \\
\hline 30.7 & 297.9 & 34971 & 0.75 & 9.23 \\
\hline 30.7 & 299.8 & 34976 & 0.79 & 9.30 \\
\hline 31.2 & 399.1 & 15025 & 0.08 & 7.48 \\
\hline 31.3 & 401.3 & 15026 & 0.13 & 7.23 \\
\hline 30.6 & 399.7 & 15026 & 0.17 & 6.40 \\
\hline 30.7 & 400.6 & 15026 & 0.23 & 6.23 \\
\hline 30.9 & 401.9 & 15032 & 0.28 & 6.11 \\
\hline 31.0 & 399.0 & 15030 & 0.33 & 6.17 \\
\hline 31.0 & 401.7 & 15030 & 0.38 & 6.29 \\
\hline 31.0 & 399.0 & 15021 & 0.43 & 6.40 \\
\hline 31.0 & 400.9 & 15023 & 0.48 & 6.56 \\
\hline 31.0 & 399.8 & 15026 & 0.52 & 6.64 \\
\hline 31.0 & 398.4 & 15026 & 0.58 & 6.85 \\
\hline 31.0 & 400.4 & 15026 & 0.62 & 6.95 \\
\hline 31.0 & 401.6 & 15029 & 0.67 & 7.20 \\
\hline 31.0 & 398.9 & 15032 & 0.73 & 7.42 \\
\hline 31.0 & 399.0 & 15032 & 0.77 & 7.50 \\
\hline 31.0 & 396.9 & 15034 & 0.83 & 7.74 \\
\hline 31.6 & 396.2 & 24980 & 0.04 & 8.57 \\
\hline 31.6 & 401.6 & 24981 & 0.09 & 8.77 \\
\hline 31.7 & 399.9 & 24981 & 0.14 & 8.41 \\
\hline 31.0 & 398.2 & 24981 & 0.20 & 7.71 \\
\hline 31.0 & 400.2 & 24982 & 0.24 & 7.77 \\
\hline 31.0 & 399.6 & 24983 & 0.29 & 7.73 \\
\hline 31.0 & 400.9 & 24984 & 0.35 & 7.89 \\
\hline 31.0 & 400.9 & 24984 & 0.38 & 7.95 \\
\hline 31.0 & 400.3 & 24985 & 0.43 & 7.98 \\
\hline 31.0 & 400.5 & 24986 & 0.49 & 8.13 \\
\hline 31.1 & 399.8 & 24987 & 0.53 & 8.23 \\
\hline 30.9 & 398.2 & 24991 & 0.58 & 8.32 \\
\hline
\end{tabular}




\begin{tabular}{|c|c|c|c|c|}
\hline$T_{\text {sat }}$ & $G$ & $\phi$ & $x$ & $h$ \\
\hline 31.1 & 402.8 & 24990 & 0.63 & 8.45 \\
\hline 30.9 & 397.2 & 24996 & 0.69 & 8.59 \\
\hline 30.9 & 398.0 & 24999 & 0.74 & 8.73 \\
\hline 31.5 & 399.5 & 34976 & 0.06 & 10.60 \\
\hline 31.5 & 401.4 & 34975 & 0.11 & 10.85 \\
\hline 31.5 & 399.0 & 34977 & 0.16 & 10.47 \\
\hline 30.8 & 402.1 & 34977 & 0.21 & 9.83 \\
\hline 31.4 & 399.5 & 34976 & 0.26 & 9.86 \\
\hline 31.4 & 401.4 & 34975 & 0.30 & 9.87 \\
\hline 31.4 & 399.0 & 34977 & 0.35 & 9.85 \\
\hline 30.6 & 402.1 & 34977 & 0.40 & 9.10 \\
\hline 30.7 & 400.3 & 34974 & 0.44 & 8.99 \\
\hline 30.7 & 404.2 & 34980 & 0.49 & 8.72 \\
\hline 30.7 & 401.4 & 34979 & 0.54 & 8.97 \\
\hline 30.7 & 399.4 & 34979 & 0.60 & 9.00 \\
\hline 30.7 & 400.3 & 34979 & 0.64 & 8.97 \\
\hline 31.0 & 410.1 & 34975 & 0.68 & 8.92 \\
\hline 30.7 & 399.5 & 34976 & 0.74 & 9.01 \\
\hline 30.7 & 400.5 & 34977 & 0.80 & 9.29 \\
\hline 30.9 & 398.5 & 34979 & 0.84 & 9.67 \\
\hline 31.4 & 395.8 & 44925 & 0.12 & 11.91 \\
\hline 31.9 & 401.7 & 44939 & 0.16 & 12.24 \\
\hline 31.9 & 398.4 & 44937 & 0.22 & 11.89 \\
\hline 30.8 & 403.0 & 44923 & 0.26 & 11.98 \\
\hline 31.1 & 399.6 & 44925 & 0.32 & 11.31 \\
\hline 31.3 & 395.8 & 44925 & 0.37 & 11.11 \\
\hline 31.8 & 401.7 & 44939 & 0.41 & 11.36 \\
\hline 31.8 & 398.4 & 44937 & 0.47 & 11.52 \\
\hline 30.7 & 403.0 & 44923 & 0.50 & 10.79 \\
\hline 30.9 & 399.6 & 44925 & 0.57 & 10.46 \\
\hline 30.8 & 400.0 & 44930 & 0.60 & 10.68 \\
\hline 30.8 & 401.3 & 44928 & 0.64 & 10.93 \\
\hline 30.8 & 401.1 & 44929 & 0.71 & 10.90 \\
\hline 30.8 & 395.8 & 44927 & 0.76 & 10.82 \\
\hline 30.8 & 397.9 & 44926 & 0.81 & 11.01 \\
\hline 31.5 & 398.6 & 54964 & 0.18 & 14.24 \\
\hline 31.5 & 400.6 & 54939 & 0.24 & 14.32 \\
\hline 31.5 & 401.6 & 54948 & 0.28 & 14.37 \\
\hline 30.8 & 399.2 & 54941 & 0.34 & 13.67 \\
\hline 30.9 & 395.2 & 54944 & 0.38 & 13.23 \\
\hline 31.0 & 398.5 & 54966 & 0.43 & 13.23 \\
\hline 30.9 & 399.9 & 54969 & 0.48 & 13.30 \\
\hline 31.6 & 398.6 & 54964 & 0.49 & 12.87 \\
\hline 31.6 & 400.6 & 54939 & 0.54 & 12.97 \\
\hline 31.7 & 401.6 & 54948 & 0.58 & 12.87 \\
\hline 31.0 & 399.2 & 54941 & 0.64 & 12.23 \\
\hline 31.1 & 395.2 & 54944 & 0.68 & 12.09 \\
\hline 31.2 & 398.5 & 54966 & 0.73 & 12.01 \\
\hline 31.2 & 399.9 & 54969 & 0.78 & 11.80 \\
\hline 31.5 & 497.2 & 15023 & 0.07 & 4.69 \\
\hline 31.5 & 500.7 & 15027 & 0.12 & 5.19 \\
\hline 30.8 & 499.1 & 15027 & 0.17 & 4.86 \\
\hline 30.8 & 500.5 & 15026 & 0.22 & 4.94 \\
\hline 30.8 & 500.7 & 15025 & 0.27 & 5.05 \\
\hline 30.9 & 499.8 & 15026 & 0.32 & 5.21 \\
\hline 30.8 & 500.1 & 15024 & 0.37 & 5.35 \\
\hline 30.8 & 499.0 & 15030 & 0.41 & 5.49 \\
\hline
\end{tabular}

\begin{tabular}{|c|c|c|c|c|}
\hline$T_{\text {sat }}$ & $G$ & $\phi$ & $x$ & $h$ \\
\hline 30.8 & 496.4 & 15024 & 0.47 & 5.65 \\
\hline 30.8 & 499.6 & 15024 & 0.53 & 5.90 \\
\hline 30.8 & 499.6 & 15031 & 0.57 & 6.04 \\
\hline 30.6 & 499.8 & 15025 & 0.61 & 6.33 \\
\hline 30.9 & 500.1 & 15027 & 0.67 & 6.39 \\
\hline 30.9 & 499.4 & 15029 & 0.72 & 6.61 \\
\hline 30.8 & 502.4 & 15031 & 0.77 & 6.73 \\
\hline 30.8 & 498.1 & 15033 & 0.81 & 6.83 \\
\hline 30.8 & 500.2 & 15036 & 0.87 & 7.15 \\
\hline 30.8 & 500.2 & 15036 & 0.91 & 7.63 \\
\hline 31.5 & 503.1 & 24983 & 0.14 & 6.72 \\
\hline 31.5 & 499.5 & 24983 & 0.20 & 6.79 \\
\hline 30.8 & 497.4 & 24984 & 0.25 & 6.44 \\
\hline 30.9 & 499.9 & 24984 & 0.29 & 6.65 \\
\hline 30.9 & 500.0 & 24986 & 0.34 & 6.79 \\
\hline 30.9 & 496.9 & 24986 & 0.40 & 6.88 \\
\hline 30.9 & 497.5 & 24987 & 0.45 & 7.06 \\
\hline 30.8 & 499.7 & 24990 & 0.49 & 7.19 \\
\hline 30.8 & 503.7 & 24991 & 0.54 & 7.41 \\
\hline 30.9 & 501.0 & 24991 & 0.59 & 7.61 \\
\hline 31.0 & 504.2 & 24989 & 0.64 & 7.70 \\
\hline 31.0 & 499.4 & 24989 & 0.70 & 7.77 \\
\hline 30.9 & 502.7 & 24991 & 0.73 & 7.97 \\
\hline 30.9 & 501.3 & 24993 & 0.79 & 8.19 \\
\hline 30.9 & 499.7 & 24995 & 0.84 & 8.47 \\
\hline 31.0 & 500.0 & 25050 & 0.89 & 8.91 \\
\hline 31.5 & 497.7 & 35022 & 0.19 & 8.09 \\
\hline 31.5 & 495.8 & 35024 & 0.22 & 8.19 \\
\hline 31.4 & 505.7 & 35025 & 0.26 & 8.29 \\
\hline 30.9 & 500.4 & 35024 & 0.32 & 7.83 \\
\hline 31.2 & 499.5 & 35038 & 0.37 & 8.08 \\
\hline 31.2 & 501.3 & 35037 & 0.41 & 8.19 \\
\hline 31.0 & 500.1 & 35026 & 0.47 & 8.31 \\
\hline 31.2 & 499.7 & 35023 & 0.52 & 8.42 \\
\hline 31.3 & 496.4 & 35021 & 0.58 & 8.51 \\
\hline 31.3 & 499.5 & 35022 & 0.62 & 8.61 \\
\hline 31.2 & 500.8 & 35026 & 0.67 & 8.81 \\
\hline 31.2 & 497.9 & 35028 & 0.72 & 8.97 \\
\hline 31.2 & 505.9 & 35030 & 0.76 & 9.20 \\
\hline 31.1 & 496.6 & 35033 & 0.83 & 9.65 \\
\hline 31.1 & 498.1 & 35035 & 0.87 & 10.08 \\
\hline 31.5 & 506.1 & 44989 & 0.07 & 11.02 \\
\hline 32.0 & 503.7 & 45015 & 0.09 & 10.69 \\
\hline 32.0 & 501.3 & 45015 & 0.14 & 10.80 \\
\hline 32.0 & 501.2 & 45016 & 0.20 & 10.83 \\
\hline 31.4 & 506.1 & 44989 & 0.26 & 11.06 \\
\hline 31.9 & 503.7 & 45015 & 0.29 & 11.17 \\
\hline 31.9 & 501.3 & 45015 & 0.33 & 11.15 \\
\hline 31.9 & 501.2 & 45016 & 0.39 & 11.15 \\
\hline 30.9 & 498.5 & 44997 & 0.45 & 10.91 \\
\hline 30.8 & 499.0 & 45000 & 0.49 & 10.10 \\
\hline 30.8 & 498.2 & 44993 & 0.54 & 10.26 \\
\hline 30.8 & 504.2 & 45006 & 0.59 & 10.10 \\
\hline 31.0 & 502.7 & 45019 & 0.64 & 10.24 \\
\hline 30.8 & 502.1 & 45006 & 0.68 & 10.10 \\
\hline 31.0 & 499.6 & 45015 & 0.74 & 10.24 \\
\hline 31.0 & 500.1 & 44998 & 0.80 & 10.40 \\
\hline
\end{tabular}




\begin{tabular}{|c|c|c|c|c|}
\hline$T_{\text {sat }}$ & $G$ & $\phi$ & $x$ & $h$ \\
\hline 30.9 & 499.6 & 45002 & 0.84 & 10.69 \\
\hline 31.9 & 501.1 & 54959 & 0.11 & 13.94 \\
\hline 31.9 & 496.9 & 54953 & 0.13 & 14.01 \\
\hline 31.9 & 501.3 & 54961 & 0.18 & 13.98 \\
\hline 31.9 & 502.5 & 54955 & 0.22 & 13.16 \\
\hline 31.1 & 496.3 & 54942 & 0.28 & 12.87 \\
\hline 31.7 & 501.1 & 54959 & 0.35 & 13.11 \\
\hline 31.7 & 496.9 & 54953 & 0.37 & 13.15 \\
\hline 31.7 & 501.3 & 54961 & 0.42 & 13.27 \\
\hline 31.7 & 502.5 & 54955 & 0.46 & 13.41 \\
\hline 30.9 & 496.3 & 54942 & 0.52 & 12.26 \\
\hline 30.9 & 497.9 & 54942 & 0.57 & 12.43 \\
\hline 30.9 & 500.2 & 54943 & 0.62 & 12.64 \\
\hline 31.2 & 493.9 & 54959 & 0.68 & 11.85 \\
\hline 31.0 & 500.9 & 54936 & 0.72 & 11.82 \\
\hline 30.8 & 496.5 & 54940 & 0.77 & 11.78 \\
\hline 30.8 & 502.6 & 54941 & 0.81 & 12.08 \\
\hline 32.0 & 499.9 & 64989 & 0.15 & 15.54 \\
\hline 32.1 & 496.1 & 64986 & 0.20 & 15.63 \\
\hline 32.2 & 499.9 & 64987 & 0.26 & 15.28 \\
\hline 31.4 & 497.7 & 64988 & 0.31 & 15.10 \\
\hline 31.3 & 501.2 & 64987 & 0.35 & 14.81 \\
\hline 31.8 & 499.9 & 64989 & 0.43 & 14.91 \\
\hline 31.9 & 496.1 & 64986 & 0.49 & 14.70 \\
\hline 32.0 & 499.9 & 64987 & 0.55 & 14.83 \\
\hline 31.2 & 497.7 & 64988 & 0.60 & 14.21 \\
\hline 31.1 & 501.2 & 64987 & 0.64 & 13.89 \\
\hline 30.9 & 497.9 & 64971 & 0.70 & 13.69 \\
\hline 30.9 & 495.2 & 64976 & 0.76 & 13.54 \\
\hline 30.9 & 500.6 & 64994 & 0.78 & 13.54 \\
\hline 30.8 & 600.1 & 34838 & 0.16 & 10.01 \\
\hline 30.9 & 598.5 & 34837 & 0.19 & 9.94 \\
\hline 30.7 & 598.2 & 34853 & 0.24 & 9.85 \\
\hline 30.7 & 602.9 & 34852 & 0.29 & 9.76 \\
\hline 30.8 & 599.0 & 34851 & 0.34 & 9.43 \\
\hline 31.0 & 602.6 & 34848 & 0.39 & 9.57 \\
\hline 30.9 & 598.7 & 34845 & 0.44 & 9.78 \\
\hline 30.3 & 599.4 & 34845 & 0.49 & 9.90 \\
\hline 30.4 & 603.7 & 34852 & 0.53 & 9.98 \\
\hline 30.5 & 599.4 & 34859 & 0.58 & 10.08 \\
\hline 30.7 & 600.2 & 34856 & 0.64 & 10.20 \\
\hline 30.7 & 602.8 & 34856 & 0.68 & 10.28 \\
\hline 30.8 & 597.0 & 34856 & 0.74 & 10.44 \\
\hline 31.0 & 601.3 & 34852 & 0.77 & 10.65 \\
\hline 31.2 & 600.7 & 34849 & 0.83 & 11.14 \\
\hline 31.3 & 597.7 & 34850 & 0.87 & 11.49 \\
\hline 31.9 & 600.7 & 54961 & 0.07 & 13.77 \\
\hline 32.1 & 598.7 & 54958 & 0.09 & 13.70 \\
\hline 32.2 & 597.5 & 54956 & 0.14 & 14.04 \\
\hline 32.3 & 598.6 & 54956 & 0.18 & 13.87 \\
\hline 31.8 & 600.7 & 54961 & 0.27 & 13.88 \\
\hline 31.9 & 598.7 & 54958 & 0.29 & 13.71 \\
\hline 32.0 & 597.5 & 54956 & 0.35 & 13.36 \\
\hline 32.1 & 598.6 & 54956 & 0.39 & 13.24 \\
\hline 31.0 & 600.6 & 54948 & 0.44 & 12.79 \\
\hline 31.0 & 598.9 & 54949 & 0.50 & 12.07 \\
\hline 31.2 & 598.4 & 54961 & 0.54 & 12.39 \\
\hline
\end{tabular}

\begin{tabular}{|c|c|c|c|c|}
\hline$T_{\text {sat }}$ & $G$ & $\phi$ & $x$ & $h$ \\
\hline 30.9 & 599.9 & 54948 & 0.59 & 11.93 \\
\hline 30.9 & 599.4 & 54940 & 0.63 & 11.88 \\
\hline 31.3 & 601.5 & 54958 & 0.68 & 12.12 \\
\hline 31.2 & 600.7 & 54958 & 0.74 & 12.26 \\
\hline 31.1 & 599.7 & 54959 & 0.79 & 12.47 \\
\hline 30.9 & 599.4 & 54957 & 0.83 & 12.77 \\
\hline 32.1 & 602.5 & 64987 & 0.18 & 15.48 \\
\hline 32.2 & 598.5 & 64988 & 0.21 & 15.56 \\
\hline 32.2 & 598.8 & 64987 & 0.26 & 15.38 \\
\hline 32.3 & 599.8 & 64988 & 0.31 & 15.24 \\
\hline 31.5 & 599.9 & 64988 & 0.36 & 14.22 \\
\hline 31.4 & 600.7 & 64992 & 0.41 & 14.21 \\
\hline 31.4 & 599.8 & 64989 & 0.46 & 13.79 \\
\hline 31.4 & 599.5 & 64990 & 0.52 & 13.61 \\
\hline 31.3 & 600.4 & 64988 & 0.56 & 13.57 \\
\hline 31.3 & 598.6 & 64978 & 0.61 & 13.64 \\
\hline 31.4 & 596.9 & 64994 & 0.66 & 13.37 \\
\hline 31.2 & 599.5 & 64990 & 0.67 & 13.32 \\
\hline 31.0 & 600.4 & 64988 & 0.72 & 13.46 \\
\hline 30.9 & 598.6 & 64978 & 0.77 & 13.88 \\
\hline 31.1 & 596.9 & 64994 & 0.82 & 13.90 \\
\hline 41.7 & 198.7 & 14806 & 0.16 & 6.61 \\
\hline 41.8 & 201.3 & 14805 & 0.20 & 6.84 \\
\hline 41.8 & 200.8 & 14807 & 0.26 & 7.11 \\
\hline 41.9 & 200.4 & 14807 & 0.31 & 7.08 \\
\hline 41.8 & 202.8 & 14808 & 0.36 & 7.22 \\
\hline 41.6 & 206.5 & 14814 & 0.40 & 6.91 \\
\hline 41.4 & 199.2 & 14822 & 0.47 & 6.96 \\
\hline 41.2 & 206.5 & 14825 & 0.50 & 6.82 \\
\hline 41.2 & 202.8 & 14827 & 0.55 & 7.26 \\
\hline 41.2 & 202.8 & 14825 & 0.59 & 7.48 \\
\hline 41.3 & 202.8 & 14824 & 0.65 & 7.42 \\
\hline 41.3 & 201.0 & 14824 & 0.71 & 7.55 \\
\hline 41.3 & 202.8 & 14822 & 0.73 & 7.66 \\
\hline 41.3 & 201.0 & 14823 & 0.79 & 7.65 \\
\hline 41.1 & 195.5 & 14827 & 0.87 & 7.81 \\
\hline 41.1 & 197.3 & 24752 & 0.12 & 9.12 \\
\hline 41.0 & 200.0 & 24752 & 0.19 & 9.00 \\
\hline 41.1 & 197.3 & 24753 & 0.25 & 9.01 \\
\hline 41.3 & 201.0 & 24754 & 0.31 & 9.12 \\
\hline 41.3 & 197.3 & 24752 & 0.39 & 9.25 \\
\hline 41.2 & 195.5 & 24752 & 0.46 & 9.19 \\
\hline 41.2 & 197.3 & 24753 & 0.51 & 9.14 \\
\hline 41.2 & 201.0 & 24754 & 0.55 & 9.35 \\
\hline 41.2 & 193.7 & 24754 & 0.61 & 9.33 \\
\hline 41.2 & 199.2 & 24753 & 0.63 & 9.46 \\
\hline 41.4 & 208.3 & 24768 & 0.66 & 9.78 \\
\hline 41.5 & 199.2 & 24768 & 0.72 & 9.89 \\
\hline 41.5 & 199.2 & 24771 & 0.79 & 10.79 \\
\hline 41.4 & 405.6 & 14811 & 0.05 & 6.72 \\
\hline 41.5 & 404.2 & 14819 & 0.11 & 6.91 \\
\hline 41.5 & 400.9 & 14818 & 0.15 & 7.13 \\
\hline 41.5 & 399.8 & 14819 & 0.20 & 7.26 \\
\hline 41.5 & 400.6 & 14820 & 0.26 & 7.31 \\
\hline 41.6 & 400.9 & 14820 & 0.32 & 7.43 \\
\hline 41.6 & 400.6 & 14818 & 0.36 & 7.57 \\
\hline 41.7 & 400.7 & 14818 & 0.41 & 7.76 \\
\hline
\end{tabular}




\begin{tabular}{|l|l|l|l|l|}
\hline \multicolumn{1}{|c|}{$\boldsymbol{T}$ sat } & \multicolumn{1}{|c|}{$\boldsymbol{\phi}$} & $\boldsymbol{x}$ & \multicolumn{1}{|c|}{$\boldsymbol{h}$} \\
\hline 41.6 & 397.3 & 14820 & 0.46 & 7.89 \\
\hline 41.7 & 397.3 & 14819 & 0.51 & 8.15 \\
\hline 41.7 & 399.7 & 14821 & 0.55 & 8.39 \\
\hline 41.7 & 396.7 & 14821 & 0.60 & 8.55 \\
\hline 41.8 & 402.6 & 14821 & 0.63 & 8.75 \\
\hline 41.8 & 402.0 & 14822 & 0.70 & 9.09 \\
\hline 41.8 & 399.6 & 14823 & 0.76 & 9.48 \\
\hline 41.8 & 401.2 & 14822 & 0.81 & 9.94 \\
\hline 41.8 & 399.4 & 14823 & 0.86 & 10.35 \\
\hline 41.8 & 400.6 & 14825 & 0.90 & 10.80 \\
\hline 41.5 & 400.7 & 24750 & 0.09 & 9.44 \\
\hline 41.5 & 400.4 & 24749 & 0.12 & 9.54 \\
\hline 41.5 & 401.5 & 24764 & 0.18 & 9.55 \\
\hline 41.6 & 401.2 & 24763 & 0.22 & 9.60 \\
\hline 41.6 & 400.3 & 24763 & 0.27 & 9.64 \\
\hline 41.6 & 399.1 & 24762 & 0.32 & 9.78 \\
\hline 41.6 & 400.3 & 24762 & 0.37 & 9.86 \\
\hline 41.7 & 400.3 & 24763 & 0.43 & 9.99 \\
\hline 41.7 & 400.0 & 24762 & 0.48 & 10.14 \\
\hline 41.8 & 401.0 & 24762 & 0.52 & 10.29 \\
\hline 41.8 & 400.5 & 24762 & 0.58 & 10.50 \\
\hline 41.8 & 401.8 & 24762 & 0.63 & 10.58 \\
\hline 41.8 & 397.3 & 24763 & 0.69 & 10.77 \\
\hline 41.9 & 399.5 & 24763 & 0.73 & 10.96 \\
\hline 41.9 & 398.1 & 24763 & 0.78 & 11.36 \\
\hline 41.9 & 400.6 & 24764 & 0.82 & 11.69 \\
\hline 41.9 & 397.3 & 24765 & 0.87 & 11.65 \\
\hline 41.4 & 400.6 & 34825 & 0.21 & 11.55 \\
\hline 41.4 & 400.3 & 34824 & 0.24 & 11.55 \\
\hline 41.4 & 398.0 & 34824 & 0.29 & 11.55 \\
\hline 41.4 & 397.5 & 34824 & 0.35 & 11.64 \\
\hline 41.4 & 400.0 & 34824 & 0.39 & 11.71 \\
\hline 41.4 & 401.7 & 34825 & 0.45 & 11.92 \\
\hline 41.5 & 401.5 & 34825 & 0.50 & 12.00 \\
\hline 41.5 & 399.7 & 34825 & 0.54 & 12.20 \\
\hline 41.5 & 401.4 & 34825 & 0.59 & 12.52 \\
\hline 41.6 & 398.1 & 34824 & 0.65 & 12.56 \\
\hline 41.6 & 400.9 & 34824 & 0.69 & 12.43 \\
\hline 41.6 & 411.0 & 34824 & 0.70 & 12.66 \\
\hline 41.7 & 389.5 & 34825 & 0.79 & 13.19 \\
\hline 41.7 & 403.8 & 34824 & 0.78 & 13.02 \\
\hline 41.4 & 399.6 & 44806 & 0.32 & 13.37 \\
\hline 41.4 & 401.9 & 44806 & 0.36 & 13.41 \\
\hline 41.5 & 401.2 & 44820 & 0.41 & 13.56 \\
\hline 41.5 & 401.3 & 44826 & 0.45 & 13.61 \\
\hline 41.6 & 400.3 & 44824 & 0.51 & 13.68 \\
\hline 41.7 & 400.2 & 44823 & 0.55 & 13.76 \\
\hline 41.7 & 399.5 & 44823 & 0.59 & 14.00 \\
\hline & & & & \\
\hline
\end{tabular}

\begin{tabular}{|l|l|l|l|l|}
\hline \multicolumn{1}{|c|}{$\boldsymbol{T}_{\text {sat }}$} & \multicolumn{1}{|c|}{$\boldsymbol{\phi}$} & $\boldsymbol{\phi}$ & \multicolumn{1}{|c|}{$\boldsymbol{h}$} \\
\hline 41.7 & 400.5 & 44827 & 0.66 & 14.72 \\
\hline 41.7 & 400.1 & 44827 & 0.71 & 14.95 \\
\hline 41.8 & 401.2 & 44825 & 0.76 & 15.20 \\
\hline 41.8 & 386.4 & 44824 & 0.84 & 15.14 \\
\hline 41.7 & 402.3 & 54807 & 0.43 & 15.17 \\
\hline 41.7 & 402.7 & 54808 & 0.47 & 15.24 \\
\hline 41.7 & 400.6 & 54807 & 0.52 & 15.24 \\
\hline 41.8 & 400.7 & 54807 & 0.57 & 15.26 \\
\hline 41.8 & 402.2 & 54807 & 0.61 & 15.37 \\
\hline 41.7 & 400.2 & 54809 & 0.67 & 15.54 \\
\hline 41.7 & 399.3 & 54809 & 0.72 & 15.90 \\
\hline 41.7 & 401.9 & 54812 & 0.75 & 16.45 \\
\hline 40.3 & 600.6 & 15020 & 0.07 & 5.62 \\
\hline 40.4 & 602.4 & 15020 & 0.12 & 5.93 \\
\hline 40.5 & 601.3 & 15023 & 0.18 & 6.08 \\
\hline 40.7 & 599.5 & 15033 & 0.23 & 6.22 \\
\hline 40.9 & 600.3 & 15033 & 0.27 & 6.29 \\
\hline 40.9 & 600.6 & 15033 & 0.32 & 6.42 \\
\hline 41.0 & 604.3 & 15034 & 0.37 & 6.63 \\
\hline 41.1 & 600.4 & 15032 & 0.42 & 6.74 \\
\hline 41.2 & 598.6 & 15033 & 0.47 & 6.89 \\
\hline 41.2 & 601.7 & 15033 & 0.52 & 6.99 \\
\hline 41.2 & 602.3 & 15033 & 0.57 & 7.04 \\
\hline 41.3 & 600.3 & 15033 & 0.62 & 7.06 \\
\hline 41.3 & 600.4 & 15033 & 0.68 & 7.12 \\
\hline 41.3 & 599.5 & 15033 & 0.72 & 7.19 \\
\hline 41.3 & 599.9 & 15033 & 0.77 & 7.31 \\
\hline 41.4 & 600.3 & 15033 & 0.82 & 7.46 \\
\hline 41.4 & 601.1 & 15034 & 0.86 & 7.62 \\
\hline 41.4 & 602.7 & 15034 & 0.91 & 8.19 \\
\hline 36.8 & 605.3 & 24953 & 0.04 & 8.65 \\
\hline 36.9 & 600.2 & 24959 & 0.09 & 8.76 \\
\hline 37.0 & 600.1 & 24970 & 0.14 & 8.75 \\
\hline 37.2 & 602.8 & 24970 & 0.21 & 8.80 \\
\hline 37.3 & 601.8 & 24970 & 0.25 & 8.91 \\
\hline 37.4 & 598.7 & 24986 & 0.31 & 9.05 \\
\hline 37.6 & 600.2 & 24987 & 0.35 & 9.15 \\
\hline 37.8 & 600.1 & 24987 & 0.40 & 9.27 \\
\hline 37.9 & 599.7 & 24987 & 0.45 & 9.40 \\
\hline 38.0 & 601.1 & 24987 & 0.50 & 9.50 \\
\hline 38.2 & 601.1 & 24987 & 0.55 & 9.56 \\
\hline 38.3 & 598.8 & 24987 & 0.61 & 9.73 \\
\hline 38.4 & 601.4 & 24987 & 0.65 & 9.79 \\
\hline 38.5 & 599.5 & 24988 & 0.70 & 9.98 \\
\hline 38.6 & 601.1 & 24992 & 0.75 & 10.15 \\
\hline 38.7 & 600.7 & 24999 & 0.79 & 10.29 \\
\hline 38.7 & 600.8 & 24998 & 0.84 & 10.75 \\
\hline 38.4 & 601.8 & 24987 & 0.89 & 9.89 \\
\hline & & & & \\
\hline
\end{tabular}

